Universidad deValladolid

PROGRAMA DE DOCTORADO EN INGENIERÍA INDUSTRIAL

TESIS DOCTORAL:

\title{
OPTIMIZACIÓN DEL USO DE LOS COLECTORES SOLARES TÉRMICOS DE AIRE PARA LA REDUCCIÓN DEL CONSUMO DE ENERGÍA EN EDIFICIOS.
}

Presentada por Sergio Lorenzo González González para optar al grado de Doctor/a por la Universidad de Valladolid

Dirigida por:

Dr. Francisco Javier Rey Martínez

Dra. Ana Tejero González 


\section{AGRADECIMIENTOS}

Nunca me hubiera atrevido a emprender esta "aventura" de no haberme cruzado en el camino de Eloy Velasco y Francisco Javier Rey, sin su trabajo y enseñanzas nada de esto hubiera sido posible.

Gracias a ambos por haberme dado esta oportunidad.

Sin el apoyo, ayuda y dedicación de Ana Tejero no me encontraría en este punto, su impulso ha sido fundamental para alcanzar este objetivo.

Gracias Ana.

No puedo dejar sin nombrar al resto de compañeros y compañeras que he tenido oportunidad de conocer en esta etapa en Valladolid, que me han aportado ánimos y conocimientos indispensables no solo para esta labor, sino también para mi trabajo y vida profesional.

Gracias a Manu, Julio, Cristina y Eva.

Nada de esto hubiera sido posible sin mi familia y amigos, tanto los que siguen a mi lado como los que por unas circunstancias $u$ otras ya no lo están. Ellos tienen mucho que ver en todo esto de una manera $u$ otra.

GRACIAS. 


\section{ÍNDICE}

\section{AGRADECIMIENTOS}

ÍNDICE

RESUMEN

\section{ENERGÍA Y BIENESTAR EN LA EDIFICACIÓN}

I.1.- PANORAMA ENERGÉTICO MUNDIAL.

I.2.- DESARROLLO SOSTENIBLE, ENERGÍA, MEDIO AMBIENTE Y SALUD.

Política energética en EUROPA.

La tecnología como elemento de mejora.

I.3.- EFICIENCIA ENERGÉTICA EN EDIFICIOS.

Políticas energéticas en la Edificación.

I.4.- CALIDAD DEL CLIMA INTERIOR EN EDIFICIOS.

I.5.- AHORRO ENERGÉTICO EN SISTEMAS DE CLIMATIZACIÓN. TECNOLOGÍAS EFICIENTES Y RENOVABLES INTEGRADAS EN EDIFICIOS.

I.5.1.- TECNOLOGÍAS PARA EL AHORRO EN LA GENERACIÓN DE CALOR O FRÍO. 29

I.5.1.1.- Calderas de Baja temperatura y Condensación. 29

I.5.1.2.- Bombas de Calor. $\quad 36$

I.5.1.3.- Generación integral de energía: Cogeneración y Trigeneración. 43

I.5.1.4.- Sistemas de enfriamiento gratuíto. 46

I.5.1.5.- Sistemas de recuperación de energía.

I.5.2.- USO DE ENERGÍAS RENOVABLES.

I.5.2.1.- Sistemas solares térmicos de baja temperatura. 54

$\begin{array}{ll}\text { I.5.2.2.- Solar fotovoltáica. } & 65\end{array}$

$\begin{array}{ll}\text { I.5.2.3.- Biomasa. } & 67\end{array}$

$\begin{array}{ll}\text { I.5.2.4.- Geotérmia de baja temperatura. } & 69\end{array}$

$\begin{array}{ll}\text { I.5.2.5.- Minieólica. } & 70\end{array}$

REFERENCIAS $\quad 72$

$\begin{array}{ll}\text { NORMATIVA } & 73\end{array}$

$\begin{array}{ll}\text { PÁGINAS WEB } & 74\end{array}$ 


\section{CAPÍTULO II.-}

\section{COLECTORES TÉRMICOS SOLARES DE AIRE}

75

II.1.- INTRODUCCIÓN.

EVOLUCIÓN DEL APROVECHAMIENTO DE LA ENERGÍA SOLAR.-

II.2.- FUNDAMENTOS

II.2.1.- ANÁLISIS TÉRMICO DE UN COLECTOR.

II.3.- TIPOS DE COLECTORES SOLARES DE AIRE. 95

II.3.1.- TIPO NO POROSO.

II.3.1.1.- Colectores de una sola exposición.

II.3.1.2.- Colectores de doble exposición. 102

$\begin{array}{ll}\text { II.3.1.3.- Colectores de dos pasos. } & 103\end{array}$

$\begin{array}{ll}\text { II.3.1.4.- Colector con placa absorbedora aleteada. } & 107\end{array}$

$\begin{array}{ll}\text { II.3.1.5.- Colector con absorbedor corrugado - dentado. } & 108\end{array}$

II.3.1.6.- Colector con placa absorbedora en el reverso (colectores invertidos) 110

II.3.2.- TIPO POROSO.

II.3.2.1.- Colectores con absorbedor de placas de cristal solapadas. $\quad 117$

$\begin{array}{ll}\text { II.3.2.2.- Colectores con el absorbedor en forma de panel de abeja. } & 118\end{array}$

II.4.- ESTUDIO DE PARÁMETROS. 120

$\begin{array}{ll}\text { II.4.1.- EFECTO DE LAS FUGAS DE AIRE. } & 120\end{array}$

II.4.2.- EFECTO DE LAS PARTÍCULAS. 121

II.5.- COMPARACIÓN ENTRE EL COMPORTAMIENTO DE UN COLECTOR DE AIRE Y UNO DE

AGUA.

II.6.- APLICACIONES DEL COLECTOR SOLAR DE AIRE 123

II.6.1.- CLIMATIZACIÓN Y ACONDICIONAMIENTO DE EDIFICIOS. 123

$\begin{array}{ll}\text { II.6.2.- SECADO. } & 123\end{array}$

II.7.- COMERCIALIZACIÓN DEL COLECTOR SOLAR DE AIRE 126

REFERENCIAS 132

PÁGINAS WEB. $\quad 133$ 


\section{CAPÍTULO III.- \\ BANCO EXPERIMENTAL DE ENSAYOS DE UN C.T.S. DE AIRE}

III.1.- DESCRIPCIÓN DE LA INSTALACIÓN EXPERIMENTAL.

141

142

142

III.2.1.- UNIDAD DE TRATAMIENTO DE AIRE (UTA).

146

147

III.2.3.- CÁMARA CLIMÁTICA.

149

III.2.4.- SISTEMA DE DISTRIBUCIÓN DE AIRE.

152

III.3.- ELEMENTOS DE MEDIDA Y REGISTRO.

152

158

159

165

165

NORMATIVA.

166

\section{CAPÍTULO IV.-}

\section{CARACTERIZACIÓN DE LOS C.T.S. DE AIRE: RESULTADOS EXPERIMENTALES.}

IV.1.- INTRODUCCIÓN.

IV.2.- INSTALACIÓN EXPERIMENTAL.

IV.2.1.- COLECTOR TÉRMICO SOLAR DE AIRE ESTUDIADO.

IV.2.2.- BATERÍA DE LÁMPARAS INCANDESCENTES HALÓGENAS.

IV.4.- ANÁLISIS DE RESULTADOS.

PARÁMETROS CONSIDERADOS EN LA CARACTERIZACIÓN EXPERIMENTAL. 185

RESULTADOS DE LA CARACTERIZACIÓN EXPERIMENTAL.

IV.5.- ANÁLISIS DE VARIANZA.

191

REFERENCIAS

198

NORMATIVA.

198 


\section{CAPÍTULO V.-}

\section{SIMULACIÓN ENERGÉTICA DE LOS C.T.S. DE AIRE}

V.1.- INTRODUCCIÓN: DESCRIPCIÓN DE LA CONFIGURACIÓN OBJETO DEL MODELADO.

V.2.- MODELO MATEMÁTICO.

V.2.1.- BALANCE ENERGÉTICO.

V.2.2.- PARÁMETROS DE CONVECCIÓN.

V.2.2.1.- Efecto del viento: convección forzada entre la cubierta y el ambiente. 207

V.2.2.2.- Convección natural entre el absorbedor y la cubierta.

V.2.2.3.- Convección forzada en el paso del flujo.

V.2.3.- COEFICIENTES DE RADIACIÓN.

V.2.3.1.- Intercambio radiante entre el absorbedor y la cubierta.

V.2.3.2.- Intercambio radiante entre las caras de los conductos de paso.

V.3.- RESOLUCIÓN DEL MODELO MATEMÁTICO POR EL MÉTODO DE DIFERENCIAS FINITAS. 213

V.3.1.- MÉTODO Y DISCRETIZACIÓN.

V.3.2.- PROCESO DE CÁLCULO.

V.3.3.- PARÁMETROS DE LA SIMULACIÓN.

V.4.- RESULTADOS DEL MODELO.

CONCLUSIONES:

\section{CAPÍTULO VI.-}

\section{AHORROS ENERGÉTICOS EN VENTILACIÓN Y CALEFACCIÓN.}

VI.1.- INTRODUCCIÓN: APLICACIONES DE LOS C.T.S. DE AIRE PARA EL AHORRO DE ENERGÍA EN EDIFICIOS.

VI.2.- SIMULACIÓN DE LOS C.T.S. DE AIRE EN INVIERNO.

VI.2.1.- LOCALIDADES CONTEMPLADAS EN EL ESTUDIO.

VI.2.2.- PERIODO DE ESTUDIO CONSIDERADO.

VI.2.3.- INCLINACIÓN ÓPTIMA DEL C.T.S. PARA EL USO PROPUESTO. 237

VI.2.4.- NIVELES DE IRRADIANCIA.

VI.2.5.- SALTOS TÉRMICOS ALCANZADOS EN EL C.T.S. 
VI.3.1.- INCLINACIONES ÓPTIMAS PARA LAS LOCALIDADES DE ESTUDIO. 241

VI.3.2.- AHORROS ENERGÉTICOS EN INVIERNO. 242

VII.4.- CONCLUSIONES.

REFERENCIAS

$\begin{array}{ll}\text { NORMATIVA. } & 254\end{array}$

\section{CAPÍTULO VII.- \\ AHORROS ENERGÉTICOS EN VERANO.}

VII.1.- INTRODUCCIÓN: USO ANUAL DE LOS COLECTORES SOLARES DE AIRE. ALTERNATIVAS.

VII.2.- PROPUESTA DE USO DE LOS COLECTORES SOLARES PARA PRODUCCIÓN DE ACS.

VII.3.- METODOLOGÍA DE ESTUDIO.

VII.3.1.- MODELOS MATEMÁTICOS DE LOS ELEMENTOS DEL SISTEMA.

VII.3.1.1.- Modelado de la batería de tubos aleteados.

VII.3.1.2.- Modelado de los captadores solares de aire.

273

VII.3.1.3.- Depósito de acumulación.

274

VII.3.2.- CONDICIONES DE OPERACIÓN.

VII.3.2.1.- Condiciones climáticas.

276

VII.3.2.2.- Demanda de ACS.

VII.3.3.- AHORROS DE ENERGÍA.

280

VII.4.- RESULTADOS Y DISCUSIÓN.

281

VII.4.1.- FUNCIONAMIENTO CON DOS ACUMULADORES.

281

VII.4.2.- EVOLUCIÓN DE LA TEMPERATURA DEL AGUA EN EL DEPÓSITO.

284

VII.5.- CONCLUSIONES.

286

REFERENCIAS 


\section{CAPÍTULO VIII.--}

\section{CONCLUSIONES Y FUTUROS TRABAJOS..}

VIII.1.- CONCLUSIONES.

\section{ANEXO A.-}

CALIBRACIONES..

\section{ANEXO B.-}

\section{PROCEDIMIENTO DE DISEÑO DE EXPERIMENTOS Y ANÁLISIS DE VARIANZA..}




\section{ANEXO C.-}

\section{CONSIDERACIONES SIMULACIÓN \\ CÓDIGOS DE

AC.1.- FACTOR DE CORRECCIÓN K PARA SUPERFICIES INCLINADAS.

AC.2.- CONSIDERACIONES PARA EL DISEÑO DEL INTERCAMBIADOR DE CALOR.

AC.3.- CÓDIGO DE SIMULACIÓN DE LA BATERÍA AIRE - AGUA.

AC.4.- CÓDIGO DE SIMULACIÓN DEL COLECTOR.

AC.5.- TEMPERATURAS DEL AGUA DE RED EN ESPAÑA.

AC.6.- EVOLUCIÓN DE LA TEMPERATURA DEL AGUA EN EL DEPÓSITO DE ACUMULACIÓN. 360

AC.6.1.- DEPÓSITO DE 100 LITROS.

360

AC.6.1.1.- Caudal de aire: $100 \mathrm{~m} 3 / \mathrm{h}$.

360

AC.6.1.2.- Caudal de aire: $200 \mathrm{m3} / \mathrm{h}$.

363

AC.6.1.3.- Caudal de aire: $300 \mathrm{~m} 3 / \mathrm{h}$.

AC.6.2.- DEPÓSITO DE 300 LITROS.

368

AC.6.2.1.- Caudal de aire: $100 \mathrm{~m} 3 / \mathrm{h}$.

AC.6.2.2.- Caudal de aire: $200 \mathrm{~m} 3 / \mathrm{h}$.

370

AC.6.2.3.- Caudal de aire: $300 \mathrm{m3} / \mathrm{h}$.

AC.6.3.- DEPÓSITO DE 300 LITROS.

AC.6.3.1.- Caudal de aire: $100 \mathrm{~m} 3 / \mathrm{h}$.

375

AC.6.3.2.- Caudal de aire: $200 \mathrm{~m} 3 / \mathrm{h}$.

378

AC.6.3.3.- Caudal de aire: $300 \mathrm{~m} 3 / \mathrm{h}$.

380

REFERENCIAS

383 
ÍNDICE 


\section{RESUMEN}

El presente trabajo de Tesis Doctoral se centra en el estudio de la tecnología de los colectores térmicos solares de aire, a través de su caracterización y análisis de comportamiento y ahorros de energía obtenidos bajo diferentes condiciones de operación esperables.

Las reglamentaciones relacionadas con los requisitos de bienestar y consumo de energía en los edificios siguen una creciente tendencia hacia la mejora de las condiciones de la Calidad del Aire Interior IAQ y la consecución de edificios de consumo de energía casi nula. El desarrollo y estudio de la tecnología de los colectores térmicos solares de aire, a través de su incorporación en los sistemas e instalaciones de los edificios, permite satisfacer estos requerimientos de forma conjunta a través del empleo de una fuente de origen renovable y gratuita como es la radiación solar.

El análisis de los sistemas de colectores térmicos solares de aire se basa en la caracterización de un captador comercial (TwinSolar 4.0-SLK del fabricante Grammer Solar) instalado en un banco de ensayos equipado de tal forma que permite la experimentación del colector en diferentes condiciones de operación esperables. Este equipamiento permite controlar y regular los factores considerados como determinantes en el comportamiento y realizar ensayos con diferentes niveles de estos. Los resultados permiten definir una serie de parámetros que definen el comportamiento del colector. La relevancia o incidencia de los factores se comprueba posteriormente con el planteamiento de un análisis de varianza ANOVA.

Con las regresiones obtenidas de los diferentes parámetros establecidos para la definición del funcionamiento del equipo se desarrolla y valida un modelo matemático que simula el comportamiento del colector para las condiciones de operación ensayadas. Esta herramienta permite el análisis de los potenciales ahorros obtenidos gracias al empleo del colector.

También se plantea un estudio de ahorros energéticos que pueden alcanzarse en período invernal por la utilización del colector en el aporte de calor para la cobertura total o parcial de las cargas térmicas de ventilación y/o calefacción en edificios. El estudio se lleva a cabo para diferentes localidades españolas con diferentes condiciones climáticas de temperatura e irradiación solar.

La estacionalidad del uso habitual de los colectores solares de aire es uno de los principales hándicaps de esta tecnología. El uso más extendido de los colectores en edificación es el calentamiento de espacios o el preacondicionamiento del aire primario, limitado al periodo invernal. Después de revisar la literatura existente al respecto del uso anual de colectores de aire, se analiza una alternativa no estudiada antes como es el uso en la generación de agua caliente sanitaria durante el periodo de verano. Se plantean diferentes configuraciones de funcionamiento y se comparan los resultados obtenidos por cada una de ellas en términos de ahorro de energía y de temperaturas de agua alcanzadas. 
De los resultados obtenidos de la caracterización experimental, el desarrollo del modelo matemático y del estudio de la aplicación de los colectores solares térmicos de aire en los diferentes periodos estudiados, se derivan una serie de conclusiones y trabajos futuros que permiten poner en valor el potencial de esta tecnología. 
PARTE I:

INTRODUCCIÓN

CAPÍTULO I:

ENERGÍA Y

BIENESTAR EN LA

EDIFICACIÓN.

CAPÍTULO II:

COLECTORES

TÉRMICOS SOLARES

DE AIRE. 


\section{CAPÍTULO I.- \\ ENERGÍA Y BIENESTAR EN LA EDIFICACIÓN.}

\section{CONTENIDOS DEL CAPÍTULO:}

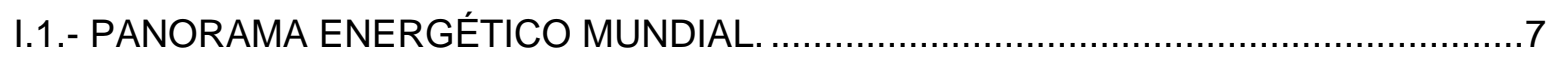

I.2.- DESARROLLO SOSTENIBLE, ENERGÍA, MEDIO AMBIENTE Y SALUD..................8

Política energética en EUROPA. ...........................................................................11

La tecnología como elemento de mejora.............................................................11

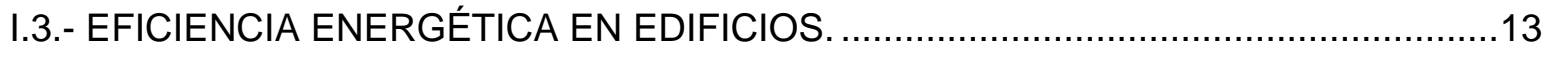

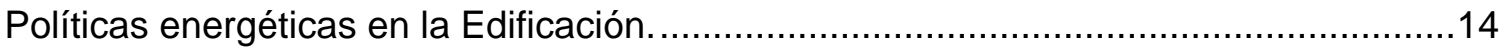

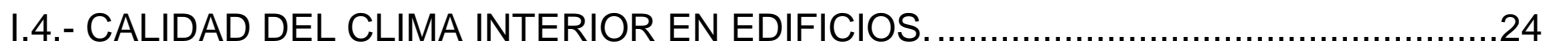

I.5.- AHORRO ENERGÉTICO EN SISTEMAS DE CLIMATIZACIÓN. TECNOLOGÍAS EFICIENTES Y RENOVABLES INTEGRADAS EN EDIFICIOS. .......................................

I.5.1.- TECNOLOGÍAS PARA EL AHORRO EN LA GENERACIÓN DE CALOR O FRÍO.

I.5.1.1.- Calderas de Baja temperatura y Condensación............................................29

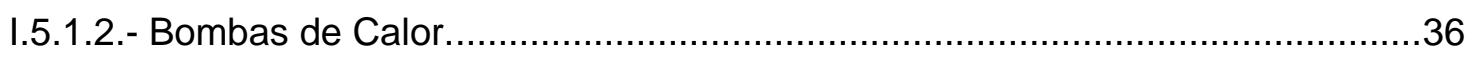

I.5.1.3.- Generación integral de energía: Cogeneración y Trigeneración.....................43

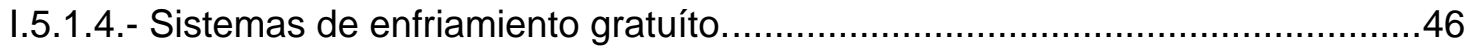

I.5.1.5.- Sistemas de recuperación de energía.............................................................53 


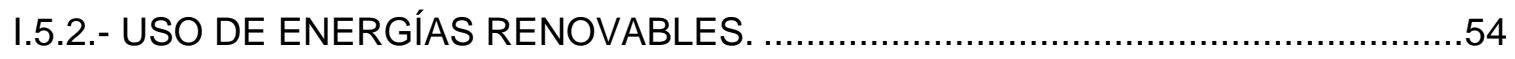

I.5.2.1.- Sistemas solares térmicos de baja temperatura. .........................................54

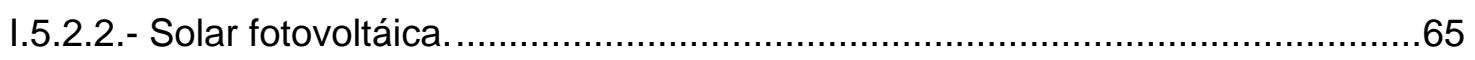

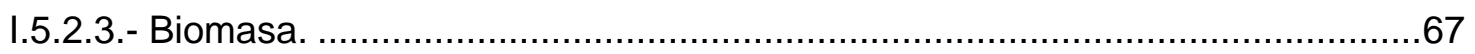

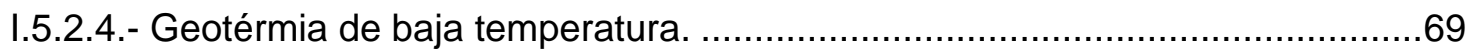

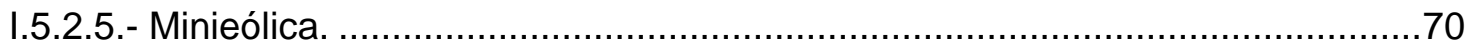

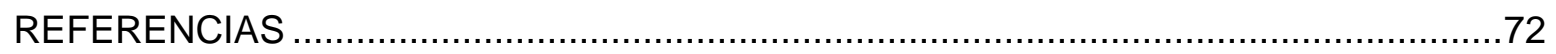

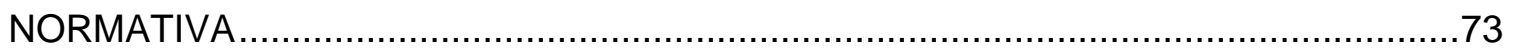

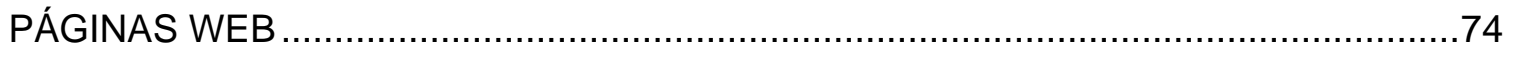




\section{LISTA DE FIGURAS:}

Figura I.3- Principales usos energéticos en edificios en España (izquierda) y Europa (derecha) [W$1]$

Figura I.4.- Reducción del consumo energético en edificios. 14

Figura I.5.- Esquema del marco normativo Europeo y su trasposición a nivel estatal. 18

Figura I.6.- Perfil de temperaturas en calderas de pared simple y pared doble........................... 32

Figura I.7.- Tecnología de doble pared en diferentes elementos de una caldera.......................... 32

Figura I.8.- Esquema de un aparato de condensación [12] ...................................................... 33

Figura I.9.- Operación en una caldera de condensación, según temperatura exterior................... 35

Figura I.10.- Elementos intervinientes en el sistema de Bomba de Calor. ................................... 37

Figura I.11.- Esquema de funcionamiento de una bomba de calor reversible............................. 38

Figura I.12.- Diagrama P-h del ciclo de refrigeración simple de Rankine...................................... 40

Figura I.13.- Diagrama P-h del ciclo de refrigeración real de Rankine. ...................................... 40

Figura I.14.- Balance energético de los sistemas convencionales y de cogeneración................... 43

Figura I.15.- Esquema de principio de cogeneración con turbina de gas..................................... 44

Figura I.16.- Evolución de la demanda de energía a lo largo del año.......................................... 45

Figura I.17.- Esquema básico de un sistema de enfriamiento gratuito por aire ............................ 47

Figura I.18.- Esquema del proceso de refrigeración por aire utilizando control por entalpía. ......... 48

Figura I.20.- Esquema del proceso de refrigeración por aire utilizando control por temperatura.... 50

Figura I.21.- Representación en el diagrama psicrométrico de la zona de aire exterior donde sería adecuado utilizar enfriamiento gratuito con control de temperatura. 50

Figura I.22.- Esquema básico del enfriamiento gratuito por agua. .......................................... 51

Figura I.23.- Zonas de control del proceso de free-cooling por agua. ......................................... 52

Figura I.24.- Enfriamiento gratuito utilizando enfriamiento evaporativo de agua.......................... 53

Figura I.25.- Instalación de energía solar para producir ACS en una vivienda............................... 55

Figura I.26.- Instalación de energía solar para calentamiento de piscina.....................................56

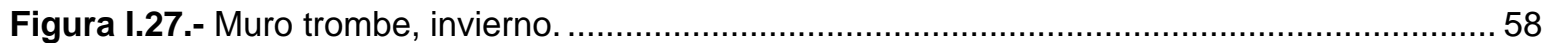




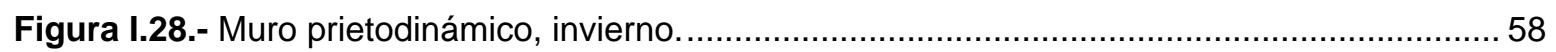

Figura I.29.- A la izqda., colector solar formado por tubos de vacío. A la dcha., esquema básico de un tubo de alto vacio con heat pipe.

Figura I.30.- Rectas de rendimiento del colector en función de la tipología. ................................ 61

Figura I.31.- Configuraciones más habituales del intercambiador de calor................................. 64

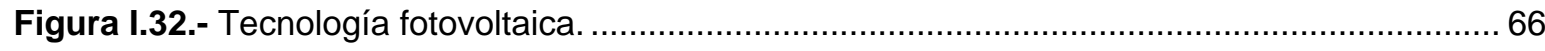

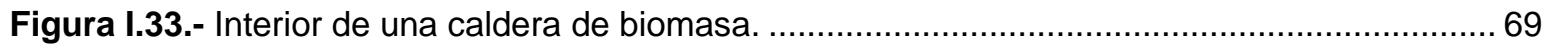

Figura I.34.- Ejemplos de instalaciones eólicas en edificaciones. ............................................... 71

Figura I.35.-Área de turbulencia alrededor de un edificio. ....................................................... 71

\section{LISTA DE TABLAS:}

Tabla I.1.- Coeficientes de paso de energía final. Año 2016 [7] 


\section{I.1.-PANORAMA ENERGÉTICO MUNDIAL.}

La energía, en cualquiera de sus formas, es el eje alrededor del cual se encuentran todas las actividades en una sociedad, es el pilar que sostiene cualquier sistema productivo, y no solo eso, el nivel de productividad, confort y movilidad dependen directamente de la disposición de energía asequible y abundante.

La creciente sensibilización en el mundo sobre el futuro energético ha establecido un importante punto de partida respecto a los patrones utilizados en el pasado en la producción y uso de la energía. Por esta razón, la necesidad de garantizar la seguridad energética, controlar la contaminación provocada por la quema de combustibles y, obviamente, presentar batalla al creciente desafío que supone el cambio climático, requiere la reducción de las emisiones de gases de efecto invernadero, en especial de dióxido de carbono.

En todos los escenarios de tendencias energéticas mundiales contemplados por la Agencia Internacional de la Energía (de aquí en adelante IEA) en sus últimos informes, se prevén incrementos en la demanda de energía a nivel mundial [1]. Este incremento de la demanda estimado está cerca de un tercio entre 2013 y 2040 para un escenario central contemplado. La relación entre el crecimiento económico global, la demanda de energía y las emisiones asociadas de gases a la atmosfera está disminuyendo, como consecuencia de que algunos mercados importantes como China están siendo objetos de cambios estructurales en su economía, otros han alcanzado un punto de saturación de demanda de servicios energéticos, y todos adoptan tecnologías más eficientes energéticamente. Pese a estas señales de transición a un mercado de bajo carbono, las emisiones de $\mathrm{CO}_{2}$ relacionadas con la energía se prevé que sean un $16 \%$ superiores en 2040 .

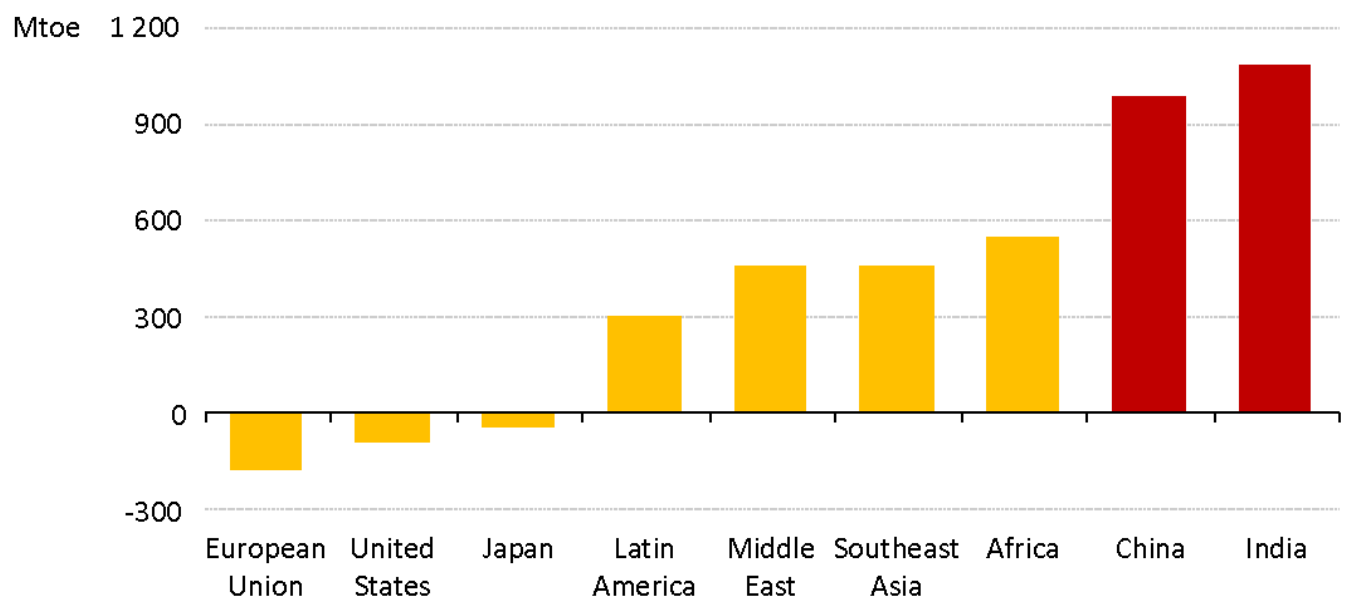

Figura I.1.- Cambio en la demanda de energía en diferentes regiones, 2014-2040. [1]

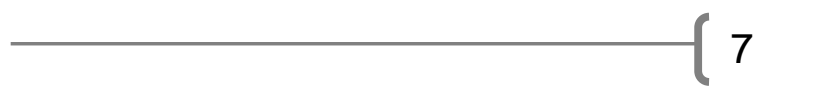


La necesidad mundial de electricidad provocará un aumento de la demanda de más de un $70 \%$ en 2040, en la generación de este tipo de energía se está llevando a cabo un gran esfuerzo por reducir las consecuencias medioambientales asociadas. A principios de la década de 2030 las renovables se posicionarán por delante del carbón como principal fuente de generación eléctrica, alcanzando en 2040 el 50\% de la generación en la Unión Europea, alrededor del 30\% en China y Japón, y por encima del 25\% en los Estados Unidos la India[1].

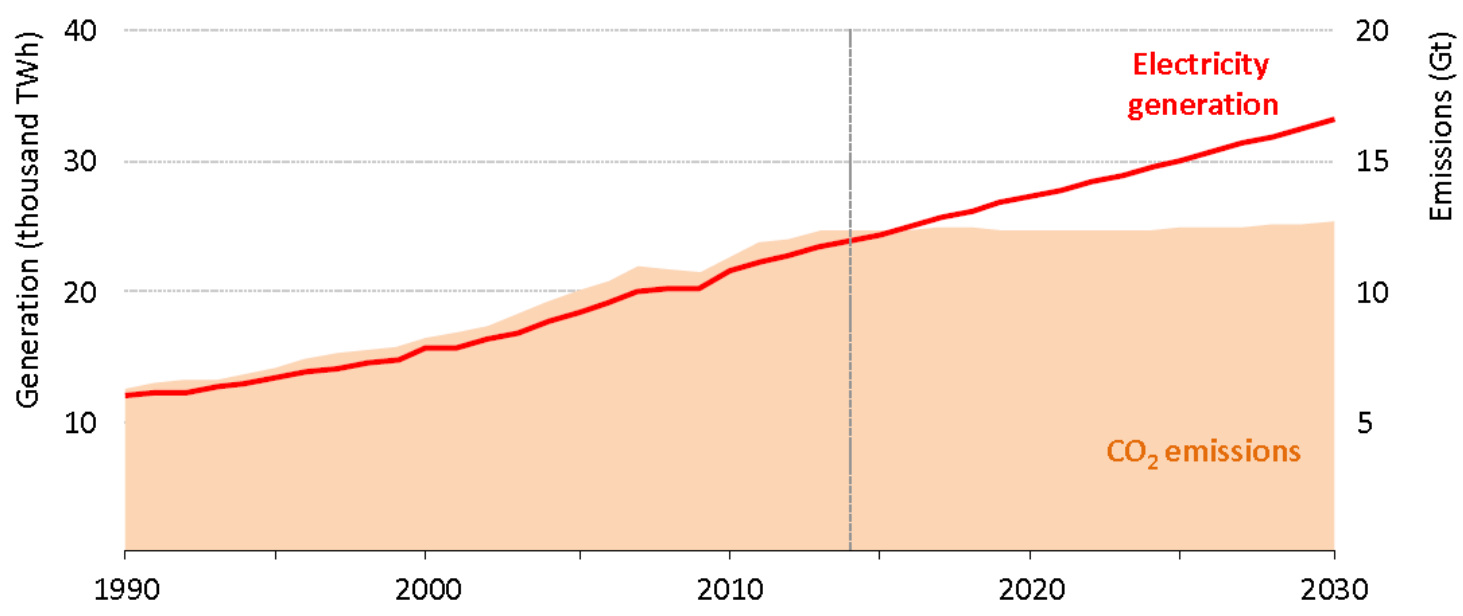

Figura I.2.- Generación mundial de energía eléctrica y emisiones de $\mathrm{CO}_{2}$ asociadas.

Fuente: Presentación World Energy Outlook 2015.

\section{I.2.- DESARROLLO SOSTENIBLE, ENERGÍA, MEDIO AMBIENTE Y SALUD.}

El impacto ambiental originado por el empleo de la energía no es nuevo. La utilización de la madera como combustible, durante siglos, ha dado lugar a la deforestación de muchas regiones. La industrialización en sus fases iniciales ocasionó niveles de contaminación muy importantes a nivel local en el aire, el agua y la tierra. A pesar de que el potencial de la energía para mejorar el bienestar es evidente, el vínculo entre la producción, el consumo de energía convencional y la problemática medioambiental lastra las condiciones iniciales hasta el punto de poner en juicio este sistema productivo con claras evidencias de impactos perjudiciales para el planeta.

Al igual que el impacto provocado por el uso de la energía no es nuevo, la preocupación por dicho impacto tampoco. Antes de la celebración, en junio de 1992, de la Conferencia de Medio Ambiente y Desarrollo de las Naciones Unidas (UNCED) en Río de Janeiro, eran pocas las personas que habían oído hablar de la expresión "desarrollo sostenible". En esta Conferencia se 
adoptó la "Declaración de Rio sobre el Medio Ambiente y el Desarrollo" [2], donde se recogían una serie de principios sin fuerza jurídicamente vinculante con el objetivo de alcanzar el desarrollo sostenible, reconociendo el derecho de los seres humanos a una vida saludable y productiva en armonía con la naturaleza (Principio 1), así como el derecho soberano de los Estados para aprovechar sus recursos naturales y haciendo explícita la responsabilidad de los mismos de velar por la conservación del medio ambiente, en el sentido de evitar que las actividades que se realizan bajo su jurisdicción o control causen daño al medio ambiente de otros Estados o en áreas fuera de cualquier jurisdicción nacional (Principio 2). En el marco de este objetivo, la Declaración contempla acciones que se deberían adoptar en el ámbito social, económico, cultural, científico, institucional, legal y político.

Pese a que fue en 1992 en Rio donde el concepto de desarrollo sostenible comenzó a amplificar su alcance, fue antes, en 1987 donde se introduce por primera vez dentro del Informe Brundtland denominado Nuestro Futuro Común, donde queda definido de la siguiente manera [3]:

«El conjunto de estrategias que garantizan la satisfacción de las necesidades actuales sin comprometer la capacidad de las generaciones futuras para satisfacer las suyas».

Además, este Informe concibe el desarrollo sostenible como un proceso multidimensional que afecta al sistema económico, ecológico y social.

Desde entonces han tenido lugar muchas Cumbres y Conferencias mundiales que han demostrado la disponibilidad, o no, de muchos países para hacer frente a los diferentes problemas que se presentan con el modelo energético que se desarrolla. Las Conferencias de Naciones Unidas sobre el Medio ambiente y el Desarrollo, conocidas como Cumbres de la Tierra, han sido:

- Cumbre de la Tierra de Estocolmo (1972), a la que asistieron representantes de 113 países, 19 organismos intergubernamentales, y más de 400 organizaciones intergubernamentales y no gubernamentales, es ampliamente reconocido como el comienzo de la conciencia moderna política y pública de los problemas ambientales globales. Fue dirigida por el primer ministro sueco para discutir el estado del medio ambiente mundial.

- Cumbre de la Tierra de Rio de Janeiro (1992), participaron 172 gobiernos, incluidos 108 Jefes de Estado y de Gobierno. Se adoptó un programa de acción llamado Agenda 21 (o Programa 21), que tiene en cuenta las cuestiones relacionadas con la salud, la vivienda, la contaminación del aire, la gestión de los mares, bosques y montañas, la desertificación, la gestión de los recursos hídricos y el saneamiento, la gestión de la agricultura, la gestión de residuos. Incluso hoy, la Agenda 21es la referencia para la aplicación del desarrollo sostenible en los territorios. 
- Cumbre de la Tierra de Rio de Johannesburgo (2002), participaron alrededor de 180 gobiernos y asistieron más de 60.000 personas. Se acordó mantener los esfuerzos de promoción del desarrollo sostenible como lucha a la pobreza creciente y el aumento del impacto negativo sobre el medio ambiente.

- Cumbre Rio + 20 (2012), participaron 193 delegaciones. Se alcanzó un acuerdo de mínimos que no cubría las expectativas existentes en el momento para muchos de los asistentes.

- Cumbre de Paris (2015), reunión del Clima COP21, tras dos semanas de intensas negociaciones las 196 delegaciones de los países participantes alcanzaron un pacto global que intentará limitar el aumento de las temperaturas del planeta a menos de 2 grados centígrados. Los principales aspectos del acuerdo son:

- La mencionada limitación de aumento de temperaturas a menos de dos grados.

- El acuerdo es jurídicamente vinculante para los países firmantes.

- Creación de fondos cercanos a los 100.000 millones de dólares para los países en desarrollo a partir de 2020.

- Revisión de los objetivos cada cinco años. Objetivos nacionales de cada país para reducir emisiones de gases de efecto invernadero.

- Aunque no se incluyen sanciones para los países incumplidores, sí les compromete a informar sobre sus emisiones y sus esfuerzos para reducirlas.

Un desarrollo sostenible debe basarse en la optimización de los recursos convencionales existentes y en la potenciación del uso de los recursos renovables alternativos, que permita garantizar una adecuada salud para las personas, un bienestar óptimo global a través de un mantenimiento o incluso mejora de las condiciones medioambientales, no solo de su entorno más próximo, si no a nivel global. 


\section{POLÍTICA ENERGÉTICA EN EUROPA.}

La estrategia Europa 2020 es una estrategia para un crecimiento inteligente, sostenible e integrador que propone, como uno de los cinco objetivos principales para la Unión Europea, el aprobado en el Consejo Europeo de marzo de 2007, conocido como 20-20-20 [4]:

- Reducción de las emisiones de gases de efecto invernadero en un 20\% respecto de 1990 con el compromiso bajo acuerdo internacional de elevar el objetivo hasta el $30 \%$.

- Alcanzar el $20 \%$ de fuentes renovables en el consumo energético de la UE en 2020 y un $10 \%$ en el sector del transporte.

- Aumentar la eficiencia energética con el fin de ahorrar un $20 \%$ del consumo energético de la UE respecto de las proyecciones para el año 2020.

La Unión Europea se encuentra actualmente en el umbral de cambios sin precedentes en la política energética, que precisan que la estrategia energética esté alineada con otros ejes de la acción pública: política económica, industrial, transporte, agricultura, cambio climático, competencia, investigación y desarrollo; y acción exterior.

Para ello, las cinco prioridades de actuación futura de la UE son las siguientes:

- Eficiencia energética

- Consolidación e integración del mercado europeo de la energía

- Desarrollo y promoción de tecnologías energéticas

- Facilitar el acceso a un suministro competitivo y seguro de energía

- Relaciones internacionales

Para alcanzar los objetivos establecidos en la planificación energética de la UE, se aprueban una serie de directivas y resoluciones que constituyen su marco legal.

\section{LA TECNOLOGÍA COMO ELEMENTO DE MEJORA.}

La aplicación de la tecnología ha supuesto el medio principal para alcanzar un mayor grado de productividad humana y, por consiguiente, del aumento de la calidad de vida. La tecnología basada en el desarrollo sostenible es clave para resolver los problemas arrastrados del pasado, así como para evitar la futura aparición de otros problemas.

Las tecnologías sostenibles reducen la contaminación del medio ambiente mediante el aprovechamiento de los avances técnicos. Puesto que la sociedad en general se beneficia de estas tecnologías, pueden considerarse un buen objetivo para la inversión pública. Los desarrollos tecnológicos se pueden entender como sostenibles económica y medioambientalmente cuando [5]: 
1) Reducen la contaminación del medio ambiente de forma efectiva.

2) Suponen un avance técnico importante con una tasa inferior de generación de residuos.

3) Son, de forma genérica, aplicables a partir de sus fases iniciales de desarrollo

4) Ofrecen una relación favorable de rendimiento social y de rendimiento para el sector privado.

El criterio relativo a la contaminación del medio ambiente debe interpretarse con suficiente amplitud de miras como para proteger la salud, el bienestar público y los intereses ecológicos. Los avances tecnológicos deben evitar la contaminación o reducir en gran medida los costes de prevención y control de esta.

Los posibles avances técnicos a incorporar a las tecnologías del futuro o existentes en las que mediante la incorporación de nuevos mecanismos permitan la disminución de la generación productos procedentes del proceso sin valorización fuera o dentro del mismo proceso productivo, deben de ser competitivos en el ámbito de la gestión para que tengan capacidad de penetración en los escenarios actuales. Un avance técnico importante podría radicar en que se haga realidad un método completamente nuevo para abordar un problema tal como el empleo de una fuente de energía renovable que elimine por completo la necesidad de quemar combustibles fósiles.

En resumen, las tecnologías sostenibles son aquellas asociadas a las técnicas preventivas o de un menor grado de impacto ambiental. Dichas tecnologías deben estar disponibles a escala comercial, mantener la compatibilidad económica y ser aceptables tanto desde la perspectiva social como medioambiental. Puesto que la tecnología constituye el elemento clave del desarrollo sostenible, es preciso asignar más recursos para las tareas correspondientes a la investigación y desarrollo en este sentido. 


\section{I.3.- EFICIENCIA ENERGÉTICA EN EDIFICIOS.}

Los edificios son los grandes consumidores de energía de nuestras ciudades. Gran parte del consumo final de energía en Europa, un tercio aproximadamente, se emplea en el acondicionamiento térmico de los espacios en los edificios y del agua caliente sanitaria.

La demanda de energía en los edificios residenciales deriva de una amplia variedad de usos y servicios, como la provisión de agua caliente sanitaria (ACS), climatización (sistemas HVAC), refrigeración, iluminación, cocina, etc. En lo que concierne a los equipos de climatización, incluyendo tanto calefacción como ventilación y acondicionamiento de aire, comprenden el mayor consumo energético tanto en el sector residencial, como se muestra en la siguiente figura [W-1]; como en el no residencial, cuando no tiempo atrás podían considerarse un lujo.

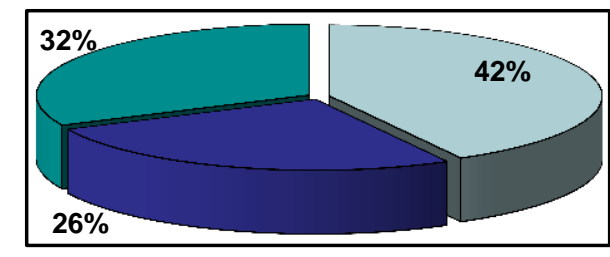

$\square$ Acondicionamiento térmico

口ACS

口lluminación y aparatos eléctricos

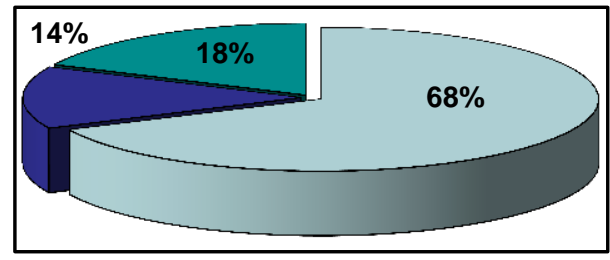

口Acondicionamiento térmico 口ACS

口lluminación y aparatos eléctricos

Figura I.3- Principales usos energéticos en edificios en España (izquierda) y Europa (derecha) [W-1].

Así mismo, y en función de la climatología local, el aumento en el número de instalaciones de sistemas de acondicionamiento en verano supone en los países desarrollados un incremento anual importante de demanda de electricidad, que no sólo implica las consecuencias conocidas derivadas de la producción, transformación y transporte, sino además la existencia de demandas punta que pueden saturar la red eléctrica (especialmente en los países meridionales; sólo España e Italia representan más del $50 \%$ del mercado europeo).

De forma aproximada, para naciones desarrolladas, la climatización representa la mitad de la energía consumida en los edificios y entre la décima y la quinta parte de la energía total. Además, los pronósticos indican un fuerte crecimiento del consumo y de la superficie climatizada en la UE [6].

No cabe duda que este motivo es más que suficiente para tratar de incorporar al sector de los edificios medidas de ahorro y eficiencia energética, ya sea mediante el reequipamiento de sistemas de climatización modernos y eficientes, empleando recursos energéticos renovables, o intentando 
disminuir la demanda térmica (mejorando la envolvente del edificio con aislamiento, elementos pasivos, etc.).

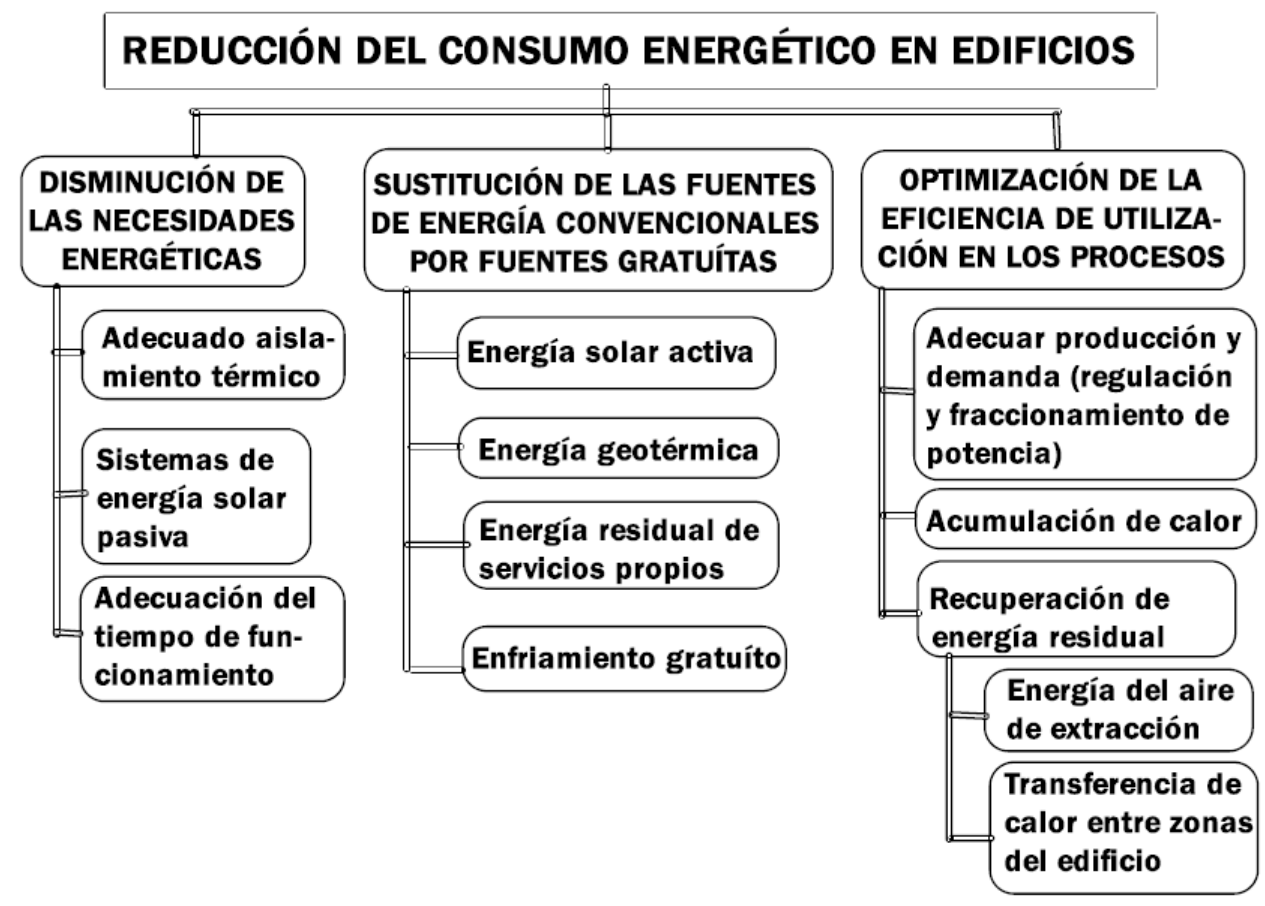

Figura I.4.- Reducción del consumo energético en edificios.

En las últimas décadas se ha producido un importante avance en el sector de las tecnologías con muy importantes mejoras en la eficiencia de los equipos y en la reducción de emisiones asociadas a la explotación de las instalaciones. Estas mejoras tecnológicas han venido impulsadas y acompañadas por mejoras y actualizaciones de las normativas técnicas que permiten con su nuevo carácter prestacional la incorporación de estos avances, estableciendo unos mínimos requisitos que fomentan la implantación de medidas que disminuyen la demanda y el consumo, favoreciendo a la vez el empleo de recursos energéticos renovables en el ámbito edificatorio.

\section{POLÍTICAS ENERGÉTICAS EN LA EDIFICACIÓN.}

\section{$\underline{E P D B}$.}

El sector de la edificación representa el $40 \%$ del consumo energético total de la Unión Europea (UE). La reducción del consumo de energía en este ámbito constituye, por lo tanto, una prioridad en el marco de los objetivos «20-20-20» en materia de eficiencia energética. La Directiva 2010/31//CE del Parlamento Europeo y del Consejo, del 19 de mayo de 2010 [N-1], se inscribe en 
esta voluntad proponiendo directrices para los Estados miembros en relación con la eficiencia energética de los edificios. Esta Directiva deroga a la Directiva 2002/91/CE.

Esta Directiva, conocida como la Directiva EPBD (Energy Performance of Builidings Directive) [N-1] [W-2] tiene por objeto promover la eficiencia energética de los edificios y unidades de los mismos, e implica para los Estados miembros una serie de obligaciones que se resumen a continuación.

Los Estados miembros tienen la obligación de adoptar, a nivel nacional o regional, una metodología de cálculo de la eficiencia energética de los edificios que tiene en cuenta determinados elementos, en especial:

- las características térmicas del edificio (capacidad térmica, aislamiento, etc.);

- la instalación de calefacción y de agua caliente;

- las instalaciones de aire acondicionado;

- la instalación de iluminación incorporada;

- las condiciones ambientales interiores.

La influencia positiva de otros elementos como la exposición solar local, la iluminación natural, la producción eléctrica por cogeneración y los sistemas de calefacción y refrigeración urbanos o colectivos también se tienen en cuenta.

Los Estados miembros tienen la obligación de establecer, con arreglo a la metodología de cálculo anteriormente citada, requisitos mínimos en materia de eficiencia energética para alcanzar niveles óptimos en términos de costes. El nivel de estos requisitos se revisa cada cinco años.

Cuando fijan los requisitos mínimos, los Estados miembros pueden hacer una distinción entre edificios nuevos y edificios existentes y entre diferentes categorías de edificios.

Los edificios nuevos deben respetar estas exigencias y, antes del inicio de su construcción, ser objeto de un estudio de viabilidad relativo a la instalación de sistemas de abastecimiento de energías renovables, bombas de calor, sistemas de calefacción y refrigeración urbanos o colectivos y sistemas de cogeneración.

Los edificios existentes, cuando son objeto de trabajos de renovación importantes, deben beneficiarse de una mejora de su eficiencia energética de tal forma que pueda satisfacer igualmente los requisitos mínimos.

Quedan excluidos de la aplicación de los requisitos mínimos:

- Los edificios protegidos oficialmente (por ejemplo, edificios históricos).

- Los edificios utilizados como lugares de culto.

- Las construcciones provisionales. 
- Los edificios residenciales destinados a una duración de uso anual limitada.

- Los edificios independientes de una superficie útil total inferior a $50 \mathrm{~m}^{2}$.

Cuando son de instalación nueva, se sustituyen o modernizan tanto los sistemas técnicos del edificio como los sistemas de calefacción, agua caliente, climatización y grandes instalaciones de ventilación, estos también deben cumplir los requisitos en materia de eficiencia energética.

Los Estados miembros adoptarán las medidas necesarias para garantizar que, cuando se proceda a la sustitución o mejora de los elementos de un edificio que integren la envolvente del edificio y que repercutan de manera significativa en la eficiencia energética de dicha envolvente (por ejemplo, marcos de ventana), se fijen unos requisitos mínimos de eficiencia energética para ellos, con el fin de alcanzar unos niveles óptimos de rentabilidad.

Siempre que se reconstruya o renueve un edificio, la presente Directiva fomenta la introducción de sistemas inteligentes de medición del consumo de energía, con arreglo a la Directiva sobre normas comunes para el mercado interior de la electricidad.

\section{Edificios de consumo de energía casi nulo.}

A partir del 31 de diciembre de 2020, todos los edificios nuevos deben tener un consumo de energía casi nulo. Los nuevos edificios que estén ocupados y que sean propiedad de las autoridades públicas deben cumplir los mismos criterios después del 31 de diciembre de 2018.

La Comisión promueve el crecimiento del número de edificios de este tipo mediante la puesta en marcha de planes nacionales, que incluyen la aplicación detallada en la práctica por el Estado miembro de la definición de edificios de consumo de energía casi nulo; unos objetivos intermedios para mejorar la eficiencia energética de los edificios nuevos; e información sobre las políticas y medidas financieras o de otro tipo adoptadas para promover este tipo de edificios.

Los Estados miembros se encargan de establecer una lista de instrumentos existentes y potenciales cuyo objetivo es promover la mejora de la eficiencia energética de los edificios.

\section{Certificados de eficiencia energética:}

Los Estados miembros deben poner en marcha un sistema de certificación de la eficiencia energética de los edificios. Esto incluye, en especial, la información sobre el consumo energético de los edificios, así como las recomendaciones relativas a la reducción de costes.

Cuando un edificio o una unidad de un edificio se proponga para la venta o alquiler, el indicador de eficiencia energética del certificado de eficiencia debe figurar en la publicidad que aparezca en los medios publicitarios. 
Durante la construcción, venta o alquiler de un edificio o de una unidad de un edificio, este certificado se mostrará al nuevo inquilino o al comprador potencial, y se le transmitirá.

En cuanto a los edificios con una superficie total superior a $250 \mathrm{~m}^{2}$ que estén ocupados por una autoridad pública y los edificios con una superficie total superior a $250 \mathrm{~m}^{2}$ que reciban visitas frecuentes del público, se colocará el certificado de eficiencia energética en un sitio claramente visible.

Esta Directiva también indica que los Estados se encargan de poner en marcha un sistema de control regular de los sistemas de calefacción y climatización de los edificios.

Otras Directivas enmarcadas en los objetivos "20-20-20" y relacionadas con la eficiencia energética en la edificación son las relativas al [W-3]:

- Fomento del uso de energía de fuentes renovables (RES) [N-2]. Con la Directiva RES debe aumentarse sustancialmente el porcentaje de energía renovable en la UE. Los Estados miembros se comprometen a tomar medidas con las que se aumente el porcentaje de energías renovables en la UE en, al menos, un $20 \%$ hasta 2020. En el marco del llamado «Burden-sharing», a cada Estado miembro se le imponen normas en particular.

- Diseño ecológico de productos que utilizan energía (ErP) [N-3]. La ErP determina los requisitos mínimos en relación a las propiedades ecológicas de los productos que consumen energía. En esta Directiva se comprenden, por ejemplo, calderas, calentadores de agua, bombas, ventiladores y equipos de climatización y ventilación de viviendas. A día de hoy el texto de la Directiva ErP ha sido refundido debido a la necesidad de ampliar su alcance: pasando de incluir los productos que utilizan energía a todos aquellos productos relacionados con la energía. De esta forma, a partir de ahora se hablará de la Directiva ErP.

- Indicación del consumo de energía y otros recursos por parte de los productos relacionados con la energía, mediante el etiquetado y una información normalizada (Directiva 2010/30/UE) [N-4]. Esta Directiva establece un marco relativo a la indicación y a la información de los consumidores sobre el consumo de energía de los productos relacionados con la energía. Se aplicará a los productos susceptibles de tener una incidencia directa o indirecta sobre el consumo de energía y sobre otros recursos potenciales durante el consumo. 

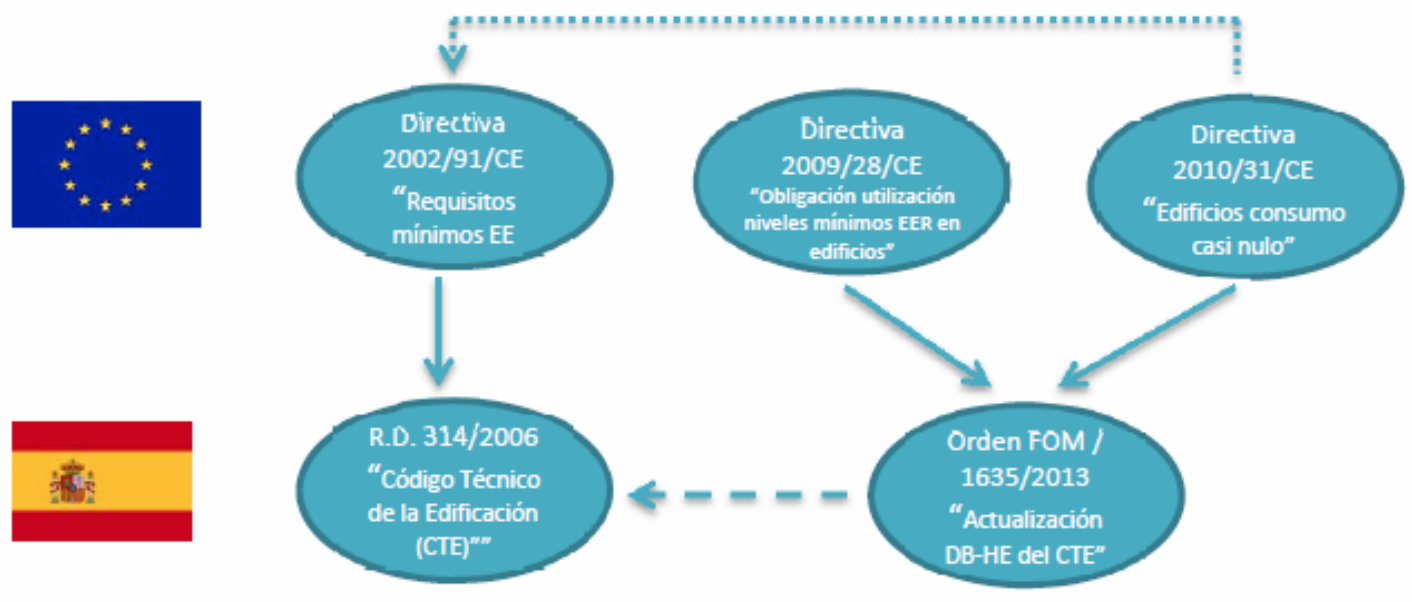

Figura I.5.- Esquema del marco normativo Europeo y su trasposición a nivel estatal.

La intensificación de los requisitos energéticos sobre la eficiencia energética total de edificios a través de la EPBD, la determinación de requisitos mínimos para los productos que consumen energía y los ambiciosos objetivos para el aumento del porcentaje de energía renovable, fuerzan a una consecuente mejora de la calidad energética de los edificios. Para la tecnología de las instalaciones esto significa que en el futuro sólo se podrán modernizar en combinación con energías renovables.

Este aumento en el consumo energético y emisiones de dióxido de carbono asociadas al sector de la edificación, ha convertido los conceptos de eficiencia y ahorro energético en estrategias prioritarias de las políticas energéticas en la mayoría de los países.

A nivel nacional, dicha directiva europea (queda transpuesta al ordenamiento jurídico español a través del Real Decreto 47/2007, más tarde derogado por el R.D. 235/2013 de 5 de abril [N-5], por el que se aprueba el procedimiento básico para la certificación de eficiencia energética de edificios; así como por el Real Decreto 314/2006 de 17 de marzo, en el que se aprobaba el Código Técnico de la Edificación [N-6] que ha sufrido diversas modificaciones desde su entrada en vigor, introducido por la Ley de Ordenación de la Edificación [N-8]. Así mismo ha sido necesaria una revisión del antiguo Reglamento de Instalaciones Térmicas en Edificios con el Real Decreto 1027/2007 [N-7] para implantar estas nuevas normativas (modificado este último por el Real Decreto 238/2013). En los siguientes subapartados se resumen brevemente estas normativas nacionales. 


\section{CERTIFICACIÓN ENERGÉTICA DE EDIFICIOS.}

El Real Decreto 235/2013 [N5] establece la obligación de poner a disposición de los compradores o usuarios de los edificios un certificado de eficiencia energética que deberá incluir información objetiva sobre la eficiencia energética de un edificio y valores de referencia tales como requisitos mínimos de eficiencia energética con el fin de que los propietarios o arrendatarios del edificio o de una unidad de éste puedan comparar y evaluar su eficiencia energética. Los requisitos mínimos de eficiencia energética de los edificios o unidades de éste no se incluyen en este real decreto, ya que se establecen en el Código Técnico de la Edificación [N6]. De esta forma, valorando y comparando la eficiencia energética de los edificios, se favorecerá la promoción de edificios de alta eficiencia energética y las inversiones en ahorro de energía. Además, este real decreto contribuye a informar de las emisiones de $\mathrm{CO}_{2}$ por el uso de la energía proveniente de fuentes emisoras en el sector residencial, lo que facilitará la adopción de medidas para reducir las emisiones y mejorar la calificación energética de los edificios.

A partir de la entrada en vigor de este Real Decreto se hace extensible la obligatoriedad de contar con dicho certificado a los edificios existentes o partes de los mismos que se vendan o alquilen a un nuevo arrendatario a partir de mayo de 2013, existiendo esa obligatoriedad desde finales de 2007 para los edificios nuevos, los cuales ya debían de disponer de un certificado para la fase del proyecto y otro del edificio una vez terminada su construcción.

Este Certificado de Eficiencia Energética contiene una etiqueta de eficiencia energética, entre otra documentación, en la cual se asigna a cada edificio o unidad del mismo objeto de la certificación una clase energética de eficiencia, que varía desde la clase $A$, para los energéticamente más eficientes, a la clase G, para los menos eficientes.

\section{CÓDIGO TÉCNICO DE LA EDIFICACIÓN (CTE)}

Por su parte, el Código Técnico de la Edificación [N5] (mediante su aprobación en el R.D. 314/2006) transpone parcialmente la Directiva europea 2002/91/CE en lo que se refiere a los requisitos mínimos de eficiencia energética que deben cumplir los edificios nacionales para que se ajusten a los requisitos básicos, establecidos en la Ley de Ordenación de la Edificación (LOE) [N14], que garanticen ciertas necesidades de las personas en cuestiones de seguridad y habitabilidad (acústicas, térmicas, estructurales, etc.). Con motivo de la entrada en vigor de la nueva Directiva que derogaba a la citada 2002/91/CE, el CTE ha sufrido actualizaciones en el documento básico relativo al uso de la energía, el CTE-HE, entrando en vigor esta actualización en septiembre de 2013. 
Las Exigencias Básicas de calidad que deben cumplir los edificios se refieren a materias de seguridad: seguridad estructural, seguridad contra incendios, seguridad de utilización; y habitabilidad: salubridad, protección frente al ruido y ahorro de energía.

EI CTE pretende dar respuesta a la demanda de la sociedad en cuanto a la mejora de la calidad de la edificación a la vez que persigue mejorar la protección del usuario y fomentar el desarrollo sostenible. EI CTE se aplica a edificios de nueva construcción, a obras de ampliación, modificación, reforma o rehabilitación y a determinadas construcciones protegidas desde el punto de vista ambiental, histórico o artístico.

Una de las principales novedades que introduce CTE respecto a la legislación anterior de la edificación en España fue el enfoque por objetivos o prestaciones, que son el conjunto de características objetivas de un edificio que contribuyen a determinar su aptitud para responder a diferentes a las funciones para las que fue diseñado.

Hasta la aprobación del CTE en 2006, la regulación de la edificación había sido de carácter prescriptivo, es decir, establecía los procedimientos aceptados o las guías técnicas que debían seguirse a la hora de construir un edificio. Este tipo de códigos suponen en la práctica una barrera técnica que obstaculiza la aplicación de innovaciones tecnológicas al proceso de edificación.

EI CTE se encarga de enunciar los criterios que deben cumplir los edificios pero deja abierta la forma en que deben cumplirse estas reglas. Esta particularidad, que está presente en las regulaciones de la mayor parte de los países de nuestro entorno, permite la configuración de un entorno normativo más flexible.

De esta forma, el CTE favorece el desarrollo de tareas de investigación, desarrollo e innovación $(\mathrm{I}+\mathrm{D}+\mathrm{i})$, así como un aumento del uso de las nuevas tecnologías al integrar de forma más directa los avances logrados gracias a estas actividades. Así, el enfoque de prestaciones permite la utilización de innovaciones técnicas sin perder de vista los elementos tradicionales del método de la construcción.

El Código Técnico de la Edificación está dividido en dos partes. En la primera se detallan todas las exigencias en materia de seguridad y de habitabilidad que son preceptivas a la hora de construir un edificio, según la Ley de Ordenación de la Edificación. La segunda de un carácter más técnico.

La primera parte está subdividida a su vez en varias secciones referidas cada una de ellas a las distintas áreas que deben regularse. En el ámbito de la seguridad nos encontramos las disposiciones referidas a la seguridad estructural, la seguridad en caso de incendios y la seguridad de utilización. Mientras, en el área de habitabilidad están incluidos los requisitos relacionados con la salubridad, la protección frente al ruido y el ahorro de energía. 
La segunda se compone de los Documentos Básicos (DB), que son textos de carácter técnico que se encargan de trasladar al terreno práctico las exigencias detalladas en la primera parte del CTE. Cada uno de los documentos incluye los límites y la cuantificación de las exigencias básicas y una relación de procedimientos que permiten cumplir los requisitos.

Los Documentos Básicos son los siguientes:

- DB SE: Seguridad estructural.

- DB SI: Seguridad en caso de incendio

- DB SUA: Seguridad de utilización y accesibilidad

- DB HS: Salubridad

- DB HE: Ahorro de energía

- DB HR: Protección frente al ruido.

La normativa se completa con los documentos reconocidos, que son textos de carácter técnico y sin poder reglamentario. Estos documentos cuentan con el visto bueno del Ministerio de Vivienda, que configura periódicamente una lista actualizada de los mismos denominada Registro General del Código Técnico de la Edificación.

Dentro del Documento Básico HE de ahorro de energía se encuentran las siguientes secciones:

-HE 0 Limitación del consumo energético.

-HE 1 Limitación de la demanda energética.

-HE 2 Rendimiento de las instalaciones térmicas.

-HE 3 Eficiencia energética de las instalaciones de iluminación.

-HE 4 Contribución solar mínima de agua caliente sanitaria.

-HE 5 Contribución fotovoltaica mínima de energía eléctrica.

\section{REGLAMENTO DE INSTALACIONES TÉRMICAS EN EDIFICIOS (RITE)}

La necesidad de transponer la Directiva europea 2002/91/CE, así como la coherencia con el CTE, implicaba la incorporación de nuevas exigencias de ahorro y eficiencia energética de las instalaciones térmicas en los edificios, lo que convergió en la revisión del Reglamento de Instalaciones Térmicas en Edificios [N-7], derogándose el anterior con el Real Decreto 1027/2007. Además, dicha revisión permitía introducir en el nuevo documento la experiencia acumulada de la aplicación del viejo RITE desde su puesta en vigor.

Este nuevo reglamento tiene un marcado carácter ambiental y de atención a las personas y su salud, aplicando medidas que se dirigen a la mejora de la calidad del aire en las ciudades y a la reducción del impacto ambiental a nivel más global. 
Este reglamento establece las condiciones que deben cumplir las instalaciones destinadas a atender la demanda de bienestar térmico e higiene a través de las instalaciones de calefacción, climatización y agua caliente sanitaria, para conseguir un uso racional de la energía.

Las mayores exigencias en eficiencia energética que establecen en el último RITE, se concretan en:

- Mayor Rendimiento Energético en los equipos de generación de calor y frío, así como los destinados al movimiento y transporte de fluidos.

- Mejor aislamiento en los equipos y conducciones de los fluidos térmicos.

- Mejor regulación y control para mantener las condiciones de diseño previstas en los locales climatizados.

- Utilización de energías renovables disponibles, en especial la energía solar y la biomasa.

- Incorporación de subsistemas de recuperación de energía y el aprovechamiento de energías residuales.

- Sistemas obligatorios de contabilización de consumos en el caso de instalaciones colectivas.

- Desaparición gradual de combustibles sólidos más contaminantes.

- Desaparición gradual de equipos generadores menos eficientes.

- Establecimiento de unos requisitos en relación con la eficiencia energética general, la instalación correcta y el dimensionamiento, control y ajuste de las instalaciones térmicas.

- Inspecciones periódicas en las instalaciones.

Con el fin de facilitar el cumplimiento de las exigencias del RITE se crean los denominados documentos reconocidos, que se definen como documentos técnicos sin carácter reglamentario, pero que cuentan con el reconocimiento conjunto del Ministerio de Industria, Energía y Turismo y el Ministerio de Fomento.

Además, el Reglamento impone la obligación de revisar y actualizar las exigencias de eficiencia energética en períodos de al menos 5 años; tarea encargada a la Comisión Asesora del RITE, la cual elabora las propuestas conforme a la evolución de la técnica y la política energética nacional.

El Reglamento de Instalaciones Térmicas en Edificios está conformado por dos partes: una primera en la que se describen las disposiciones generales y una segunda en la que se desarrollan las instrucciones técnicas relativas a su aplicación. Dentro de esta segunda, existe un apartado dedicado a las exigencias de eficiencia energética de las instalaciones (IT 1.2.), para cuya correcta aplicación se establecen la necesidad de un procedimiento de verificación.

EI RITE plantea dos posibles procedimientos de verificación: uno simplificado y prescriptivo, y otro alternativo que deja abierta la posibilidad de innovación (procedimiento prestacional). El 
primero de ellos consiste en la adopción de soluciones basadas en la limitación indirecta del consumo de energía de la instalación, mediante el cumplimiento de valores límite y soluciones especificadas en el propio reglamento para cada sistema o subsistema diseñado, y cuyo cumplimiento asegura la superación de la exigencia de eficiencia energética. Por su parte, el segundo procedimiento plantea la posibilidad de recurrir a propuestas ajenas a lo establecido en el texto, siempre y cuando estas sean válidas; es decir, que cumplan o mejoren los requerimientos de eficiencia establecidos, en $\mathrm{kg}$ de $\mathrm{CO}_{2}$ emitidos por el sistema.

La metodología seguida para la caracterización de la eficiencia energética sigue una serie de pasos que concluyen en la determinación de la energía primaria consumida y las emisiones de $\mathrm{CO}_{2}$ asociadas. Para ello se parte de la obtención de la demanda térmica del sistema, a partir de la cual se obtiene el valor del consumo solicitado al mismo. Una vez realizada la simulación de las instalaciones térmicas a fin de obtener el rendimiento medio de las mismas, se procede a calcular los consumos como el cociente entre la demanda y dicho rendimiento. Obtener las emisiones de $\mathrm{CO}_{2}$ ocasionadas por ese consumo resulta ya inmediato, recurriendo al correspondiente valor del coeficiente de paso para la energía primaria, o en su caso para la energía eléctrica consumida. Estos coeficientes de paso deberán ser suministrados por la Administración con frecuencia anual.

Tabla I.1.- Coeficientes de paso de energía final. Año 2016 [7].

\begin{tabular}{|c|c|c|c|}
\hline & \multirow{2}{*}{ ENERGÍA } & \multicolumn{2}{|c|}{ COEFICIENTES DE PASO } \\
\hline & & $\begin{array}{l}\text { kWh energía primaria/ } \\
\text { kWh energía final }\end{array}$ & $\mathrm{g} \mathrm{CO}_{2} / \mathrm{kWh}(\mathrm{t} \circ \mathrm{e})$ \\
\hline \multirow{7}{*}{$\begin{array}{l}\text { Energía } \\
\text { Térmica }\end{array}$} & Gas Natural & 1,195 & 252 \\
\hline & Gasóleo-C & 1,182 & 311 \\
\hline & GLP & 1,204 & 254 \\
\hline & Carbón (doméstico) & 1,084 & 472 \\
\hline & Biomasa & $1, .37 / 1,113$ & 0,018 \\
\hline & Biocarburantes & Neutro (0) & Neutro (0) \\
\hline & Solar térmica & 0 & 0 \\
\hline \multirow{3}{*}{$\begin{array}{l}\text { Energía } \\
\text { eléctrica }\end{array}$} & Convencional peninsular & 2,403 & 331 \\
\hline & Convencional extrapeninsular & 3,011 & 833 \\
\hline & Solar fotovoltaica & 0 & 0 \\
\hline
\end{tabular}




\section{I.4.- CALIDAD DEL CLIMA INTERIOR EN EDIFICIOS.}

El gran interés en el desarrollo de mejores niveles de vida, unido al aumento del tiempo que las personas pasan en el interior de los edificios (estimado en un $90 \%$ en la actualidad), crea la necesidad de asegurar unas condiciones ambientales aceptables en los espacios interiores. Esta reciente necesidad evoluciona de forma paralela al desarrollo de los conocimientos sobre las repercusiones asociadas a estas condiciones ambientales.

No solo el confort de los ocupantes es necesariamente el único factor a tener en cuenta a la hora de determinar las condiciones ambientales de un espacio. A nivel global, se estudia la calidad de un ambiente o espacio interior IEQ (Indoor Environmental Quality) a través de la cuantificación y cualificación de varios factores como: la calidad del aire que respiran IAQ (Indoor Air Quality) [N-8] [N-9], el ruido, las vibraciones, la iluminación, la temperatura, radiación, la humedad [N-10] y otros factores visuales o ergonómicos que pueden tener repercusión en la salud de las personas.

Se habla de Calidad del Clima Interior ICQ (Indoor Climate Quality) en referencia a los factores asociados a la calidad del aire, IAQ, y al confort térmico. La calidad del ambiente interior está relacionada directamente con la productividad de las personas en sus lugares de trabajo o estudio. Esta circunstancia que ha comenzado a ser tenida en cuenta recientemente, puede llegar a tener un peso relevante en los costes asociados al personal, ya que no sólo su bienestar puede suponer un aumento de un $1 \%$ en su productividad, sino que también se reducen los costes debidos a problemas de su salud o a daños y averías en los equipos utilizados [8]

Sin embargo, el alcance de unas condiciones ambientales óptimas que aseguren tanto el confort como la salud y productividad de sus ocupantes, no tiene que suponer un hándicap para la consecución de un edificio energéticamente eficiente $[9,10]$. La evaluación de la calidad de los espacios interiores debe orientarse, por lo tanto, a compatibilizar estos requisitos con los de eficiencia energética establecidos por las distintas normativas, derivadas a nivel europeo de la ya presentada Directiva sobre Eficiencia Energética en Edificios (Energy Performance of Buildings Directive 2002/91/EC) [N-1]. De esta forma, un edificio y sus instalaciones deberán proporcionar un adecuado ambiente para las personas con un consumo razonable a tenor de lo recogido en las reglamentaciones de aplicación.

No obstante, es importante tener en cuenta que el consumo del edificio no solo va a estar influenciado por las necesidades derivadas de unas adecuadas condiciones ambientales. Las acciones llevadas a cabo para alcanzar esos niveles de confort, su actividad, los horarios de ocupación y la operación de los sistemas de climatización van a determinar el consumo final. 


\section{CONFORT TÉRMICO}

Los criterios de confort térmico, su campo de aplicación y la definición de los índices introducidos para su caracterización en función de los parámetros de relevancia, están recogidos en diversas normativas internacionales [N-10] [N-11], a su vez traspuestos a nivel nacional a través de la normativa correspondiente [N-12].

La norma CEN 15251 abarca de forma general todos los aspectos de calidad de espacios interiores IEQ, por lo que no sólo se limita a regular el ámbito del confort térmico sino que también aborda la calidad del aire, iluminación o ruido. En este documento se proporcionan criterios de dimensionamiento de los edificios y sus sistemas de climatización, además de aquéllos requeridos sobre los parámetros ambientales para el cálculo energético establecido en la EPBD, y los de evaluación, clasificación e inspección de los ambientes interiores. Asimismo recopila en los anexos una amplia relación de recomendaciones e indicaciones sobre los distintos criterios.

El estándar europeo ISO 7730, y análogamente su correspondiente normativa Española UNEEN ISO 7730, se centra en consideraciones sobre el bienestar térmico, indicando qué condiciones son precisas para alcanzar dicho estado de confort y estableciendo las vías de categorización en función de la evaluación subjetiva prevista por los propios ocupantes.

\section{CALIDAD DEL AIRE}

Los aspectos citados en cuanto a calidad del aire vienen especificados y regulados en diversa normativa internacional y los correspondientes documentos que trasponen dichas directrices a nivel nacional, referenciados a lo largo del texto anterior. Las normas internacionales orientadas a la calidad del aire de espacios interiores son, en EEUU, la norma ASHRAE 62 [N-13]; y en Europa la norma CR 1752 [N-8], traspuesta en España directamente a través de la PN CR 1752 [N-9], y la más reciente EN 15251 [N-10].

La norma 62 de ASHRAE (American Society of Heating, Refrigeration and Air Conditioning Engineers) sobre "Ventilación para una Calidad del Aire Interior Aceptable" establece un método prescriptivo de determinación de los requisitos de ventilación de los espacios interiores, basado en el cálculo, en función de la carga contaminante por ocupación y debida al propio edificio, de los caudales de ventilación necesarios para mantener las concentraciones de contaminantes bajo los valores límites.

En Europa, la norma CR 1752 de la Comisión Europea de Normalización (CEN), y su equivalente a nivel nacional PN CR 1752, establecen un conjunto de criterios para la clasificación de los edificios en términos de calidad ambiental proporcionada en su interior. Adopta la utilización de tres clases de aceptación de los ambientes interiores - A, B y C - según varios aspectos 
respecto a los cuales pueden ser evaluados los ambientes interiores (ambiente térmico, calidad del aire interior, ruido e iluminación). Esta norma plantea la introducción de la posibilidad de utilización de criterios subjetivos basados en la percepción sensorial humana para el estudio de la calidad ambiental interior. A partir de evaluaciones de ambientes interiores realizados, la norma establece los porcentajes de personas insatisfechas en función del caudal de aire de ventilación aportado al espacio. También esta considera el efecto tanto de la carga contaminante debida a ocupación como la del propio edificio

La norma europea EN 15251 es una norma elaborada por la Comisión Técnica TC 156 Ventilación para Edificios de CEN, la cual adopta los mismos criterios que la CR 1752 en cuanto a la calidad del aire interior y a los requisitos de ventilación. Esta norma suele resultar en valores de caudal de ventilación más elevados que la norma ASHRAE 62, ya que considera la evaluación subjetiva por sensación de aire viciado realizada por un ocupante que llega a un determinado ambiente.

La semejanza que presentan las normas europeas CR 1752 y EN 15251 con la norma ASHRAE 62, es que consideran la posibilidad de definir los caudales de aire de ventilación necesarios para la dilución de los contaminantes en base a un método analítico. También está contemplada la posibilidad de utilizar sistemas de control de la tasa de ventilación en función de las necesidades ("demand controlled ventilation") controlados por medidores de calidad de aire interior, particularmente sensores de concentración de dióxido de carbono.

\section{REGLAMENTO DE INSTALACIONES TÉRMICAS EN LOS EDIFICIOS: EXIGENCIAS DE} BIENESTAR E HIGIENE.

El Reglamento de Instalaciones Térmicas en los Edificios (RITE) [N-7] recoge las exigencias relacionadas con el bienestar e higiene en los edificios, enmarcándolas en cuatro categorías:

1. Exigencia de calidad térmica del ambiente: define una serie de parámetros y establece unos límites para ellos:

a. Temperatura operativa y humedad relativa.

b. Velocidad media del aire.

c. Otras condiciones de bienestar. Pide tener en consideración las molestias por corrientes de aire, la estratificación del aire, suelos calientes y fríos y asimetría de temperatura radiante (valorándolos de acuerdo a la norma UNE-EN-ISO7730).

2. Exigencia de la calidad del aire interior. 
a. En edificios de viviendas: remite al CTE-HS3 [N-6], Calidad del aire interior. Allí se definen unos caudales mínimos de ventilación. Posibilita la obtención de los caudales por ocupantes, por metro cuadrado útil o por otros parámetros. Ofrece valores para cada una de las posibilidades.

b. En el resto de edificios es exigido un sistema de ventilación para el aporte del suficiente caudal de aire exterior que evite, en los distintos locales en los que se realice alguna actividad humana, la formación de elevadas concentraciones de contaminantes. Para ello establece unas categorías de calidad del aire interior en función del uso de los edificios:

i. IDA 1 (aire de óptima calidad): hospitales, clínicas, laboratorios y guarderías.

ii. IDA 2 (aire de buena calidad): oficinas, residencias (locales comunes de hoteles y similares, residencias de ancianos y de estudiantes), salas de lectura, museos, salas de tribunales, aulas de enseñanza y asimilables y piscinas.

iii. IDA 3 (aire de calidad media): edificios comerciales, cines, teatros, salones de actos, habitaciones de hoteles y similares, restaurantes, cafeterías, bares, salas de fiestas, gimnasios, locales para el deporte (salvo piscinas) y salas de ordenadores.

iv. IDA 4 (aire de calidad baja).

En función de esa categoría permite el cálculo del caudal exterior con cinco métodos diferentes:

i. Método indirecto de caudal de aire exterior por persona

ii. Método directo por calidad del aire percibido.

iii. Método directo por concentración de $\mathrm{CO}_{2}$.

iv. Método indirecto de caudal de aire por unidad de superficie.

v. Método de dilución.

También recoge las necesidades de filtración mínimas del aire exterior de ventilación en función de la calidad del aire exterior (ODA) y de la calidad del aire interior requerida (IDA). La calidad del aire exterior (ODA) se clasificará de acuerdo con los siguientes niveles:

i. ODA 1: aire puro que se ensucia sólo temporalmente (por ejemplo polen). 
ii. ODA 2: aire con concentraciones altas de partículas y, o de gases contaminantes.

iii. ODA 3: aire con concentraciones muy altas de gases contaminantes (ODA 3G) y, o de partículas (ODA 3P).

3. Exigencia de higiene en la preparación del agua caliente sanitaria, en piscinas climatizadas, en humidificadores y con la exigencia de limpieza de conduxtos y plenums de aire.

4. Exigencia de calidad del ambiente acústico. CTE-HR: Protección frente al ruido [N-6].

\section{5.- AHORRO ENERGÉTICO EN SISTEMAS DE CLIMATIZACIÓN. TECNOLOGÍAS EFICIENTES Y RENOVABLES INTEGRADAS EN EDIFICIOS.}

Las estrategias que permiten alcanzar un ahorro energético en los edificios se enmarcan dentro de dos grandes grupos:

A. Estrategias pasivas encaminadas a disminuir la demanda. De vital importancia en la fase de diseño y planificación. La compacidad del edificio, la orientación de los cerramientos y de los huecos, la aportación de luz natural a los espacios de ocupación permanente, la calidad de los materiales y elementos, los niveles de aislamiento y la eliminación de los puentes térmicos. son algunos de los factores que establecerán cuánta energía solicita el edificio para mantener unas condiciones de bienestar para los ocupantes en su interior.

B. Estrategias activas encaminadas a disminuir el consumo energético asociado a esa demanda existente. Aquí es donde tiene repercusión el empleo de tecnologías eficientes y de origen renovable. Una adecuada integración de las mismas junto con una gestión energética optimizada permitirá reducir el consumo energético y el impacto ambiental debido a la operación del edificio.

No hay que olvidar que no es únicamente en la fase de ocupación o uso del edificio cuando se consume energía; hay que tener en cuenta que en la construcción y al final de la vida útil también se consume un ratio de energía importante. Es por ello, que el empleo de materiales y elementos reciclados, reciclables, reutilizables y/o de bajo consumo energético durante su fabricación disminuye sustancialmente el empleo de energía asociado al edificio. 
Particularizando en los sistemas de climatización, existen actualmente diversas tecnologías que permiten obtener condiciones óptimas en el interior de los edificios empleando mucha menos energía de origen fósil que años atrás, o incluso sin necesidad de emplearla, utilizando energías renovables y/o sistemas de recuperación de energía ya empleada en el propio edificio o proximidades antes de que sea desechada.

De este modo, a continuación se presentan en cuatro grandes grupos estas opciones existentes:

- Tecnologías eficientes en la generación de calor y frío.

- Sistemas de enfriamiento gratuito.

- Recuperación de energía.

- Tecnologías que emplean energías de origen renovable.

\section{I.5.1.- TECNOLOGÍAS PARA EL AHORRO EN LA GENERACIÓN DE CALOR O FRÍO.}

El uso de sistemas más eficientes en la generación de calor o frío, trae como consecuencia una reducción del consumo de energía convencional, bien eléctrica o de origen fósil. $A$ continuación se describen algunos sistemas que se pueden utilizar como alternativas a los tradicionales.

\section{I.5.1.1.- CALDERAS DE BAJA TEMPERATURA Y CONDENSACIÓN.}

La necesidad de nuevas tecnologías más eficientes en la producción de calor surgió después de la década de los 70, ante la crisis energética y la carencia de calderas que permitieran ajustar su temperatura de funcionamiento a las necesidades reales. Hasta entonces era habitual encontrar edificios con temperaturas de más de $27-28^{\circ} \mathrm{C}$ en el interior en donde los usuarios se veían obligados a abrir las ventanas en pleno invierno para alcanzar el confort en el interior.

Es destacable que la temperatura de diseño que se emplea para el cálculo de las instalaciones se alcanza muy pocas horas al año en la temporada de calefacción. Sin ir más lejos, nos podemos encontrar con temperaturas de diseño de $-4^{\circ} \mathrm{C}$ para una localidad en la que la temperatura media durante las horas de uso de los sistemas en los meses de calefacción sea de $10^{\circ} \mathrm{C}$. Como es lógico, la opción de dejar sin cobertura esas franjas con temperaturas exteriores muy bajas no es viable, por lo que la solución para disminuir el consumo de estos sistemas y tener 
cubierta toda la demanda es el empleo de equipos o sistemas cuyos rendimientos a cargas parciales sean óptimos.

Las primeras soluciones que aparecieron fueron la incorporación a las instalaciones de elementos mecánicos como válvulas de tres o cuatro vías que realizan esa compensación por temperatura exterior, estos sistemas de regulación permiten reducir la temperatura de impulsión a los elementos terminales (radiadores, fancoils,...) hasta adecuar la temperatura a las necesidades (20-22ํ C). El empleo de estas válvulas de regulación permite la reducción en el circuito secundario de la temperatura de impulsión en función de la temperatura exterior y por lo tanto el consumo de energía. La posibilidad de que se produzcan condensaciones ácidas en combinación con otros productos de la combustión que pueden provocar deterioros a largo plazo en la caldera, provoca que la temperatura del circuito primario no pueda ser inferior a la temperatura del punto de rocío de los productos de la combustión, valor en el cual el vapor de agua producido durante la combustión condensa y humedece la superficie de intercambio térmica del cuerpo de caldera. Esta temperatura está en torno a los $48 \stackrel{\circ}{\mathrm{C}}$ para el funcionamiento con gasóleo y de $58 \stackrel{\circ}{\mathrm{C}}$ para el gas natural [11]. Cuando la caldera funciona por encima de esta temperatura, para evitar estas condensaciones, continúa existiendo un $15 \%$ de derroche energético. Para poder adaptar la temperatura de funcionamiento a las necesidades reales de la instalación también en el circuito primario ya desde la propia caldera y reducir así las pérdidas por disposición de servicio, se hizo necesario desarrollar nuevas tecnologías que permitieran trabajar con bajas temperaturas de retorno sin riesgo de condensaciones ácidas.

El perfeccionamiento de estas técnicas ha dado lugar a los equipos que conocemos como calderas de baja temperatura y condensación:

\section{CALDERAS DE BAJA TEMPERATURA}

La definición oficial de este tipo de calderas, según la Directiva Europea de Rendimientos 92/42/CEE [N-15], es la siguiente: "Una caldera que puede funcionar continuamente con una temperatura del agua de alimentación de entre $35 \stackrel{\circ}{\circ}$ y $40 \stackrel{\circ}{\circ}$ y que en determinadas condiciones puede producir condensación".

La principal diferencia entre las calderas de Baja Temperatura y las calderas convencionales estriba en que las primeras ofrecen la posibilidad de adaptar la temperatura de funcionamiento en función de la demanda calorífica, o dicho de otra forma, de las necesidades reales. Las calderas convencionales de funcionamiento a temperatura constante trabajan durante todo el año, independientemente de la temperatura exterior y la demanda de la instalación, a una temperatura media de caldera $80 \stackrel{\circ}{\circ}$. 
Las calderas de baja temperatura operan con temperaturas de retorno del agua bajas (40$\left.60^{\circ} \mathrm{C}\right)$ y con baja temperatura de humos $\left(90-120^{\circ} \mathrm{C}\right)$. Su principal aplicación es en instalaciones donde se pueda trabajar un número elevado de horas a temperaturas bajas del circuito de agua caliente.

Las pérdidas de calor en los sistemas de calefacción incluyen las pérdidas desde la superficie de la caldera y las de distribución. Cuanto menor sea la temperatura del agua en la generación menores pérdidas habrá. Las calderas de baja temperatura basan el aumento del rendimiento en aportar la temperatura del agua a la temperatura mínima posible necesaria para aportar la energía demandada por la instalación, reduciendo las pérdidas por este concepto al reducir la diferencia de temperatura entre el agua y el ambiente.

El problema que hay que evitar es la condensación del vapor de agua contenido en los humos, por ser muy corrosivo de forma que deterioraría algunas partes de la caldera y chimenea. En una caldera convencional, si la temperatura de los humos se reduce por debajo de la de rocío se produce condensación. En las calderas de baja temperatura, la técnica más habitual consiste en utilizar superficies de calefacción por convección que están diseñadas de forma que se evite, en el lado de los humos, el descenso de su temperatura por debajo del punto de rocío del vapor de agua, tanto durante el funcionamiento a baja temperatura como bajo una carga parcial con quemadores de dos etapas o modulantes.

Como en todos los procesos de transmisión térmica, el intercambio de calor entre los humos y el agua depende del coeficiente global de intercambio, que es el inverso del resultado de la suma de las resistencias parciales convectivas y conductivas, que a su vez dependen de factores tales como la conductividad térmica de los distintos materiales a través de los que se realiza la transmisión térmica o de los coeficientes de película entre superficies y fluidos [11].

La técnica habitual en las calderas consiste en modificar la resistencia de conducción introduciendo una cámara de aire intermedia, asegurando que la temperatura de los humos en contacto con la superficie de la caldera esté siempre por encima de la temperatura de rocío, según se muestra en la Figura I.6. 


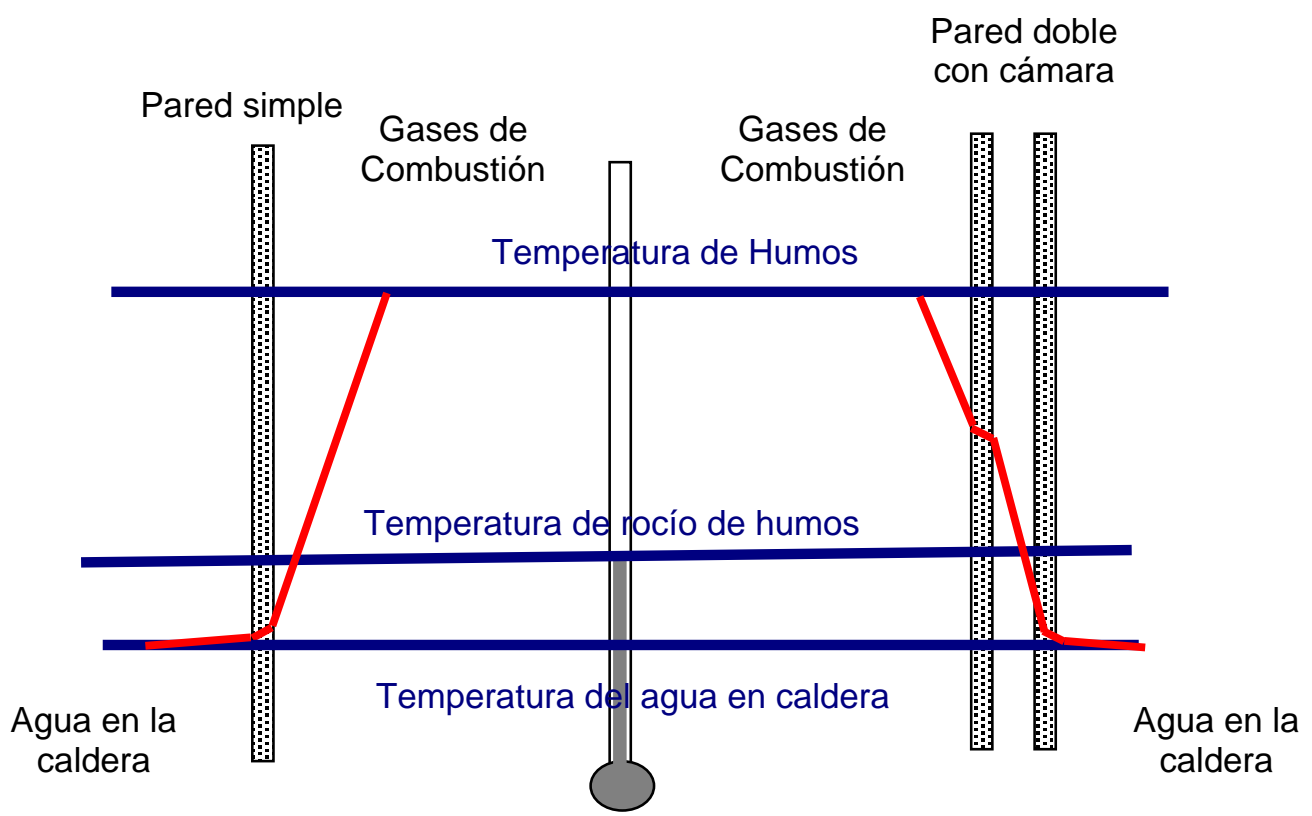

Figura I.6.- Perfil de temperaturas en calderas de pared simple y pared doble.

El perfil en pared simple muestra cómo, dado que la principal resistencia térmica se produce en el lado de los gases calientes, los humos en contacto con la superficie pueden estar a una temperatura inferior a la de rocío y provocará condensación y el condensado, por sus características corrosivas, destruir el cuerpo de caldera.

Las superficies de calefacción de pared doble (múltiple en general), permiten que se genere una resistencia adicional a la transmisión de calor en una cámara intermedia, evitando que, incluso con bajas temperaturas del agua de la caldera, la temperatura en el lado de los gases de combustión se mantenga por encima del punto de rocío del vapor de agua, evitando, de este modo, el descenso por debajo de este punto. En la Figura 1.7 se muestra un ejemplo de la tecnología de doble pared o cámara intermedia. Los esquemas corresponden a diferentes zonas de la caldera.
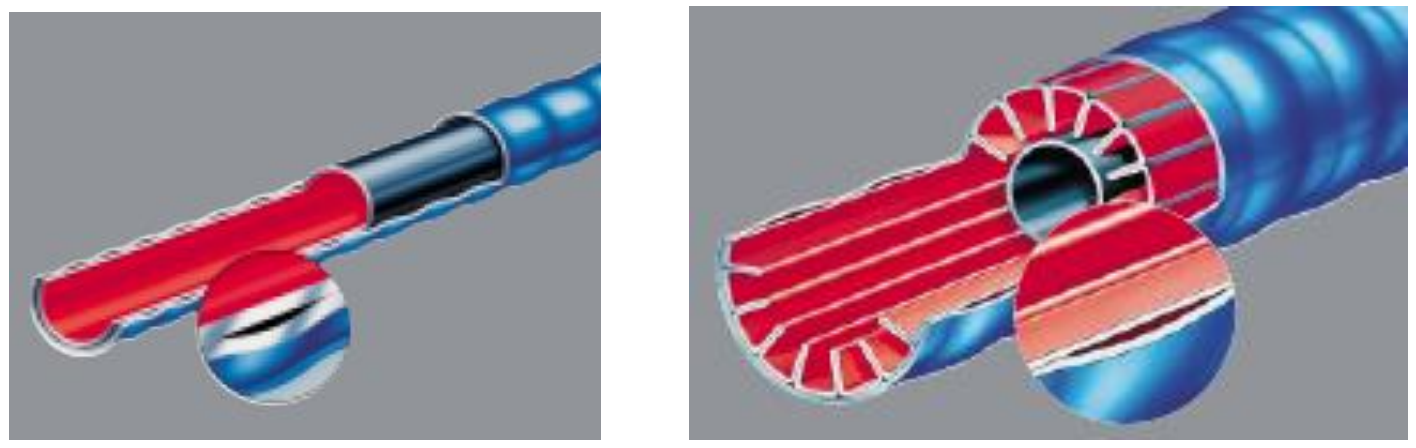

Figura I.7.- Tecnología de doble pared en diferentes elementos de una caldera. 
No obstante, según establecen las ecuaciones de intercambio térmico, un aumento de la resistencia a la transmisión reduce el coeficiente de intercambio de calor, lo que obliga a establecer algún mecanismo que anule este efecto, como aumentar la superficie de intercambio, con el consiguiente incremento del precio; o incrementar el coeficiente global aumentando el coeficiente de película del lado de los humos.

\section{CALDERAS DE CONDENSACIÓN}

Esta técnica se basa en el aprovechamiento del poder calorífico de los gases de expulsión de la caldera. Se refrigeran los gases de escape de la combustión, se condensa el vapor de agua contenido y se puede aprovechar el calor latente. Para ello los gases de escape tienen que refrigerarse por debajo de la temperatura del punto de rocío para que se condensen. La temperatura del punto de condensación depende de la proporción de agua en los gases de escape (de la presión del vapor de agua). Otra propiedad es que emiten los humos casi fríos, a temperaturas de sólo 40-60C , lo que permite condensar parte del vapor de agua que contienen.

Cuando la temperatura en las paredes de las superficies del lado de los humos en la caldera desciende por debajo del punto de rocío, se forman condensados de vapor de agua. En la combustión de gas natural, en condiciones de combustión ideal, el punto de rocío se alcanza a una temperatura de aproximadamente $58,5^{\circ} \mathrm{C}$ y, en la del gasóleo, a unos $48,1^{\circ} \mathrm{C}$ [11].

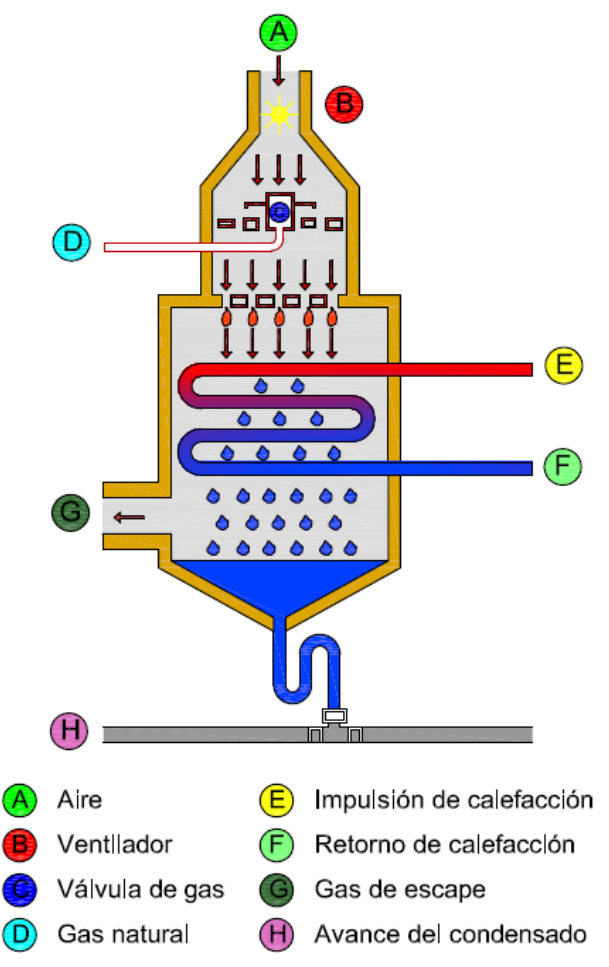

Figura I.8.- Esquema de un aparato de condensación [12] 
El aprovechamiento de la condensación es especialmente rentable en el caso del gas natural, pero también la condensación de gasóleo supone importantes potenciales de ahorro energético. En la combustión de gas natural, el rendimiento estacional puede, en comparación con una caldera de baja temperatura, aumentarse en hasta un $15 \%$.

Para poder utilizar esta técnica es necesario emplear como material del cuerpo de caldera, materiales que sean capaces de soportar las características corrosivas de los condensados, como acero inoxidable de alta aleación porcentual de cromo-níquel-molibdeno, para una alta seguridad de funcionamiento y una larga vida útil.

Las superficies de caldera, para aumentar la capacidad de transporte, suelen estar aleteadas, aumentando, además de la superficie de intercambio, la turbulencia en la corriente de humos y por tanto el coeficiente de película de los humos.

La temperatura de los humos es superior sólo entre 5 y $15 \stackrel{\circ}{\circ}$ a la temperatura de retorno, reduciendo al mínimo las pérdidas de calor sensible por humos, durante todo el período de calefacción y en cualquier tipo de condiciones de servicio. Las mínimas temperaturas de los humos y la intensa condensación proporcionan, en función de la temperatura del sistema de calefacción, unos rendimientos estacionales, con relación al Poder Calorífico Superior (PCl) del gas natural, de hasta el $109 \%$.

En el lado de los gases de combustión, la temperatura, en función de la de retorno, se mantiene por debajo del punto de rocío del vapor de agua $\left(57^{\circ} \mathrm{C}\right)$, provocando que el vapor de agua de los gases de combustión se condense transmitiendo energía adicional al agua de la caldera.

Aunque el funcionamiento más eficaz de esta técnica de condensación se da en sistemas de calefacción de baja temperatura (suelo radiante o fancoils), donde siempre estaría funcionando en condiciones de condensación, también en diseños donde se controle la temperatura de la impulsión en función de la temperatura exterior, pueden operar con condensación cuando la temperatura exterior sea suficientemente alta como para poder reducir la temperatura de retorno del agua a la caldera por debajo de la de rocío de los humos, donde se generará condensación del vapor contenido en los mismos. 


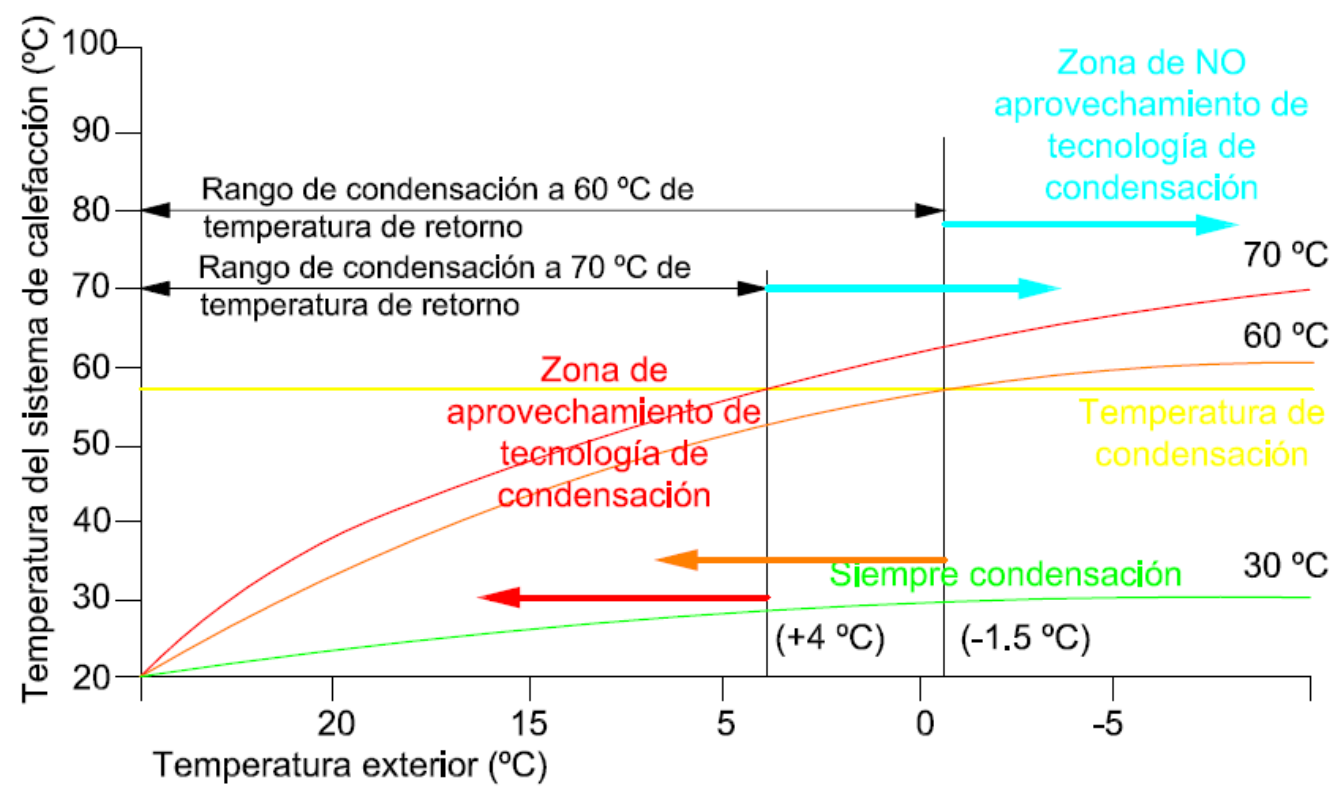

Figura I.9.- Operación en una caldera de condensación, según temperatura exterior.

El poder aprovechar la tecnología de condensación sobre todo es consecuencia del elevado desarrollo que ha tenido la tecnología de los materiales, que permiten soportar las propiedades corrosivas de los condensados. Aunque el uso de estos materiales encarece el producto, a la larga este incremento del precio se ve compensado con el incremento en el rendimiento energético de la instalación.

Debido a estas propiedades corrosivas del agua condensada de los humos, es recomendable que el condensado sea tratado previamente a su vertido al alcantarillado público, procediendo a su neutralización. Esta manera de operar, que en muchos países de la comunidad es obligatoria cuando se utiliza tecnología de condensación, asegura que se minimiza el impacto medioambiental por el uso de esta técnica. En la actualidad, los fabricantes de estos equipos disponen de sistemas comerciales de neutralización de condensados que contienen filtros de carbón activo y un granulado neutralizador que permiten que el agua obtenida sea prácticamente nula. Existe la posibilidad de emplear combustible bajo en azufre (gasóleo) que permite no tener que tratar esos condensados [11].

Debe destacarse que si no se realiza una adecuada gestión de la operación en la instalación y no se permite que la caldera opere a regímenes de carga donde se produzca condensación o reducción de la temperatura de impulsión, las ventajas que pueden aportar las instalaciones de condensación o de baja temperatura desaparecen. Una instalación de condensación que siempre funcione a plena carga y opere con temperaturas elevadas, que eviten la condensación del agua de los humos, operará igual que cualquier instalación convencional y no provocará una mejora en 
el rendimiento estacional, no siendo justificable el mayor coste de inversión por la incorporación de esta tecnología.

Por lo tanto, la dosificación del paso de calor es, junto con una regulación adecuada, la característica constructiva que permite a las calderas de baja temperatura adaptar la temperatura de funcionamiento a las necesidades reales de la instalación, sin que se produzcan en su interior condensaciones ácidas perjudiciales para la caldera. Mientras que el aprovechamiento energético de estas condensaciones es el que aporta ese pequeño salto cuantitativo del rendimiento en las caderas de condensación.

En ambos casos, el funcionamiento en función de las necesidades reales de la instalación reduce significativamente las pérdidas por radiación y convección y en consecuencia las pérdidas por disposición de servicio. Las calderas de condensación, mediante la recuperación del calor latente (calor de condensación) no sólo reducen aún más las pérdidas por calor sensible al enfriar intensivamente los humos y reduciendo, por lo tanto, las pérdidas globales de energía, sino que el aprovechamiento de la condensación les permite obtener rendimientos estacionales máximos y las convierte en el más alto exponente de ahorro y eficiencia energética.

\section{I.5.1.2.- BOMBAS DE CALOR.}

Se trata de una tecnología que permite utilizar energías renovables para su funcionamiento. Las Bombas de calor aparecen en las Directivas Europeas sobre el uso de Energías renovables RES, Eficiencia energética en edificios EPBD y Productos relacionados con la energía ErP.

Además, en la Directiva RES, se reconoce a la energía empleada por las Bombas de calor, procedente del aire, el agua y la tierra, como fuentes de energía renovables [13].

La Bomba de calor, recogiendo las consideraciones de las Directivas anteriores, podemos definirla como una máquina, equipo o instalación que usa el calor de fuentes naturales de energías renovables, aerotérmicas, geotérmicas e hidrotérmicas, o de procesos no naturales de recuperación de calor del aire o del agua, transfiriéndolo a las aplicaciones del edificio a través de un ciclo termodinámico desde una fuente externa a baja temperatura a otra interna de alta temperatura.

Para que el ciclo termodinámico se produzca se debe alimentar con energía primaria (electricidad, gas). En condiciones climáticas extremas se requiere un apoyo mediante un equipo de calefacción para compensar la reducción del flujo de calor de la bomba de calor. Sólo se considerarán las bombas de calor como fuente de energía renovable, y se podrá contabilizar ésta, en aquellas en las que el balance neto entre la energía que produce la bomba y la que requiere para su funcionamiento es significativamente positivo. 


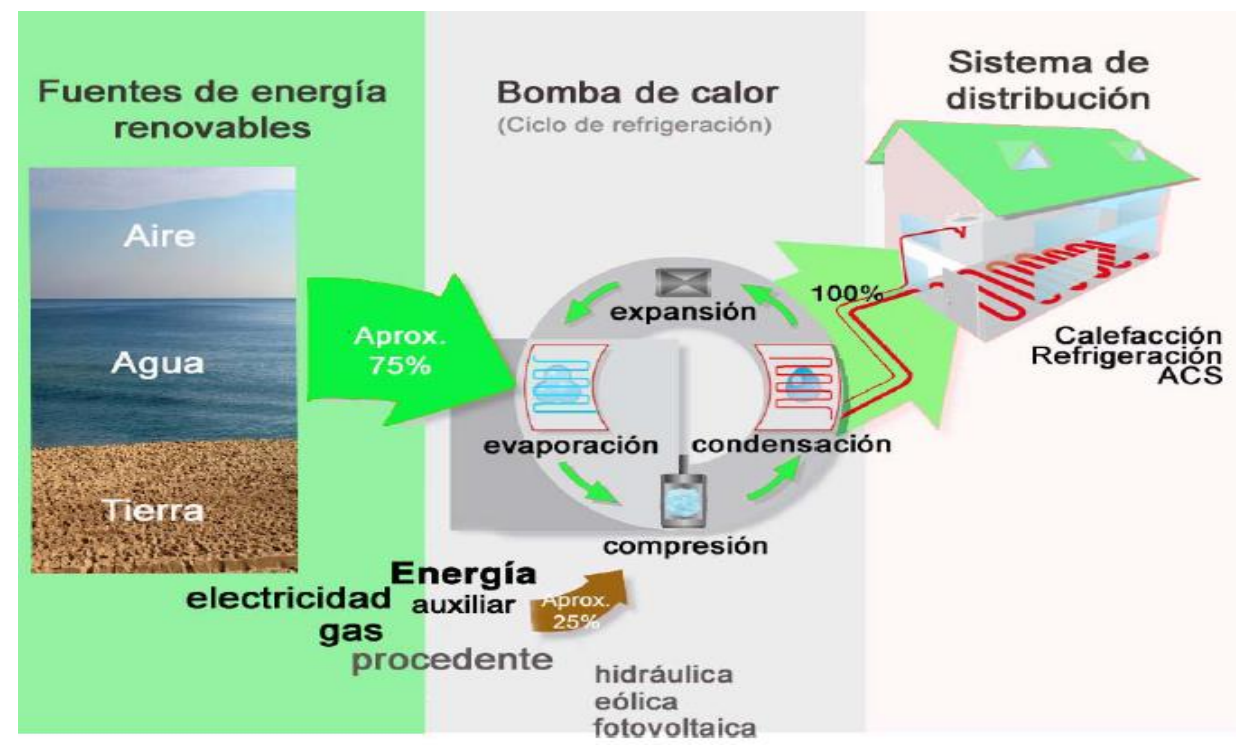

Figura I.10.- Elementos intervinientes en el sistema de Bomba de Calor.

La Directiva 2009/28/CE de la Comisión Europea, conocida como Directiva RES [N-2], relativa al fomento del uso de energía procedente de fuentes renovables, establece que la energía aerotérmica, geotérmica e hidrotérmica capturada por las Bombas de calor se tendrá en cuenta a efectos del cálculo de la cuota de energía procedente de fuentes renovables, siempre que la producción final de energía supere de forma significativa el consumo de energía primaria necesaria para impulsar la bomba de calor. La cantidad de calor que se ha de considerar como energía procedente de fuentes renovables a efectos de la presente Directiva se calculará de conformidad con la metodología establecida en el anexo VII de esta Directiva, que indica el balance energético de las Bombas de calor.

La cantidad de energía aerotérmica, geotérmica o hidrotérmica capturada por bombas de calor que debe considerarse energía procedente de fuentes renovables a los efectos de la presente Directiva, ERES, se calculará de acuerdo con la fórmula siguiente:

$$
\text { ERES }=Q_{\text {usable }}(1-1 / S P F)
$$

Siendo:

- $Q_{u s a b l e}=$ el calor útil total estimado proporcionado por bombas de calor conformes a los criterios mencionados en el artículo 5, apartado 4 de la Directiva, aplicada como sigue: solo se tendrán en cuenta las bombas de calor para las que $S P F>1.15^{*} 1 / \eta$

- $S P F=$ el factor de rendimiento medio estacional estimativo para dichas bombas de calor, $\eta$ el cociente entre la producción total bruta de electricidad y el consumo primario de energía para la 
producción de electricidad, y se calculará como una media de la UE basada en datos de Eurostat [14].

Una bomba de calor es esencialmente una máquina termodinámica que trabaja siguiendo un ciclo frigorífico clásico (compresor, condensador, sistema de expansión y evaporador), dimensionada para aprovechar la energía calorífica cedida por el condensador (aire caliente o agua caliente que sale del condensador) y no la que se absorbe en el evaporador (fuente fría) del aire ambiente, del agua de un pozo o de un río, o del propio terreno. De esta forma, se produce un flujo de calor desde el ambiente exterior, más frío, al espacio calefactado del interior del local. Sin embargo, es posible la reversión del flujo de calor producido para su aplicación en verano, de tal forma que la unidad encargada de extraer calor (evaporador) sea la situada en el interior del espacio que se desea climatizar, realizándose la cesión de calor desde el condensador al ambiente exterior, más cálido. Hablamos en este caso de bomba de calor reversible. En la figura I.11 se observa el esquema del principio de funcionamiento de una bomba de calor, trabajando con una válvula de 4 vías para revertir el sentido del flujo de calor según el sistema funcione en período invernal o estival [13].

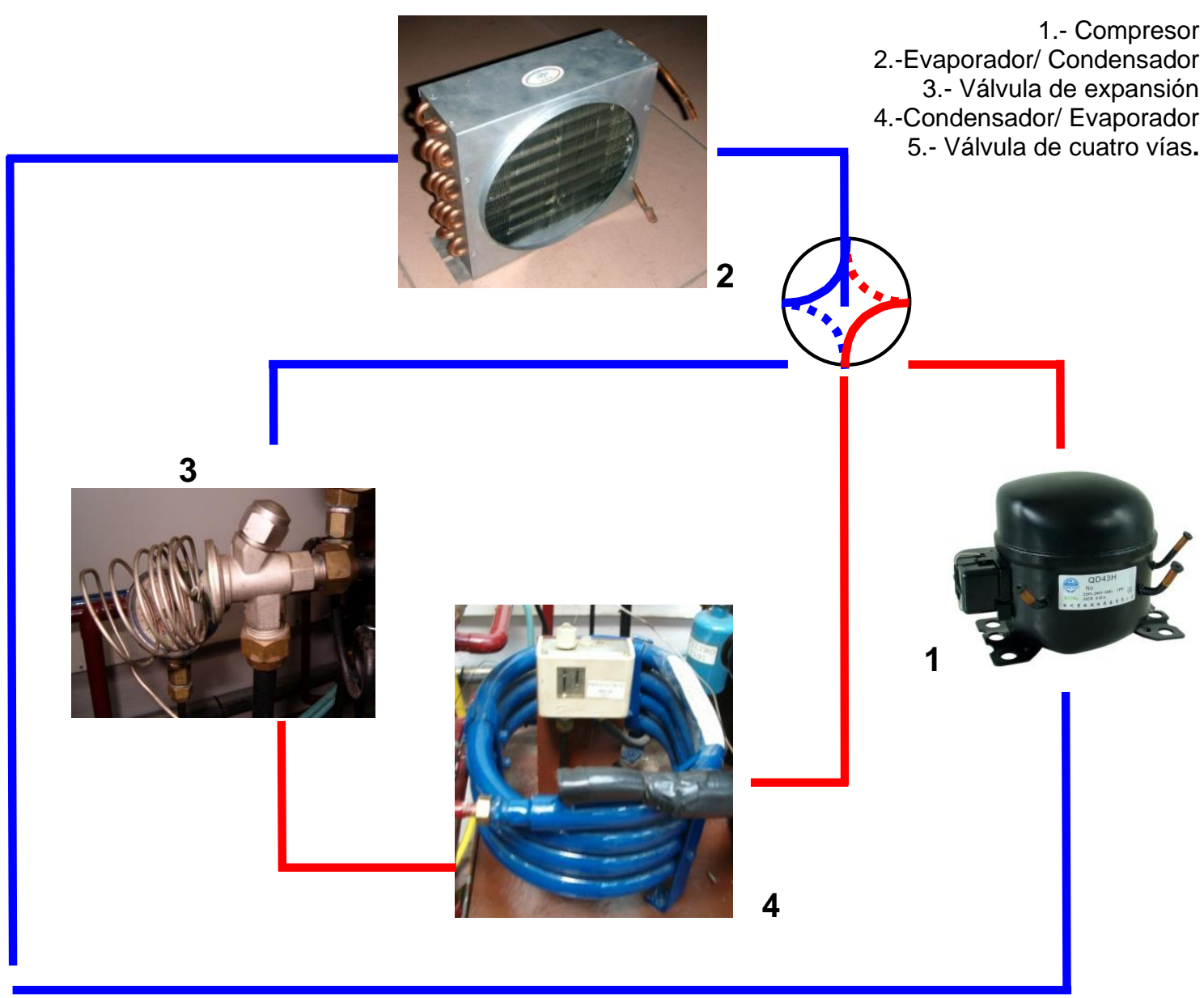

Figura I.11.- Esquema de funcionamiento de una bomba de calor reversible. 
En estos intercambios intervienen los calores latentes de evaporación y de condensación del fluido refrigerante utilizado. En la evaporación, este fluido absorbe energía del ambiente en forma de calor, pasando del estado líquido al estado gaseoso a temperatura y presión constantes. Por su parte, en la condensación se libera la energía al medio que se pretende calentar, mediante el paso del refrigerante del estado vapor al estado líquido a temperatura constante. Por lo tanto, se requiere que el refrigerante sea un fluido de elevado calor latente cuyo punto de ebullición a presiones bajas se produzca a las bajas temperaturas a las que trabaje el evaporador. Para cerrar el ciclo será necesario por lo tanto licuar de nuevo el fluido de trabajo, para lo cual se eleva su presión una vez en estado gaseoso mediante un compresor. Tras la compresión se conduce al condensador, refrigerado por aire o por agua, y finalmente un sistema de expansión retornará el fluido al estado de baja presión en forma de vapor húmedo a la entrada del evaporador, cerrándose así el ciclo frigorífico. El calor total cedido por el condensador será igual al calor absorbido por el evaporador en el foco frío más el calor resultante de la transformación del trabajo mecánico realizado por el compresor que se transforma en calor.

Se requieren por lo tanto para su funcionamiento cuatro elementos básicos: dos intercambiadores de calor que actúen como evaporador y condensador respectivamente, un sistema que permita llevar el vapor de refrigerante a los niveles de presión de condensación y que generalmente se tratará de un compresor mecánico (en el caso de las máquinas de absorción, se tratará de un compresor térmico), y un sistema de expansión que permita su retorno a los niveles de presión del evaporador. Sin embargo, para la aplicación práctica de este ciclo serán necesarios numerosos dispositivos auxiliares que permitan el funcionamiento real, como el arrastre de aceite desde el compresor que pueda ensuciar el sistema y reducir la eficacia del intercambio, para lo cual se dispone un separador de aceite a la salida del mismo; o eliminación de agua e impurezas que puedan existir en el refrigerante, mediante filtros y deshidratadores; elementos de amortiguación de las vibraciones y silenciador de ruidos asociados al funcionamiento del compresor; etc. Además de los accesorios anteriores, en bombas de calor reversibles es necesaria la función de una válvula de cuatro vías, que permita dirigir el flujo de refrigerante desde la descarga del compresor hacia la denominada batería exterior o hacia la batería interior para que actúen una u otra como unidad condensadora según se requiera, pudiendo impulsar calor en cualquier dirección (exterior en verano e interior en invierno).

Dado que se busca producir un flujo de calor desde un foco frío a otro foco a mayor temperatura, proceso que según el segundo principio de la termodinámica no podría producirse de forma natural, será necesario realizar un aporte de energía que se traduce a efectos prácticos en el trabajo aportado en la compresión del refrigerante en estado gaseoso. Normalmente se dispone de una fuente de corriente eléctrica, siendo el caso más habitual el de conexión a red. Sin embargo, los compresores y aparatos auxiliares también pueden funcionar mediante un motor a gas, gasolina o diesel, con la ventaja suplementaria, en este caso, de poder recuperar el calor perdido 
residual desprendido en las camisas de los cilindros, en el aceite de refrigeración y en los gases de escape como foco frío de operación de la máquina.

En el ciclo simple por compresión de vapor, o ciclo de refrigeración saturado simple, denominado ciclo inverso de Rankine, el fluido recorre el ciclo en sentido contrario a como lo haría en una máquina térmica funcionando como ciclo Rankine. La figura 1.12 muestra el ciclo de refrigeración simple en el diagrama P-h (Presión - entalpía). El punto 3 representa la aspiración o salida del evaporador (estado de vapor saturado); el punto 4 la salida del compresor (estado de vapor recalentado); el punto 1 la salida del condensador (estado de líquido saturado) y finalmente el 2 la entrada del evaporador [13].

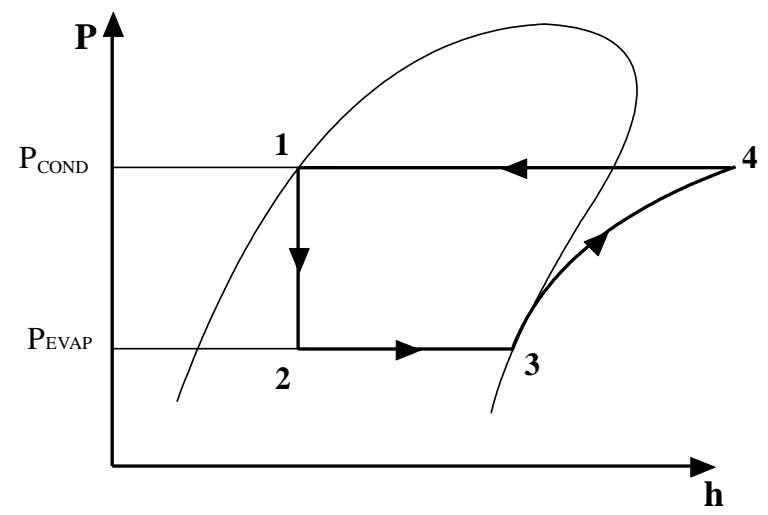

Figura I.12.- Diagrama P-h del ciclo de refrigeración simple de Rankine.

En la realidad las máquinas de producción de frío o las bombas de calor (poseen esquemas de operación iguales), no funcionan como ciclo simple, pues el compresor no es isentrópico, siempre hay subenfriamiento a la salida del condensador y sobrecalentamiento del gas a la entrada del compresor, se producen pérdidas de carga al circular el refrigerante por el condensador y el evaporador, etc. El ciclo real es por lo tanto irreversible, y su diagrama P-h puede ser representado como el que se expone en la figura I.13.
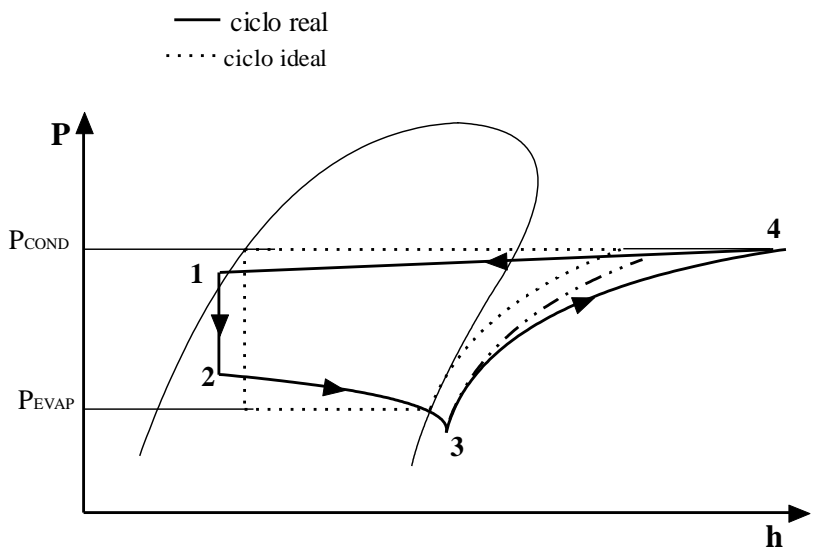

Figura I.13.- Diagrama P-h del ciclo de refrigeración real de Rankine. 


\section{EFICIENCIA DE LOS SISTEMAS.}

A la eficiencia de las máquinas frigoríficas y de las bombas de calor lo denominaremos de forma abreviada COP o coeficiente de prestaciones (Coefficient Of Performance), factor con el cual deben compararse los consumos de energía para el funcionamiento de las diferentes alternativas de calefacción o refrigeración.

Para la aplicación en período estival de los sistemas de bomba de calor, estos trabajan como máquina frigorífica aprovechando el calor extraído en el evaporador para proporcionar un fluido frío (aire, agua o el propio refrigerante del circuito frigorífico) que sirva para refrigerar los locales. En este caso, es cuando la bomba de calor opera en "modo refrigeración", y el $\mathrm{COP}_{\mathrm{REF}}$ (o Energy Efficiency Ratio EER) se define como:

$$
C O P_{R E F}=\frac{\text { Efecto útil }}{\text { Trabajo aportado }}=\frac{\dot{Q_{F}}}{\dot{W}}=\frac{\dot{Q_{F}}}{\dot{Q_{C}}-\dot{Q_{F}}}=\frac{\dot{m_{F}} \cdot\left(h_{3}-h_{2}\right)}{\dot{m_{F}} \cdot\left(h_{4}-h_{3}\right)}
$$

Para el ciclo inverso de Carnot (ciclo teórico) el COP máximo (COP REF IDEAL viene dado por la siguiente expresión:

$$
C O P_{R E F ~ I D E A L}=\frac{\dot{Q}_{F}}{\dot{Q}_{C}-\dot{Q}_{F}}=\frac{T_{F} \cdot\left(s_{2}-s_{1}\right)}{\left(T_{C}-T_{F}\right) \cdot\left(s_{2}-s_{1}\right)}=\frac{T_{F}}{T_{C}-T_{F}}
$$

Donde $T_{C}$, es temperatura del foco caliente y $T_{F}$ la del foco frío.

De este resultado se deduce que:

El COP para el caso del ciclo inverso de Carnot, COPREF IDEAL, sólo depende de las temperaturas de los focos.

Será tanto más elevado cuanto menor sea la diferencia entre las dos isotermas $T_{C}$ y $T_{F}$.

El $C O P$ será mayor cuanta más alta es la temperatura del foco frío $T_{F}$.

Según el segundo Principio de la Termodinámica, ninguna máquina frigorífica puede tener un $C O P$ superior al establecido por el ciclo inverso de Carnot, $C O P_{R E F} \leq C O P_{R E F ~ I D E A L}$. Por tanto, la producción de frío será tanto más difícil de conseguir cuanto menor sea la temperatura a la que se debe producir. También es importante observar que la disipación de calor del condensador en una máquina frigorífica, será peor en un ambiente cálido que en uno frío. Por ello, para tener un $C O P_{R E F}$ alto en época estival, la temperatura ambiente, que en esta situación será la del foco 
caliente $\left(\mathrm{T}_{\mathrm{C}}\right)$ debe ser lo más baja posible; es decir, el COP será más alto para una temperatura ambiente de $20 \stackrel{\circ}{\circ}$ que para el caso de una temperatura ambiente de $40 \stackrel{\circ}{\circ}$. Este último punto puede mejorarse recurriendo al aprovechamiento de fuentes de energía residuales que actúen como foco frío; por ejemplo, aprovechando un nivel térmico más adecuado de la corriente de aire de expulsión del local, mejorando así el rendimiento de la máquina. Se habla en este caso de bomba de calor trabajando en modo recuperación o recuperación activa, siendo un recurso especialmente interesante en términos de eficiencia energética.

La relación entre el $C O P$ de una máquina frigorífica determinada y el de una de Carnot que operase entre los mismos focos, se denomina grado de reversibilidad o coeficiente económico de la instalación. El grado de reversibilidad expresa, en tanto por uno, la aproximación del comportamiento de una máquina dada al modelo ideal, constituido por la máquina frigorífica totalmente reversible.

\section{TIPOS DE SISTEMAS DE BOMBAS DE CALOR}

Existen muchas posibilidades de clasificar las bombas de calor pero, dentro de las más interesantes en el campo de la edificación, la clasificación que hace referencia al medio de donde se capta y al que se cede la energía es la que nos permite obtener una tipología que obedece a su posible utilización constructiva propiamente dicha. Según este criterio, encontramos siete tipos de sistemas [15]:
1. Aire - Aire
2. Aire-Agua
3. Agua - Aire
4. Agua - Agua
5. Tierra - Agua
6. Tierra - Aire
7. Tierra - Tierra

Seguramente, la tipología Aire - Aire es la más utilizada, ya que la fuente fría de donde se toma el calor es inagotable y su instalación es muy sencilla. En invierno se toma calor del aire exterior y es bombeado al interior del edificio a la temperatura deseada gracias al cambio de fase del refrigerante, según el funcionamiento ya descrito. En verano, toma calor del interior y lo transporta y expulsa al ambiente exterior. Por su parte, las tres últimas están asociadas a instalaciones geotérmicas. 
Para minimizar los consumos energéticos del sistema convencional de bomba de calor, deben considerarse, junto a los objetivos de mejora de eficiencia de la propia operación del sistema, el abanico de opciones asociadas a la disminución de la demanda y el aprovechamiento de fuentes gratuitas. Este análisis se abordará para las opciones presentadas para instalaciones de climatización por aire.

\section{I.5.1.3.- GENERACIÓN INTEGRAL DE ENERGÍA: COGENERACIÓN Y TRIGENERACIÓN.}

Se define la cogeneración como la producción conjunta, en proceso secuencial, de energía eléctrica (o mecánica) y energía térmica útil a partir de un cierto combustible. Es precisamente este aprovechamiento de la energía térmica lo que hace posible un rendimiento global muy elevado en la utilización de energía y en definitiva, un ahorro de energía primaria.

El término trigeneración se utiliza para referirse a instalaciones que producen conjuntamente electricidad, calor y frío, este último utilizando una máquina de absorción o adsorción.

La aplicación de estos sistemas puede ser muy interesante en barrios, urbanizaciones, pueblos de tamaño adecuado, donde los mismos consumidores demandan energía eléctrica y térmica. Incluso en los meses de verano, si el emisor térmico es el adecuado en los edificios (fancoils o suelo refrescante), podrían suministrar frío, utilizando una máquina de absorción que sería el nuevo destino del efluente térmico residual del proceso de cogeneración cuando exista una demanda de refrigeración.

En los siguientes esquemas se puede visualizar el interés energético de los sistemas de cogeneración (Figuras I.14 y l.15).

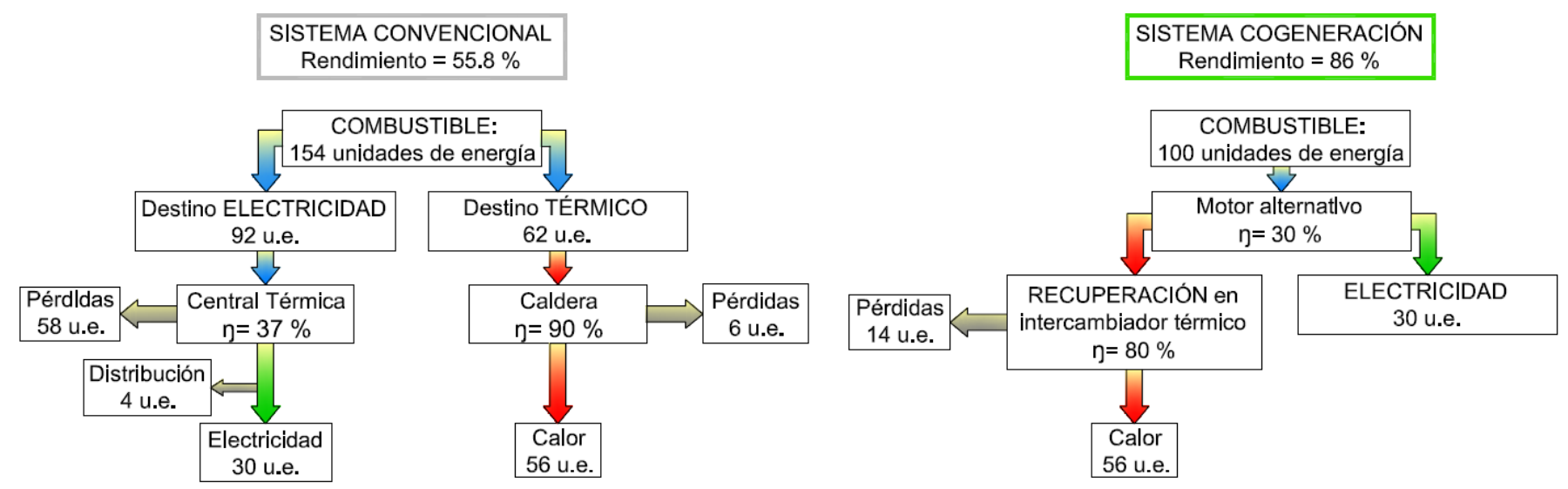

Figura I.14.- Balance energético de los sistemas convencionales y de cogeneración. 
Las instalaciones que más posibilidades tienen para ser utilizadas en climatización, debido sobre todo a la potencia necesaria, son las plantas de cogeneración de turbina de gas (posibles microturbinas), y a motores alternativos.

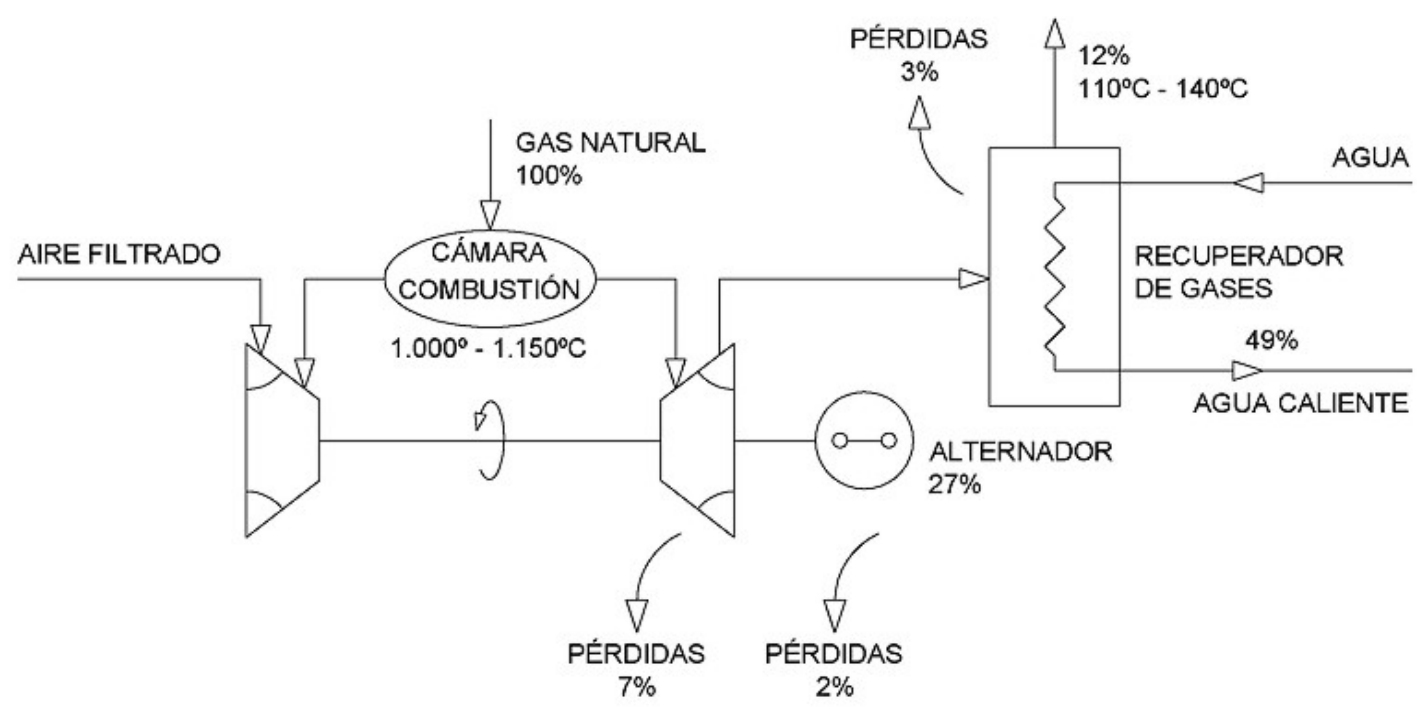

Figura I.15.- Esquema de principio de cogeneración con turbina de gas.

Los motores alternativos son de un gran interés para la cogeneración en climatización. Se caracterizan por su versatilidad en operación, ya que pueden utilizar combustibles de distinta calidad y están disponibles en el mercado en un amplio rango de potencias, existiendo diversos fabricantes nacionales.

En el caso de la turbina de gas, el rendimiento es más elevado cuánto más alta sea la temperatura de los gases a la salida de la cámara de combustión y más elevada sea la relación de compresión.

Las instalaciones de climatización centralizadas suficientemente grandes, pueden ser destinatarias de un sistema de cogeneración, ya que los usuarios finales van a ser consumidores de energía eléctrica y energía térmica.

Un análisis de los consumos térmicos de las instalaciones de climatización, más o menos generalizado, para un clima continental como el de la mayoría de la península ibérica, puede ser representado según se muestra en la gráfica de la Figura I.16. 


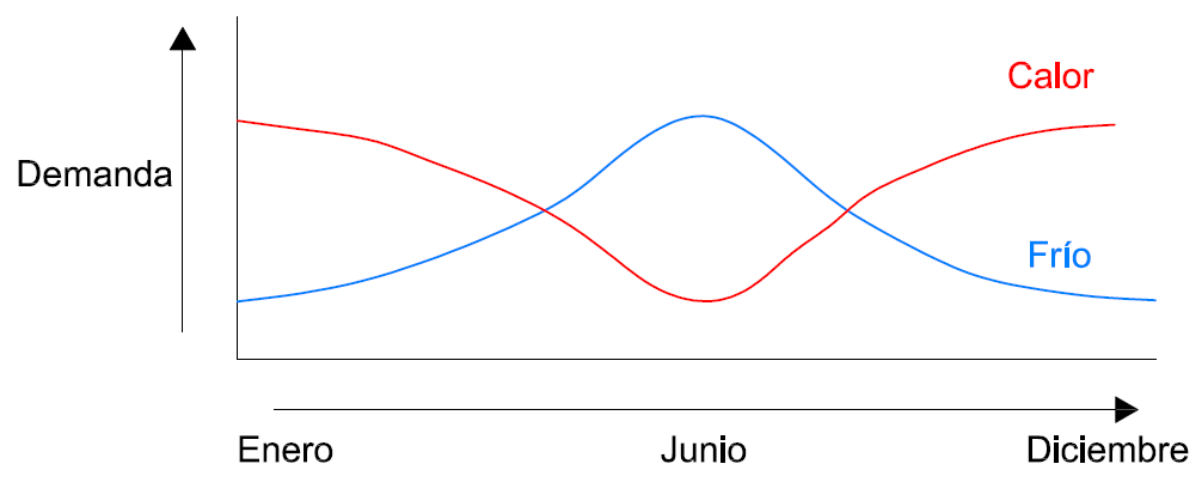

Figura I.16.- Evolución de la demanda de energía a lo largo del año.

Una alternativa posible utilizando una planta de cogeneración, es la utilización de este sistema dentro de una red de calor centralizada (District Heating) para invierno, y en verano utilizar la energía térmica residual con un sistema de máquina de absorción para generar frío, bien sea de forma centralizada también o con diferentes equipos conectados a la red.

Mientras que para grandes edificios, bloques de viviendas, complejos industriales o comerciales los consumidores emplean soluciones adecuadas de cogeneración a sus demandas, para viviendas unifamiliares o pequeños edificios de viviendas se emplean microcogeneradores.

Se habla de microcogeneración cuando la potencia instalada es menor a $50 \mathrm{~kW}$ eléctricos [N-16]. Gracias al aprovechamiento altamente eficiente de la energía primaria que así se logra, la calefacción obtenida no sólo contribuye a reducir el consumo y los costes energéticos, también contribuye directamente a la protección medioambiental. Por ello, la microcogeneración está subvencionada en muchos países. Además, en algunos de estos países, la electricidad que no se destina al consumo propio y se exporta a la red eléctrica, se remunera adicionalmente.

Las tecnologías básicas de microcogeneración se diferencian entre motores de combustión interna y externa (motores Otto o motores Stirling), máquinas de expansión de vapor y pilas de combustible. Los motores de combustión y la expansión de vapor son tecnologías ensayadas y contrastadas desde hace mucho tiempo, siendo también las más comunes.

Ya existen instalaciones en las que se utilizan recursos de energía renovables, como biogás, aceite vegetal, biomasa o bioetanol en plantas de cogeneración. 


\section{I.5.1.4.- SISTEMAS DE ENFRIAMIENTO GRATUÍTO.}

A pesar de que el caso más habitual es aquél en el que las condiciones requeridas para que el aire de impulsión sea capaz de vencer las cargas internas de los locales son más próximas a las que posee el aire del retorno que a las del aire exterior, presentándose por lo tanto necesaria la recirculación de aire en cuestión de eficiencia energética, pueden darse a lo largo del año diferentes situaciones que pueden hacer más conveniente la utilización de aire del exterior que no recircular aire, lo que reduce los consumos energéticos y a la calidad del aire interior que se consigue en los locales [16], [17].

Es precisamente en esta idea en la que se basa el concepto de enfriamiento gratuito por aire exterior, comúnmente conocido como "free-cooling". Esta aplicación es sin duda el líder del ahorro energético, ya que consiste simplemente en utilizar aire del exterior, normalmente sólo filtrado, en vez de recircular aire del retorno, por tener unas características energéticas que le hacen más eficiente energéticamente que el aire procedente del interior. El objetivo de un sistema de enfriamiento gratuito es por lo tanto reducir la energía necesaria para la adecuación higrotérmica del aire impulsado por los sistemas de acondicionamiento. Pero además de ser más económico utilizar aire frío del exterior para disipar las cargas internas, al aumentar el caudal de aire exterior, repercutirá en una mejora de la calidad del aire interior (IAQ).

Por lo tanto, los aspectos más relevantes que se pueden destacar de este dispositivo son:

- El ahorro de energía en períodos interestacionales o en climatologías suaves.

-La reducción del impacto medioambiental referido a emisiones de $\mathrm{CO}_{2}$ como consecuencia de la reducción del consumo energético.

- Mejora de la calidad del aire interior (IAQ), al aumentar el caudal de renovación.

El reglamento RITE obliga al uso de enfriamiento gratuito por aire exterior para aquellos sistemas de climatización de tipo "todo aire" cuya potencia térmica nominal sea mayor de 70 kW en régimen de refrigeración $[\mathrm{N}-7]$.

Cuando se aplica el enfriamiento gratuito o free-cooling en un ciclo de acondicionamiento de aire para alcanzar las condiciones de confort térmico en un espacio interior, hablamos de "ciclo economizador". Este recurso se puede aplicar de dos formas: directamente utilizando aire exterior, lo cual se presenta como la aplicación más directa o evidente; o aprovechando el aire exterior para enfriar agua en una torre de enfriamiento, en lugar de enfriarla mediante un sistema convencional de producción de frío por compresión mecánica, y utilizar esta agua fría para adecuar térmicamente la corriente de aire de impulsión al interior mediante un intercambiador de calor, similar a lo que anteriormente se ha denominado como enfriador evaporativo indirecto convencional [16]. 


\section{FREE COOLING POR AIRE. ENFRIAMIENTO GRATUITO POR AIRE EXTERIOR}

Estos sistemas consiguen utilizar la capacidad de enfriamiento gratuito del aire exterior en sustitución de un sistema convencional de enfriamiento por refrigeración mecánica, utilizando hasta un $100 \%$ de aire exterior, de manera que sea capaz incluso de disipar el total de la carga térmica del local.

Sin embargo, resulta evidente que para poder utilizar un sistema de enfriamiento gratuito por aire, es necesario que los sistemas de climatización de los locales sean por aire y que las unidades de tratamiento de aire estén equipadas con los adecuados sistemas de compuertas, ventiladores y control, necesarios para realizar un control adecuado de la instalación. Este control es especialmente relevante, ya que la opción de free-cooling debe habilitarse y regularse en función de las diferentes situaciones que se pueden plantear de cargas internas y condiciones climáticas exteriores, actuando sobre las compuertas de aire y los equipos que deben estar en operación, para conseguir que el aire de impulsión alcance las condiciones higrotérmicas adecuadas con el menor coste energético.

El dispositivo consta por lo tanto de un sistema con tres compuertas de aire colocadas de manera que la compuerta de aire de retorno está en serie con los ventiladores de aire de retorno e impulsión, mientras que las otras dos compuertas están en paralelo, la de expulsión en el circuito del ventilador de retorno y la de aire exterior en el circuito del ventilador de impulsión, como se puede ver en la figura I.17. Este sistema de compuertas deberá permitir regular el caudal de aire exterior en función de los requisitos establecidos por el sistema de control.

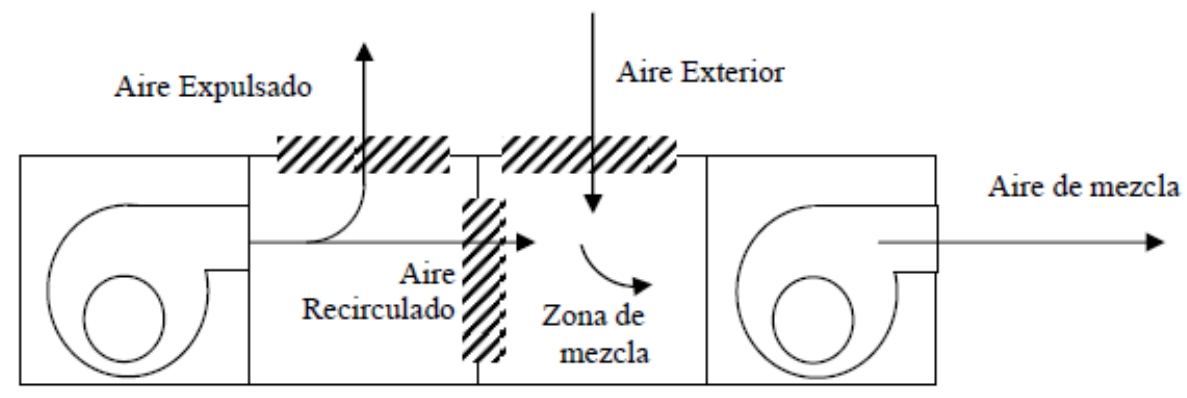

Figura I.17.- Esquema básico de un sistema de enfriamiento gratuito por aire.

El control puede realizarse por criterio de entalpía o por temperatura. Cuando la entalpía del aire exterior o en su caso la temperatura, dependiendo del sistema de control utilizado, sea inferior a la entalpía o temperatura del aire procedente del local, será más eficiente energéticamente utilizar aire exterior que no recircular aire de retorno del local. Los sistemas se pueden dividir por lo tanto en dos grandes grupos atendiendo al tipo control.

En el primer tipo de control, por comparación de entalpías, se miden las condiciones exteriores de temperatura seca y humedad relativa, parámetros a partir de los cuales el sistema 
puede calcular la entalpía del aire exterior. Si la entalpía del aire exterior es superior a la de retorno del local, las compuertas de aire de renovación y expulsión se mantendrán cerradas en la mínima posición que permita proporcionar el caudal de aire de renovación mínimo requerido, y manteniéndose abierta en su máxima posición la compuerta que regula la recirculación de aire de retorno. Por el contrario, si las condiciones energéticas del aire exterior resultan ser más adecuadas que las del retorno, la compuerta de recirculación se mantendrá cerrada y las de aire exterior y expulsión abiertas en su máxima posición.

Pueden darse sin embargo casos intermedios. Existe por lo tanto para la regulación una sonda de temperatura adicional que mide la temperatura del aire de mezcla. Cuando la temperatura exterior sea inferior a la temperatura establecida como consigna del aire de impulsión, To $\leq \mathrm{T}^{*}$, entonces el regulador del equipo modula la posición de las compuertas de aire (exterior, expulsión y recirculado) de manera que se mantenga la temperatura de la mezcla del aire en el valor establecido en la consigna $T^{*}$. En esta situación, el sistema de producción de frío convencional estará parado.

En las figuras 1.18 y l.19 se muestran los esquemas de operación y el sistema de control por entalpía, así como la identificación en el diagrama psicrométrico de las condiciones exteriores adecuadas en este caso.

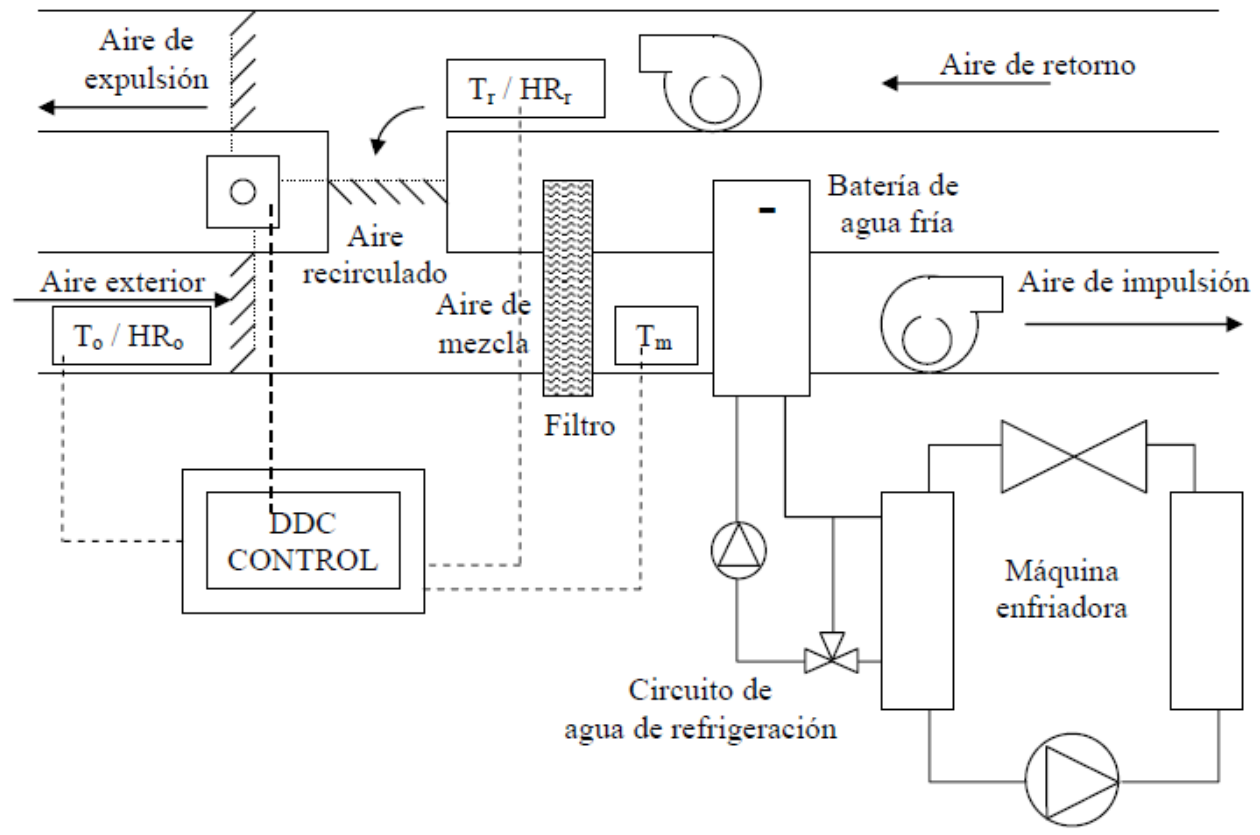

Figura I.18.- Esquema del proceso de refrigeración por aire utilizando control por entalpía. 


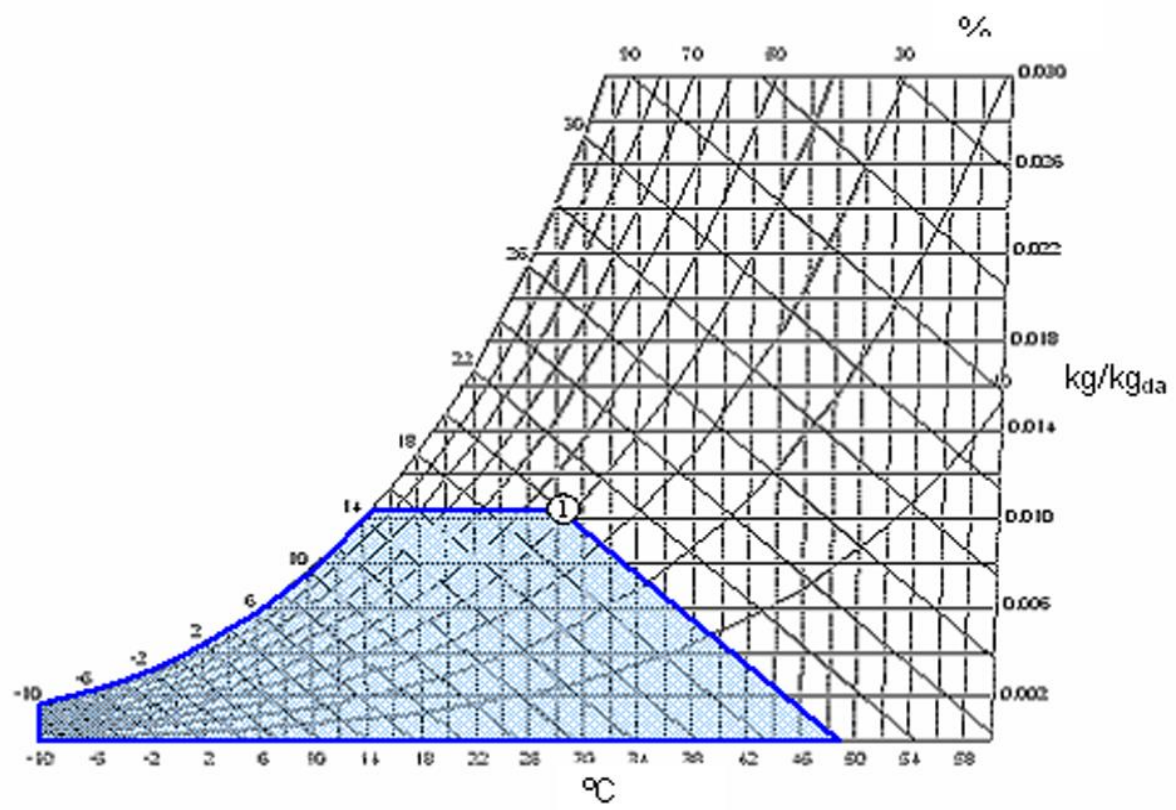

Figura I.19.- Representación en el diagrama psicrométrico de la zona de aire exterior donde sería adecuado utilizar enfriamiento gratuito con control de entalpía.

Teóricamente, se consigue más eficiencia energética con el control de entalpía que con el control de temperatura, pero en muchas ocasiones el enfriamiento del aire precisa de un enfriamiento adiabático cuando la humedad es muy baja. Sin embargo, para poder comparar los valores de entalpía se precisan sondas de temperatura y humedad, por lo que desde un punto de vista práctico, dado que las sondas de humedad pueden proporcionar errores (incluso del $10 \%$ ) como consecuencia de una baja precisión o de derivaciones de la calibración en cortos periodos de tiempo que hacen dificultoso su mantenimiento, y adicionalmente su precio es relativamente elevado, hacen que el sistema más utilizado de control de enfriamiento gratuito sea el de temperatura.

Este segundo método de control por temperatura resulta por otra parte más sencillo, ya que se comparan solamente temperaturas secas utilizando una única sonda de temperatura. La comparación se realiza entre la temperatura del aire exterior To con la temperatura del aire recirculado $\operatorname{Tr}$ (o con el valor de un punto de consigna predeterminado). En este caso, las compuertas de aire de renovación y de expulsión se mantendrán en la mínima posición y la de aire de retorno totalmente abierta cuando la temperatura exterior exceda la de retorno o la de consigna; mientras que se interrumpirá la recirculación de aire permitiendo entrada de aire exterior cuando la temperatura exterior sea inferior a la de retorno, regulándose las posiciones intermedias en relación a la medida adicional de una sonda de temperatura de mezcla. 
El esquema de operación y el sistema de control serían los representados en la figura I.20, mientras que la zona de condiciones climáticas de interés en este caso sería la reflejada en el diagrama psicrométrico de la figura I.21.

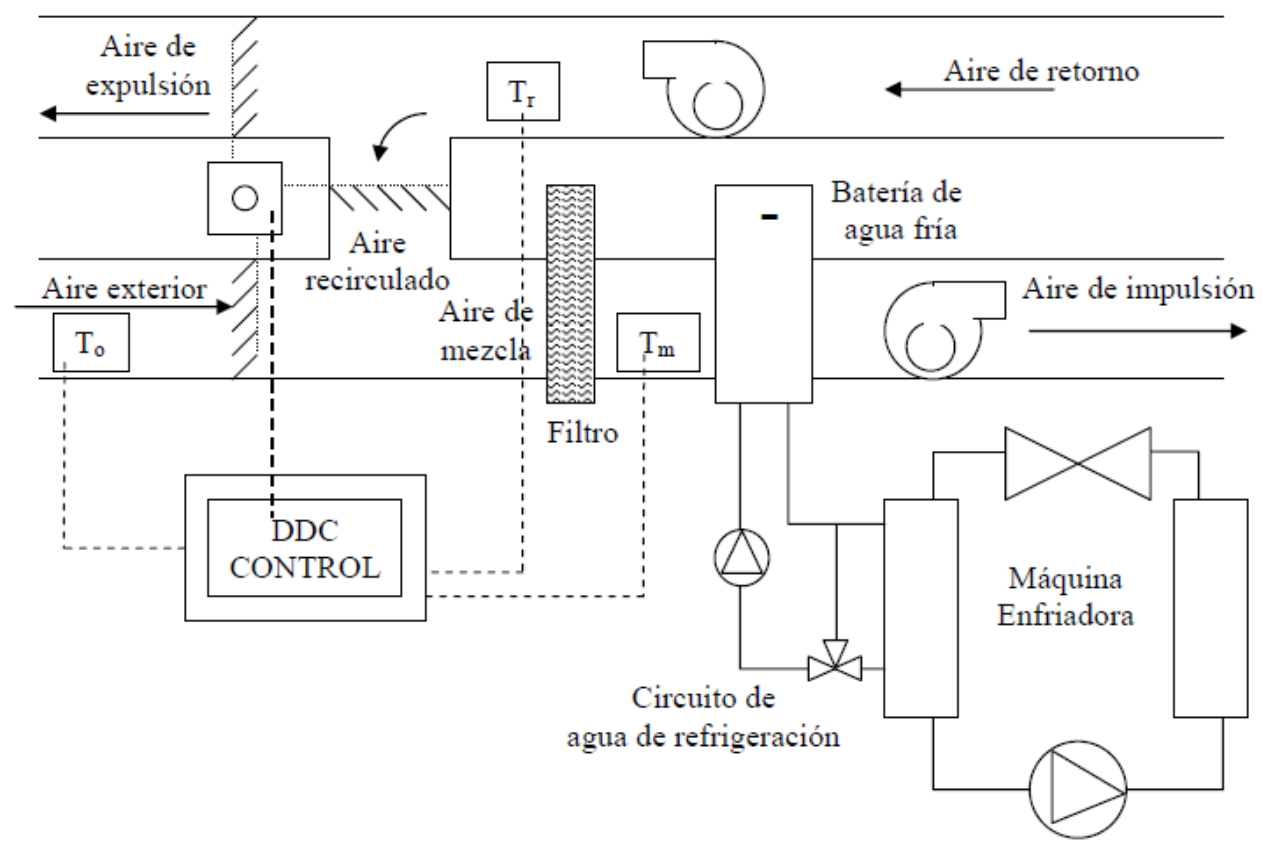

Figura I.20.- Esquema del proceso de refrigeración por aire utilizando control por temperatura.

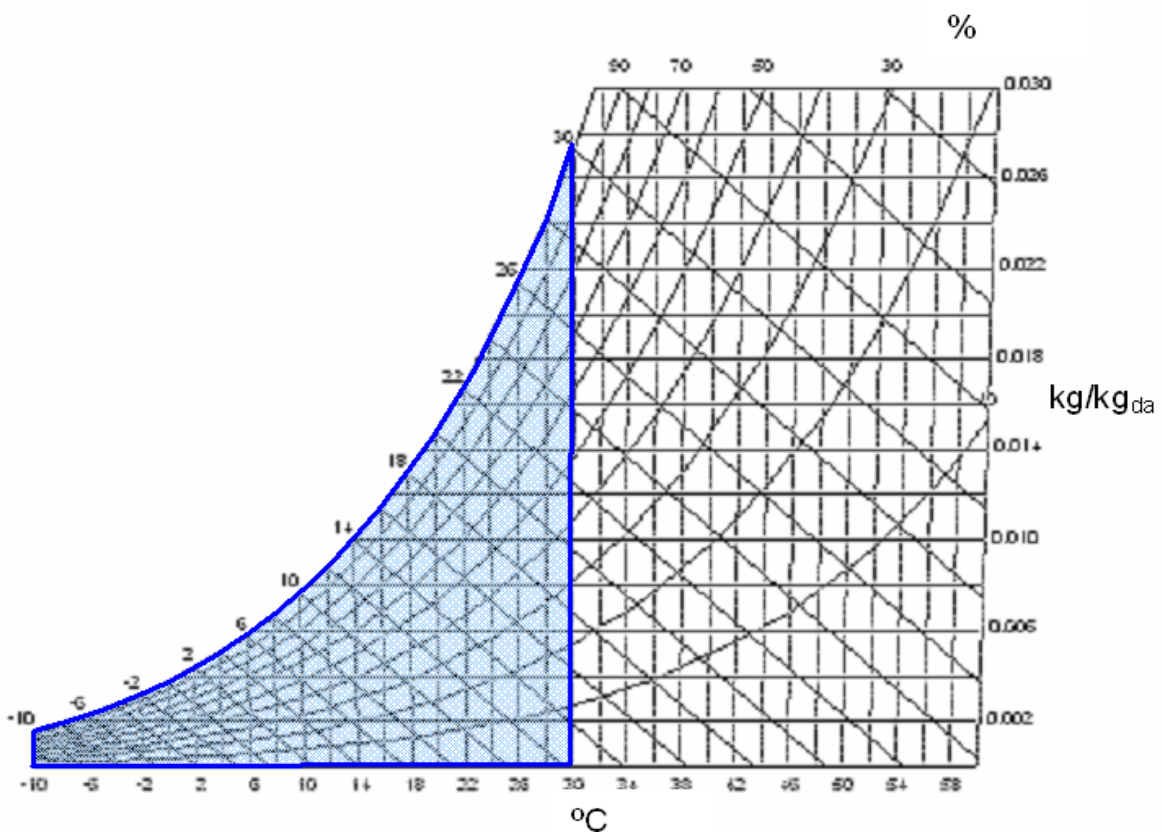

Figura I.21.- Representación en el diagrama psicrométrico de la zona de aire exterior donde sería adecuado utilizar enfriamiento gratuito con control de temperatura. 


\section{FREE COOLING POR AGUA.}

Por otro lado, como ya se ha indicado, cabe también la posibilidad de utilizar el agua procedente de una torre de enfriamiento, que idealmente puede ser enfriada hasta la temperatura de saturación adiabática del aire exterior que circula por dicha torre, para enfriar el aire enviado a la unidad de tratamiento, reduciendo de esta forma el consumo energético de la misma respecto al que requeriría utilizando un sistema convencional para enfriar el agua de la batería de la UTA. No obstante, si es necesario utilizar las dos baterías para alcanzar las condiciones deseadas en el aire de impulsión, estas se conectan siempre en serie y primero la que utiliza free cooling por agua. La disposición esquemática de esta instalación es la que se presenta en la figura I.22.

En lo que concierne a este modo de enfriamiento gratuito, las condiciones climáticas pueden ser divididas en tres zonas en función de la temperatura de bulbo húmedo del aire exterior, según se muestra en el diagrama psicrométrico de la figura 1.23, y consecuentemente quedarán distinguidos tres modos de funcionamiento del sistema:

En la Zona I la torre de refrigeración está parada.

En la Zona II, la torre trabaja reemplazando parte de la refrigeración mecánica.

En la Zona III la torre sola soporta totalmente la demanda energética.

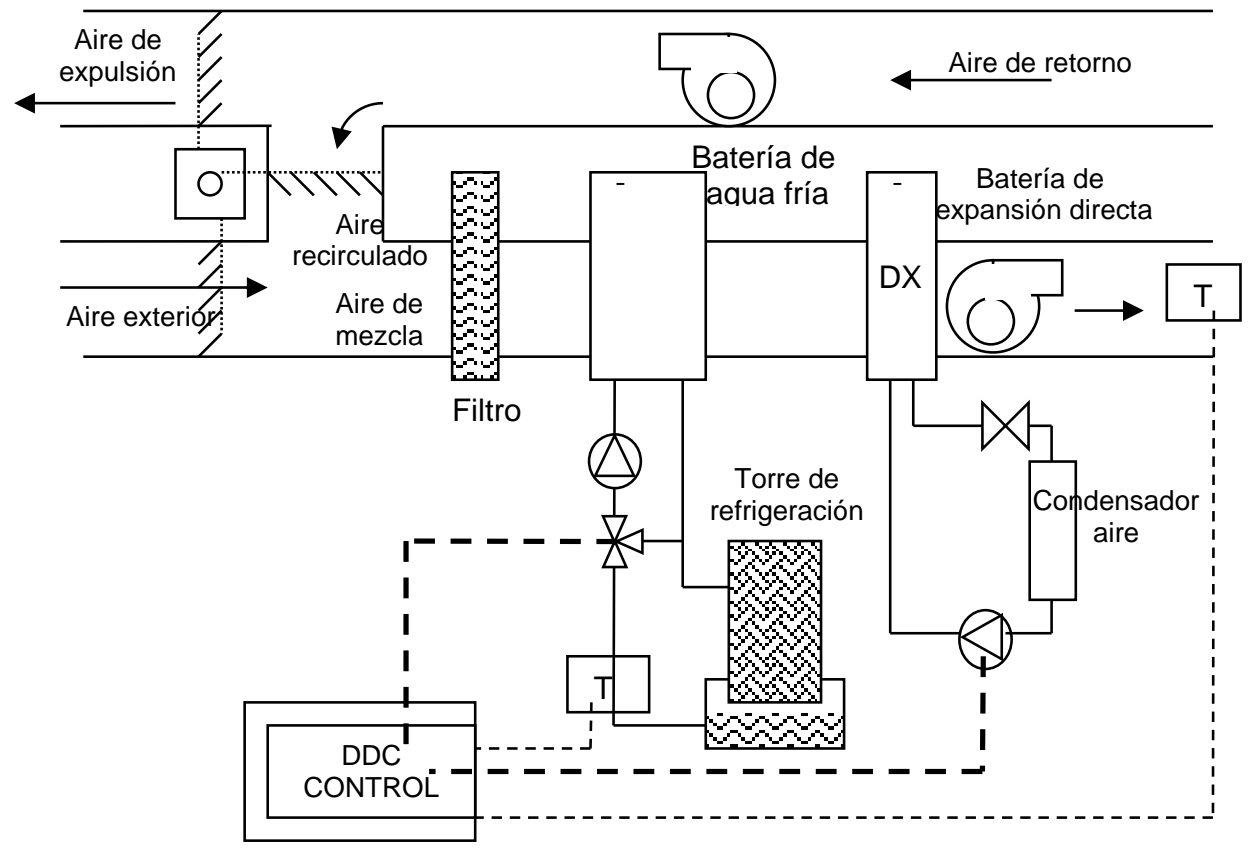

Figura I.22.- Esquema básico del enfriamiento gratuito por agua. 


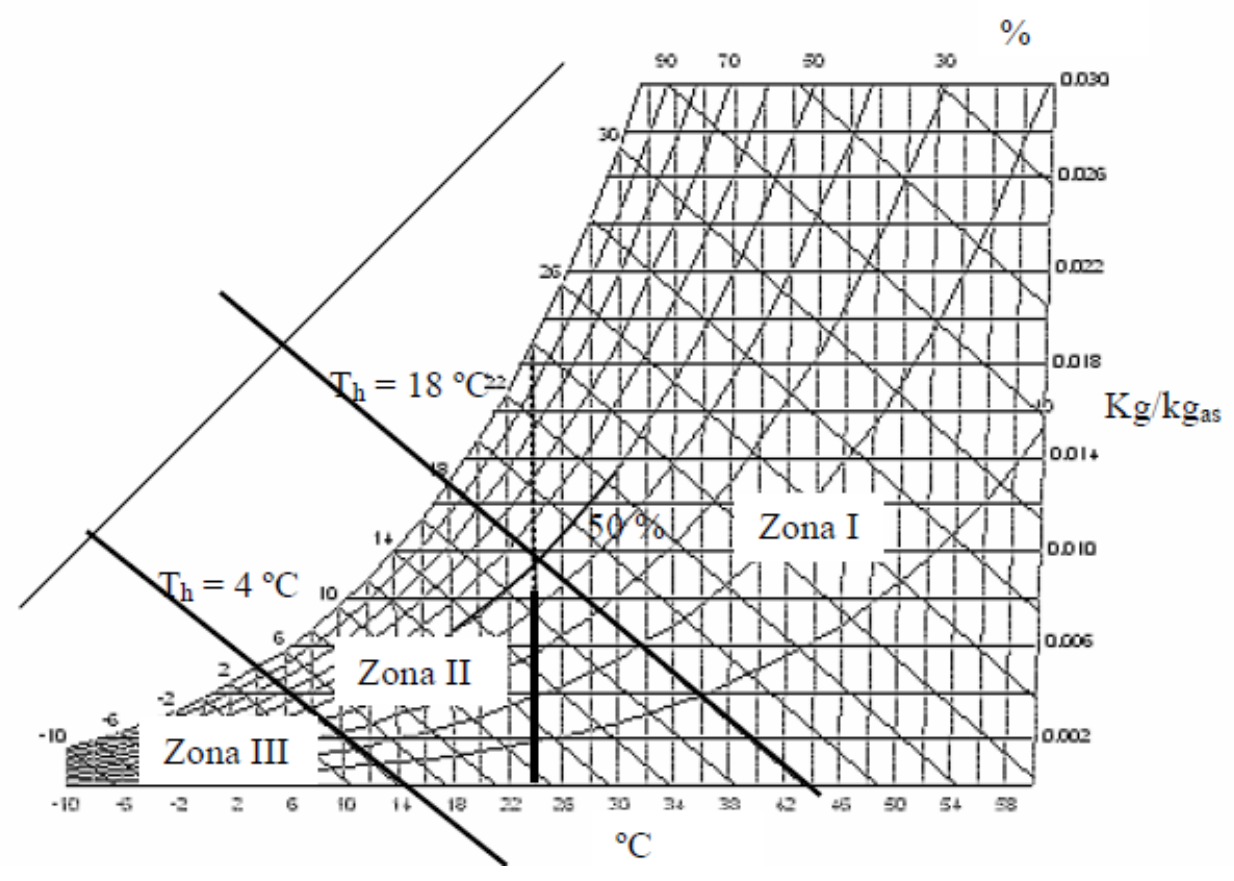

Figura I.23.- Zonas de control del proceso de free-cooling por agua.

Puede observarse que la división de las zonas I y II está caracterizada por la línea de temperatura húmeda, que para las condiciones particulares del local supuestas en el diagrama correspondería a $18 \stackrel{\circ}{\circ}$. Por debajo de este valor el enfriamiento de aire utilizando agua enfriada en una torre de refrigeración puede operar de manera efectiva. La división entre las zonas II y III está caracterizada por la temperatura húmeda, que en esta situación se ha supuesto de $4 \stackrel{\circ}{ } \mathrm{C}$, que determina las condiciones exteriores límite que permitirían compensar por enfriamiento gratuito por agua todas las cargas de refrigeración del sistema de climatización. Por debajo de ese valor la máquina de producción de frío por compresión mecánica estaría parada.

En el control del funcionamiento de estos sistemas, se toman como variables la temperatura del agua a la salida de la torre, y la temperatura de impulsión del aire tras atravesar la batería, siendo los valores de consigna considerados respectivamente la temperatura húmeda del interior del local y la temperatura establecida en la impulsión para soportar las cargas internas del local. La torre de enfriamiento estará en funcionamiento mientras la temperatura alcanzada por el agua sea inferior a la temperatura húmeda del local, y siempre que esta no descienda por debajo de los $2^{\circ} \mathrm{C}$, caso en el que existiría riesgo de congelación. Para temperaturas alcanzadas por agua suficientemente bajas (generalmente establecidas en $10^{\circ} \mathrm{C}$ ), el sistema de enfriamiento gratuito por agua bastará para adecuar la corriente de aire; pero en otro caso la temperatura de impulsión del aire resultaría superior a la requerida, y habría que recurrir al apoyo de un sistema de refrigeración auxiliar. Si por el contrario el sistema de enfriamiento gratuito por agua puede soportar toda la carga y la temperatura de impulsión del aire registrada es igual o menor que el valor de consigna, 
un regulador controlará el caudal de paso de agua por la batería a fin de ajustar dicha temperatura. El esquema de funcionamiento y control se puede observar en la figura I.24.

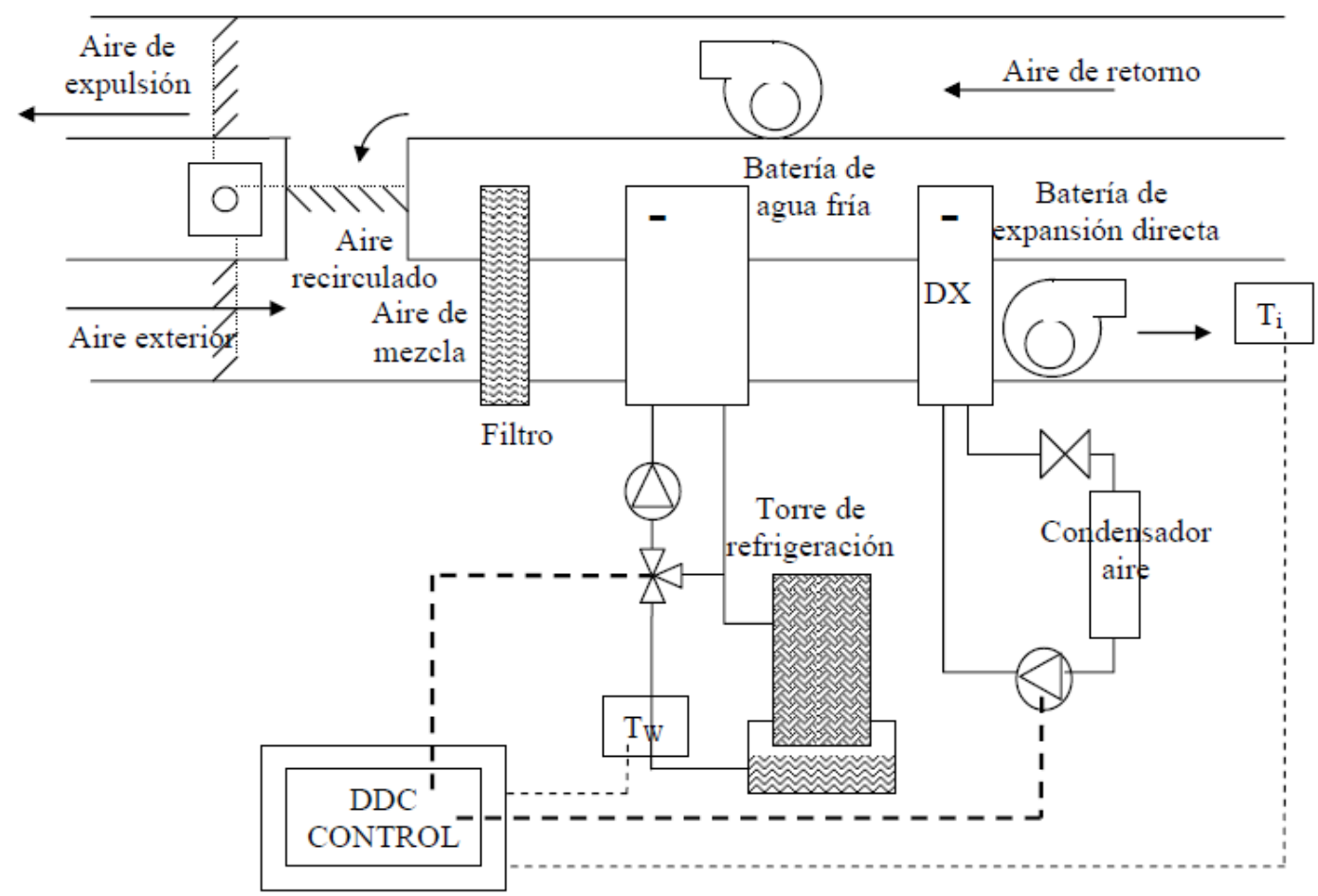

Figura I.24.- Enfriamiento gratuito utilizando enfriamiento evaporativo de agua.

Resulta evidente la limitación del aprovechamiento de este recurso respecto a las circunstancias particulares del clima exterior, lo que restringe su periodo de funcionamiento. Se presenta por lo tanto interesante su combinación con otros sistemas y aplicaciones, como puede ser la recuperación de energía. En estos sistemas el control regulará la utilización del recuperador de energía cuando sea necesario utilizar aire exterior aunque posea unas características energéticas peores que el aire de retorno. En estas condiciones el recuperador permitirá reducir la energía eliminada en el aire de expulsión, aportándosela al aire exterior.

\section{I.5.1.5.- SISTEMAS DE RECUPERACIÓN DE ENERGÍA.}

Los recuperadores de energía en los sistemas de climatización permiten mantener una adecuada calidad del aire interior sin penalizar energéticamente los sistemas de adecuación higrotérmica del aire impulsado a los locales.

Se entiende por recuperador de energía a aquel dispositivo que permite la reutilización del calor residual de un sistema y cuyo objetivo final es alcanzar la eficiencia máxima de la instalación. 
El calor residual de un proceso se escapa siempre a través de un fluido, gaseoso o líquido. El sistema más económico y eficaz de recuperación de calor será el que permita emplear directamente el fluido que lo contiene en el mismo u otro proceso. Ahora bien, esto no es siempre posible; de hecho esta situación raramente se da en las aplicaciones prácticas, por lo que hay que pensar en un equipo que permita transmitir el calor a otro fluido que pueda aplicarse al proceso. Por lo tanto, en general, los equipos de recuperación del calor residual son intercambiadores térmicos más o menos complejos.[18].

Se debe tener presente que toda recuperación de calor ha de constituir un sistema integrado dentro de un proceso, de modo que se reduzca el consumo de energía con un costo global aceptable. Como consecuencia, la recuperación del calor sólo podrá considerarse efectiva como parte integrante de un esquema bien concebido y cuidadosamente diseñado.

El empleo de recuperadores de calor en instalaciones de climatización permite utilizar el calor sensible y latente residual del propio proceso, consiguiendo así:

- Reducir la central energética (costes de inversión).

- Reducir el consumo de energía de funcionamiento (costes de explotación).

\section{I.5.2.- USO DE ENERGÍAS RENOVABLES.}

Las aportaciones energéticas de carácter renovable que ayudan a reducir la consumo energético de las instalaciones son cada vez más demandadas por la creciente sensibilidad de la sociedad, y por tanto requieren encontrar nuevas soluciones a las instalaciones tradicionales de las edificaciones.

\section{I.5.2.1.- SISTEMAS SOLARES TÉRMICOS DE BAJA TEMPERATURA.}

La energía solar, como recurso energético terrestre, se convierte de manera inmediata en una de los soluciones para poder conseguir un ahorro de energía. La energía solar en la obtenida a partir del aprovechamiento de la radiación electromagnética procedente del Sol. Los rayos solares sufren procesos de dispersión al atravesar nuestra atmósfera, encontrándonos, en consecuencia, dos tipos de radiación fundamentalmente:

Directa. Es aquella porción de radiación que llega a la superficie sin sufrir desviaciones.

Difusa. Es la radiación recibida en la superficie terrestre que se ha visto afectada por grandes dispersiones en su recorrido. 
La energía solar térmica de baja temperatura consiste en el aprovechamiento de la radiación solar para el calentamiento de un fluido, agua 0 aire, a temperaturas inferiores a las de evaporación, comúnmente inferiores a $100^{\circ} \mathrm{C}$, en el caso de que el fluido empleado sea agua. En este capítulo únicamente se introduce la tecnología que emplea agua como fluido caloportador y de almacenamiento. En el capítulo II se profundiza en la tecnología de los colectores solares de aire, objeto de estudio de este trabajo de Tesis Doctoral.

El aprovechamiento de la energía solar térmica de baja temperatura, principalmente en nuestro país, donde la capacidad de la solar térmica instalada se limita principalmente a colectores solares de agua, tiene tres aplicaciones fundamentales en la edificación:

Producción de Agua Caliente Sanitaria (ACS). Es la más extendida de todas, por ser la que mejor se adapta a las características de la energía solar, debido a que los niveles de temperatura a alcanzar no son elevados ( $45^{\circ} \mathrm{C}$ a $60 \stackrel{\circ}{\circ}$ ) y que su utilización abarca los doce meses del año.
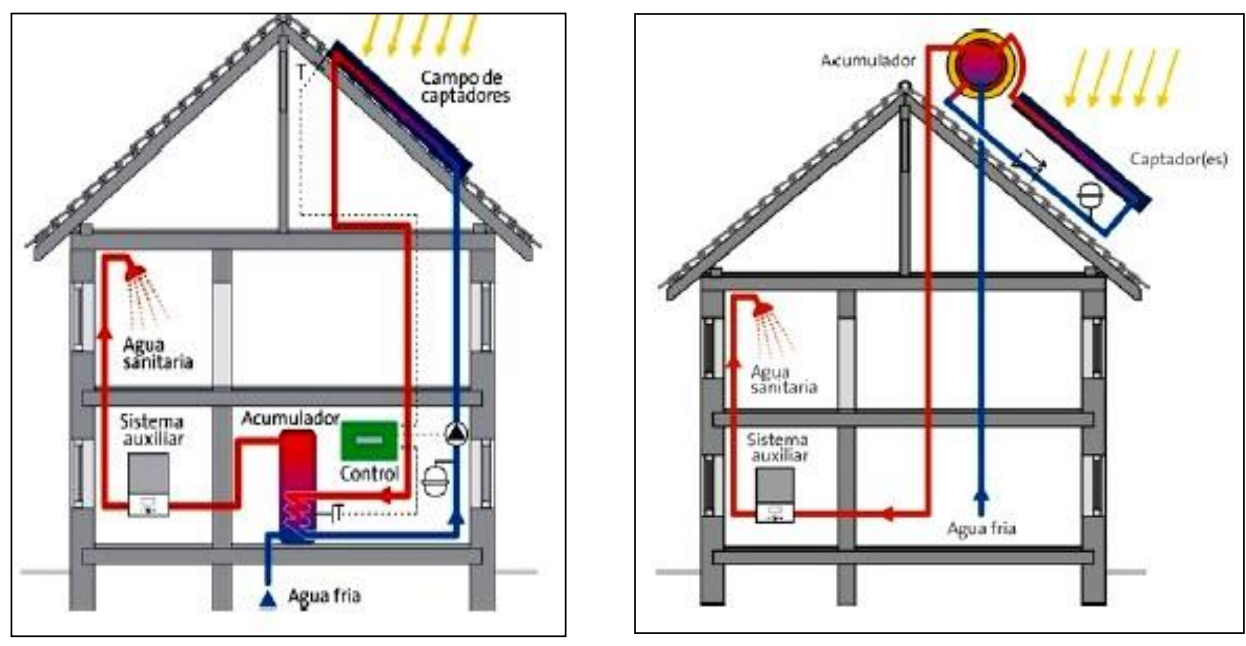

Figura I.25.- Instalación de energía solar para producir ACS en una vivienda.

Climatización de Piscinas. Al igual que en la producción de agua caliente, la temperatura a lograr $(24 \stackrel{\circ}{\circ}$ y $26 \stackrel{\circ}{\circ})$ se engloba dentro del abanico de temperaturas más apropiadas para una buena eficacia del colector, pero en cambio, en el caso de piscinas descubiertas, su uso es estacional por lo que el aprovechamiento de la instalación está condicionado a su uso en una cierta época del año. Por el contrario, en el caso de piscinas cubiertas, al igual que en el caso del ACS su aprovechamiento abarca la totalidad del año; es por ello, que tanto para instalaciones de producción de ACS como para climatización de piscinas cubiertas su uso es de obligado cumplimiento según rige la normativa del Código Técnico de la Edificación en su Documento Básico DB HE. 


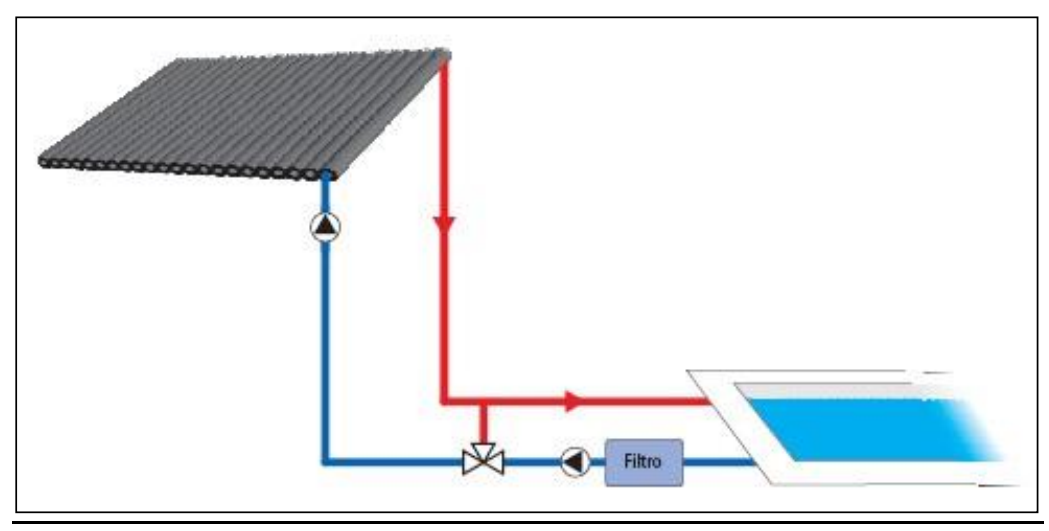

Figura I.26.- Instalación de energía solar para calentamiento de piscina.

Calefacción. De finalidad diferente a la climatización de piscina pero con las mismas ventajas siempre y cuando se opte por soluciones de climatización de baja temperatura tales como suelo radiante o radiadores de baja temperatura con temperaturas típicas de impulsión de entre $40{ }^{\circ} \mathrm{C}$ y $55^{\circ} \mathrm{C}$. Tal y como sucedía en el caso de piscinas descubiertas, el uso de calefacción con apoyo de energía solar térmica sufre una acusada estacionalidad que merma su aprovechamiento anual, ya que abarca únicamente los meses de invierno.

Refrigeración solar. Es una aplicación interesante de la energía solar, puesto que las épocas en que más se necesita suelen coincidir con las que disfrutan de más radiación solar.

Un sistema tipo de esta clase usa la producción a temperaturas altas que aportan los colectores planos de alta eficiencia o lo de tubos de vacío para alimentar una máquina frigorífica de absorción.

La refrigeración por energía solar se puede llevar a cabo con diversas tecnologías:

- Ciclos de absorción: $\mathrm{NH}_{3}-\mathrm{H}_{2} \mathrm{O}$ y $\mathrm{H}_{2} \mathrm{O}-\mathrm{LiBr}$. Opción más desarrollada.

- Ciclos desecantes (deshumidificación - humidificación): propuestos muchos tipos de sistemas. Su combinación con energía solar está poco madura.

- Compresión mecánica: alimentación de un ciclo Rankine para mover el compresor con energía solar o producción intermedia de energía eléctrica. 


\section{TIPOS DE TECNOLOGÍAS.}

En función de la forma de utilización de la radiación solar terrestre, distinguimos dos tipos de tecnología:

\section{PASIVA.}

Cuando la captación solar se realiza sin ningún elemento intermedio. Una de las aplicaciones de la energía solar es directamente como calefacción al permitir calentar recintos por radiación directa. Aprovechando las diferentes trayectorias de la radiación solar, dependiendo de la época del año, se introducen elementos arquitectónicos para aumentar en invierno y reducir en verano las cargas solares favoreciendo los distintos tipos de climatización (calefacción o refrigeración). Estos elementos pueden ser voladizos, persianas, salientes o entrantes en la fachada, entramados, toldos, pérgolas, etc.

Existen diferentes soluciones constructivas con altas prestaciones higrotérmicas empleadas en edificación, que potencian el aprovechamiento de la energía solar y que se engloban bajo la denominación de doble epidermis. Las soluciones pueden ir desde la interposición de una cámara con ventilación y paso de aire entre las hojas que constituyen el cerramiento, a otras como muro trombe, muro parietodinámico o invernadero adosado. La aplicación de estas soluciones más avanzadas se está extendiendo por varios países europeos, aunque está prácticamente restringida al sector terciario.

Cuando hablamos de fachadas ventiladas, nos podemos encontrar con que la cámara de aire recorra la fachada del edificio de la parte superior a la inferior en toda su altura, o esté dividida en cada planta, dependerá de la solución constructiva empleada para resolver los encuentros con los forjados. El empleo de esta cámara de aire ventilada proporciona importantes ahorros en las instalaciones de climatización, además de favorecer el confort térmico y visual en el interior del edificio.

Una de las soluciones más avanzadas es el empleo del llamado muro trombe, también llamado muro solar ventilado, en el que se utiliza la radiación solar que incide sobre el cerramiento para el calentamiento por recirculación del aire interior del edificio. Generalmente está formado por una hoja interior de fábrica, una cámara de aire y un acristalamiento exterior. La circulación del aire en la cámara puede ser forzada o por termosifón. 


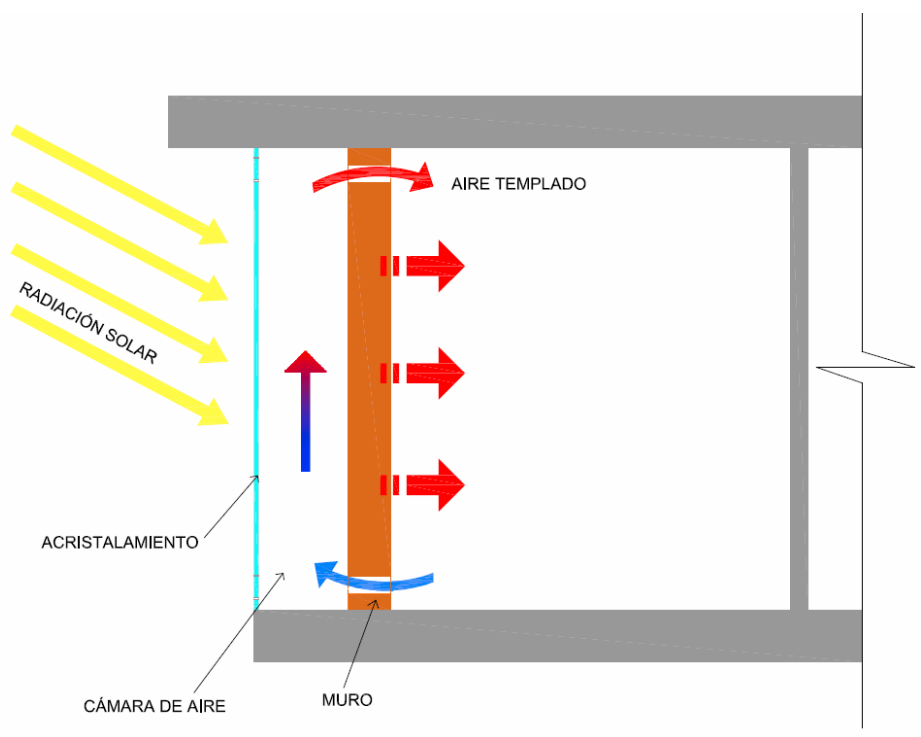

Figura I.27.- Muro trombe, invierno.

Otra de las soluciones es el muro parietodinámico, que emplea la radiación solar incidente sobre el cerramiento para precalentar el aire exterior que se incorpora a la cámara de aire comprendida entre la hoja interior de fábrica y la hoja exterior acristalada o metálica que absorbe la radiación. En este muro la circulación del aire también puede ser forzada o natural.

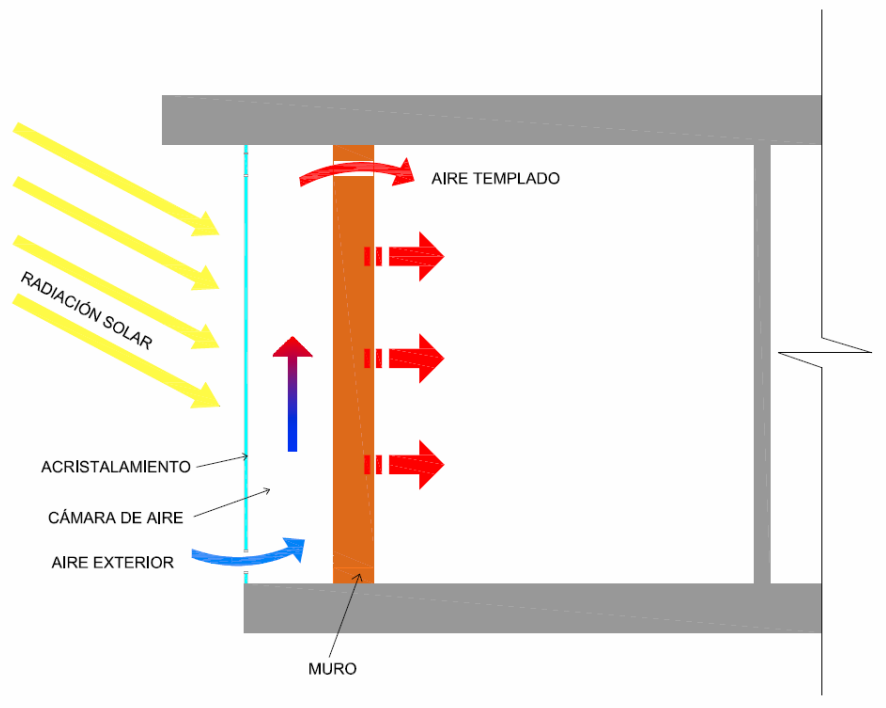

Figura I.28.- Muro prietodinámico, invierno.

En cuanto al invernadero adosado, se denomina así al espacio o recinto no acondicionado formado por un cerramiento exterior con un alto porcentaje de superficie acristalada que se coloca adyacente a la fachada del edificio. También puede contar con acristalamiento el elemento de fachada, una puerta, una ventana, etc., que separa el espacio no acondicionado del interior. Entran 
dentro de esta definición las galerías y balcones acristalados. Habitualmente se cuenta con un sistema de ventilación forzada para que el aire circule en el interior de este espacio, bien sea el aire interior del edificio o el exterior que se precalienta para la ventilación.

\section{ACTIVA.}

Para obtener rendimiento de la energía solar, se intercala un dispositivo de captación intermedio. Se distinguen dos tipos de tecnologías:

- Térmica. Se denomina térmica a la energía solar cuyo aprovechamiento se logra por calentamiento de algún medio. La calefacción de viviendas, calentamiento de agua, calentamiento de piscinas, secado, frío solar, etc.

- Fotovoltaica. Se llama fotovoltaica a la energía solar aprovechada por medio de células fotovoltaicas, capaces de convertir la radiación en corriente eléctrica.

Tal y como ocurre con los elementos pasivos, los elementos activos verán condicionada su posición e inclinación en función de las necesidades de generación de la instalación solar. Tomando como forma típica y más extendida del elemento que capta la energía solar la de un paralepípedo rectangular donde una de las caras de mayor superficie coincide con la parte activa de captación solar, y considerando que el aprovechamiento debe ser anual, la inclinación óptima será en torno a la latitud del emplazamiento, siendo conveniente aumentar en torno a 10\% la inclinación si las necesidades energéticas tienen una clara estacionalidad con requerimientos mayores en épocas de invierno o disminuir en torno a 10 la inclinación si las necesidades energéticas mayores son en verano. La razón se debe a que es recomendable que la radiación solar incida lo más perpendicularmente a la superficie captadora para evitar reflexiones sobre la misma.

Para conseguir la optimización de los sistemas se aplican técnicas de simulación que emplean motores de cálculo complejos mediante herramientas informáticas.

\section{Partes de una instalación de energía solar térmica.}

\section{Sistema de captación.}

Puede estar formado por uno o varios captadores de diferentes superficies que transforman la radiación solar incidente en energía térmica que es transferida al fluido de trabajo contenido en su interior. Dado que se trata del principal elemento del sistema se debe prestar una atención especial a su elección según las distintas posibilidades que ofrecen los fabricantes. La superficie absorbente (absorbedor) es el elemento principal del colector térmico, pues es la responsable de la capacidad de captación de energía térmica, que posteriormente será transferida al fluido de trabajo. 
Existen diferentes tipos de captadores en función de la aplicación a la que vaya destinada el sistema, los clasificamos como:

- Colector solar plano. El más extendido ya que ofrece una excelente relación prestaciones/coste para las aplicaciones de baja temperatura que se aplican en la edificación. Existe una primera clasificación de los diferentes modelos según el tratamiento que recibe la superficie absorbente. Atendiendo al tipo de tratamiento, los absorbedores pueden ser presentados con pinturas negras especiales o con tratamiento selectivo absorbente (alta absortividad en longitudes de onda corta y baja emisividad en longitudes de onda larga).

- Colector con tubos de vacío. El vacío que existe dentro de cada una de las ampollas que conforman la superficie de captación del captador anula las pérdidas por convección lo que provoca que el rendimiento de los captadores de tubo de vacío sea superior al de los captadores solares planos. No obstante según la aplicación, la fragilidad, superior tiempo de montaje y mayor coste suponen que se opte por un captador solar plano en detrimento del captador de tubos de vacío.
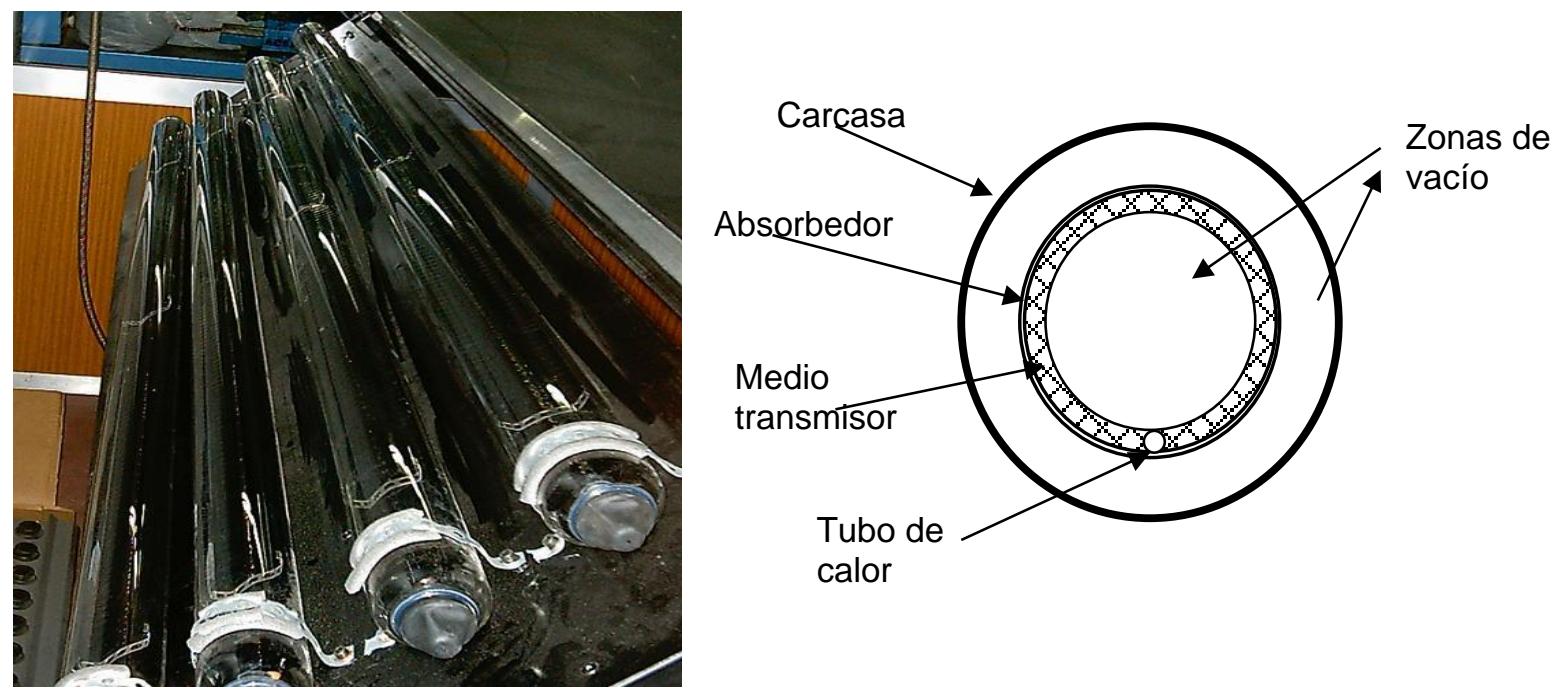

Figura I.29.- A la izqda., colector solar formado por tubos de vacío. A la dcha., esquema básico de un tubo de alto vacio con heat pipe.

- Captador de polipropileno. Es el modelo más simplificado de captador solar. Se compone de un conjunto de tubos negros de EPDM o polipropileno, sin aislamiento y aunque tiene un coste reducido, sus prestaciones energéticas son modestas, solamente aptas para climatización de piscinas y en especial de exteriores donde la normativa no exige ningún tipo de aporte solar. 


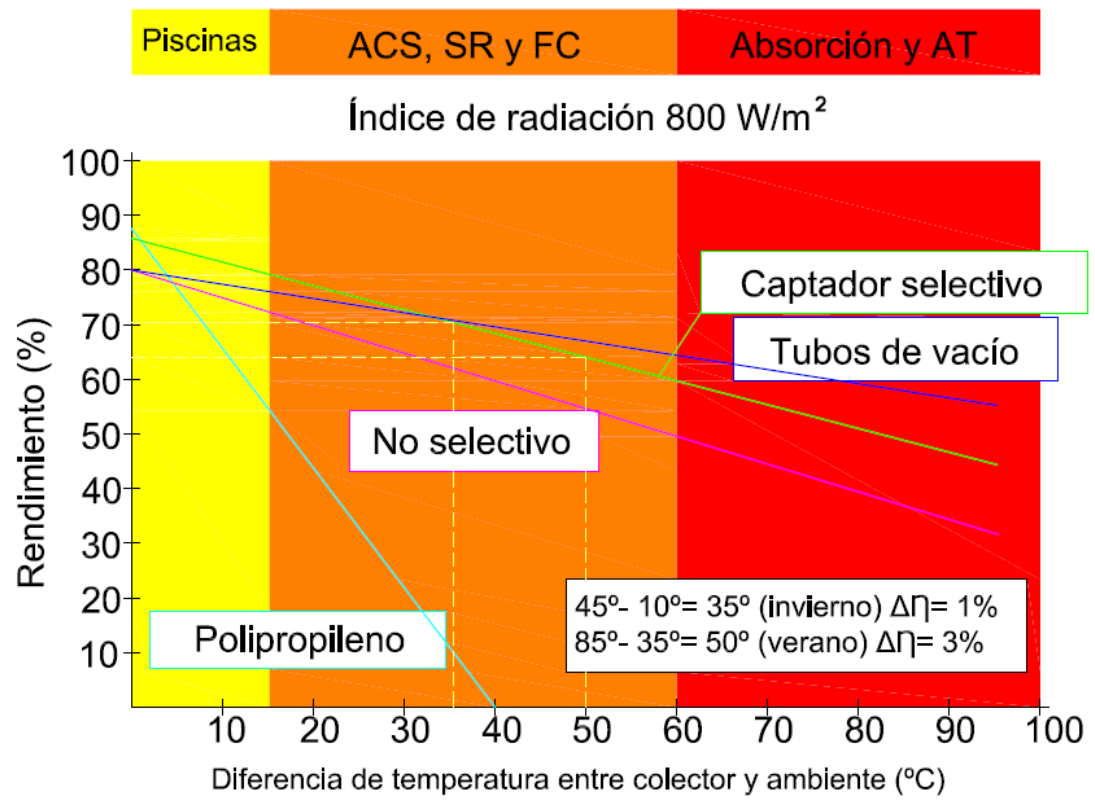

Figura I.30.- Rectas de rendimiento del colector en función de la tipología.

Es importante la selección del absorbedor o del material de recubrimiento del mismo, si el absorbedor consigue reflejar menor proporción de las longitudes de onda más energéticas conseguiremos obtener una mayor ganancia de energía. La ganancia térmica influye directamente en el rendimiento del colector, en la siguiente figura se puede observar las rectas de rendimiento en función del tipo de colector.

Dependiendo de la aplicación a la que vaya destinada nuestra instalación tendremos diferentes temperaturas de referencia. Así, si nuestra instalación está destinada al abastecimiento de ACS la temperatura de referencia es de $45-60^{\circ} \mathrm{C}$, para la climatización de piscinas será suficiente con $25^{\circ} \mathrm{C}$, para calefacción por suelo radiante $(\mathrm{SR})$ la temperatura de referencia es de $45^{\circ} \mathrm{C}$, si empleamos radiadores (AT) necesitaremos $75^{\circ} \mathrm{C}$, y, para poder producir frío a partir de los colectores (Frío solar) y un sistema de absorción necesitaremos alcanzar los 85ํㅡ.

La elección del captador o colector va a depender de la aplicación a la que esté destinada la instalación (lo que nos va a indicar la temperatura de referencia que va a tener que alcanzar el fluido caloportador) y de la recta de rendimiento de cada tipo de colector.

Como puede observarse los captadores de polipropileno, debido a su bajo coste pueden ser una solución óptima para aplicaciones de climatización de piscinas donde la diferencia entre la temperatura de retorno o de entrada al colector, que se debe equiparar a la de la aplicación (en este caso en torno a $25^{\circ} \mathrm{C}$ ) y la temperatura ambiente $\left(15^{\circ} \mathrm{C}\right.$ y $35^{\circ} \mathrm{C}$ típica de la temporada de baño) se encuentra en el rango de $0 \stackrel{\circ}{\circ} \mathrm{C}$ a $10 \stackrel{\circ}{\circ} \mathrm{C}$ donde el rendimiento del captador es suficientemente elevado como para valorarlo como una opción. Sin embargo a medida que la temperatura de la aplicación es más elevada el rendimiento del captador, al no disponer de 
cubierta de vidrio y por tanto no favorecerse del efecto invernadero y de tener altas pérdidas por convección, cae rápidamente descartándolo como opción a valorar.

Cuando la aplicación combine ACS y climatización de piscinas el bajo rendimiento de los captadores de polipropileno para las temperaturas asociadas a la preparación de ACS y la recomendación de tener un campo de captación único para optimizar los costes de los elementos comunes del sistema hidráulico y de circulación provocan que todo el sistema deba dimensionarse con captadores más eficientes, y por tanto, descartar la opción de captadores de polipropileno 0 similares.

Para aplicaciones de ACS y climatización mediante Suelo Radiante (SR) o, en su defecto, radiadores de baja temperatura, la diferencia de temperatura entre el ambiente, en las épocas de más necesidad de energía térmica (típicamente en invierno con temperaturas en torno a $10{ }^{\circ} \mathrm{C}$ ) y la de la aplicación (entre $45^{\circ} \mathrm{C}$ y $60^{\circ} \mathrm{C}$ ) se sitúa en torno a $35^{\circ} \mathrm{C}$ donde la diferencia entre el rendimiento de captadores solares térmicos de absorbedor con tratamiento selectivo y los captadores de tubo de vacío en comparación con los captadores de absorbedor no selectivo se sitúa en torno al 10\%. Esta diferencia puede ser definitiva a la hora de descartar los captadores no selectivos, ya que si bien su coste suele ser inferior, la obligatoriedad de llegar a aportaciones solares según dicta el CTE en construcciones donde escasea la superficie donde instalar los captadores, tal y como pueden ser las cubiertas de viviendas en altura, puede significar que la aportación de dichos captadores no sea suficiente y se deban descartar a favor de captadores más eficientes como son los selectivos o los tubos de vacío.

A la hora de valorar la opción de decantarse por captadores selectivos o tubos de vacío se debe estudiar el coste de la totalidad del sistema y el tiempo de instalación asociado a cada tipología de captador, que son típicamente más elevados en los captadores de tubos de vacío que los captadores planos selectivos, mientras que el rendimiento de ambos para este tipo de aplicaciones es muy similar.

Otro dato a tener en cuenta es que para épocas estivales donde se producen traslados de las zonas residenciales a las zonas de disfrute de vacaciones provocan una disminución del consumo energético del edificio coincidiendo con la época de más alta radiación. Una opción muy extendida para mitigar las sobre temperaturas que provoca esa situación es aumentar la temperatura de acumulación por lo que la temperatura media de retorno al captador aumenta y a su vez la diferencia entre ésta y la del ambiente, por tanto la eficiencia de los captadores de tubo de vacío aumenta en relación a la de los captadores solares selectivos provocando una mayor ganancia de temperatura y agravando el problema de sobre temperaturas [19]. 


\section{Sistema de acumulación.}

Tanto la energía que se recibe del sol como la demanda de agua caliente son magnitudes que dependen del tiempo. Sin embargo, no siempre la demanda de agua caliente se producirá en aquellos momentos en que se dispone de suficiente radiación solar. Por tanto, si se quieren aprovechar al máximo las horas de sol, será necesario acumular la energía en aquellos momentos del día en que esto sea posible y utilizarla cuando se produzca la demanda.

La energía puede acumularse en forma de calor sensible, calor latente, energía química, etc. Para los sistemas de producción de agua caliente la energía se almacena como calor sensible acumulado en un depósito de agua.

Cuando el depósito de acumulación tiene un gran volumen y la relación altura-diámetro es considerable, debe tenerse en cuenta la estratificación de temperaturas dentro del mismo por la incidencia que ésta puede tener sobre el rendimiento de los colectores. Para sistemas pequeños el efecto de la estratificación puede considerarse despreciable.

El volumen de acumulación podrá fraccionarse en dos o más depósitos que se conectarán preferentemente, en serie. En el caso de que se conecten en paralelo, debe hacerse por el sistema de retorno invertido para equilibrar la pérdida de carga en las conexiones.

\section{Sistema de intercambio.}

Cuando se proyecta una instalación solar para zonas donde existe riesgo de congelación, o bien cuando el fluido caloportador no deba entrar en contacto con el agua, la solución más normal consiste en colocar un intercambiador de calor entre los colectores y el depósito de acumulación. Por el primario circulará el fluido caloportador, y por el secundario, agua.

El intercambiador puede estar integrado en el depósito de acumulación o bien ser exterior al mismo. En el primer caso, el intercambio por el lado del acumulador se realiza por convección natural y la superficie de intercambio debe ser notablemente mayor que en el segundo, en el que la transferencia en ambos lados se realiza por convección forzada.

Los intercambiadores de calor se caracterizan por su eficacia, $\varepsilon$, que se define como la relación entre la energía intercambiada y la máxima que teóricamente podría intercambiarse. No obstante la eficacia de intercambio depende del tipo de sistema de intercambio que se esté utilizando, ya sea intercambiador externo de placas en contracorriente o equicorriente, de serpentín sumergido, etc. En la figura I.31se presentan las dos configuraciones de intercambio más comunes en las instalaciones de energía solar 

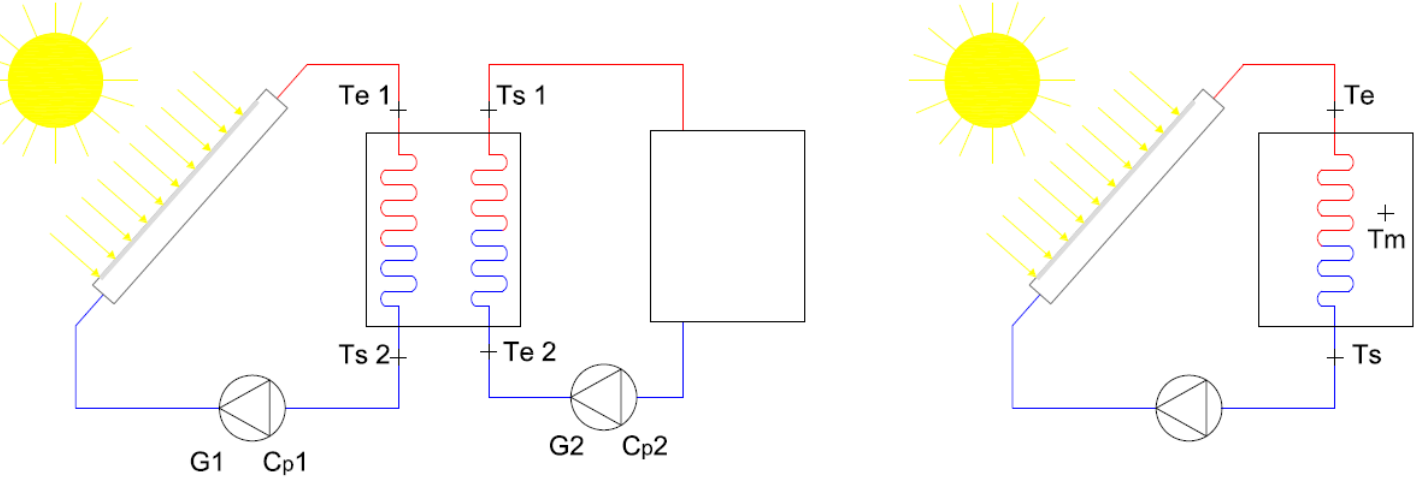

Figura I.31.- Configuraciones más habituales del intercambiador de calor.

\section{Sistema de transporte o hidráulico.}

Compuesto por tuberías, bombas de circulación, válvulas y demás elementos que se encargan de conducir el movimiento del fluido caliente desde el sistema de captación hasta el sistema de acumulación y de éste a la red de consumo.

Entre sus parámetros de funcionamiento destacan los caudales de diseño y su distribución, la longitud y diámetro de las tuberías y el espesor y conductividad térmica del aislamiento. Respecto a las bombas de circulación se ha de considerar su potencia eléctrica.

Dentro de este sistema quedan definidas las características energéticas de los fluidos empleados en los diversos circuitos de la instalación y entre las propiedades a considerar destacan: calor específico, temperaturas de ebullición y de congelación, densidad, viscosidad y coeficiente de expansión térmica.

\section{Sistema de regulación y control.}

Es el responsable de asegurar el correcto funcionamiento del equipo para aprovechar la máxima energía solar térmica posible activando o desactivando los distintos elementos eléctricos activos de la instalación como son las bombas de circulación hidráulica entre otros.

Queda definido por la posición de los sensores de control (en captadores, acumuladores, intercambiadores, tuberías, etc.), por la estrategia y los criterios de activación/parada (diferencias de temperatura de arranque, temperaturas de corte (máxima en acumuladores, sistema antiheladas, etc.), histéresis, valores mínimos de irradiancia solar, etc.).

También se pueden incorporar las características de funcionamiento y estrategia de control del sistema de apoyo y, en su caso, de la bomba del circuito de recirculación así como de las válvulas mezcladoras. 


\section{Sistema de apoyo auxiliar.}

Se utiliza para complementar el aporte solar suministrando la energía necesaria para cubrir la demanda prevista, garantizando la continuidad del suministro de agua caliente en los casos de escasa radiación solar o consumo superior al previsto. El sistema entrará en funcionamiento cuando sea estrictamente necesario y de forma que se aproveche lo máximo posible la energía extraída del campo de captación, además en caso de que el sistema no disponga de acumulación, es decir, sea una fuente instantánea, el equipo deberá ser modulante, es decir, capaz de regular su potencia de forma que se obtenga la temperatura de manera permanente con independencia de cual sea la temperatura del agua de entrada al citado equipo. No se permite la conexión de un sistema de generación auxiliar en el acumulador solar, ya que esto puede suponer una disminución de las posibilidades de la instalación solar para proporcionar las prestaciones energéticas que se pretenden obtener con este tipo de instalaciones.

\section{I.5.2.2.- SOLAR FOTOVOLTÁICA.}

La tecnología fotovoltaica (FV) genera electricidad a partir de la radiación solar. Este proceso se basa en el uso de un material semiconductor que puede ser adaptado para liberar electrones, las partículas de carga negativa que son la base de la electricidad. El material semiconductor más utilizando en las células fotovoltaicas es el silicio, un elemento que se encuentra en la arena. Todas las células FV tienen al menos dos capas de este tipo de semiconductores, una con carga positiva y otra con carga negativa. Cuando la luz incide en el semiconductor, el campo eléctrico que se crea en la unión entre ambas capas hace que fluya electricidad. A mayor intensidad de la luz, mayor será el flujo de electricidad, aunque un sistema fotovoltaico no necesita luz solar potente para funcionar, ya que puede generar electricidad incluso en días nublados. El sistema solar FV difiere de un sistema solar basado en termocolectores donde los rayos del sol se utilizan para generar calor, empleado generalmente para obtener agua caliente en los hogares, calentar el aire en un sistema de climatización o ventilación, calentamiento de piscinas, etc.

Las piezas más importantes de un sistema FV son las células, que representan los componentes básicos, los módulos que unen grandes cantidades de células en una unidad y, en algunos casos, los inversores utilizados para convertir la electricidad generada a una forma adecuada para el uso diario. Cuando se habla de una instalación FV de una capacidad de $3 \mathrm{kWp}$ (pico), se refiere al rendimiento o salida del sistema bajo condiciones de prueba estándar, permitiendo la comparación entre diferentes módulos. 


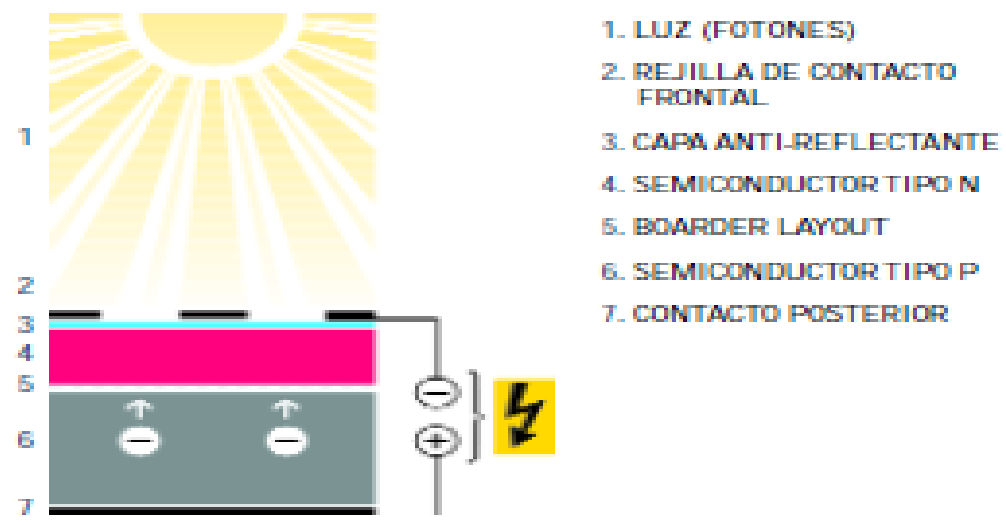

Figura I.32.- Tecnología fotovoltaica.

Tipos de sistemas fotovoltaicos en cuanto a su configuración.

- Conectado a la red: Este tipo de sistema solar FV es el más popular para hogares y oficinas en el mundo industrializado. La conexión con la red eléctrica local permite vender a la compañía la electricidad sobrante. La electricidad se importa desde la red después durante las horas de oscuridad. Se utiliza un convertidor de voltaje para convertir la corriente continua producida por el sistema en corriente alterna para su empleo con aparatos eléctricos normales.

- Soporte a la red: También puede conectarse un sistema a la red eléctrica local como batería de refuerzo. La electricidad sobrante producida después de la descarga de la batería se vende a la red eléctrica. Es un sistema ideal para zonas donde no se garantiza un suministro eléctrico fiable

- Aislada de la red: Totalmente independiente de la red eléctrica, el sistema se conecta a una batería mediante un regulador de carga, que almacena la electricidad generada y actúa como la principal fuente de suministro eléctrico. Puede utilizarse un inversor para obtener corriente alterna y poder utilizarla en electrodomésticos usuales. Aplicaciones típicas aisladas de la red son las estaciones repetidoras para teléfonos móviles o la electrificación en zonas rurales. Para esta última se emplean pequeños sistemas solares domésticos (SHS) que cubren las necesidades básicas de electricidad, o mini-redes solares, que son sistemas de electricidad solar más grandes que producen electricidad para varios hogares.

- Sistema híbrido: Puede combinarse un sistema solar con otra fuente de energía (un generador de biomasa, una turbina eólica o un generador diesel) para garantizar un suministro constante de electricidad. Un sistema híbrido puede conectarse a la red, funcionar con autonomía o con soporte de la red eléctrica. 


\section{I.5.2.3.- BIOMASA.}

El potencial de biomasa disponible en España, bajo hipótesis conservadoras, se sitúa en torno a 87 millones de toneladas de biomasa primaria en verde, incluyendo restos de masas forestales existentes, restos agrícolas, masas existentes sin explotar y cultivos energéticos a implantar. A este potencial se suman más de 12 millones de toneladas de biomasa secundaria seca obtenida de residuos de industrias agroforestales.

La biomasa es una excelente alternativa energética por dos razones. La primera es que, a partir de ella se pueden obtener una gran diversidad de productos; la segunda, se adapta perfectamente a todos los campos de utilización actual de los combustibles tradicionales. Así, mediante procesos específicos, se puede obtener toda una serie de combustibles sólidos, líquidos o gaseosos que pueden ser aplicados para cubrir las necesidades energéticas de confort, transporte, cocinado, industria y electricidad, o servir de materia prima para la industria.

Para usos térmicos en edificios los "pellets", las astillas de calidad, los huesos de aceituna y las cáscaras de almendra son combustibles que, con la tecnología actual, presentan las características adecuadas y son los más extendidos.

La combustión directa de la biomasa es sin duda el proceso mejor conocido y del que en la actualidad se obtiene la práctica totalidad de la energía de este recurso, siendo el más desarrollado a nivel comercial. Consiste en una oxidación total de la materia orgánica de la biomasa efectuada a altas temperaturas $\left(800-1.000^{\circ} \mathrm{C}\right)$ utilizando el aire atmosférico como agente oxidante. El proceso libera calor y se obtienen como productos finales principales dióxido de carbono, agua y cenizas, que corresponden básicamente a los componentes minerales presentes en la biomasa y que pueden ser restituidas al suelo como fertilizantes.

En las calderas de biomasa, el sistema más común es un quemador en parrilla horizontal, alimentado con tornillo (husillo) que permite la combustión de gran variedad de tipos de biomasa, pero una característica común de los materiales biomásicos originales es la gran heterogeneidad que presentan en sus propiedades físicas, tales como la forma y tamaño de sus partículas, la distribución granulométrica y su grado de humedad. Estas propiedades, hacen que sea preciso llevar a cabo procesos de acondicionamiento, tales como el astillado, molienda, secado, y densificado previos a su utilización. El tipo de pretratamiento vendrá dado por las especificaciones de combustible requeridas por cada tecnología de conversión y supone un aumento del coste de producción de la energía final.

Las calderas de biomasa son equipos compactos diseñados específicamente para su uso, ya sea doméstico en viviendas unifamiliares, edificios de viviendas o comerciales, existiendo también modelos para instalaciones industriales. Todas ellas presentan sistemas automáticos de encendido 
y regulación. En algunos casos pueden estar equipadas con sistemas de retirada de cenizas, que facilitan el manejo al usuario. Para aplicaciones de calefacción doméstica o comercial, estos equipos son de potencia baja a media, hasta 150-200 kW, proporcionando rendimientos entre el 85 y $92 \%$, valores similares a los de las calderas de gasóleo o de gas.

En el mercado existe una amplia gama de modelos de calderas de biomasa que pueden ajustarse a las necesidades de los distintos usuarios, desde viviendas unifamiliares hasta grandes bloques de viviendas y desarrollos urbanísticos. Las modernas calderas de biomasa disponen de alimentación de combustible en continuo y automatizada, y de limpieza automática del intercambiador, con rendimientos de hasta el 90\%, sin producción de humos visibles. También hay sistemas de compactación de cenizas que evitan tener que retirarlas todos los días, reduciendo esta tarea a dos o tres veces por temporada.

Un sistema de calefacción con biomasa consta de una serie de equipos o sistemas principales:

- Almacén de combustible: silo, tolva.

- Sistema de alimentación: tornillo sinfín, neumático o gravedad.

- Caldera: cámara de combustión, zona de intercambio, cenicero y caja de humos.

- Chimenea: similar a la de un sistema convencional, aunque de un diámetro ligeramente mayor, debido a que el volumen de humos es mayor porque la humedad de la biomasa al arder se convierte en vapor de agua.

- Sistema de distribución de calor: igual que un sistema convencional.

- Sistema de regulación y control: igual que un sistema convencional en cuanto a la interfaz del usuario.

La biomasa es una excelente opción para la combinación con energía solar térmica para producción de agua caliente, calefacción y aire acondicionado. Además, la biomasa es un combustible más barato y ecológico que los convencionales (fósiles) que permite generar empleo en áreas rurales, prevenir incendios, y mantener ecosistemas naturales.

La instalación de calderas de biomasa en los edificios no es obligatoria por ley, no obstante si se recoge en el CTE que si por alguna razón no se puede conseguir la energía suficiente requerida con la energía solar, se ha de complementar la instalación con otro tipo de energía renovable, por ejemplo la de la biomasa.

Como inconvenientes se pueden indicar la necesidad de espacio para acumular el combustible y la potencia necesaria para el encendido del combustible dado que, sobre todo en calderas de baja potencia, a menudo se produce utilizando una resistencia eléctrica que calienta el 
aire hasta temperaturas suficientes como para que el combustible biomásico comience a arder. En la figura 1.33 se muestra como ejemplo un equipo comercial para vivienda unifamiliar alimentado con pellets.
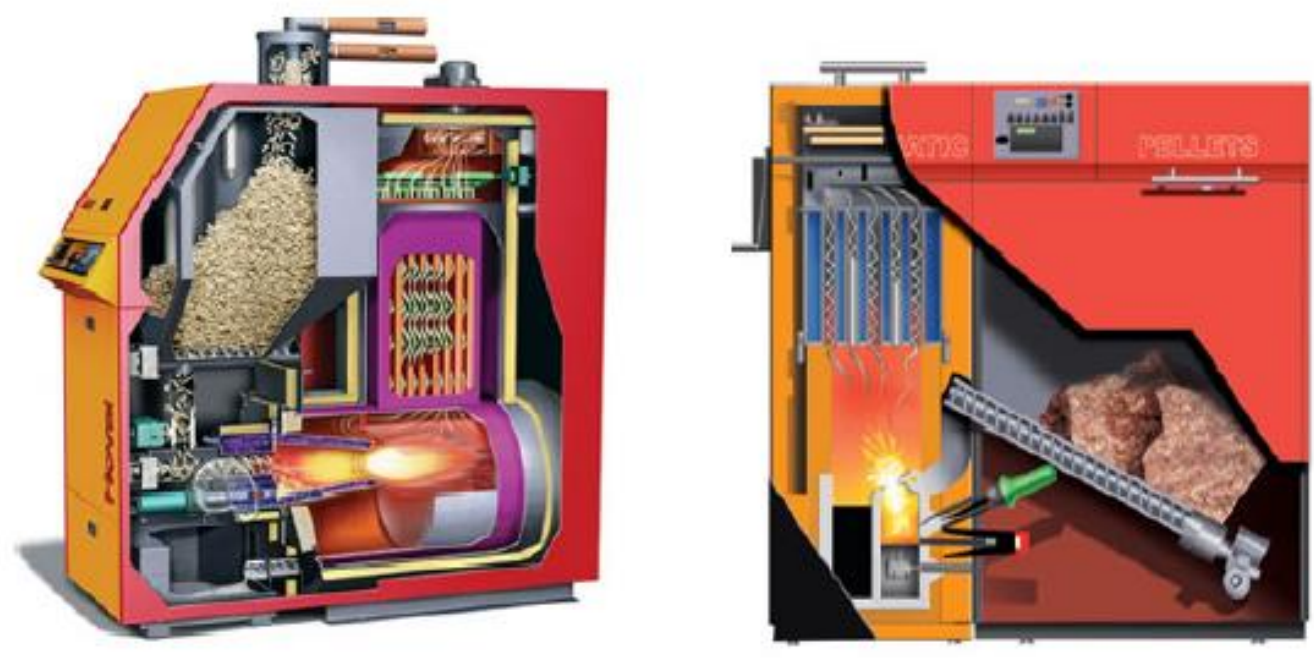

Figura I.33.- Interior de una caldera de biomasa.

\section{I.5.2.4.- GEOTÉRMIA DE BAJA TEMPERATURA.}

Esta tecnología se basa en el aprovechamiento de la energía acumulada en el subsuelo mediante el empleo de una bomba de calor, utilizando el subsuelo como foco frío en invierno y foco caliente en verano. La temperatura prácticamente constante a la que se encuentra el terreno a partir de cierta profundidad permite obtener unas condiciones de funcionamiento estables sin dependencia de las condiciones exteriores.

Una instalación geotérmica aprovecha la energía existente en el subsuelo con el fin de utilizarla en diversas aplicaciones, entre las cuales cabe destacar la climatización o calefacción de casas, locales, edificios, etc. El aprovechamiento se realiza a través de un intercambio energético entre los tubos de nuestro intercambiador de calor subterráneo y el subsuelo, evacuando o absorbiendo calor. Esta energía del subsuelo se capta en función de la necesidad de calefacción, o bien, el subsuelo se emplea como foco caliente, absorbiendo calor para conseguir la refrigeración del local.

Por dicha instalación subterránea se hace circular un fluido, que es el que sirve de elemento de transporte energético conectando el subsuelo con el local a climatizar. La temperatura natural del subsuelo es relativamente constante e independiente de las fluctuaciones estacionales. 
En la temporada fría, el fluido del circuito, que circula por el bucle subterráneo, absorbe calor del subsuelo, ya que la temperatura de este fluido está aproximadamente entre 0 y $5 \stackrel{\circ}{\circ}$, y la del subsuelo entre 10 y $15 \stackrel{\circ}{\circ}$. Esto se ve favorecido sobre todo por la unidad bomba de calor geotérmica que es la responsable de aportar calor al local intercambiando calor con nuestro bucle subterráneo. Dicha unidad trabaja con un rango de temperaturas de agua en el bucle muy amplia, de $-4 \stackrel{\circ}{ } \mathrm{C}$ a $45^{\circ} \mathrm{C}$. Una vez que el fluido está en superficie, la unidad extrae el calor del fluido y lo aporta al aire por impulsión directa o a través de una red de conductos de aire, distribuyéndose de esta forma por el interior de los locales.

En verano el proceso es el inverso, la bomba de calor geotérmica absorbe el calor de la casa o aplicación y lo envía por medio del fluido caloportador al subsuelo, donde será disipado por la diferencia de temperatura existente entre la temperatura del bucle (entre 35 y $50 \stackrel{\circ}{\circ}$ ) y la del subsuelo (entre $13^{\circ} \mathrm{C}$ y $\left.20^{\circ} \mathrm{C}\right)$.

\section{I.5.2.5.- MINIEÓLICA.}

La energía eólica se fundamenta en la producción de electricidad mediante la energía contenida en el viento, haciendo girar las palas de las máquinas eólicas, y transmitiendo su movimiento a un generador que produce electricidad.

La tecnología eólica ya está en su fase de madurez y presenta un gran desarrollo comercial. La instalación de estas máquinas, cuando son de baja o muy baja potencia, está indicada para edificios, que además se encuentren en zonas de vientos.

Los aerogeneradores que actualmente existen en el mercado para uso doméstico son aerogeneradores de muy baja potencia (inferior a $10 \mathrm{~kW}$ ). Utilizados tradicionalmente para bombeo de agua (aerobombas multipala) y minigeneradores eólicos para producción de energía eléctrica (normalmente formando conjuntos mixtos eólico-fotovoltaicos). Las inversiones en energías renovables para satisfacer las necesidades energéticas de una vivienda alejada de núcleos urbanos adquieren un especial atractivo. Hay que tener en cuenta que el llevar una línea eléctrica a un punto aislado tiene un coste muy importante para el consumidor.

La tecnología más aplicada para su integración en edificios es la miniturbina eólica. Los sistemas de generación eléctrica basados en las miniturbinas eólicas son ideales para aplicaciones diversas que requieran un suministro de energía independiente de la red eléctrica convencional, o bien que complemente a ésta. Un metro cuadrado de estas turbinas puede llegar a producir $130 \mathrm{KW} / \mathrm{h}$. 

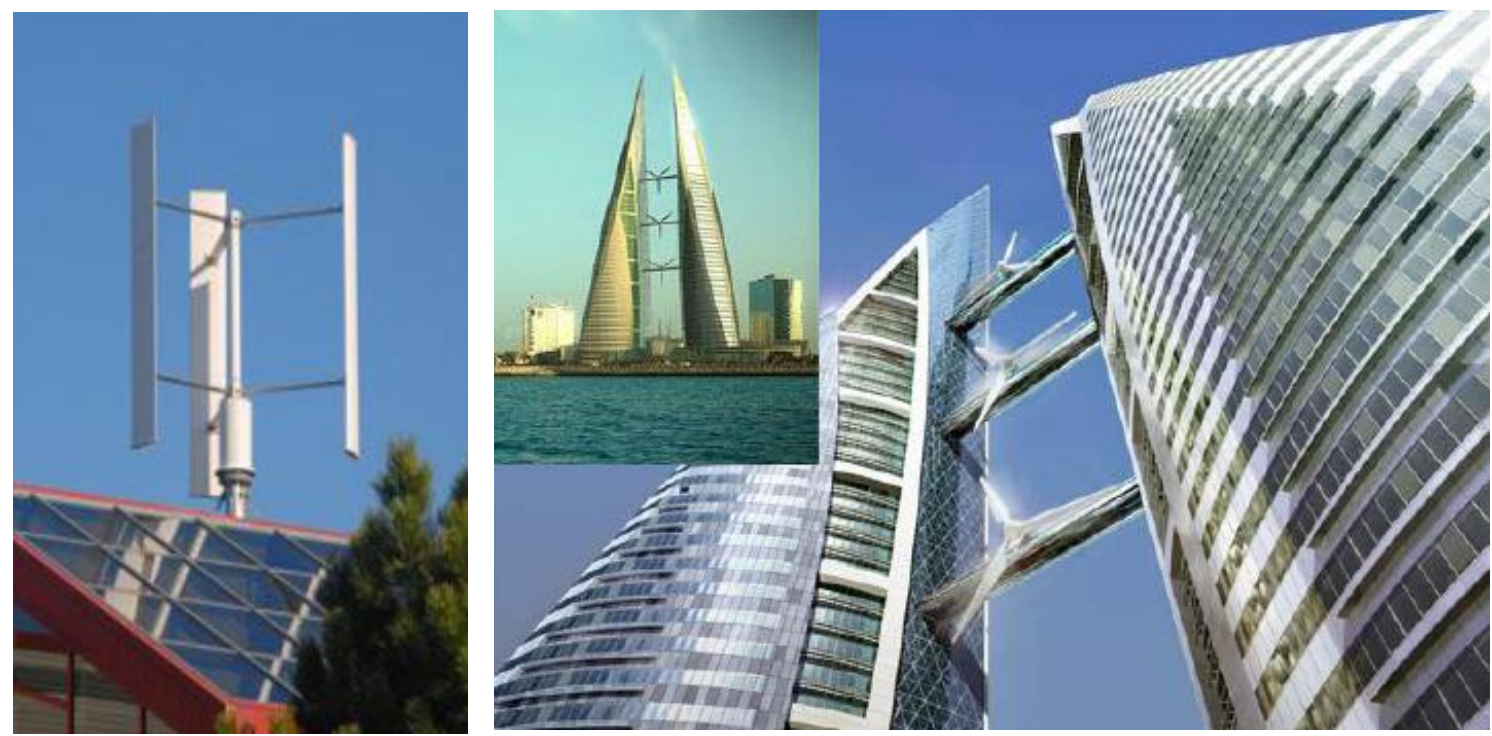

Figura I.34.- Ejemplos de instalaciones eólicas en edificaciones.

Recientes estudios han mostrado que hay un potencial significativo para generar energía eólica dentro de los ambientes urbanos. El término urbano se refiere a todas aquellas áreas con construcciones, áreas industriales, ciudades, áreas densamente pobladas con muchos edificios, o áreas en la cual la densidad de edificaciones crea comportamientos del viento complejos.

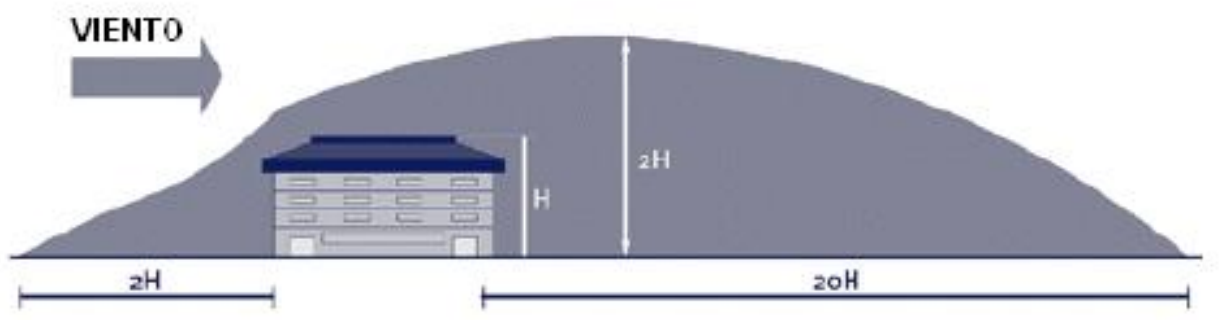

Figura I.35.-Área de turbulencia alrededor de un edificio.

Esta tecnología cuenta con una serie de ventajas:

- Permite el suministro de electricidad en lugares aislados y alejados de la red eléctrica.

- Genera energía de manera distribuida (Microgeneración distribuida) reduciendo de este modo las pérdidas de transporte y distribución.

- Produce electricidad en los puntos de consumo, adaptándose a los recursos renovables y a las necesidades energéticas de cada lugar.

- Puede combinarse con fotovoltaica en instalaciones híbridas. 


\section{REFERENCIAS}

[1] IEA, Energy and Climate Change, World Energy Outlook 2015. (2015) 1-200. doi:10.1038/479267b.

[2] Conferencia de las Naciones Unidas, Declaracion de Rio sobre el Medio Ambiente y el Desarrollo, in: 1992.

[3] F. Douglas Muschett., Principios del Desarrollo Sostenible, AENOR, 1998.

[4] European Comission, Europa 2020: Una estrategia para un crecimiento inteligente, sostenible e integrador, $\operatorname{Com}(2010)$ 2020. 1 (2010) 1-119. doi:10.1007/s13398-014-01737.2 .

[5] National Commission on the Environmental., Choosing a Sustainable Future, Washington, D.C., 1993.

[6] L. Pérez-Lombard, J. Ortiz, C. Pout, A review on buildings energy consumption information, Energy Build. 40 (2008) 394-398. doi:10.1016/j.enbuild.2007.03.007.

[7] E. y T. Ministerio de Industria, Factores de emisión de CO2 y coeficientes de paso a energía primaria de diferentes fuentes de energía final consumidas en el sector de edificios en España, (2016) 16. doi:10.1017/CBO9781107415324.004.

[8] S.P. Corgnati, M.C. Gameiro da Silva, R. Ansaldi, E. Asadi, J.J. Costa, M. Filippi, J. Kaczmarczyk, A.K. Melikov, B.W. Olesen, Z. Popiolek, P. Wargocki, Indoor Climate Quality Assessment, REHVA Guideb. No.14. (2011).

[9] S. Alvarez, R. Baldwin, G. Clausen, E. De Oliveira Fernandes, Indoor Air Quality and the Use of Energy in Buildings, 2013. http://be.dev.netcorps.org/publications/ECA_Report17.pdf.

[10] F.J. Rey, E. Velasco, Experimental study of indoor air quality, energy saving and analysis of ventilation norms in climatised areas, Energy Build. 33 (2000) 57-67. doi:10.1016/S03787788(00)00064-5.

[11] A. García Lastra, DTIE 10.05 Principios básicos de las calderas de condensación, Madrid, 2005.

[12] FEGECA, Sistemas eficientes de climatización y uso de energías renovables, n.d.

[13] F.J. Rey Martínez, E. Velasco Gómez, Bombas de Calor y Energías Renovables en Edificios, Thomson, Madrid, 2005.

[14] R. Monasterio Larrinaga, P. Hernández Martín, J. Saiz Fernández, La bomba de calor: fundamentos, técnicas y aplicaciones, Madrid, 1993.

[15] F.J. Rey Martínez, E. Velasco Gómez, BOMBAS DE CALOR Y ENERGÍAS RENOVABLES EN EDIFICIOS, Madrid, 2005.

[16] Asociación Técnica Española de Climatización y Refrigeración (ATECYR), Ahorro y recuperación de energía en instalaciones de climatización, 2012.

http://www.minetur.gob.es/energia/desarrollo/EficienciaEnergetica/RITE/Reconocidos/Recon ocidos/Climatizacion_Ahorro_y_Recup_Inst_Climatizacion_09.pdf.

[17] C. Ghiaus, F. Allard, Potential for free-cooling by ventilation, Sol. Energy. 80 (2006) $402-$ 413. doi:10.1016/j.solener.2005.05.019.

[18] F.J. Rey Martínez, E. Velasco Gómez, Avances en Ingeniería de climatización y refrigeración, in: I.W. 2006 (Ed.), 2006.

[19] V. Ruiz Hernández, G. López Lara, Instalaciones solares térmicas para producción de ACS, 2007. 


\section{NORMATIVA}

[N-1] DIRECTIVA 2010/31/UE DEL PARLAMENTO EUROPEO Y DEL CONSEJO de 19 de mayo de 2010 relativa a la eficiencia energética de los edificios. http://eurlex.europa.eu/legal-content/es/ALL/?uri=CELEX:32010L0031

[N-2] DIRECTIVA 2009/28/CE DEL PARLAMENTO EUROPEO Y DEL CONSEJO de 23 de abril de 2009relativa al fomento del uso de energía procedente de fuentes renovables. http://eurlex.europa.eu/LexUriServ/LexUriServ.do?uri=OJ:L:2009:140:0016:0062:es:PDF

[N-3] DIRECTIVA 2009/125/CE DEL PARLAMENTO EUROPEO Y DEL CONSEJO de 21 de octubre de 2009 por la que se instaura un marco para el establecimiento de requisitos de diseño ecológico aplicables a los productos relacionados con la energía. http://eurlex.europa.eu/LexUriServ/LexUriServ.do?uri=OJ:L:2009:285:0010:0035:ES:PDF

[N-4] Directiva 2010/30/UE del Parlamento Europeo y del Consejo, de 19 de mayo de 2010, relativa a la indicación del consumo de energía y otros recursos por parte de los productos relacionados con la energía, mediante el etiquetado y una información normalizada.

[N-5] MINISTERIO DE LA PRESIDENCIA Real Decreto 235/2013, de 5 de abril, por el que se aprueba el procedimiento básico para la certificación de la eficiencia energética de los edificios.

[N-6] Ministerio de Vivienda de España, Real Decreto 314/2006 de 17 de marzo por el que se aprueba el Código Técnico de la Edificación.

[N-7] Ministerio de Industria, Turismo y Comercio y Ministerio de Vivienda de España, "Real Decreto 1027/2007: Reglamento de Instalaciones Térmicas en Edificios".

[N-8] CR 1752:1998. Ventilation for Buildings: Design Criteria for the Indoor Environment. CEN.

[N-9] PNE-CR 1752:1998 Norma Española: Ventilación de edificios: Criterios de diseño para el ambiente interior.

[N-10] EN 15251: 2008. Criteria for the indoor environment including thermal, indoor air quality, light and noise.

[N-11] ISO 7730:2005 Moderate thermal environment- Determination of the PMV and PPD indices and specification of the conditions for thermal comfort. International Organization for Standardization. 
[N-12] UNE-EN ISO 7730:2006 Ergonomía del ambiente térmico. Determinación analítica e interpretación del bienestar térmico mediante el cálculo de los índices PMV y PPD y los criterios de bienestar térmico local.

[N-13] ANSI/ASHRAE Standard 62.1-2010. "Ventilation for Acceptable Indoor Air Quality", American Society of Heating and Air-Conditioning Engineers Inc., Atlanta.

[N-14] Ministerio de la Presidencia; Ley 38/1999, de 5 de noviembre, de Ordenación de la Edificación.

[N-15] Directiva 92/42/CEE del Consejo de 21 de mayo de 1992, relativa a los requisitos de rendimiento para las calderas nuevas de agua caliente alimentadas con combustibles líquidos o gaseosos.

[N-16] Directiva 2004/8/CE del Parlamento Europeo y del Consejo, de 11 de febrero de 2004, relativa al fomento de la cogeneración.

\section{PÁGINAS WEB}

[W-1] Instituto para la Diversificación y Ahorro Energético (IDAE) http://www.idae.es/ (Día de consulta: 24 mayo 2017)

[W-2] Energy Performance of Buildings Directive, Concerted Action. http://www.epbd-ca.org/(Día de consulta: 24 junio de 2017).

[W-3] Comisión Europea, Energía: http://ec.europa.eu/energy/index en.htm (Día de consulta: 25 de mayo de 2017). 


\section{CAPÍTULO II.- \\ COLECTORES TÉRMICOS SOLARES DE AIRE.}

\section{CONTENIDOS DEL CAPÍTULO:}

II.1.- INTRODUCCIÓN. 79

EVOLUCIÓN DEL APROVECHAMIENTO DE LA ENERGÍA SOLAR.-.... .82

II.2.- FUNDAMENTOS 89

II.2.1.- ANÁLISIS TÉRMICO DE UN COLECTOR.............................................. 92

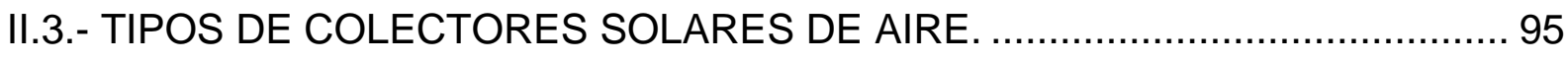

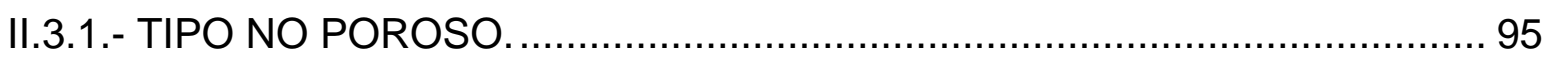

II.3.1.1.- Colectores de una sola exposición. ..........................................................95

II.3.1.2.- Colectores de doble exposición. ................................................................ 102

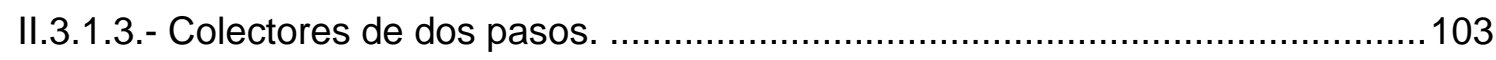

II.3.1.4.- Colector con placa absorbedora aleteada. ……………............................ 107

II.3.1.5.- Colector con absorbedor corrugado - dentado. ........................................ 108

II.3.1.6.- Colector con placa absorbedora en el reverso (colectores invertidos) ..........110

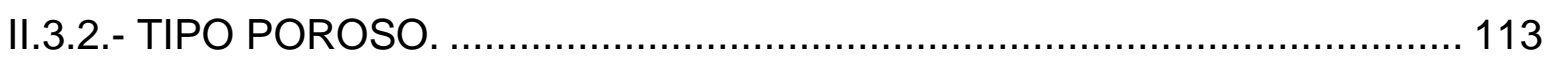

II.3.2.1.- Colectores con absorbedor de placas de cristal solapadas..........................117

II.3.2.2.- Colectores con el absorbedor en forma de panel de abeja. .........................118 


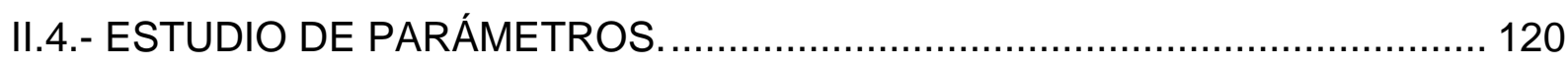

II.4.1.- EFECTO DE LAS FUGAS DE AIRE................................................ 120

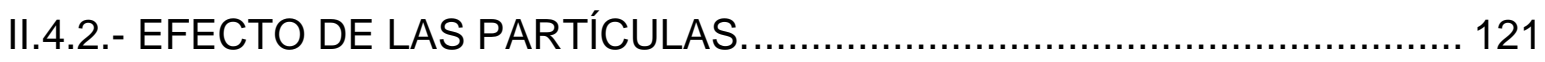

II.5.- COMPARACIÓN ENTRE EL COMPORTAMIENTO DE UN COLECTOR DE

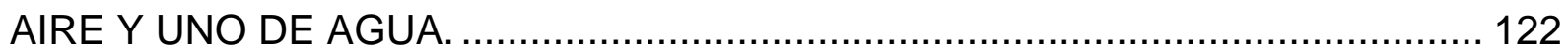

II.6.- APLICACIONES DEL COLECTOR SOLAR DE AIRE ................................ 123

II.6.1.- CLIMATIZACIÓN Y ACONDICIONAMIENTO DE EDIFICIOS. ................ 123

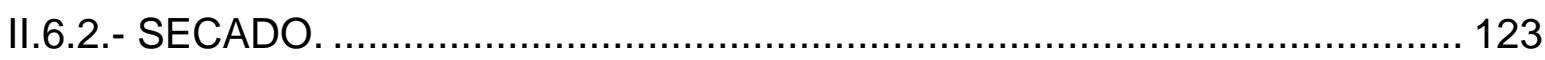

II.7.- COMERCIALIZACIÓN DEL COLECTOR SOLAR DE AIRE.......................... 126

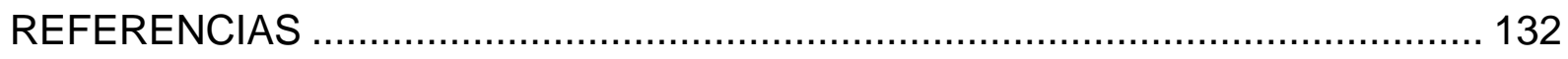

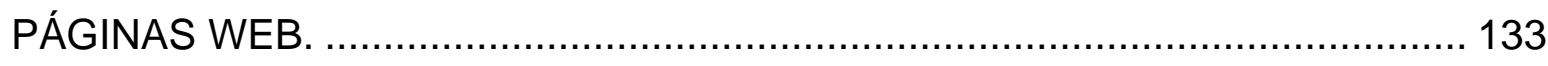




\section{LISTA DE FIGURAS:}

Figura II.1.- Reconstrucción de una casa griega clásica [3].

82

Figura II.2.-Colectores solares de vidrio, Inglaterra, siglo XVII. Fuente:" A Golden Thread". Ken Butti, John Perlin. 1985 Ed. Hermann Blume.

Figura II.3.-Esquema de la caja caliente de Saussure en 1967 [3]

Figura II.4.-Propaganda publicitaria del Day \& Night Solar Heater Co [3] 86

Figura II.5.-Calentador solar de Morse, 1881. Izquierda, posición invernal diurna. Centro, posición invernal nocturna. Derecha, posición estival para ventilación forzada [3]

Figura II.6.-A la izqda., Primera casa solar del MIT. A la drcha.., Esquema del diseño de Löf [3] ....... 87

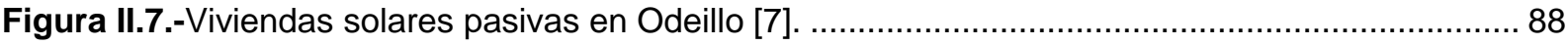

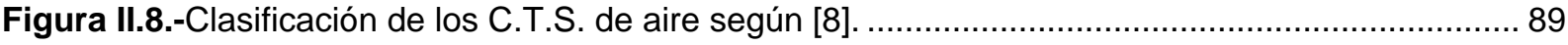

Figura II.9. (a-d)- Esquema de colectores de aire de absorbedor de tipo no poroso y una sola exposición

Figura II.10.- Proceso de transferencia de calor en un colector de aire convencional.

Figura II.11.- Representación de las resistencias térmicas en las pérdidas de calor en un colector de aire convencional

Figura II.12.- Porcentaje de pérdidas de calor en un colector de aire convencional. 94

Figura II.13.-Curva de óptimo comportamiento (Selcuk, 1977)................................................. 95

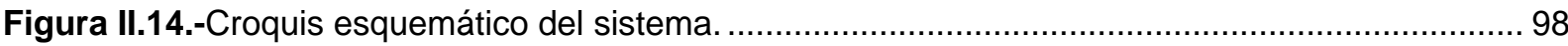

Figura II.15.-Vista esquemática de un colector solar de aire de doble flujo...................................... 100

Figura II.16.-Croquis esquemático de un colector de aire de doble exposición. .............................. 102

Figura II.17 (a-c).-Vista esquemática de diferentes configuraciones de colector solar de aire de dos pasos. 103

Figura II.18.-Curva de eficacia; $m=0.0171 \mathrm{~kg} / \mathrm{s} ; \mathrm{Ta}=303 \mathrm{~K} ; \mathrm{Ac}=1269 \mathrm{~m} 2 ;$ gap= $0.0381 \mathrm{~m} ; \mathrm{V}=5.1 \mathrm{~m} / \mathrm{s}$.

106

Figura II.19.-Incremento de la temperatura del aire en un colector de un solo paso y en uno de doble paso; $\mathrm{m}=0.0171 \mathrm{~kg} / \mathrm{s} ; \mathrm{Ta}=303 \mathrm{~K} ; \mathrm{Ac}=1269 \mathrm{~m}^{2} ; \mathrm{gap}=0.0381 \mathrm{~m} ; \mathrm{V}=5.1 \mathrm{~m} / \mathrm{s}$. 107

Figura II.20.- Esquema de un colector de aire con placa absorbedora corrugada- dentada. 108

Figura II.21.- Esquema de un colector de aire con conductos triangulares. 109 
Figura II.22 .- Vista esquemática de un colector de aire con placa absorbedora invertida de un solo paso (RFP).

Figura II.23 (b-e).- Vista esquemática de otras configuraciones del colector RFP. 111

Figura II.24.- Variación de la temperatura de salida del aire con $x$ para diferentes $\mathrm{N}$. 112

Figura II.25.- Variación de la temperatura de salida del aire con $x$ para diferentes $\mathrm{m}$. 113

Figura II.26. (a-c).- Esquema de colectores de aire de absorbedor de tipo poroso. 114

Figura II.27 (a-c).-Esquemas de los colectores de aire de matrices. 115

Figura II.28.- Esquema de un colector de cristales solapados (Selcuk, 1977). Dimensiones en milímetros, placas de cristal de $3 \mathrm{~mm}$ de espesor; ancho de los colectores es $690 \mathrm{~mm}$.

Figura II.29.- Esquema de un colector con colector de panel de abeja transpirable. 118

Figura II.30.- Comparación entre un colector líquido y un colector de aire de placas gruesa. 119

Figura II.31.- Vista esquemática de un secador de grano indirecto 124

Figura II.32.- Esquema de un secador indirecto de grano. 124

Figura II.33.- Esquema de un colector de aire de dos pasos conectado a una cámara de secado... 125

Figura II.34.- Vista del TWINSOLAR. Fuente: GRAMMER SOLAR. ......................................... 126

Figura II.35.- Esquema de diferentes modelos del TWINSOLAR. Fuente: GRAMMER SOLAR....... 126

Figura II.36.- Vista del SOLARSHEAT 1500GS. Fuente: YOUR SOLAR HOME........................... 127

Figura II.37.- Vista del SOLAR MAX 240 RA 1500GS. Fuente: CANSOLAIR ................................. 128

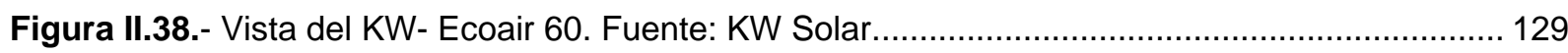

Figura II.39.- SV30AX Aire. Fuente: Solar Venti. ........................................................................ 129

Figura II.40.- Vista del Sun Lizard Solar Collector. Fuente: Sun Lizard......................................... 130

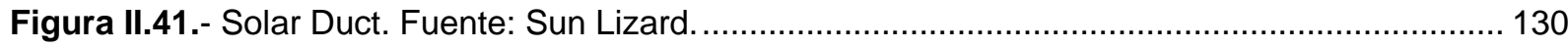

Figura II.42.- SunMate. Fuente: Enviromental Solar Systems. ................................................. 131 


\section{Nomenclatura:}

$A$ :área $\left[\mathrm{m}^{2}\right]$

$C_{\text {air }}$ : calor específico del aire $\left[\mathrm{J} /\left(\mathrm{kg}^{\circ} \mathrm{C}\right)\right]$

$F_{R}$ : factor de calor disipado en el colector

$h$ : coeficiente de transferencia de calor por convección $\left[\mathrm{W} /\left(\mathrm{m}^{2}{ }^{\circ} \mathrm{C}\right)\right]$

$k$. conductividad térmica $\left[\mathrm{W} /\left(\mathrm{m}^{\circ} \mathrm{C}\right)\right]$

$L:$ longitud [m]

I: irradiancia $\left(\mathrm{kW} / \mathrm{m}^{2}\right)$

$Q$ : transferencia de calor [W]

$F^{\prime}$ : factor de eficiencia

$T:$ temperatura $\left[{ }^{0} \mathrm{C}\right]$

$U$ : coeficiente global de pérdidas $\left[\mathrm{W} /\left(\mathrm{m}^{2}{ }^{\circ} \mathrm{C}\right)\right]$

$\dot{\mathrm{m}}$ : flujo másico $[\mathrm{kg} / \mathrm{s}]$

a: energía absorbida

$\eta$ : eficacia térmica o rendimiento

$Q_{\text {int }}$ : ratio de generación de calor interno por unidad de volumen $\left[\mathrm{W} / \mathrm{m}^{3}\right]$

Subíndices:

a: ambiente

pm: placa principal

t: absorbedor

f: fluido (aire)

bm: placa de fondo

fi: aire en la entrada

fo: aire a la salida

$f t$ : aire en el conducto superior

$f b$ : aire en el conducto inferior

Números adimensionales:

$\mathrm{Nu}:$ Nusselt 
CAPÍTULO II: COLECTORES TÉRMICOS SOLARES DE AIRE 


\section{II.1.- INTRODUCCIÓN.}

Dentro de las tecnologías de aprovechamiento a baja temperatura de la radiación solar, la que denominamos solar térmica, nos encontramos principalmente con sistemas que utilizan como fluido caloportador al agua o al aire, como ya se ha mencionado en el primer capítulo de esta Tesis Doctoral. La tecnología que nos ocupa en este capítulo y sobre la que se centra el estudio y desarrollo de esta tesis es la de los colectores térmicos solares que emplean aire como fluido caloportador (C.T.S. de aire de aquí en adelante).

La solar térmica es una tecnología en desarrollo que en los últimos años, a partir de 2015, ha visto frenado su crecimiento en cuanto número de nuevas instalaciones de colectores llevadas a cabo.

En los siguientes párrafos se presentan algunos datos actuales sobre el estado del mercado y aplicación de los colectores solares a nivel mundial [1]:

A finales de 2014, la capacidad mundial instalada era de $410,2 \mathrm{GW}_{\mathrm{th}}$, correspondiente a un total de 586 millones de metros cuadrados de área de colectores. La gran mayoría de la capacidad instalada en operación se encuentra en China $\left(289,5 \mathrm{GW}_{\mathrm{th}}\right)$ y Europa $\left(47,5 \mathrm{GW}_{\mathrm{th}}\right)$, quienes cuentan con el $82,1 \%$ del total. El resto de capacidad instalada está repartida entre Estados Unidos y Canada (18,0 GW $\mathrm{GW}_{\text {th }}$ ), Asía sin China (10,7 $\mathrm{GW}_{\text {th }}$ ), Latino América (10,0 $\mathrm{GW}_{\mathrm{th}}$ ), los países del Medio Oriente y norte de África como Israel, Jordania, Libano, Marruecos, los Territorios Palestinos y Túnez (6,6 $\left.\mathrm{GW}_{\mathrm{th}}\right)$, Australia y Nueva Zelanda $\left(6,2 \mathrm{GW}_{\mathrm{th}}\right)$, y los países Sub-Sahariano de África como Lesoto, Mauritania, Mozambique, Namibia, Sudáfrica y Zimbabue (1,3 $\left.\mathrm{GW}_{\text {th }}\right)$. El resto de países se estima que computen en torno al $5 \%$ del total (unos $20,5 \mathrm{GW}_{\text {th }}$ ).

Atendiendo al tipo, los colectores planos acristalados suponen el 22,1\% de la potencia total instalada (unos 90,9 $\mathrm{GW}_{\text {th }}$ ), los de tubos de vacío el $71,1 \%\left(291,8 \mathrm{GW}_{\mathrm{th}}\right.$ ), los colectores no acristalados (sin cubierta) de agua el 6,3\% (26 GW $\left.\mathrm{GW}_{\mathrm{th}}\right)$, y los colectores de aire el 0,4\% (1,6 GW $\left.\mathrm{Wh}_{\mathrm{th}}\right)$. Los valores alcanzados por la tecnología de los tubos de vacío son debidos a su gran éxito en el mercado chino. En Europa, en cambio, el $83,8 \%$ de la potencia instalada emplea colectores planos de placas. Los colectores de aire alcanzan el $1,2 \%$ en Europa.

En cuanto al sistema de impulsión de fluido empleado, más de tres cuartos de los colectores emplean sistemas por termosifón y el resto sistemas bombeados. Este dato también está totalmente influenciado por el éxito del termosifón en China, donde es habitual encontrarlo asociado a tubos de vacío, mientras que en el resto se emplea más con colectores planos.

Por aplicaciones, el $63 \%$ de los sistemas de colectores son empleados para preparación del agua caliente sanitaria en viviendas unifamiliares, el $28 \%$ para la preparación del ACS en bloques de viviendas, hoteles, hospitales, escuelas, etc., el $6 \%$ para el calentamiento de piscinas y aproximadamente alrededor del $2 \%$ en sistemas mixtos de ACS y calefacción. El resto de aplicaciones 
más comunes es para redes de calefacción de distrito solares, procesos industriales o producción de frío solar.

\section{EVOLUCIÓN DEL APROVECHAMIENTO DE LA ENERGÍA SOLAR.-}

Antes de entrar a detallar las particularidades de esta tecnología de aprovechamiento de la energía solar es interesante hacer una breve reseña de cómo el ser humano, a lo largo de las diferentes civilizaciones, ha tenido muy presente que la energía que aporta el Sol a través de su irradiación es una de las fuentes energéticas más importantes (o la más importante), y de cómo ha tenido en cuenta a éste en su día a día, desde la distribución de sus actividades a lo largo del día hasta el diseño de sus edificaciones y equipos de aprovechamiento de la energía solar. Se pretende presentar la evolución del aprovechamiento de la energía solar a lo largo de diferentes culturas, evolución que sigue hoy en día en pleno desarrollo tecnológico.

\section{ORIGEN DEL APROVECHAMIENTO DE LA ENERGía SOLAR Y ARQUITECTURA VERNÁCULA}

Ahora hace más de 2500 años cuando la cultura griega comenzó a diseñar sus casas para que fueran calentadas por la radiación solar en invierno [2]. La fuente energética gratuita y abundante que ya existía por aquel entonces era el Sol, y los griegos aprendieron a construir sus casas para que fueran calentadas por la energía solar en invierno y evitar el calor de los rayos del Sol en verano aprovechando la variabilidad de la altura solar a lo largo de las estaciones. Comenzaron a situar elementos arquitectónicos como pórticos y espacios libres de edificaciones delante de las fachadas, de manera que éstos permitieran el paso de la radiación en invierno y la bloquearan en verano, como se ve en la figura II.1.

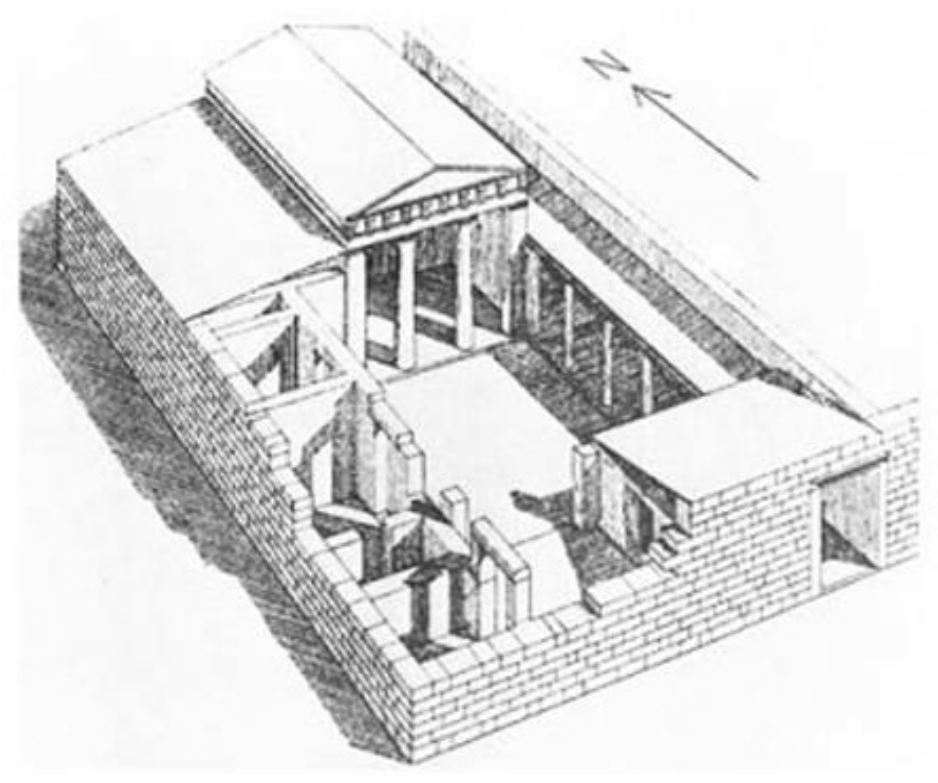

Figura II.1.- Reconstrucción de una casa griega clásica [3]. 
Los romanos adoptaron la técnica solar griega, desarrollándola y adaptándola a los diferentes climas del imperio. Una de las grandes aportaciones, fue la de incorporar el vidrio plano y transparente en el cerramiento de las ventanas para incrementar la ganancia solar evitando las pérdidas. Después de la caída del Imperio Romano solo mantuvieron estas ideas de adaptación a los recursos solares en la Europa mediterránea y Asia Menor [3].

En la Península Ibérica dada la diversidad climática existente nos encontramos con diferentes soluciones constructivas adoptadas en función de los requerimientos prioritarios de cada zona (protección de la lluvia, del viento, de las bajas temperaturas o de la radiación solar). En el sur de la Península, donde la radiación solar es alta y los veranos calurosos, los edificios se protegen evitando la entrada de la radiación. En cambio, en el norte donde la radiación solar y el número de horas de luz solar son bajas, se emplean estrategias con las que captar la radiación solar para calentar e iluminar el interior de los edificios.

Otros ejemplos de aprovechamiento de la energía solar en las civilizaciones antiguas se ven reflejados en la arquitectura vernácula de India o China. En la India, en las zonas de clima húmedo y frío las viviendas se orientan al este-oeste y sur para recibir la mayor radiación solar posible mientras que en las zonas de clima húmedo y cálido se abren huecos para mejorar la circulación del aire y se protegen estos con elementos de sombreamiento para evitar la entrada de la radiación solar al interior. En las zonas frías y nubosas los huecos son de pequeñas dimensiones en muros de gran espesor para minimizar las pérdidas térmicas desde el interior [4][5]. Situación similar se da en China. Las técnicas empleadas también abren el paso al interior a la radiación solar en invierno en climas fríos y protegen de ésta en verano favoreciendo también la ventilación por estos mismos huecos. Las orientaciones de las fachadas son dispuestas de la forma más adecuada para beneficiarse o salvaguardarse de la radiación solar y de los vientos dominantes [6].

\section{ABANDONO Y RECUPERACIÓN DE LA CONSTRUCCIÓN SOLAR}

A pesar de su interés en el acondicionamiento pasivo de los edificios y su origen en las antiguas civilizaciones de la humanidad, a lo largo de la historia el diseño de los edificios para el aprovechamiento de la energía solar se ha visto perjudicado, tanto a causa de objetivos meramente estéticos como a la implantación de medios activos de calefacción.

Ya en la segunda mitad del siglo XIX, la inmigración a las zonas más urbanas provocó tanto en Norteamérica como en las ciudades Europeas un gran crecimiento de las ciudades. Durante este crecimiento las construcciones dejaron de tener en cuenta los condicionantes de aprovechamiento solar, además de otros muchos, que conllevó la construcción de edificaciones con pésimas condiciones ambientales.

Tras las necesidades de ahorro energético derivadas de la Segunda Guerra Mundial, volvió a tenerse presente la construcción adecuada al aprovechamiento solar, por ejemplo reincorporando las 
persianas, cortinas, contraventanas y toldos que podían reducir las pérdidas de calor en las noches invernales, o la ganancia en los días de verano. Pero esta tendencia comenzó a decaer a fines de los años cuarenta, debido principalmente al bajo coste de los combustibles fósiles.

\section{CAPTACIÓN SOLAR CON SUPERFICIES ACRISTALADAS}

En el siglo XVIII el uso del colector solar en forma de invernaderos resurgió con fuerza en Inglaterra (Figura II.2). La necesidad de aislamiento nocturno se manifiesta en las contraventanas, toldos y demás partes móviles de la carpintería. También se entrevió las ocasionales necesidades de ventilación, disponiéndose ventanucos arriba y abajo para permitir la expulsión de aire caliente y poder evitar así sobrecalentamientos excesivos. Sin embargo, en el siglo XIX se continuaron empleando superficies acristaladas, pero ahora en lugar de aprovechar la radiación solar para calentar esos espacios donde se disponían los vidrios, se calentaban con estufas a carbón o gas, combustibles a muy bajo precio en la época [3].

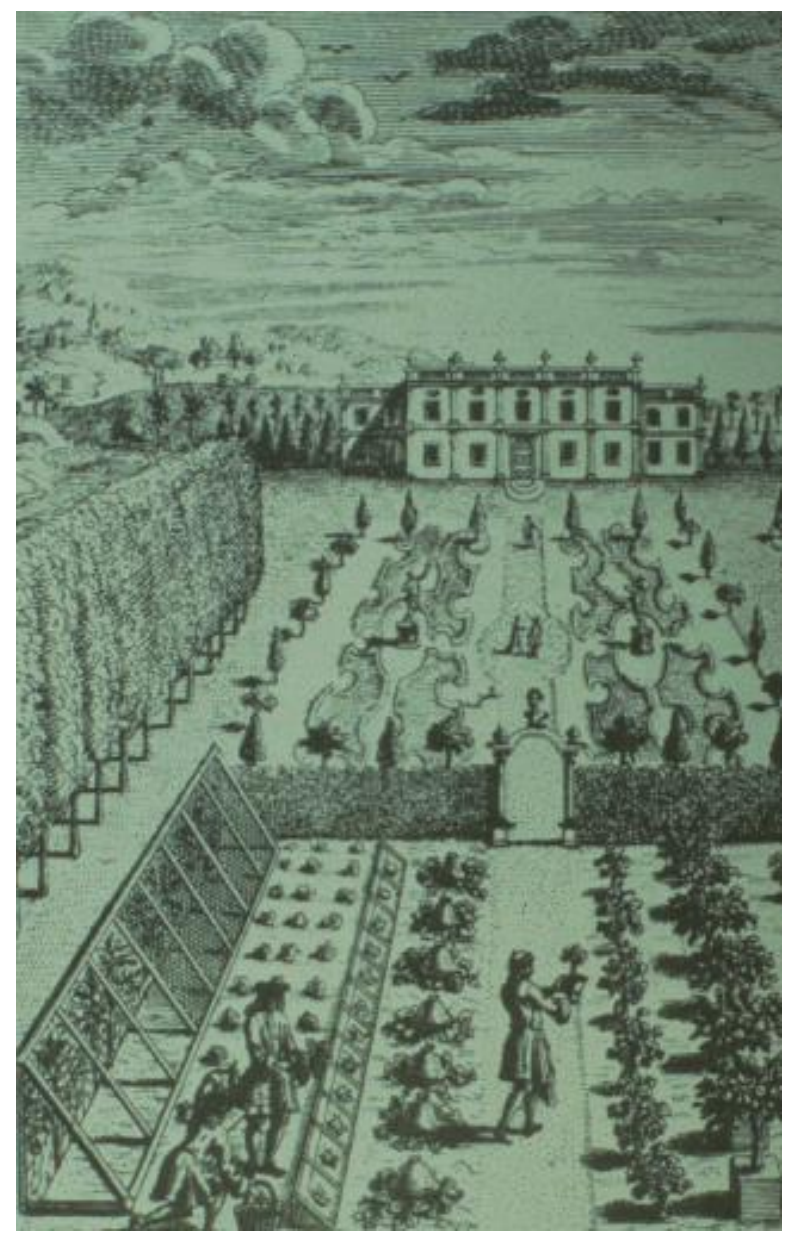

Figura II.2.-Colectores solares de vidrio, Inglaterra, siglo XVII. Fuente:" A Golden Thread". Ken Butti, John Perlin. 1985 Ed. Hermann Blume. 
La generalización del empleo de los invernaderos en el siglo XVIII llevó a que muchos interesados en la materia experimentaran las capacidades del vidrio para su utilización como elemento de cerramiento en un dispositivo captador de calor. Horace de Saussure experimentó en 1767 con el efecto físico del calentamiento de una caja negra con tapa de vidrio expuesta al Sol. Tras varios experimentos con diferentes cajas colocadas una dentro de la de tamaño inmediatamente superior, en las que iba incorporando mejoras como la colocación de aislamiento térmico para minimizar las pérdidas por las paredes laterales, consiguió alcanzar los $120^{\circ} \mathrm{C}$ en el interior de la caja.

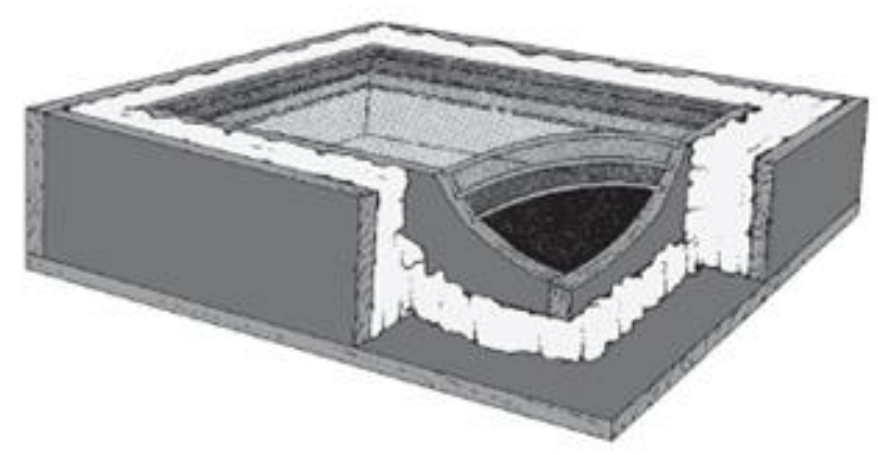

Figura II.3.-Esquema de la caja caliente de Saussure en 1967 [3].

En los comienzos del siglo XIX bajo el desarrollo de la técnica en la denominada Revolución Industrial, las máquinas a vapor y las utilizadas en las fábricas empleaban combustibles como carbón o madera que permitían manufacturar bienes a escalas sin precedentes. Este hecho supuso que el empleo de los sistemas solares desarrollados hasta el momento se abandonara casi por completo.

Se llevaron a cabo numerosos intentos de conseguir motores que emplearan la radiación solar como combustible. En 1860, el francés Mouchot intentó mover una máquina de vapor empleando cajas calientes en lugar de carbón. Con estos intentos Mouchot llegó a la conclusión de que la caja caliente que necesitaría para esta aplicación sería demasiado grande.

Afortunadamente, se descubriría un modo seguro, fácil y barato de calentar agua: el depósito metálico de agua pintado de negro y simplemente colocado donde daba más el Sol y menos la sombra. Pese a los avances en los diseños y las mejoras obtenidas, un problema evidente quedaba por solucionar: tener agua caliente durante la noche y a primera hora de la mañana. A principios del siglo XX, ingeniero llamado William J. Bailey comenzó a vender un calentador solar de agua que revolucionaría la industria. No sólo suministraba agua calentada solarmente mientras lucía el Sol, sino que también durante horas después de haber anochecido y también a la mañana siguiente; para más señas el modelo se denominó "Día y Noche" [3].

El serpentín del colector era de cobre y descansaba sobre una lámina metálica negra. La caja del colector estaba aislada con fieltro. El "Día y Noche" operaba según el principio del termosifón. Para 
garantizar suficiente agua caliente en épocas de mal tiempo o períodos de mucho uso, Bailey recomendaba a los clientes añadir un calentador auxiliar. El éxito del modelo fue espectacular.

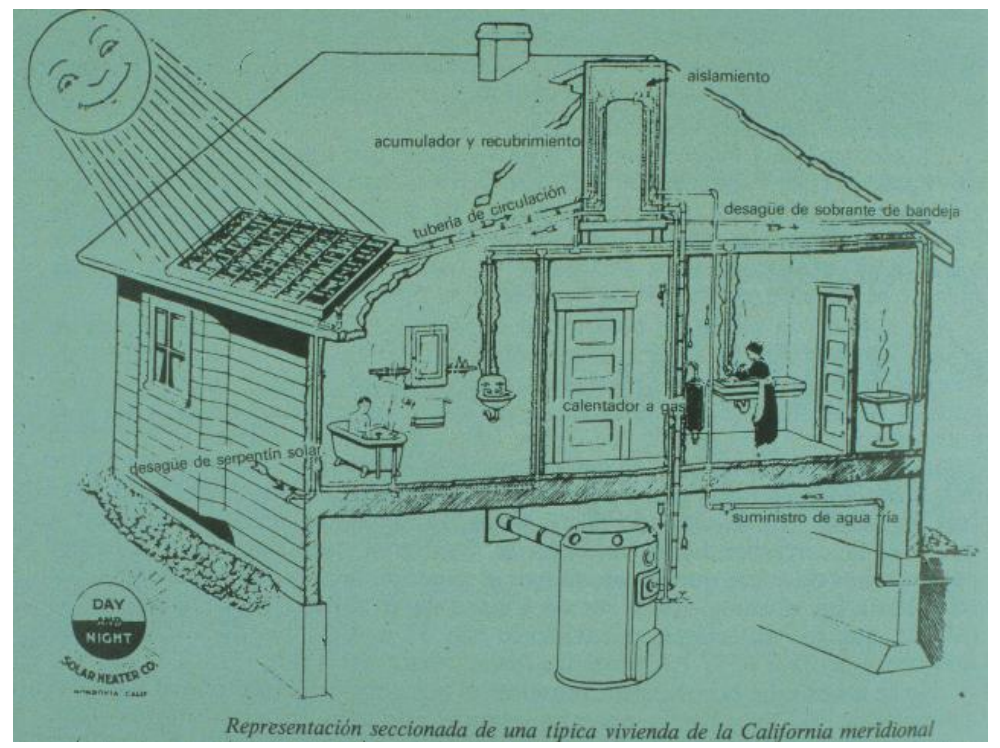

Figura II.4.-Propaganda publicitaria del Day \& Night Solar Heater Co [3]

Una aplicación más concreta de los colectores solares, y afín a esta tesis doctoral, es la calefacción solar.

Aunque el uso de colectores solares para calefacción doméstica no era totalmente nuevo, el primer caso registrado se remonta al año 1880, cuando Edward Morse construyó un primer aparato: simplemente una caja caliente adosada al muro sur de un edificio, con aberturas que permitían al aire exterior penetrar en ella y al aire calentado solarmente escapar a las habitaciones.
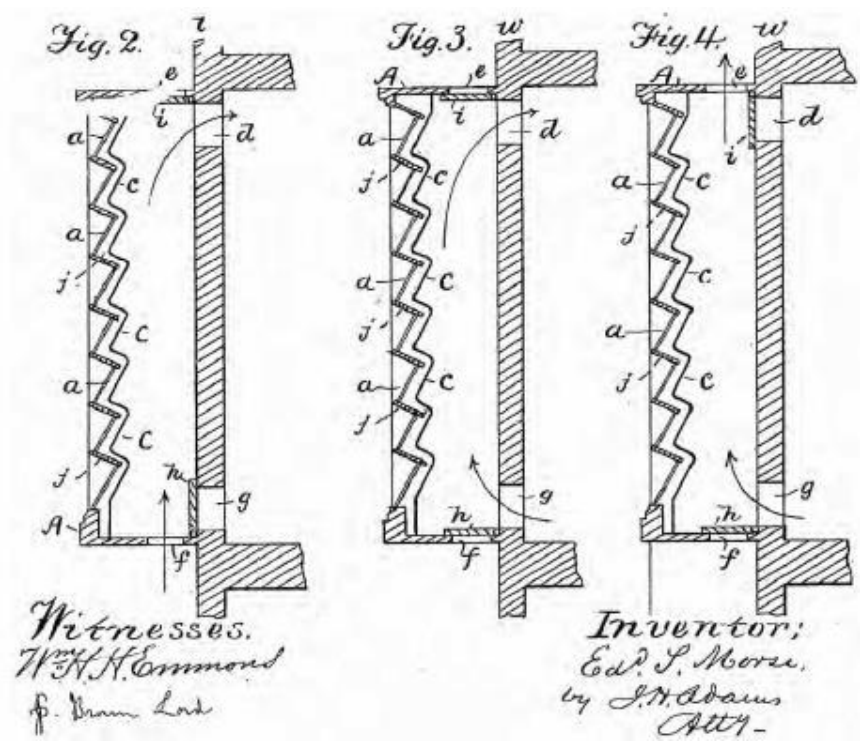

Figura II.5.-Calentador solar de Morse, 1881. Izquierda, posición invernal diurna. Centro, posición invernal nocturna. Derecha, posición estival para ventilación forzada [3] 
El otro gran hito de la calefacción solar son las casas experimentales del Massachusetts Institute of Technology (MIT). Se instalaron 14 colectores planos sobre el faldón sur de la cubierta de un edificio construido como laboratorio para investigar el desarrollo de esta tecnología. El agua caliente era bombeada hasta la cumbrera de la vivienda, desde donde se enviaba hasta un depósito acumulador en el sótano. El aire frío era extraído de las habitaciones mediante ventiladores y era insuflado al depósito caliente. Una vez templado el aire retornaba a las habitaciones, calentando el edificio.
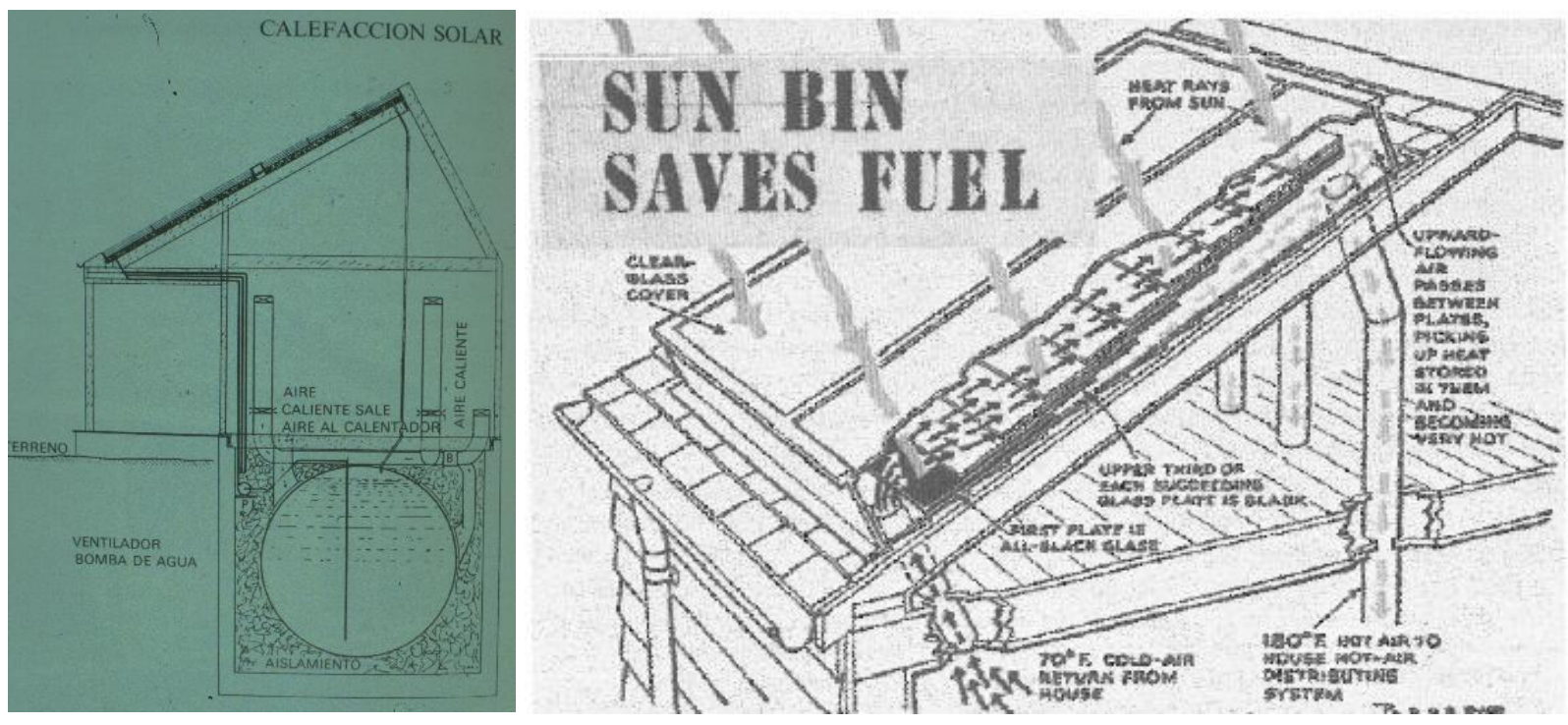

Figura II.6.-A la izqda., Primera casa solar del MIT. A la drcha.., Esquema del diseño de Löf [3]

Después del MIT, hubo otros que intentaron desarrollar y perfeccionar el uso del calentamiento solar de aire para calefacción, como George Löf, instalado en su propia casa un sistema solar de aire integrándolo con el sistema de calefacción de gas que tenía. Empleaba el aire calentado con los colectores solares en el sistema de conductos de calefacción convencional, y la caldera apoyaba cuando no era suficiente. El captador aumentaba hasta $60^{\circ} \mathrm{C}$ la temperatura del aire en los días favorables, generando un $25 \%$ del calor necesario durante el primer invierno. Para aumentar el rendimiento trató de almacenar el calor, utilizando materiales con elevada inercia térmica. Colocó una base de rocas bajo el suelo que mejoraba el rendimiento durante las noches y los días nublados. 


\section{OTRAS SOLUCIONES SOLARES PASIVAS ACTUALES.}

Como se ha podido ver, el aprovechamiento de la radiación solar para la mejora de las condiciones interiores en los edificios se viene dando desde las antiguas civilizaciones. Una adecuada combinación de la orientación, disposición, color y material empleado en algunos de los elementos que conforman el edificio pueden permitir que el aprovechamiento de la radiación solar sea una fuente energética gratuita que permita reducir considerablemente el consumo energético del edificio.

Uno de los principales sistemas desarrollados y que más éxito en cuanto a su aplicación ha tenido ha sido el muro Trombe. En 1957 el francés F. Trombe y J. Michel comienzan a desarrollar un sistema de captación solar, que pasará a denominarse así. Se compone básicamente por un muro de gran inercia térmica y normalmente pintado de color oscuro, un espacio de aire, una lámina de vidrio y un sistema de ventilación. De esta forma se utiliza el propio cerramiento como captador solar.
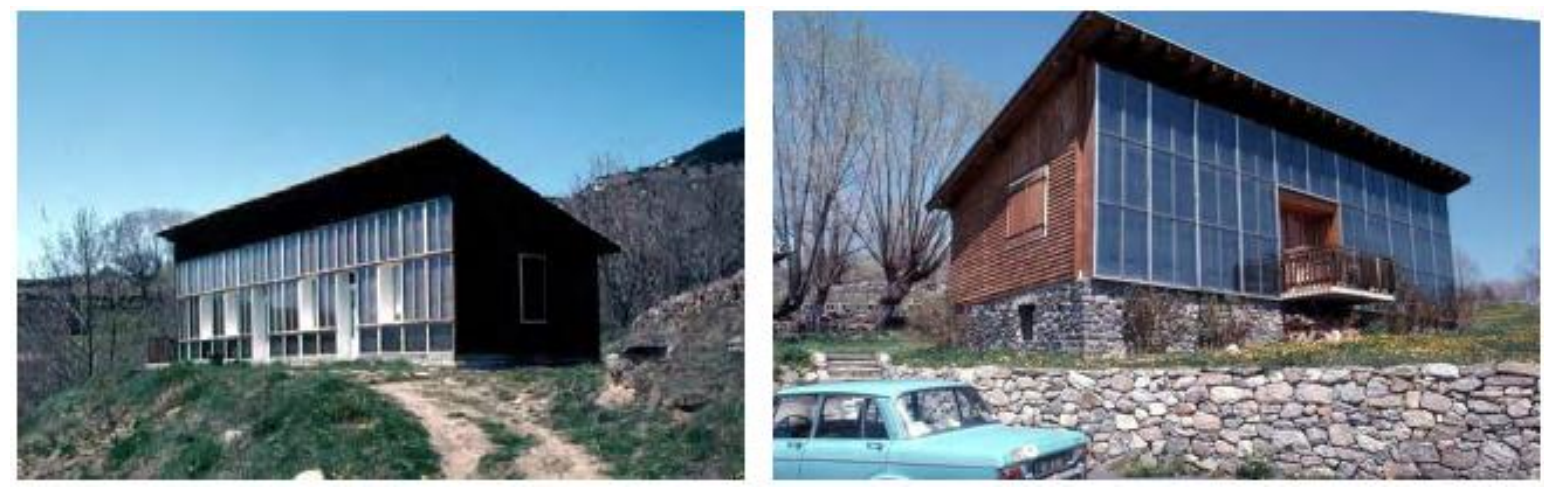

Figura II.7.-Viviendas solares pasivas en Odeillo [7].

Durante los años 70 muchos granjeros canadienses utilizaron en sus construcciones paredes solares. El diseño consistía en la utilización de un cerramiento metálico separado del muro dejando una cámara de aire, por la que entraba el aire procedente del interior del edificio. El aire se calentaba en contacto con la chapa, y ascendía, volviendo a entrar por la parte superior del muro. 


\section{II.2.- FUNDAMENTOS}

En este capítulo se intentará proporcionar una descripción y análisis de varios tipos de colectores solares de aire usados para diferentes aplicaciones. No es fácil establecer una clasificación formal de los C.T.S. de aire, existen muy diversas formas, composiciones y principios de operación de los mismos. Tyagi et al. [8] clasifican los C.T.S. en función de la dirección del flujo del aire, de la capacidad de almacenamiento de energía, superficies de absorción, número de cubiertas y el modo de trabajo como se puede observar en la figura II.8:

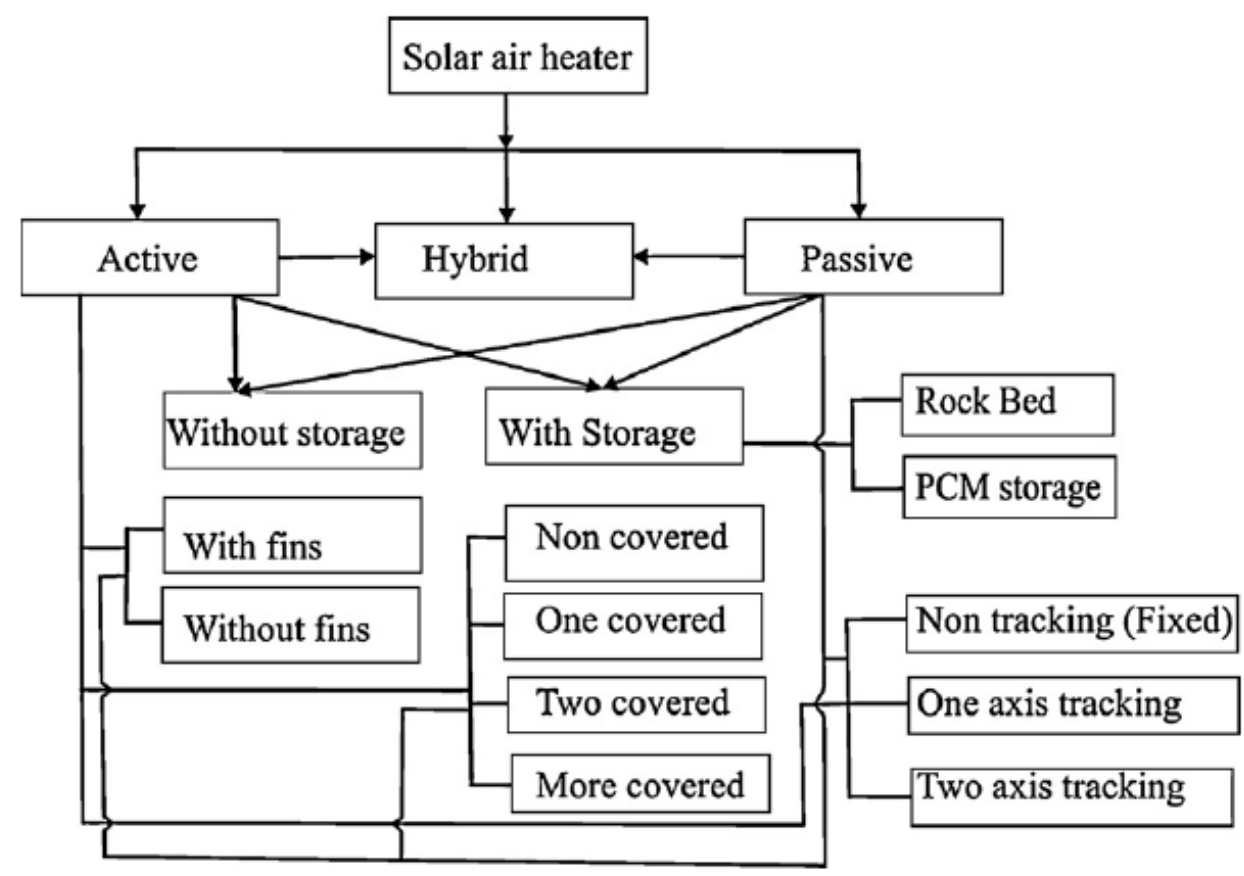

Figura II.8.-Clasificación de los C.T.S. de aire según [8].

Desde otra perspectiva los C.T.S. de aire pueden ser clasificados de acuerdo al número de pasos del aire por el colector, material del absorbedor, forma de la placa absorbedora, exposición del absorbedor a la radiación incidente, etc. En este capítulo se presenta una clasificación teniendo en cuenta varios aspectos de los aquí mencionados.

Un colector solar de aire está formado fundamentalmente por una placa plana colectora con una placa absorbedora, un sistema de cobertura en la parte superior y aislamiento en el fondo o parte posterior y en las caras laterales para evitar las pérdidas de calor. El conjunto ensamblado forma una caja. El fluido usado es aire, y el conducto para su circulación varía en función del colector de aire. 
Los colectores solares de aire tienen las siguientes ventajas respecto a otros colectores solares:

- La necesidad de transferir el calor del fluido utilizado a otro fluido es eliminada, ya que el aire está siendo usado directamente como la sustancia o fluido calentado. El sistema es compacto y menos complicado.

- La corrosión, que causa serios problemas en los colectores de agua, se elimina completamente.

- Las fugas de aire desde los conductos no suponen un mayor problema.

- No existe riesgo de congelación del fluido de trabajo.

- El sobrecalentamiento no supone un riesgo.

- La presión en el interior de los colectores no es muy alta.

- Son sencillos y fáciles de instalar.

Pero los colectores de aire también tienen desventajas:

- La primera y más importante es las pobres propiedades de transferencias de calor del aire frente al agua. Otra desventaja es la necesidad de manipular o trabajar con grandes volúmenes de aire debido a su baja densidad.

- También, como la capacidad térmica del aire es baja, este no puede ser usado como un fluido de almacenamiento.

- Si el diseño no es adecuado, el coste de producción del aire caliente puede ser muy alto.

Los materiales empleados en la fabricación de un colector solar de aire son similares a los empleados en los colectores de agua, aunque su configuración es más sencilla y sus requerimientos en algunos aspectos son menos exigentes. La transmisión de la radiación solar a través del sistema de cobertura y su posterior absorción en la placa absorbedora puede ser dada por idénticas expresiones a las de las placas de los colectores de agua.

La Figura II.9 muestra los esquemas de diferentes tipos de colectores solares de aire, todos los aquí presentados son conocidos como colectores de una sola exposición y de tipo no poroso (por el material empleado en la placa absorbedora). El aire circula en un conducto paralelo al absorbedor y puede hacerlo por encima del absorbedor (figura II.9 a), por debajo (figura II.9 b), por encima y por debajo (figura II.9 c) y por debajo con diferentes formas de la placa para mejorar la transmisión de calor desde el absorbedor a la corriente de aire (figura II.9 d). 
a)

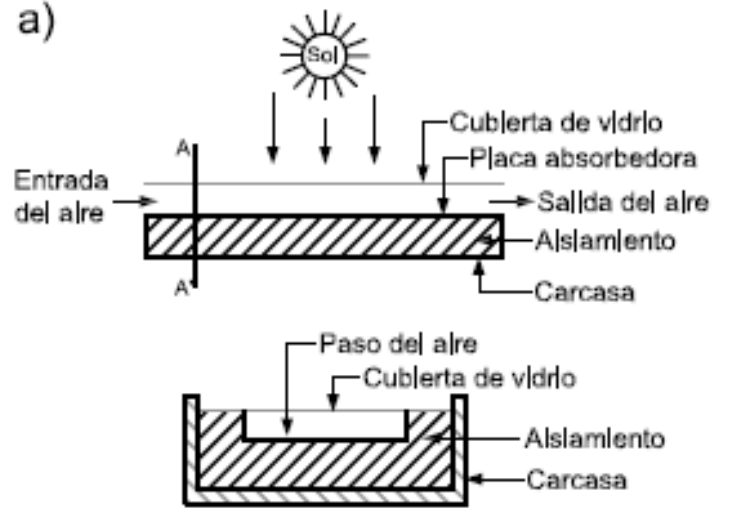

b)

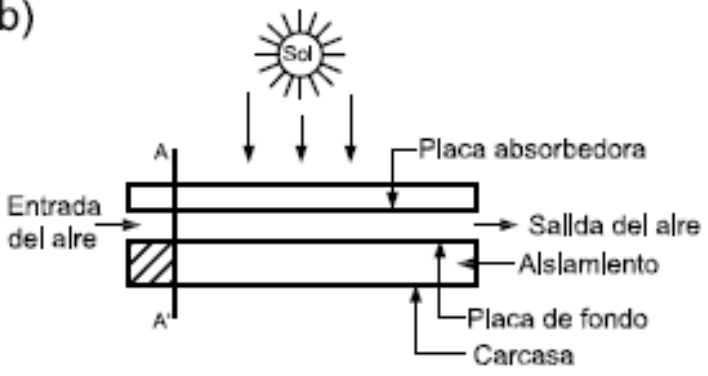

Cublerta de vidrlo $]$ Paso del alre

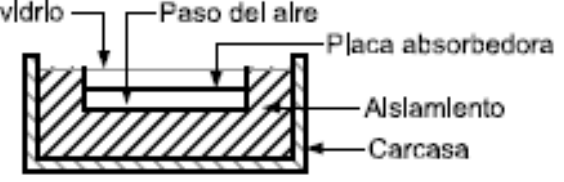

c)

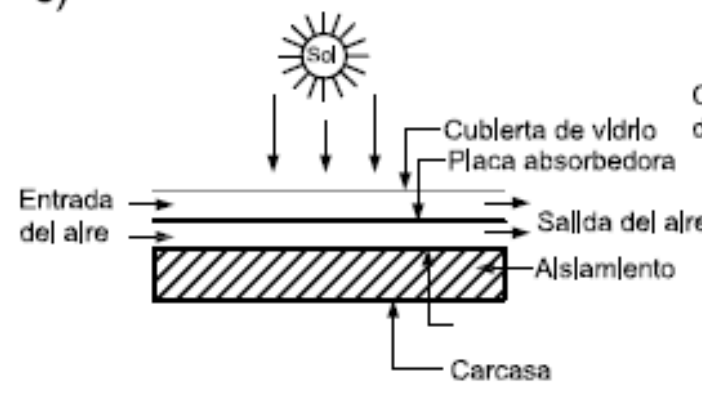

d)

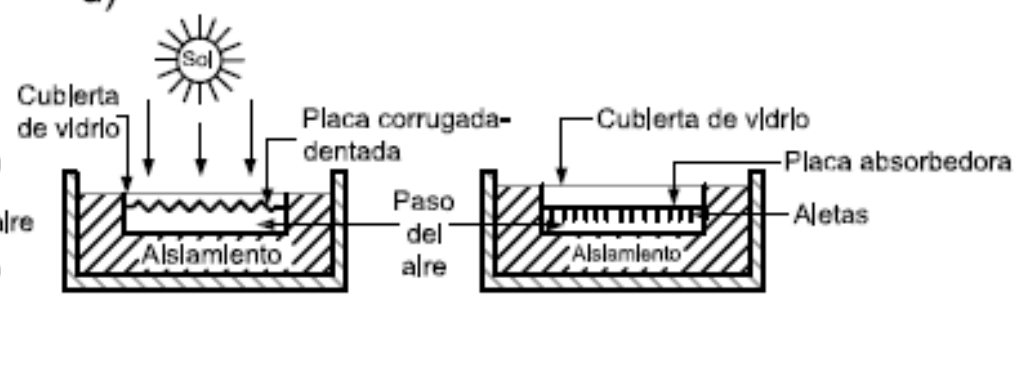

Figura II.9. (a-d)- Esquema de colectores de aire de absorbedor de tipo no poroso y una sola exposición.

A continuación se presenta el análisis térmico de un colector de aire. En la presentación y descripción de cada tipo de colector también se presentará un análisis térmico para las particularidades de cada uno de ellos. 


\section{II.2.1.- ANÁLISIS TÉRMICO DE UN COLECTOR.}

El estudio analítico del rendimiento térmico de los diferentes tipos de colectores solares de aire que se presentan proporciona un análisis del modelo en un estado estacionario. A continuación se desarrolla el análisis para un colector de un solo paso de aire sobre el absorbedor y con cubierta de vidrio.

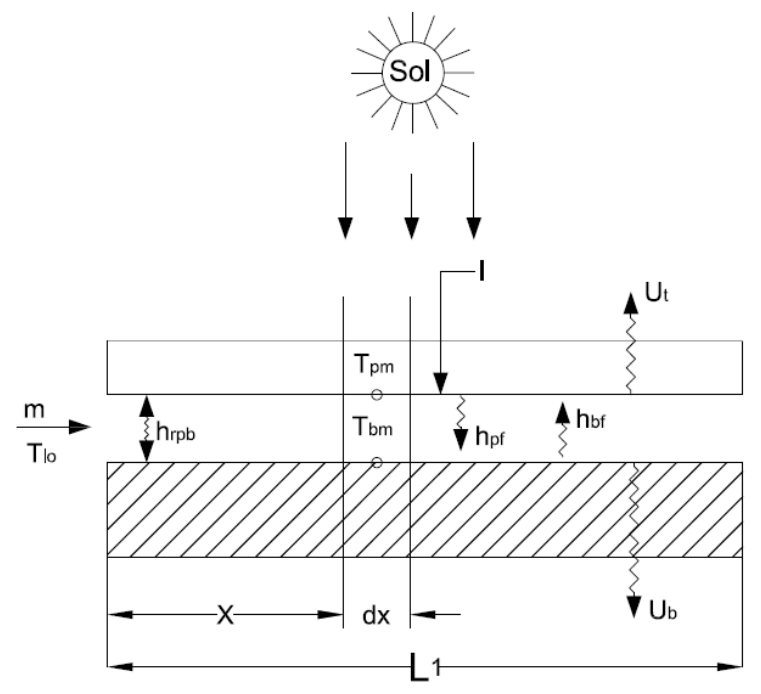

Figura II.10.- Proceso de transferencia de calor en un colector de aire convencional.

Dada la longitud y el ancho de la placa absorbedora, siendo $L_{1}$ y $L_{2}$ respectivamente, consideramos un elemento de área $L^{2} d x$, a una distancia $x$ desde la entrada (Figura II.10). Las ecuaciones del balance de energía para la placa absorbedora, el fondo de la placa y la corriente de aire pueden ser escritas de la siguiente forma [9]:

$$
\begin{aligned}
& I(t)=U_{t}\left(T_{p m}-T_{a}\right)+h_{p f}\left(T_{p m}-T_{f}\right)+h_{r p b}\left(T_{p m}-T_{b m}\right) \\
& h_{r p b}\left(T_{p m}-T_{b m}\right)=h_{p f}\left(T_{b m}-T_{f}\right)+U_{b}\left(T_{b m}-T_{a}\right) \\
& y \quad \dot{m} C_{a i r} \Delta T_{f}=h_{p f} L_{2} d x\left(T_{p m}-T_{f}\right)+h_{b f} L_{2} d x\left(T_{b m}-T_{f}\right)
\end{aligned}
$$

Estas ecuaciones pueden ser resueltas de una forma similar a la de colectores de líquidos de placas planas. El aumento en la temperatura del aire a través del conducto puede ser estimado expresando la ganancia de calor útil en el colector de la siguiente forma:

$$
\dot{Q}_{u}=F_{R} A_{P}\left[I-U_{L}\left(T_{f i}-T_{a}\right)\right]
$$


Donde $F_{R}$ es el factor de calor disipado en el colector y es dado por:

$F_{R}=\dot{m} C_{a i r} /\left(U_{L} A_{P}\right)\left[1-\exp \left[-F^{\prime} U_{L} A_{P} / \dot{m} C_{\text {air }}\right]\right]$

Donde $U_{L}$ es el coeficiente de pérdidas de calor del colector y

$U_{L}=U^{\prime}+\left(1 / F^{\prime}\right)\left[U_{b} h_{b f} /\left(h_{r p b}+h_{b f}+U_{b}\right)\right]$

$U^{\prime}=U_{t}+\left[h_{r p b} U_{b} /\left(h_{r p b}+h_{b f}+U_{b}\right)\right]$

$Y$ el factor de eficiencia del colector $\left(F^{\prime}\right)$ es dado por:

$F^{\prime}=\left[1+U^{\prime} / h_{e}\right]^{-1} \quad$ con $\quad h_{e}=h_{p f}+\left[h_{b f} h_{r a b} /\left(h_{r p b}+h_{b f}+U_{b}\right)\right]$

Donde $A_{p}$ es el área de la placa absorbedora $\left(\mathrm{m}^{2}\right), I$ la irradiancia solar $\left(\mathrm{W} / \mathrm{m}^{2}\right), U_{b}$ el coeficiente de pérdida del fondo $\left(\mathrm{W} / \mathrm{m}^{2} \stackrel{\circ}{\circ}\right), U_{t}$ el coeficiente de pérdida desde el absorbedor $\left(\mathrm{W} / \mathrm{m}^{2}{ }^{2} \mathrm{C}\right), h_{p f}$ el coeficiente de transmisión convectivo de calor entre la placa y el fluido $\left(\mathrm{W} / \mathrm{m}^{2}{ }^{\circ} \mathrm{C}\right), h_{r p b}$ el coeficiente de transmisión de calor por radiación entre la placa y el fondo $\left(\mathrm{W} / \mathrm{m}^{2}{ }^{\circ} \mathrm{C}\right), T_{a}, T_{f}, T_{f i}, T_{p m}$ y $T_{b m}$ son respectivamente las temperaturas ambiente, la del fluido (el aire), la del aire en la entrada, la de la placa principal y la de la placa de fondo o placa trasera (en $\left.{ }^{\circ} \mathrm{C}\right), \dot{m}$ el flujo de aire $(\mathrm{kg} / \mathrm{s})$ y $C_{\text {air }}$ el calor específico del aire $\left(\mathrm{J} / \mathrm{kg}^{\circ} \mathrm{C}\right)$.

En la figura II.11 se representa el balance de energía en el colector de aire mediante un símil eléctrico:

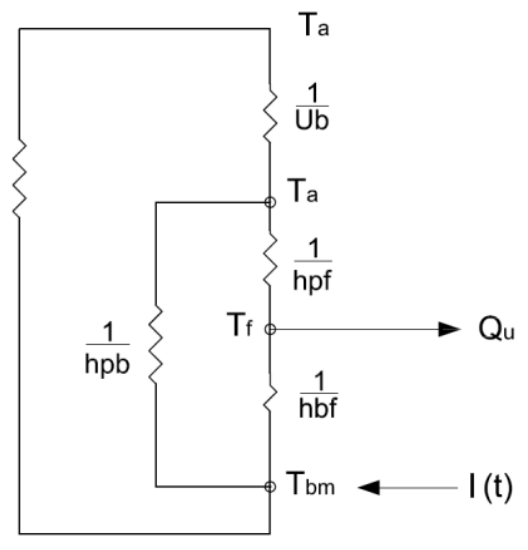

Figura II.11.- Representación de las resistencias térmicas en las pérdidas de calor en un colector de aire convencional. 
La distribución de los porcentajes de calor perdido en el colector pueden observarse en la figura II.12.

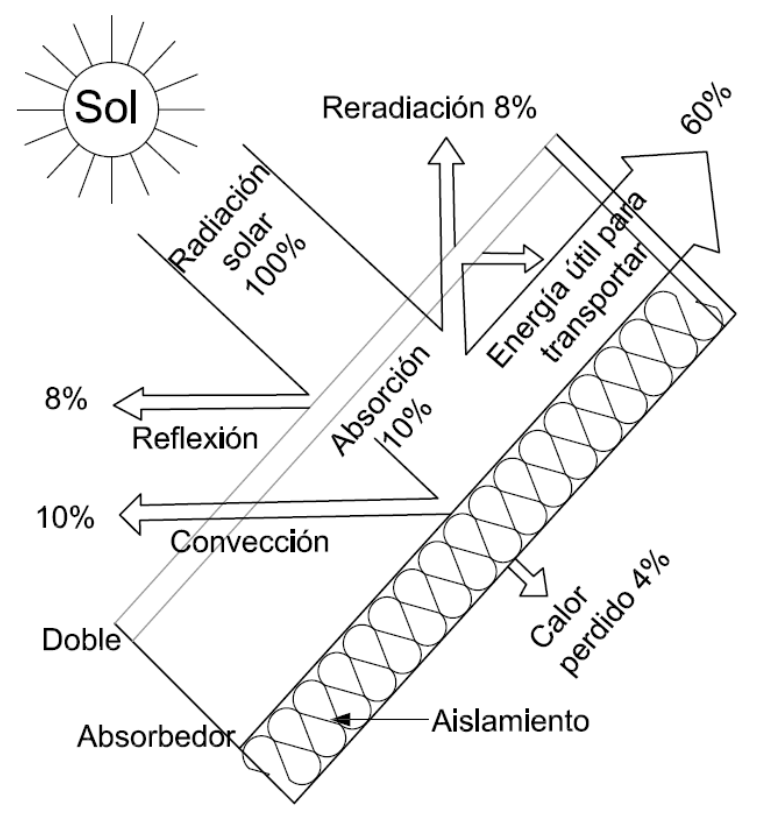

Figura II.12.- Porcentaje de pérdidas de calor en un colector de aire convencional.

Malik y Buelow, después de su estudio del proceso de transferencia de calor en colectores de aire, recomendaron la siguiente relación para el número de Nusselt en el caso de una placa absorbedora lisa [10]:

$$
N u=\frac{0.01344 R e^{3 / 4}}{1.1586 R e^{-1 / 8}}
$$

En otro estudio, Selcuk presentó curvas generalizadas para el comportamiento de los colectores de aire de tipo no poroso [11]. Como se ve en la figura II.13, para bajos aumentos de temperatura, los colectores sin cubierta no son del todo adecuados. Sin embargo, pasando de cierta temperatura, la reducción de pérdida de calor debida a un sistema de cubierta sencillo compensa las pérdidas de transmisión y llega a ser ventajoso el empleo de un colector sin cubierta. 


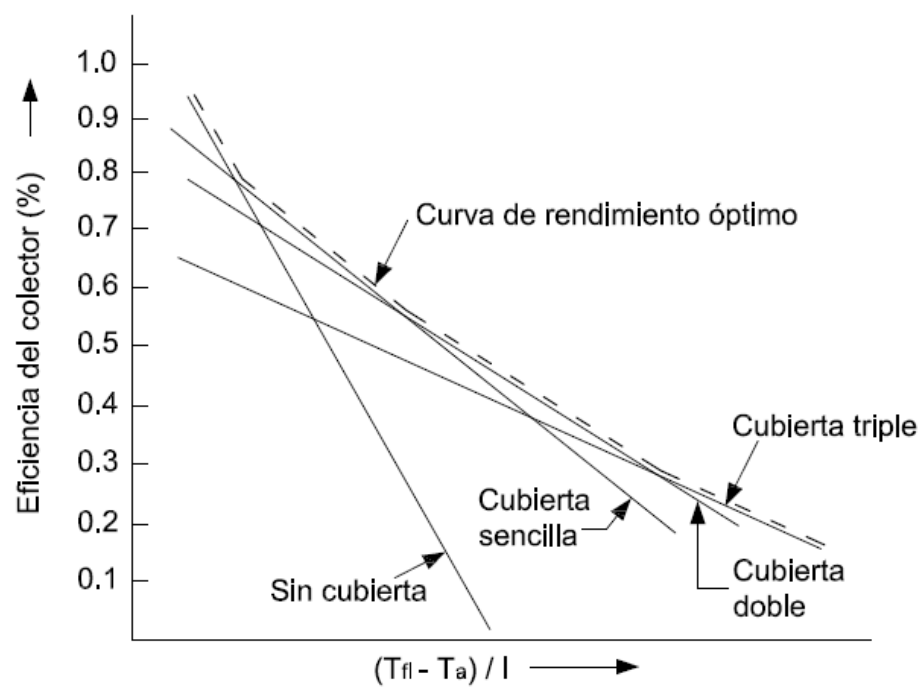

Figura II.13.-Curva de óptimo comportamiento (Selcuk, 1977).

\section{II.3.- TIPOS DE COLECTORES SOLARES DE AIRE.}

Como se ha visto en el apartado anterior se puede atender a diferentes criterios para establecer una clasificación de los C.T.S. de aire. Se ha optado por establecer una clasificación en función varios parámetros: del tipo de material del absorbedor, de su forma, del paso del aire por el colector, de la exposición de la placa o placas absorbedoras a la radiación incidente, de la forma de la placa absorbedora y de la posición de la placa absorbedora.

\section{II.3.1.- TIPO NO POROSO.}

En los tipos no porosos, la placa absorbedora no es permeable al paso del aire, de manera que esta hace de barrera física que impide el paso del aire pero no la transferencia de calor a través de ella. En este tipo la corriente de aire no solo circula por debajo de la placa absorbedora si no que puede circular por delante y/o detrás de la placa [12].

\section{II.3.1.1.- COLECTORES DE UNA SOLA EXPOSICIÓN.}

En este tipo de C.T.S. una única placa es expuesta a la radiación solar mientras la otra es aislada en el fondo. En el apartado II.2, en la figura II.9 se han presentado varios tipos de colectores convencionales o de una sola exposición: 
a) En el primer tipo, no son necesarios conductos de aire separados, el aire circula entre el sistema de cubierta transparente y la placa absorbedora (Figura II.9 (a)). En este colector, como el aire caliente circula por encima del absorbedor, la cubierta recibe gran parte de calor del aire calentado, la cubierta devuelve parte de este calor al ambiente, produciéndose pérdidas. Debido a que esta cantidad de calor perdida es considerable, no es recomendable esta configuración.

b) El tipo no poroso con conductos de aire bajo el absorbedor es el más usado. Una placa paralela a la placa absorbedora es colocada en el interior, entre el absorbedor y el aislamiento, así se forma un conducto de gran proporción para la circulación del aire (Figura II.9 (b)).

c) Otra variedad de colectores de aire de tipo no poroso, es en la cual la placa absorbedora es enfriada por la corriente de aire que circula por ambas caras de la placa (Figura II.9 (c)).

Hay que tener en cuenta que en los colectores de aire se transfiere calor entre la placa absorbedora y una corriente de aire, si esta corriente de aire disminuye, la eficacia de éstos también disminuye como se podrá comprobar en la experimentación llevada a cabo con un tipo de C.T.S. en el capítulo IV. El rendimiento, sin embargo, puede ser mejorado con superficies rugosas en el absorbedor o usando una placa corrugada - dentada. El calor transferido puede ser también incrementado añadiendo aletas a la placa absorbedora (Figura II.9 (d)). La turbulencia inducida a la corriente de aire ayuda a incrementar la transferencia convectiva del calor.

Dado que la radiación perdida desde la placa absorbedora es significativa, si no se usan adecuadas cubiertas, disminuye la eficacia. También, el uso de aletas puede dar lugar a una prohibitiva pérdida de presión, este factor limita la aplicabilidad de los tipos no porosos.

\section{COLECTORES CON FLUJO DE AIRE POR LA PARTE SUPERIOR DEL ABSORBEDOR.}

En la figura II.9 (a) se ha mostrado ya el esquema de este tipo de colectores. Consiste en una placa absorbedora con una cubierta transparente en la parte superior y aislamiento en la parte posterior. La cubierta y la placa forman un conducto para el aire. La radiación solar, después de transmitirse a través de la cubierta, es absorbida por la placa absorbedora. Parte de la energía absorbida es transmitida al aire, moviéndose este aire caliente hacia arriba, y el resto de la energía se pierde al ambiente a través de la cubierta y del fondo aislado.

A continuación, se muestra el resumen del análisis transitorio para un caso simple de este tipo de colector. El análisis puede ser extrapolado a otros casos. Primero, resumimos el análisis del funcionamiento en estado estacionario y después del transitorio. 


\section{Análisis en estado estacionario}

Se puede estudiar el comportamiento en estado estacionario de este tipo de colector de aire de forma similar a la que se hizo en el caso del colector de aire convencional (II.2.1), La diferencia es que en el apartado II.2.1, el análisis se hizo en el modo de convección forzada mientras que en este caso es en modo de libre convección. Las condiciones de los balances de energía pueden escribirse como:

Absorbedor:

$I(t)=h_{p} J\left(T_{p m}-T_{f}\right)+h_{r p c}\left(T_{p m}-T_{c m}\right)+U_{b}\left(T_{p m}-T_{a}\right)$

Cubierta:

$h_{r p c}\left(T_{p m}-T_{c m}\right)+h_{1 f}\left(T_{f}-T_{c m}\right)=h_{2}\left(T_{c m}-T_{a}\right)$

Fluido:

$\dot{q}_{u}=h_{p f}\left(T_{p m}-T_{f}\right)+h_{1 f}\left(T_{c m}-T_{f}\right)$

Donde $q_{u}$ es el ratio de ganancia de energía útil para el fluido por $\mathrm{m}^{2}$.

Resolviendo las ecuaciones (E-II.9) y (E-II.10) para $T_{p m}$ y $T_{c m}$ y sustituyendo los valores en (EII.11), podemos resolver y obtener para $q_{u}$.

$\dot{q}_{u}=F^{\prime}\left[I(t)-U_{L}\left(T_{f}-T_{a}\right)\right]$

Donde el factor de eficacia del colector $\left(F^{\prime}\right)$ y el factor de calor perdido $\left(U_{L}\right)$ son dados por:

$$
\begin{aligned}
& F^{\prime}=\frac{B}{h_{1 f}\left(h p f+U_{b}\right)+h_{p f} h_{2}+h_{r p c}\left(h_{1 f}+h_{p f}+U_{b}+h_{2}\right)+U_{b} h_{2}} \\
& U_{L}=\frac{h_{1 f}\left(h_{p f} U_{b}+h_{p f} h_{2}+U_{b} h_{2}\right)+h_{r p c}\left(h_{1 f} U_{b}+h_{1 f} h_{2}+h_{p f} U_{b}+h_{p f} h_{2}\right)}{B}
\end{aligned}
$$

Donde

$$
B=h_{1 f} h_{p f}+h_{p f} h_{2}+h_{r p c}\left(h_{1 f}+h_{p f}\right)
$$


Una vez los valores de $F^{\prime}$ y $U_{L}$ son conocidos, el calor disipado $F_{R}$, en modo de circulación forzada, puede ser calculado para un flujo dado (E-II.5). La energía útil puede ser calculada a través de la ecuación (E-II.4) conociendo la temperatura del aire a la entrada ( $T_{f i}$ ) (como en el caso del colector convencional). Destacar que la forma de obtener el factor de eficacia del colector $F^{\prime}$ es diferente de cómo lo planteábamos en el apartado del colector convencional [13].

\section{Análisis en estado transitorio}

En vista de que el comportamiento de los parámetros depende del tiempo, se hace más apropiado un análisis transitorio del colector. El siguiente análisis se refiere a la configuración que se muestra en la figura II.14 [14].

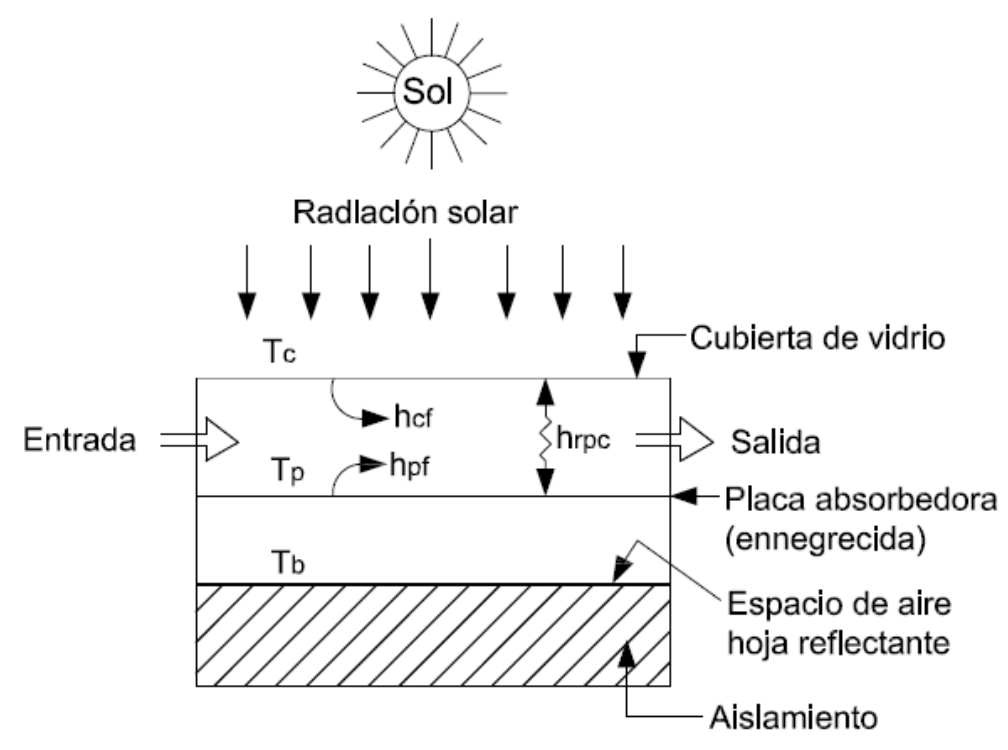

Figura II.14.-Croquis esquemático del sistema.

En este caso, un espacio de aire (cámara) se coloca entre la placa absorbedora y el aislamiento con la ayuda de una lámina reflectante. Esto ayuda a reducir las pérdidas por el fondo (parte posterior). Se toman las siguientes suposiciones para describir los balances de energía para la cubierta y la placa absorbedora:

-Las temperaturas en la cubierta y en la placa absorbedora son uniformes.

-Los coeficientes de transferencia de calor que representan la transferencia de calor desde el interior de la corriente de aire se consideran constantes y se usan sus valores promedios.

-El flujo de aire se considera constante.

-Las pérdidas por laterales son despreciadas ya que la superficie del colector es grande comparada con su espesor. 
-La mayor parte de los cambios de temperatura del aire son en la dirección del flujo.

-Las pérdidas de la placa a través del fondo aislado son representadas por una expresión de estado constante.

De esta forma, el balance de energía para la cubierta y la placa absorbedora puede ser escrita como:

Cubierta:

$$
\propto_{c} I(t)+h_{1 f}\left(T_{f}-T_{c}\right)+h_{r p c}\left(T_{p}-T_{c}\right)=U_{t}\left(T_{c}-T_{a}\right)
$$

Donde $\alpha_{c}$ es la fracción de energía solar que es absorbida por la cubierta, $h_{1 f}$ el coeficiente de transmisión de calor entre el fluido y la cubierta, $h_{r p c}$ el coeficiente de transferencia de calor por radiación entre la placa y la cubierta e $I(t)$ la radiación solar incidente.

La ecuación difiere de la Ecuación (E-II.10) al tener en cuenta el término correspondiente a la absorción de la radiación solar en la cubierta de cristal $\left(\alpha_{c} I(t)\right)$, aunque su valor es pequeño, por lo que esto no contribuye mucho.

Placa absorbedora:

$$
(\propto \tau)_{p} I(t)=h_{p f}\left(T_{p}-T_{f}\right)+h_{r p c}\left(T_{p}-T_{c}\right)+C\left(T_{p}-T_{b}\right)+M_{p}\left(d T_{p} / d t\right)
$$

Donde $(\alpha T)_{p}$ es la fracción de energía solar que es absorbida por el absorbedor y $M_{p}$ la capacidad calorífica de la placa absorbedora por unidad de área $\left(\mathrm{J} / \mathrm{m}^{2} \circ \mathrm{C}\right)$. Para hacerlo más simple tomamos algunas consideraciones del estado constante para las pérdidas por el fondo de forma que:

$$
C\left(T_{p}-T_{b}\right)=U_{b}\left(T_{b}-T_{a}\right)
$$

Para escribir el balance de energía de la corriente de aire, consideramos un volumen elemental de anchura L2 (anchura de la placa absorbedora), altura $d$ (altura de del conducto o paso del aire) y longitud $d x$ a una distancia $x$ de la entrada.

Teniendo en cuenta esto, para el aire:

$$
\left[h_{1 f}\left(T_{c}-T_{f}\right)+h_{p f}\left(T_{p}-T_{f}\right)\right] L_{2} d x=\left(\rho L_{2} d\right) C_{a i r}\left(d T_{f} / d t\right) d x+\dot{m} C_{a i r}\left(d T_{f} / d x\right) d x
$$




\section{COLECTORES CON FLUJO DE AIRE POR AMBAS CARAS DEL ABSORBEDOR.}

Consideramos un colector solar como el que se ve en la figura II.15. Si es comparado con el colector de flujo de aire por la parte superior del absorbedor (figura II.14), esta disposición proporciona un incremento de la superficie de contacto entre el absorbedor y la corriente de aire. Consideramos que los flujos sobre y bajo la placa absorbedora son iguales. Además consideramos que el coeficiente de transmisión de calor entre el aire y ambos lados de la placa es el mismo.

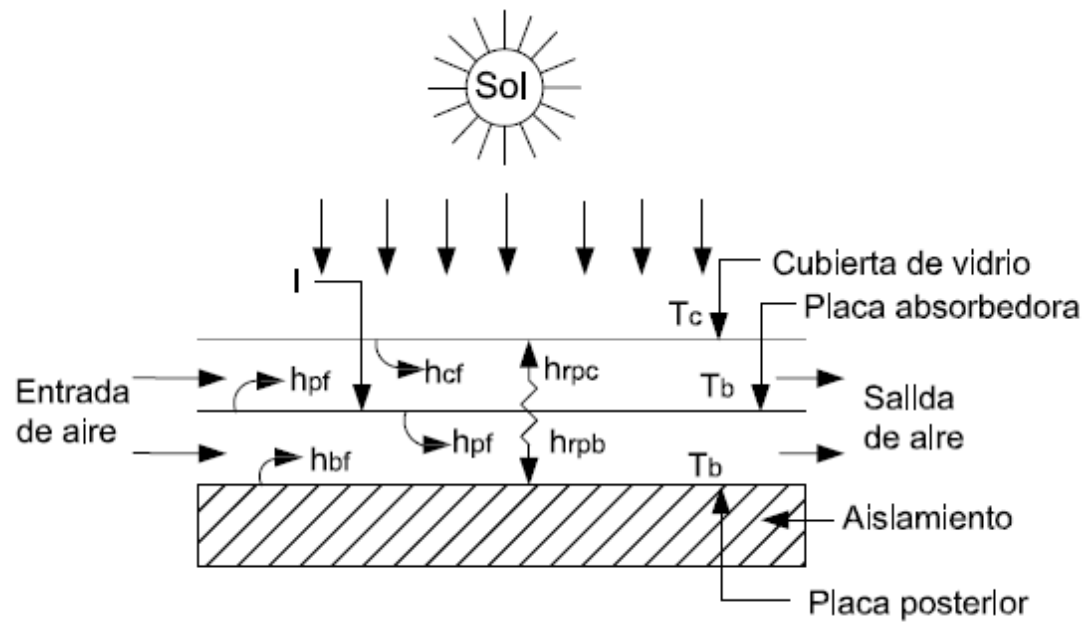

Figura II.15.-Vista esquemática de un colector solar de aire de doble flujo.

El análisis hecho en el apartado anterior se puede utilizar para el estudio del comportamiento térmico de este colector [12]. Para estudiar este colector, el análisis no tiene en cuenta la interacción de la cubierta y el fondo con la corriente de aire, la radiación intercambiada entre la placa absorbedora y la cubierta, y entre la placa absorbedora y la placa posterior (la del fondo) tampoco han sido consideradas.

La ganancia de calor en la corriente de aire para un régimen estacionario se puede escribir [13]:

$$
\dot{q}_{u}=h_{p f}\left(T_{p m}-T_{f t}\right)+h_{p f}\left(T_{p m}-T_{f b}\right)-h_{c f}\left(T_{f t}-T_{c}\right)-h_{c f}\left(T_{f b}-T_{b m}\right)
$$

Donde $T_{f t}$ es la temperatura del aire en el conducto superior y $T_{f b}$ en el inferior.

Las ecuaciones del balance de energía para la cubierta, la placa absorbedora y la placa posterior (fondo) pueden ser escritas eliminándose $T_{p}, T_{b}$ y $T_{c}$ de la ecuación (E-II.20). Las dos temperaturas del aire (una encima de la placa y otra bajo la placa) pueden ser eliminadas de la forma dada a continuación. 
En general, las pérdidas de calor de la parte superior de la placa son mayores a las pérdidas por el fondo. Como resultado, la temperatura en el conducto inferior será más alta que la temperatura en el conducto superior. Los flujos son los mismos en ambas caras. Si $T_{f}$ es el promedio de $T_{f t}$ y $T_{f b}$, entonces las desviaciones de $T_{f t}$ y $T_{f b}$ respecto de $T_{f}$ deben ser iguales. Las desviaciones entre las temperaturas del fluido y del ambiente podrían además servir para indicar las desviaciones de $T_{f t}$ y $T_{f b}$ respecto de $T_{f}$. Por lo tanto, un coeficiente de desviación $n$ es definido como:

$$
\begin{aligned}
& \left(T_{f}-T_{a}\right)-(1-n)=\left(T_{f t}-T_{a}\right) \\
& \mathrm{y}\left(T_{f}-T_{a}\right)-(1+n)=\left(T_{f b}-T_{a}\right)
\end{aligned}
$$

Estas dos ecuaciones se pueden usar para expresar $T_{f t}$ y $T_{f b}$ en términos de $T_{f}$, por lo que la ecuación (E-II.21) se puede expresar en términos de la temperatura principal del aire $T_{f}$.

Resolviendo estas ecuaciones, conseguimos las expresiones para $F^{\prime}$ y $U_{L}$ como:

$$
\begin{aligned}
\mathrm{F}^{\prime}= & \mathrm{D} / 2 \mathrm{~h}_{\mathrm{cf}} \mathrm{h}_{\mathrm{pf}} \mathrm{P}+2 \mathrm{~h}_{\mathrm{pf}} \mathrm{U}_{\mathrm{b}} \mathrm{h}_{2}+\mathrm{h}_{\mathrm{rpc}}\left(\mathrm{h}_{\mathrm{cf}}+\mathrm{h}_{\mathrm{rpb}}\right)\left(\mathrm{P}+2 \mathrm{~h}_{\mathrm{pf}}\right)+\mathrm{U}_{\mathrm{b}}\left[2 \mathrm{~h}_{\mathrm{pf}}+\mathrm{h}_{2}\right]+\left(h_{c f} h_{r p b}\right)+ \\
& h_{r p b}\left(h_{1 f}\left[P+h_{p f}\right]+2 h_{p f} h_{2}+U_{b} h_{2}\right) \\
\mathrm{U}_{\mathrm{L}}= & 4 \mathrm{~h}_{\mathrm{cf}} \mathrm{h}_{\mathrm{pf}} \mathrm{U}_{\mathrm{b}} \mathrm{h}_{2}+2 \mathrm{~h}_{\mathrm{rpc}}\left(\left[\mathrm{h}_{\mathrm{cf}}+\mathrm{h}_{\mathrm{pf}}\right]\left[\mathrm{h}_{\mathrm{rpb}} \mathrm{h}_{2}+\mathrm{U}_{\mathrm{b}} \mathrm{h}_{2}+\mathrm{h}_{\mathrm{rpb}} \mathrm{U}_{\mathrm{b}}\right]+\mathrm{h}_{\mathrm{cf}}\right)+2 \mathrm{~h}_{\mathrm{rpb}} \mathrm{U}_{\mathrm{b}}\left(\mathrm{h}_{\mathrm{cf}} \mathrm{h}_{\mathrm{pf}}+\mathrm{h}_{\mathrm{cf}} \mathrm{h}_{2}+\right. \\
& \left.\mathrm{h}_{\mathrm{pf}} \mathrm{h}_{2}\right)+(1-\mathrm{n}) \mathrm{h}_{\mathrm{cf}} \mathrm{h}_{2}\left(\mathrm { h } _ { \mathrm { cf } } \left[2 \mathrm{~h}_{\mathrm{pf}}+\mathrm{h}_{\mathrm{rpc}}+(1+\mathrm{n}) \mathrm{h}_{\mathrm{cf}} \mathrm{U}_{\mathrm{b}}\left(\mathrm{h}_{\mathrm{cf}}\left[\mathrm{h}_{\mathrm{rpb}}+2 \mathrm{~h}_{\mathrm{pf}}\right]+\mathrm{h}_{\mathrm{rpc}} \mathrm{Q}\right] / \mathrm{D}\right.\right.
\end{aligned}
$$

Donde

$$
\begin{aligned}
& D=\left[2 h_{c f} h_{p f} P+2 h_{p f} U_{b} h_{2}+h_{r p c}\left(Q\left(h_{c f+} h_{r p b}+U_{b}\right)+h_{c f} h_{r}+h_{r p b} Q\left(h_{1 f}+h_{2}\right)\right)\right. \\
& D=h_{c f}+U_{b}+h_{2} \text { y } Q=h_{c f}+2 h_{p f}
\end{aligned}
$$

Podría apuntarse, que aunque el método para calcular $F^{\prime}$ y $U_{L}$ es el mismo que en los casos anteriores, la expresión se complica debido a la configuración del colector. Además, el valor de $U_{L}$ cambia con $n$, esto implica que no considerar las desviaciones de las temperaturas de la parte superior y posterior podría conllevar un error considerable en el valor de $U_{L}$. 


\section{II.3.1.2.- COLECTORES DE DOBLE EXPOSICIÓN.}

En el punto anterior, discutíamos el comportamiento de los colectores de aire convencionales, también denominados colectores de aire de una sola exposición. Otra alternativa es que la placa posterior sea ennegrecida (pintada de negro) e irradiada (lo cual puede ser hecho quitando el aislamiento y utilizando reflectores adecuados), entonces el colector de aire puede ser llamado colector de aire de doble exposición. De esta forma, se consigue un conducto entre dos placas paralelas metálicas las cuales son ennegrecidas y cubiertas con un vidrio. Como la corriente de aire recibe calor desde ambas placas que forman el conducto (figura II.16), la eficacia se verá incrementada considerablemente.

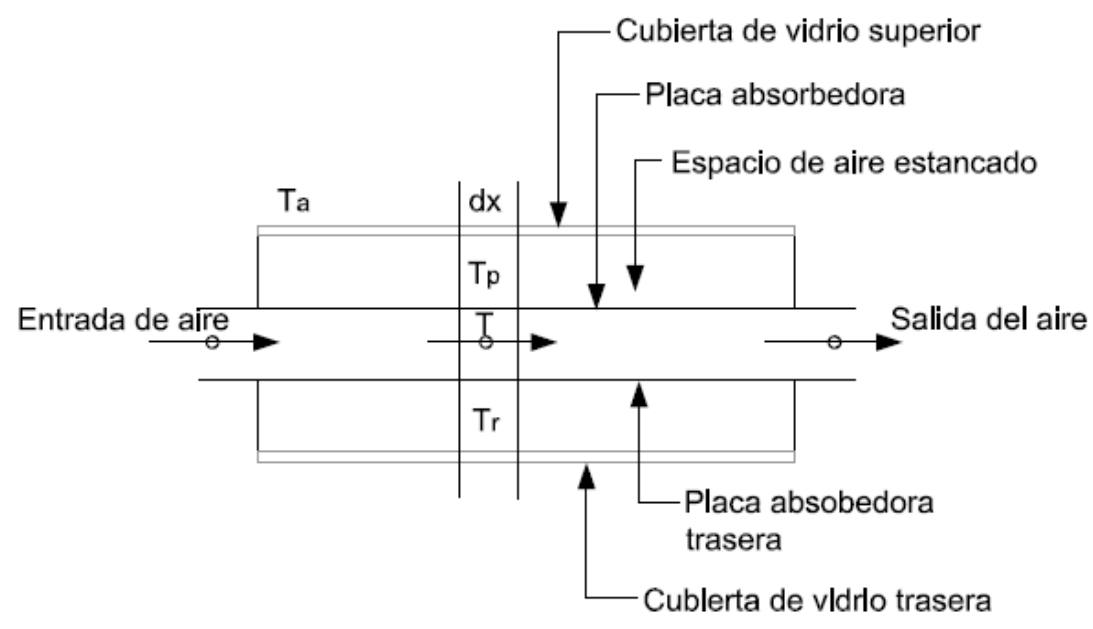

Figura II.16.-Croquis esquemático de un colector de aire de doble exposición.

El análisis del comportamiento de este colector puede ser hecho de una manera similar a la de los de una sola exposición.

Los balances de energía para los diferentes componentes de los colectores de doble exposición son:

$$
\begin{aligned}
& I_{1}\left(L_{2} d x\right)=U_{t}\left(T_{p m}-T_{a}\right)\left(L_{2} d x\right)+h_{p f}\left(T_{p m}-T_{f}\right)\left(L_{2} d x\right)+\left(h_{r p b}\left(T_{p m}-T_{b m}\right)\left(L_{2} d x\right)\right. \\
& I_{b}\left(L_{2} d x\right)+\left(h_{r p b}\left(T_{p m}-T_{b m}\right)\left(L_{2} d x\right)=h_{b f}\left(T_{b m}-T_{f}\right)\left(L_{2} d x\right)+U_{b}\left(T_{b m}-T_{a}\right)\left(L_{2} d x\right) \quad\right. \text { (E-II.27a) } \\
& \text { у } \dot{m} C_{a i r}\left(d T_{f} / d x\right) d x=h_{f b}\left(T_{p m}-T_{f}\right)\left(L_{2} d x\right)+h_{b f}\left(T_{b m}-T_{f}\right)\left(L_{2} d x\right)
\end{aligned}
$$

Donde $I_{1}$ es el flujo solar incidente en la placa absorbedora $\left(\mathrm{W} / \mathrm{m}^{2}\right)$ e $I_{b}$ es el flujo solar incidente en la placa absorbedora trasera $\left(\mathrm{W} / \mathrm{m}^{2}\right)$. Estas ecuaciones pueden ser resueltas como en el caso de los colectores convencionales del apartado II.2.1 de este capítulo. 


\section{II.3.1.3.- COLECTORES DE DOS PASOS.}

En este tipo de colectores, el aire circula entre dos cubiertas (figura II.17 (a)), o entre la cubierta interior y la placa absorbedora (figura II.17 (b)), para posteriormente hacerlo a través del conducto de detrás de la placa absorbedora.
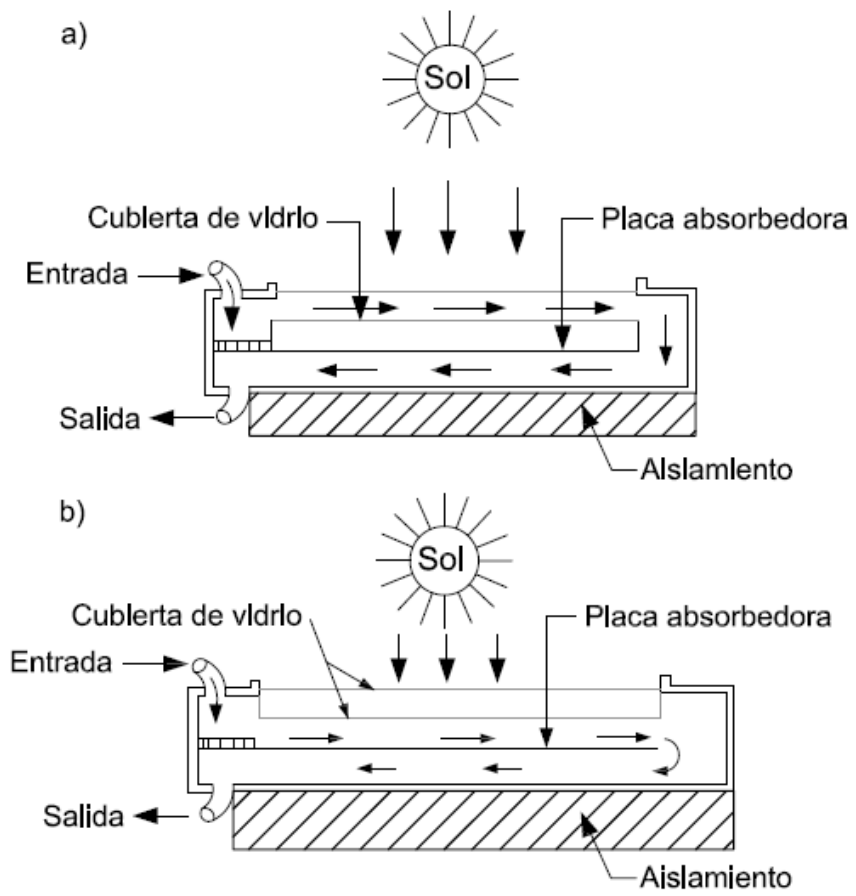

c)

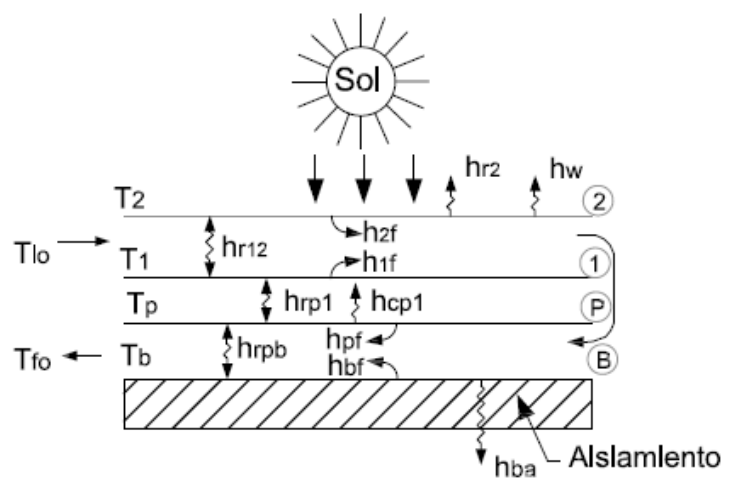

Figura II.17 (a-c).-Vista esquemática de diferentes configuraciones de colector solar de aire de dos pasos.

El concepto de colector de aire de dos pasos fue introducido por Satcunanathan y Deonarine en 1973. Después de realizar estudios del comportamiento térmico de este tipo de colectores, se desarrollaron detallados modelos de transferencia de calor validados con datos experimentales, en los cuales se concluyó que se mejoraba entre un 10 y un $15 \%$ la eficacia del colector incorporando este doble paso. Esta mejora de la eficacia del colector, sin embargo, también suponía un elevado incremento de los costes del colector [15]. 
La figura II.17 (a) muestra la configuración del colector de aire estudiado por Satcunanathan y Deonarine [16]. En este tipo, el aire entra a un canal formado por el espacio comprendido entre una primera cubierta de vidrio (la que separa el flujo interior del aire del entorno del colector) y una segunda cubierta que ocupa la parte superior de la placa absorbedora, para posteriormente circular entre el absorbedor y el fondo del colector. La entrada del aire toma calor de la cubierta para que esta se mantenga fría y la parte de calor perdido se reduzca. La figura II.17 (b) muestra la configuración de otro colector de aire de dos pasos. En este tipo, el flujo de aire primero atraviesa el conducto formado por la placa absorbedora y una cubierta interior y pasa luego al conducto formado por la placa absorbedora y la placa posterior o de fondo. En ambos casos, el análisis conlleva similares consideraciones, por lo que se explica el procedimiento para la configuración mostrada en la figura II.17 (a). Consecuentemente, las líneas de los coeficientes de transferencia de calor indican varios procesos de transferencia que se muestran en la figura II.17(c).

El concepto de colector de aire de dos pasos fue introducido por Satcunanathan y Deonarine en 1973. Después de realizar estudios del comportamiento térmico de este tipo de colectores, se desarrollaron detallados modelos de transferencia de calor validados con datos experimentales, en los cuales se concluyó que se mejoraba entre un 10 y un $15 \%$ la eficacia del colector incorporando este doble paso. Esta mejora de la eficacia del colector, sin embargo, también suponía un elevado incremento de los costes del colector [15].

El análisis corresponde a un estado "casi" constante, por lo que las consideraciones hechas en el caso anterior pueden tomarse en este caso como válidas también.

Como se considera que el sistema se encuentra en un estado "casi" constante, las temperaturas de la cubierta, placas, corrientes de aire, valores de intensidad solar y temperatura ambiente no son dependientes del tiempo. Haciendo estas consideraciones, el aumento de la temperatura del aire a lo largo del conducto se puede calcular. Establecemos, por ejemplo, el movimiento del volumen de aire como se muestra en la figura II.17 (c). Entonces, podemos escribir el balance de energía para la corriente de aire como:

$$
\dot{m} C_{\text {air }} \frac{d T_{f}}{d_{x}} d x=L_{2} h_{1 f}\left(T_{1}-T_{f}\right) d x+L_{2} h_{2 f}\left(T_{2}-T_{f}\right) d x
$$

La ecuación anterior puede ser integrada, y junto con la condición inicial $T_{f}(x=0)=T_{f i}$, tenemos,

$$
\begin{aligned}
& T_{f}(x)=\frac{\left(h_{1 f} T_{1}+h_{2 f} T_{2}\right)}{h_{1 f}+h_{2 f}}[1-\exp (-v x)]+T_{f i} \exp (-v x) \\
& \text { Donde: } \quad v=\left(h_{1 f}+h_{2 f}\right) L_{2} / \dot{m} C_{\text {air }}
\end{aligned}
$$


De ahí, el promedio de la temperatura del fluido en el conducto es,

$$
T_{f m}=\frac{1}{L_{1}} \int_{0}^{L_{1}} T_{f}(x) d x
$$

$o \quad T_{f m}=\left[\frac{h_{1 f} T_{1}+h_{2 f} T_{2}}{h_{1 f}+h_{2 f}}\right]\left[1-\left(1 / v L_{1}\right) 1-\exp \left(-v L_{1}\right)\right]+T_{f i}\left[1-\exp \left(-v L_{1}\right)\right] /\left(v L_{1}\right)$

Las condiciones del balance de energía para la cubierta y las placas puede escribirse como: Exterior de la cubierta:

$\alpha_{2} I(t)+h_{r 12}\left(T_{1}-T_{2}\right)=\left(h_{r 2 a}+h_{w}\right)\left(T_{2}-T_{a}\right)+h_{2 f}\left(T_{2}-T_{f m}\right)$

Interior de la cubierta:

$\alpha_{1} I(t)+\left(h_{r p 1}+h_{c p 1}\right)\left(T_{p}-T_{1}\right)=h_{r 12}\left(T_{1}-T_{2}\right)+h_{1 f}\left(T_{1}-T_{f m}\right)$

Placa absorbedora:

$\alpha_{P} I(t)=h_{r p b}\left(T_{p}-T_{b}\right)+h_{p f}\left(T_{p}-T_{f m}^{\prime}\right)+\left(h_{r p m}+h_{c p 1}\right)\left(T_{p}-T_{1}\right)$

Placa posterior o de fondo:

$h_{r p b}\left(T_{p}-T_{b}\right)=h_{b a}\left(T_{b}-T_{a}\right)+h_{b f}\left(T_{b}-T_{f m}^{\prime}\right)$

Donde $T_{f m}$ es la temperatura media en el conducto del fondo y su expresión puede ser obtenida como en la Ecuación (E-II.32). Puntualizar que la temperatura del aire a la salida del primer conducto es la misma que la de la entrada en el segundo. Las Ecuaciones (E-II.33) a (E-II.36) pueden ser resueltas usando las expresiones de $T_{f m}$ y $T_{f m}^{\prime}$ para obtener la temperatura del aire a la salida del colector. La eficacia instantánea del colector es dada por

$\eta_{i}=\frac{\dot{m} C_{a i r}\left(T_{f o}-T_{f i}\right)}{A_{p} I_{1}}$

Donde $T_{f o}$ la temperatura del aire a la salida. 


\section{Comparación con resultados experimentales existentes.}

Se ha podido determinar que en el sistema de dos pasos existe un aumento de la eficacia de entre el 10-15\% respecto al de un único paso del aire. Además, la disposición del sistema de dos pasos que se muestra en la figura II.17 (b), ofrece un mejor comportamiento que la disposición del modelo que se muestra en la figura II.17 (a). [15].

Wijeysundera y Tyioe validaron su modelo de transferencia de calor empleando la comparación de las predicciones teóricas con los datos experimentales de Satcunanathan y Deonarine. Los coeficientes de transferencia de calor empleados, son calculados usando procedimientos iterativos. Las figuras II.18 y II.19 muestran la eficacia y el incremento de la temperatura del aire para el colector de aire de un sólo paso y para el de dos pasos respectivamente. La aproximación entre los resultados experimentales y los cálculos teóricos es bastante buena.

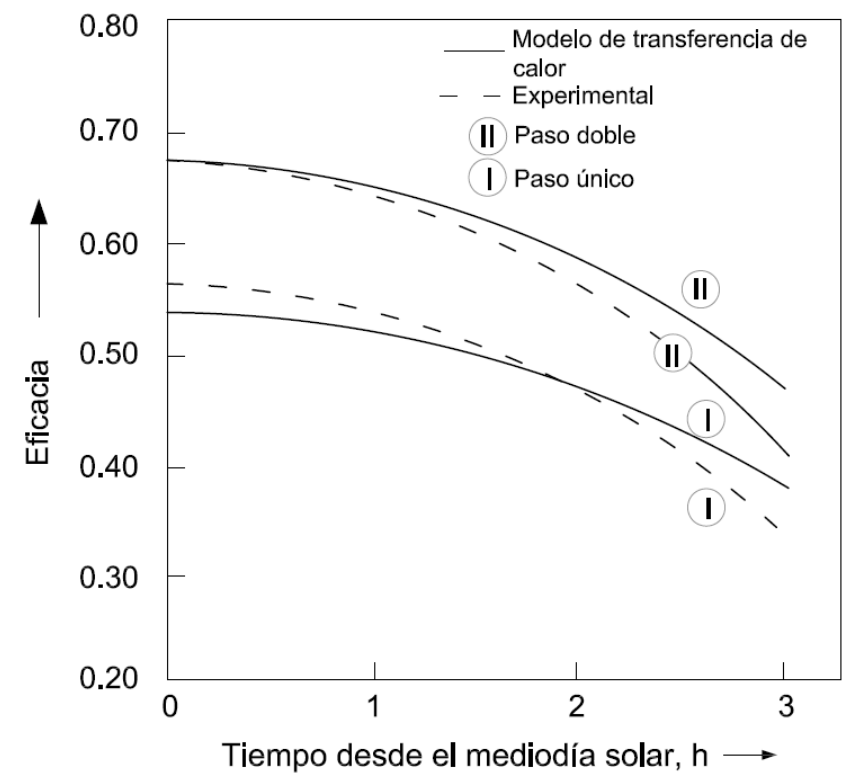

Figura II.18.-Curva de eficacia; $m=0.0171 \mathrm{~kg} / \mathrm{s} ; \mathrm{Ta}=303 \mathrm{~K} ; \mathrm{Ac}=1269 \mathrm{~m} 2 ;$ gap= $0.0381 \mathrm{~m}$; $\mathrm{V}=5.1 \mathrm{~m} / \mathrm{s}$. 


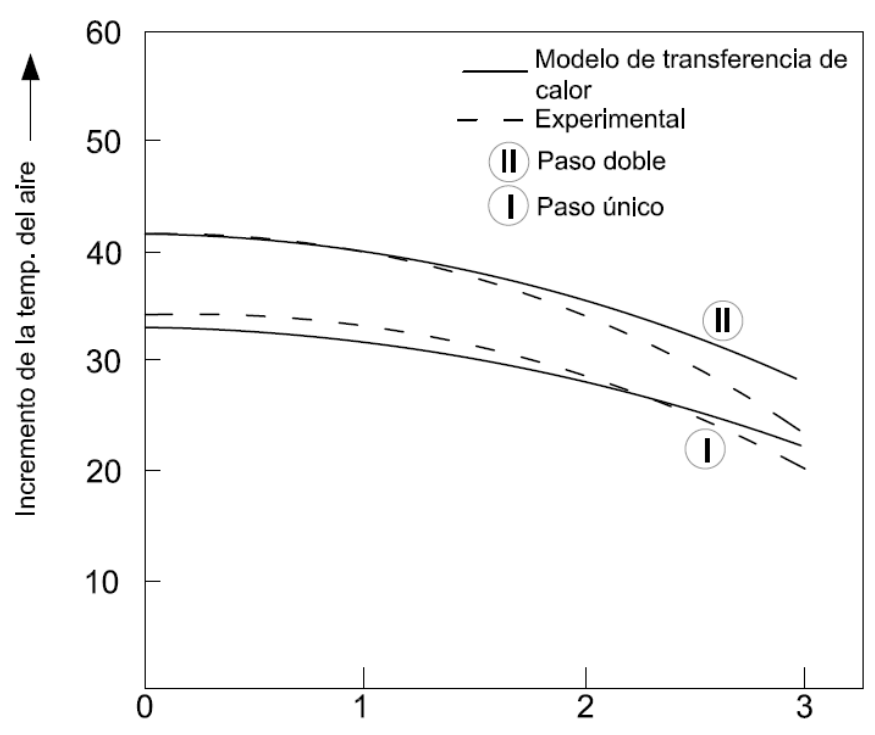

Tiempo desde el mediodía solar, $\mathrm{h} \longrightarrow$

Figura II.19.-Incremento de la temperatura del aire en un colector de un solo paso y en uno de doble paso; $\mathrm{m}=0.0171 \mathrm{~kg} / \mathrm{s} ; \mathrm{Ta}=303 \mathrm{~K} ; \mathrm{Ac}=1269 \mathrm{~m}^{2}$; gap= $0.0381 \mathrm{~m} ; \mathrm{V}=5.1 \mathrm{~m} / \mathrm{s}$.

\section{II.3.1.4.- COLECTOR CON PLACA ABSORBEDORA ALETEADA.}

Con el fin de mejorar la transferencia de calor desde la placa absorbedora a la corriente de aire, y con ello la eficacia del colector, se añaden aletas a la cara posterior del absorbedor como se veía en la figura II.9 (d)). Esto, sin embargo, conlleva una pérdida de carga adicional. A partir de cierto número y longitud de aletas puede conllevar la necesidad de un aumento de la potencia del ventilador.

La transferencia de calor en superficies aleteadas es muy común en diferentes sistemas que emplean baterías en dispositivos como condensadores o evaporadores de máquinas frigoríficas que basan parte de su funcionamiento en la transmisión de calor por convección. Podemos utilizar estos conocimientos para desarrollar el modelo de transferencia de calor para este tipo de colectores. Sin embargo, la limitación para este modelo es que no hay correlaciones apropiadas para los coeficientes de transferencia correspondientes a las situaciones que nos encontramos en colectores de aire. Malik y Buelow trabajaron en esto en 1973 [10], al igual que Kuzay y sus colegas un año después, en 1974 [17]. Selcuk en 1977 resumió sus trabajos. Los resultados de las pruebas de los colectores de aire con aletas galvanizadas escalonadas y con aletas de aluminio escalonadas con forma de $U$ fijadas a la cara posterior de la placa absorbedora demostraron que las eficacias de los colectores con aletas son sustancialmente más altas que las de los colectores de aire convencionales (los de absorbedores sin aletas). [11]. 


\section{II.3.1.5.- COLECTOR CON ABSORBEDOR CORRUGADO - DENTADO.}

El uso de un absorbedor corrugado- dentado (figura II.20) en lugar de una placa absorbedora recta o plana, proporciona una mayor superficie de intercambio para la transferencia de calor a la corriente de aire. El calor transferido por convección desde la placa a la cubierta aumenta, por lo que las pérdidas por la cubierta también aumentan, pero estas pérdidas son ampliamente compensadas por el aumento de calor transferido al flujo de aire.

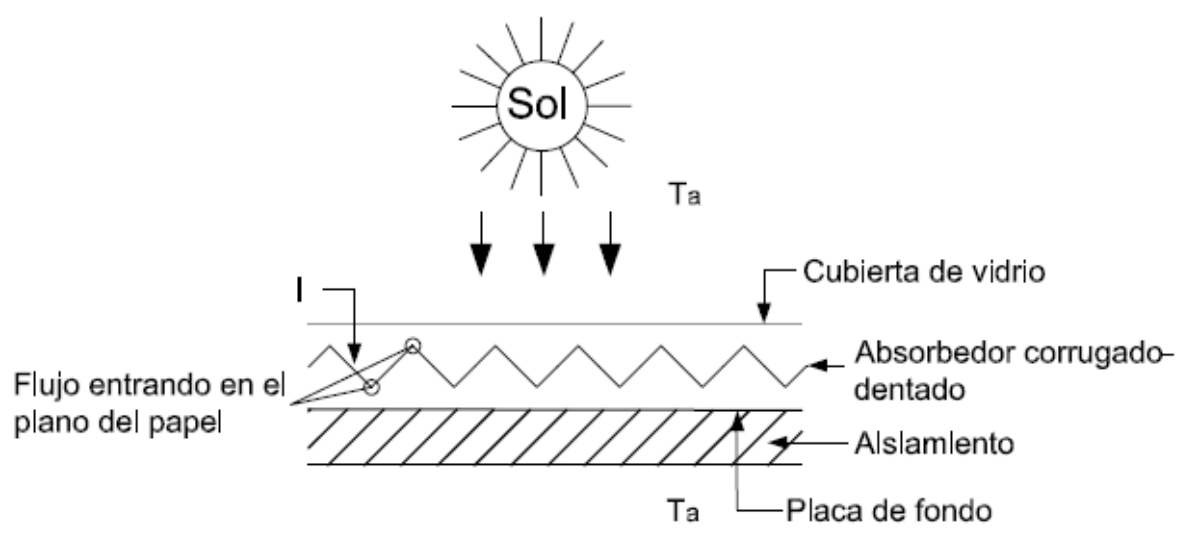

Figura II.20.- Esquema de un colector de aire con placa absorbedora corrugada- dentada.

Hay que elegir correctamente el ángulo que forman los dientes de la placa al diseñar el absorbedor, ya que una gran cantidad de calor se puede perder debido a las múltiples reflexiones. Además la emisividad efectiva del absorbedor incrementa al aumentar las reflexiones. Es recomendado un ángulo de recepción de 55ํㅡ en los dientes de la placa absorbedora con un adecuado revestimiento.

Los colectores de aire con placas absorbedoras dentadas, formadas por láminas de cobre adecuadamente pintadas, son usados en Australia para aplicaciones solares de secado. Hollands en 1963 estudió las propiedades de selectividad direccional, emisividad y absortividad de las superficies especulares corrugadas- dentadas [18].

Con este tipo de absorbedor, la corriente de aire puede circular por una o ambas caras del absorbedor. El factor de eficacia del colector $\left(F^{\prime}\right)$ y el factor de pérdida de calor $\left(U_{L}\right)$ serán los mismos que en el caso del absorbedor plano, pero el valor de $h_{p f}$ incrementa con el valor del área de la superficie del absorbedor [13].

Un caso especial se presenta cuando los vértices de los dientes de la placa tocan la placa posterior o de fondo, formando conductos triangulares. El conducto triangular formado restringe el flujo del fluido a exclusivamente su interior (figura II.21). Los conductos son de material conductor rígido (por ejemplo aluminio) para proporcionar la suficiente conducción de calor alrededor del conducto. Por 
ello, se dan pequeñas diferencias de temperatura en la placa alrededor de los conductos triangulares, ya que la transferencia de calor por radiación dentro del triángulo no es necesario considerarla. Además, los coeficientes de pérdida por la parte superior y el fondo se combinan para escribir el balance de energía para el colector como:

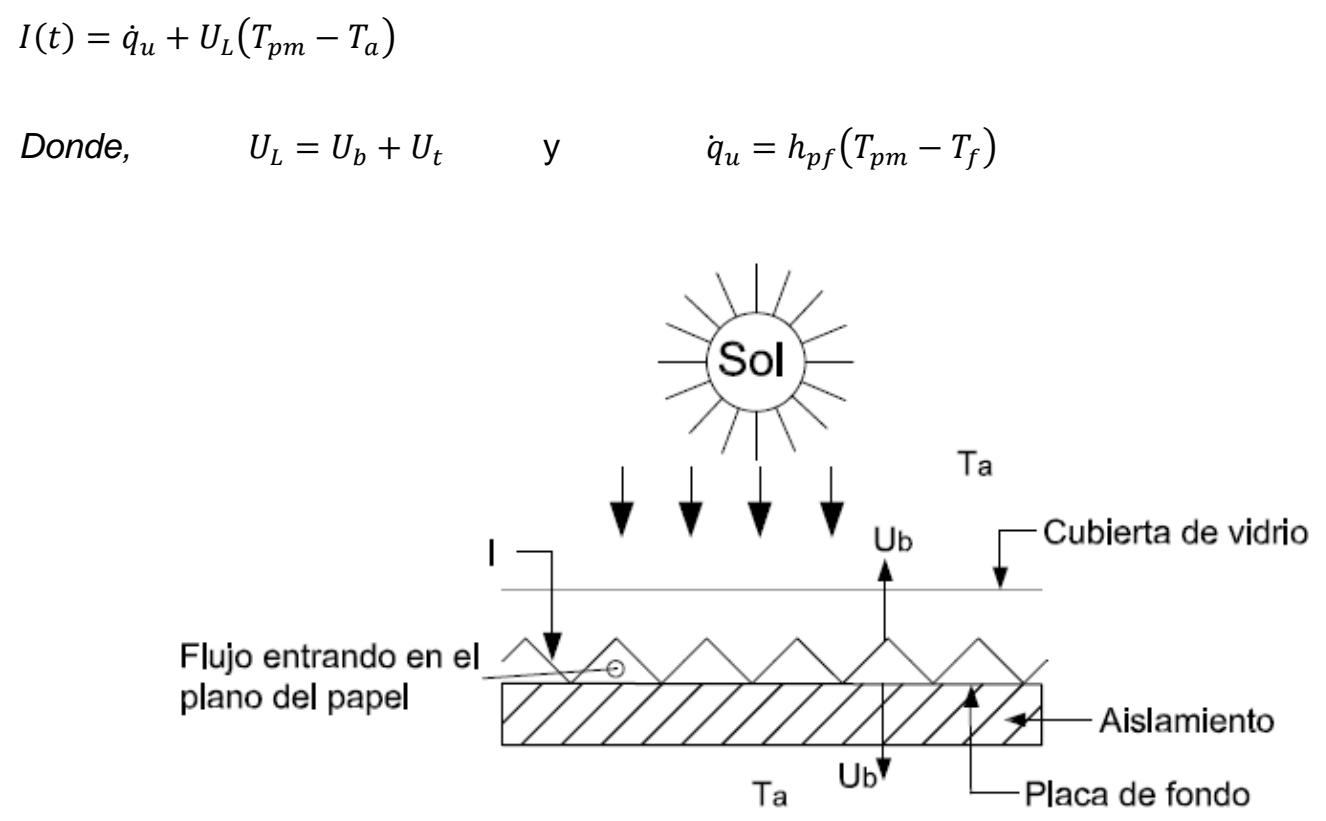

Figura II.21.- Esquema de un colector de aire con conductos triangulares.

De ahí, el factor de eficiencia del colector $F^{\prime}$ es dado como:

$F^{\prime}=h_{p f} /\left(h_{p f}+U_{L}\right)$ 


\section{II.3.1.6.- COLECTOR CON PLACA ABSORBEDORA EN EL REVERSO (COLECTORES INVERTIDOS)}

Los colectores de aire convencionales pueden proporcionar aire caliente a una temperatura que está en torno a los $15-30^{\circ} \mathrm{C}$ sobre la temperatura ambiente, la del aire a la entrada. Pero también, se pueden alcanzar incrementos de temperatura de aproximadamente $100^{\circ} \mathrm{C}$ reduciendo las pérdidas de calor por radiación y convección que se dan desde el absorbedor al ambiente a través de la cubierta de cristal superior. Esto es posible en un nuevo tipo de colector solar de aire conocido como colector de placa plana en el reverso (RFP, Resverse flat plate). Este puede absorber el calor solar a alta temperatura (aproximadamente $200^{\circ} \mathrm{C}$ ).

La vista esquemática de un colector de placa plana en el reverso se muestra en la figura II.22 (a). La radiación solar es transmitida por la cubierta de cristal primero $(\tau I(t))$ y luego reflejada por la superficie poliédrica curvada cilíndricamente $\left(r^{N} \tau I(t)\right)$ hacia el absorbedor acristalado. Después de la absorción, el absorbedor emite radiación de largas ondas longitudinales que es atrapada entre el absorbedor y la cubierta acristalada. En este caso, las pérdidas de calor por radiación y convección no existen debido a que el revestimiento de la placa caliente está hacia abajo. Hay un aislamiento de un espesor dado sobre el absorbedor para reducir la pérdida de calor por la parte superior, pérdidas debidas a la conducción, esta es la principal diferencia con el colector de aire convencional. Hay un espacio entre el absorbedor y el aislamiento para permitir que el aire circule por encima del absorbedor. El aire que pasa sobre el absorbedor es calentado al transferir la energía térmica absorbida por convección. La apertura de la superficie del colector RFP es la misma ya que la placa absorbedora y el ratio de concentración es 1:1.

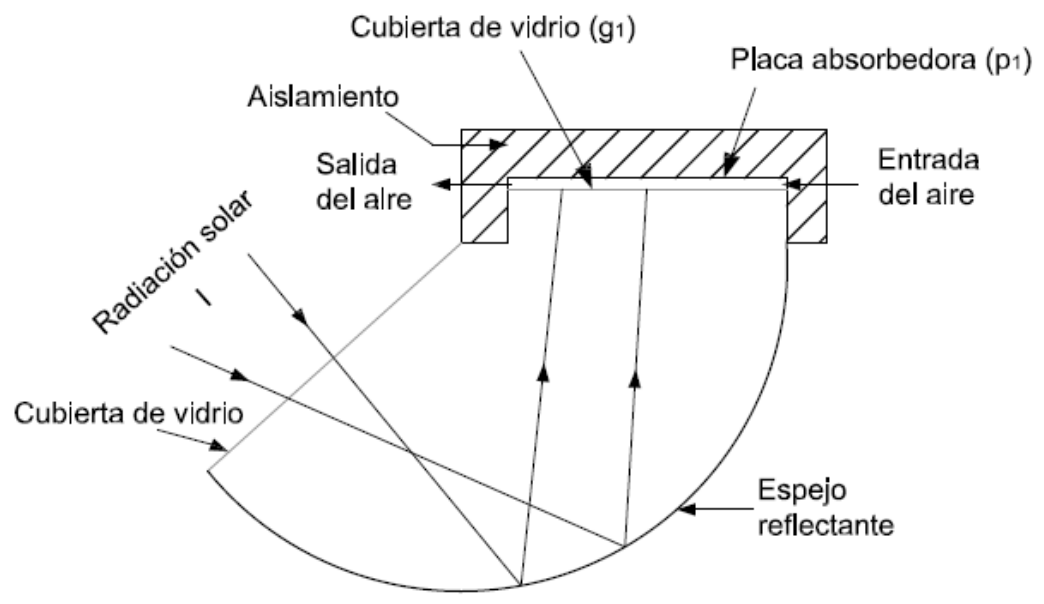

Figura II.22 .- Vista esquemática de un colector de aire con placa absorbedora invertida de un solo paso (RFP). 
Otras configuraciones del RFP utilizan también la radiación solar sobre la superficie superior como se muestra en las figuras II.23 (b-e), estas muestran el sistema de un único o doble paso del aire respectivamente.
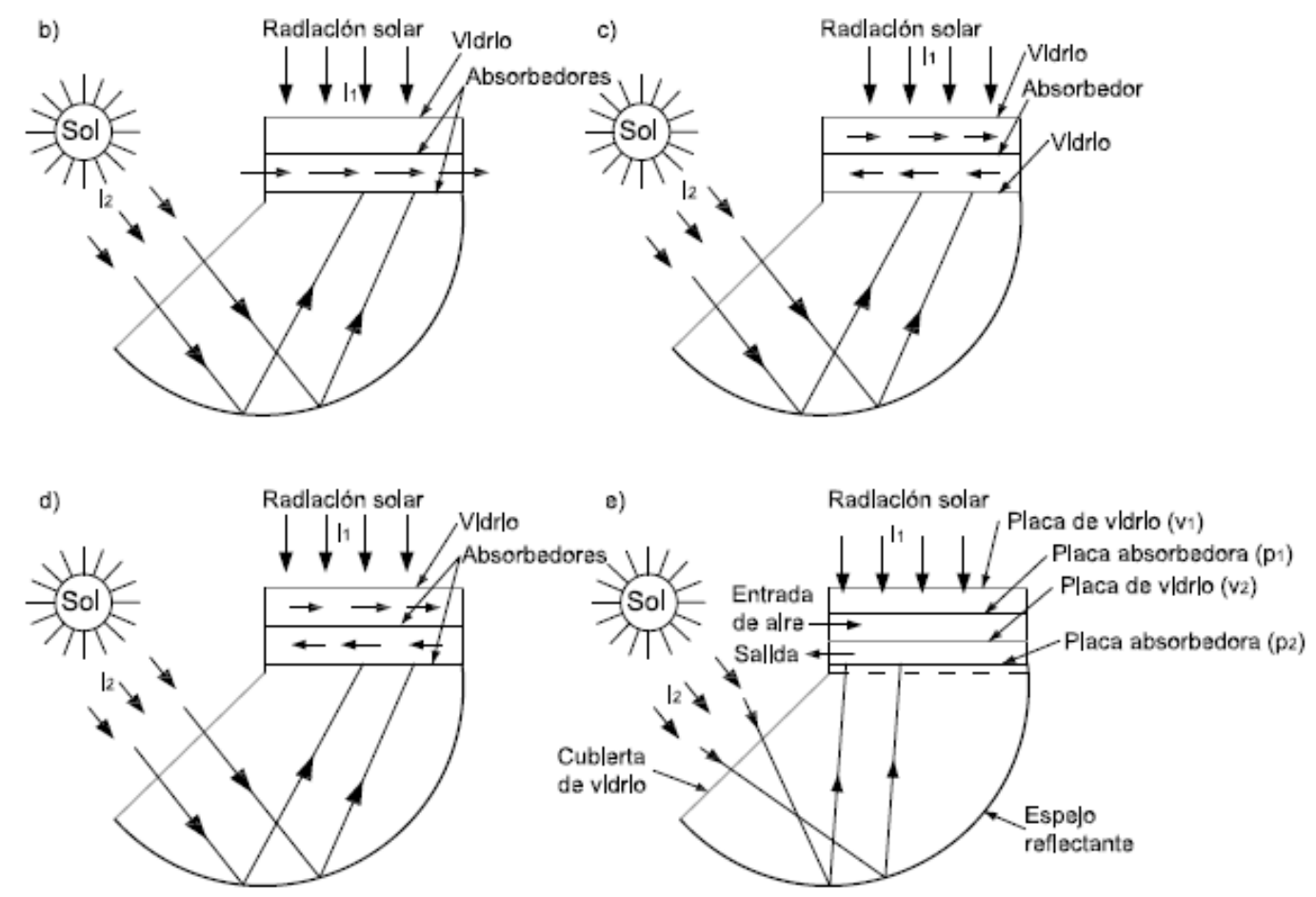

Figura II.23 (b-e).- Vista esquemática de otras configuraciones del colector RFP.

Refiriéndonos a la figura II.22, la ecuación del balance de energía para la placa absorbedora $\left(T_{p m}\right)$, el fluido $\left(T_{f}\right)$ y la cubierta de cristal en la dirección x puede escribirse como

$$
\begin{aligned}
& \tau I(t) r^{N}=h_{p f}\left(T_{p m}-T_{f}\right)+h_{r p g}\left(T_{p m}-T_{g}\right) \\
& \dot{m} C_{a i r} \frac{d T_{f}}{d x} d x=\left[h_{p f}\left(T_{p m}-T_{f}\right)-U_{b}\left(T_{f}-T_{a}\right)\right] d x \\
& \mathrm{y} \\
& h_{r p g}\left(T_{p m}-T_{g}\right)+h_{f p}+\left(T_{f}-T_{g}\right)=U_{t}\left(T_{g}-T_{a}\right)
\end{aligned}
$$

Donde $\tau I(t) r^{N}$ es la radiación reflejada por la superficie cilíndrica hacía el absorbedor.

Estas ecuaciones se pueden resolver para el ratio de ganancia de calor útil del RFC como se hizo en el apartado II.2.1 para colectores convencionales. 
Las ecuaciones del balance de energía para otras configuraciones (figuras II.23 (b-e)) pueden también escribirse de una forma similar.

Diferentes autores han comparado el comportamiento del colector de placa plana normal (NFP) y el invertido (RFP) para los sistemas de un único y doble paso. Después de estos estudios comparativos se ha concluido que la temperatura de salida del aire para el colector RFP es más alta que la del colector NFP [19].

El efecto del número de reflexiones en la temperatura del aire de salida en el colector de placa absorbedora invertida con dos pasos del aire (figura II.23 (e)) se muestra en la figura II.24. Se puede observar que la temperatura del aire a la salida disminuye al incrementar el número de reflexiones debido a las pérdidas por radiación de estas reflexiones. Además, la temperatura del aire a la salida aumenta cuando se reduce el flujo másico (figura II.25). En este caso, el calor transferido por convección aumenta debido al mayor contacto entre el aire y la placa caliente.

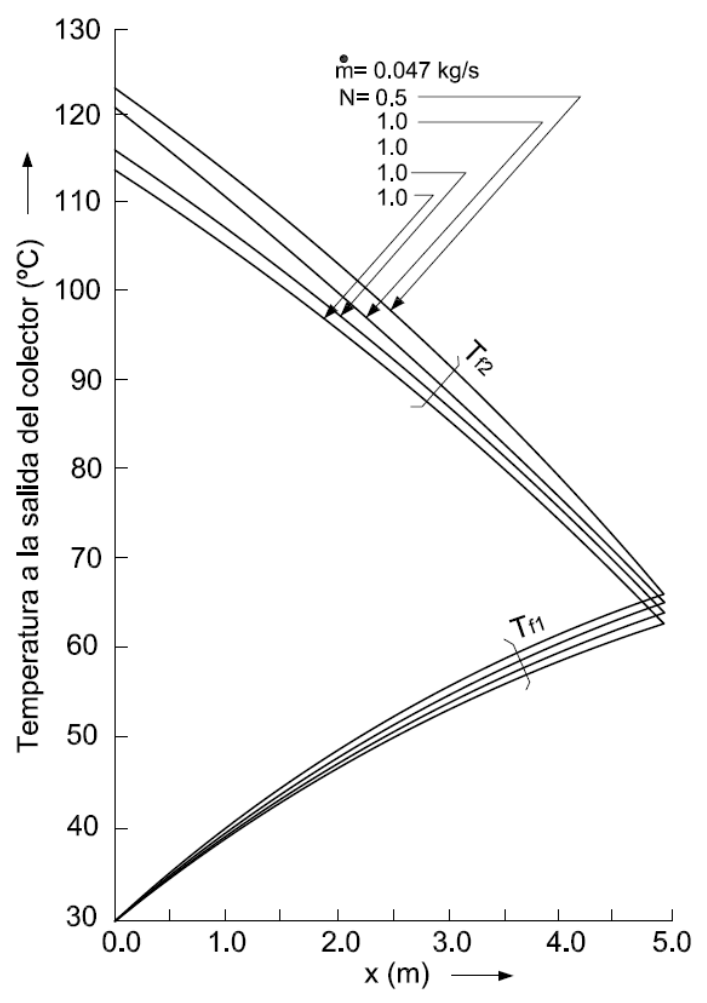

Figura II.24.- Variación de la temperatura de salida del aire con $x$ para diferentes $\mathrm{N}$. 


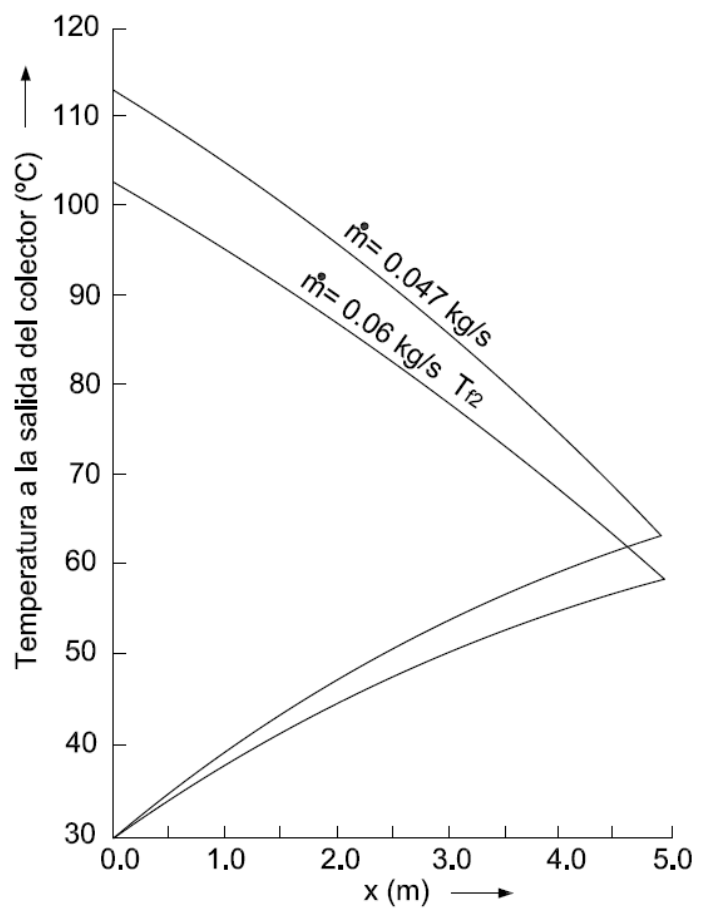

Figura II.25.- Variación de la temperatura de salida del aire con $x$ para diferentes $\mathrm{m}$.

\section{II.3.2.- TIPO POROSO.}

El segundo tipo de colectores de aire tiene un absorbedor poroso el cual puede incluir rendijas y metales expandidos, placas absorbedoras de cristales solapados y paneles transpirados.

El colector de aire de absorbedor de tipo poroso tiene las siguientes ventajas:

i. La radiación solar penetra a gran profundidad y es absorbida a lo largo de su trayecto. De este modo la radiación perdida disminuye. La corriente de aire sube ya que pasa a través de la matriz.

ii. La pérdida de presión es normalmente más baja que en los tipos no porosos.

Se debe tener en cuenta sin embargo, que una inadecuada elección de la porosidad de la matriz y de su espesor podría causar una disminución de la eficiencia. Un exceso de espesor puede provocar que la matriz no esté lo suficientemente caliente para transferir el calor a la corriente de aire. 
Son comúnmente usados tipos de absorbedores porosos como mallas metálicas, rejillas, metales expandidos y absorbedores de forma de panel de abeja transpirables. Algunos de ellos se pueden ver en las siguientes figuras: Malla de alambre (figura II.26 (a)), cama porosa formada por botellas rotas (figura II.26 (b)) y placa de cristales solapados (figura II.26 (c)).

a)
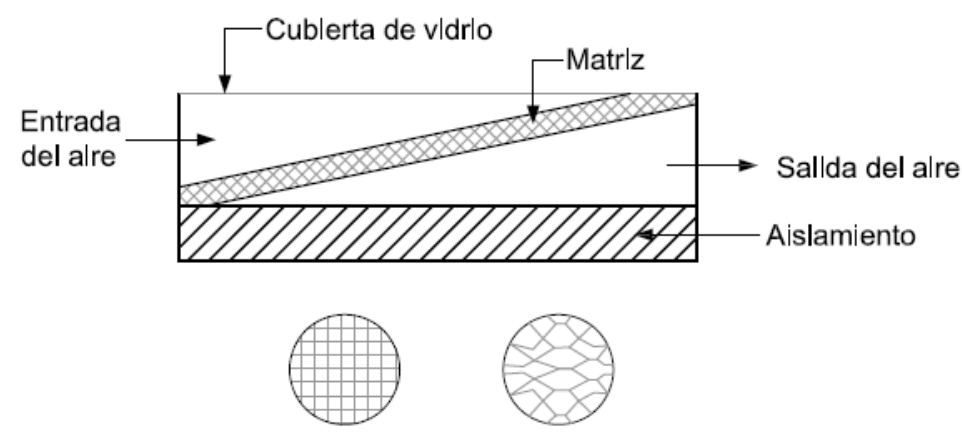

b)

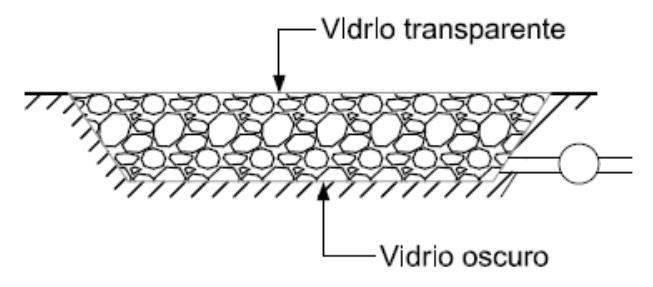

c)

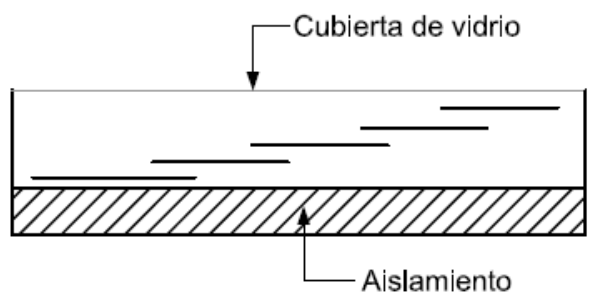

Figura II.26. (a-c).- Esquema de colectores de aire de absorbedor de tipo poroso.

Los materiales porosos son adecuados para su aplicación en intercambiadores de calor de alta temperatura. El incremento de la efectividad del calor intercambiado es debido principalmente al íntimo contacto entre las partículas de gas y la placa porosa.

La figura II.27 (a) muestra esquemáticamente un colector de aire con absorbedor de matriz porosa. El tamaño de la malla y la porosidad dependen de las características requeridas. La superficie superior se comporta como un conjunto de cavidades negras cuya absortividad excede ampliamente de la de la superficie de un sólido regular. La superficie de la matriz también puede ser pintada con adecuados revestimientos para reducir las pérdidas de la radiación de ondas largas. Los mecanismos de intercambio de calor deberían tener alguna de las tres formas mostradas en las Figuras II.27 (a), (b) y (c). La forma de la Figura II.27 (b) es más eficiente, ya que el aire frío al entrar permanece en contacto con la cubierta reduciendo las pérdidas superiores. 

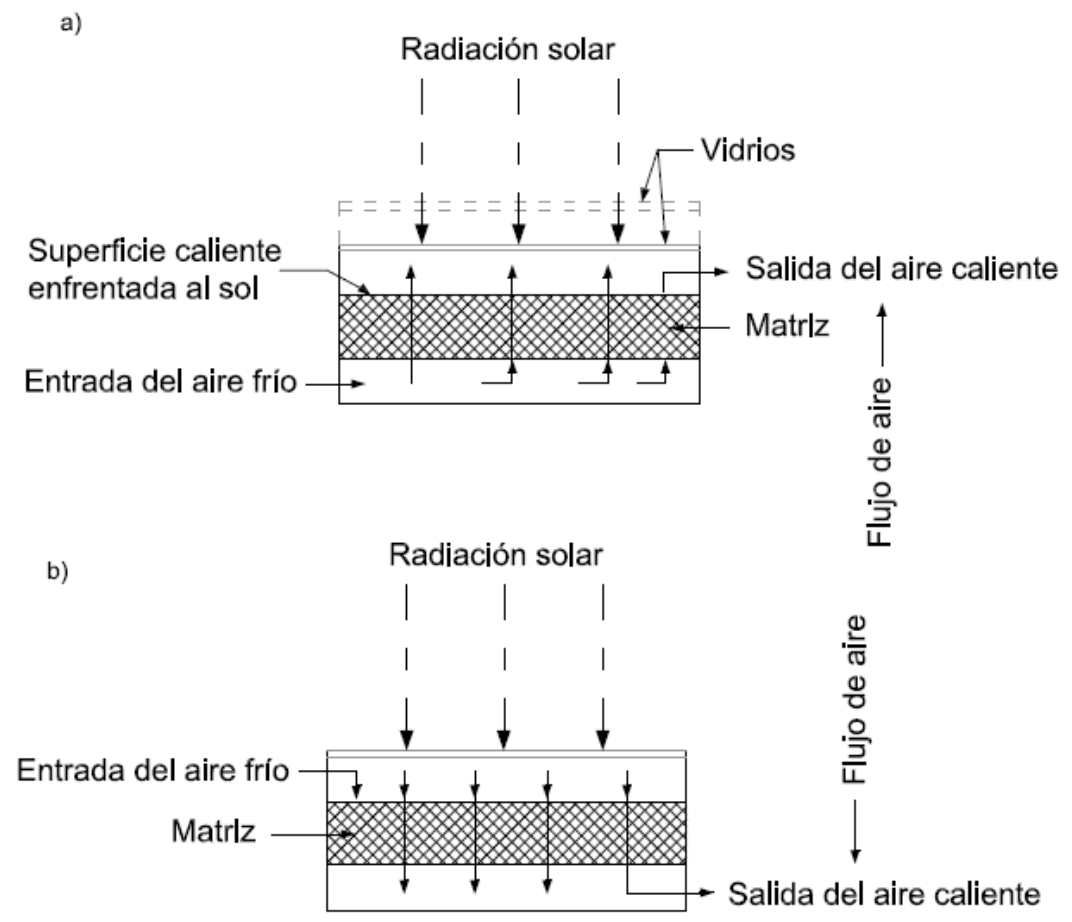

c)

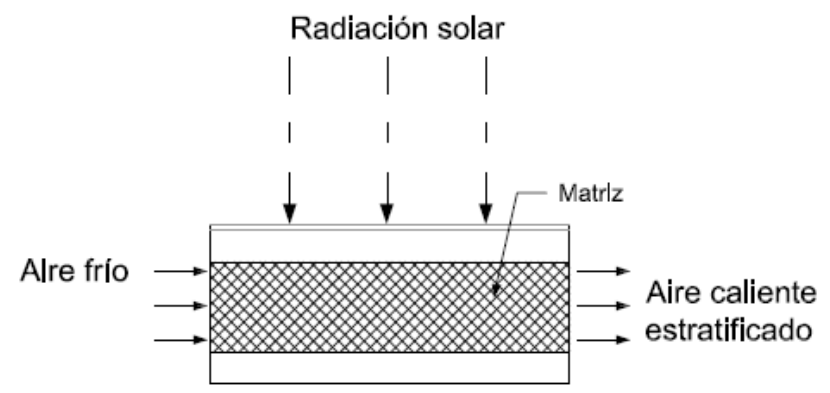

Figura II.27 (a-c).-Esquemas de los colectores de aire de matrices.

Si la matriz es un material semitransparente no muy compacto, entonces la energía solar es absorbida a lo largo de la profundidad de la matriz. En cambio, si es una malla compacta o más cerrada, entonces la mayoría de la absorción se produce en la superficie superior. Un análisis térmico del estado estacionario conlleva las siguientes suposiciones:

- Las propiedades térmicas, físicas y de transporte de la placa matriz y del aire son constantes a lo largo de toda la superficie del colector y no cambian con la temperatura.

- La conducción de calor y la corriente de aire tienen una dimensión y son perpendiculares a la superficie de la matriz. 
- El aire y los poros de la matriz están a la misma temperatura en todas las posiciones del interior de la placa.

- Las pérdidas por radiación y convección se dan lugar solo desde la superficie superior del colector.

Considerando el supuesto de una única dirección del flujo, el análisis puede explicar el comportamiento de los colectores de aire como se muestra en las figuras II.27 (a) y (b); mientras que la Figura II.27 (c) corresponde al estudio bidimensional. La distribución de temperaturas en el estado constante puede determinarse resolviendo la ecuación del balance de calor del colector.

$$
K_{f} \frac{d^{2} T_{f}}{d y^{2}}+\frac{\dot{m} C_{a i r}}{A_{p}} \frac{d T_{f}}{d y}+Q_{i n t}(y)=0
$$

Aquí, $K_{f}$ es la conductividad efectiva en la matriz $(\mathrm{W} / \mathrm{mK}), Q_{\text {int }}$ el ratio de generación de calor interno por unidad de volumen $\left(\mathrm{W} / \mathrm{m}^{3}\right)$ y $A_{p}$ el área de la placa absorbedora, $\mathrm{m}^{2}$. Para una malla compacta (cerrada), la radiación es absorbida en la superficie superior y no se da periodo de generación de calor. Se considera una matriz con superficie superior opaca. Sin embargo, para una matriz no compacta (malla más abierta) semitransparente, la absorción de la energía solar ocurre sucesivamente a lo largo de la profundidad de la matriz, y está caracterizado por un término finito de generación de calor [20].

\section{Materiales empleados en las matrices de los absorbedores.}

La elección del material para la matriz guarda relación directa con el coste del equipo. Cuanto más bajo sea el coste más competitivo será el equipo. Pese a esto, los materiales como metales expandidos o mallas, tales como mosquiteras para ventanas o puertas, coladores, o filtros de grasas de restaurantes no deben de usarse, aunque sean económicos y recurrentes no son adecuados. Tampoco se usan almohadillas de nylon de lana negra. Existen materiales más adecuados como las lanas metálicas de acero al carbono, de acero inoxidable, de bronce y de aluminio, que son las mejores opciones a utilizar. Hay que tener en cuenta, que el acero al carbono se oxida, las lanas, en general, actúan como filtros de polvo y se atascan con el tiempo. Los filtros de polvo pueden usarse como absorbedores de matriz porosa. También el aislamiento de fibra de vidrio ennegrecido se puede usar si es lo suficientemente fino para permitir el paso del aire. 


\section{II.3.2.1.- COLECTORES CON ABSORBEDOR DE PLACAS DE CRISTAL SOLAPADAS.}

Este tipo de colectores consisten en una serie de placas colocadas una sobre la otra. La porción de placa de cristal que se encuentra bajo la placa que la precede (la superior) está ennegrecida mientras que el resto de la placa es transparente (figura II.28). El sistema tiene una cubierta superior de cristal y un fondo aislado; todo el sistema se encuentra dentro de una caja metálica. Debido a la absorción de la radiación solar, las porciones negras de la placa de cristal son calentadas y así el flujo de aire paralelo a estas placas consigue calentarse.

\section{Vidrio transparente}

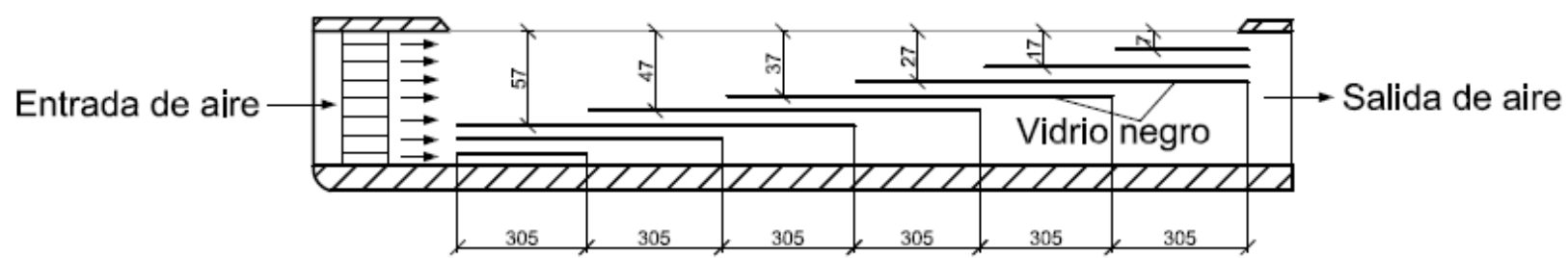

Aislamiento

Figura II.28.- Esquema de un colector de cristales solapados (Selcuk, 1977). Dimensiones en milímetros, placas de cristal de $3 \mathrm{~mm}$ de espesor; ancho de los colectores es $690 \mathrm{~mm}$.

Löf propuso este tipo de colectores en 1950, tiene la ventaja de proporcionar baja pérdida de carga y también alta eficacia para moderados incrementos de temperatura [21]. Sin embargo, la gran cantidad de cristal con que dispone conlleva un incremento del coste de la unidad. Selcuk, realizando el estudio de varios parámetros observó que la variación del espacio entre las placas y el número de placas influye levemente en la eficacia. Una distancia de separación óptima entre las placas está entre 5 y $7 \mathrm{~mm}$, y el espesor del cristal óptimo sobre $3 \mathrm{~mm}$. 


\section{II.3.2.2.- COLECTORES CON EL ABSORBEDOR EN FORMA DE PANEL DE}

\section{ABEJA.}

El uso de las estructuras de panel de abeja entre la cubierta y el absorbedor para reducir las pérdidas superiores por convección es una ventaja reconocida. En la figura II.29 podemos ver la disposición de estos paneles dentro de un colector y el desplazamiento del aire a través de este panel.

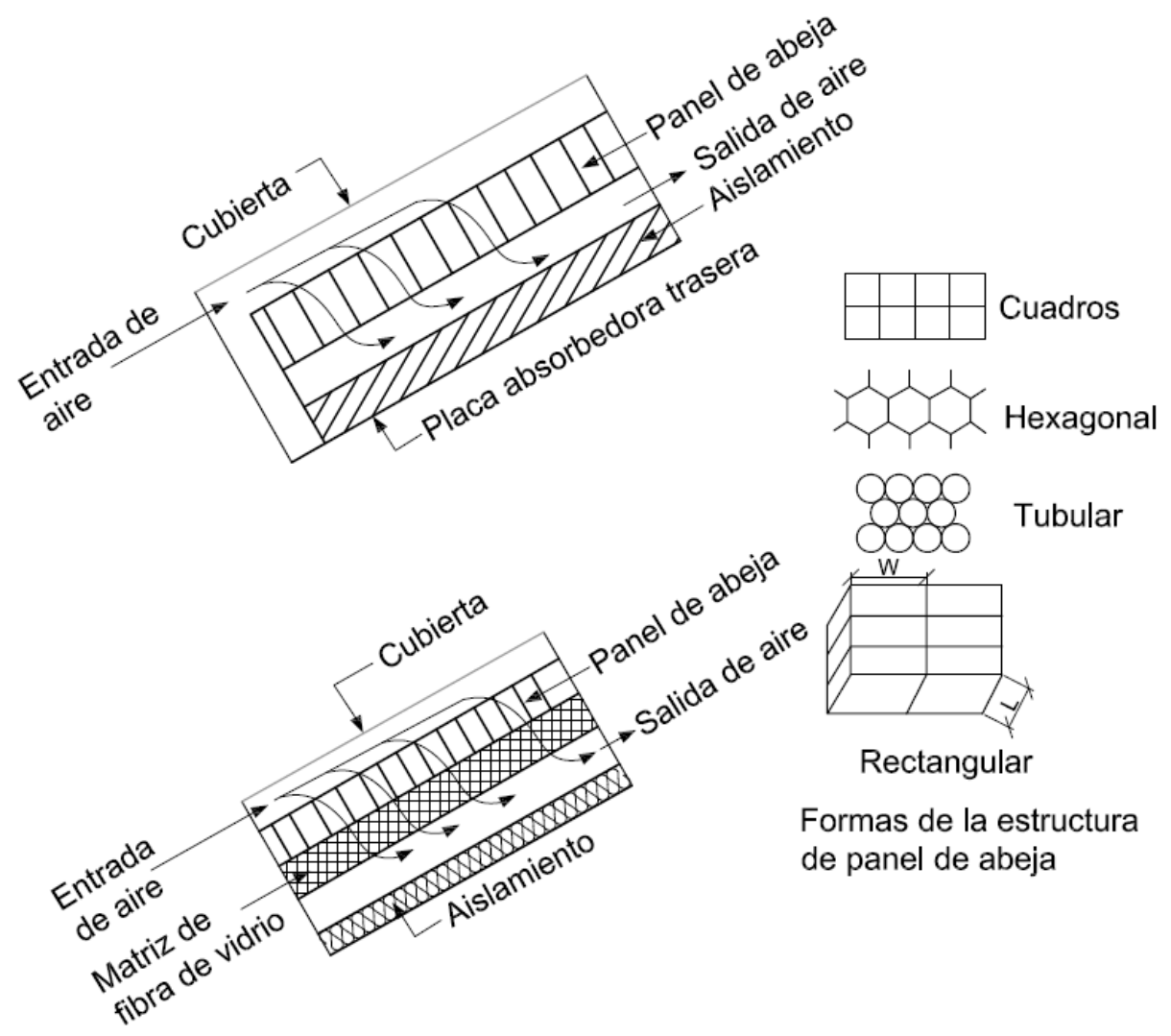

Figura II.29.- Esquema de un colector con colector de panel de abeja transpirable.

El panel de abeja puede ser transparente u opaco, y de forma hexagonal o rectangular. La estructura de panel de abeja puede ser realizada con materiales de matriz porosa para reducir la convección y radiación a la cubierta de cristal. Buchberg et al. hicieron un extenso estudio de las estructuras de panel de abeja y desarrollaron una unidad eficiente con muros reflectantes especulares cubiertos con una fina película de laca. También llevaron a cabo estudios analíticos para predecir el comportamiento de cada colector de aire [22].

La eficacia instantánea, $\eta_{i}$, puede ser calculada como

$$
\eta_{i}=\frac{\dot{m} C_{a i r}\left(T_{f o}-T_{f i}\right)}{A_{p} I(t)}
$$


El valor de $\eta_{i}$ con $\left[\left(T_{f i}-T_{a}\right) / I(t)\right]$ para 7,5 y 10 litros $/ \mathrm{m}^{2}$ s se muestra en la figura II.30. En la figura se ve claramente que el colector es más eficiente con los más altos caudales ensayados. También se observa la mayor eficiencia alcanzada por el colector de agua frente al de aire, esta comparativa se analiza más adelante en el apartado II.5 [23].

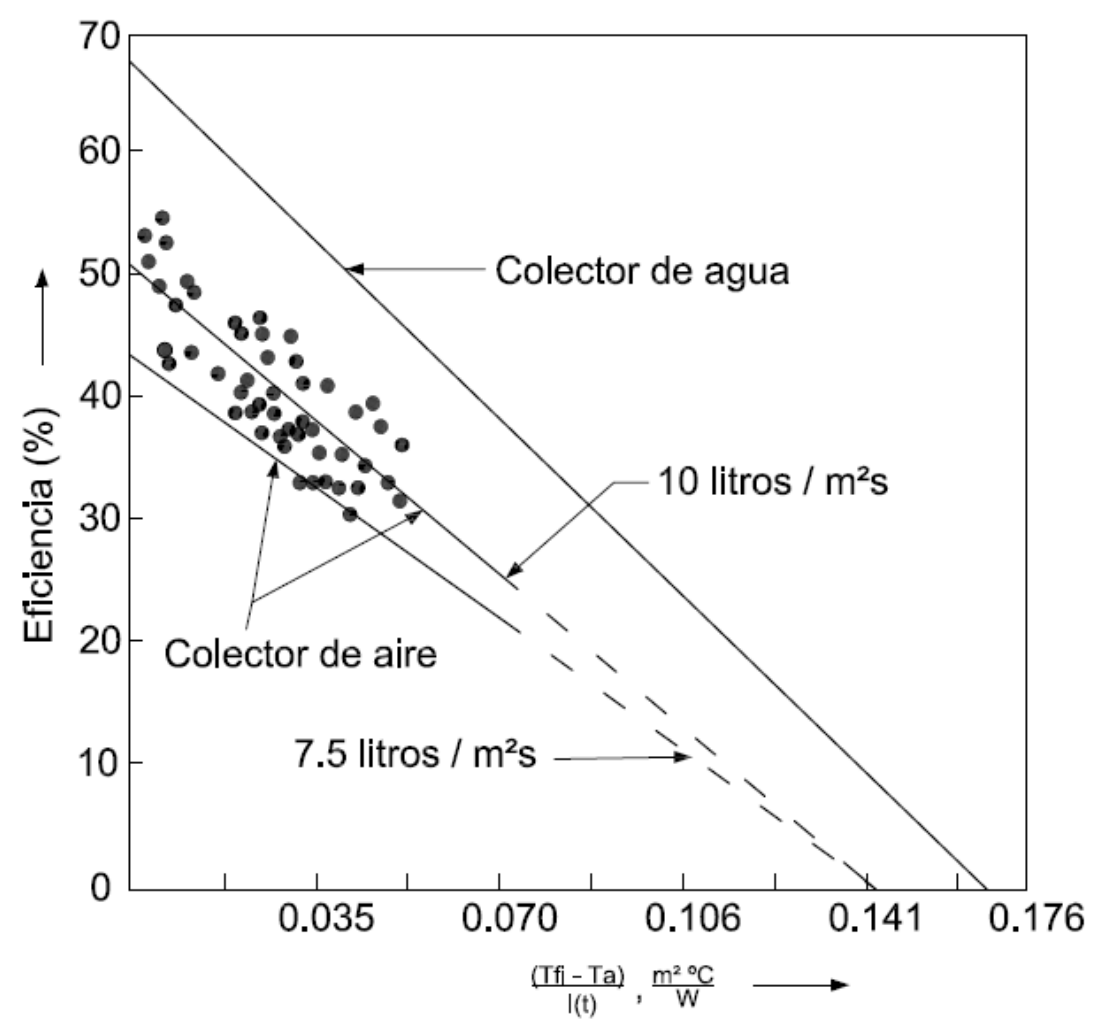

Figura II.30.- Comparación entre un colector líquido y un colector de aire de placas gruesa. 


\section{II.4.- ESTUDIO DE PARÁMETROS.}

\section{II.4.1.- EFECTO DE LAS FUGAS DE AIRE.}

El comportamiento de un colector solar de aire está afectado por las fugas de aire debidas a un inadecuado diseño y fabricación. Pese a que no son tan críticas como en el caso de los colectores de agua conviene minimizarlas. Las fugas de aire también pueden ser debidas a las siguientes razones:

i. La expansión y contracción térmica del aire caliente.

ii. La corrosión.

iii. La vibración producida en los asientos.

iv. Falta de una instalación correcta, etc.

La completa eliminación de las fugas de aire es difícil. La detección y corrección de pequeñas fugas de aire es a menudo ignorada.

La fuga de aire en el colector solar de aire puede ocurrir, desde el interior del colector al ambiente exterior y en el interior del colector entre los diferentes canales de flujo a diferente temperatura absoluta.

La medida del flujo juega un papel importante para evaluar la eficiencia térmica. Si el flujo es medido antes del colector, la eficacia térmica calculada será mayor porque se ignoran las fugas de aire en el colector. En este caso, la eficacia térmica es dada por

$$
\eta_{i}=\frac{\dot{m} C_{a i r} \Delta T}{A_{p} I(t)}
$$

La eficacia térmica calculada será más baja si el flujo es medido después del colector debido a la consideración de las fugas para la misma diferencia de temperatura. Esta opción nos aporta un dato más realista al tener en cuenta el flujo de aire calentado aprovechable.

$$
\eta_{L}=\frac{\dot{m}_{0} C_{a i r} \Delta T}{A_{p} I(t)}
$$

La diferencia entre el flujo antes y después del colector da el flujo de fugas de aire.

$$
\dot{m}_{L}=\dot{m}-\dot{m}_{0}
$$


Un indicador de eficacia es la relación entre la eficacia con fugas $\eta_{i L}$, y la eficacia sin fugas $\eta_{i}$, y es dado por lo siguiente:

a) Si el caudal es medido antes del colector

$$
\frac{\eta_{L}}{\eta_{i}}=1-\frac{\dot{m}_{L}}{\dot{m}}
$$

De la ecuación anterior, uno puede deducir que el indicador es menor a 1 para valores positivos del flujo de masa de fugas. Este indicador tiende a la unidad para flujos de fuga de valor cero.

b) Si el caudal es medido después del colector

$$
\frac{\eta_{L}}{\eta_{i}}=1
$$

Esto significa que el caudal medido es igual antes y después del colector, es decir, no existen fugas en el colector.

\section{II.4.2.- EFECTO DE LAS PARTÍCULAS.}

El comportamiento de un colector solar de aire está afectado por la deposición de polvo y algunas otras partículas que se encuentran en la corriente de aire en los conductos. Hay tres razones principales para que se depositen las partículas en la superficie interior del conducto. Son las siguientes:

a. Las partículas más densas de la corriente de aire no siguen el flujo si hay grandes curvaturas en los conductos del colector, por lo que se produce la deposición de estas partículas en las paredes del conducto,

b. Existe una resistencia al paso del flujo a través del conducto para las partículas de mayor tamaño (fibras de polvo) que se encuentran en el aire,

c. Las partículas de pequeño tamaño en el aire son depositadas en condiciones de flujo laminar debido a la difusión molecular.

Los problemas arriba indicados pueden minimizarse como sigue:

a. Colocando filtros de viscosidad normal a la entrada del conducto,

b. Usando el menor número de giros y curvas en el diseño del conducto, y

c. Deben usarse modos forzados de operación del colector (con altos flujos). 


\section{II.5.- COMPARACIÓN ENTRE EL COMPORTAMIENTO DE UN COLECTOR DE AIRE Y UNO DE AGUA.}

Existen diferencias ya mencionadas entre los colectores solares de aire y agua, como son:

- La presión en el interior de los colectores de aire es considerablemente más baja que en los de agua.

- En los colectores de agua se pueden dar problemas de corrosiones en algunos elementos, mientras que en los de aire no existe este problema.

- Los problemas por congelación del fluido que se pueden dar en los de agua, en los de aire no existen (a priori).

- Las propiedades de transferencia de calor del agua son más adecuadas que las del aire, la baja densidad del aire obliga trabajar con mayores volúmenes de aire. Frente a esto, empleando aire evitamos tener que transferir el calor de un fluido a otro (si el objetivo es tratar aire de ventilación, secar, etc.).

- Como ya se ha visto, las fugas de aire desde los conductos no suponen un problema importante. En los de agua no pueden existir.

- El aire, debido a su baja capacidad térmica, no puede ser usado como fluido de almacenamiento. El agua se emplea con este fin en las instalaciones.

La comparación entre un colector de aire de placa plana y un colector de agua se muestra en la Figura II.37 del apartado II.3.2.2. El comportamiento del colector de aire ha sido representado para dos caudales de aire. Puede observarse que el caudal de aire juega un importante y significativo papel en la eficiencia del colector de aire. Además, uno puede observar que la diferencia entre el comportamiento de ambos colectores se minimiza a altas intensidades de radiación solar. 


\section{II.6.- APLICACIONES DEL COLECTOR SOLAR DE AIRE}

Es técnicamente viable usar colectores solares de aire para proporcionar energía en casi cualquier aplicación en la que se use colectores solares de líquidos.

Las más importantes áreas de aplicación son las siguientes:

a. Climatización y acondicionamiento de edificios.

b. Calentamiento de invernaderos, y

c. Procesos industriales tales como secado de cosechas agrícolas y de madera.

\section{II.6.1.- CLIMATIZACIÓN Y ACONDICIONAMIENTO DE EDIFICIOS.}

Actualmente la aplicación fundamental de los colectores solares de aire en edificación es su utilización para el calentamiento o precalentamiento del aire de ventilación en invierno, y la cobertura total o parcial de las demandas de calefacción. Las exigencias de salubridad y de calidad de los ambientes interiores de los edificios implican un importante consumo energético asociado al tratamiento de este aire limpio a incorporar a los espacios ocupados. En aplicaciones de calefacción por aire el calentamiento del aire es directo en el colector, y en sistemas de calefacción por agua o mixtos el agua puede ser calentado a través de un intercambiador aire- agua.

El calor procedente de los colectores de aire también puede ser usado para enfriar, alimentando con aire caliente a una máquina de absorción que produce frío, aplicación de gran interés que permite un mayor aprovechamiento de los colectores y elimina la limitación estacional del empleo específico para calefacción.

Uno de los objetivos de esta tesis doctoral es optimizar el uso de los C.T.S. de aire, para ello se proponen alternativas para la eliminación de la estacionalidad de uso del colector y el aprovechamiento en el periodo estival, este estudio se presenta en el capítulo VII.

\section{II.6.2.- SECADO.}

El secado es una prometedora área para la aplicación de los colectores de aire. Ha sido la aplicación más antigua y ampliamente usada de la energía solar a lo largo de la historia. El método básicamente ha consistido en el secado a cielo abierto, al aire. 
En esta aplicación, el aire caliente procedente del colector solar se hace circular a través de los granos para reducir su contenido de humedad. El aire puede circular impulsado por un ventilador o por convección natural; por lo que los colectores se denominan secadores activos o pasivos. El principio del modo de funcionamiento de secado se muestra esquemáticamente en la figura II.31. En este diseño, el aire templado pasa a través del colector de aire y entra a continuación en la cámara de secado.

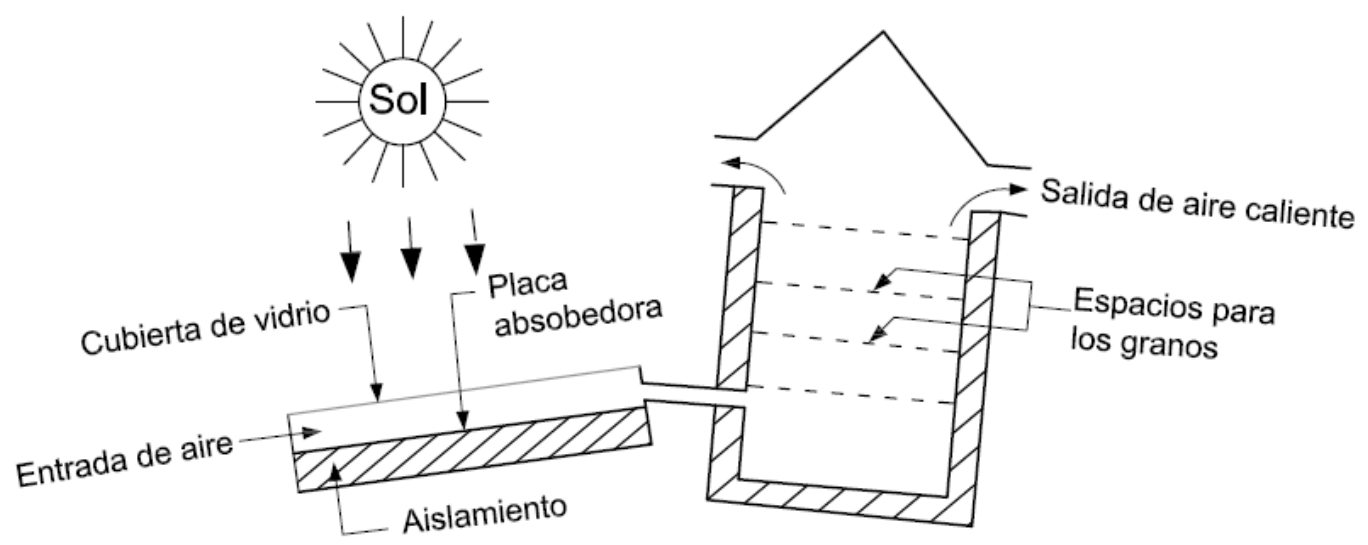

Figura II.31.- Vista esquemática de un secador de grano indirecto.

Dependiendo del modo de circulación del aire se pueden realizar diferentes diseños. La Figura II.32 muestra uno de tantos diseños en los que el aire ambiente es calentado y empujado al interior de la cámara por convección natural. El aire caliente arrastra la humedad de los granos o semillas, enfriándose y cayendo al fondo de la cámara de secado. Jamones, cosechas de diferentes cereales u otros productos pueden ser secados por este método [24].

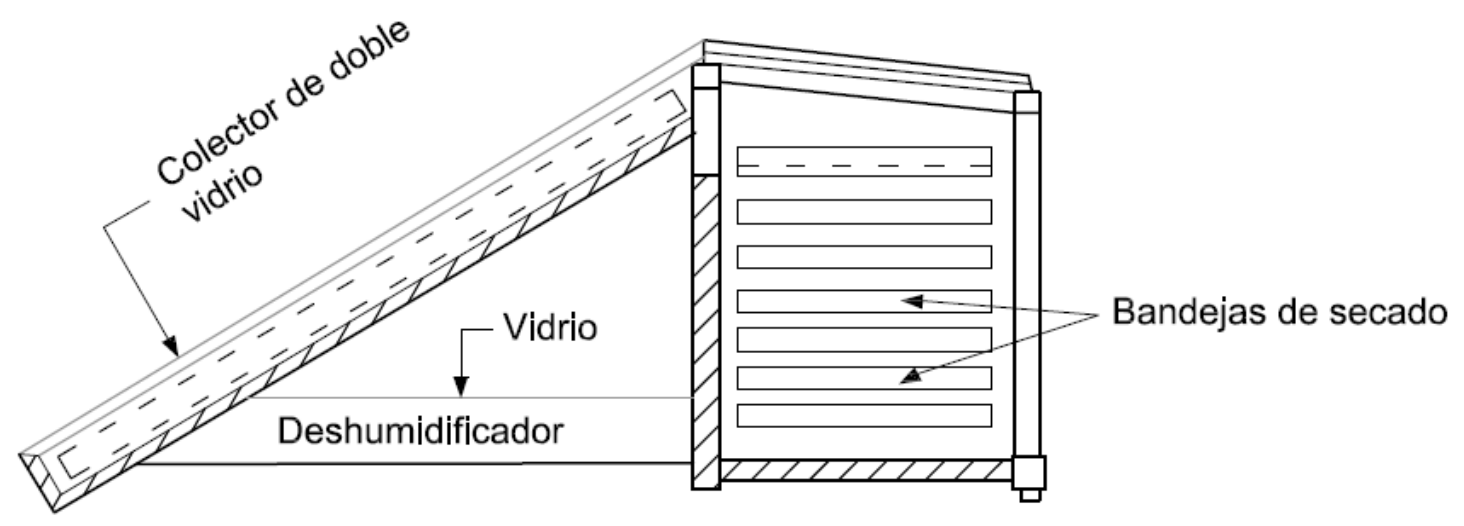

Figura II.32.- Esquema de un secador indirecto de grano. 
La figura II.33 muestra un colector de aire de dos pasos conectado a una cámara de secado. El aire pasa a través de los granos e inmediatamente después de atravesar el colector. En este colector no sería imprescindible el aislamiento [16].

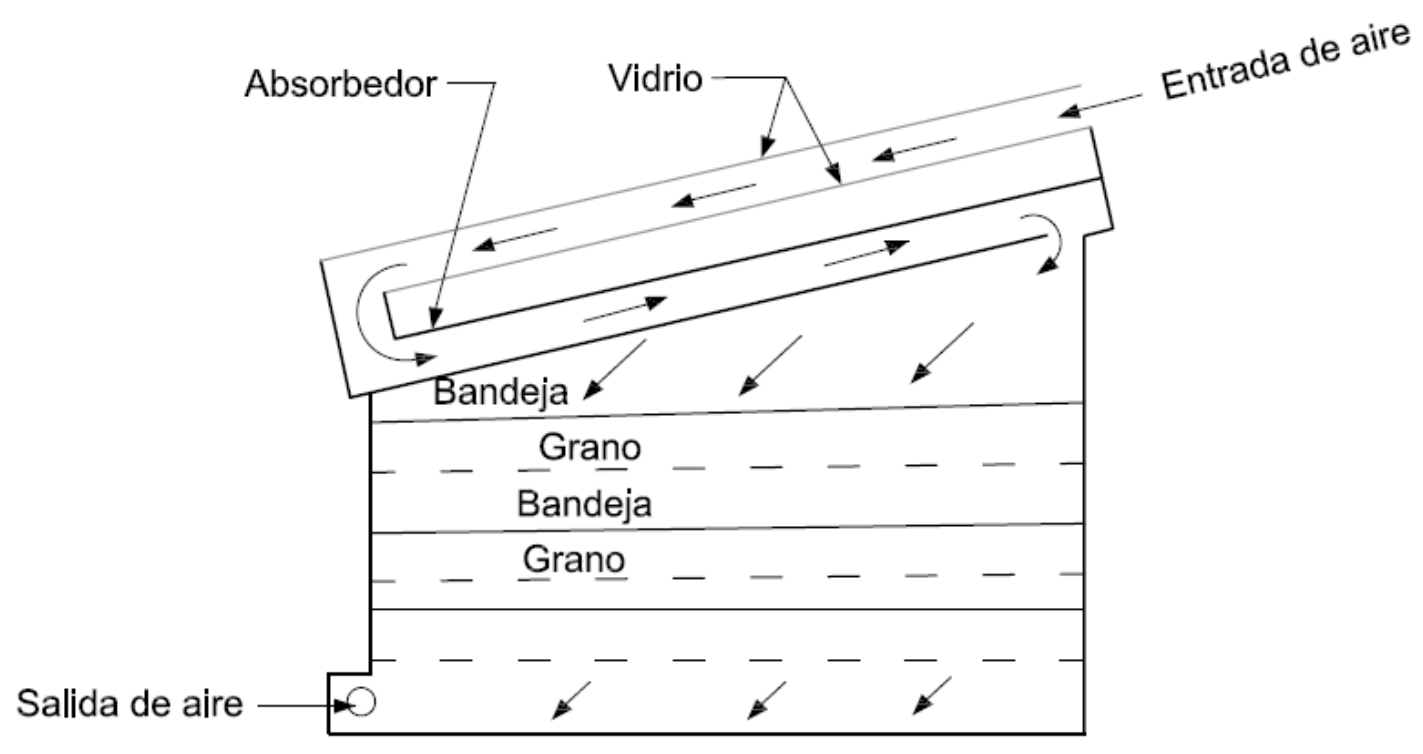

Figura II.33.- Esquema de un colector de aire de dos pasos conectado a una cámara de secado.

En lugar de usar ventiladores mecánicos, se puede emplear circulación natural del aire empleando el efecto chimenea, que induce una corriente de aire con suficiente caudal para atravesar el colector y los granos a secar. 


\section{II.7.- COMERCIALIZACIÓN DEL COLECTOR SOLAR DE}

\section{AIRE}

Algunos de los colectores solares de aire que podemos encontrar en el mercado actual son los siguientes:

TWINSOLAR - TOPSOLAR - JUMBO SOLAR (GRAMMER SOLAR). Alemania. [W-1]

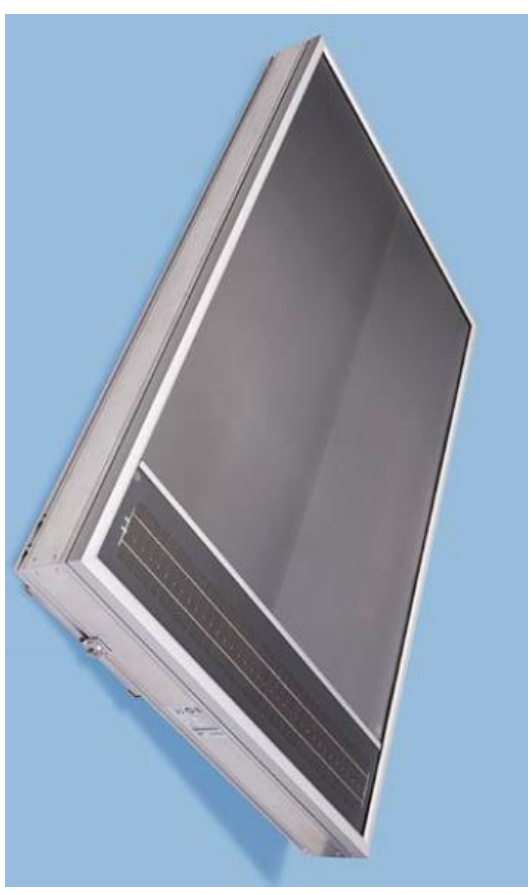

Figura II.34.- Vista del TWINSOLAR.

\section{TWINSOLAR - TOPSOLAR.-}

ESPECIFICACIONES:

-Tamaño de colectores: Desde 1,3 $\mathrm{m}^{2}$ a $1,5 \mathrm{~m}^{2}$.

-Peso de colector: de 29 a $290 \mathrm{~kg}$.

-Carcasa de aluminio.

-Vidrio de seguridad de $4 \mathrm{~mm}$.

-Absorbedor de aluminio.

-Aislamiento de fibra de vidrio $(60 \mathrm{~mm})$.

-Ventilador radial externo a partir del modelo 4.0.

-Filtros de aire integrados.

-Módulo fotovoltaico integrado de generación de la corriente eléctrica necesaria para el ventilador.

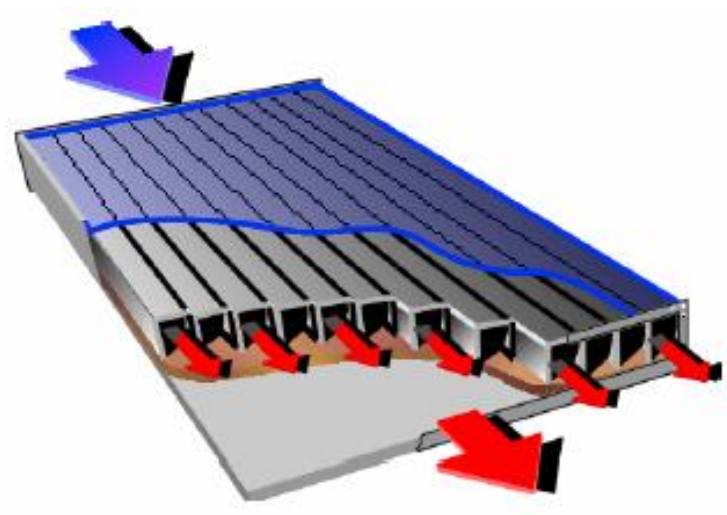

Fuente: GRAMMER SOLAR.

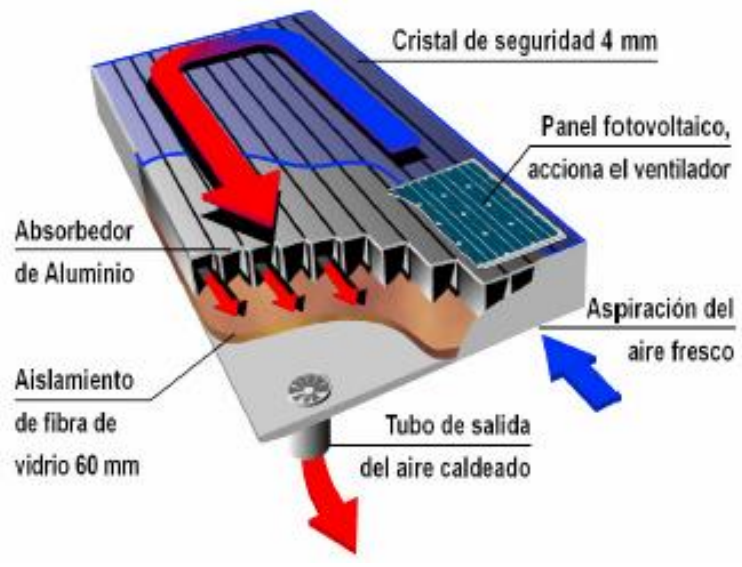

Figura II.35.- Esquema de diferentes modelos del TWINSOLAR. Fuente: GRAMMER SOLAR. 
SOLARSHEAT (YOUR SOLAR HOME). Canada. [W-2]

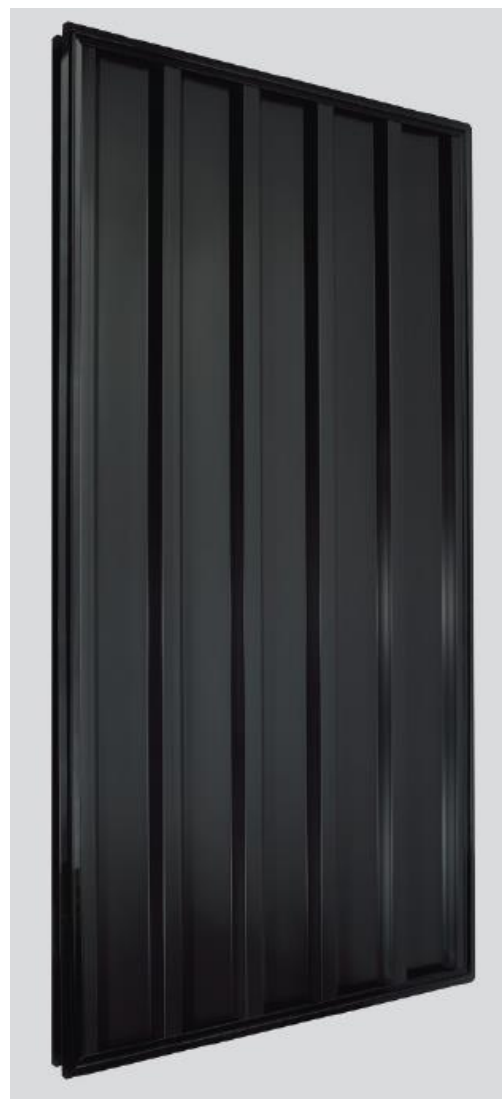

Figura II.36.- Vista del SOLARSHEAT 1500GS. Fuente: YOUR SOLAR HOME.

\section{ESPECIFICACIONES:}

- 20400 BTU/día (día claro, soleado)

- 6 MJ (SRCC, día ligeramente cubierto, categoría C)

- Superficie calefactada: $70 \mathrm{~m}^{2}$

- Dimensiones $221 \times 109,6 \times 9,7 \mathrm{~cm}$

- Superficie: $2,4 \mathrm{~m}^{2}$

- Peso: 42,6 kg

Carpintería de aluminio

- Chapa de aluminio corrugado perforada o no perforada

- Vidrio templado.

- Aislamiento de poliisocianurato.

- Funcionamiento automático mediante termostato.

- Potencia (ventilador) Solar fotovoltaica 14,5 W

- Diferencia $T^{\mathrm{a}} \underline{\mathrm{a}}$ entrada/salida $20^{\circ} \mathrm{C}-40^{\circ} \mathrm{C}$. 
SOLAR MAX 240 (CANSOLAIR). Canada. [W-3]

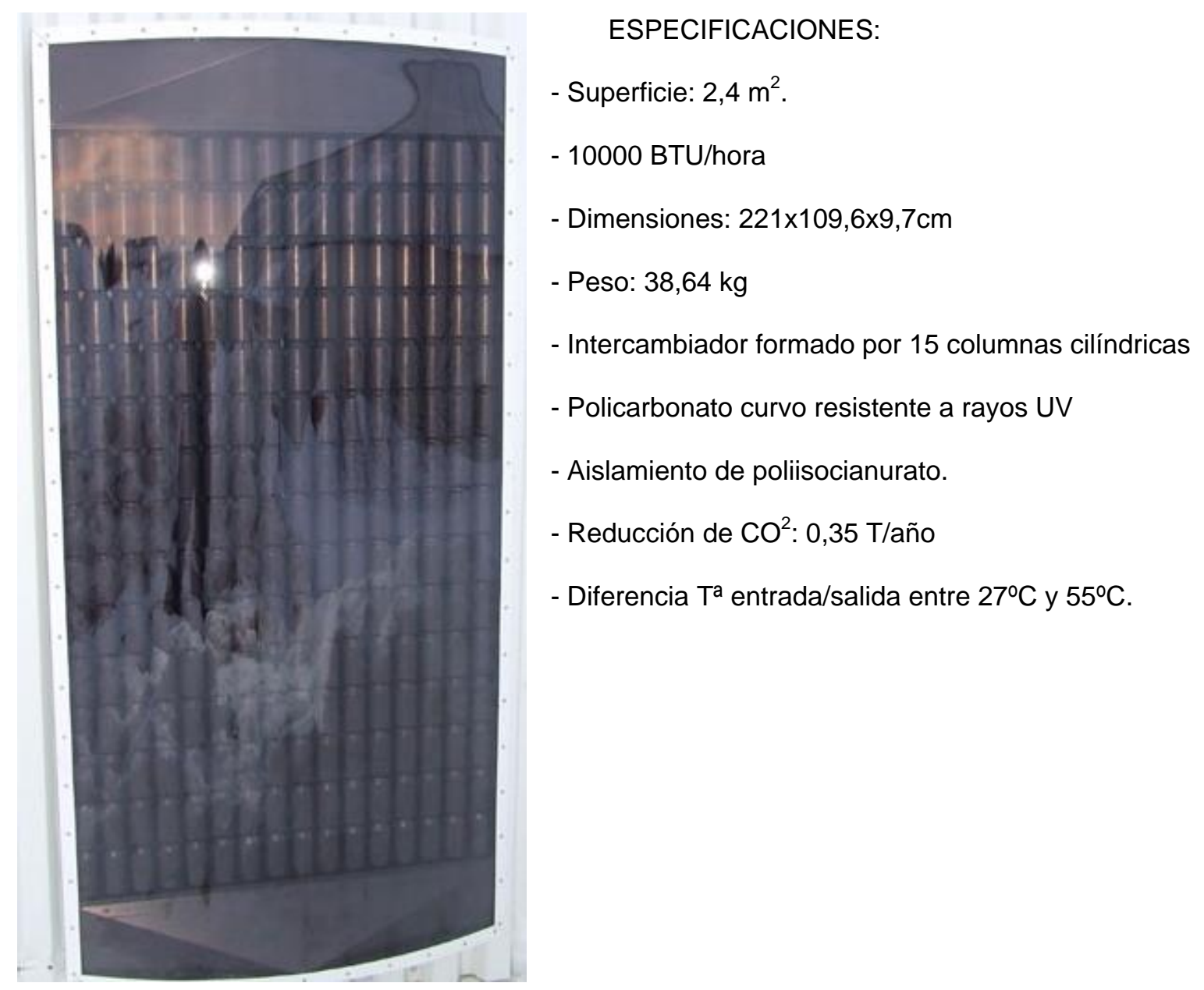

Figura II.37.- Vista del SOLAR MAX 240 RA 1500GS. Fuente: CANSOLAIR. 
KW-ECOAIR (KW SOLAR). España. [W-4]

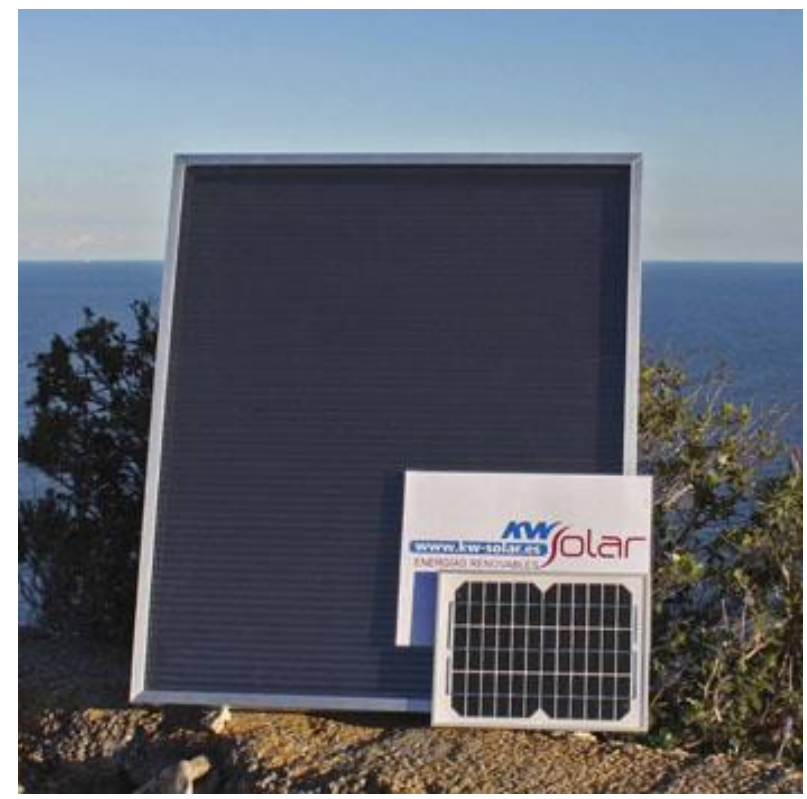

ESPECIFICACIONES (KW-Ecoair 220):

- Superficie: $1,54 \mathrm{~m}^{2}$.

- Tamaño: 2200 × 700 x 60 mm

-Superficie a acondicionar: $40-70 \mathrm{~m}^{2}$.

- Placa fotovoltaica: $5 \mathrm{~W}$.

- Potencia ventilador: $3 \mathrm{~W}$.

- Placa absorbedora: Aluminio.

- Panel frontal: policarbonato.

Figura II.38.- Vista del KW- Ecoair 60. Fuente:

KW Solar.

SV30AX (SolarVenti). Dinamarca. [W-5]

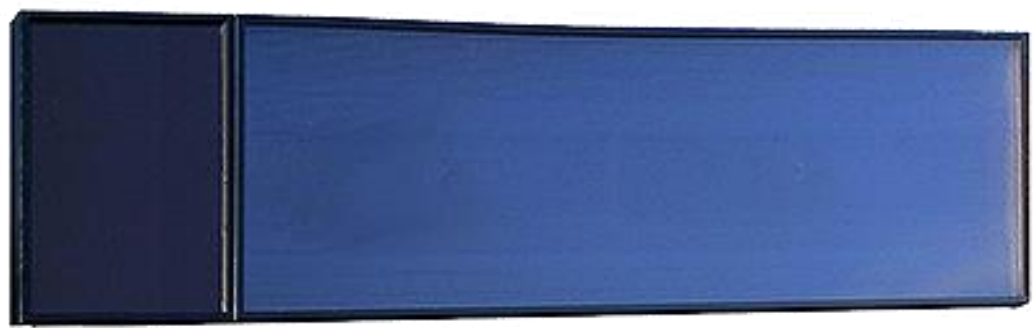

Figura II.39.- SV30AX Aire. Fuente: Solar Venti.

\section{ESPECIFICACIONES:}

-Dimensiones panel SV30AX: 341,5 x 102

$x 7,5 \mathrm{~cm}$

-Peso panel SV30AX: 25,5 kg

-Marco: Aluminio (Calidad 6000)

-Captador: Fieltro especial (negro)
-Posterior: Aluminio perforado

-Panel Fotovoltaico:

-Voltaje: 12 V; Potencia: 38 W

-Ventilador: Consumo: 5,1 Wh

-Potencia nominal: $230 \mathrm{~m}^{3} /$ hora. 
SUN LIZARD (ALTERNATIVE FUELS AND ENERGY). Australia. [W-6]

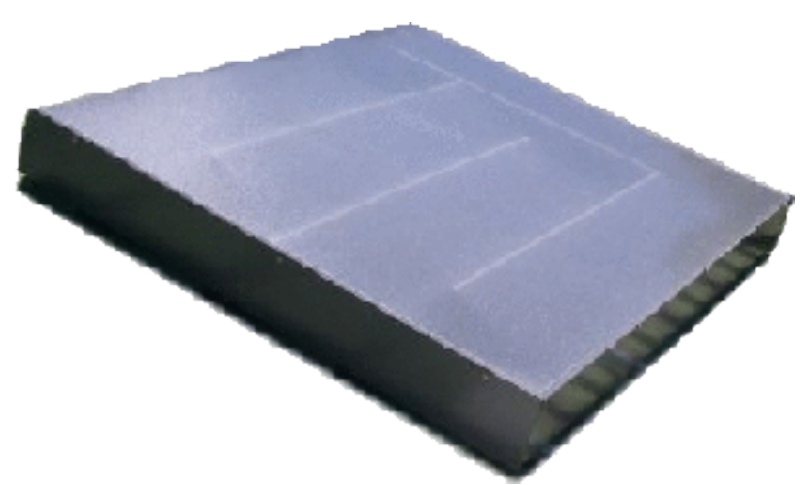

ESPECIFICACIONES:

- Dimensiones: 152x122x12cm

- Peso: $60 \mathrm{~kg}$

- Recorrido sinuoso del aire.

- Vidrio solar templado.

- Deflectores angulados.

Figura II.40.- Vista del Sun Lizard Solar

Collector. Fuente: Sun Lizard.

SOLAR DUCT (SOLAR WALL). Conserval Engineering Inc. Canadá. [W-7]

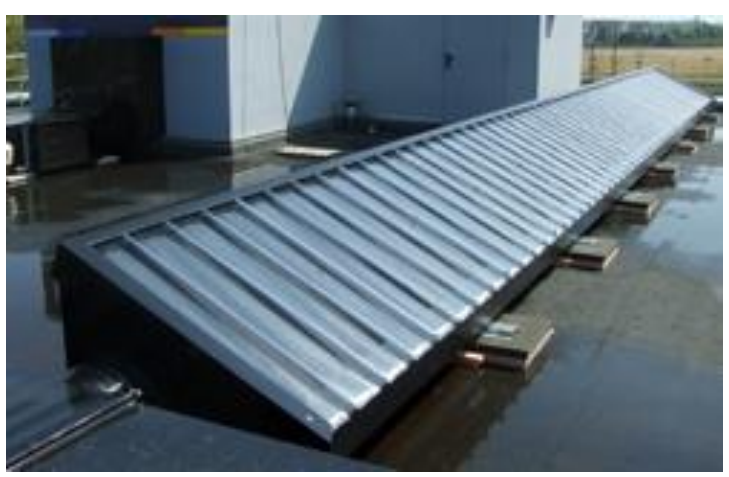

\section{ESPECIFICACIONES:}

- Unidades modulares.

- Entramados de longitud típica de 14,63 m

(8 unidades) y suministrará hasta 56,63

$\mathrm{m}^{3} / \mathrm{min}$ de aire caliente para ventilación y 8 kW de calefacción.

Figura II.41.- Solar Duct. Fuente: Sun Lizard. 
SUNMATE (ENVIROMENTAL SOLAR SYSTEMS). USA. [W-8]

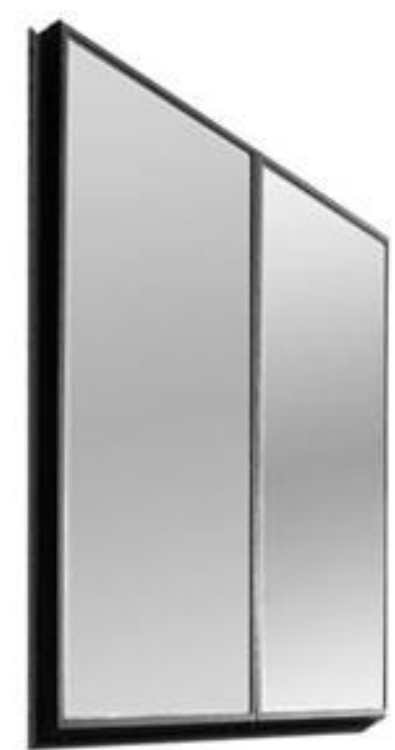

\section{ESPECIFICACIONES:}

- Peso: 90 libras.

- Dimensiones: 4" x 35" x 77"

- Bastidor de aluminio extruido.

- Aislamiento de poliisocianurato.

- Intercambiador de calor de aluminio corrugado con recubrimiento negro selectivo.

- Vidrio solar templado.

Figura II.42.- SunMate. Fuente: Enviromental Solar Systems. 
REFERENCIAS

[1] F. Mauthner, W. Weiss, M. Spörk-Dür, Solar Heat Worldwide. Markets and Contribution to the Energy Supply 2014, (2016).

[2] A.F. Tzikopoulos, M.C. Karatza, J.A. Paravantis, Modeling energy efficiency of bioclimatic buildings, Energy Build. 37 (2005) 529-544. doi:10.1016/j.enbuild.2004.09.002.

[3] K. Butti, J. Perlin, "A golden thread: 2500 years of solar architecture and technology," 1981. doi:10.1016/0301-4215(81)90191-9.

[4] M.K. Singh, S. Mahapatra, S.K. Atreya, Bioclimatism and vernacular architecture of northeast India, Build. Environ. 44 (2009) 878-888. doi:10.1016/j.buildenv.2008.06.008.

[5] M.K. Singh, S. Mahapatra, S.K. Atreya, Solar passive features in vernacular architecture of North-East India, Sol. Energy. 85 (2011) 2011-2022. doi:10.1016/j.solener.2011.05.009.

[6] J. Bouillot, Climatic design of vernacular housing in different provinces of China, J. Environ. Manage. 87 (2008) 287-299. doi:10.1016/j.jenvman.2006.10.029.

[7] F. Robert, J.L. Peube, T. F., Experimental Study of Passive Air-Cooled Flat-Plate Solar Collectors: Characteristics and Working Balance in the Odeillo Solar Houses, in: Energy Convers. Heat. Cool. Vent. Build., Hemisphere, Washington, 1978: p. Vol.2, 761-782.

[8] V. V. Tyagi, N.L. Panwar, N.A. Rahim, R. Kothari, Review on solar air heating system with and without thermal energy storage system, Renew. Sustain. Energy Rev. 16 (2012) 22892303. doi:10.1016/j.rser.2011.12.005.

[9] A. Whillier, Performance of Black-Painted Solar Air Heaters of Conventional Design, Sol. Energy. 8 (1964) 31-37.

[10] M.A.S. Malik, F.H. Buelow, HYDRODYNAMIC AND HEAT TRANSFER CHARACTERISTICS OF A HEATED AIR DUCT, 2 (1976).

[11] M.K. Selcuk, Solar air heaters and their applications, Sol. Energy Eng. (A78-27852 10-44). (1977) 155-182.

[12] M.S. Sodha, N.K. Bansal, D. Singh, Analysis of a Non-porous double flow solar air heater, Appl. Energy. 12 (1982) 251-258.

[13] B.F. Parker, Derivation of efficiency and loss factors for solar air heaters, Sol. Energy. 26 (1981) 27-32. doi:10.1016/0038-092X(81)90108-0.

[14] V. Ranjan, N.K. Dhiman, G.N. Tiwari, PERFORMANCE OF SUSPENDED FLAT PLATE, Energy Convers. Mgmt. 23 (1983) 211-215.

[15] N.E. Wijeysundera, L.L. Ah, L.E. Tjioe, Thermal performance study of two-pass solar air heaters, Sol. Energy. 28 (1982) 363-370. doi:10.1016/0038-092X(82)90253-5.

[16] S. Satcunanathan, S. Deonarine, A two-pass solar air heater, Sol. Energy. 15 (1973) 41-49. doi:10.1016/0038-092X(73)90004-2.

[17] T.M. Kuzay, M.A.S. Malik, K.W. Boer, Solar Collectors of Solar One, Proc. Work. Sol. 
Collect. Heat. Cool. Builidings. 99 (1974).

[18] K.G.T. Hollands, DIMENSIONAL RELATIONS FOR FREE CONVECTIVE HEAT TRANSFER IN FLAT-PLATE COLLECTORS, (1978).

[19] R. Chandra, M.S. Sodha, Testing procedures for solar air heaters: A review, Energy Convers. Manag. 32 (1991) 11-33. doi:10.1016/0196-8904(91)90139-A.

[20] M. a. Al-Nimr, Transient behaviour of a matrix solar air heater, Energy Convers. Manag. 34 (1993) 649-656. doi:10.1016/0196-8904(93)90099-V.

[21] G.O.G. Löf, Performance of solar energy collectors of overlapped glass plate type, Sp. Heat. by Sol. Energy. MIT (1950) 72-83.

[22] H. Buchberg, O.A. Lalude, D.K. Edwards, Performance characteristics of rectangular honeycomb solar-thermal converters, Sol. Energy. 13 (1971) 193-221. doi:10.1016/0038092X(71)90003-X.

[23] F. Kreilh, J.F. Kreider, Non concentrating solar collectors, in: Sol. Energy Handb., McGrawHill, New York, 1981.

[24] O.S.C. Headley, B.G.F. Springer, Natural convection dryer, A Survey of Solar Agriculture Driers, in: Brace Res. Inst. Tech. Rep. No. T-99, CS/EC/N-1, 1975.

\section{PÁGINAS WEB.}

[W-1] GRAMMER SOLAR. Gama de productos de aire solar. http://www.grammersolar.com/cms/es.html (Día de consulta: 26 Junio 2017).

[W-2] YOUR SOLAR SHEAT. Productos. http://www.yoursolarhome.com// (Día de consulta: 26 junio 2017).

[W-3] CANSOLAIR. http://www.cansolair.com/index.php (Día de consulta: 26 junio 2017).

[W-4] KW SOLAR http://www.kw-solar.es/?Inicio (Día de consulta: 26 de junio de 2017).

[W-5] SOLAR VENTI http://www.solarventi.com/index.php (Día de consulta: 26 de junio de 2017).

[W-6] SUN LIZARD http://www.sunlizard.com.au/ (Día de consulta: 26 de junio de 2017).

[W-7] SOLAR WALL http://solarwall.com/es/inicio.php (Día de consulta 26 de junio de 2017)

[W-8] SUNMATE http://sunmatesolarpanels.com/ (Día de consulta 26 de junio de 2017) 
CAPÍTULO II: COLECTORES TÉRMICOS SOLARES DE AIRE 


\section{PARTE II:}

CARACTERIZACIÓN

EXPERIMENTAL DE LOS

C.T.S. DE AIRE

\section{CAPÍTULO III:}

BANCO EXPERIMENTAL DE ENSAYOS DE UN C.T.S. DE AIRE.

\section{CAPÍTULO IV:}

CARACTERIZACIÓN DE LOS C.T.S. DE AIRE:

RESULTADOS

EXPERIMENTALES

\section{CAPÍTULO V:}

SIMULACIÓN

ENERGÉTICA DE LOS

C.T.S. DE AIRE. 


\section{CAPÍTULO III.- \\ BANCO EXPERIMENTAL \\ DE ENSAYOS DE UN C.T.S. DE AIRE.}

\section{CONTENIDOS DEL CAPÍTULO:}

III.1.- DESCRIPCIÓN DE LA INSTALACIÓN EXPERIMENTAL......................... 141

III.2.- ELEMENTOS DEL BANCO DE ENSAYOS........................................ 142

III.2.1.- UNIDAD DE TRATAMIENTO DE AIRE (UTA). .......................................142

III.2.2.- BATERÍA DE LÁMPARAS INCANDESCENTES HALÓGENAS. ....................146

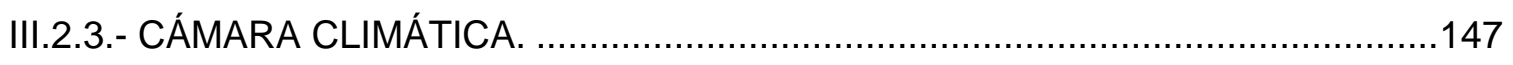

III.2.4.- SISTEMA DE DISTRIBUCIÓN DE AIRE. ...................................................149

III.3.- ELEMENTOS DE MEDIDA Y REGISTRO. .......................................... 152

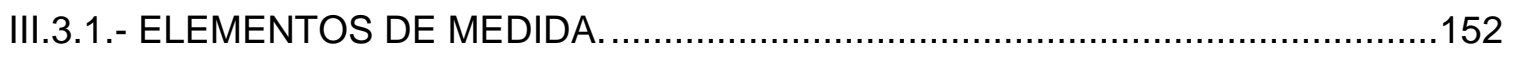

III.3.2.- SISTEMA DE ADQUISICIÓN Y SOFTWARE DE MONITORIZACIÓN DE

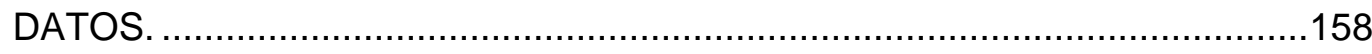

III.3.3.- CALIBRACIÓN Y ERRORES DE MEDIDA. ………..................................159

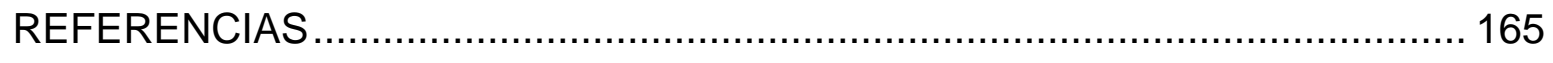

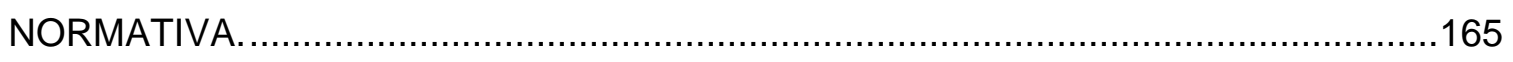

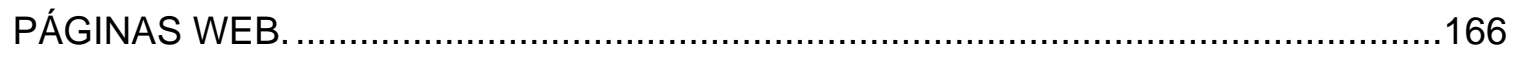


CAPÍTULO III: BANCO DE ENSAYOS 


\section{LISTA DE FIGURAS:}

Figura III.1.- Vista esquemática de la instalación con los diferentes dispositivos........................ 141

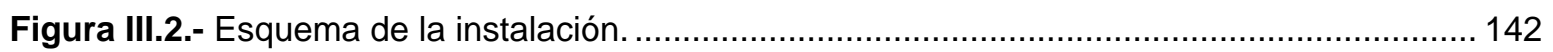

Figura III.3.- Unidad de tratamiento de aire TROX modelo TKM-30 .......................................... 143

Figura III.4.- Izqda.: Ventilador SODECA. Drcha.: Variador de frecuencia TELEMECANIC ......... 144

Figura III.5.- Izqda: Unidad exterior de la bomba de calor de la UTA. Centro: Intercambiador de la

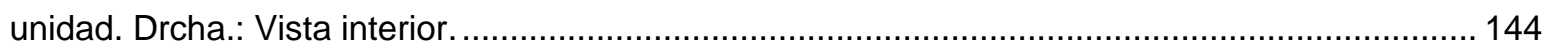

Figura III.6.- Humidificador por electrodos sumergidos, modelo HumiSteam X-Plus de la casa CAREL

Figura III.7.- Izqda.: Estructura portante de los focos. Drcha.: Foco con lámpara halógena empleado.

Figura III.8.- Vista de la cámara climática del laboratorio.

Figura III.9.- Izqda.: Unidad exterior de la bomba de calor. Drcha.: Unidad interior de la BC...... 148

Figura III.10.- Ventilador de extracción de aire de la cámara.

Figura III.11.- Izqda.: detalle de un conducto de aire flexible de $250 \mathrm{~mm}$ de diámetro. Drcha.:

Conducto de aire flexible de $160 \mathrm{~mm}$ de diámetro conectado a la salida del colector. 150

Figura III.12.- Vista del plénum de distribución conectado a la UTA

Figura III.13.- Vista de la conexión del plénum de distribución a la cámara climática. 151

Figura III.14.- Caja de mezcla y/o paso. 152

Figura III.15.- Sonda cerámica de temperatura...................................................................... 153

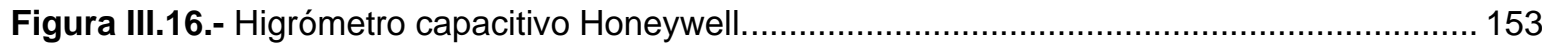

Figura III.17.- Vista de una de las placas orificio empleadas.................................................. 154

Figura III.18.- Sensores de medida de presión diferencial manométrica utilizados...................... 154

Figura III.19.- Curva de caudales medidos en la placa №1 …................................................ 155

Figura III.20.- Esquema general de un piranómetro óptico...................................................... 156

Figura III.21.- Imagen del piranómetro óptico. .................................................................... 158

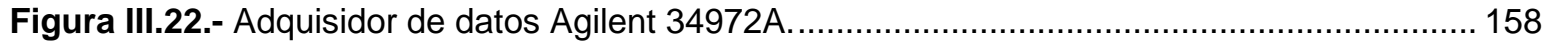

Figura III.23.- Horno de calibración FLUKE 9103. ............................................................... 160

Figura III.24.- Regresión de la calibración de la sonda de temperatura T6 ................................. 161 
Figura III.25.- Esquema del dispositivo de calibración de las sondas de humedad relativa, y sonda TESTO utilizada de patrón de referencia (derecha). 161

Figura III.26.- Regresión obtenida en la calibración de la sonda de humedad relativa №3. 162

Figura III.27.- Tobera de referencia para la calibración de las placas, a la drcha. montada en conducto. 163

Figura III.28.- Esquema de la instalación de la tobera para la calibración. 163

Figura III.29.- Placa orificio y gráfica de calibración obtenida para la misma. 164

Figura III.30.- Rectas de calibración de los manómetros de presión 164

\section{LISTA DE TABLAS:}

Tabla III.1.- Regresiones de las rectas de calibración de las sondas de temperatura. 160

Tabla III.2.- Regresiones de las rectas de calibración de las sondas de humedad relativa. 162 


\section{III.1.- DESCRIPCIÓN DE LA INSTALACIÓN EXPERIMENTAL.}

En este capítulo se define el banco de ensayos necesario para la caracterización de los colectores térmicos solares de aire objeto de esta tesis, y que está compuesto por el colector solar de aire (CTS), una serie de elementos auxiliares necesarios y unos dispositivos de medida y registro.

La no disponibilidad de un espacio exterior con unas características adecuadas para localizar el colector solar de aire y la necesidad de disponer de diferentes condiciones de operación derivadas de diferentes condiciones climáticas, obligaron a instalar el banco de ensayos íntegramente en el interior del laboratorio de calor y frío de la Escuela de Ingenierías Industriales en la Sede de Paseo del Cauce, simulando estas condiciones necesarias mediante otros equipos auxiliares. Para simular los diferentes niveles de radiación solar se instaló una batería de focos con lámparas de incandescencia halógenas, y la incorporación del aire en diferentes condiciones y flujos se consiguió utilizando una unidad de tratamiento de aire.

A continuación se puede observar un esquema de la instalación completa:

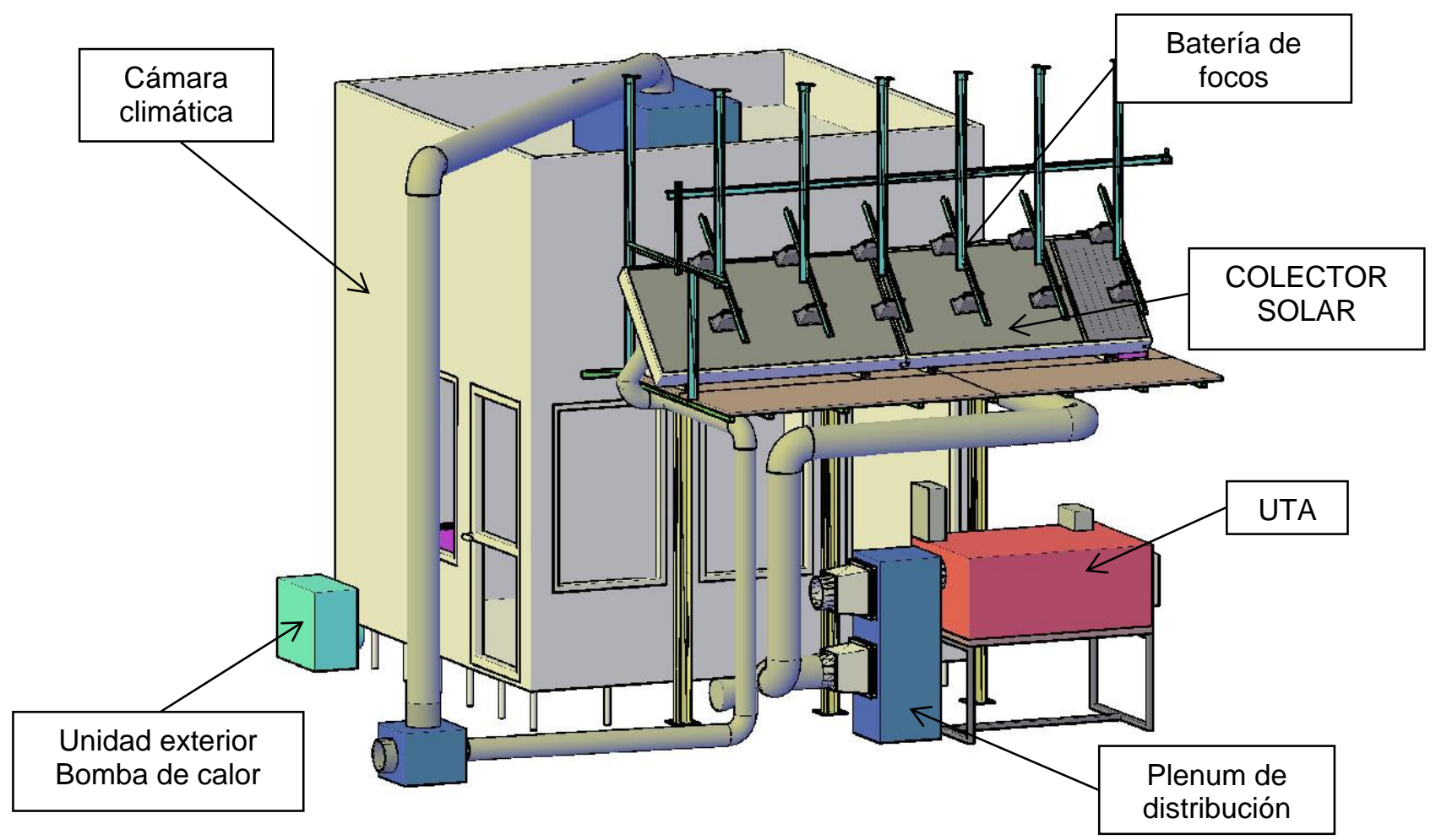

Figura III.1.- Vista esquemática de la instalación con los diferentes dispositivos. 


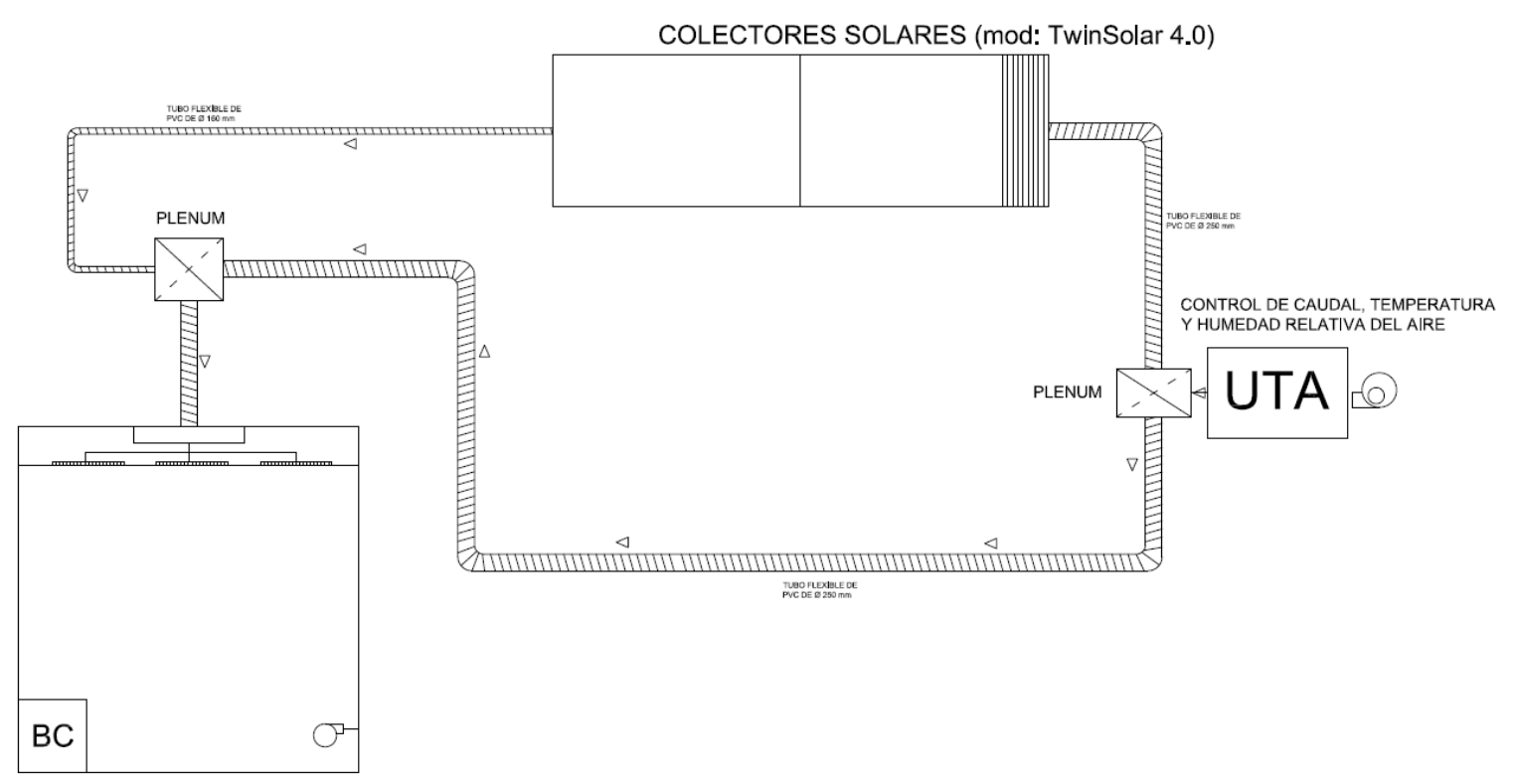

Figura III.2.- Esquema de la instalación.

\section{III.2.- ELEMENTOS DEL BANCO DE ENSAYOS.}

En este apartado se describen los distintos equipos empleados en el banco de ensayos que han permitido llevar a cabo los diferentes ensayos.

\section{III.2.1.- UNIDAD DE TRATAMIENTO DE AIRE (UTA).}

\section{UTA TROX TECHNIK}

El sistema experimental debe ser capaz de simular las diferentes condiciones climáticas que pueden presentarse. La unidad de tratamiento de aire (UTA), modelo TKM-30 de la casa TROX TECHNIK (Figura III.3), [1], [W-1], reproducirá las diferentes condiciones del aire que se desean ensayar.

El climatizador TKM-30 está compuesto por bastidor en perfil de aluminio extruido y paneles de cierre tipo sándwich de $25 \mathrm{~mm}$ de espesor con chapa galvanizada interior y chapa precalada color rojo exterior, aislamiento de poliuretano y puertas de intervención con manecillas de apertura rápida. El equipo dispone de 2 baterías eléctricas de $10 \mathrm{~kW}$ de potencia y una batería de expansión directa (20 kW de potencia calorífica y $20.035 \mathrm{Frig} / \mathrm{h}$. de potencia frigorífica) que 
permiten acondicionar térmicamente el flujo de aire. Este flujo de aire es filtrado previamente al paso por estas baterías en un filtro que dispone la UTA (filtro plano modelo F702). También cuenta con un sistema de humidificación con control de humedad mediante dardo de vapor y un sistema de impulsión de aire.

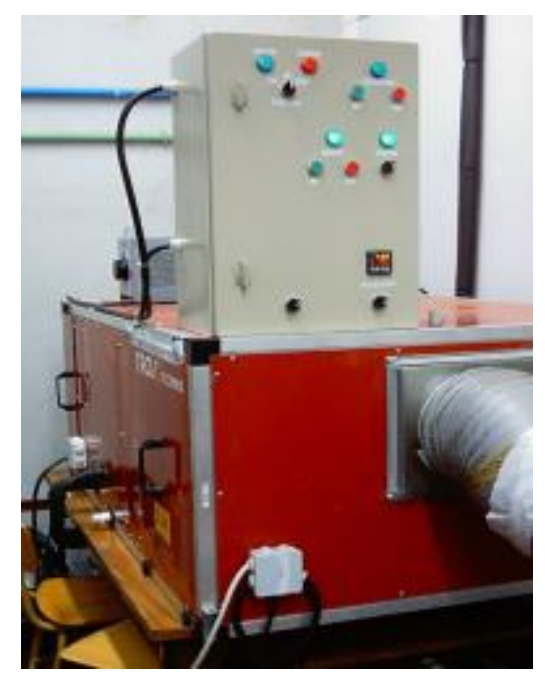

Figura III.3.- Unidad de tratamiento de aire TROX modelo TKM-30.

\section{VENTILADOR CENTRÍFUGO SODECA}

El sistema de impulsión de aire primario está constituido por un equipo ventilador acoplado a un regulador variable que permite modificar los caudales de aire impulsado (Figura III.4). Sin embargo, este elemento de regulación del caudal presenta limitaciones, en cuanto a que los niveles seleccionados no se corresponden con niveles concretos de caudal, sino que dependen de la pérdida de carga de la instalación particular conectada a la UTA. Por ello, la regulación deberá cuidarse para ajustarse el caudal de aire, más aproximado al nivel especificado para el ensayo en particular.

El ventilador centrífugo utilizado es el modelo CMP-922-2T-3 de la casa SODECA [2], [W-2], cuyas características son:

- Velocidad de giro: $2845 \mathrm{rpm}$.

- Voltaje: $230 \mathrm{~V}$.

- Intensidad máxima admisible (400 V): 4,6 A.

- Potencia instalada: 2,2 kW.

- Caudal máximo: $2900 \mathrm{~m}^{3} / \mathrm{h}$.

- Peso aproximado: 2,5 kg. 


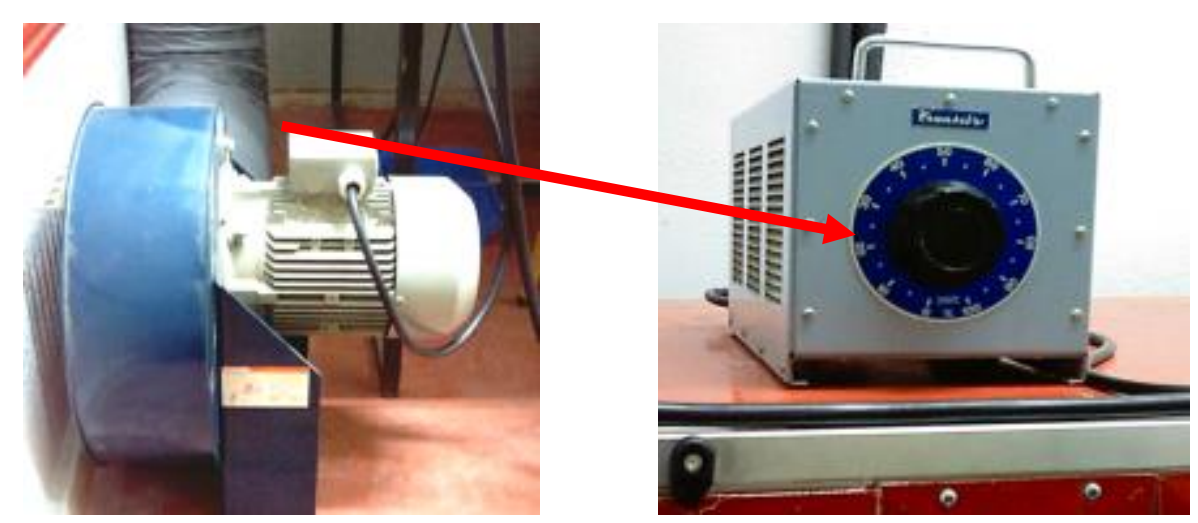

Figura III.4.- Izqda.: Ventilador SODECA. Drcha.: Variador de frecuencia TELEMECANIC

\section{BOMBA DE CALOR TRANE}

La unidad exterior, modelo RXC-75-100-125 de la casa TRANE, con R22, está ubicada en la azotea del laboratorio (Figura III.5) con las siguientes capacidades [W-3]:

- Potencia de calentamiento, $\mathrm{Q}_{\mathrm{C}}=28 \mathrm{~kW}$

- Potencia de enfriamiento, $Q_{F}=20 \mathrm{~kW}$

- Potencia requerida por el compresor, $\mathrm{W}_{\mathrm{d}}=8 \mathrm{~kW}$
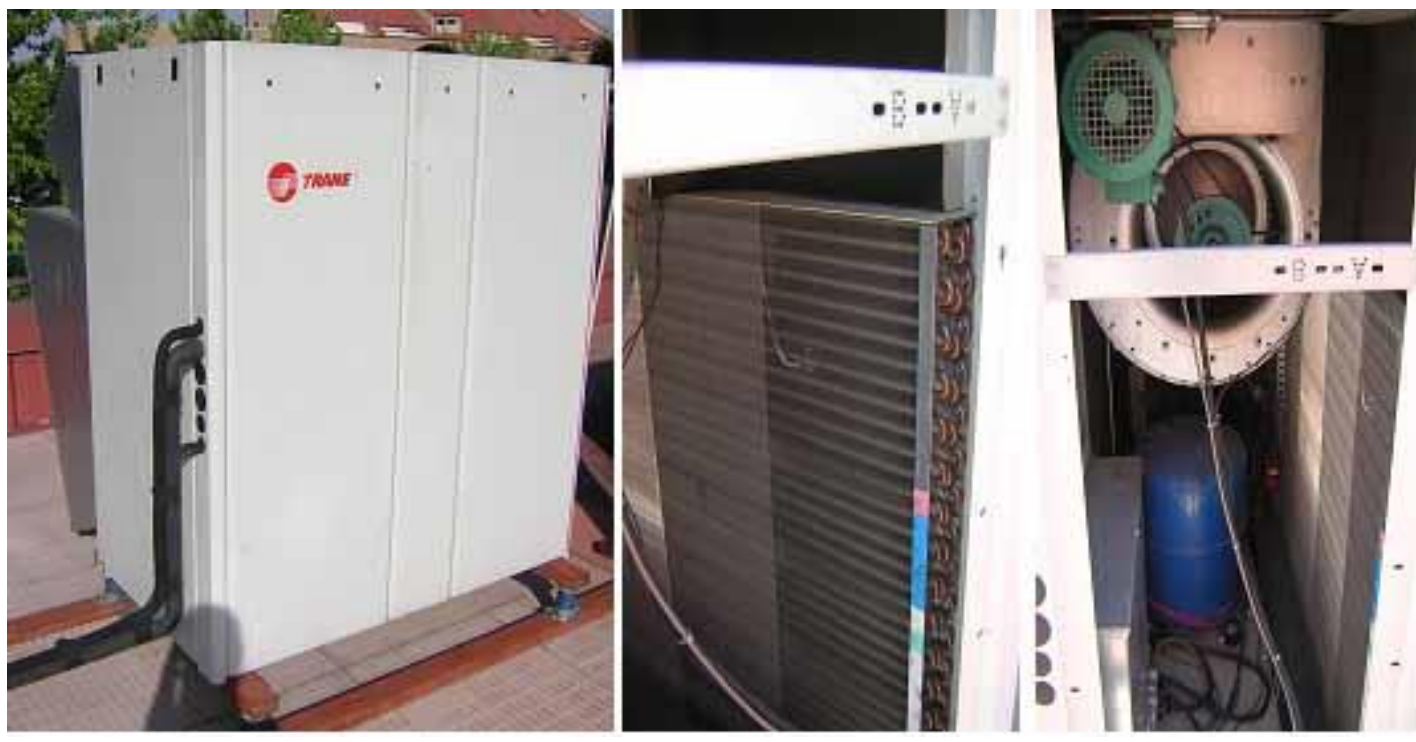

Figura III.5.- Izqda: Unidad exterior de la bomba de calor de la UTA. Centro: Intercambiador de la unidad. Drcha.: Vista interior. 
La batería interior que completa el conjunto Bomba de calor tiene las siguientes características:

- Batería de expansión directa modelo 14T 12R 800

- Capacidad térmica: $20 \mathrm{~kW}$

- Límites cond. entrada/salida aire: $25,0 \stackrel{\circ}{\circ} / 85 \% \mathrm{HR}$; $-5,0 \stackrel{\circ}{\circ} \mathrm{C} / 98 \% \mathrm{HR}$

- Temperatura de evaporación del refrigerante: $-10,0 \stackrel{\circ}{ } \mathrm{C}$

- Desescarche por resistencias eléctricas: 3 x 650 W $230 \mathrm{~V}$

- Paso de aletas: $4 \mathrm{~mm}$. tubo de 1/2"

\section{HUMIDIFICADOR HUMISTEAM X-PLUS (CAREL)}

Para poder ensayar distintos niveles de humedad relativa, la UTA original se ha combinado con un equipo humidificador, en concreto uno por electrodos sumergidos de la casa CAREL, modelo humiSteam x-plus (Figura III.6) [3], [W-4]. Este sistema permite producir vapor a razón de hasta $10 \mathrm{~kg} / \mathrm{h}$, modulable desde el $20 \%$ hasta el $100 \%$ mediante un controlador que puede trabajar en distintos modos (todo o nada, proporcional, o modulante, en función de distintas señales externas y limitaciones de seguridad). El vapor producido se inyecta en la última etapa de la UTA con ayuda de una lanza distribuidora de vapor.

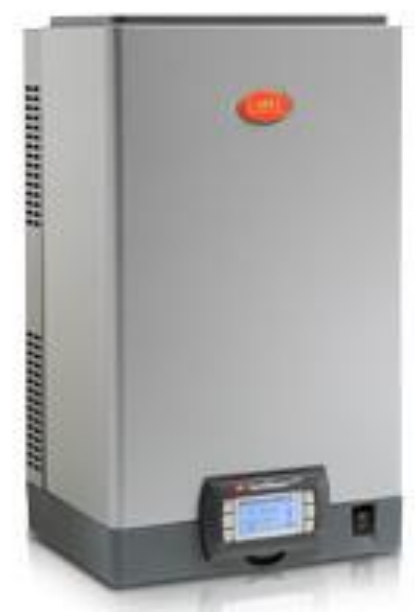

Figura III.6.- Humidificador por electrodos sumergidos, modelo HumiSteam X-Plus de la casa CAREL. 


\section{III.2.2.- BATERÍA DE LÁMPARAS INCANDESCENTES HALÓGENAS.}

Como ya se ha comentado en la descripción inicial del capítulo, la necesidad de tener independencia de las condiciones climáticas para cumplir con los objetivos planteados en la realización de los ensayos en un determinado periodo de tiempo, junto con la no disponibilidad de un espacio exterior adecuadamente situado, obligaron a la instalación de un sistema que nos permitiera simular ciertas condiciones de radiación solar incidente sobre el colector.

El sistema consiste en una batería de focos con lámparas incandescentes halógenas que nos permite cubrir la necesidad de disponer de diferentes niveles de irradiación sobre nuestro campo de colectores. Este tipo de lámparas emiten radiación en el campo visible del espectro electromagnético, con una luz muy cercana a la luz natural del Sol. La mayor parte de la energía que consumen se transforma en calor: un $5,75 \%$ es emitido como radiación visible, un $0,25 \%$ en radiación UV, un $75 \%$ en radiación IR y el resto mediante conducción y convección [4]. Permite disponer, con un número de lámparas óptimo, de valores de irradiancia sobre el colector del mismo rango que los obtenidos con la radiación solar.

Para la disposición de los focos se instaló una estructura compuesta por perfiles metálicos suspendida del techo, donde se colocaron dos hileras de focos en un plano equidistante paralelo al colector (Figura III.7).
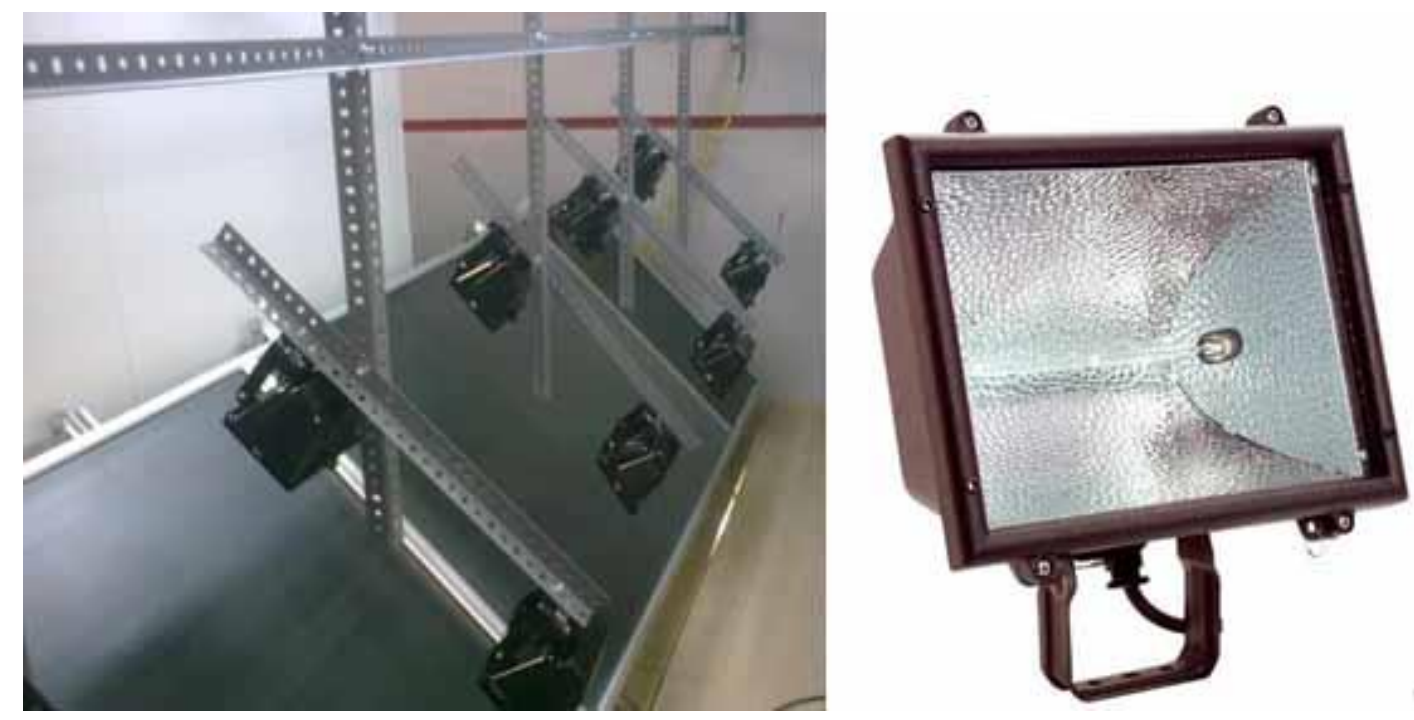

Figura III.7.- Izqda.: Estructura portante de los focos. Drcha.: Foco con lámpara halógena empleado.

El equipo de iluminación está constituido por 12 focos de lámparas lineales incandescentes halógenas de $500 \mathrm{~W}$ de potencia eléctrica cada una. Estos focos están distribuidos de forma uniforme y equidistante al colector, dispuestos en dos filas de 6 focos. La conexión o encendido se 
ha configurado en dos posiciones, una con todos los focos encendidos, y otra con la mitad de los focos encendidos distribuidos éstos a tresbolillo. Para disminuir pérdidas energéticas en la transmisión de la radiación desde la lámpara al colector, los vidrios de protección de que disponen los focos no se han empleado durante los ensayos.

En el capítulo IV donde se desarrolla el estudio experimental, se presentan los niveles y distribución de la irradiación sobre el colector que nos aporta este sistema de iluminación.

\section{III.2.3.- CÁMARA CLIMÁTICA.}

La cámara climática utilizada en el banco de ensayo experimental para la ejecución de los diferentes ensayos tiene de dimensiones aproximadas $4 \times 4 \times 3 \mathrm{~m}$, con techo variable en altura, equipada con 4 difusores rotacionales, donde se miden las condiciones higrotérmicas y de confort del acondicionamiento del aire (Figura III.8). Se encuentra elevada sobre el suelo apoyada sobre una serie de soportes, y dispone de una única puerta y una superficie total acristalada de $6,7 \mathrm{~m}^{2}$.

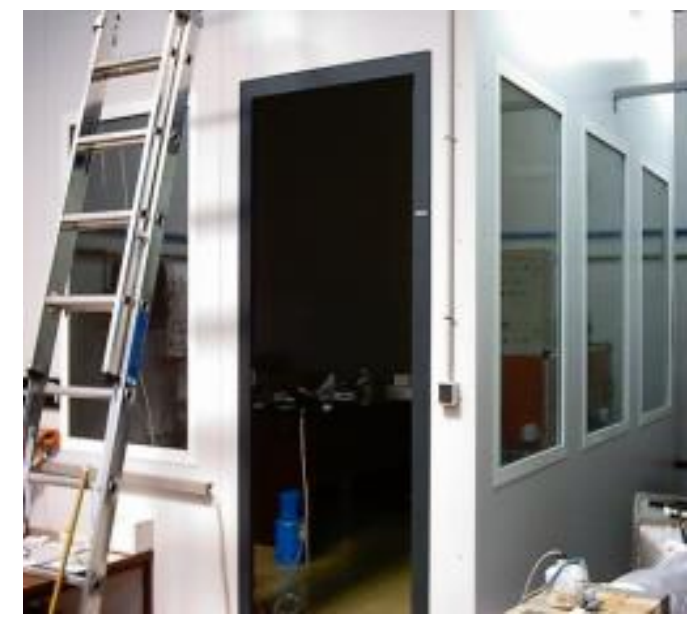

Figura III.8.- Vista de la cámara climática del laboratorio.

Para reproducir de forma válida las condiciones de funcionamiento de los sistemas en algunos ensayos en los que se hace uso de las condiciones del aire de extracción, va a ser necesario asegurar que el espacio acondicionado se encuentra dentro de unos requisitos. Según lo establecido en el RITE (Reglamento de Instalaciones Térmicas en Edificios), las condiciones interiores de diseño en verano para personas con actividad metabólica sedentaria (1,2 met) y vestimenta de 0,5 clo, asegurando un PPD entre el $10 \%$ y el $15 \%$, están comprendidas entre $23^{\circ} \mathrm{C}$ y $25^{\circ} \mathrm{C}$ de temperatura operativa, y entre $40 \%$ y $60 \%$ de humedad relativa. Estos parámetros están establecidos en consideración para edificios de nueva construcción o en reformas de edificios ya existentes [N-1]. 
Para el aporte de los caudales de aire requeridos por ventilación o para el acondicionamiento térmico por aire, la cámara dispone de cuatro difusores rotacionales, modelo VDW-Q-Z-H / $600 \times$ 24 de la casa TROX TECHNIK [W-1].

En el particular, las condiciones ambientales alcanzadas en la cámara se mantienen entre $20^{\circ} \mathrm{C}$ y $23^{\circ} \mathrm{C}$ de temperatura seca, y entre un $35 \%$ y un $65 \%$ de humedad relativa. Estas condiciones se adecuan a los requisitos de confort térmico y salubridad, puesto que valores de temperatura seca más relajados están orientados simplemente a un ahorro energético, y por lo tanto valores menores alcanzados con equipos de consumo energético casi nulo serían admisibles.

\section{BOMBA DE CALOR AIRE-AIRE}

Con el objetivo de conseguir que la temperatura y humedad relativa de la sala estén próximas a las condiciones de confort requeridas, es necesario disponer de un dispositivo auxiliar con el que podremos aportar o extraer calor del recinto cuando la temperatura seca del aire se encuentre por debajo o por encima de la temperatura de confort. Para ello se dispone de una bomba de calor tipo Split Aire-Aire con la que se alcanza la temperatura adecuada en la cámara (figura III.9).

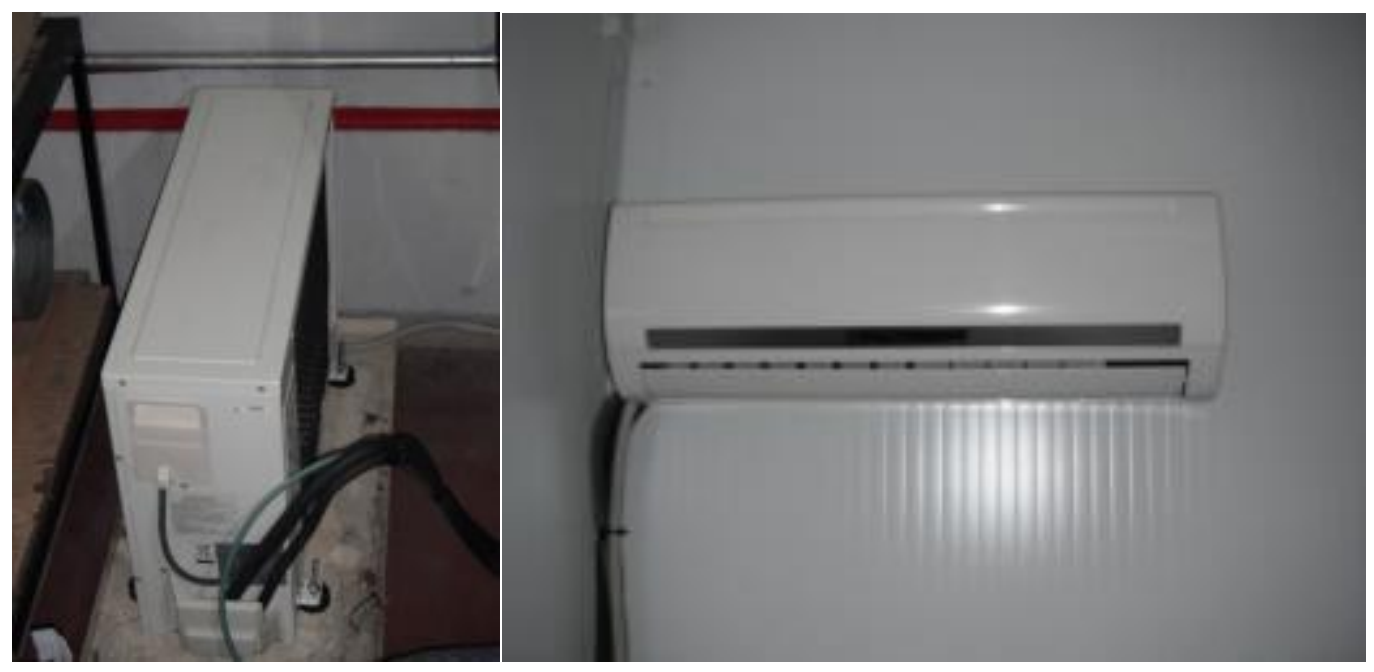

Figura III.9.- Izqda.: Unidad exterior de la bomba de calor. Drcha.: Unidad interior de la BC.

El equipo disponible es un acondicionador modelo Diamond 9000 de la casa Ferroli [5], [W-5], algunas de cuyas características generales son:

- Refrigerante: R410A.

- Potencia frigorífica: $2,6 \mathrm{~kW}$ (a $35^{\circ} \mathrm{C}$ de temperatura seca exterior y $27^{\circ} \mathrm{C} / 19^{\circ} \mathrm{C}$ de temperatura seca/ de bulbo húmedo en el ambiente).

- Potencia calorífica: $3,2 \mathrm{~kW}$ (a $7^{\circ} \mathrm{C} / 6^{\circ} \mathrm{C}$ de temperatura seca/ de bulbo húmedo exterior y $20^{\circ} \mathrm{C}$ de temperatura seca en el ambiente).

- Alimentación: 230 V/ 50 Hz. 


\section{VENTILADOR CENTRÍFUGO S\&P}

Además, será también necesario disponer de un ventilador en el interior de la cámara climática para extraer el aire de retorno. El ventilador se encuentra instalado como se muestra en la figura III.10.

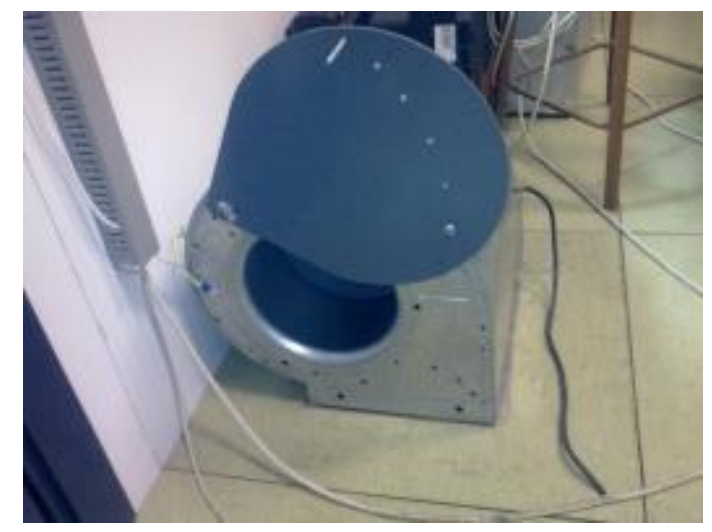

Figura III.10.- Ventilador de extracción de aire de la cámara.

Se trata de un ventilador centrífugo tipo CBM/4-240/240 T3/4 CV de la casa Soler \& Palau [6], [W-6], de características:

- Potencia: 0,55 kW.

- Velocidad de giro: $1320 \mathrm{rpm}$.

- Alimentación: 230 V/50 Hz.

\section{III.2.4.- SISTEMA DE DISTRIBUCIÓN DE AIRE.}

\section{CONDUCTOS DE AIRE}

Se han empleado conductos de aire flexibles de diámetro de 160 y $250 \mathrm{~mm}$ para conectar los elementos disponibles en el banco de ensayos, según los requerimientos de las distintas configuraciones a ensayar. El tubo flexible de $160 \mathrm{~mm}$ únicamente se emplea para conectar la salida del colector con la caja de mezcla o de paso. Un detalle de estos conductos se muestra en la figura III.11: 

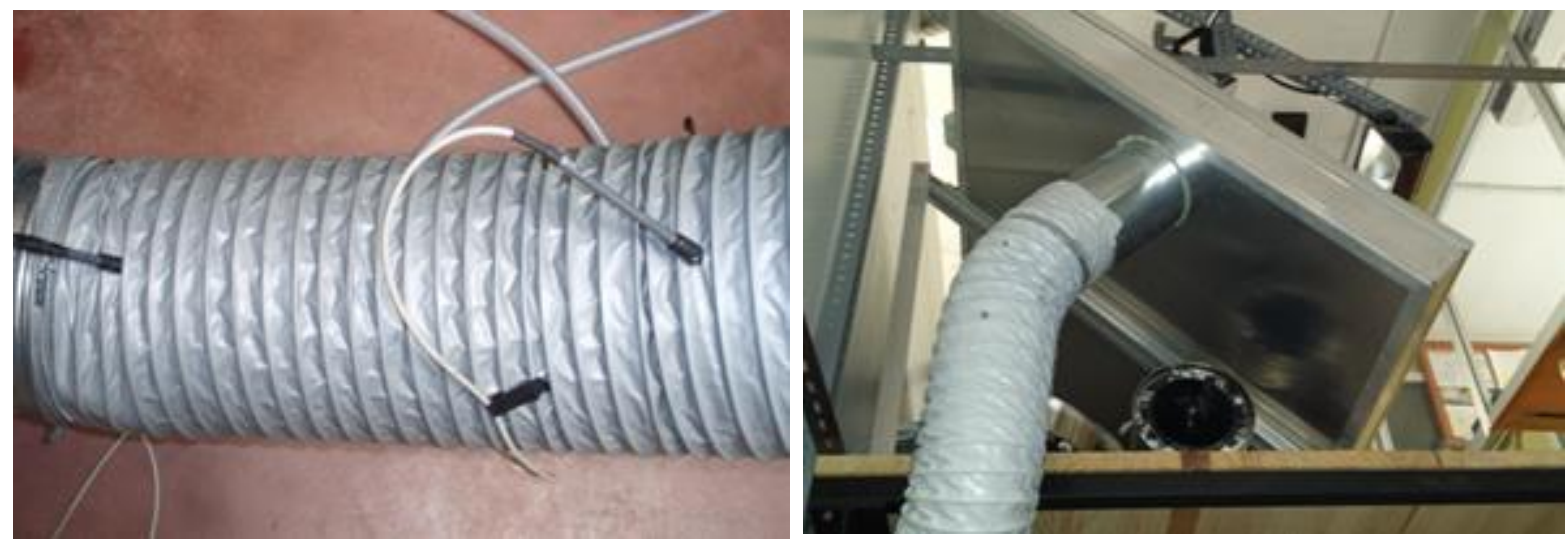

Figura III.11.- Izqda.: detalle de un conducto de aire flexible de $250 \mathrm{~mm}$ de diámetro. Drcha.:

Conducto de aire flexible de $160 \mathrm{~mm}$ de diámetro conectado a la salida del colector.

Para minimizar las pérdidas térmicas en estos conductos durante la realización de los ensayos en los que se requerían bajas temperaturas de aporte de aire a los colectores, se forró el conducto de aire entre el colector solar y la UTA con una manta de aislamiento flexible [7]. Las características de este aislamiento térmico son:

- Material: Silicato de Calcio- Magnesio.

- $\quad$ Espesor: $25 \mathrm{~mm}$.

- Densidad: $128 \mathrm{~kg} / \mathrm{m}^{3}$.

- Conductividad térmica: $0,08 \mathrm{~W} / \mathrm{mK}, 0,12 \mathrm{~W} / \mathrm{mK}$.

Estos conductos van a permitir la conducción de las corrientes de aire de retorno de la cámara climática y las proporcionadas por la UTA, así como las procedentes del sistema ensayado en cada caso particular. Sin embargo, para ello va a ser también necesario disponer de elementos que permitan realizar la conexión de los conductos a los distintos elementos que se describen a continuación.

\section{PLENUMS DE DISTRIBUCIÓN Y CONEXIÓN}

Existen diferentes elementos en la instalación cuya misión es la de distribuir y/o servir de conexionado o paso al aire que estamos incorporando a los diferentes equipos. Hasta estos elementos llegarán los diferentes conductos, y desde ellos se distribuirá el aire hacia los puntos que lo requieran. Estos elementos son los plénums, cajas de mezcla y/o paso y los colectores de conexión.

En la Figura III.12 se observa el plénum instalado a la salida de la UTA que permite dividir el caudal de aire aportado por ésta en dos corrientes, mediante un sistema de compuertas, pudiendo alimentar varios equipos con unas condiciones de aire establecidas para los ensayos. 


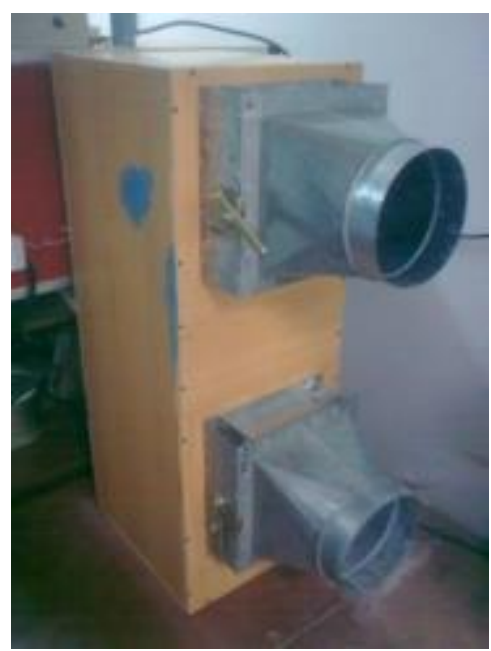

Figura III.12.- Vista del plénum de distribución conectado a la UTA

Es necesario también disponer de un plénum a la entrada de la cámara climática para la distribución del aire hacia las 4 entradas de aire disponibles en ésta, correspondientes a los 4 difusores rotacionales ya descritos en el apartado anterior.

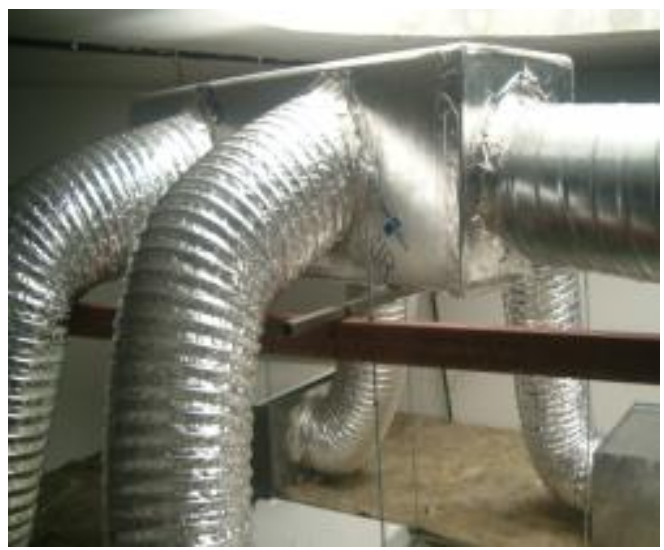

Figura III.13.- Vista de la conexión del plénum de distribución a la cámara climática.

Otro elemento de conexionado necesario, debido a la existencia en el banco de ensayos de conductos con diferentes diámetros, y a diferentes corrientes de aire procedentes de distintos equipos que se han de mezclar para incorporarse a la cámara, son las cajas de mezcla (si unen dos corrientes) o de paso (si no existe mezcla con otra corriente). En la Figura III.14 se observa la caja empleada en este banco de ensayo. 


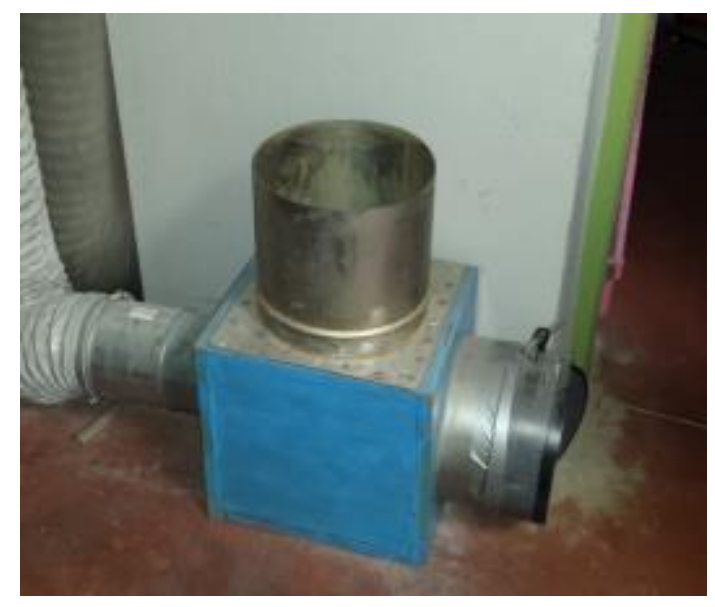

Figura III.14.- Caja de mezcla y/o paso.

\section{III.3.- ELEMENTOS DE MEDIDA Y REGISTRO.}

Los últimos dispositivos necesarios para obtener los valores de las múltiples variables de interés sobre las condiciones de los fluidos de trabajo, así como de los elementos que permitan el registro de dichas medidas, son los elementos de medida.

\section{III.3.1.- ELEMENTOS DE MEDIDA.}

\section{SENSORES DE MEDIDA DE TEMPERATURA}

Para la medida de la temperatura en los puntos de interés de la instalación, se ha optado por sensores Pt100 a 4 hilos cerámicos (Figura III.15) de la casa RS [W-7]. Aunque su coste es alto, es el material más idóneo y con mejores características para emplearlo como sensor de temperatura por su alto grado de linealidad y estabilidad así como por su elevada precisión, llegando a ser esta del orden de $0,1^{\circ} \mathrm{C}$. El rango de temperaturas de trabajo abarca de $-50^{\circ} \mathrm{C}$ a $+250^{\circ} \mathrm{C}$. 


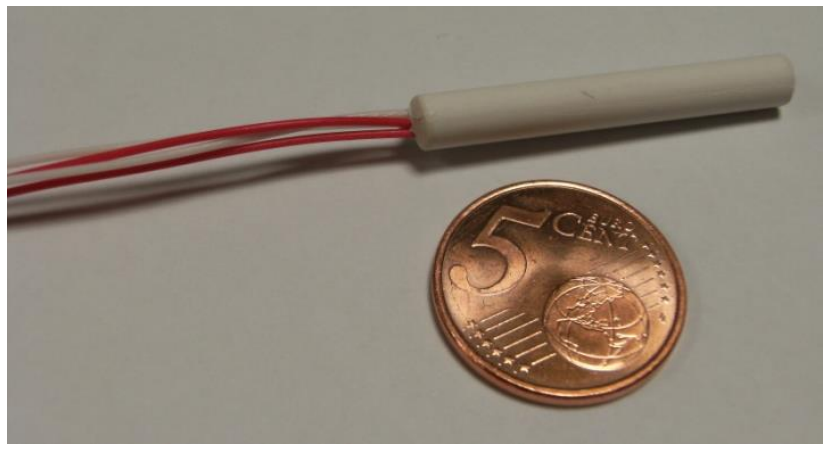

Figura III.15.- Sonda cerámica de temperatura.

\section{SENSORES DE MEDIDA DE HUMEDAD}

Como sondas de medida de la humedad relativa se emplean sensores capacitivos de detección fabricados en polímero termoestable (figura III.16), de la casa Honeywell [W-8].

En algunos casos, como por ejemplo en los instrumentos situados en el conducto de impulsión, en un mismo tubo de protección se incorporan dos sensores: temperatura y humedad relativa.

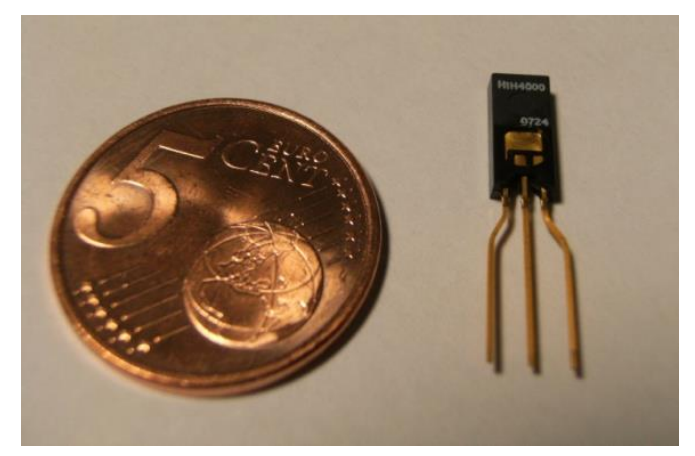

Figura III.16.- Higrómetro capacitivo Honeywell.

Sus principales características son:

- Tensión de alimentación: 5 Vcc

- Escala de medida: de $0 \%$ a $100 \%$ de HR.

- Precisión del instrumento: $+/-2 \%$.

- Estabilidad: $+/-1 \% \mathrm{HR}$.

- Tiempo de respuesta: $15 \mathrm{~s}$.

- Salida de tensión: de 0,8 a 3,9 Vcc

- Temperatura de funcionamiento: de $-40^{\circ} \mathrm{C}$ a $+85^{\circ} \mathrm{C}$. 


\section{MEDIDA DE LA PRESIÓN DIFERENCIAL Y CAUDAL VOLUMÉTRICO. PLACA ORIFICIO.}

Para la medida del caudal volumétrico, se parte de las medidas de presión diferencial obtenidas a partir de los valores proporcionados por los manómetros dispuestos a entrada y salida de una placa orificio de $10 \mathrm{~cm}$ de diámetro, como la mostrada en la figura III.17.

Esta placa orificio ha sido previamente calibrada con una tobera, la cual se describe más adelante en este capítulo.

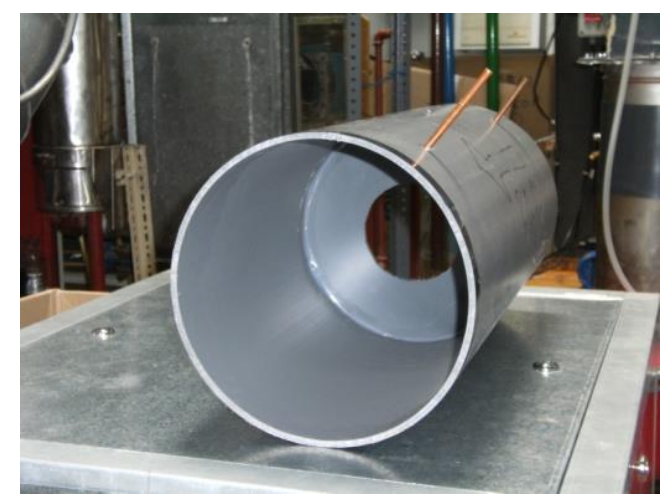

Figura III.17.- Vista de una de las placas orificio empleadas.

Para la medida de la caída de presión en la placa orificio, se emplean sensores de diferencia de presión ultrabaja como el mostrado en la figura III.18, que proporcionan una salida de tensión proporcional a la presión aplicada.

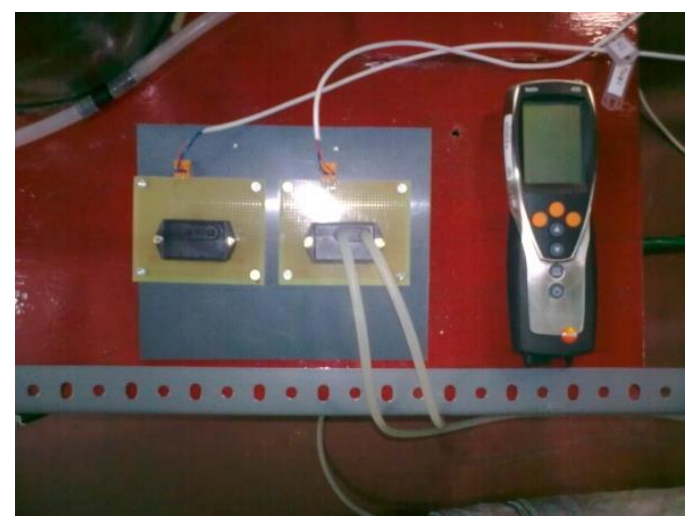

Figura III.18.- Sensores de medida de presión diferencial manométrica utilizados.

Las especificaciones técnicas de los sensores de presión manométrica son [W-7]:

- FSO (Salida a Fin de Escala: Diferencia algebraica entre puntos extremos de salida de presión nula y máxima): mín 4,85 típ 5,00 máx 5,15 V

- Desplazamiento del cero: mín 0,95 típ 1,00 máx 1,05 V 
- Excitación: mín 3,45 típ 3,5 máx 3,55 V

- Excitación: mín 6,0 típ 8,00 máx 16,0 Vcc

- Corriente de salida: Fuente 10,0 mA, Sumidero 5,0

- Corriente de alimentación (carga 10k1ㅡ) 8,0 - 20,0 mA

- Sobrepresión 5 p.s.i.

- Temperatura de operación $-40^{\circ} \mathrm{C}$ to $+85^{\circ} \mathrm{C}$

- Temperatura de almacenaje $-55^{\circ} \mathrm{C}$ to $+125^{\circ} \mathrm{C}$

La figura III.19 muestra la interrelación entre caudal y $\Delta \mathrm{P}$ determinada experimentalmente:

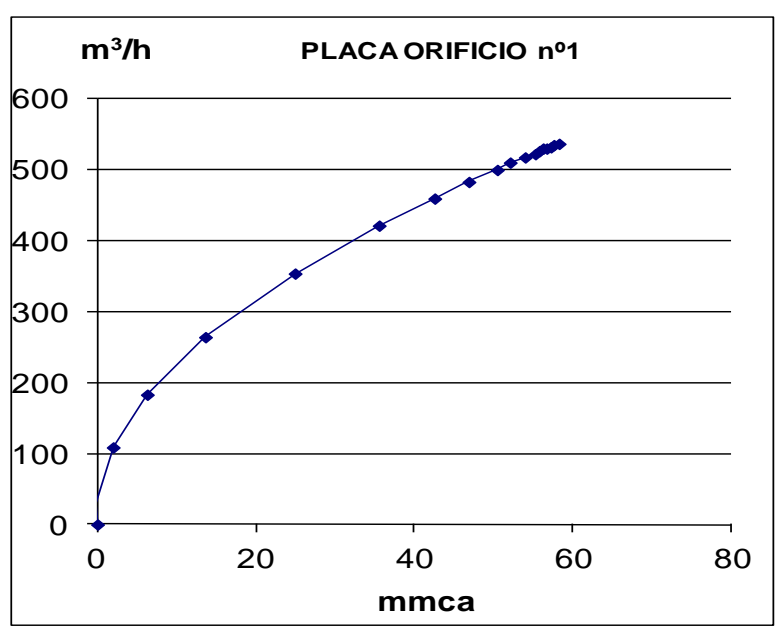

Figura III.19.- Curva de caudales medidos en la placa №1.

\section{MEDIDA DE LA POTENCIA RADIANTE INCIDENTE. EL PIRANÓMETRO ÓPTICO.}

La irradiancia es la magnitud que describe la radiación solar que llega hasta una superficie. Es la potencia por unidad de superficie y habitualmente se mide en $\mathrm{W} / \mathrm{m}^{2} \mathrm{o}$ unidades equivalentes. La irradiación es la cantidad de irradiancia recibida en un determinado periodo de tiempo.

El piranómetro es el equipo que empleamos para medir la irradiancia procedente de nuestro sistema de iluminación sobre el colector solar de aire. Este dispositivo se basa en un elemento térmico pasivo llamado pila termoeléctrica. Este elemento responde a la energía total absorbida por la superficie negra, que es una pintura no espectralmente selectiva, y se calienta. El calor genera corriente desde la resistencia al "heat-sink" (el cuerpo del piranómetro). La diferencia de 
temperatura a lo largo de la resistencia térmica del detector es convertida en una diferencia de tensión como una función lineal de la irradiancia solar absorbida. El incremento de temperatura es fácilmente afectado por el viento, la lluvia y pérdidas de radiación térmica. Para evitar esto, el detector va protegido exteriormente mediante una cúpula. Esta bóveda permite la misma transmitancia del componente solar directo para cada posición del Sol en la esfera terrestre.

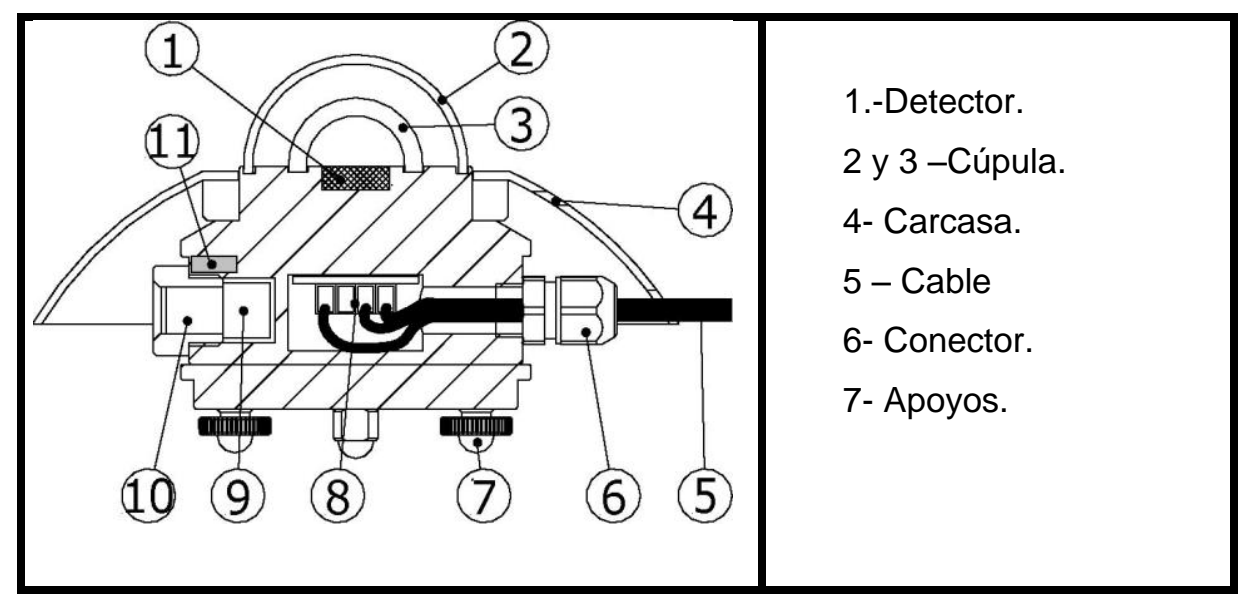

Figura III.20.- Esquema general de un piranómetro óptico.

Los componentes que constituyen el piranómetro son:

- La cúpula.

El material de la cúpula del radiómetro define el rango de medida espectral del instrumento. En general, entorno al 97-98\% del espectro de radiación solar es transmitida a través de la cúpula y es absorbida por el detector. La irradiancia solar puede provenir de cualquier dirección, así que la cúpula está diseñada para minimizar el error de la medida en todos los ángulos incidentes.

- $\quad$ El detector.

El elemento sensible de la pila termoeléctrica está compuesto por un gran número de parejas unidas de termopares conectados eléctricamente en serie. La absorción de la radiación térmica por una de las uniones de termopares, llamada unión activa o caliente, incrementa su temperatura. La diferencia de temperatura entre la unión activa y una de referencia, que mantiene una temperatura fija, produce una fuerza electromotriz directamente proporcional a la diferencia de temperaturas creada. Este es el efecto termoeléctrico creado. La sensibilidad del piranómetro depende delas propiedades físicas de la pila termoeléctrica. La zona pintada de negro del elemento sensible forma el detector. 
- La carcasa.

La carcasa alberga todas las partes fundamentales del piranómetro y debe proporcionar alta estabilidad mecánica y térmica al instrumento. La protección solar protege todas las partes externas de la radiación y reduce el calentamiento solar de la carcasa.

- $\quad$ Cartucho secante.

En caso de que entre humedad en el cuerpo del radiómetro, el desecante de silica-gel regula el nivel de humedad dentro del piranómetro. Cuando el material está saturado cambia de color y es preciso reemplazarlo.

- Cable y conector.

El cable es del tipo de bajo ruido particularmente adaptado al bajo voltaje de la salida de la pila termoeléctrica o del sensor de temperatura. La protección del cable está conectada al cuerpo metálico del conector y preferiblemente debe ser conectado a la toma de tierra del equipo.

En este caso, el piranómetro empleado para la realización de los ensayos de medida de la irradiancia sobre el colector solar ha sido el modelo Star Pyranometer Type FLA628S de la casa AHLBORN [8], se puede observar en la figura III.21 y tiene las siguientes características:

- Rango de medida: de 0 a $1500 \mathrm{~W} / \mathrm{m}^{2}$.

- Resolución: $0,1 \mathrm{~W} / \mathrm{m}^{2}$.

- Rango espectral: de 0,3 a $3 \mu \mathrm{m}$.

- Señal de salida: aprox. de $15 \mu \mathrm{V} / \mathrm{Wm}^{-2}$.

- Impedancia: aprox. $35 \Omega$.

- Rango de operatividad: $-40^{\circ} \mathrm{C}$ a $+60^{\circ} \mathrm{C}$.

- Precisión: dependiente del efecto coseno + efecto acimut + influencia de la temperatura.

- Efecto coseno: $<3 \%$ del valor de la medida ( 0 a $80^{\circ}$ de inclinación).

- Efecto de la inclinación del acimut: $<3 \%$ del valor de la medida.

- Influencia de la temperatura: $<1 \%$ del valor de la medida $\left(-20^{\circ} \mathrm{C}\right.$ a $\left.40^{\circ} \mathrm{C}\right)$.

- Temperatura nominal: $22^{\circ} \mathrm{C} \pm 2^{\circ} \mathrm{C}$.

- Linealidad: $<0,5 \%\left(0,5\right.$ a $\left.1330 \mathrm{~W} / \mathrm{m}^{2}\right)$. 
- Estabilidad: $<1 \%$ del rango de las medidas por año.

- Dimensiones: $160 \mathrm{~mm} \varnothing, 75 \mathrm{~mm}$ de altura.

- Peso: $1 \mathrm{~kg}$.

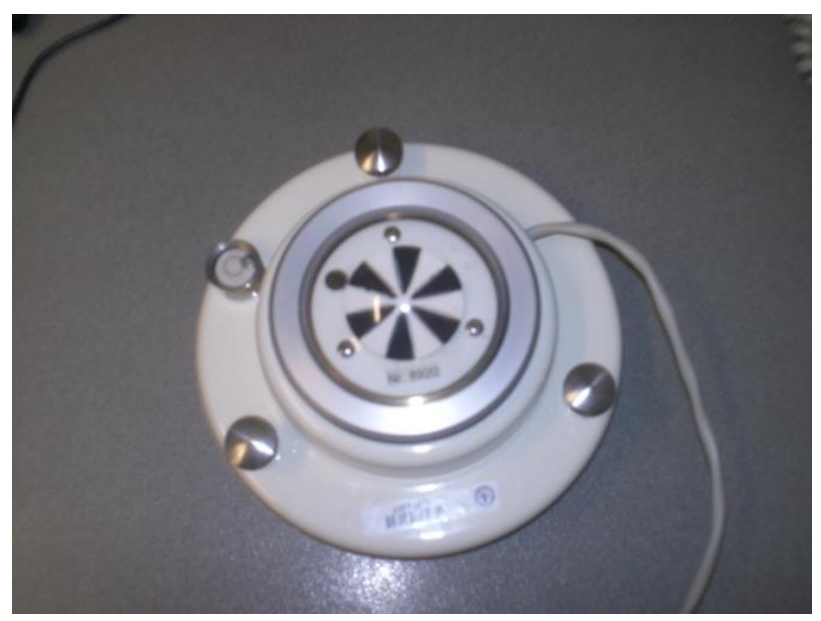

Figura III.21.- Imagen del piranómetro óptico.

\section{III.3.2.- SISTEMA DE ADQUISICIÓN Y SOFTWARE DE MONITORIZACIÓN DE DATOS.}

El sistema de instrumentación y adquisición de datos ha de posibilitar la medida del mayor número de variables posible con la precisión adecuada, además de controlar las interacciones y relaciones entre las variables estudiadas. Para ello se requiere el uso de instrumentos potentes y flexibles que adquieran toda la información, la registren y la traten, a la vez que efectúan decisiones y controlan el sistema. En particular se emplea un adquisidor de datos «Agilent 34972A» como el mostrado en la figura III.22 [9], [W-9].

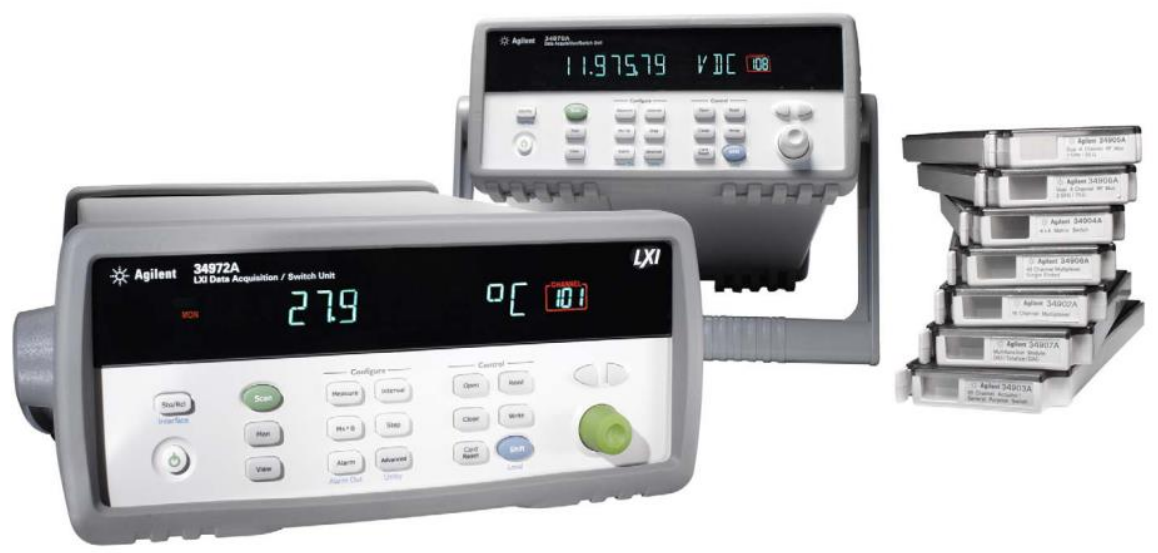

Figura III.22.- Adquisidor de datos Agilent 34972A. 
El sistema de adquisición de datos (SAD) sirve de interfaz entre el computador digital y el sistema físico. Permite capturar, acondicionar, procesar y generar señales, transformando las señales de tensión procedentes de sensores de presión, termorresistencias, sensores de humedad, etc. en valores numéricos para su posterior representación gráfica y análisis numérico. Para ello constará de distintos elementos, como son transductores, actuadores, acondicionamiento de la señal, circuitería de adquisición de datos, circuitería de análisis de los datos, control y software.

\section{III.3.3.- CALIBRACIÓN Y ERRORES DE MEDIDA.}

Para reducir la incertidumbre de una medida, es necesario determinar los límites entre los que se comprende el error de medida del instrumento utilizado, lo que requiere de una calibración adecuada de éste. De esta forma, se dice que un instrumento estará bien calibrado cuando en todos los puntos de su campo de medida, la diferencia entre el valor real de la variable y el valor transmitido esté comprendida entre los límites determinados por la precisión del instrumento.

El objetivo de la calibración de los equipos de medida es poder efectuar su confirmación metrológica, es decir, determinar a través de los resultados obtenidos en las calibraciones si el equipo está en condiciones de medir o si es adecuado para garantizar la precisión requerida en las medidas. Los equipos a verificar se contrastarán con patrones de referencia debidamente reconocidos por los organismos competentes.

Las sondas de medida de temperatura, humedad relativa y los manómetros de medida de presión utilizados para el cálculo del caudal de aire, se han calibrado previamente a su uso según se describe a continuación.

En el anexo A se incluyen los resultados de las calibraciones de los sensores empleados.

\section{CALIBRACIÓN DE LAS SONDAS DE TEMPERATURA.}

Las sondas de temperatura cerámicas se han calibrado con la ayuda de un horno de calibración FLUKE 9103 (rango de calibración entre -25 hasta 140드) utilizado como patrón primario (figura III.23) [W-12]. El rango de calibración de las sondas está comprendido entre -5 y $45^{\circ} \mathrm{C}$, el cual cubre las condiciones de trabajo ensayadas. Para la calibración, la temperatura del horno se ha variado desde el valor mínimo al máximo y, una vez alcanzado este, manteniendo constante la temperatura en dicho valor durante un período mínimo de 1 hora. Tras esto, se disminuye de nuevo la temperatura hasta el valor inferior, a fin de reflejar la histéresis de la medida. 


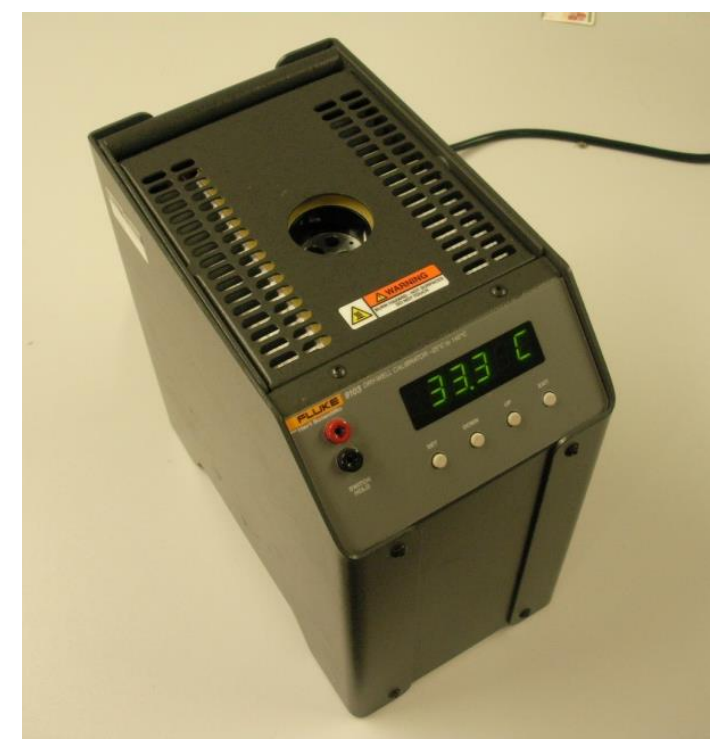

Figura III.23.- Horno de calibración FLUKE 9103.

La tabla III.1 recoge las regresiones obtenidas para las curvas de calibración de las diferentes sondas utilizadas.

Tabla III.1.- Regresiones de las rectas de calibración de las sondas de temperatura.

\begin{tabular}{|c|c|c|c|}
\hline $\mathbf{T}_{\text {medida }}=\mathbf{a} \cdot \mathbf{T}_{\text {horno }}+\mathbf{b}$ & $\mathbf{a}$ & $\mathbf{b}$ & $\mathbf{R}^{\mathbf{2}}$ \\
\hline T1 & 1,03 & $-0,5716$ & 0,9997 \\
\hline T2 & 1,0949 & $-2,3401$ & 0,9994 \\
\hline T3 & 1,0195 & $-0,2901$ & 1 \\
\hline T4 & 1,061 & $-0,9978$ & 0,9998 \\
\hline T5 & 0,9245 & $-3,6188$ & 0,8168 \\
\hline T6 & 1,027 & $-0,4408$ & 0,9999 \\
\hline T7 & 1,0091 & $-0,2464$ & 1 \\
\hline T8 & 1,0137 & $-0,5062$ & 0,9999 \\
\hline
\end{tabular}

La sonda de temperatura T5 se desconsideró en la realización de los ensayos, debido a los malos resultados registrados en la calibración, como puede observarse por la baja regresión. El resto de las sondas se consideraron válidas para la realización de medidas, dado que la regresión es superior a 0,999. La figura III.24 muestra a modo de ejemplo una de las gráficas de estas regresiones. 


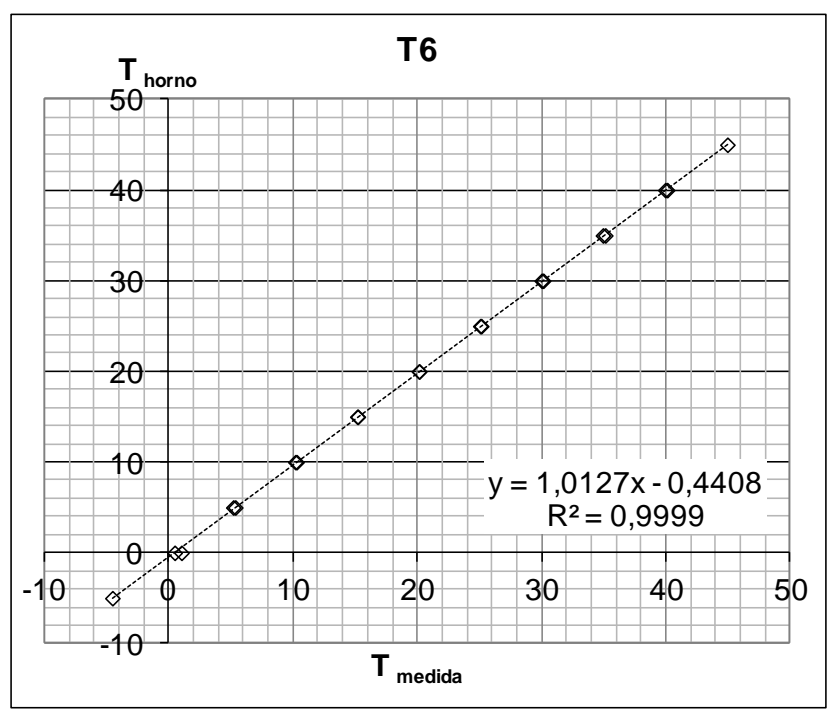

Figura III.24.- Regresión de la calibración de la sonda de temperatura T6.

Estas regresiones se programaron en el adquisidor de datos para obtener de forma directa los valores corregidos de temperatura, ya aplicado el ajuste de calibración.

\section{CALIBRACIÓN DE LAS SONDAS DE HUMEDAD RELATIVA}

La calibración de las sondas de humedad se ha realizado de forma simultánea, y utilizando como referencia la sonda de humedad relativa TESTO [W-10], según se muestra en la figura III.25: se proporciona un caudal de aire a humedad relativa determinada, y en un cierto punto de su canalización se disponen todas las sondas de humedad relativa junto con la sonda patrón. Se realiza el registro de las medidas en comparación a la referencia para un rango de humedades de entre el $20 \%$ y el $90 \%$.
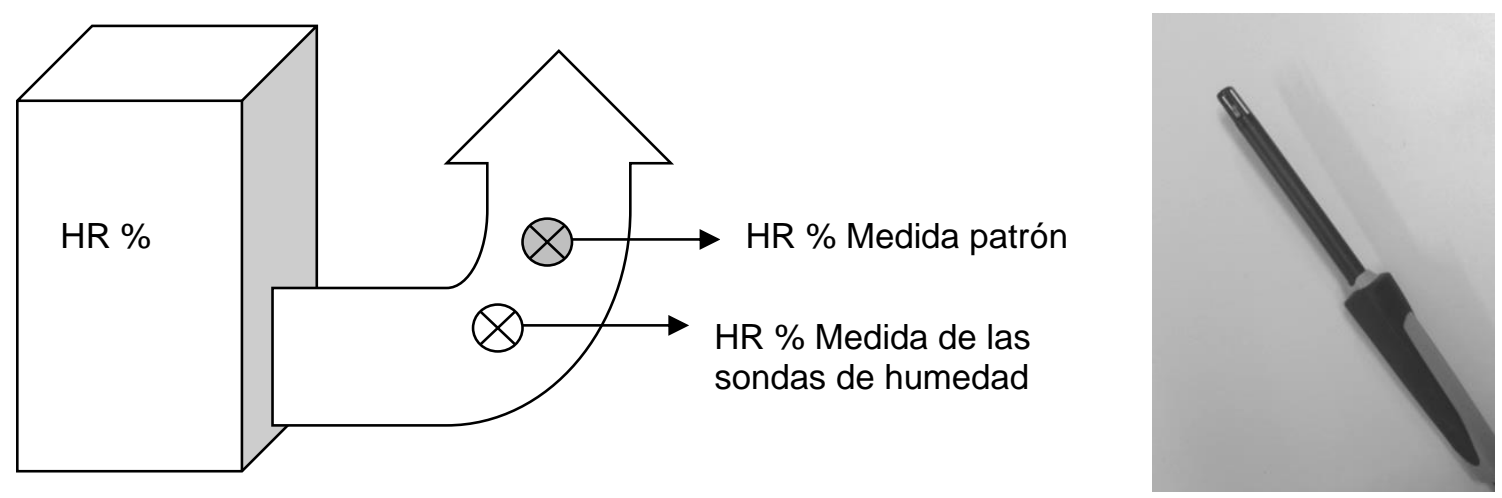

Figura III.25.- Esquema del dispositivo de calibración de las sondas de humedad relativa, y sonda TESTO utilizada de patrón de referencia (derecha). 
En la tabla III.2 se recogen las regresiones obtenidas para las 4 sondas de humedad relativa empleadas.

Tabla III.2.- Regresiones de las rectas de calibración de las sondas de humedad relativa.

\begin{tabular}{|c|c|c|c|}
\hline DifV $_{\text {medida }}=\mathbf{a} \cdot \mathbf{H R}_{\text {horno }}+\mathbf{b}$ & $\mathbf{a}$ & $\mathbf{b}$ & $\mathbf{R}^{\mathbf{2}}$ \\
\hline Sonda 1 & 0,0396 & 0,1422 & 0,9344 \\
\hline Sonda 2 & 0,026 & 0,629 & 0,8629 \\
\hline Sonda 3 & 0,029 & 0,5249 & 0,935 \\
\hline Sonda 4 & 0,0269 & 0,5899 & 0,8861 \\
\hline
\end{tabular}

Aunque las regresiones no son óptimas, los resultados de la calibración serían aceptables, ya que los rangos en los que varía la humedad relativa real para medidas iguales, debidos a la histéresis de las sondas, aunque elevados, no suponen diferencias importantes en las humedades específicas asociadas.

Estos resultados se programan directamente en el adquisidor de datos para la obtención directa de los valores de humedad relativa. A modo de ejemplo, se muestra en la figura III.26 la gráfica de la regresión obtenida para una de éstas.

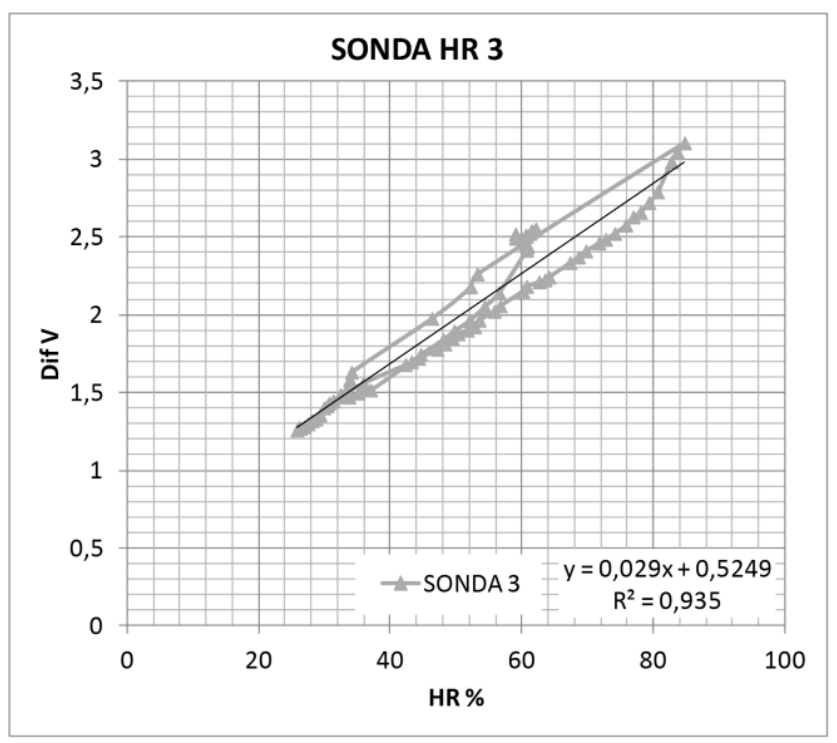

Figura III.26.- Regresión obtenida en la calibración de la sonda de humedad relativa 끄․ 


\section{CALIBRACIÓN DE LA PLACA ORIFICIO PARA LA MEDIDA DEL CAUDAL}

La placa orificio utilizada en la medición del caudal de aire en la instalación, ha sido previamente calibrada mediante una tobera de acero inoxidable de la casa TECNER Ingeniería [W -11], modelo TG50 (figura III.27), con rango de trabajo entre $3200 \mathrm{l} / \mathrm{min}$ y $13000 \mathrm{l} / \mathrm{h}$, y con pérdida de carga conocida.
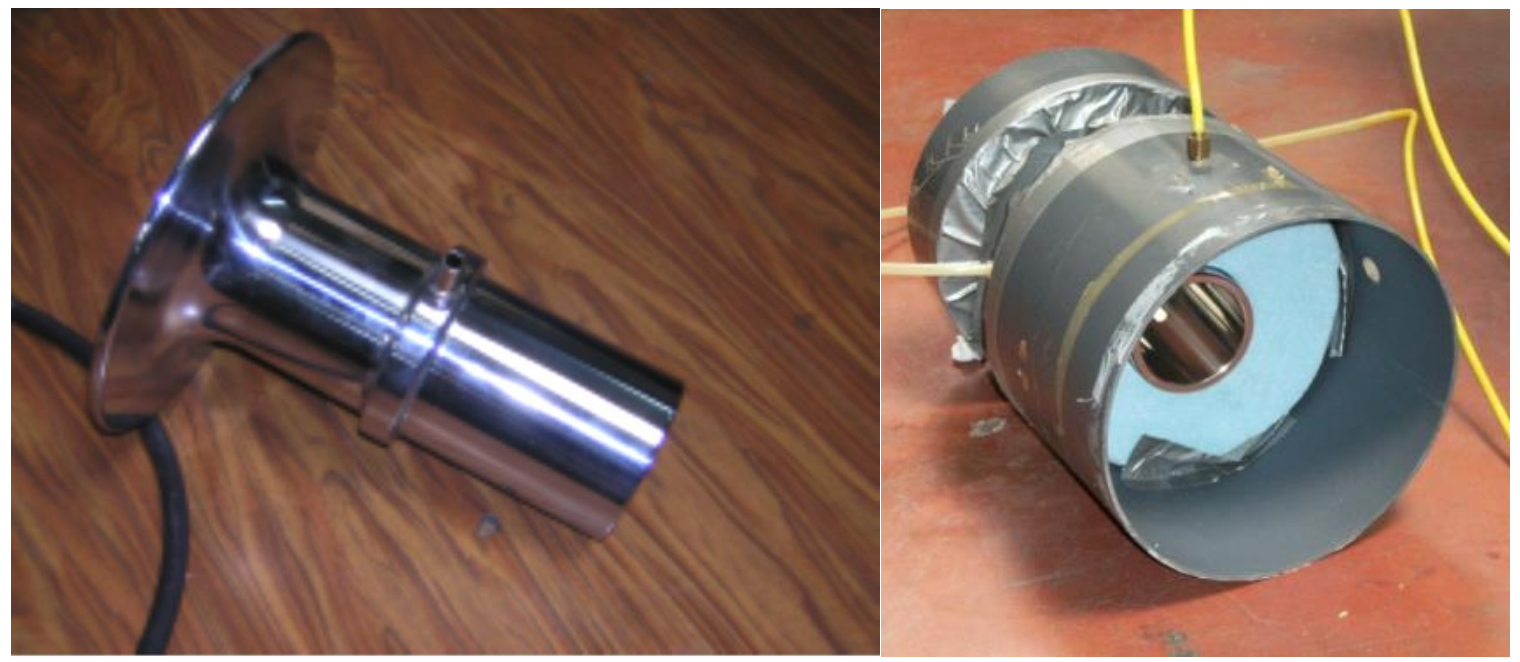

Figura III.27.- Tobera de referencia para la calibración de las placas, a la drcha. montada en conducto.

En su instalación intercalada en un conducto para la calibración, hay que prever una longitud recta equivalente a 6 diámetros aguas arriba de la tobera, y a 3 diámetros aguas debajo de la tobera (figura III.28).

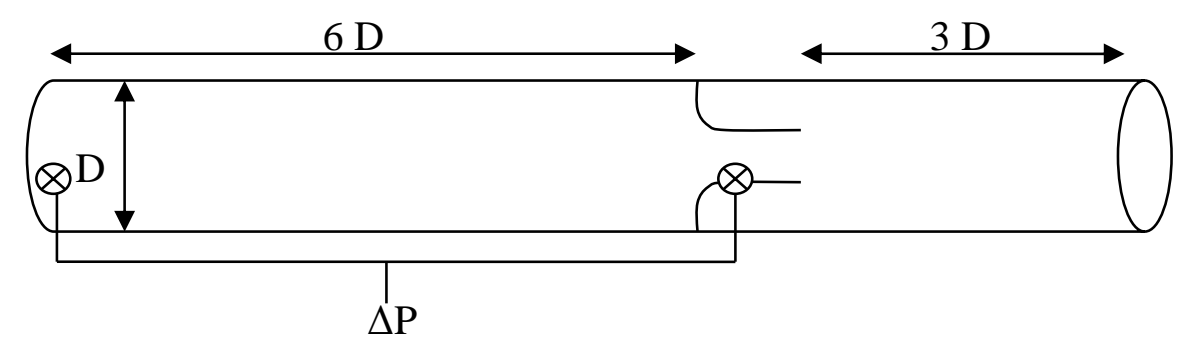

Figura III.28.- Esquema de la instalación de la tobera para la calibración.

Las especificaciones dadas para la tobera por el fabricante se proporcionan en el anexo A.

Con el caudal calculado a partir de las medidas de caída de presión registradas en la tobera, se procede a calibrar la placa orificio. El resultado de esta calibración se puede observar en la figura III.29. 

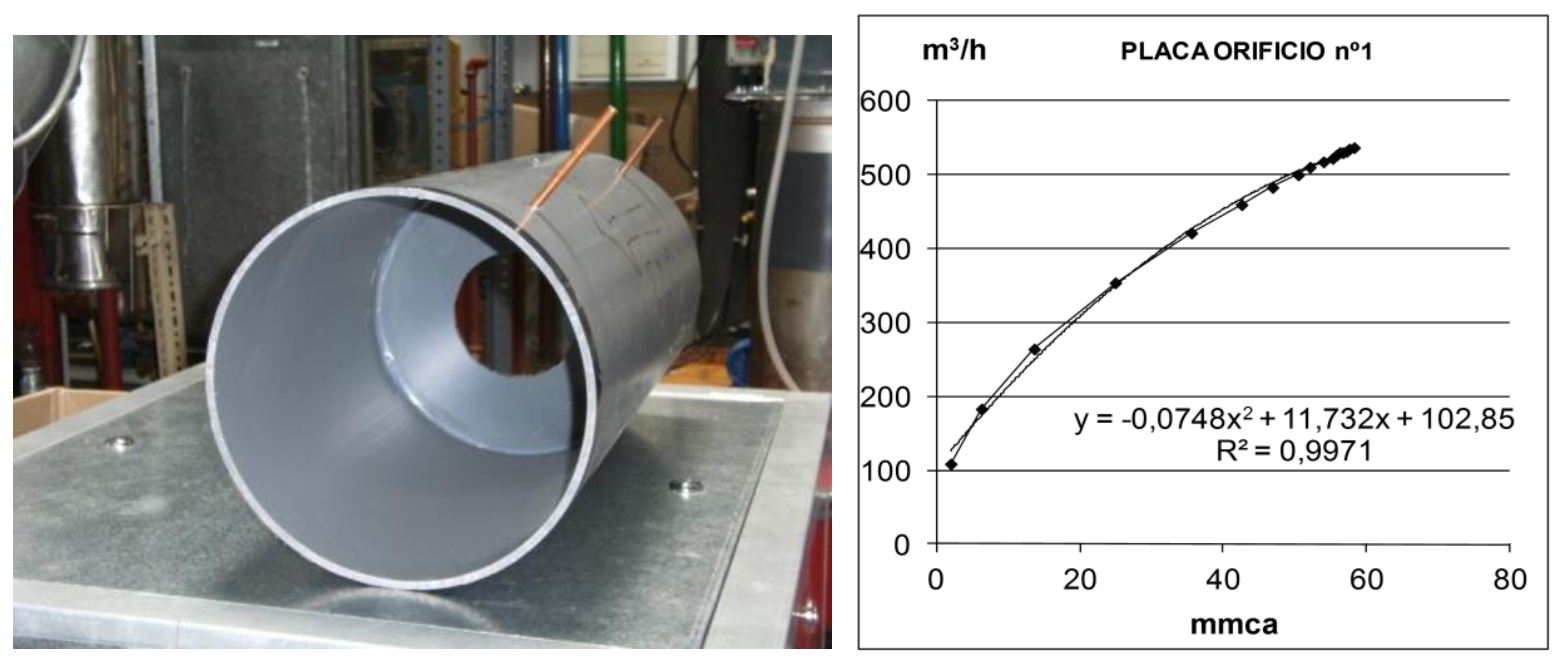

Figura III.29.- Placa orificio y gráfica de calibración obtenida para la misma.

\section{CALIBRACIÓN DE LOS MANÓMETROS DE PRESIÓN DIFERENCIAL}

Los manómetros de presión (figura III.30), utilizados en la determinación del caudal de aire circulante por los distintos canales mediante la medición de la diferencia de presión generada en la tobera, también calibrada a su vez. Se han calibrado registrando su respuesta ante presiones manométricas del aire comprendidas entre 0 y 90 mmca. Estos sensores proporcionan una salida de tensión proporcional a la presión aplicada. Se han empleado dos sensores de presión ultrabaja de la casa RS, modelo V9966 [10]. La recta de regresión de uno de estos manómetros se muestra a modo de ejemplo en la figura III.31 (véase el anexo $A$ ).

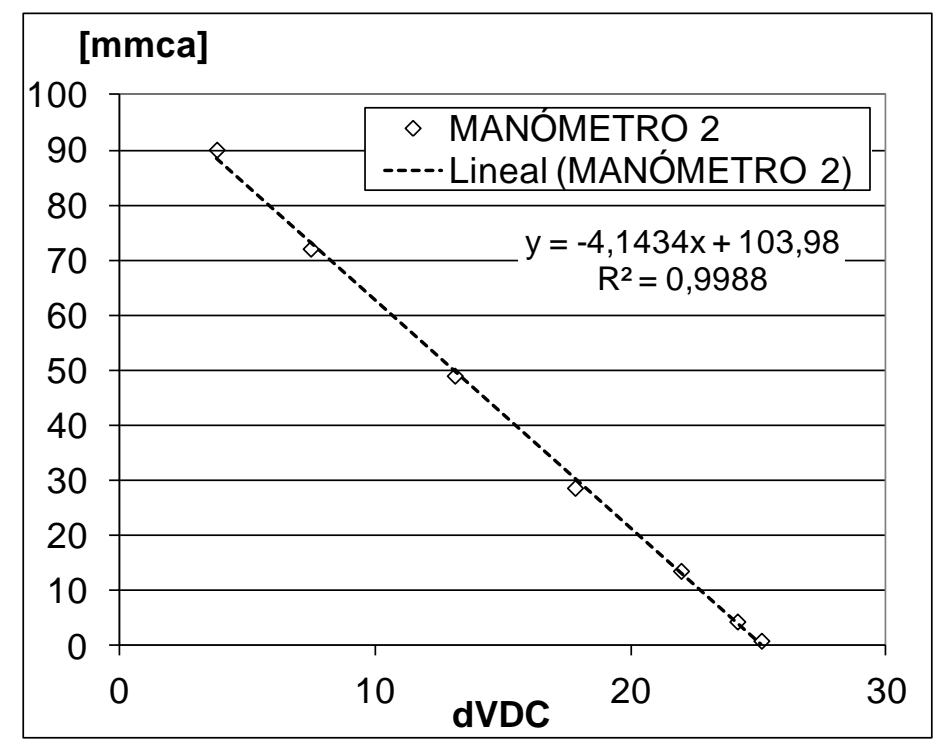

Figura III.30.- Rectas de calibración de los manómetros de presión. 


\section{REFERENCIAS}

[1] TROX TECHNIK, 2002. Climatizadores serie TKM-30. Información del producto, 2002.

[2] SODECA, 2009]. Catálogo de ventiladores SODECA. Tarifa de precios, 2009.

[3[] CAREL, 2007. Humidificador por electrodos sumergidos CAREL HumiSteam X-Plus. Manual de usuario, 2007.

[4] CEI, 1996. Aplicaciones eficientes de Lámparas. Cuadernos de eficacia energética en iluminación №1. Comité Español de lluminación. 1996.

[5] Ferroli, 2007. Acondicionador de Ambiente DIAMOND, Ferroli. Manual del Instalador, 2007.

[6] SOLER \& PALAU. Extractores centrífugos de baja presión, gama CBM. Catálogo. Soler\&Palau

[7] Thermal Ceramics. Hoja de características técnicas de las mantas aislantes Superwool Bulk and Blanket. Thermal Ceramics.

[8] Ahlborn, 2008. Hoja de características técnicas piranómerto Star Pyranometer Type FLA628S.Ahlborn, 2008.

[9] Agilent, 2010. Agilent 34970A Data Acquisition/Switch Unit Family, Product Overview 34970A 34972A. Agilent Technologies Inc., USA.

[10] RS, 2002. Hoja de instrucciones del sensor de presión diferencial V9966, RS, 2002]

\section{NORMATIVA.}

[N-1] Ministerio de Industria, Turismo y Comercio y Ministerio de Vivienda de España, "Real Decreto 1027/2007: Reglamento de Instalaciones Térmicas en Edificios". 


\section{PÁGINAS WEB.}

[W-1] TROX TECHNIK. http://www.trox.es/es/ Página del fabricante Trox Technik en España donde se puede descargar la información técnica sobre los climatizadores de la serie TKM y de los difusores de la serie VDW. (Último día de consulta: 3 de julio de 2017).

[W-2] SODECA. http://www.sodeca.com/Página del fabricante SODECA, donde se puede descargar la información técnica sobre los ventiladores centrífugos de la gama CMP. (Último día de consulta: 3 de julio 2017).

[W-3] TRANE. http://www.trane.com/commercial/europe/es Página del fabricante TRANE, donde se puede descargar información técnica sobre sus productos (Último día de consulta: 3 julio 2017).

[W-4] CAREL. http://www.carel.com Página del fabricante CAREL, donde se puede descargar la información técnica sobre los humidificadores de electrodos HumiSteam X-plus. (Último día de consulta: 5 de julio de 2017).

[W-5] FERROLI http://www.ferroli.es Página del fabricante Ferroli en España, donde se puede descargar la información técnica sobre los acondicionadores de ambiente de los modelos Diamond. (Último día de consulta: 5 de julio de 2017).

[W-6] SOLER \& PALAU http://www.solerpalau.es/ Página del fabricante Soler\&Palau, donde se puede descargar la información técnica sobre los ventiladores centrífugos CBM. (Último día de consulta: 5 de julio de 2017).

[W-7] RS http://es.rs-online.com Página del fabricante y proveedor RS, donde se puede consultar y descargar información técnica sobre los productos. (Último día de consulta: 10 de julio de 2017).

[W-8] HONEYWELL http://sensing.honeywell.com Página de los productos de control y medida del fabricante Honeywell, donde se puede consultar y descargar información técnica sobre las sondas de humedad relativa capacitivas. (Último día de consulta: 10 de julio de 2017).

[W-9] AGILENT http://www.agilent.com Página del fabricante AGILENT, de donde se puede descargar información sobre los SAD. (Último día de consulta: 11 de julio de 2017).

[W-10] TESTO https://www.testo.com/es-ES/ Página del fabricante TESTO (Último día de consulta: 11 de julio de 2017).

[W-11] TECNER INGENIERÍA http://www.tecner.com/ Página del fabricante TECNER ingeniería. (Último día de consulta: 11 de julio de 2017). 
[W-12] FLUKE http://eu.flukecal.com/products/process-calibration-tools/temperaturecalibrators/field-temperature-sources/9103-9140-9141-?quicktabs product details=1

Página del fabricante FLUKE donde se puede descargar información sobre el horno de calibración de temperatura. (Último día de consulta: 11 de julio de 2017). 
CAPÍTULO III: BANCO DE ENSAYOS 


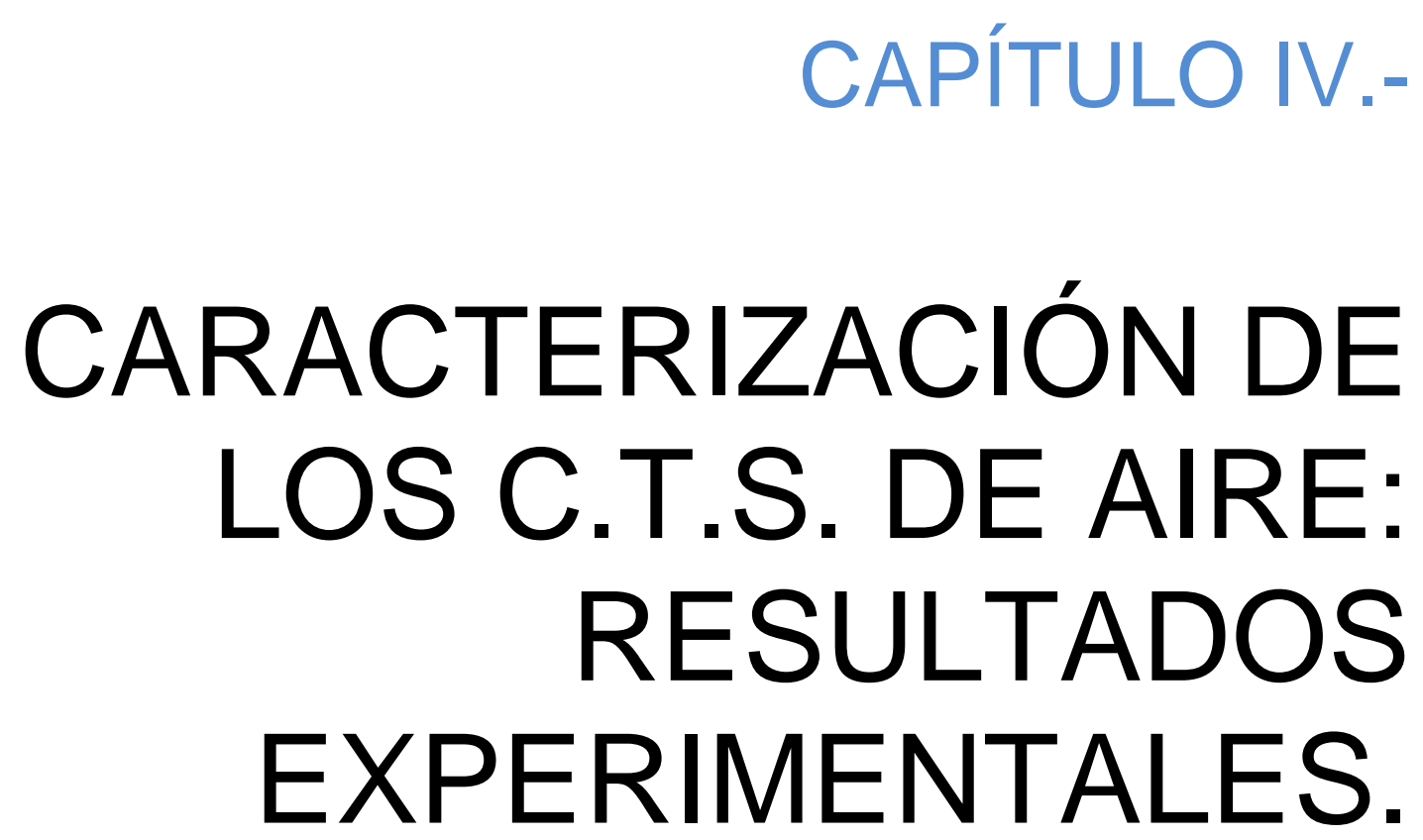

CONTENIDOS DEL CAPÍTULO:

IV.1.- INTRODUCCIÓN. 173

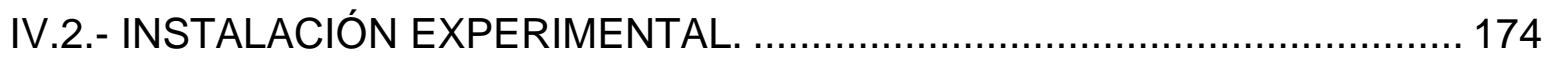

IV.2.1.- COLECTOR TÉRMICO SOLAR DE AIRE ESTUDIADO. ..............................175

IV.2.2.- BATERÍA DE LÁMPARAS INCANDESCENTES HALÓGENAS. .....................178

IV.3.- DISEÑO DE EXPERIMENTOS. METODOLOGÍA DE ENSAYOS............. 182

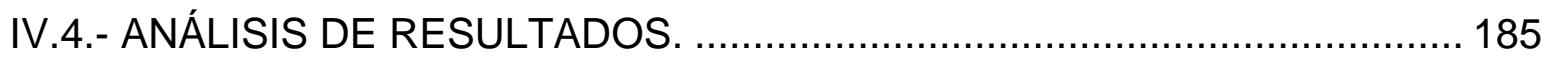

PARÁMETROS CONSIDERADOS EN LA CARACTERIZACIÓN EXPERIMENTAL. ..185

RESULTADOS DE LA CARACTERIZACIÓN EXPERIMENTAL. ................................185

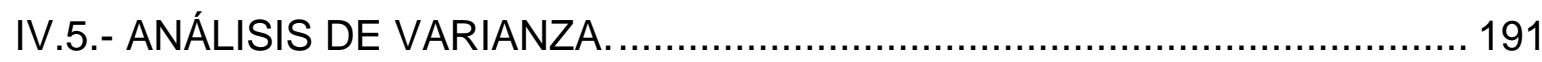

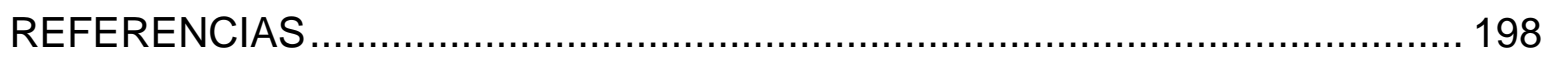

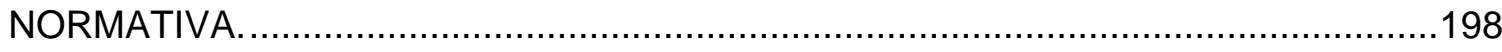


CAPÍTULO IV: CARACTERIZACIÓN DE LOS C.T.S. RESULTADOS EXPERIMENTALES

170 


\section{LISTA DE FIGURAS:}

Figura IV.1.- Vista esquemática de la instalación con los diferentes dispositivos. 174

Figura IV.2.- Esquema del dispositivo experimental. 175

Figura IV.3.- Colector solar de aire estudiado. 175

Figura IV.4.- Esquema del TWIN SOLAR 4.0.[3] 177

Figura IV.5.- Vista del trazado de la malla empleado para la medida de la irradiancia. 178

Figura IV.6.- Distribución de la irradiancia sobre los paneles. Nivel de irradiancia máximo. 179

Figura IV.7.- Distribución de la irradiancia sobre los paneles, vista alternativa. Nivel de irradiancia máximo. 180

Figura IV.8.- Distribución de la irradiancia sobre los paneles. Nivel de irradiancia intermedio. .... 181 Figura IV.9.- Distribución de la irradiancia sobre los paneles, vista alternativa. Nivel de irradiancia intermedio. 181

Figura IV.9.- Esquema de los distintos ensayos a realizar. 183

Figura IV.10.- Evolución registrada de las medidas de temperatura y presión diferencial durante el ensayo para $I_{R}=828,4 \mathrm{~W} / \mathrm{m}^{2}, \mathrm{Q}=300 \mathrm{~m}^{3} / \mathrm{h}$ y $\mathrm{T}_{\text {entrada }}=10^{\circ} \mathrm{C}$. 184

Figura IV.11.- Salto térmico alcanzado para los diferentes caudales de aire ensayados con la irradiancia máxima $\left(828,4 \mathrm{~W} / \mathrm{m}^{2}\right)$...... 186

Figura IV.12.- Salto térmico alcanzado para los diferentes caudales de aire ensayados con la irradiancia media $\left(447,9 \mathrm{~W} / \mathrm{m}^{2}\right)$. 186

Figura IV.13.- Energía aportada para la irradiancia máxima $\left(828,4 \mathrm{~W} / \mathrm{m}^{2}\right)$............................ 188

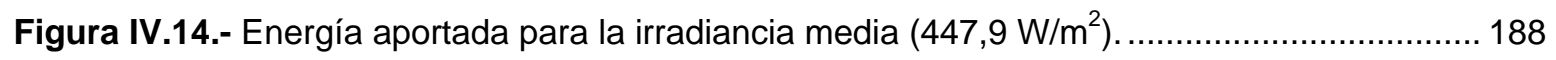

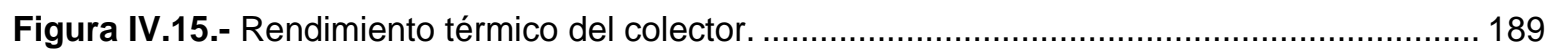

Figura IV.16.- Gráficas factoriales para el salto de temperaturas............................................. 191

Figura IV.16.- Gráficas factoriales para la potencia útil....................................................... 191

Figura IV.17.- Gráficas factoriales para el rendimiento..................................................... 192

Figura IV.18.- Gráficas de las interacciones factoriales dobles para el salto térmico................... 193

Figura IV.19.- Gráficas de las interacciones factoriales dobles para la potencia útil................... 194

Figura IV.20.- Gráficas de las interacciones factoriales dobles para el rendimiento. ................... 195 


\section{LISTA DE TABLAS:}

Tabla IIV.1.- Valores de irradiancia, en $\mathrm{W} / \mathrm{m}^{2}$, en cada uno de los sectores de la malla sobre el colector. Nivel de irradiancia máximo. 179

Tabla IV.2.- Valores de irradiancia, en $\mathrm{W} / \mathrm{m}^{2}$, en cada uno de los sectores de la malla sobre el colector. Nivel de irradiancia intermedio. 180

Tabla IV.3.- Configuración del diseño de experimentos. 182

Tabla IV.4.- Recopilación de los resultados de los experimentos 190

Tabla IV.5.- Recopilación de los valores medios de los ensayos realizados para cada nivel de los factores mantenido constante. 191

Tabla IV.6.- Valores medios de las interacciones dobles para el salto térmico. 193

Tabla IV.7.- Valores medios de las interacciones dobles para la potencia útil. 194

Tabla IV.8.- Valores medios de las interacciones dobles para el rendimiento. 195

Tabla IV.9.- Recopilación de los coeficientes de contribución derivados del ANOVA realizado sobre los factores del diseño de experimentos. 196

Tabla IV.10.- Desglose del porcentaje de error en los coeficientes de contribución de las interacciones entre los factores del diseño de experimentos. 196 


\section{IV.1.- INTRODUCCIÓN.}

Se ha visto en el capítulo I de esta Tesis Doctoral que es en el sector de la edificación donde existe una mayor posibilidad de reducción del consumo de energía de origen no renovable, planteando alternativas que permitan una disminución de la demanda, la mejora de la eficiencia energética de equipos y el aprovechamiento de fuentes de energía alternativas.

Al mismo tiempo, las normativas tienden a exigir cada vez unos mayores caudales de ventilación para garantizar una adecuada calidad del aire interior que conlleva un aumento de las necesidades energéticas destinadas al acondicionamiento higrotérmico de los locales [N-1].

Ante esta situación, los colectores solares de aire constituyen una de las tecnologías con mayor potencial de aplicación de la energía solar, permitiendo con su utilización un importante ahorro energético en los sistemas de climatización de los edificios, especialmente en invierno [1] [2].

Como ya se ha visto en el capítulo II de esta tesis, cuentan con numerosas ventajas con respecto a los colectores solares de agua: menor inercia térmica debido a la capacidad calorífica del fluido de trabajo, incrementan la eficiencia de las instalaciones al evitar intercambios de calor intermedios, operación notablemente más sencilla evitando entre otros, problemas de corrosión, fugas, congelación del fluido, etc., lo que a su vez conlleva unos costes de fabricación más reducidos [2].

El interés hacia el estudio de esta tecnología para una incorporación más extendida a los sistemas de climatización de los edificios es el principal objetivo del presente proyecto de Tesis Doctoral impulsado por el Grupo de Termotecnia de la Universidad de Valladolid, disponiendo para ello del dispositivo experimental equipado con el colector solar de aire comercial presentado en el capítulo anterior. La caracterización experimental va a permitir prever las opciones y optimizaciones del sistema para su aplicación en instalaciones.

Como se va a poder observar, la caracterización del funcionamiento de los colectores requiere de un delicado control y registro de los distintos parámetros de interés que permita extraer conclusiones para las diferentes posibilidades de operación del sistema dentro de una aplicación real. 


\section{IV.2.- INSTALACIÓN EXPERIMENTAL.}

Una vez se cuenta con los diferentes elementos expuestos en el capítulo anterior es necesario disponerlos y conectarlos de tal forma que el espacio disponible en el laboratorio sea suficiente y que esta configuración permita alcanzar las diferentes condiciones de operación a ensayar. Esta configuración se lleva a cabo a partir de los recursos disponibles en el laboratorio, descritos en capítulo IIV. Como los C.T.S. se establecieron en el laboratorio para este estudio, se dispuso de una estructura metálica que permitió la ubicación de los colectores en un nivel superior sobre la UTA (ver figura IV.1). De forma similar, se colocó suspendida del techo del laboratorio otra estructura construida con perfiles metálicos que soportaba la batería de focos que permitió simular las condiciones de irradiación solar. Como ya se ha visto en el capítulo IV el transporte del aire de unos elementos a otros se llevó a cabo a través de unos conductos flexibles que permiten una mayor versatilidad.

En la figura IV.1 se puede observar la disposición particularizada de los elementos del banco de ensayos que veíamos en el capítulo IV para llevar a cabo esta caracterización, mientras que en la figura IV.2 se representa un esquema del dispositivo experimental:

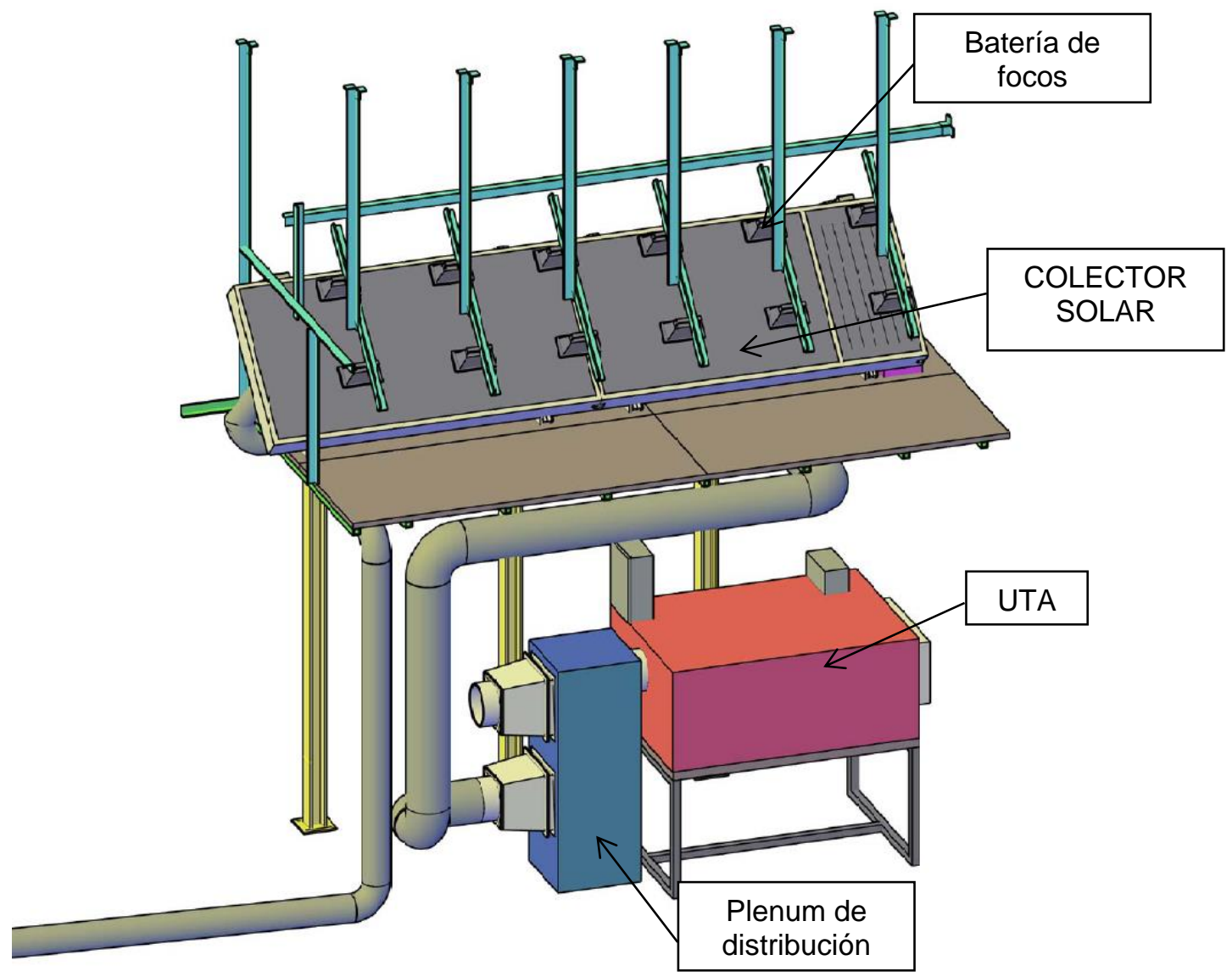

Figura IV.1.- Vista esquemática de la instalación con los diferentes dispositivos. 
BATERIA DE LÁMPARAS
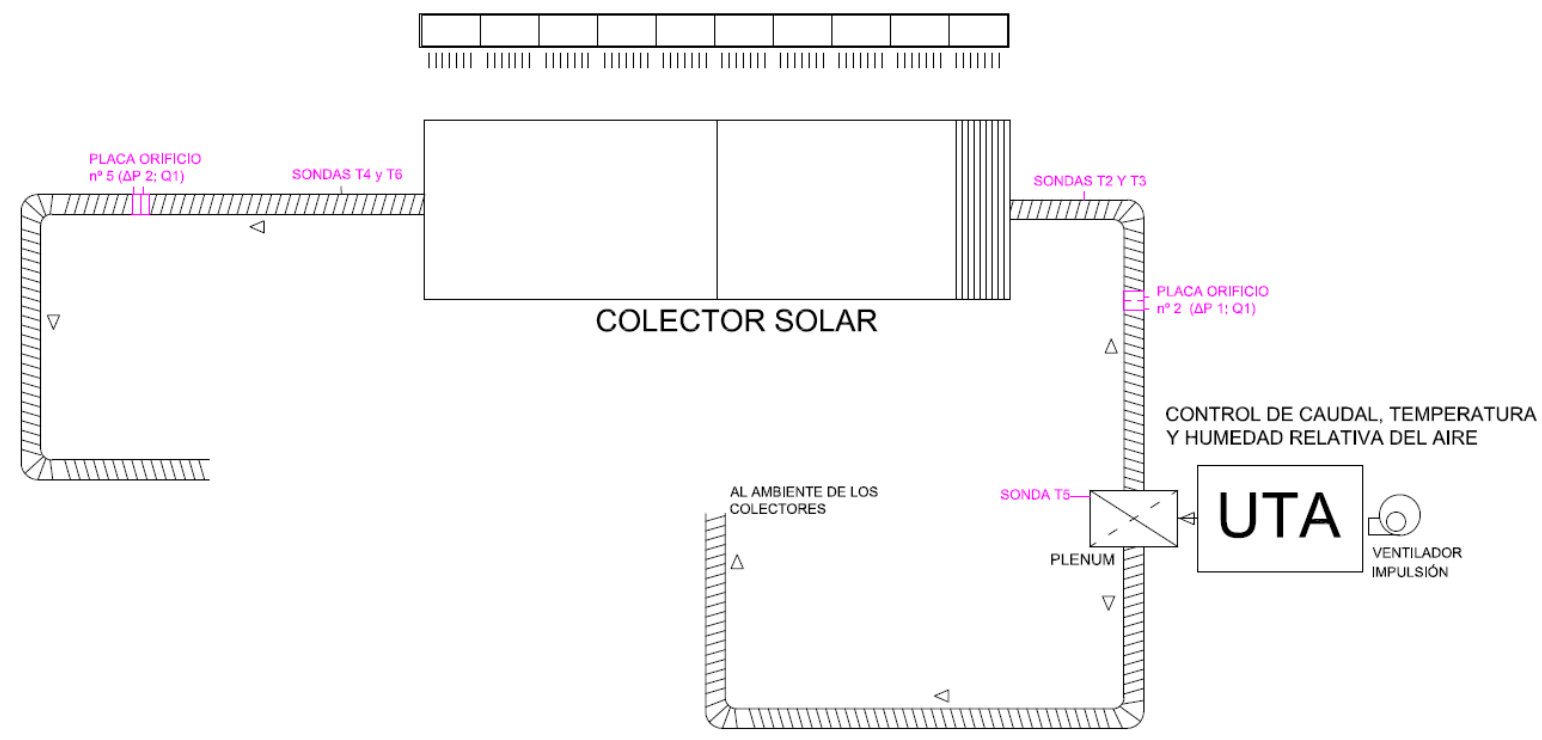

Figura IV.2.- Esquema del dispositivo experimental.

\section{IV.2.1.- COLECTOR TÉRMICO SOLAR DE AIRE ESTUDIADO.}

La figura IV.3 muestra una vista real y un esquema del colector de aire estudiado. Se trata del modelo comercial TwinSolar 4.0-SLK del fabricante Grammer Solar, con unas dimensiones de 4000 x 1006 x $136 \mathrm{~mm}$ (longitud $\mathrm{x}$ ancho $\mathrm{x}$ altura) y un peso de $90 \mathrm{Kg}$ [3].

El equipo es un colector con cubierta de vidrio simple y con un solo paso del caudal de aire por la parte posterior del absorbedor. Este caudal se reparte en 24 canales de sección rectangular $(40 \mathrm{~mm} \times 34 \mathrm{~mm})$. Las pérdidas de calor hacia el exterior se limitan gracias al aislamiento de fibra de vidrio en las caras laterales y en la posterior, así como a una cámara de aire estanca de $1 \mathrm{~cm}$ de espesor dispuesta entre la cubierta transparente y el absorbedor.

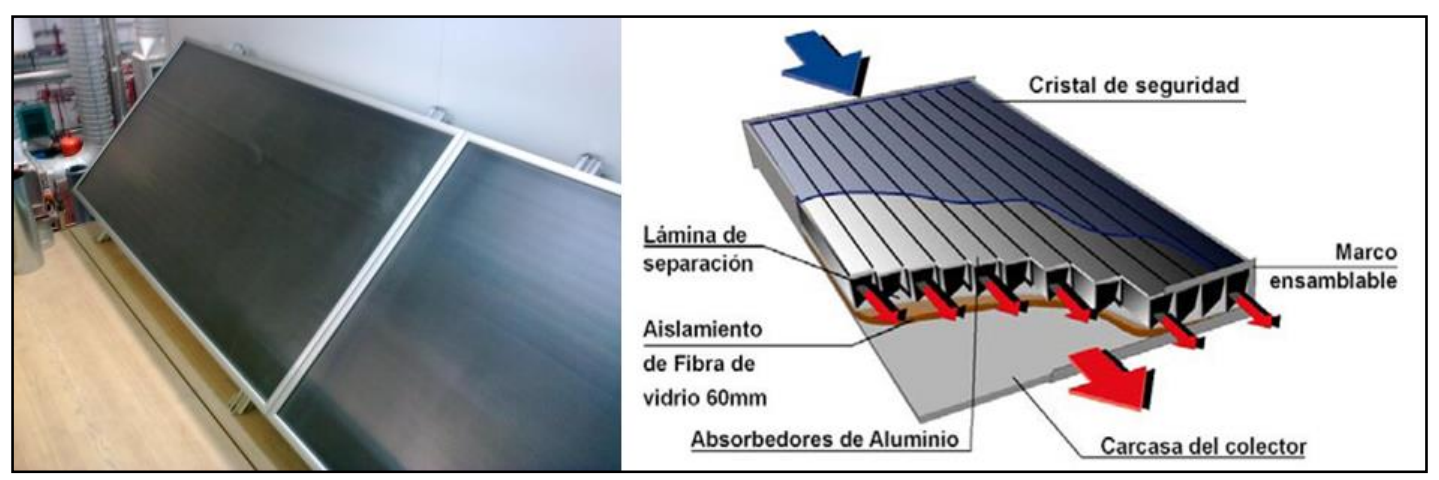

Figura IV.3.- Colector solar de aire estudiado. 
Las características del colector y sus componentes son las siguientes [^]:

- Carcasa:

Dimensiones (longitud $x$ anchura $x$ altura en $\mathrm{mm}$ ): $4000 \times 1006 \times 136$

Material: Aluminio

- Absorbedor

Material: Aluminio de 0,6 $\mathrm{mm}$ de espesor

- Cubierta transparente

Material: ESG. Vidrio de seguridad templado resistente a las condiciones climáticas.

Espesor: $4 \mathrm{~mm}$

Características del vidrio: -Peso específico: $2500 \mathrm{~kg} / \mathrm{m}^{3}$

-Resistencia elástica: $12-20 \mathrm{~kg} / \mathrm{mm}^{2}$

-Calor específico: $670 \mathrm{~J} / \mathrm{kg} \cdot \mathrm{K}$

-Coeficiente de dilatación lineal: $9 \cdot 10^{-6}$

-Índice de refracción: 1,52

-Transmitancia media: 0,91

-Absortancia media: 0,09

-Conductividad térmica: $1,05 \mathrm{~W} / \mathrm{m} \cdot \mathrm{K}$

\section{- Aislamiento térmico}

Material: Planchas de lana mineral

Conductividad térmica: $0,040 \mathrm{~W} / \mathrm{m} \cdot \mathrm{K}$

Espesor: $50 \mathrm{~mm}$ (parte trasera), $20 \mathrm{~mm}$ (laterales)

El colector dispone de un módulo fotovoltaico que permite accionar un ventilador que opcionalmente se puede colocar a la salida del colector para forzar la circulación del aire a través del colector. La potencia pico de este módulo fotovoltaico es de $54 \mathrm{~W}$, mientras que la potencia del ventilador centrífugo mencionado es de $50 \mathrm{~W}$. También dispone de ser necesario de silenciadores para la atenuación del ruido provocado por el ventilador.

En la disposición de nuestro banco de ensayos no hemos hecho uso de ninguno de estos elementos (ventilador, silenciador, módulo PV), ya que se disponía de presión de aire suficiente aportada por la UTA que permitió la caracterización con diferentes caudales de aire.

En la figura IV.4 se puede observar un esquema del colector TwinSolar 4.0-SLK [3]: 

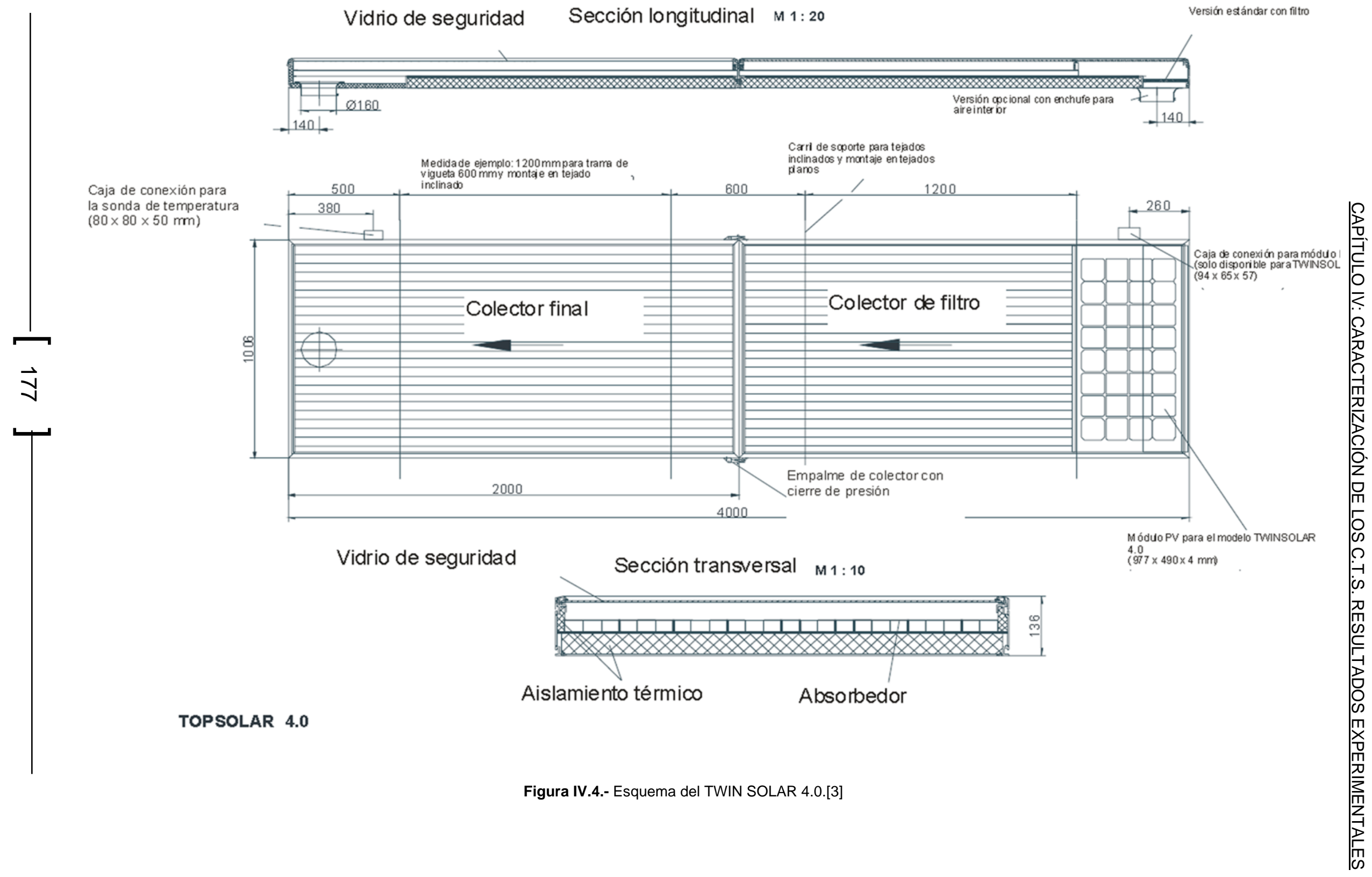


\section{IV.2.2.- BATERÍA DE LÁMPARAS INCANDESCENTES HALÓGENAS.}

Este sistema nos permite cubrir la necesidad de disponer de diferentes niveles de irradiación sobre nuestro campo de colectores. En el capítulo IV se han descrito las características de los focos y su disposición.

En este capítulo se desarrolla el estudio experimental y se presentan los niveles y distribución de la irradiancia sobre el colector que nos aporta este sistema de iluminación.

Para conocer la potencia radiante incidente sobre la superficie de los colectores en los dos niveles de irradiación, asociados a las dos posiciones de funcionamiento establecidas para los ensayos, se han llevado a cabo una serie de medidas con un piranómetro. Para ello se trazó una malla sobre la cubierta de uno de los colectores y se llevó a cabo la medida de la irradiancia en cada uno de esos puntos que definen la malla, en la Figura IV.5 se puede observar la disposición seguida para las medidas.

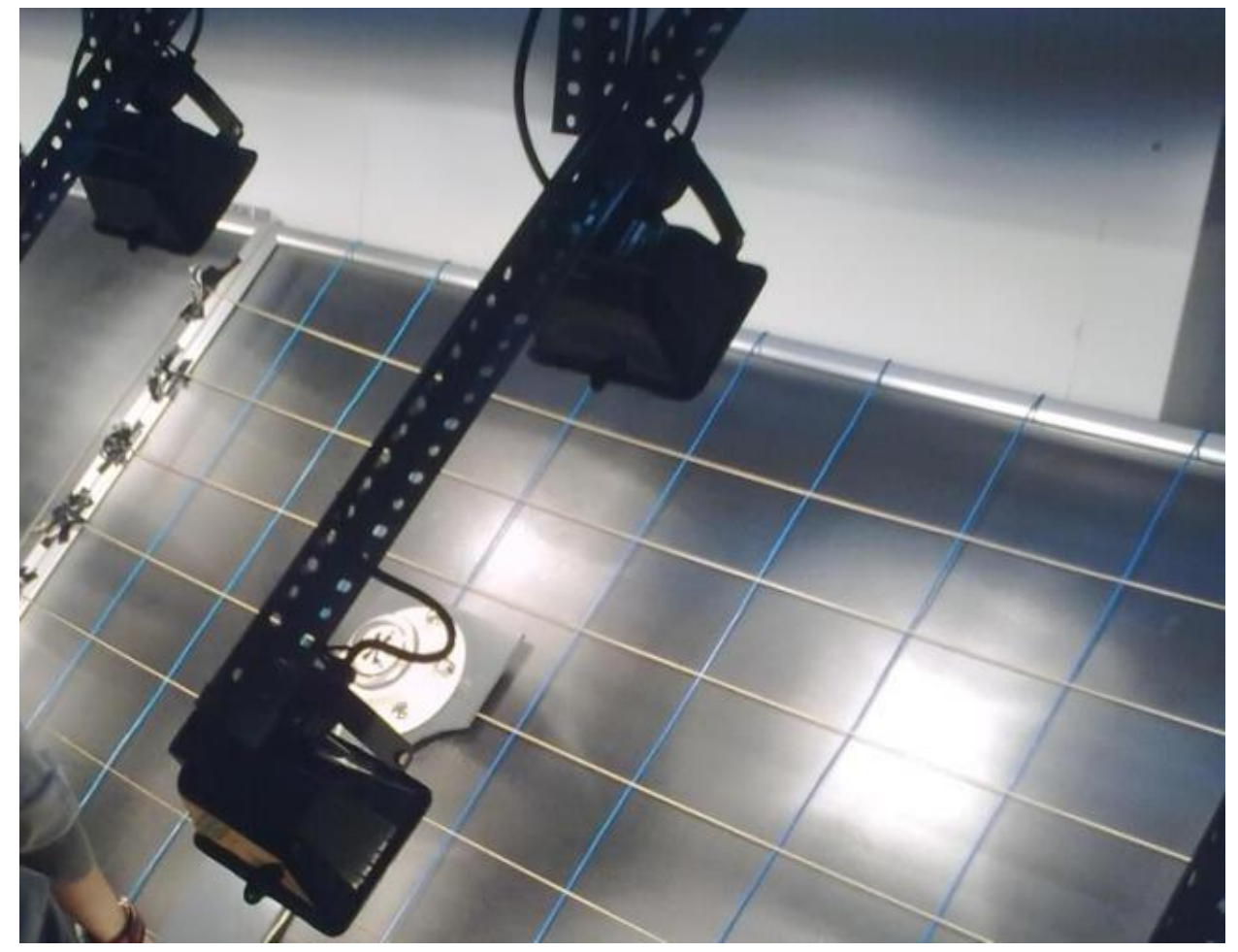

Figura IV.5.- Vista del trazado de la malla empleado para la medida de la irradiancia.

Las medidas llevadas a cabo con el piranómetro nos han arrojado los siguientes resultados: 
a) Nivel de irradiancia máxima, correspondiente a la posición de funcionamiento con todos los focos encendidos:

- Nivel de irradiancia máximo medido: $1758,0 \mathrm{~W} / \mathrm{m}^{2}$.

- Nivel de irradiancia medio aproximado: $828,4 \mathrm{~W} / \mathrm{m}^{2}$.

- Nivel de irradiancia medio aproximado sin despreciar zonas de sombreamiento elevado: $731,5 \mathrm{~W} / \mathrm{m}^{2}$.

A continuación se representa la distribución de la irradiancia sobre los colectores:

Tabla IV.1.- Valores de irradiancia, en $\mathrm{W} / \mathrm{m}^{2}$, en cada uno de los sectores de la malla

sobre el colector. Nivel de irradiancia máximo.

\begin{tabular}{|c|c|c|c|c|c|c|c|c|c|c|c|c|}
\hline 147,0 & 638,3 & 69,1 & 638,3 & 69,1 & 638,3 & 326,0 & 715,3 & 12,2 & 595,5 & 369,1 & 604,0 & 47,0 \\
\hline 247,0 & 1595,7 & 579,3 & 595,7 & 579,3 & 15957 & 493,0 & 0 & 61 & 157 & 3 & 0 & 0 \\
\hline 203,0 & 1062 & 5 & & 57 & & & & & & & & 0 \\
\hline 247,0 & 1595,7 & 579,3 & 1595,7 & 579,3 & 1595,7 & 579,3 & 1595,7 & 579,3 & 1595,7 & 579,3 & 1595,1 & 247,0 \\
\hline 147,0 & 638,3 & 369,1 & 638,3 & 369,1 & 638,3 & 369,1 & 638,3 & 369,1 & 638,3 & 369 , & 638,3 & 147,0 \\
\hline
\end{tabular}

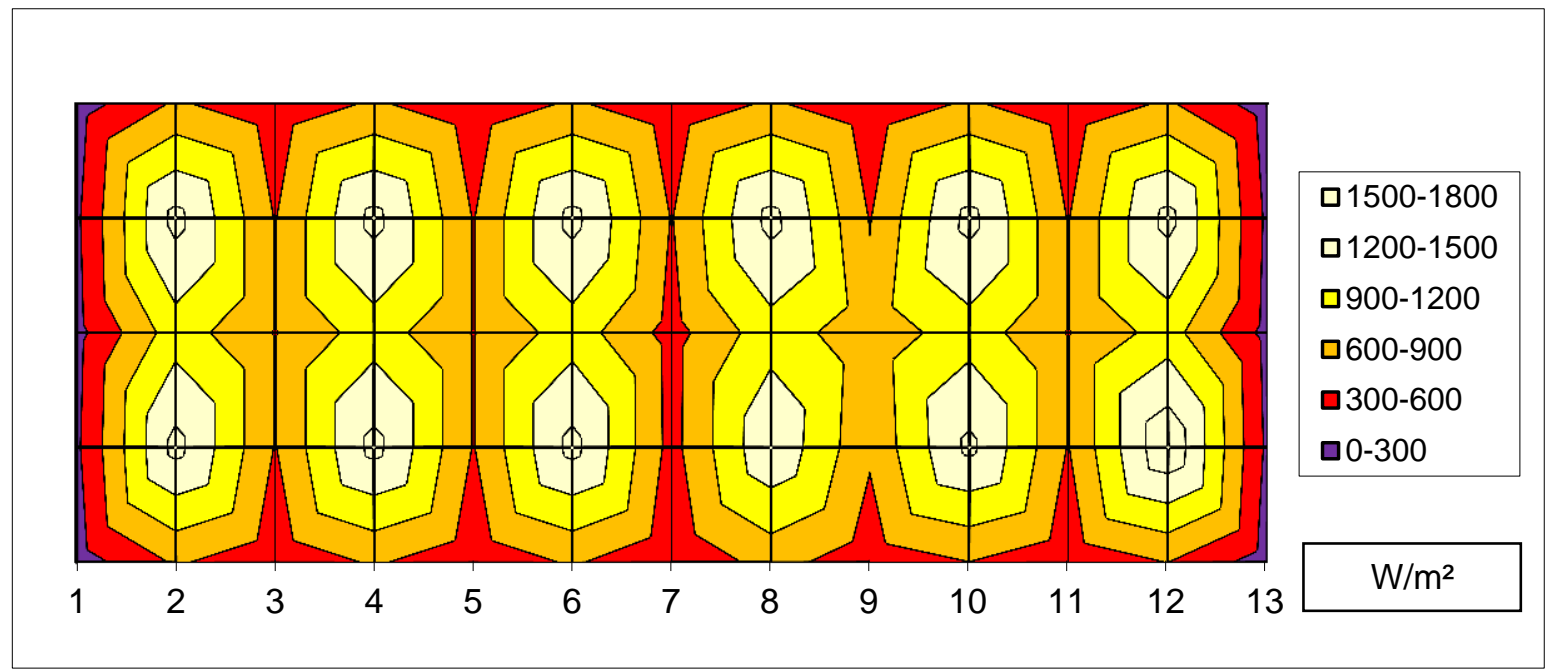

Figura IV.6.- Distribución de la irradiancia sobre los paneles. Nivel de irradiancia máximo.

Podemos ver en el mapa de irradiancia para este nivel que las zonas con mayor incidencia de la radiación son las que se encuentran bajo la perpendicular de cada una de las lámparas, como era de prever. 


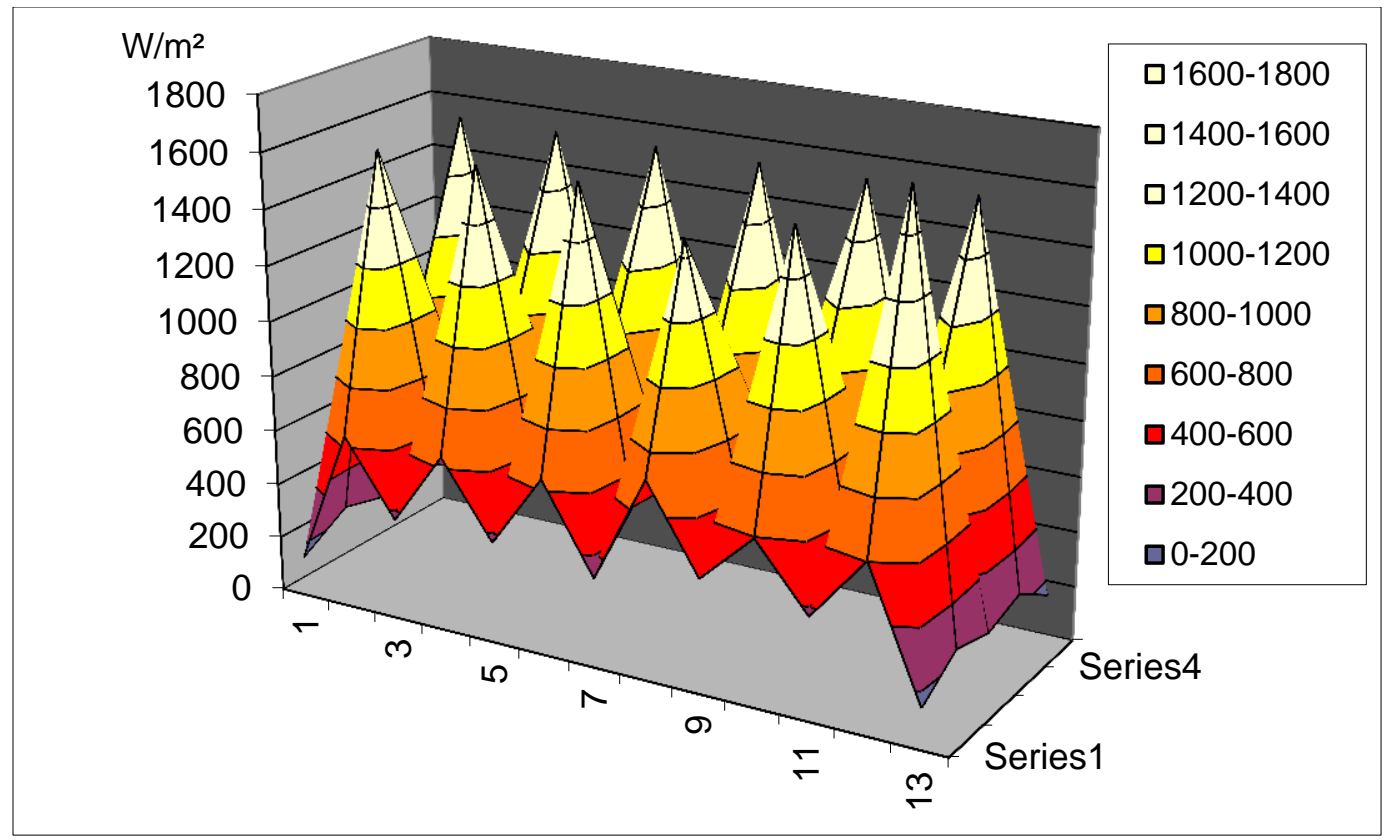

Figura IV.7.- Distribución de la irradiancia sobre los paneles, vista alternativa. Nivel de irradiancia máximo.

b) Nivel de irradiancia intermedio, correspondiente a la posición de funcionamiento con la mitad de los focos encendidos:

- Nivel de irradiancia máximo medido: $1670,0 \mathrm{~W} / \mathrm{m}^{2}$.

- Nivel de irradiancia medio aproximado: $447,9 \mathrm{~W} / \mathrm{m}^{2}$.

- Nivel de irradiancia medio aproximado sin despreciar zonas de sombreamiento elevado: $389,3 \mathrm{~W} / \mathrm{m}^{2}$.

A continuación se representa la distribución de la irradiancia sobre los colectores:

Tabla IV.2.- Valores de irradiancia, en $\mathrm{W} / \mathrm{m}^{2}$, en cada uno de los sectores de la malla sobre el colector. Nivel de irradiancia intermedio.

\begin{tabular}{|r|r|r|r|r|r|r|r|r|r|r|r|r|}
\hline 83,0 & 565,0 & 218,5 & 4,0 & 218,5 & 565,0 & 218,5 & 4,0 & 218,5 & 565,0 & 218,5 & 4,0 & 1,2 \\
155,0 & 1520,0 & 411,5 & 12,0 & 411,5 & 1520,0 & 411,5 & 12,0 & 416,3 & 1520,0 & 411,5 & 12,0 & 2,7 \\
92,0 & 419,0 & 393,0 & 637,5 & 393,0 & 419,0 & 393,0 & 637,5 & 393,0 & 419,0 & 393,0 & 637,5 & 92,0 \\
2,7 & 18,1 & 421,0 & 1670,0 & 421,0 & 18,1 & 421,0 & 1670,0 & 421,0 & 18,1 & 421,0 & 1670,0 & 155,0 \\
1,2 & 5,0 & 218,5 & 589,0 & 218,5 & 5,0 & 218,5 & 589,0 & 218,5 & 5,0 & 218,5 & 589,0 & 83,0 \\
\hline
\end{tabular}




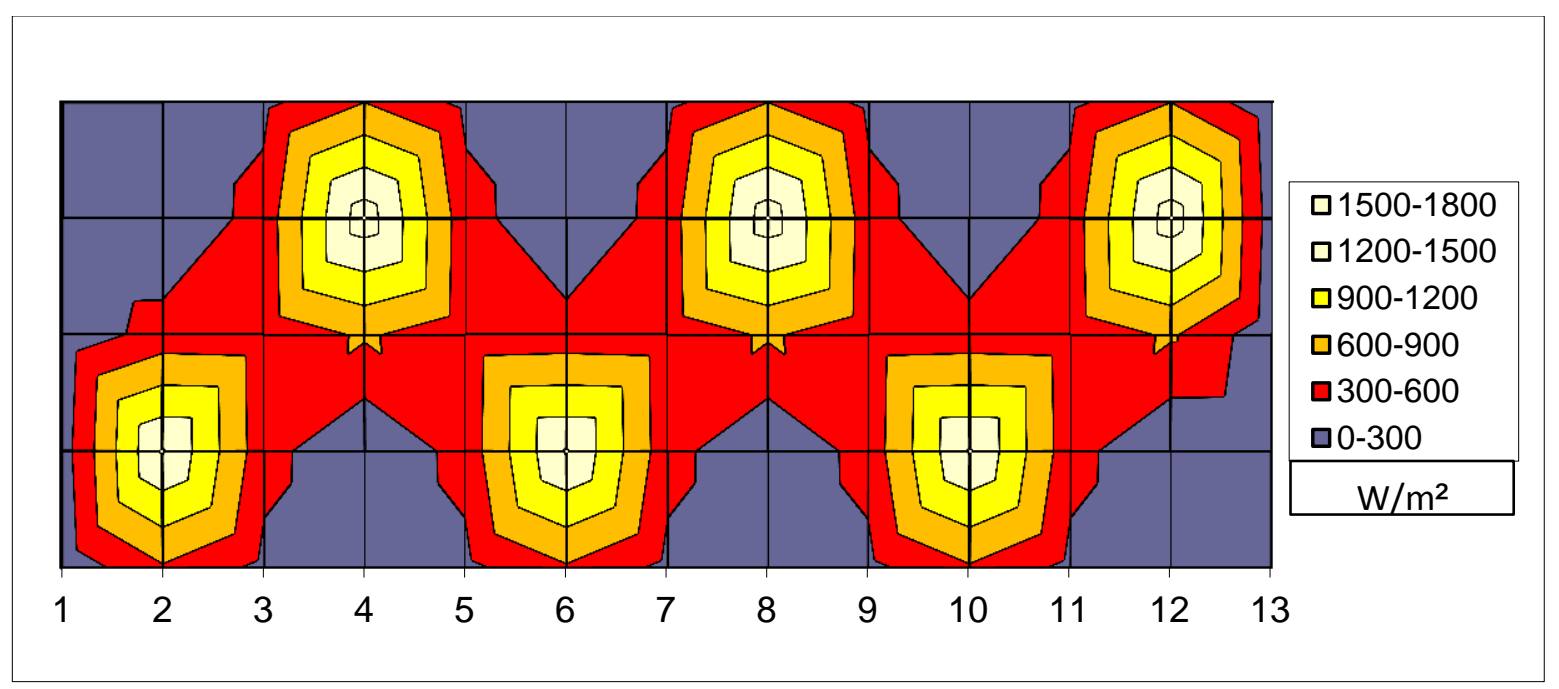

Figura IV.8.- Distribución de la irradiancia sobre los paneles. Nivel de irradiancia intermedio.

En este mapa de irradiancia se puede observar la distribución de encendido de los focos a tresbolillo en este nivel de irradiancia estudiado.

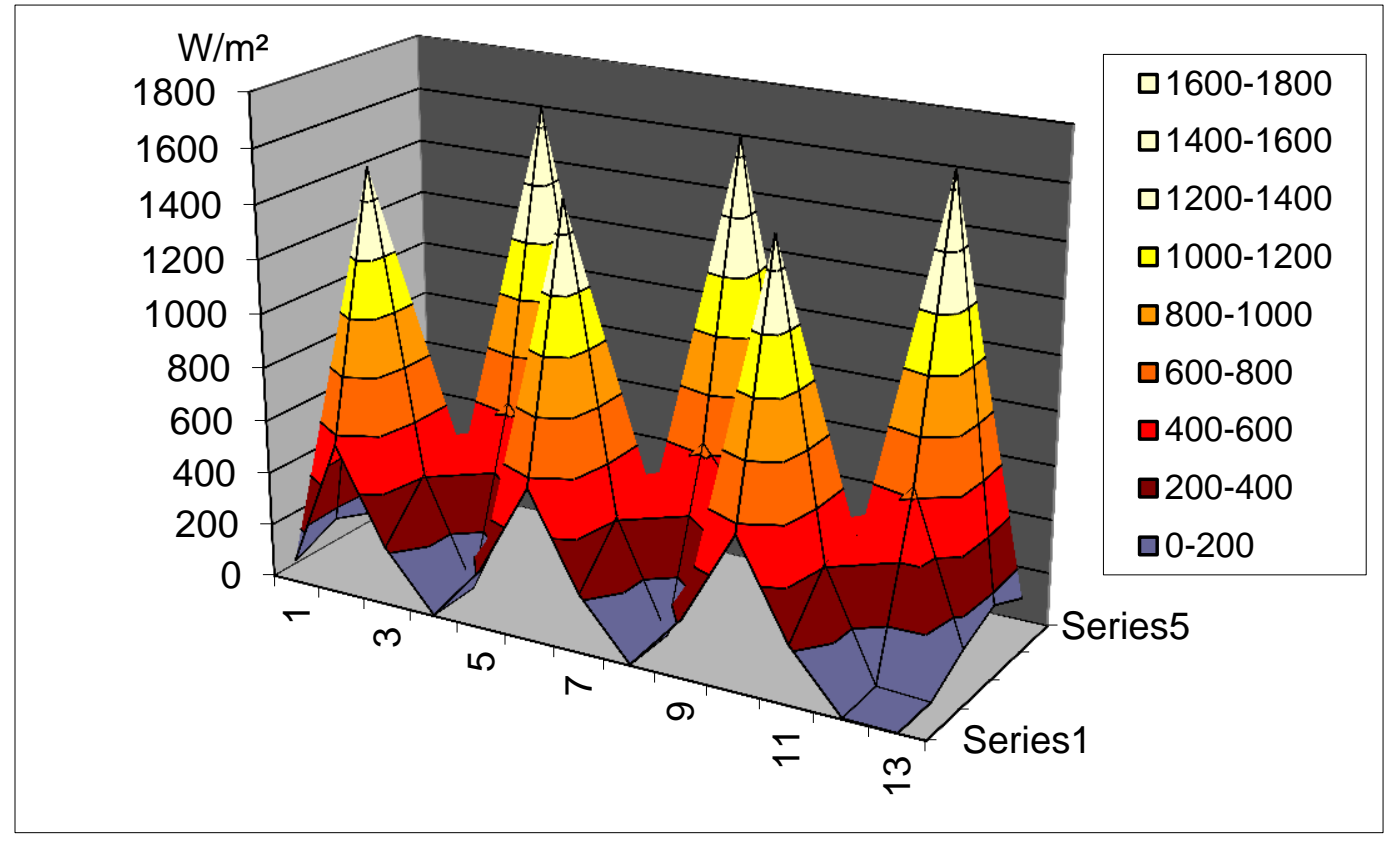

Figura IV.9.- Distribución de la irradiancia sobre los paneles, vista alternativa. Nivel de irradiancia intermedio.

Resumiendo, trabajaremos con dos niveles de irradiancia en los diferentes ensayos; un nivel de radiación máximo cuando todos los focos del banco de ensayos se encuentren encendidos, con una irradiancia media sobre la superficie del colector de $828,4 \mathrm{~W} / \mathrm{m}^{2}$; y un nivel intermedio de radiación, con la mitad de los focos encendidos con una distribución a tresbolillo, y una irradiancia media sobre la superficie del colector de $447,9 \mathrm{~W} / \mathrm{m}^{2}$. 


\section{IV.3.- DISEÑO DE EXPERIMENTOS. METODOLOGÍA DE ENSAYOS.}

Para realizar la caracterización experimental de los colectores solares de aire se propuso un Diseño de Experimentos (véase el Anexo B), según el cual se decidió considerar tres parámetros como factores determinantes del comportamiento del sistema, dos relacionados con el flujo de aire aportado: la temperatura de bulbo seco en la entrada del colector y el caudal, y el tercero relacionado con la radiación térmica sobre el colector solar de aire: la irradiación.

En cuanto a los niveles de irradiancia sobre el colector se fijaron dos niveles aportados por el sistema de iluminación que hemos visto en el apartado anterior, un nivel de irradiancia máximo de $828,4 \mathrm{~W} / \mathrm{m}^{2}$ (I1) y un nivel de irradiancia intermedio de $447,9 \mathrm{~W} / \mathrm{m}^{2}(\mathrm{I} 2)$.

Respecto a los parámetros relacionados con el flujo de aire, se establecieron tres niveles de caudales de aire $\left(\mathrm{C} 1=100 \mathrm{~m}^{3} / \mathrm{h}, \mathrm{C} 2=200 \mathrm{~m}^{3} / \mathrm{h}\right.$ y $\left.\mathrm{C} 3=300 \mathrm{~m}^{3} / \mathrm{h}\right)$. Para el otro parámetro, la temperatura de entrada del aire al colector, se fijaron 4 niveles de temperatura $\left(\mathrm{T} 1=0^{\circ} \mathrm{C}, \mathrm{T} 2=5^{\circ} \mathrm{C}\right.$, $\mathrm{T} 3=10^{\circ} \mathrm{C}$ y $\mathrm{T} 4=15^{\circ} \mathrm{C}$ ), en la tabla IV.3 se muestra la configuración del diseño de experimentos realizado.

Tabla IV.3.- Configuración del diseño de experimentos.

\begin{tabular}{|c|c|c|c|c|c|c|c|}
\hline & & \multicolumn{4}{|c|}{ FACTOR TEMPERATURA } & & \\
\hline & & T1 & T2 & T3 & T4 & & \\
\hline \multirow{6}{*}{ 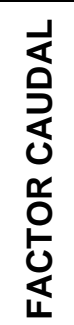 } & C1 & $\mathrm{T} 1 \mathrm{C} 1 \mathrm{I1}$ & $\mathrm{T} 2 \mathrm{C} 1 \mathrm{I1}$ & $\mathrm{T} 4 \mathrm{C} 111$ & $\mathrm{~T} 4 \mathrm{C} 111$ & I1 & \multirow{6}{*}{ 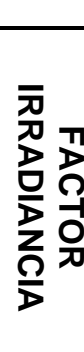 } \\
\hline & $\mathrm{C2}$ & T1C2I2 & T2C2I2 & $\mathrm{T} 4 \mathrm{C} 2 \mathrm{I} 2$ & $\mathrm{~T} 4 \mathrm{C} 2 \mathrm{I} 2$ & 12 & \\
\hline & C3 & T1C3I1 & T2C3I1 & T4C3I1 & T4C3I1 & I1 & \\
\hline & C1 & $\mathrm{T} 1 \mathrm{C} 1 \mathrm{I2}$ & $\mathrm{T} 2 \mathrm{C} 1 \mathrm{I2}$ & $\mathrm{T} 4 \mathrm{C} 1 \mathrm{I} 2$ & $\mathrm{~T} 4 \mathrm{C} 1 \mathrm{l} 2$ & 12 & \\
\hline & $\mathrm{C} 2$ & T1C2I1 & T2C2I1 & T4C2I1 & T4C2I1 & I1 & \\
\hline & C3 & T1C3I2 & T2C3I2 & T4C3I2 & T4C3I2 & 12 & \\
\hline
\end{tabular}




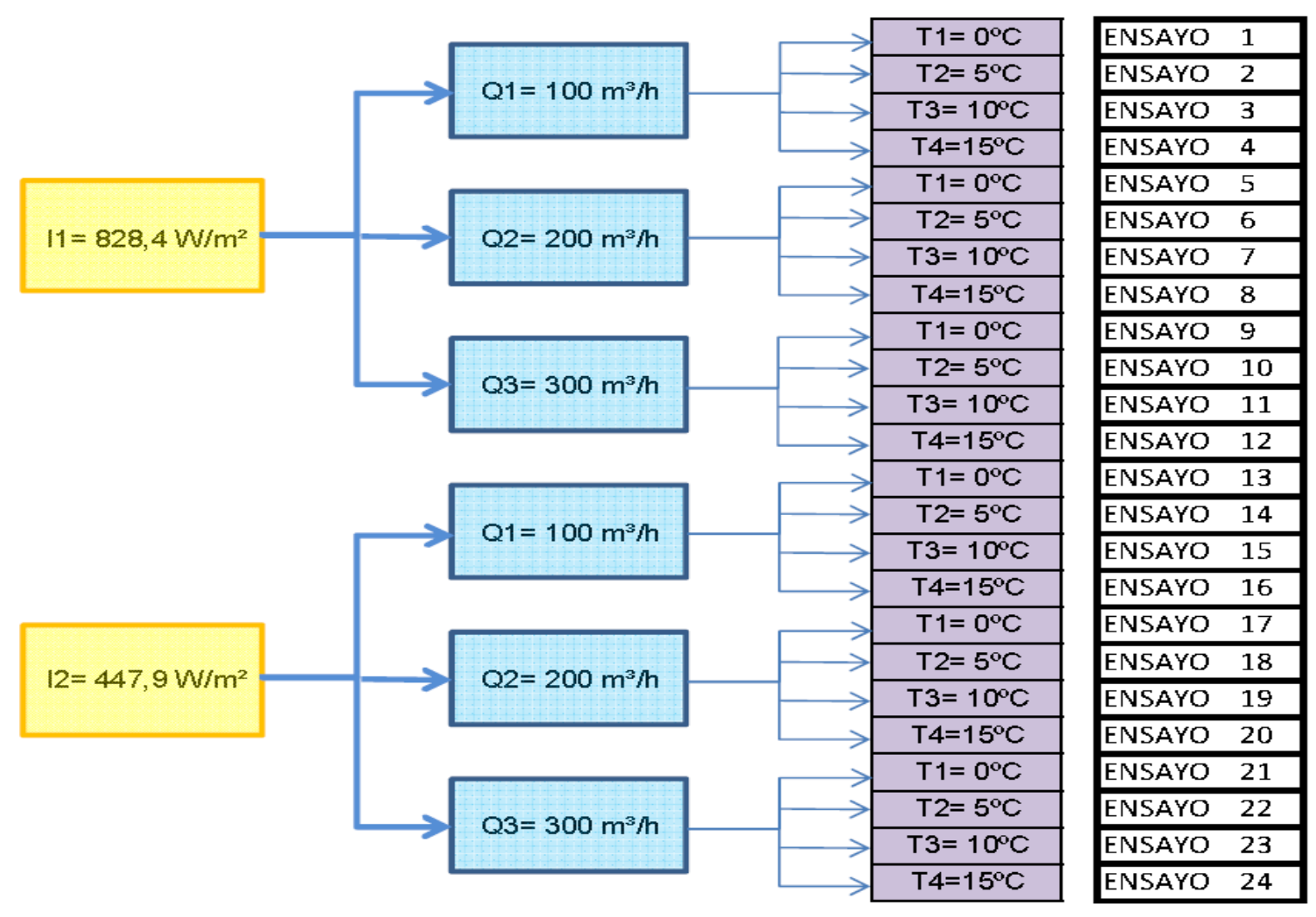

Figura IV.9.- Esquema de los distintos ensayos a realizar.

Los rangos establecidos para el caudal de aire y temperatura seca del aire fueron considerados adecuados para llevar a cabo la caracterización en un amplio espectro de operación 8.del colector. Inicialmente se planteó la posibilidad de alcanzar un caudal mayor, de $400 \mathrm{~m}^{3} / \mathrm{h}$, pero la pérdida de carga del dispositivo experimental no permitía al ventilador de la UTA proporcionar dicho caudal. Del mismo modo, la capacidad de enfriamiento de la batería de frío de la UTA no permitió llevar a cabo ensayos a temperaturas secas negativas de la corriente de aire con altos caudales. Estos rangos o niveles establecidos para las temperaturas secas y caudal de aire durante la experimentación son niveles o valores de referencia, los valores exactos se podrán observar en los registros tomados.

En cuanto a los parámetros de interés a registrar para estudiar el comportamiento del colector son la temperatura seca a la entrada y salida del colector y el caudal de aire que lo atraviesa.

El colector se ha instalado en el banco de ensayos descrito en el apartado anterior, debidamente conectado a los elementos que constituyen este mediante los conductos de conexión disponibles. Los sensores de medida de temperatura se disponen a la entrada y salida del equipo, mientras que la placa orificio para la medida del caudal se ha dispuesto entre la salida de la UTA y la entrada al colector según se ha indicado en el esquema de la figura IV.2. 
Al comienzo de cada ensayo, previo a la lectura de datos, se establecen los parámetros de temperatura seca y caudal volumétrico de operación del equipo en el ensayo correspondiente mediante la UTA, tras lo cual ya se procede a registrar los valores de temperatura seca a la entrada y salida del colector, una vez alcanzado el régimen estacionario de funcionamiento del equipo.

Los datos registrados mediante el sistema de adquisición de datos han sido exportados a formato Excel para su tratamiento. A partir de estos datos se han obtenido distintos parámetros de utilidad para la caracterización del funcionamiento del colector. Los resultados de estos parámetros obtenidos para cada sistema y el estudio de caracterización y comparación derivado de los mismos se muestran en los apartados siguientes.

El gráfico de la figura IV.10 se muestra como ejemplo del registro de datos de las sondas de temperatura y presión diferencial para la medida del caudal de aire durante la realización de uno de los ensayos. Los valores medios obtenidos de las variables adquiridas se recogen como recopilación de resultados de los ensayos, los cuales se proporcionan en los subapartados siguientes.

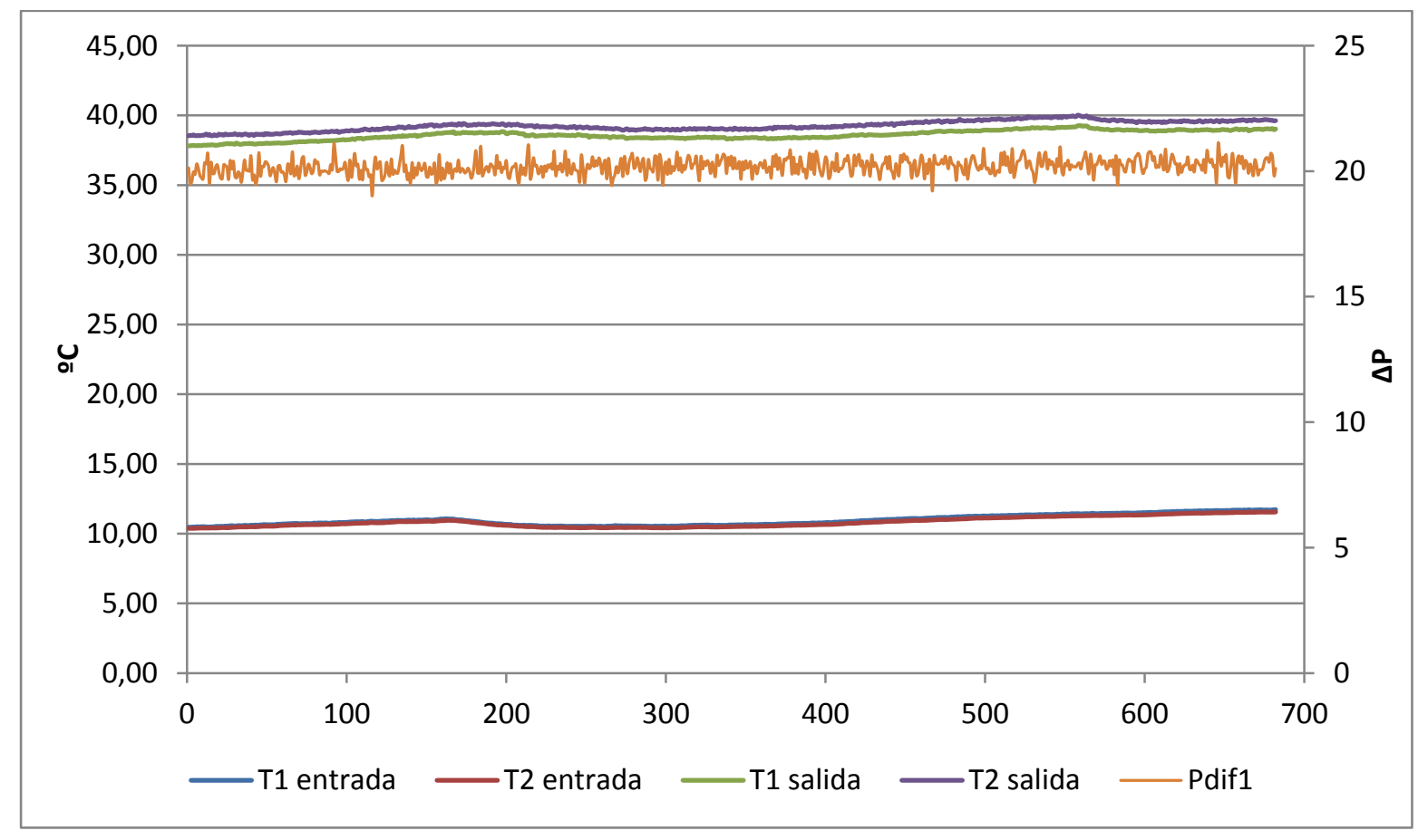

Figura IV.10.- Evolución registrada de las medidas de temperatura y presión diferencial durante el ensayo para $I_{R}=828,4 \mathrm{~W} / \mathrm{m}^{2}, Q=300 \mathrm{~m}^{3} / \mathrm{h}$ y $T_{\text {entrada }}=10^{\circ} \mathrm{C}$. 


\section{IV.4.- ANÁLISIS DE RESULTADOS.}

\section{PARÁMETROS CONSIDERADOS EN LA CARACTERIZACIÓN EXPERIMENTAL.}

Para el estudio de la operación del sistema en las distintas condiciones indicadas en el Diseño de Experimentos, se ha trabajado con los resultados experimentales obtenidos del registro de medidas consideradas de interés para determinar una serie de factores que permitan caracterizar el funcionamiento.

En un primer lugar se analizan los resultados obtenidos directamente en salto de temperaturas del aire logrado en el colector en los distintos casos (ecuación E-IV.1).

$$
\Delta T=T_{a, s a l}-T_{a, e n t}
$$

Otro parámetro estudiado es la energía aportada a la corriente de aire en el colector, directamente relacionado con el salto térmico alcanzado y el flujo másico de aire que atraviesa el colector. Esta energía es calculada según la siguiente expresión (ecuación E-IV.2):

$$
Q_{\text {útil }}=\dot{m} \cdot C_{p} \cdot\left(T_{a, s a l}-T_{a, e n t}\right)
$$

El otro parámetro a estudiar y que nos permite cuantificar el aprovechamiento de energía en el colector es el rendimiento. Analizamos este parámetro de acuerdo a la siguiente expresión (ecuación E-IV.3):

$$
\eta=\frac{\dot{m} \cdot C_{p} \cdot\left(T_{a, s a l}-T_{a, e n t}\right)}{I \cdot S}
$$

El diseño de experimentos planteado nos permite aplicar directamente la relación a partir de las temperaturas del aire a la entrada y salida del colector y el flujo másico medido en cada ensayo.

\section{RESULTADOS DE LA CARACTERIZACIÓN EXPERIMENTAL.}

El análisis de resultados se ha focalizado, con la definición de los parámetros de interés indicados, en el rendimiento térmico del colector para condiciones en las que se hace necesario el calentamiento del aire de aporte de ventilación, fundamentalmente en periodos en los que la temperatura de este aire sea inferior a $20^{\circ} \mathrm{C}$. Para ello, como paso previo, se estableció el salto 
térmico obtenido en el colector en las diferentes situaciones ensayadas. Para los dos niveles de irradiación estudiados los saltos térmicos obtenidos se pueden observar en las figuras IV.11 y IV.12:

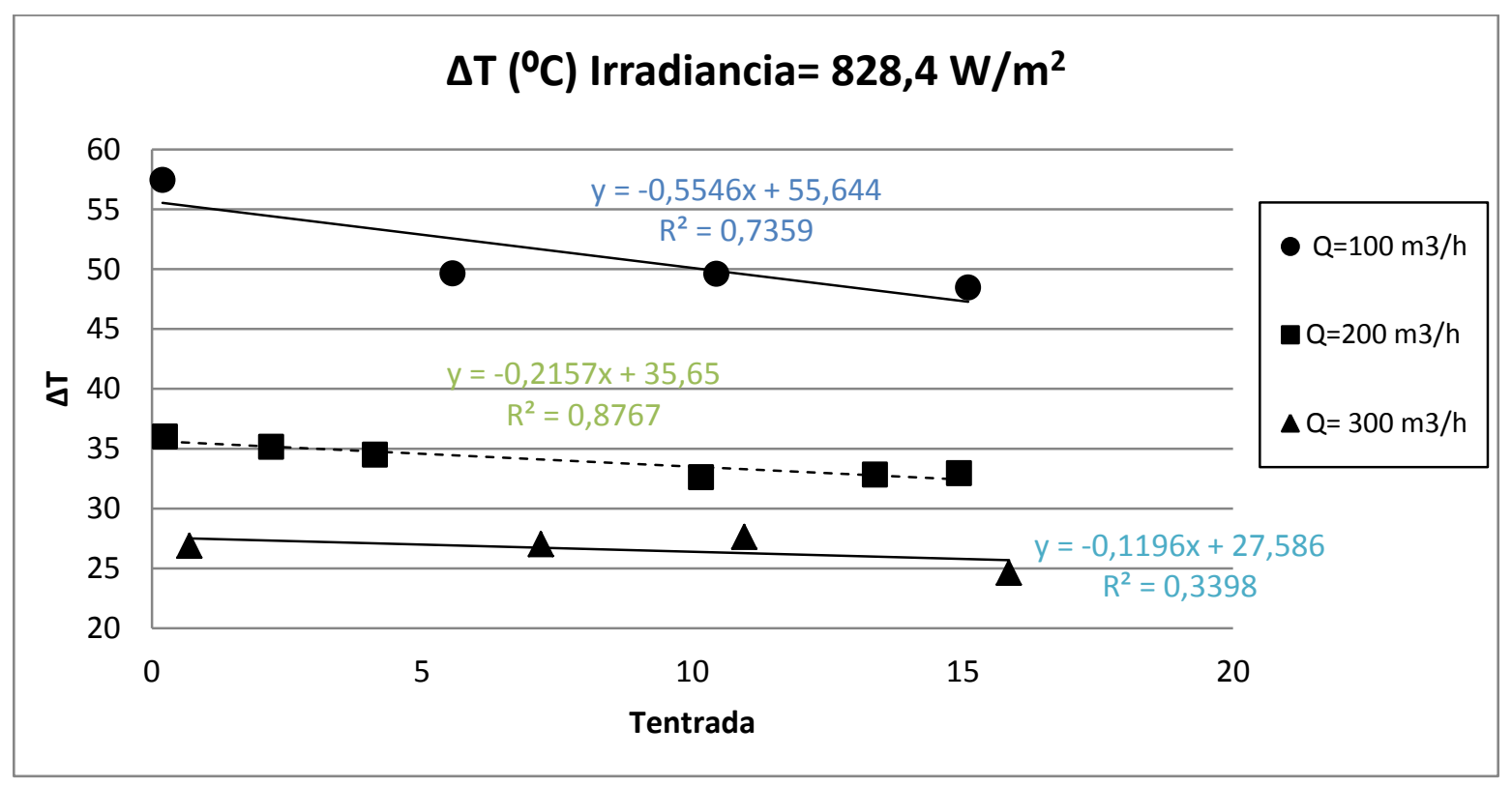

Figura IV.11.- Salto térmico alcanzado para los diferentes caudales de aire ensayados con la irradiancia máxima $\left(828,4 \mathrm{~W} / \mathrm{m}^{2}\right)$.

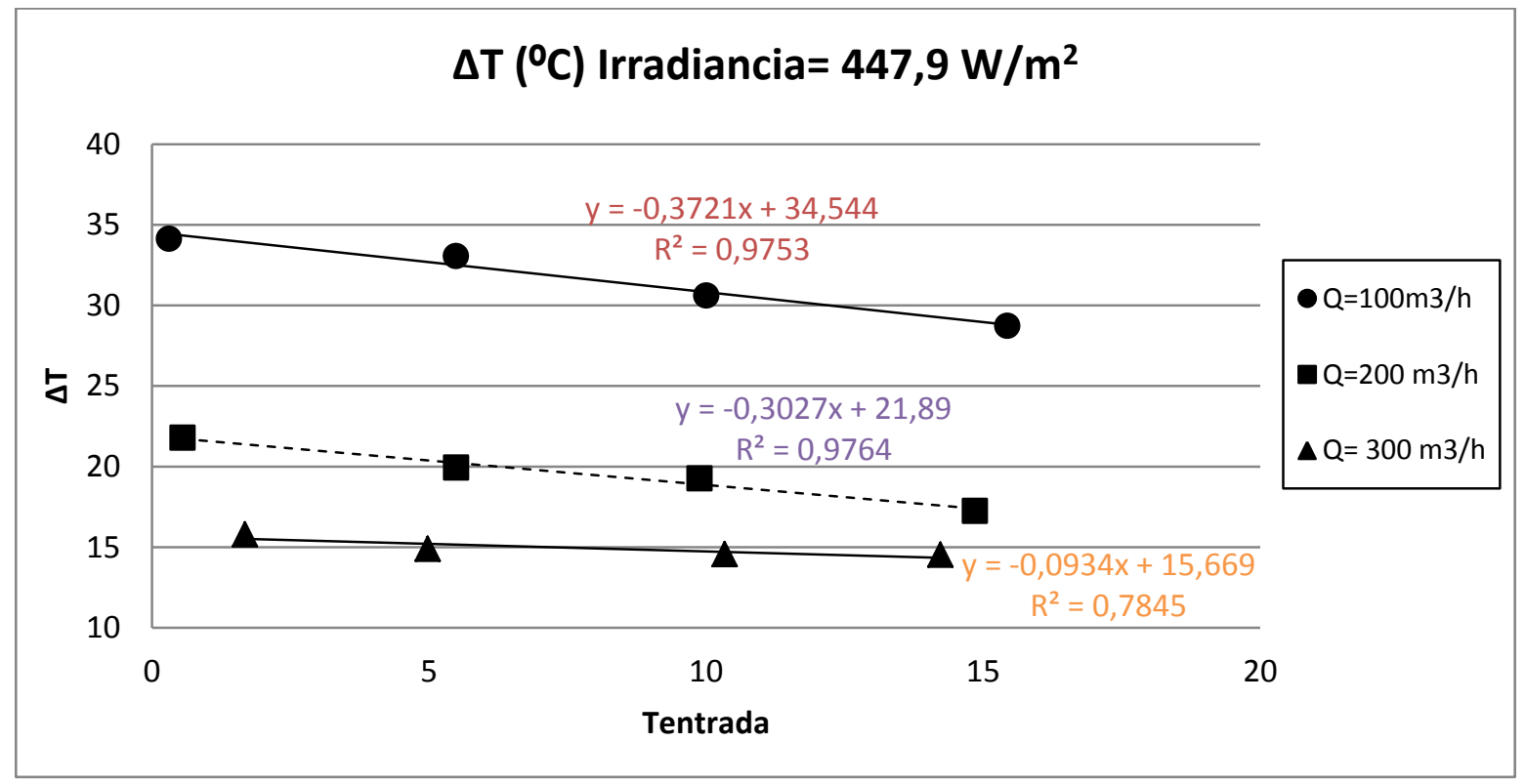

Figura IV.12.- Salto térmico alcanzado para los diferentes caudales de aire ensayados con la irradiancia media $\left(447,9 \mathrm{~W} / \mathrm{m}^{2}\right)$. 
Como puede observarse, el salto de temperaturas es mayor cuando se la temperatura de entrada del aire es más baja, la intensidad radiante mayor y el caudal de aire es el más bajo. Que el mayor salto de temperaturas se obtenga con el nivel más alto de radiación incidente era previsible, la energía incidente sobre el dispositivo es mayor. Asimismo, se intuye que el efecto de los factores irradiancia y caudal es mayor que el del factor temperatura de entrada, lo cual se estudiará en detalle en el ANOVA desarrollado más adelante.

A medida que se incrementa el caudal de aire el salto térmico disminuye, ya que el tiempo de residencia del fluido en el interior del colector es menor. El salto térmico obtenido para caudales más altos tiende a establecerse prácticamente constante.

El ligero incremento de la pendiente de la recta para los caudales más bajos nos muestra un pequeño aumento del salto térmico cuanto menor es la temperatura de entrada del aire. En el ANOVA desarrollado se estudia la incidencia del factor de temperatura de entrada del aire en el salto térmico alcanzado.

Puede notarse alguna desviación en alguna de las tendencias observadas. Esta desviación es fruto principalmente de pequeñas variaciones en los caudales de aire en los ensayos a diferentes niveles de temperatura de entrada. El ajuste del caudal a través del potenciómetro del ventilador de la UTA es uno de los factores más complicados de ajustar, viéndose afectado por cualquier modificación en la configuración del banco de ensayos que altere las pérdidas de carga introducidas por la instalación.

Otro de los parámetros establecidos, el calor aportado, como era de prever aumenta cuando aumenta la irradiancia y el caudal. El factor caudal aparece expresado explícitamente en la ecuación del calor, por lo que su efecto es directo, mayor caudal supone mayor calor aportado. También, el calor es directamente proporcional al salto térmico alcanzado. Sin embargo, el factor caudal influye en el salto de temperaturas, pero en esta ocasión el caudal afecta de manera inversa como hemos podido ver en los párrafos anteriores. Por lo tanto, el efecto global se ve ligeramente "compensado" como se refleja en el ANOVA llevado a cabo y presentado más adelante. Para los dos niveles de irradiación, la energía aportada se puede observar en las figuras IV.13 y IV.14. 


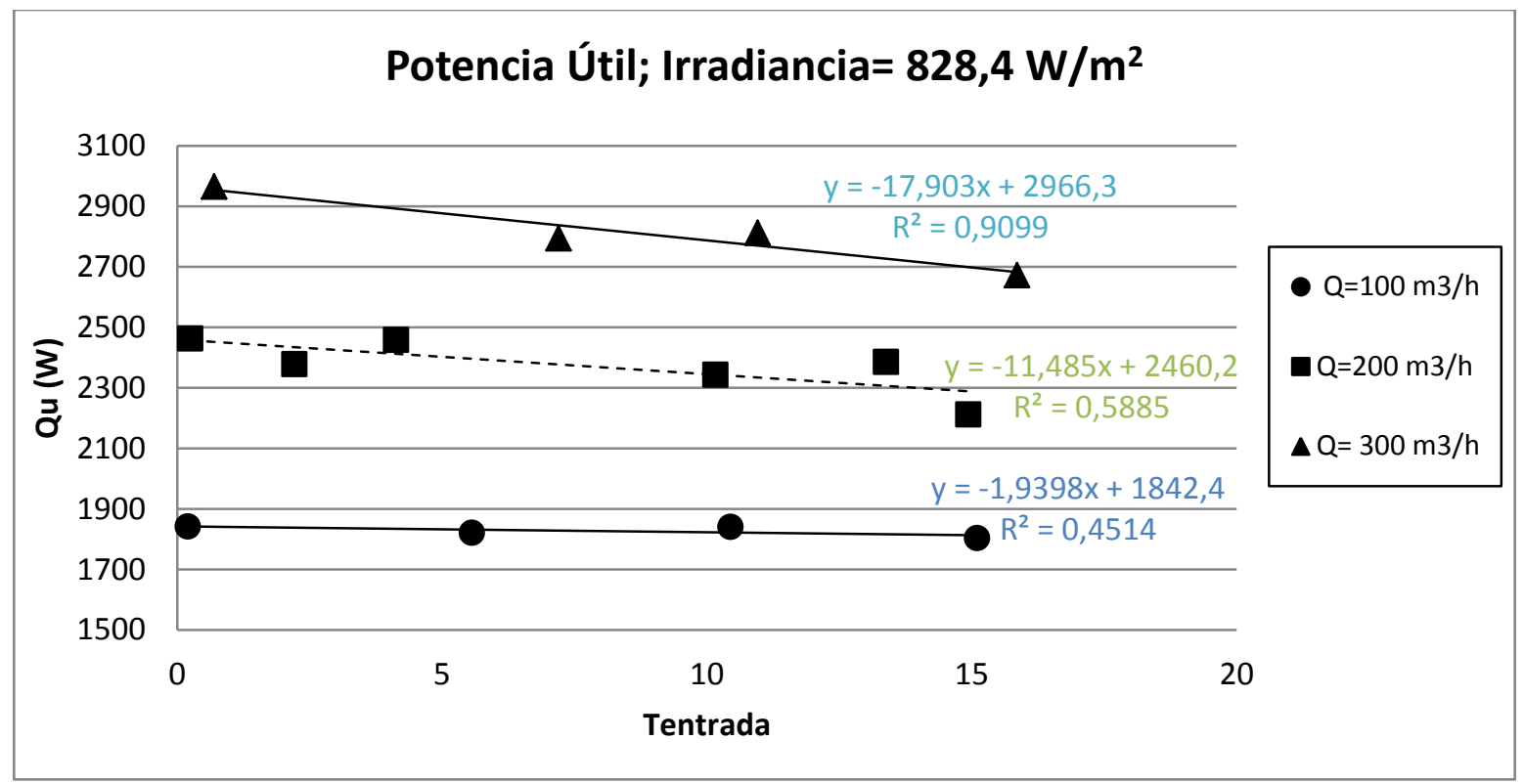

Figura IV.13.- Energía aportada para la irradiancia máxima $\left(828,4 \mathrm{~W} / \mathrm{m}^{2}\right)$.

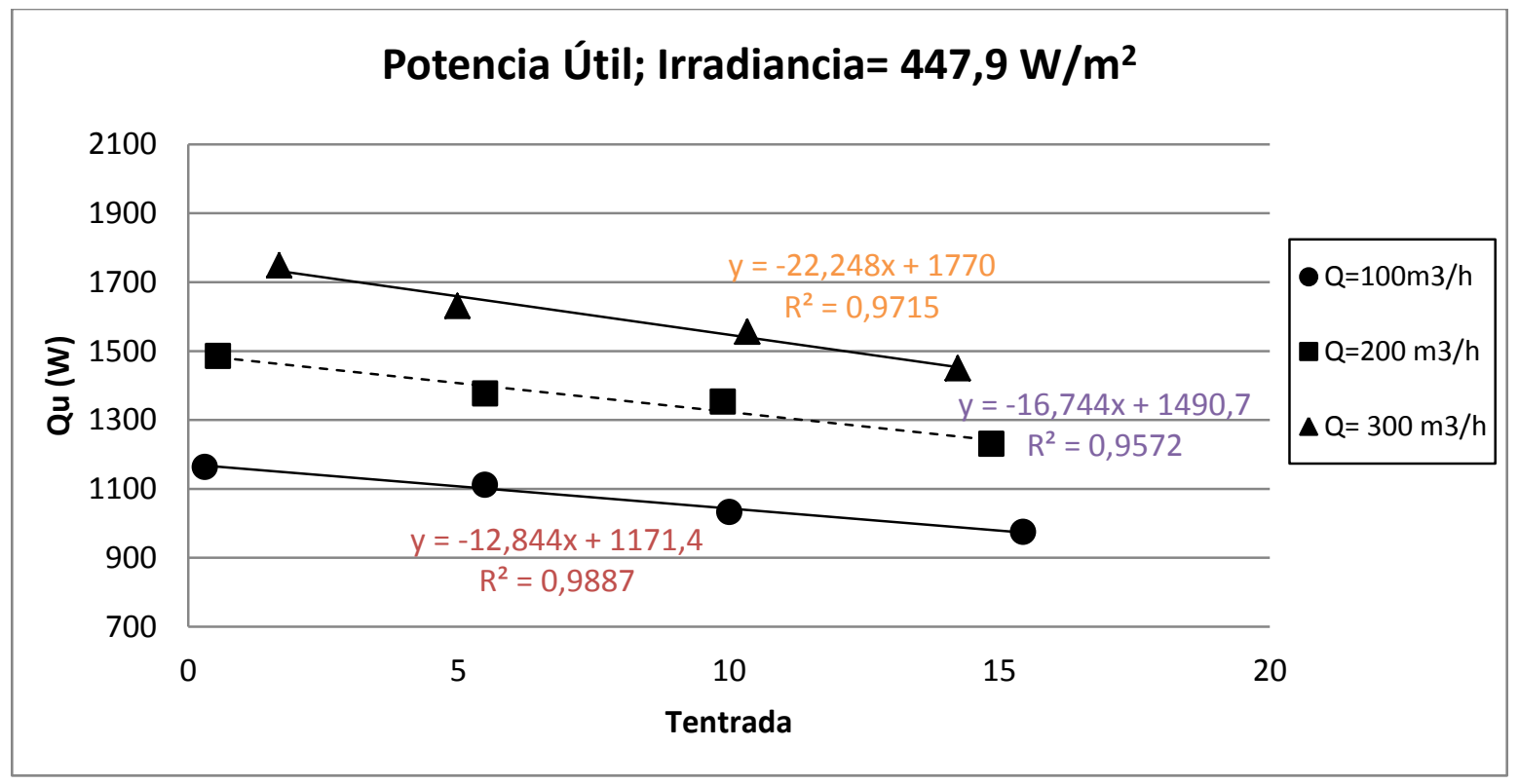

Figura IV.14.- Energía aportada para la irradiancia media $\left(447,9 \mathrm{~W} / \mathrm{m}^{2}\right)$.

Al igual que ocurre para el salto térmico, el factor más influyente en los niveles estudiados es la irradiancia sobre el colector, a mayor energía radiante incidente mayor potencia es aportada por el colector.

Al contrario que para el salto de temperaturas, el calor aportado a la corriente de aire aumenta al incrementarse el caudal. Este incremento de calor debido al caudal se ve parcialmente compensado por la disminución del salto térmico obtenido como consecuencia de ese aumento de 
caudal como ya se ha mencionado anteriormente. En el ANOVA desarrollado se puede observar que la contribución del factor caudal es mayor para el salto térmico que para el calor aportado, dejando de ser el factor más influyente de los tres estudiados.

A un menor nivel térmico del aire a la entrada del colector, es decir, a mayor capacidad de calentamiento del aire, la potencia útil aportada en el colector aumenta.

También se puede observar alguna pequeña desviación en la tendencia de este parámetro, relacionada con el ajuste del factor caudal, que pese a no ser el factor influyente, su incidencia es representativa como se puede ver el ANOVA presentado a continuación.

Por último; el análisis del rendimiento obtenido para los tres caudales experimentados muestra resultados similares a los expuestos para el calor aportado, pero aparentemente siendo el factor más influyente el del caudal, afirmación que se refuerza y contrasta con los resultados obtenidos del ANOVA. Los resultados obtenidos para el parámetro del rendimiento son los representados en la figura IV.15.

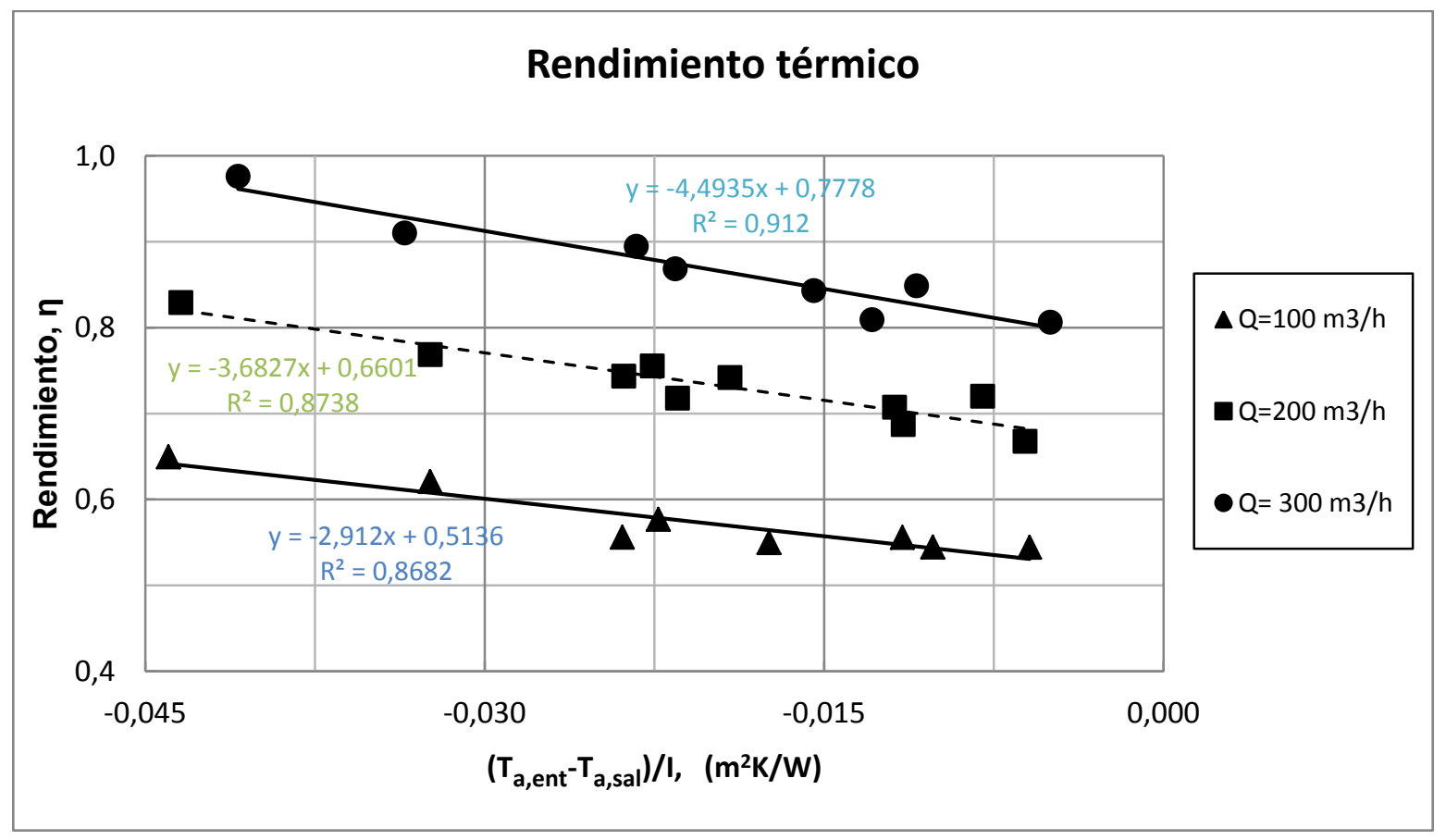

Figura IV.15.- Rendimiento térmico del colector.

A medida que aumentamos el caudal de aire incorporado al colector obtenemos un mejor rendimiento, podemos observar que duplicar el caudal supone aumentar en torno al $50 \%$ el rendimiento del colector. Como se puede ver, las rectas para los diferentes caudales estudiados son paralelas, este rendimiento disminuye en la misma proporción para todos los caudales estudiados a medida que aumenta la relación entre el salto térmico y la irradiancia. En el ANOVA 
llevado a cabo se puede observar la escasa influencia de los factores irradiancia y temperatura seca de entrada.

A modo de resumen en la tabla IV.4 se recopilan los resultados de todos los ensayos válidos llevados a cabo, como se puede observar se aceptaron ensayos con niveles intermedios a los planteados con el objetivo de definir mejor el comportamiento en algunos de esos niveles.

Tabla IV.4.- Recopilación de los resultados de los experimentos.

\begin{tabular}{|c|c|c|c|c|c|c|c|}
\hline \multirow[b]{2}{*}{$\begin{array}{c}\text { Irradiancia } \\
\left(\mathrm{W} / \mathrm{m}^{2}\right)\end{array}$} & \multirow[b]{2}{*}{$\begin{array}{c}\text { Caudal } \\
\text { medio Q } \\
\left(\mathrm{m}^{3} / \mathrm{h}\right)\end{array}$} & \multicolumn{3}{|c|}{ TEMPERATURAS MEDIAS } & \multirow[b]{2}{*}{$\begin{array}{l}\text { Irradiancia } \\
I^{*} S(W)\end{array}$} & \multirow[b]{2}{*}{$Q_{u \text { útil }}(W)$} & \multirow[b]{2}{*}{ Rendimiento } \\
\hline & & $\begin{array}{l}\text { Entrada a } \\
\text { colectores } \\
\quad\left({ }^{\circ} \mathrm{C}\right)\end{array}$ & $\begin{array}{l}\text { Salida de } \\
\text { colectores } \\
\text { (ํㅡ) }\end{array}$ & $\begin{array}{c}\text { Salto } \\
\text { térmico en } \\
\text { colectores } \\
\left({ }^{\circ} \text { C }\right)\end{array}$ & & & \\
\hline 828,4 & 111,6 & 15,1 & 63,6 & 48,5 & 3314 & 1804 & 0,544 \\
\hline 828,4 & 111,3 & 10,4 & 60,1 & 49,6 & 3314 & 1841 & 0,556 \\
\hline 828,4 & 110,0 & 5,6 & 55,2 & 49,7 & 3314 & 1821 & 0,550 \\
\hline 828,4 & 96,2 & 0,2 & 57,7 & 57,5 & 3314 & 1843 & 0,556 \\
\hline 447,9 & 101,8 & 15,4 & 44,2 & 28,7 & 1792 & 975 & 0,544 \\
\hline 447,9 & 100,7 & 10,0 & 40,8 & 30,6 & 1792 & 1033 & 0,577 \\
\hline 447,9 & 100,9 & 5,5 & 38,5 & 33,1 & 1792 & 1112 & 0,621 \\
\hline 447,9 & 102,3 & 0,3 & 34,4 & 34,1 & 1792 & 1164 & 0,649 \\
\hline 828,4 & 201,3 & 14,9 & 47,9 & 33,0 & 3314 & 2213 & 0,668 \\
\hline 828,4 & 217,9 & 13,4 & 46,2 & 32,9 & 3314 & 2386 & 0,720 \\
\hline 828,4 & 214,3 & 10,2 & 43,0 & 32,6 & 3314 & 2344 & 0,707 \\
\hline 828,4 & 213,7 & 4,1 & 38,6 & 34,5 & 3314 & 2459 & 0,742 \\
\hline 828,4 & 202,9 & 2,2 & 37,4 & 35,2 & 3314 & 2379 & 0,718 \\
\hline 828,4 & 205,1 & 0,2 & 36,3 & 36,0 & 3314 & 2464 & 0,744 \\
\hline 447,9 & 214,0 & 14,9 & 32,1 & 17,3 & 1792 & 1231 & 0,687 \\
\hline 447,9 & 210,7 & 9,9 & 29,2 & 19,3 & 1792 & 1353 & 0,755 \\
\hline 447,9 & 207,3 & 5,5 & 25,4 & 19,9 & 1792 & 1377 & 0,769 \\
\hline 447,9 & 204,6 & 0,6 & 22,3 & 21,8 & 1792 & 1486 & 0,829 \\
\hline 828,4 & 322,8 & 15,9 & 40,7 & 24,6 & 3314 & 2672 & 0,806 \\
\hline 828,4 & 305,4 & 11,0 & 38,6 & 27,6 & 3314 & 2812 & 0,849 \\
\hline 828,4 & 310,1 & 7,2 & 34,2 & 27,0 & 3314 & 2794 & 0,843 \\
\hline 828,4 & 330,8 & 0,7 & 27,6 & 26,9 & 3314 & 2965 & 0,895 \\
\hline 447,9 & 298,9 & 14,2 & 28,8 & 14,5 & 1792 & 1450 & 0,809 \\
\hline 447,9 & 320,6 & 10,3 & 24,9 & 14,6 & 1792 & 1556 & 0,869 \\
\hline 447,9 & 328,4 & 5,0 & 19,9 & 14,9 & 1792 & 1631 & 0,910 \\
\hline 447,9 & 332,4 & 1,7 & 17,5 & 15,8 & 1792 & 1749 & 0,976 \\
\hline
\end{tabular}




\section{IV.5.- ANÁLISIS DE VARIANZA.}

Se ha observado que las variaciones en los distintos factores considerados en el diseño de experimentos afectan al comportamiento del equipo de forma más o menos notoria, y distinta en función de cada parámetro abordado para estudiar dicho comportamiento. Resulta pues interesante realizar un análisis de varianza que nos permita determinar la medida relativa en que cada factor influye en los resultados obtenidos para estos parámetros. En el anexo B se encuentra definido el procedimiento seguido para el análisis de varianza realizado.

Del análisis realizado, los valores medios obtenidos de los parámetros abordados (salto térmico, calor útil aportado y rendimiento del colector) para los distintos ensayos realizados habiéndose mantenido constante un determinado nivel de un factor, son los recopilados en la tabla IV.5 y representados en las figuras IV.16 a IV.18.

Tabla IV.5.- Recopilación de los valores medios de los ensayos realizados para cada nivel de los factores mantenido constante.

\begin{tabular}{|c|c|c|c|c|c|c|c|c|c|}
\cline { 2 - 10 } \multicolumn{1}{c|}{} & $\mathbf{1 1}$ & $\mathbf{1 2}$ & $\mathbf{Q 1}$ & $\mathbf{Q 2}$ & $\mathbf{Q 3}$ & $\mathbf{T 1}$ & $\mathbf{T 2}$ & $\mathbf{T 3}$ & T4 \\
\hline $\boldsymbol{\Delta} \mathbf{T}$ & 36,8 & 22,0 & 41,5 & 28,2 & 20,7 & 32,0 & 29,8 & 29,1 & 27,8 \\
\hline Qutil & 2342,6 & 1343,1 & 1449,2 & 1969,1 & 2203,6 & 1944,9 & 1865,7 & 1823,4 & 1724,2 \\
\hline $\mathbf{n}$ & 0,71 & 0,75 & 0,57 & 0,73 & 0,87 & 0,77 & 0,74 & 0,72 & 0,68 \\
\hline
\end{tabular}
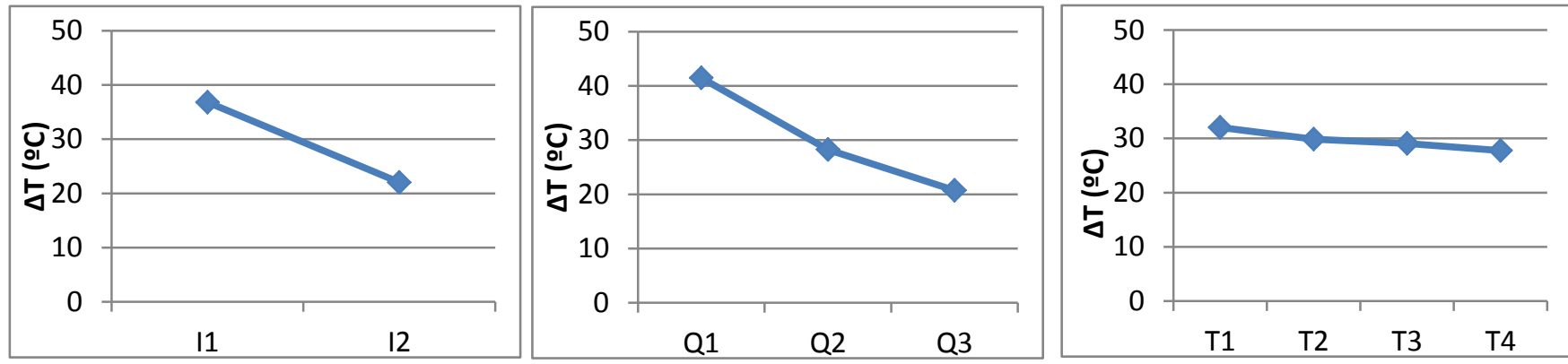

Figura IV.16.- Gráficas factoriales para el salto de temperaturas.
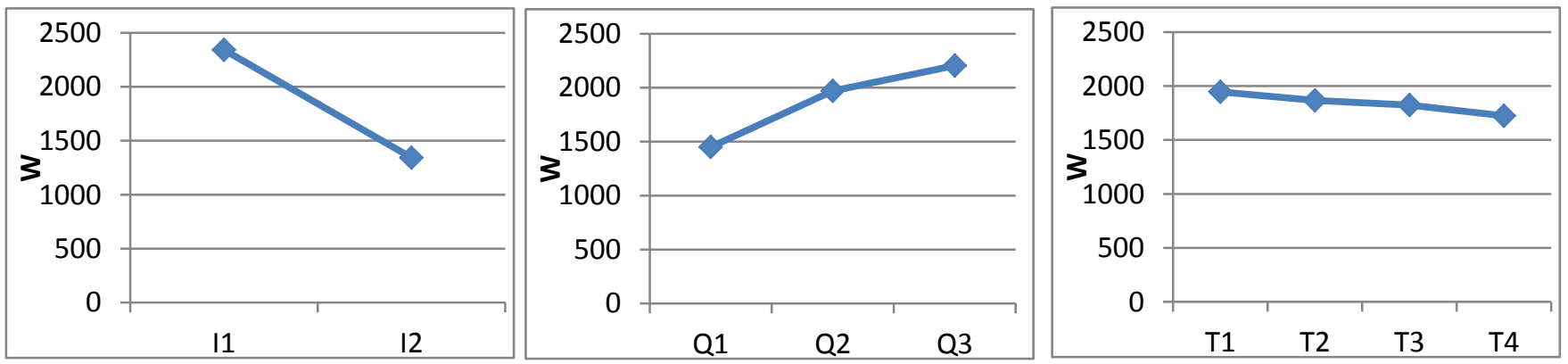

Figura IV.16.- Gráficas factoriales para la potencia útil. 

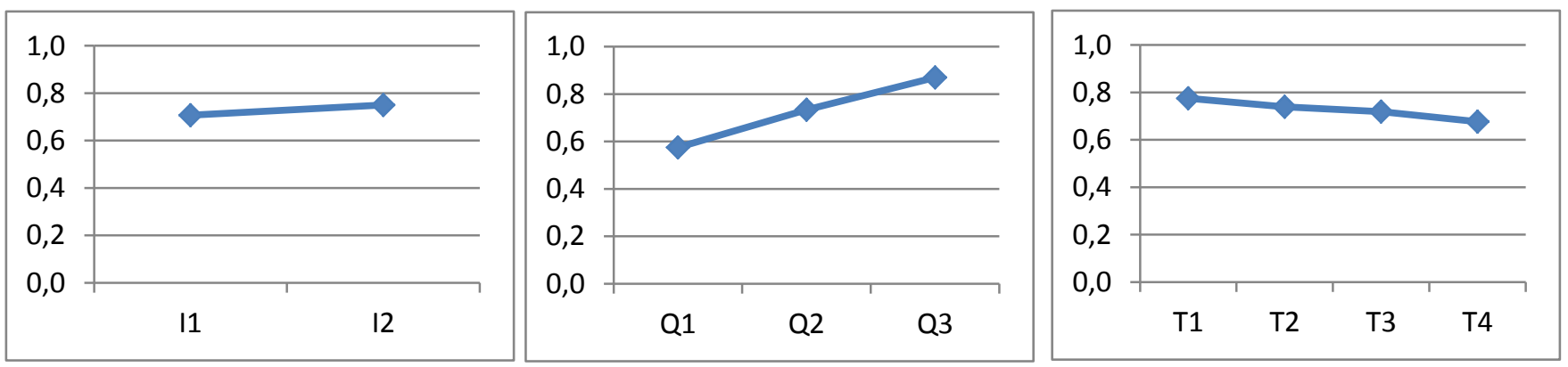

Figura IV.17.- Gráficas factoriales para el rendimiento.

Analizando como varían los resultados medios entre niveles de cada factor, se comprueba que el factor irradiancia tiene una significativa incidencia en el salto térmico obtenido en el colector, siendo aún más importante para el calor aportado al aire. Sin embargo, en el análisis del rendimiento del colector para estos dos niveles de irradiancia no se ve significativamente modificado.

Del estudio de los valores medios de los parámetros estudiados pare el factor caudal de aire se observa que en mayor o menor medida este factor influye en los resultados, siendo un factor determinante para algún parámetro. La tendencia del salto térmico indica que al aumentar el caudal de aire el salto térmico disminuye. En cambio, al analizar los otros dos parámetros, vemos que la tendencia se invierte, y a medida que aumentamos el caudal de aire, el rendimiento y el calor aportado a la corriente de aire también ven incrementados sus valores de forma significativa.

Finalmente, el análisis del factor temperatura de entrada del aire nos indica que es el factor menos influyente en el comportamiento del colector en relación a los parámetros estudiados. La pendiente de la recta para todos parámetros es similar y poco pronunciada, disminuyendo ligeramente a medida que aumentamos la temperatura de entrada del aire al colector.

Resta estudiar la posible interacción entre factores. Para ello se han obtenido los valores medios de los ensayos realizados para cada par de factores establecidos en un nivel dado, como se muestra en las tablas IV.6, IV.7 y IV.8, cuyos datos se representan en las figuras IV.18, IV.19 y IV.20. Las interacciones triples no se presentan aquí por poder considerarse despreciables, tal y como puede observarse del error remanente tras las interacciones dobles, cuyo valor es prácticamente nulo como puede observarse en la tabla IV.10. 
Tabla IV.6.- Valores medios de las interacciones dobles para el salto térmico.

\begin{tabular}{|c|c|c|c|}
\hline & Q1 & Q2 & Q3 \\
\hline $\mathbf{I 1}$ & 51,30 & 34,03 & 26,55 \\
\hline $\mathbf{I} 2$ & 31,64 & 19,56 & 14,94 \\
\hline
\end{tabular}

\begin{tabular}{|c|c|c|c|c|}
\hline & T1 & T2 & T3 & T4 \\
\hline I1 & 40,13 & 37,07 & 36,63 & 35,36 \\
\hline I2 & 23,90 & 22,63 & 21,48 & 20,17 \\
\hline
\end{tabular}

\begin{tabular}{|c|c|c|c|c|}
\hline & T1 & T2 & T3 & T4 \\
\hline Q1 & 45,80 & 41,36 & 40,12 & 38,60 \\
\hline Q2 & 28,91 & 27,23 & 25,95 & 25,11 \\
\hline Q3 & 21,34 & 19,58 & 21,10 & 19,58 \\
\hline
\end{tabular}
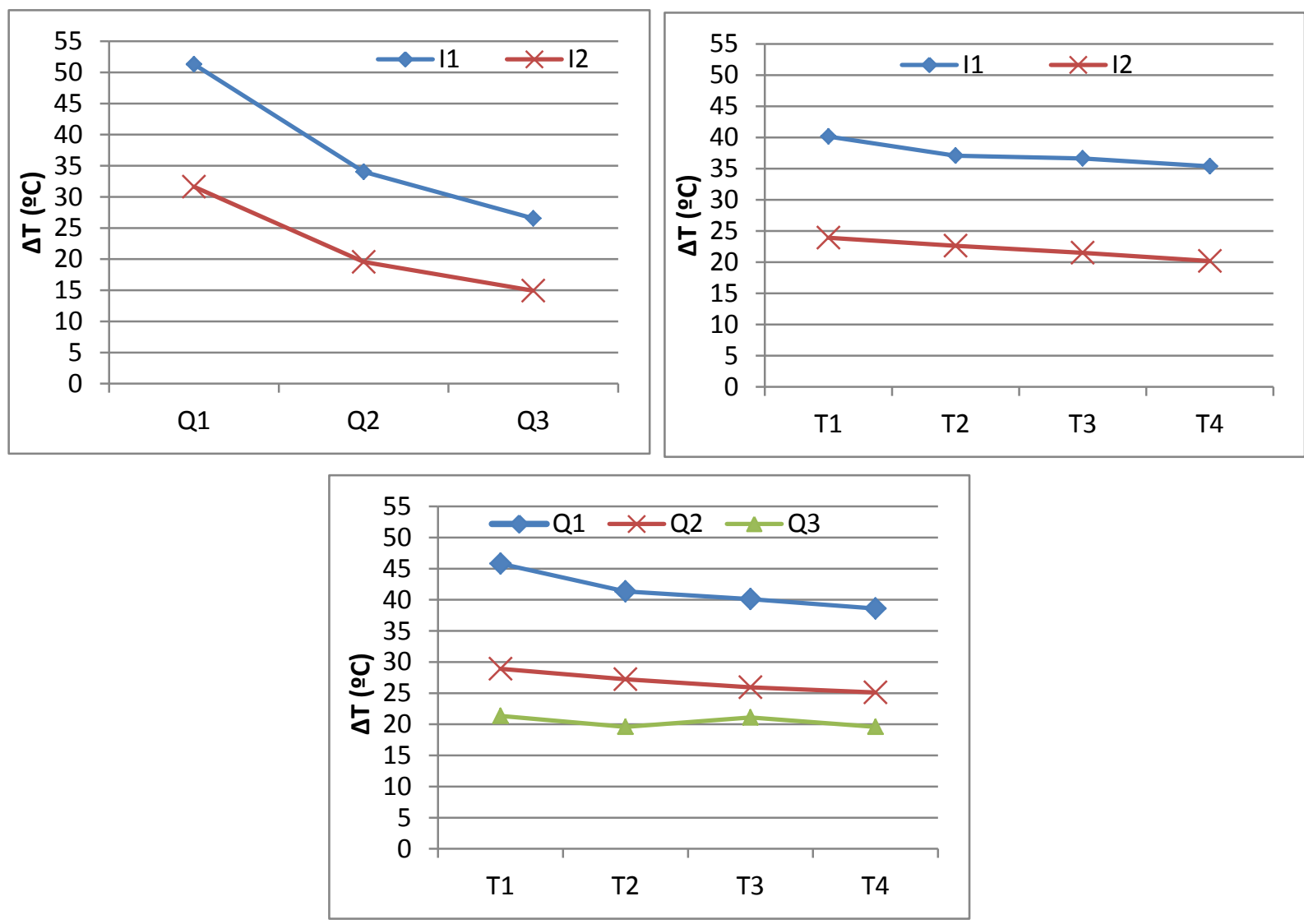

Figura IV.18.- Gráficas de las interacciones factoriales dobles para el salto térmico. 
Tabla IV.7.- Valores medios de las interacciones dobles para la potencia útil.

\begin{tabular}{|c|c|c|c|}
\hline & Q1 & Q2 & Q3 \\
\hline $\mathbf{I 1}$ & 1827,2 & 2373,9 & 2810,9 \\
\hline $\mathbf{I}$ & 1071,1 & 1361,9 & 1596,3 \\
\hline
\end{tabular}

\begin{tabular}{|c|c|c|c|c|}
\hline & T1 & T2 & T3 & T4 \\
\hline I1 & 2423,7 & 2358,1 & 2332,5 & 2229,5 \\
\hline I2 & 1466,0 & 1373,3 & 1314,3 & 1218,8 \\
\hline
\end{tabular}

\begin{tabular}{|c|c|c|c|c|}
\hline & T1 & T2 & T3 & T4 \\
\hline Q1 & 1503,1 & 1466,7 & 1437,3 & 1389,5 \\
\hline Q2 & 1974,7 & 1918,0 & 1848,6 & 1721,9 \\
\hline Q3 & 2356,8 & 2079,1 & 2184,3 & 2061,0 \\
\hline
\end{tabular}
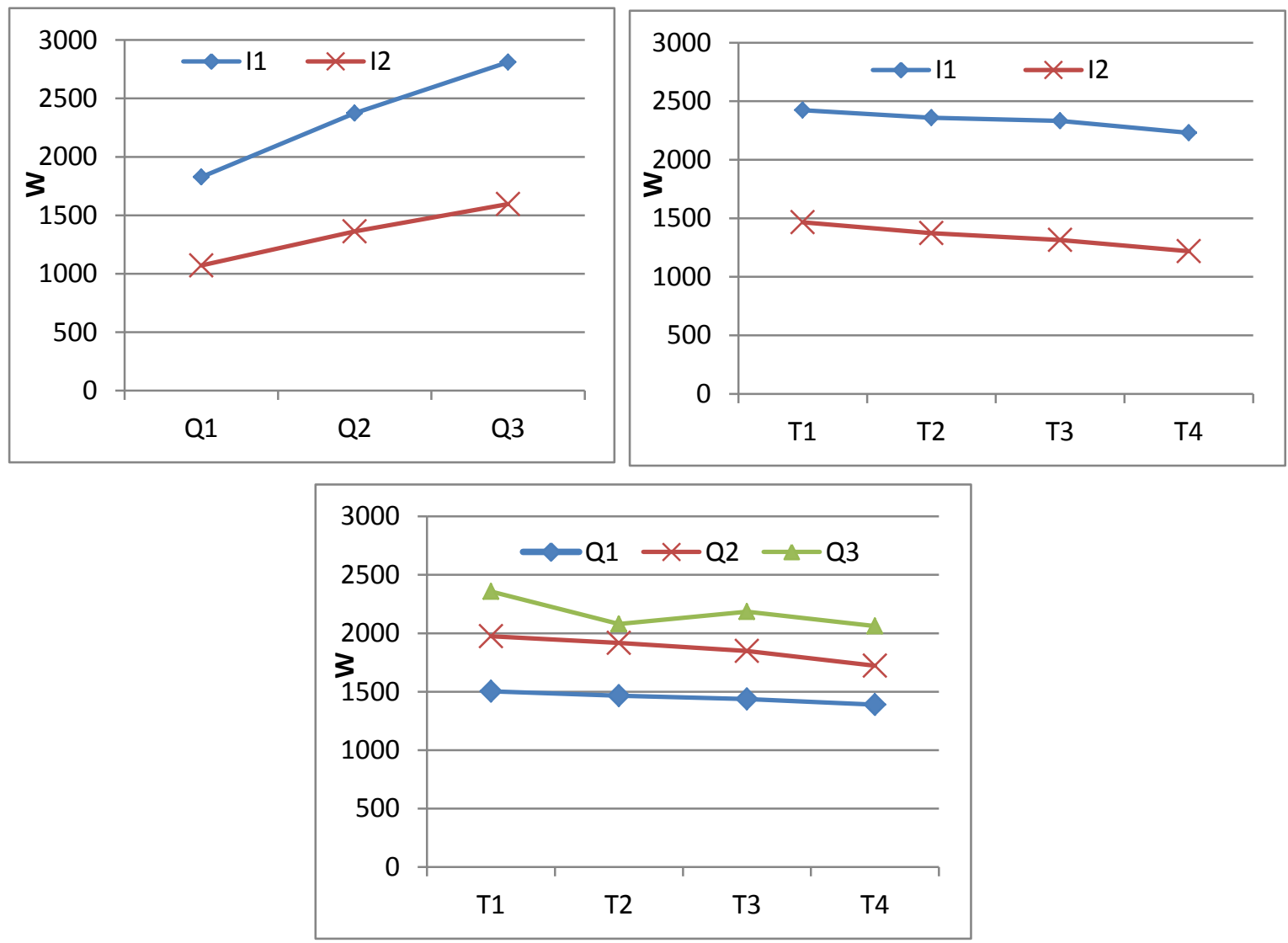

Figura IV.19.- Gráficas de las interacciones factoriales dobles para la potencia útil. 
Tabla IV.8.- Valores medios de las interacciones dobles para el rendimiento.

\begin{tabular}{|c|c|c|c|}
\hline & Q1 & Q2 & Q3 \\
\hline $\mathbf{I 1}$ & 0,55 & 0,72 & 0,85 \\
\hline $\mathbf{I} 2$ & 0,60 & 0,76 & 0,89 \\
\hline
\end{tabular}

\begin{tabular}{|c|c|c|c|c|}
\hline & T1 & T2 & T3 & T4 \\
\hline I1 & 0,73 & 0,71 & 0,70 & 0,67 \\
\hline I2 & 0,82 & 0,77 & 0,73 & 0,68 \\
\hline
\end{tabular}

\begin{tabular}{|c|c|c|c|c|}
\hline & T1 & T2 & T3 & T4 \\
\hline Q1 & 0,60 & 0,59 & 0,57 & 0,54 \\
\hline Q2 & 0,79 & 0,76 & 0,73 & 0,68 \\
\hline Q3 & 0,94 & 0,87 & 0,86 & 0,81 \\
\hline
\end{tabular}
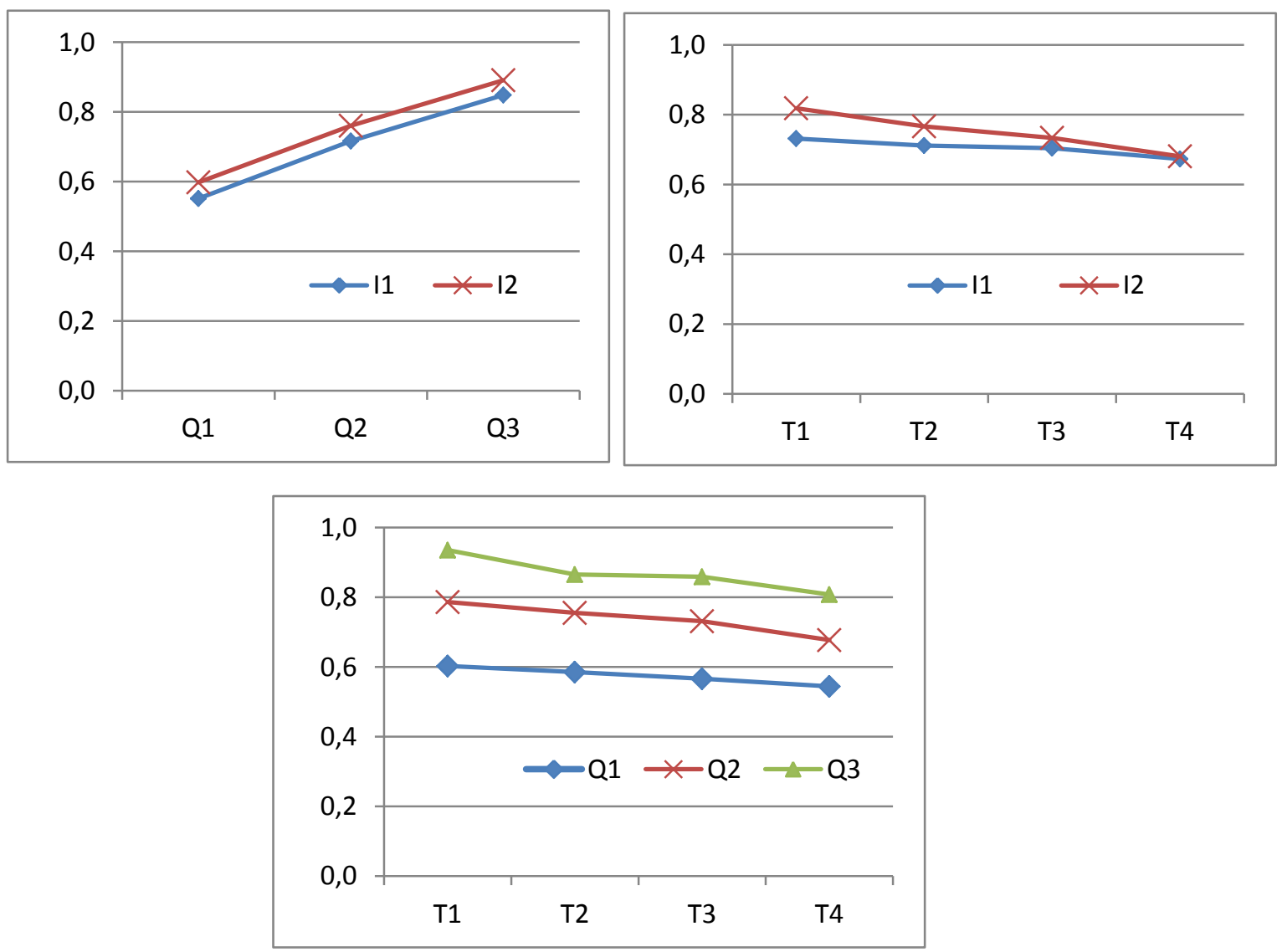

Figura IV.20.- Gráficas de las interacciones factoriales dobles para el rendimiento.

Se comprueba que las interacciones entre factores son despreciables en todos los casos ya que no se observa irregularidad alguna significativa en las tendencias de las interacciones planteadas. 
Las distintas contribuciones de los factores analizados son las recopiladas en la tabla IV.9, mostrándose el error desglosado en las correspondientes contribuciones de las posibles interacciones dobles en la tabla IV.10.

Tabla IV.9.- Recopilación de los coeficientes de contribución derivados del ANOVA realizado sobre los factores del diseño de experimentos.

\begin{tabular}{|c|c|c|c|}
\hline & $\Delta \mathbf{T}\left({ }^{\circ} \mathbf{C}\right)$ & Qútil (W) & $\boldsymbol{\eta}$ \\
\hline SSı (\%) & 41,38 & 68,79 & 2,99 \\
\hline SSQ (\%) & 53,88 & 26,58 & 87,19 \\
\hline SST (\%) & 1,70 & 1,77 & 7,56 \\
\hline SSerror (\%) & 3,04 & 2,86 & 2,26 \\
\hline
\end{tabular}

Tabla IV.10.- Desglose del porcentaje de error en los coeficientes de contribución de las interacciones entre los factores del diseño de experimentos.

\begin{tabular}{|c|c|c|c|}
\hline & $\Delta \mathbf{T}\left({ }^{\circ} \mathbf{C}\right)$ & Qútil (W) & $\mathbf{\eta}$ \\
\hline SSıQ (\%) & 1,98 & 2,45 & 0,00 \\
\hline SSIT (\%) & 0,07 & 0,04 & 1,31 \\
\hline SSQT (\%) & 0,61 & 0,25 & 0,70 \\
\hline SS error rem (\%) & 0,39 & 0,12 & 0,25 \\
\hline
\end{tabular}

Se puede observar que para el salto térmico alcanzado en el aire, los factores caudal de aire e irradiancia tienen una importante incidencia, siendo algo mayor la contribución del caudal de aire (un 54\%) que la ofrecida por la irradiancia (41\%). La temperatura de entrada del aire no es determinante para el salto térmico alcanzado. También se comprueba que no se dan interacciones entre los tres factores estudiados que afecten al salto térmico alcanzado.

Respecto a la potencia térmica útil o calor aportado a la corriente de aire, se puede ver que el factor determinante en la variabilidad de este parámetro es la irradiancia, ya que contribuye en un $69 \%$, mientras que el factor caudal lo hace en un $26,6 \%$. Esta circunstancia ya se podía observar en los resultados recogidos en la tabla IV.5. La temperatura de entrada del aire al colector tampoco es influyente en la potencia térmica útil obtenida. En la tabla IV.10 podemos ver que no se dan interacciones entre factores que modifiquen significativamente los resultados del calor aportado al aire.

Por último, es el caudal de aire el factor influyente en el rendimiento del colector, alcanzando más de $87 \%$ de contribución a los resultados de este parámetro. Como ya se ha visto, el caudal de aire es directamente proporcional a la energía aportada a la corriente, pero el aumento de este factor caudal de aire disminuye el salto térmico alcanzado que es otro parámetro directamente 
proporcional al calor útil aportado. Aquí reside principalmente la influencia en el rendimiento térmico del colector que relaciona la energía útil aportada con la incidente sobre el equipo. Al igual que ocurría en los otros dos parámetros, no se identifican interacciones entre los distintos factores que supongan contribuciones signicativas. 


\section{REFERENCIAS}

[1] F. Javier, R. Martínez, E.V. Gómez, R.R. Valdivieco, Sergio L.G. González, A.T. González, Characterization of solar air heaters for ventilation in buildings, (n.d.) 1-10.

[2] M.K. Selcuk, Solar air heaters and their applications, Sol. Energy Eng. (A78-27852 10-44). (1977) 155-182.

[3] G. Solar, Manual técnico TwinSolar-SLK TopSolar, (2004).

\section{NORMATIVA.}

[N-1] Ministerio de Industria, Turismo y Comercio y Ministerio de Vivienda de España, "Real Decreto 1027/2007: Reglamento de Instalaciones Térmicas en Edificios". 


\section{CAPÍTULO V.- \\ SIMULACIÓN ENERGÉTICA DE LOS C.T.S. DE AIRE}

\section{CONTENIDOS DEL CAPÍTULO:}

V.1.- INTRODUCCIÓN: DESCRIPCIÓN DE LA CONFIGURACIÓN OBJETO DEL

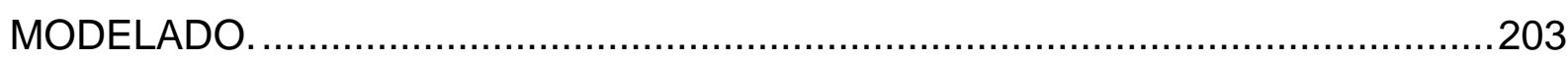

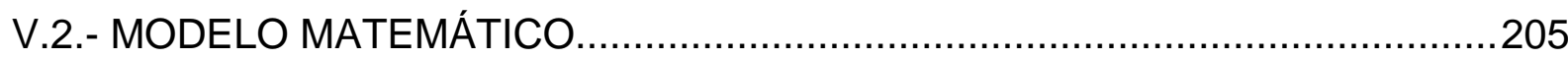

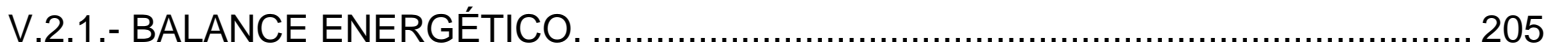

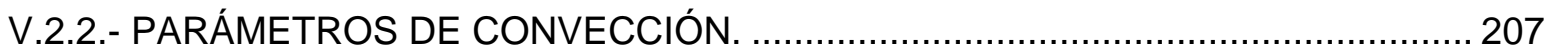

V.2.2.1.- Efecto del viento: convección forzada entre la cubierta y el ambiente........... 207

V.2.2.2.- Convección natural entre el absorbedor y la cubierta................................... 208

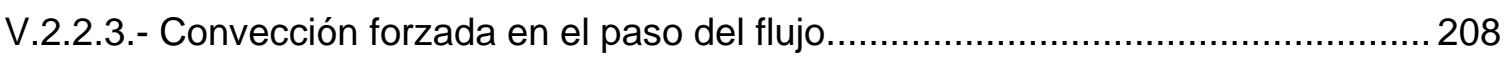

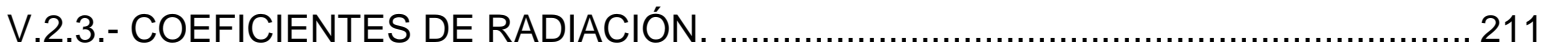

V.2.3.1.- Intercambio radiante entre el absorbedor y la cubierta.................................211

V.2.3.2.- Intercambio radiante entre las caras de los conductos de paso. ................... 212

V.3.- RESOLUCIÓN DEL MODELO MATEMÁTICO POR EL MÉTODO DE

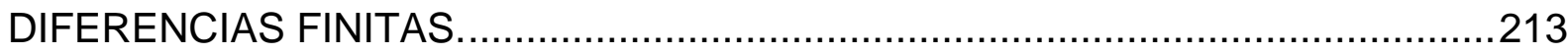

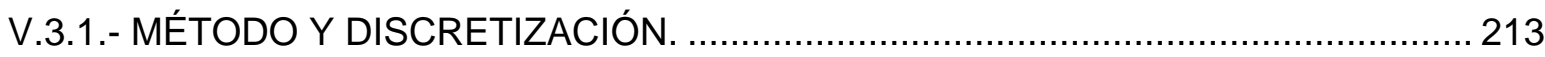

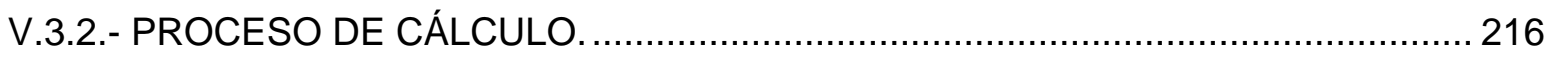

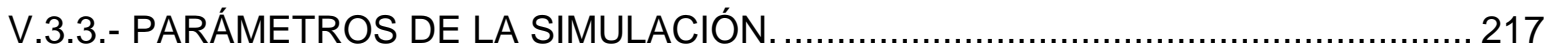




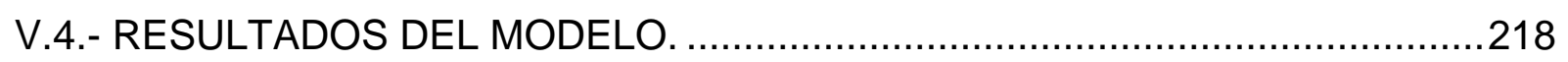

CONCLUSIONES:

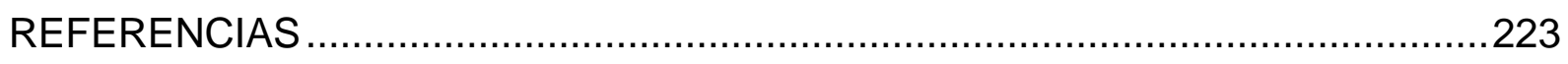

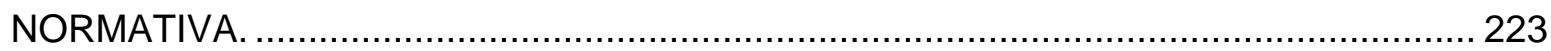




\section{LISTA DE FIGURAS:}

Figura V.1.- Configuración y flujos de calor en un colector solar de aire con cubierta, de paso simple entre absorbedor y base. Fuente: Ong, 1995 [1] ............................................ 203

Figura V.2.- Esquema de la sección transversal del colector solar de estudio e intercambios de calor asociados. 204

Figura V.3.- Representación de las resistencias térmicas en el colector a través de un esquema de resistencias eléctricas equivalente. 205

Figura V.4.- Factor de forma entre dos superficies rectangulares paralelas....................... 212

Figura V.5.- Factor de forma entre dos superficies rectangulares perpendiculares............213

Figura V.6.- Discretización geométrica de un conducto de paso..........................................214

Figura V.7.- Discretización geométrica de dos conductos y el aislante. ...............................2214

Figura V.8.- Distribución de la radiación incidente entre los componentes del colector. .... 215

Figura V.9.- Diagrama de flujo del procedimiento de cálculo programado en C++_...........217

Figura V.10.- Esquema de las simulaciones llevadas a cabo. ............................................2 218

Figura V.11.- Temperatura de salida del colector experimental y calculada........................220

Figura V.12.- Comparación de las rectas de rendimiento, experimentales y calculadas....221

\section{LISTA DE TABLAS:}

Tabla V.1.- Propiedades radiantes y dimensiones del colector. 204

Tabla V.2.- Parámetros característicos empleados en el estudio de simulación del colector.217

Tabla V.3.- Resumen de los resultados de la simulación 219 


\section{Nomenclatura:}

$C_{p}$ : calor específico $(\mathrm{J} / \mathrm{kgK})$

$D_{h}$ : diámetro hidráulico [m]

$F$ : factor de visión $\left[\mathrm{m}^{-2}\right]$

$F_{R}$ : factor de ganancia de la ecuación de Bliss

$h$ : coeficiente de transferencia de calor por convección o radiación $\left[\mathrm{W} /\left(\mathrm{m}^{2} \mathrm{~K}\right)\right]$

I: Irradiancia $\left(\mathrm{W} / \mathrm{m}^{2}\right)$

$L$ : longitud del colector [m]

$M$ : Masa [kg]

$Q$ : Flujo de calor (W)

$R$ : resistencia a la transferencia de calor $\left[\mathrm{m}^{2} \mathrm{~K} / \mathrm{W}\right]$

$S$ : superficie del colector $\left(\mathrm{m}^{2}\right)$

T. Temperatura $\left[{ }^{\circ} \mathrm{C}\right]$

$U$ : coeficiente de pérdidas $\left[\mathrm{W} /\left(\mathrm{m}^{2} \mathrm{~K}\right)\right]$

$V$ : velocidad del viento $[\mathrm{m} / \mathrm{s}]$

$\alpha$ : absortividad

$\varepsilon$ : emisividad

$\tau$ : transmisividad

Subíndices:

a: ambiente

abs: absorbedor

$b$ : base o fondo

c: convección

cam: aire en la cámara entre absorbedor y cubierta

$f$ flujo de aire

$p$ : paredes de los conductos

$r$ radiación

sky: cielo

v. cubierta (vidrio)

$W$. viento

Números adimensionales:

$\mathrm{Nu}:$ Nusselt

Ra : Rayleigh

Re : Reynolds

$\operatorname{Pr}$ : Prandt 


\section{V.1.- INTRODUCCIÓN: DESCRIPCIÓN DE LA CONFIGURACIÓN OBJETO DEL MODELADO.}

Como se ha descrito en el capítulo IV, y dentro de los distintos colectores solar de aire existentes a su vez presentados en el capítulo II , el colector solar de aire de estudio se clasificaría según su configuración como de tipo no poroso, de paso simple por debajo del absorbedor, con cubierta de vidrio simple y con canales de sección rectangular por donde circula el flujo de aire a calentar, correspondiéndose por lo tanto con uno de los tipos básicos propuestos por Ong [1], como se muestra en la figura V.1.

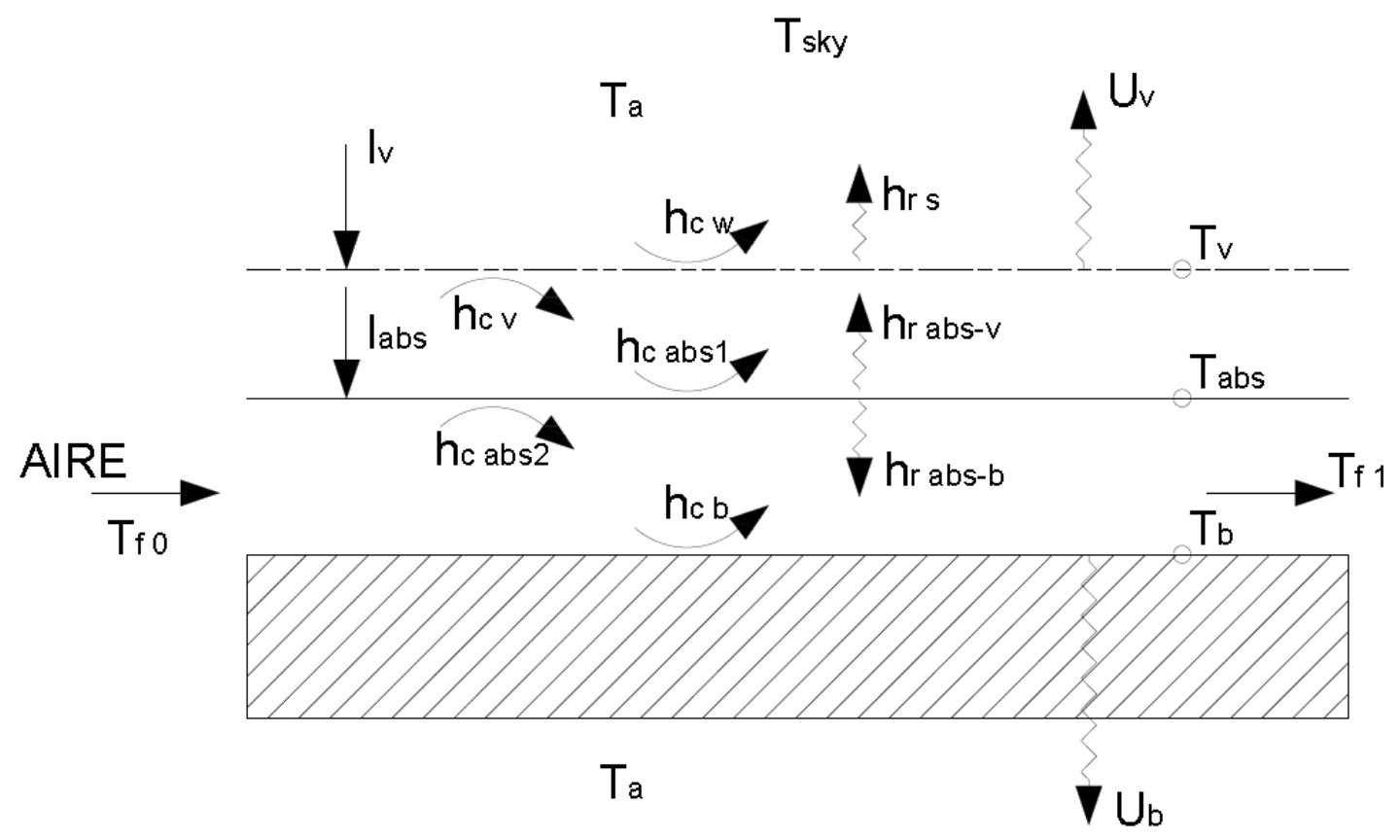

Figura V.1.- Configuración y flujos de calor en un colector solar de aire con cubierta, de paso simple entre absorbedor y base. Fuente: Ong, 1995 [1]

No obstante, presenta la peculiaridad de tener el canal de paso de aire dividido en conductos de sección rectangular. Los flujos de calor involucrados en este tipo de sistema se ajustarían a los mostrados en la figura V.2 en la que se ve el esquema de una sección del colector. 


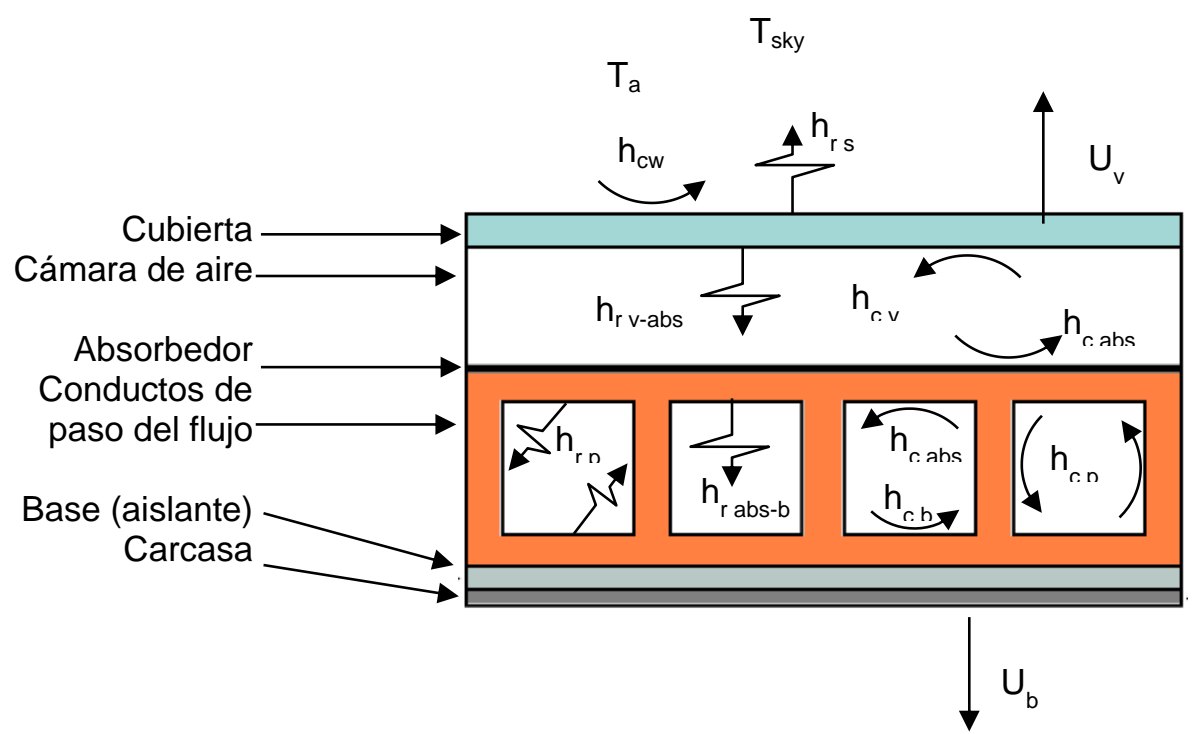

Figura V.2.- Esquema de la sección transversal del colector solar de estudio e intercambios de calor asociados.

Los parámetros y dimensiones consideradas de los distintos elementos del colector son los correspondientes al catálogo del fabricante [2], ya presentados en el capítulo IV. En la tabla V.1 se recopilan aquellos valores requeridos en la definición del modelo matemático.

Tabla V.1.- Propiedades radiantes y dimensiones del colector.

\begin{tabular}{|l|c|}
\hline PROPIEDADES RADIANTES & VALOR \\
\hline Absortividad del vidrio (cara inferior) & 0,08 \\
\hline Emisividad del vidrio (cara superior) & 0,9 \\
\hline $\begin{array}{l}\text { Absortividad/ Emisividad del absorbedor (cara } \\
\text { superior) }\end{array}$ & $\begin{array}{c}0,97 \text { (onda corta) } \\
0,11 \text { (onda larga) }\end{array}$ \\
\hline Emisividad del absorbedor (cara inferior) & 0,1 \\
\hline Emisividad de la superficie base & 0,1 \\
\hline Transmisividad del vidrio & 0,9 \\
\hline DIMENSIONES GEOMÉTRICAS & VALOR \\
\hline Espesor del vidrio & $4 \mathrm{~mm}$ \\
\hline Espacio entre vidrio y absorbedor & $10 \mathrm{~mm}$ \\
\hline Altura de los conductos de paso & $40 \mathrm{~mm}$ \\
\hline Espesor de la pared de los conductos & $3 \mathrm{~mm}$ \\
\hline Espesor del aislante inferior & $50 \mathrm{~mm}$ \\
\hline Número de conductos & 24 \\
\hline Longitud del colector (conductos) & $2 \mathrm{~m}$ \\
\hline
\end{tabular}

En el siguiente apartado se va a describir el modelo matemático considerado para la caracterización analítica del sistema. 


\section{V.2.- MODELO MATEMÁTICO.}

Este tipo de colectores en particular no se encuentra tan extensamente estudiado en la literatura. Amari [3] plantea un modelo matemático para un colector solar de aire de paso simple, con cubierta, donde el paso de fluido se realiza a través de espacios rectangulares. Por su parte, Assari et al. [4] proponen, dentro del diseño original que plantean para un colector de doble función de calentamiento de agua y aire, la división del conducto en secciones rectangulares o triangulares con el fin de favorecer la transferencia de calor.

\section{V.2.1.- BALANCE ENERGÉTICO.}

Atendiendo a la configuración indicada en las figuras V.1 y V.2, sería adecuado plantear el estudio energético a través de una red eléctrica equivalente de la forma mostrada en la figura V.3.

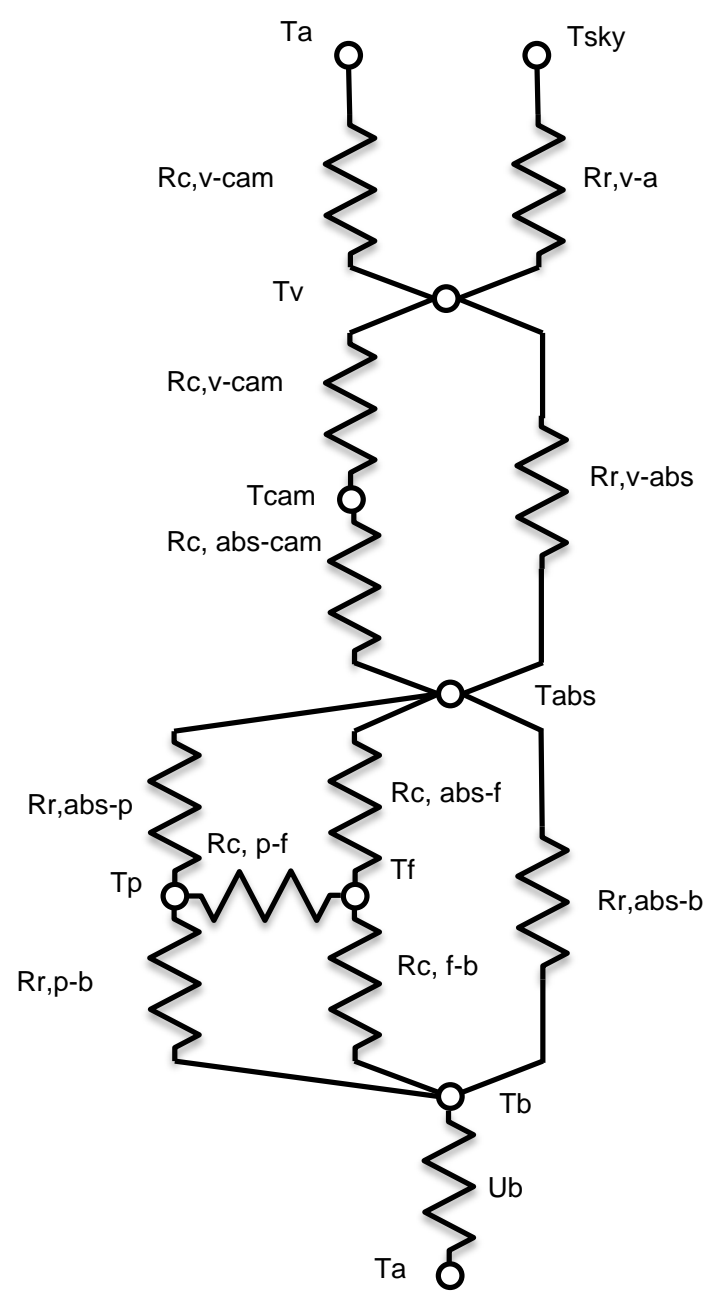

Figura V.3.- Representación de las resistencias térmicas en el colector a través de un esquema de resistencias eléctricas equivalente. 
Planteando un balance energético en cada elemento del colector, representado por un nodo en la figura V.3, las ecuaciones en régimen transitorio consideradas serían las siguientes:

Para la cubierta:

$M_{v} c_{p, v} \frac{d T_{v}}{d t}=I S \alpha_{v}-Q_{c, v-c a m}-Q_{r, v-a b s}-Q_{c, v-a}-Q_{r, v-a}$

Donde:

$$
\begin{aligned}
& Q_{c, v-c a m}=h_{v-c a m} \cdot\left(T_{v}-T_{c a m}\right) \\
& Q_{c, v-a}=h_{v-a} \cdot\left(T_{v}-T_{a}\right) \\
& Q_{r, v-a}=\sigma \cdot \varepsilon_{v} \cdot\left(T_{v}^{4}-T_{s k y}^{4}\right)
\end{aligned}
$$

Y, considerando la cubierta y la placa absorbedora como placas paralelas infinitas, despreciando el efecto del contorno del colector:

$$
Q_{r, v-a b s}=\frac{\sigma \cdot\left(T_{v}^{4}-T_{a b s}^{4}\right)}{\frac{1}{\varepsilon_{v}}+\frac{1}{\varepsilon_{a b s}}-1}
$$

En el aire confinado en la cámara entre absorbedor y cubierta:

$M_{c a m} c_{p, c a m} \frac{d T_{c a m}}{d t}=Q_{c, v-c a m}-Q_{c, c a m-a b s}$

Donde:

$$
Q_{c, c a m-a b s}=h_{c a m-a b s} \cdot\left(T_{c a m}-T_{a b s}\right)
$$

En cuanto al balance energético en el absorbedor:

$$
M_{a b s} c_{p, a b s} \frac{d T_{a b s}}{d t}=I S \tau_{v} \alpha_{a b s}+Q_{c, c a m-a b s}+Q_{r, v-a b s}-Q_{c, a b s-f}-Q_{r, a b s-p}-Q_{r, a b s-b}
$$

Donde:

$$
\begin{aligned}
& Q_{c, a b s-f}=h_{a b s-f} \cdot\left(T_{a b s}-T_{f}\right) \\
& Q_{r, a b s-p}=\frac{\sigma \cdot\left(T_{a b s}^{4}-T_{p}^{4}\right)}{\left[\frac{1-\varepsilon_{a b s}}{\varepsilon_{a b s}}+\frac{1}{F_{a b s-p}}+\frac{1-\varepsilon_{p}}{\varepsilon_{p}}\right]} \\
& Q_{r, a b s-b}=\frac{\sigma \cdot\left(T_{a b s}^{4}-T_{b}^{4}\right)}{\left[\frac{1-\varepsilon_{a b s}}{\varepsilon_{a b s}}+\frac{1}{F_{a b s-b}}+\frac{1-\varepsilon_{b}}{\varepsilon_{b}}\right]}
\end{aligned}
$$


Para el flujo de aire:

$M_{f} c_{p, f} \frac{d T_{f}}{d t}=\rho V_{f} c_{p}\left(T_{f, e n t}-T_{f}\right)+Q_{c, p-f}+Q_{c, b-f}+Q_{c, a b s-f}$

Donde:

$$
\begin{aligned}
& Q_{c, p-f}=h_{p-f} \cdot\left(T_{p}-T_{f}\right) \\
& Q_{c, b-f}=h_{b-f} \cdot\left(T_{b}-T_{f}\right)
\end{aligned}
$$

Finalmente, en la base:

$M_{b} c_{p, b} \frac{d T_{b}}{d t}=-Q_{c, b-f}-Q_{r, b-p}-Q_{c, b-a}$

Donde:

$$
\begin{aligned}
& Q_{r, b-p}=\frac{\sigma \cdot\left(T_{b}^{4}-T_{p}^{4}\right)}{\left[\frac{1-\varepsilon_{b}}{\varepsilon_{b}}+\frac{1}{F_{b-p}}+\frac{1-\varepsilon_{p}}{\varepsilon_{p}}\right]} \\
& Q_{c, b-a}=U_{b} \cdot\left(T_{b}-T_{a}\right)
\end{aligned}
$$

Es necesario en este punto definir los coeficientes de intercambio de calor convectivos y los factores de visión que determinan las resistencias radiantes.

\section{V.2.2.- PARÁMETROS DE CONVECCIÓN.}

Los coeficientes de transferencia de calor por convección involucrados en el modelo atienden a las pérdidas desde la superficie de la cubierta hacia el exterior por efecto del viento, a las pérdidas desde el absorbedor hacia la cubierta por convección natural y a la transferencia efectiva de calor por convección forzada hacia la corriente de aire que atraviesa el colector.

\section{V.2.2.1.- EFECTO DEL VIENTO: CONVECCIÓN FORZADA ENTRE LA CUBIERTA Y EL AMBIENTE.}

La convección forzada entre la cubierta y el ambiente exterior se ve determinada por el efecto del viento. Para caracterizar este, se considera la correlación de McAdams al igual que propone Ong [1]:

$$
h_{w}=5,7+3,8 \cdot V
$$


Donde la velocidad del viento $V$ vamos a considerarla prácticamente nula en nuestro caso, para poder así comparar los resultados del modelo con el estudio experimental ya realizado de los colectores reales. De esta forma, se toma en este modelo un coeficiente de película convectivo entre la cubierta y el ambiente de $6 \mathrm{~W} /\left(\mathrm{m}^{2} \mathrm{~K}\right)$.

\section{V.2.2.2.- CONVECCIÓN NATURAL ENTRE EL ABSORBEDOR Y LA CUBIERTA.}

En cuanto a la convección natural que tiene lugar en el espacio confinado entre absorbedor y cubierta, debe considerarse que se trata de una cavidad inclinada. Existen diversas correlaciones para este tipo de geometrías [5]. Sin embargo, la más extendida en la caracterización de este tipo de colectores es la desarrollada por Hollands, en este caso aplicable a inclinaciones entre $0^{\circ}$ y $60^{\circ}$ [6]:

$N u_{n c}=1+1,44\left[1-\frac{1708 \cdot(\sin 1.8 \varnothing)^{1,6}}{R a \cos \emptyset}\right]\left[1-\frac{1708}{R a \cos \emptyset}\right]^{+}+\left[\left(\frac{R a \cos \emptyset}{5830}\right)^{1 / 3}-1\right]^{+}$

Para valores del Rayleigh entre 0 y $10^{5}$. Los términos con superíndice "+" indica que el término sólo se considera si es positivo. Debido a la inestabilidad que introduce en la iteración del modelo matemático no se va a considerar la ecuación explícitamente en éste, sino que se toma un valor del Nusselt igual a 2, el cual se encuentra dentro del rango (por otro lado, reducido) de variación de este parámetro para las condiciones de trabajo esperables.

\section{V.2.2.3.- CONVECCIÓN FORZADA EN EL PASO DEL FLUJO.}

En cuanto al estudio de la convección forzada en el interior del paso del flujo de aire, existen también diversas opciones recurridas repetidamente en la literatura. Estas consideran generalmente una geometría de flujo interno a dos placas paralelas, una de ellas sometida a un flujo de calor constante y la otra aislada. En ésta, la longitud característica del problema de convección viene dada por el doble de la separación entre las placas.

Por otro lado, suele distinguirse entre los distintos flujos posibles: laminar, de transición o turbulento.

Para flujo laminar, correspondiente a un valor del Reynolds inferior a 2300 en geometrías de flujo interno, Ong [7] y Ammari [3] proponen la correlación de Heaton (ecuación E-V.20):

$$
N u_{n c}=N u_{\infty}+\frac{a\left[R e \operatorname{Pr}\left(D_{h} / L\right)\right]^{m}}{1+b\left[\operatorname{Re} \operatorname{Pr}\left(D_{h} / L\right)\right]^{n}}
$$

Donde las constantes son $a=0,00190 ; b=0,00563 ; m=1,71 ; n=1,17$, y $N u_{\infty}=5,4$ para $\quad P r$ $=0,7$. Flujo turbulento, $\operatorname{Re}>2300$. 
Para ese mismo tipo de geometría pero en cuanto al caso de flujo transitorio $(2300<\operatorname{Re}<6000)$, este sólo es distinguido por Ong [7], quien propone para su estudio la correlación de Hausen (ecuación $E-V \cdot 21)$ :

$$
N u=0,116\left(\operatorname{Re}^{2 / 3}-125\right) \operatorname{Pr}^{1 / 3}\left[1+\left(D_{h} / L\right)^{2 / 3}\right] \cdot\left(\frac{\mu}{\mu_{w}}\right)^{0,14}
$$

Por otro lado, las opciones propuestas para flujo turbulento (Re>6000) son más variadas. Ong [7] propone la correlación de Nusselt, que sigue la expresión de la ecuación E-V.21:

$$
N u=0,036 \operatorname{Re}^{0,8} \operatorname{Pr}^{1 / 3}\left(D_{h} / L\right)^{0,055}
$$

Otra posible correlación en este régimen de flujo es la de Kays and Crawford, como propone Ammari [3].

$$
N u=\frac{h D_{h}}{k_{\text {air }}}=0,0158 R e^{0,8}
$$

Si la variación entre propiedades del aire es notoria (pero la rugosidad de las superficies no es importante), según Ong [1] es recomendable utilizar la correlación propuesta por Sieder y Tate (ecuación E-V.24), siempre que el valor del Reynolds sea superior a 10000 y la relación entre longitud de conducto y longitud característica sea superior a 60 .

$$
N u=0,027 \operatorname{Re}^{0,8} \operatorname{Pr}^{1 / 3}\left(\mu / \mu_{w}\right)^{0,14}
$$

No obstante, cuando la rugosidad de las superficies es importante es preferible el uso de la correlación planteada por Petukhov, tal y como indican Ong [1] y Ammari [3]. Esta expresión es de hecho propuesta por Kays y Crawford como alternativa para el estudio del flujo interno a conductos, y responde a la ecuación $E$-V.25.

$$
N u=\frac{(f / 8) \operatorname{Re} \operatorname{Pr}}{k_{\text {air } 1,07+12,7} \sqrt{(f / 8)}\left(\operatorname{Pr}^{2 / 3}-1\right)}\left(\frac{\mu}{\mu_{w}}\right)^{0,11}
$$

Donde el factor de fricción, $f$, para conductos no rugosos es obtenido de:

$$
f=(0,79 \ln R e-1,64)^{-2}
$$

Hay que tener en cuenta que la longitud característica en este caso es el diámetro hidráulico, definido como la relación entre 4 veces el área de paso del fluido partido del perímetro mojado. Por lo tanto, para las dimensiones que nos repercuten:

$$
D_{h}=4\left(b \cdot h_{p}\right) / 2\left(b+h_{p}\right)
$$


Donde, $b$, es la longitud de la base del conducto de paso y $h_{p}$, la altura de la pared del conducto de paso del aire.

Por otro lado, si debe considerarse flujo no desarrollado, los coeficientes de transferencia esperados serán mayores [1]. En este caso, la relación presentada por Tan y Charters sería más ajustada al contemplar el efecto de la región de entrada y salida del canal de paso [8]. Esta relación está dada por la ecuación E-V.28:

$$
N u=N u_{\infty}(1+M D / L)
$$

Donde:

$$
N u_{\infty}=0,0182 \operatorname{Re}^{0,8} \operatorname{Pr}^{0,4}
$$

Y:

$$
M=14,3 \log _{10} N-7,9
$$

Con: $N=L / D$ si $O<L / D \leq 60$, y $N=60$ si $L / D>60$.

Dentro de un rango del Reynolds entre 9500 y 22000 [1].

Sin embargo, al trabajar con una sección de paso dividida en conductos rectangulares como es nuestro caso, el uso de estas correlaciones, definidas para la geometría de placas planas paralelas, resulta poco riguroso o incompleto. Asimismo, las referencias en la bibliografía sobre las que basarse para plantear un modelo para esta geometría más particular son limitadas, como ya se ha comentado. Entre estas, Ammari [3] propone completar el estudio evaluando el coeficiente de película en las caras verticales de los conductos haciendo uso de la correlación de Petukhov ya descrita (ecuación $E$ V.25).

Por su parte, Assari [4] recurre a una de las expresiones estudiadas por Sukhatme para la caracterización de geometrías de paso rectangulares con aletas longitudinales [9], que pueden asemejarse al caso de estudio cuando la separación superior entre las aletas y la frontera de la sección es nula. La expresión en cuestión es la correlación de Dittus-Boelter [6] (ecuación E-V.28), donde la longitud característica sería de nuevo el diámetro hidráulico definido conforme a la ecuación E-V.27.

$$
N u_{D}=0,023 \operatorname{Re}_{D}^{0,8} \operatorname{Pr}^{0,4}
$$

Teniendo en cuenta todo lo anterior, en el presente trabajo se ha optado por recurrir a la correlación de Colburn [6]:

$$
N u=0,0395 \operatorname{Pr}^{1 / 3} \operatorname{Re}^{0,75} \quad \text { si } 10^{4}<\operatorname{Re}<5 \cdot 10^{4}
$$




$$
N u=0,023 \operatorname{Pr}^{1 / 3} \operatorname{Re}^{0,8} \quad \text { si } 10^{4}<\operatorname{Re}<\cdot 10^{6}
$$

El uso de las ecuaciones $E$-V.32 y $E$-V.33 sería válido cuando $0,7<P r<160$ y la longitud del conducto/diámetro hidráulico $(L / D>60)$

Esta decisión se ha basado en varias razones: por un lado, en la experiencia de algunos de los trabajos anteriormente referenciados con el uso de esta correlación, aún modificada para geometría de flujo interno a dos placas planas, siendo además la expresión original de la correlación asociada a flujo interno en conductos; por otro, por la simplicidad de su expresión a la hora de implementarla en el modelo matemático de cálculo; asimismo, por poder preverse buenos resultados derivados de su uso por correspondencia formal con la correlación de Dittus-Boelter recurrida por Assari; finalmente, por el hecho de presentar la ventaja adicional de que Colburn distingue en su propia definición entre los casos de flujo laminar y turbulento. La justificación definitiva de esta decisión se basará en la correspondencia de los resultados teóricos obtenidos del modelo con los experimentales definidos en el capítulo IV.

\section{V.2.3.- COEFICIENTES DE RADIACIÓN.}

Para el cálculo de las resistencias de intercambio radiante entre superficies, se va a considerar recinto cerrado atendiendo a las dimensiones relativas de los colectores (tabla V.1).

La obtención de los factores de visión correspondientes se describe a continuación. Estos factores determinan las resistencias espaciales al intercambio radiante, las cuales definen los flujos de calor por radiación expresados en los balances de energía del punto V.2.1. (ecuaciones $E$-V.5, $E$ V.10, E-V.11 y $E-V .16)$.

\section{V.2.3.1.- INTERCAMBIO RADIANTE ENTRE EL ABSORBEDOR Y LA CUBIERTA.}

El intercambio radiante entre la placa absorbedora y la cubierta de vidrio se corresponde con una geometría de placas planas paralelas, por lo que el correspondiente factor de visión puede calcularse como se muestra en la figura V.4 y la ecuación E-V.34[10]. 


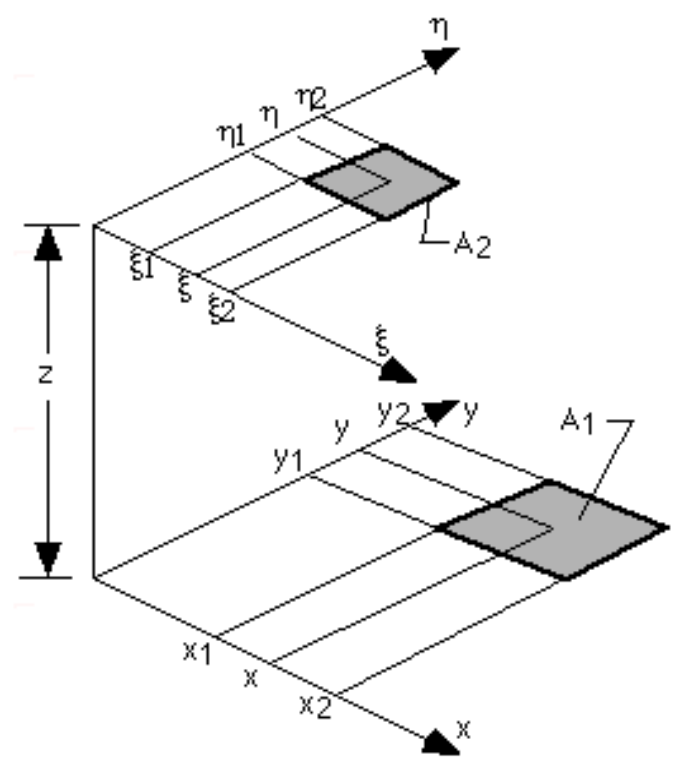

Figura V.4.- Factor de forma entre dos superficies rectangulares paralelas.

$$
\begin{gathered}
\mathrm{F}_{1-2}=\frac{1}{\left(\mathrm{x}_{2}-\mathrm{x}_{1}\right)\left(\mathrm{y}_{2}-\mathrm{y}_{1}\right)} \sum_{\mathrm{l}=1}^{2} \sum_{\mathrm{k}=1}^{2} \sum_{\mathrm{f}=1}^{2} \sum_{\mathrm{i}=1}^{2}(-1)^{(t+f+k+l)} \mathrm{G}\left(x_{i}, y_{f}, \eta_{k}, \varepsilon_{l}\right) \\
\mathrm{G}=\frac{1}{2 \pi}\left(\begin{array}{c}
(y-\eta)\left[(x-\varepsilon)^{2}+z^{2}\right]^{1 / 2} \tan ^{-1}\left\{\frac{y-\eta}{\left[(x-\varepsilon)^{2}+z^{2}\right]^{1 / 2}}\right\} \\
+(x-\varepsilon)\left[(y-\eta)^{2}+z^{2}\right]^{1 / 2} \tan ^{-1}\left\{\frac{x-\varepsilon}{\left[(y-\eta)^{2}+z^{2}\right]^{1 / 2}}\right\} \\
-\frac{z^{2}}{2} \ln \left[(x-\varepsilon)^{2}+(y-\eta)^{2}+z^{2}\right]
\end{array}\right)
\end{gathered}
$$

\section{V.2.3.2.- INTERCAMBIO RADIANTE ENTRE LAS CARAS DE LOS CONDUCTOS DE PASO.}

En este caso, el intercambio radiante se da entre las cuatro caras del mismo, concurriendo superficies con geometrías de placas planas paralelas y perpendiculares. El cálculo de los factores de visión para las caras perpendiculares entre sí se lleva a cabo según se muestra en la figura V.5 y en la ecuación E-V.35, para las paralelas podemos emplear las expresiones del apartado anterior (ecuación $E$-V.34) [10]. 


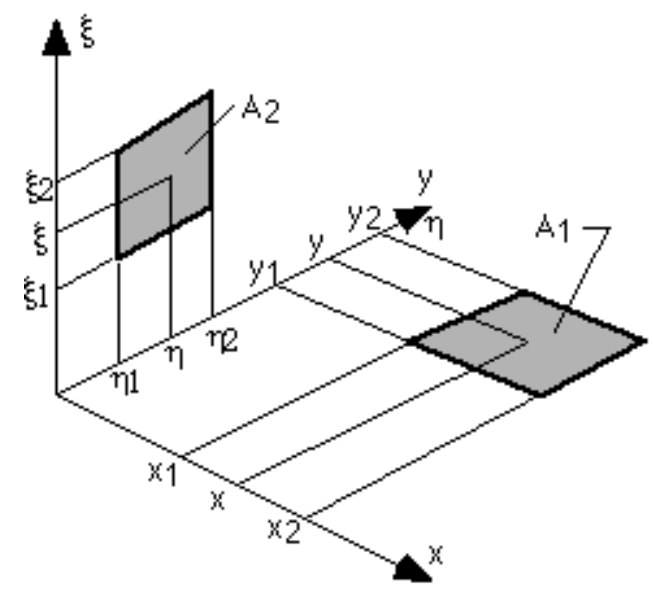

Figura V.5.- Factor de forma entre dos superficies rectangulares perpendiculares.

$$
\begin{aligned}
& \mathrm{F}_{1-2}=\frac{1}{\left(\mathrm{x}_{2}-\mathrm{x}_{1}\right)\left(\mathrm{y}_{2}-\mathrm{y}_{1}\right)} \sum_{\mathrm{l}=1}^{2} \sum_{\mathrm{k}=1}^{2} \sum_{\mathrm{f}=1}^{2} \sum_{\mathrm{i}=1}^{2}(-1)^{(t+f+k+l)} \mathrm{G}\left(x_{i}, y_{f}, \eta_{k}, \varepsilon_{l}\right) \\
& \mathrm{G}=\frac{1}{2 \pi}\left\{(y-\eta)\left(x^{2}-\varepsilon^{2}\right)^{1 / 2} \tan ^{-1}(K)-\frac{1}{4}\left[\left(x^{2}-\varepsilon^{2}\right) \ln \left(1+K^{2}\right)-(y-n)^{2} \ln \left(1+\frac{1}{K^{2}}\right)\right]\right\} \\
& \text { donde } K=(y-n) /\left(x^{2}-\varepsilon^{2}\right)^{1 / 2}
\end{aligned}
$$

\section{V.3.- RESOLUCIÓN DEL MODELO MATEMÁTICO POR EL MÉTODO DE DIFERENCIAS FINITAS.}

Los modelos matemáticos que han sido recurridos hasta la fecha para el estudio de los colectores solares de aire son muy diversos. Los utilizados en algunos de los trabajos más destacados han sido recopilados recientemente por Tchinda [11] para las distintas configuraciones de colector solar de aire existentes.

\section{V.3.1.- MÉTODO Y DISCRETIZACIÓN.}

Para el desarrollo del modelo particular en este trabajo se ha optado por el método de diferencias finitas. Para su resolución se ha programado un código en lenguaje $\mathrm{C}_{++}$.

El método de las diferencias finitas es el empleado para obtener la solución numérica de las ecuaciones diferenciales planteadas en los balances de energía presentados en los apartados anteriores de este capítulo. Para ello, se dividió el dominio del colector en un número finito de 
elementos en las tres direcciones del espacio. La sencilla geometría del colector solar permite una discretización espacial o geométrica mediante mallas estructuradas. Con todo esto, se lleva a cabo la discretización o mallado de los conductos que conforman el colector. En la figura V.6 se puede observar la discretización de uno de los conductos de paso del aire del colector y en la figura V.7 la discretización de dos conductos y el aislamiento. La discretización del resto de conductos que forman el colector se hace de forma similar.

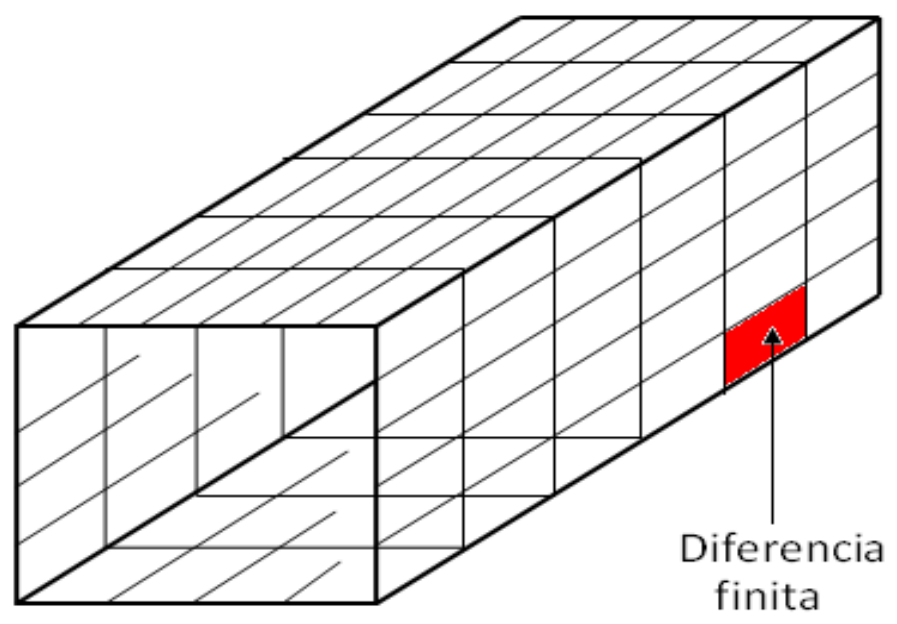

Figura V.6.- Discretización geométrica de un conducto de paso.

El número de elementos de mallado se determina en función de las necesidades temporales de resolución y de exactitud de los resultados.

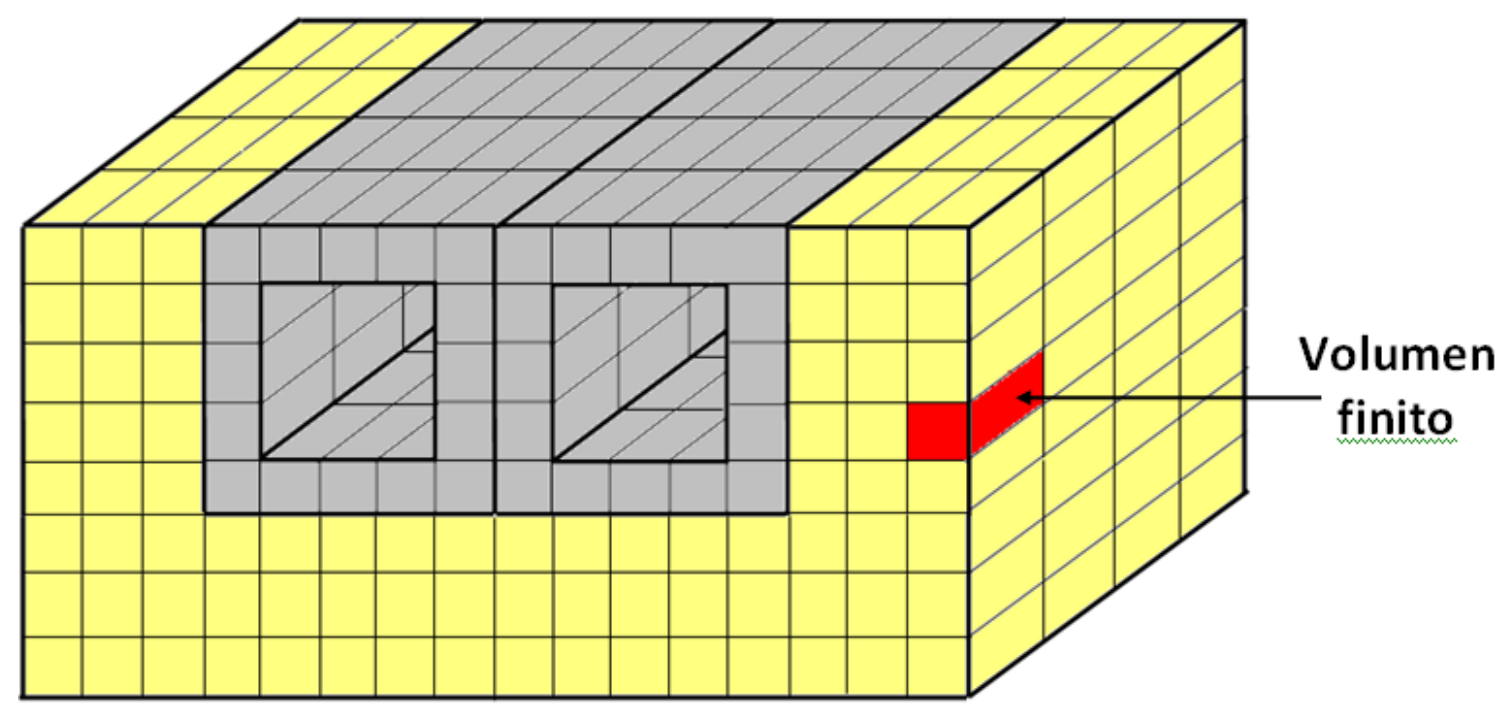

Figura V.7.- Discretización geométrica de dos conductos y el aislante. 
Para cada volumen finito se obtiene la siguiente transformación de la ecuación genérica transitoria (ecuación E-V.36):

$$
M c_{p} \frac{d T_{i}}{d t}=\sum_{j} Q_{j} \rightarrow M c_{p} \frac{T_{i, n+1}-T_{i, n}}{\Delta t}=\sum_{j} Q_{j}
$$

En la ecuación $E$-V.36 se tienen en cuenta los flujos de calor que afectan al elemento $i$ en las tres direcciones del espacio $(x, y, z)$ según la posición concreta de dicho elemento dentro del colector.

Las condiciones iniciales fueron dadas como una única temperatura a la cual se encuentra todo el dominio del colector en el instante $\mathrm{t}=0$. Por su parte, como condiciones de contorno se consideraron los valores predefinidos en cada caso para la intensidad radiante, el caudal de aire y la temperatura de entrada, así como la presión atmosférica y las temperaturas del entorno (fijadas para todos los casos en $20^{\circ} \mathrm{C}$ ).

\section{HIPÓTESIS EN EL MODELADO DE LA TRANSFERENCIA DE CALOR.}

Como primera hipótesis se asumió que las superficies de las caras internas de los conductos de aire se comportan como cuerpos grises con un valor constante de la emisividad igual a 0,1. Para calcular los factores de forma y por tanto las conductancias radiantes, se recurrió a las expresiones desarrolladas en el apartado V.2.3.2 Las relativas a el flujo radiante entre la cubierta y el absorbedor son las recogidas en el apartado V.2.3.1.

La radiación solar incidente (onda corta) fue contemplada de acuerdo al esquema de distribución de la figura V.8.

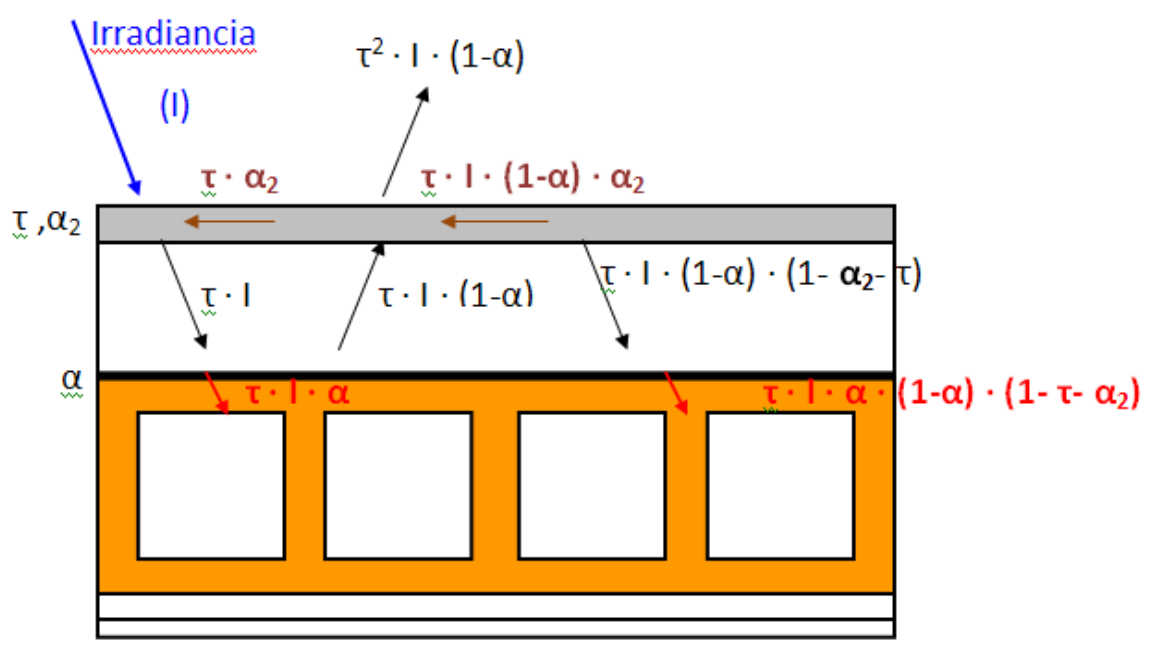

Figura V.8.- Distribución de la radiación incidente entre los componentes del colector. 
A partir del esquema de la figura V.8 se obtiene que las irradiancias absorbidas por absorbedor y cubierta de vidrio son:

Absorbedor:

$$
\tau \cdot I \cdot \alpha \cdot\left[\sum_{n=0}^{\infty}(1-\alpha)^{n}\left(1-\alpha_{2}-\tau\right)^{n}\right]=\frac{\tau \cdot I \cdot \alpha}{1-(1-\alpha) \cdot\left(1-\tau-\alpha_{2}\right)}
$$

Cubierta de vidrio:

$I \cdot \alpha_{2}+\tau \cdot I \cdot \alpha_{2} \cdot\left[\sum_{n=0}^{\infty}(1-\alpha)^{n}\left(1-\alpha_{2}-\tau\right)^{n-1}\right]=I \cdot \alpha_{2}+\frac{(1-\alpha) \cdot \tau \cdot I \cdot \alpha_{2}}{1-(1-\alpha) \cdot\left(1-\tau-\alpha_{2}\right)}$

Por otra parte, entre elementos finitos contiguos dentro del dominio sólido del colector, tendrá lugar una transferencia de calor por conducción que fue estimada de acuerdo a la ley de Fourier tomando valores constantes de la conductividad térmica de los distintos materiales.

Por último, el coeficiente convectivo en los conductos de aire fue calculado de acuerdo a lo establecido en el apartado V.2.2.

\section{V.3.2.- PROCESO DE CÁlCULO.}

Los datos de entrada necesarios para el funcionamiento del modelo son las características geométricas del colector y las diferentes propiedades de los materiales que lo componen, se pueden observar en la tabla V.1.

El siguiente paso sería definir las condiciones iniciales y de contorno ya mencionadas en el apartado anterior.

A continuación determinaremos las condiciones del mallado, el número de elementos en los que queremos dividir los elementos modelados, y el tiempo de simulación.

Después de esto, el programa comenzará a realizar los cálculos pertinentes en dos etapas. Primeramente se obtienen los flujos de calor que afectan a cada volumen finito en el instante actual para calcular a continuación las temperaturas de dichos volúmenes en el instante siguiente. Al llegar al final de la simulación, el programa vuelca los resultados obtenidos en un archivo externo.

En la figura V.9 se muestra un esquema con las distintas etapas del procedimiento de cálculo integrado en la programación $\mathrm{C}++$ para resolver las ecuaciones de balance planteadas. 


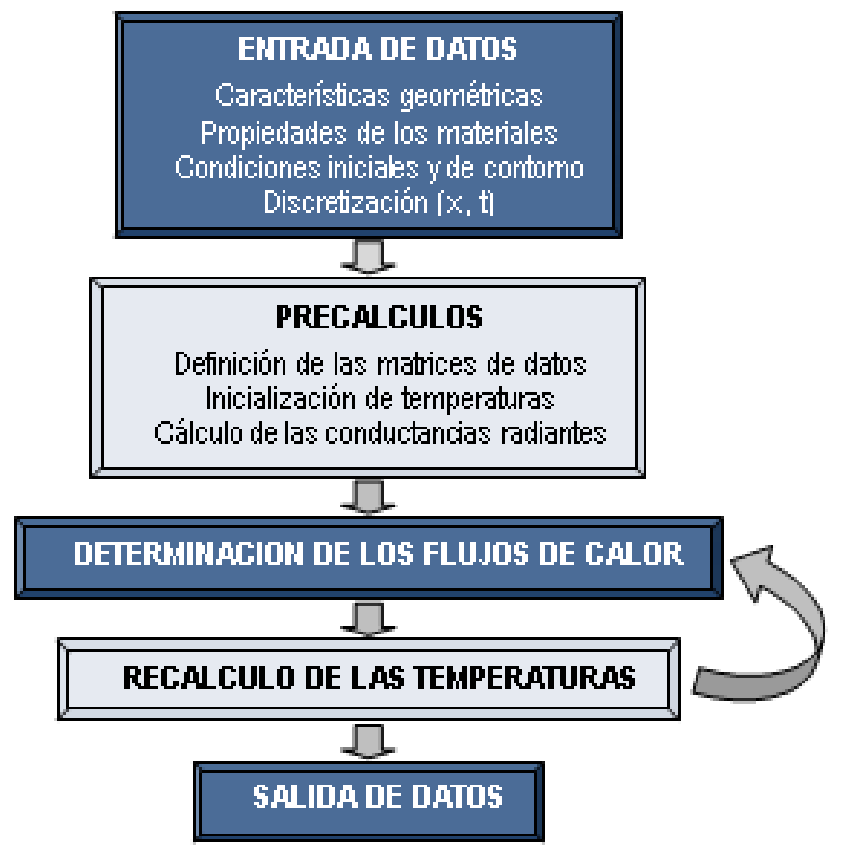

Figura V.9.- Diagrama de flujo del procedimiento de cálculo programado en $\mathrm{C}++$.

\section{V.3.3.- PARÁMETROS DE LA SIMULACIÓN.}

En la tabla V.2 se recogen los valores fundamentales empleados en las simulaciones y necesarios para reproducir los resultados obtenidos presentados a continuación.

Tabla V.2.- Parámetros característicos empleados en el estudio de simulación del colector.

\begin{tabular}{|c|c|}
\hline Parámetro & $\begin{array}{c}\text { Valor } \\
\text { utilizado }\end{array}$ \\
\hline Incremento temporal & $0,02 \mathrm{~s}$ \\
\hline Tiempo real total simulado & $3600 \mathrm{~s}$ \\
\hline paredes interiores) & 0,1 \\
\hline Emisividad de onda larga del aluminio (absorbedor y & 0,95 \\
\hline Absortividad de onda corta del absorbedor & 0,9 \\
\hline Transmitancia de onda corta de la cubierta de vidrio & 0,08 \\
\hline Absortividad de onda corta de la cubierta de vidrio & 0,9 \\
\hline Emisividad de onda larga de la cubierta de vidrio & $1007 \mathrm{~J} / \mathrm{kgK}$ \\
\hline Calor específico del aire (valor constante) & $4 \mathrm{~W} / \mathrm{m}^{2} \mathrm{~K}$ \\
\hline Coeficiente convectivo vidrio-exterior & $4 \mathrm{~W} / \mathrm{m}^{2} \mathrm{~K}$ \\
\hline Coeficiente convectivo vidrio-cámara de aire & $4 \mathrm{~W} / \mathrm{m}^{2} \mathrm{~K}$ \\
\hline Coeficiente convectivo aislante-exterior & $91100 \mathrm{~Pa}$ \\
\hline Presión atmosférica & 1 \\
\hline Número de elementos en las paredes de los conductos & 10 \\
\hline Número de elementos en el aislante lateral y posterior & 10 \\
\hline Número de elementos en la dirección del flujo de aire $(\mathrm{z})$ & 8 \\
\hline Número de elementos de las paredes horizontales $(\mathrm{x})$ & 10 \\
\hline Número de elementos en las paredes verticales $(\mathrm{x})$ & \\
\hline
\end{tabular}




\section{V.4.- RESULTADOS DEL MODELO.}

El planteamiento para la validación del modelo es la comparación con los datos obtenidos en la experimentación presentados en el capítulo IV de esta tesis doctoral. Por ello el número de simulaciones coincide con número de ensayos planteado en el diseño de experimentos a tenor de la combinación de los parámetros considerados como determinantes en el comportamiento del sistema. En la figura V.10 se puede observar el número de simulaciones establecido:

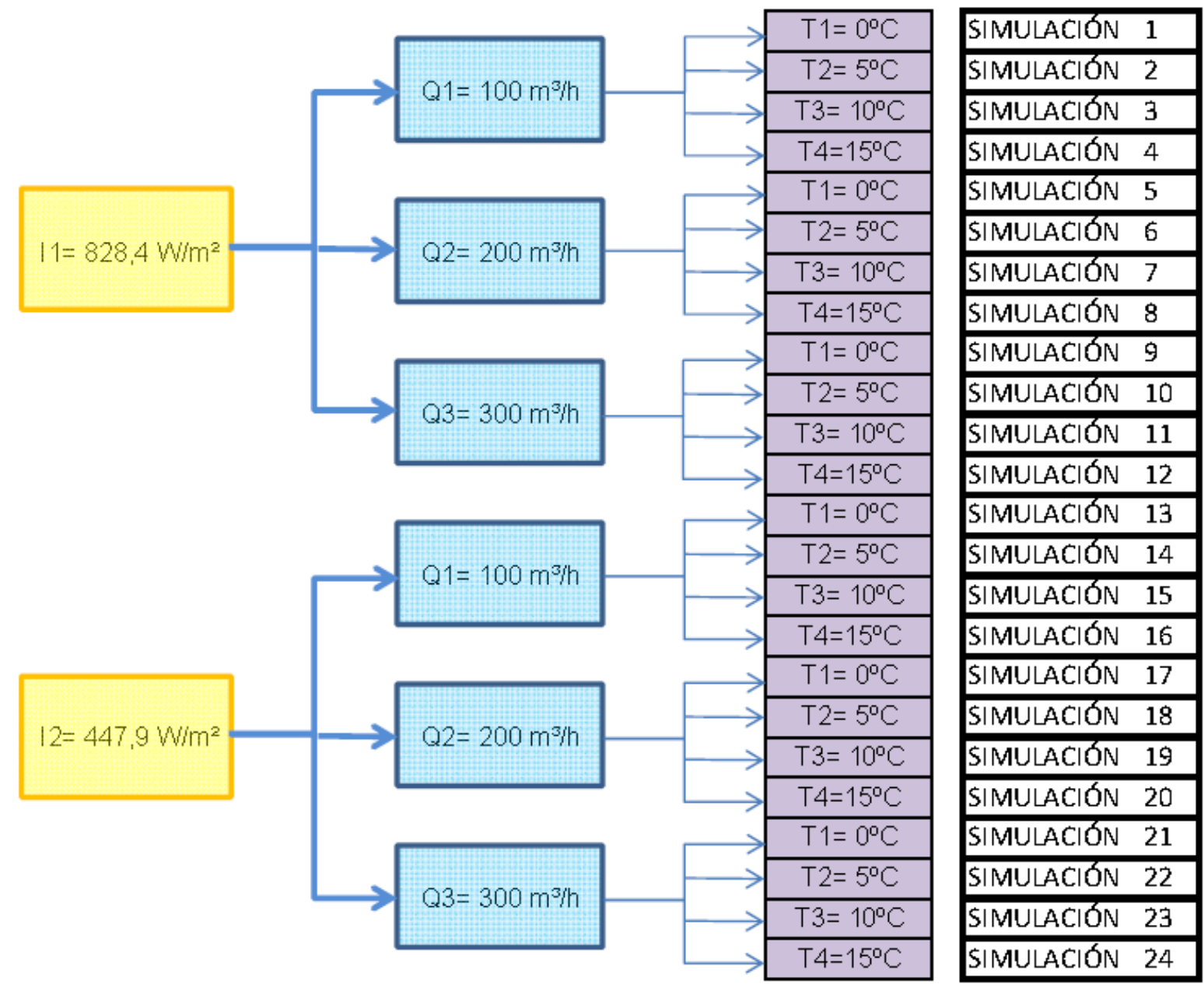

Figura V.10.- Esquema de las simulaciones llevadas a cabo.

Los resultados derivados de las simulaciones realizadas a partir del modelo numérico presentado se muestran en la tabla V.3. Se pueden observar los saltos térmicos del aire en el colector, la potencia útil aportada al aire y el rendimiento del colector, los parámetros estudiados en la experimentación. También se presentan los resultados obtenidos de la comparativa con los valores experimentales. 
Tabla V.3.- Resumen de los resultados de la simulación.

\begin{tabular}{|c|c|c|c|c|c|c|c|c|c|c|c|c|c|c|}
\hline \multirow[b]{2}{*}{ Simulación } & \multicolumn{3}{|c|}{ Consignas } & \multicolumn{2}{|c|}{ Temperatura salida $\left({ }^{\circ} \mathrm{C}\right)$} & \multicolumn{3}{|c|}{ Salto térmico $\Delta \mathrm{T}\left({ }^{\circ} \mathrm{C}\right)$} & \multicolumn{4}{|c|}{ Potencia (W) } & \multicolumn{2}{|c|}{ Rendimiento } \\
\hline & $\begin{array}{c}\text { Irradiancia } \\
\left(\mathrm{W} / \mathrm{m}^{2}\right)\end{array}$ & $\begin{array}{c}\text { Caudal } \\
\left(\mathrm{m}^{3} / \mathrm{h}\right)\end{array}$ & \begin{tabular}{|c|}
$\begin{array}{c}\text { Temp. } \\
\text { entrada } \\
\text { (ㅇ) }\end{array}$ \\
\end{tabular} & Experimental & Simulación & Experimental & Simulación & $\begin{array}{l}\text { Desviación } \\
\quad\left({ }^{\circ} \mathrm{C}\right)\end{array}$ & Experimental & Simulación & $\begin{array}{c}\text { Desviación } \\
\text { (W) }\end{array}$ & Desviación & Experimental & Simulación \\
\hline 1 & 828,4 & 100 & 15 & 63,6 & 55,3 & 48,5 & 40,3 & 8,2 & 1816,3 & 1507,1 & 309,2 & $17,0 \%$ & 0,55 & 0,46 \\
\hline 2 & 828,4 & 100 & 10 & 60,1 & 53,3 & 49,6 & 43,3 & 6,3 & 1854,2 & 1601,4 & 252,8 & $13,6 \%$ & 0,56 & 0,48 \\
\hline 3 & 828,4 & 100 & 5 & 55,2 & 51,1 & 49,7 & 46,1 & 3,6 & 1834,0 & 1680,9 & 153,1 & $8,3 \%$ & 0,55 & 0,51 \\
\hline 4 & 828,4 & 100 & 0 & 57,7 & 51,1 & 57,5 & 51,1 & 6,4 & 1855,5 & 1643,4 & 212,1 & $11,4 \%$ & 0,56 & 0,50 \\
\hline 5 & 447,9 & 100 & 15 & 44,2 & 38,8 & 28,7 & 23,8 & 5,0 & 982,3 & 797,2 & 185,1 & $18,8 \%$ & 0,55 & 0,45 \\
\hline 6 & 447,9 & 100 & 10 & 40,8 & 36,6 & 30,6 & 26,6 & 4,0 & 1040,6 & 898,0 & 142,6 & $13,7 \%$ & 0,58 & 0,50 \\
\hline 7 & 447,9 & 100 & 5 & 38,5 & 34,6 & 33,1 & 29,6 & 3,4 & 1119,8 & 987,6 & 132,2 & $11,8 \%$ & 0,63 & 0,55 \\
\hline 8 & 447,9 & 100 & 0 & 34,4 & 32,2 & 34,1 & 32,2 & 1,9 & 1171,7 & 1094,7 & 77 & $6,6 \%$ & 0,65 & 0,61 \\
\hline 9 & 828,4 & 200 & 15 & 47,9 & 46,7 & 33,0 & 31,7 & 1,3 & 2228,2 & 2146,7 & 81,5 & $3,7 \%$ & 0,67 & 0,65 \\
\hline 10 & 828,4 & 200 & 10 & 43,0 & 42,6 & 32,6 & 32,6 & 0,0 & 2360,2 & 2336,5 & 23,7 & $1,0 \%$ & 0,71 & 0,71 \\
\hline 11 & 828,4 & 200 & 5 & 38,7 & 39,1 & 34,5 & 34,1 & 0,5 & 2476,0 & 2504,8 & $-28,8$ & $-1,2 \%$ & 0,75 & 0,76 \\
\hline 12 & 828,4 & 200 & 0 & 36,3 & 37,4 & 36,0 & 37,4 & $-1,4$ & 2480,9 & 2558,2 & $-77,3$ & $-3,1 \%$ & 0,75 & 0,77 \\
\hline 13 & 447,9 & 200 & 15 & 32,1 & 32,0 & 17,3 & 17,0 & 0,3 & 1239,7 & 1229,3 & 10,4 & $0,8 \%$ & 0,69 & 0,69 \\
\hline 14 & 447,9 & 200 & 10 & 29,2 & 29,2 & 19,3 & 19,2 & 0,1 & 1362,9 & 1364,3 & $-1,4$ & $-0,1 \%$ & 0,76 & 0,76 \\
\hline 15 & 447,9 & 200 & 5 & 25,4 & 26,7 & 19,9 & 21,7 & $-1,7$ & 1386,9 & 1474,5 & $-87,6$ & $-6,3 \%$ & 0,77 & 0,82 \\
\hline 16 & 447,9 & 200 & 0 & 22,3 & 23,8 & 21,8 & 23,8 & $-2,0$ & 1496,2 & 1593,1 & $-96,9$ & $-6,5 \%$ & 0,84 & 0,89 \\
\hline 17 & 828,4 & 300 & 15 & 40,7 & 40,0 & 24,6 & 25,0 & $-0,3$ & 2691,0 & 2611,8 & 79,2 & $2,9 \%$ & 0,81 & 0,79 \\
\hline 18 & 828,4 & 300 & 10 & 38,6 & 40,0 & 27,6 & 30,0 & $-2,4$ & 2832,2 & 2975,4 & $-143,2$ & $-5,1 \%$ & 0,86 & 0,90 \\
\hline 19 & 828,4 & 300 & 5 & 34,2 & 34,7 & 27,0 & 29,7 & $-2,6$ & 2813,7 & 2859,5 & $-45,8$ & $-1,6 \%$ & 0,85 & 0,86 \\
\hline 20 & 828,4 & 300 & 0 & 27,6 & 28,9 & 26,9 & 28,9 & $-2,0$ & 2985,5 & 3127,8 & $-142,3$ & $-4,8 \%$ & 0,90 & 0,94 \\
\hline 21 & 447,9 & 300 & 15 & 28,8 & 28,7 & 14,5 & 13,7 & 0,9 & 1460,0 & 1446,5 & 13,5 & $0,9 \%$ & 0,82 & 0,81 \\
\hline 22 & 447,9 & 300 & 10 & 24,9 & 25,4 & 14,6 & 15,4 & $-0,8$ & 1567,0 & 1619,0 & -52 & $-3,3 \%$ & 0,88 & 0,90 \\
\hline 23 & 447,9 & 300 & 5 & 19,9 & 21,4 & 14,9 & 16,4 & $-1,5$ & 1642,0 & 1807,1 & $-165,1$ & $-10,1 \%$ & 0,92 & 1,01 \\
\hline 24 & 447,9 & 300 & 0 & 17,5 & 18,9 & 15,8 & 18,9 & $-3,1$ & 1761,0 & 1922,1 & $-161,1$ & $-9,1 \%$ & 0,98 & 1,07 \\
\hline
\end{tabular}


Además, la figura V.10 presenta una comparación gráfica entre los resultados experimentales y simulados para la temperatura del aire a la salida del colector. Se observan resultados muy satisfactorios en la gran mayoría de condiciones estudiadas con diferencias inferiores a $2 \stackrel{\circ}{ } \mathrm{C}$ respecto los datos experimentales.

Sin embargo, las simulaciones realizadas para el menor nivel de caudal de aire $\left(100 \mathrm{~m}^{3} / \mathrm{h}\right)$ proporcionan peores resultados que se desvían entre 4 y $8 \stackrel{\circ}{\circ}$. A la vista de la figura V.10 se aprecia igualmente que el comportamiento de los resultados simulados muestra una tendencia con el nivel térmico alcanzado por el colector. Los resultados de menor caudal coinciden con los mayores niveles térmicos alcanzados en el captador, para los cuales la temperatura de salida simulada aparece claramente infra-estimada. En cambio, las simulaciones con caudales superiores, que corresponden con menores temperaturas en el colector, se ajustan muy bien. No obstante, conforme disminuye el nivel térmico de trabajo del colector, los resultados simulados pasan a sobre-estimar ligeramente la temperatura de salida.

El diferente comportamiento del modelo en función del nivel térmico podría ser debido a pequeñas variaciones de las propiedades radiantes del colector que son supuestas constantes en el modelo. Sin embargo, las desviaciones más importantes parecen estar claramente asociadas a los valores bajos de caudal, lo cual podría indicar que la discretización empleada en la dirección del flujo no es suficientemente adecuada. En futuros trabajos de optimización del modelo, sin duda este debe ser un aspecto a tratar.

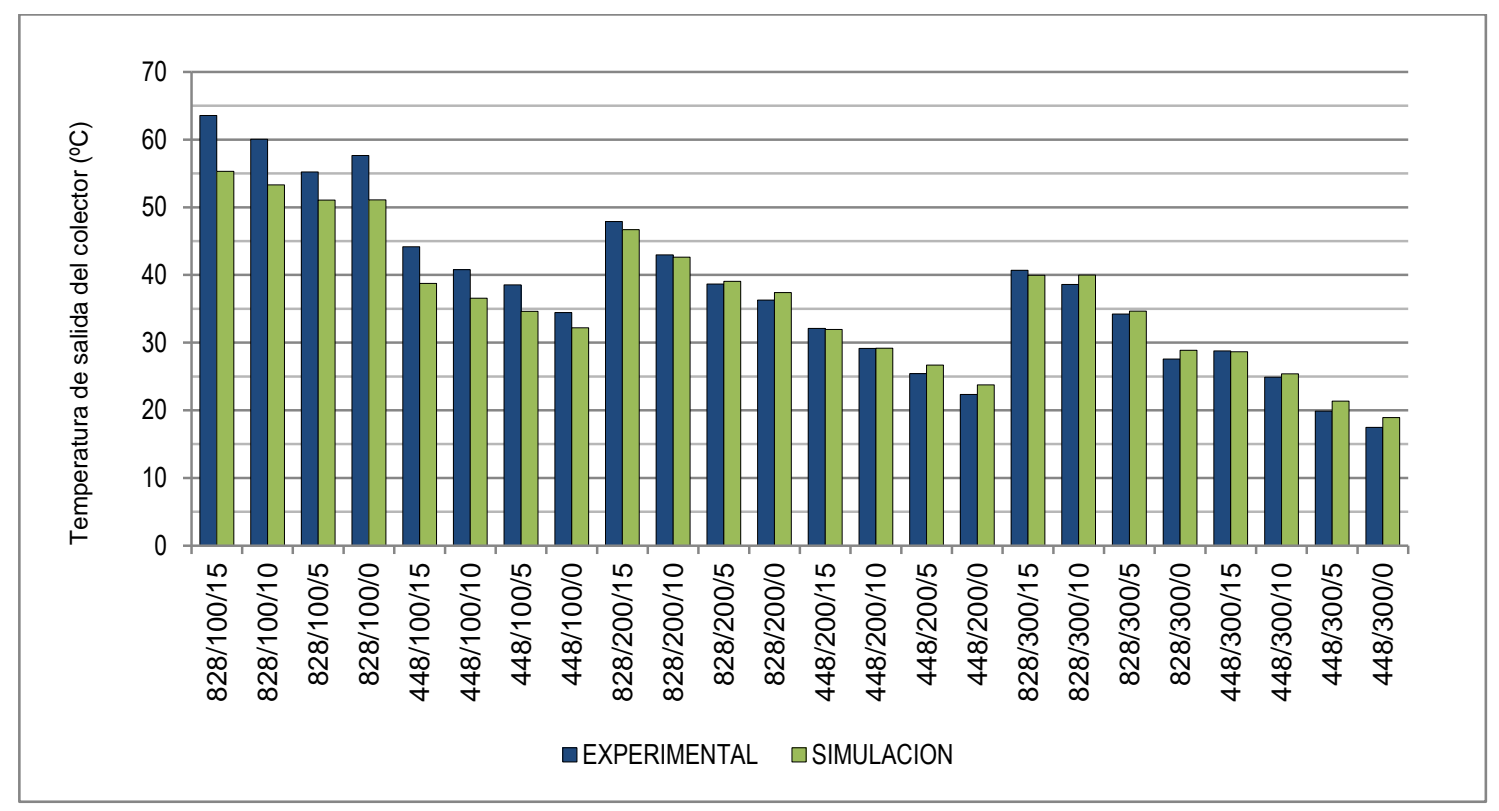

Figura V.11.- Temperatura de salida del colector experimental y calculada. 
Por último, en la figura V.11 se representan las rectas de rendimiento obtenidas para los tres niveles de caudal analizados de acuerdo a la expresión habitual empleada en la caracterización de colectores solares térmicos (ecuación de Bliss -ecuación E-V.39-) [12]:

$$
\eta=\frac{\dot{m} c_{p}\left(T_{a, s a l}-T_{a, e n t}\right)}{I S}=F_{R} \tau_{v} \alpha_{a b s}-F_{R} U\left(\frac{T_{a, e n t}-T_{e x t}}{I}\right)
$$

Como era de esperar debido a la caracterización experimental previamente disponible, la operación con caudales mayores supone mejores rendimientos. Las simulaciones proporcionan resultados muy similares a los experimentales en el rango de condiciones de validación. En cambio, la pendiente de las rectas simuladas (directamente relacionada con las pérdidas del colector) es ligeramente superior a la experimental, lo cual ha de tenerse en consideración si se desease aplicar el modelo en un rango de condiciones con valores de la abscisa muy elevados.

Por otro lado, nuevamente los resultados para el menor nivel de caudal son menos satisfactorios. Sin embargo, las diferencias no son tan importantes dado que para estos ensayos, el error en las temperaturas de salida se compensa en cierto modo con el bajo caudal másico al calcular la energía útil cedida a la corriente de aire.

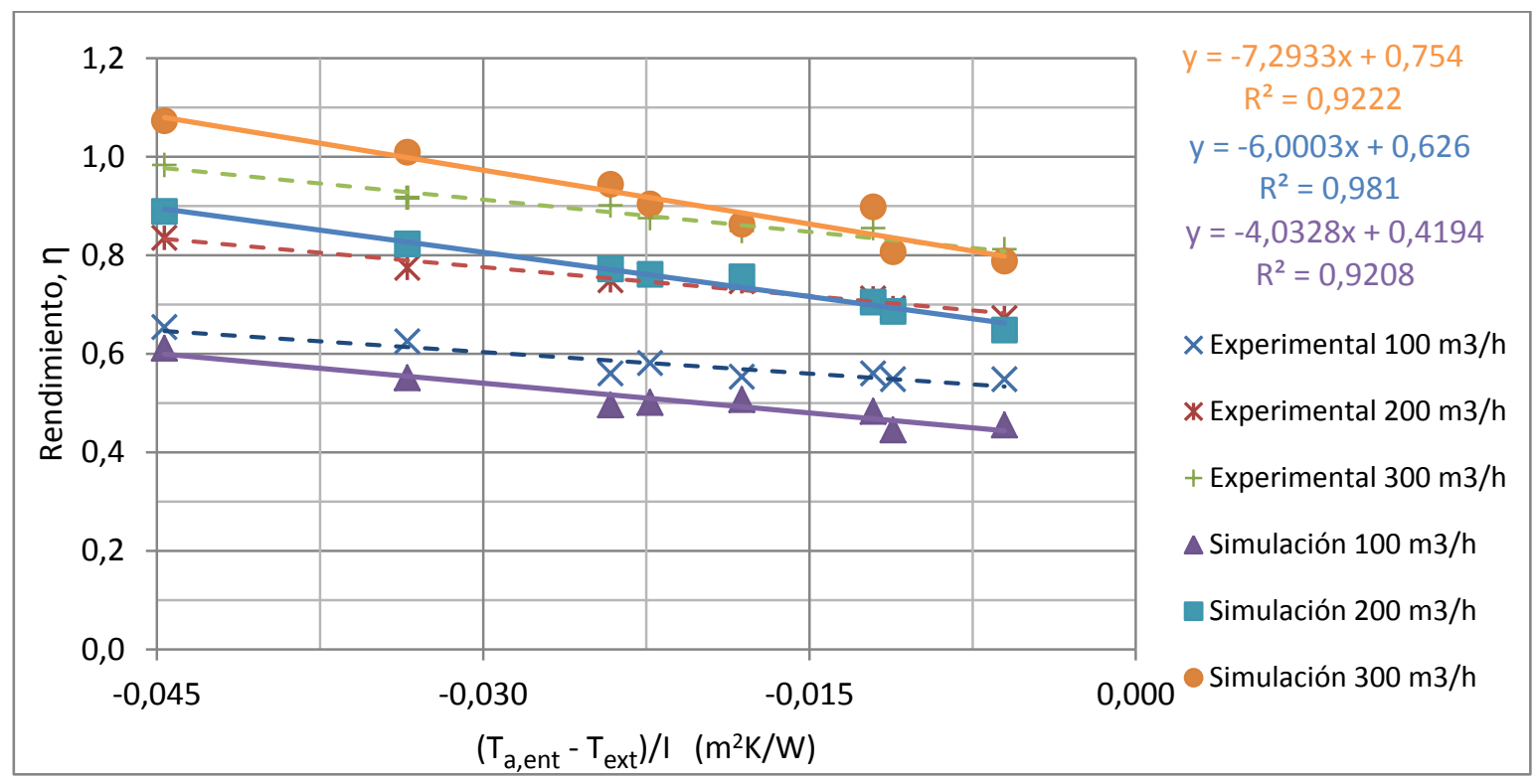

Figura V.12.- Comparación de las rectas de rendimiento, experimentales y calculadas. 


\section{CONCLUSIONES:}

El desarrollo del modelo numérico para la simulación del comportamiento energético del colector de aire estudiado ha reportado valores satisfactorios en su validación frente a los resultados experimentales llevados a cabo para un amplio rango de condiciones de operación típico en los periodos de invierno de un clima de interior en España.

Los resultados simulados para bajos caudales de aire proporcionan ligeras desviaciones en algunas circunstancias que podrían ser mejoradas. De todos modos, el factor caudal compensa parcialmente estas desviaciones al obtener las rectas de rendimiento energético del colector analizado. Así, los resultados derivados de este trabajo son, sin duda, interesantes y validan el modelo para su aplicación en estudios más amplios acerca del potencial y capacidades de esta tecnología en el pre-acondicionamiento del aire exterior de ventilación en los edificios.

La disponibilidad de una herramienta de simulación como esta permite llevar a cabo un estudio previo de adecuación de la incorporación del colector solar en las circunstancias consideradas, como elemento de ahorro energético en las instalaciones de acondicionamiento térmico de aire de los edificios. 


\section{REFERENCIAS}

[1] K.S. Ong, Thermal performance of solar air heaters: Mathematical model and solution procedure, Sol. Energy. 55 (1995) 93-109. doi:10.1016/0038-092X(95)00021-I.

[2] G. Solar, Manual técnico TwinSolar-SLK TopSolar, (2004).

[3] H.D. Ammari, A mathematical model of thermal performance of a solar air heater with slats, Renew. Energy. 28 (2003) 1597-1615. doi:10.1016/S0960-1481(02)00253-7.

[4] M.R. Assari, H. Basirat Tabrizi, I. Jafari, Experimental and theoretical investigation of dual purpose solar collector, Sol. Energy. 85 (2011) 601-608. doi:10.1016/j.solener.2011.01.006.

[5] H.H. Al-Kayiem, T.A. Yassen, On the natural convection heat transfer in a rectangular passage solar air heater, Sol. Energy. 112 (2015) 310-318. doi:10.1016/j.solener.2014.11.031.

[6] F. P. Incropera, D. P. DeWitt, Fundamentos de transferencia de calor, $4^{a}$ edición, 1999.

[7] K.S. Ong, Thermal performance of solar air heaters-Experimental correlation, Sol. Energy. 55 (1995) 209-220. doi:10.1016/0038-092X(95)00027-O.

[8] C. Choudhury, P.M. Chauhan, H.P. Garg, Design curves for conventional solar air heaters, Renew. Energy. 6 (1995) 739-749. doi:10.1016/0960-1481(95)00007-7.

[9] S.B. Thombre, S.P. Sukhatme, Turbulent flow heat transfer and friction factor characteristics of shrouded fin arrays with uninterrupted fins, Exp. Therm. Fluid Sci. 10 (1995) 388-396. doi:10.1016/0894-1777(94)00059-H.

[10] A.J. Chapman, Transmisión de calor, $3^{\mathrm{a}}$ ed., 1974.

[11] R. Tchinda, A review of the mathematical models for predicting solar air heaters systems, Renew. Sustain. Energy Rev. 13 (2009) 1734-1759. doi:10.1016/j.rser.2009.01.008.

[12] F.J. Rey Martínez, E. Velasco Gómez, Bombas de Calor y Energías Renovables en Edificios, Thomson, Madrid, 2005.

\section{NORMATIVA.}

[N-1] Ministerio de Industria, Turismo y Comercio y Ministerio de Vivienda de España, "Real Decreto 1027/2007: Reglamento de Instalaciones Térmicas en Edificios". 
CAPÍTULO V: SIMULACIÓN ENERGÉTICA DE LOS C.T.S.

224 


\section{PARTE III:}

APLICACIONES DE LOS

COLECTORES TÉRMICOS

\section{SOLARES DE AIRE}

CAPÍTULO VI:

AHORROS ENERGÉTICOS

EN VENTILACIÓN Y

CALEFACCIÓN.

CAPÍTULO VII:

AHORROS ENERGÉTICOS

EN VERANO. 


\section{CAPÍTULO VI.- \\ AHORROS ENERGÉTICOS EN VENTILACIÓN Y CALEFACCIÓN.}

\section{CONTENIDOS DEL CAPÍTULO:}

VI.1.- INTRODUCCIÓN: APLICACIONES DE LOS C.T.S. DE AIRE PARA EL AHORRO DE ENERGÍA EN EDIFICIOS. 233

VI.2.- SIMULACIÓN DE LOS C.T.S. DE AIRE EN INVIERNO..........................235

VI.2.1.- LOCALIDADES CONTEMPLADAS EN EL ESTUDIO. ................................. 235

VI.2.2.- PERIODO DE ESTUDIO CONSIDERADO. .......................................... 236

VI.2.3.- INCLINACIÓN ÓPTIMA DEL C.T.S. PARA EL USO PROPUESTO................. 237

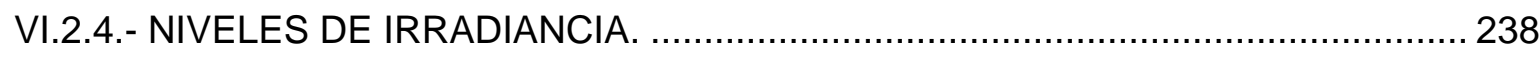

VI.2.5.- SALTOS TÉRMICOS ALCANZADOS EN EL C.T.S ................................... 238

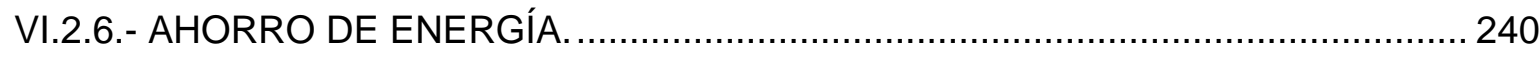

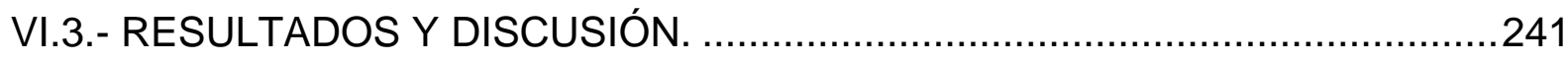

VI.3.1.- INCLINACIONES ÓPTIMAS PARA LAS LOCALIDADES DE ESTUDIO.......... 241

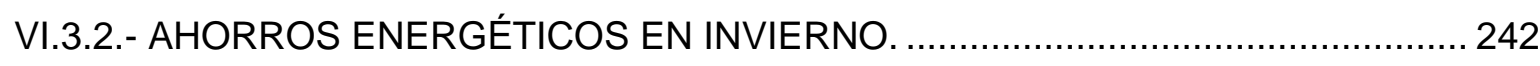

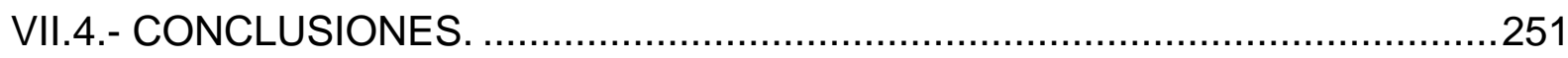

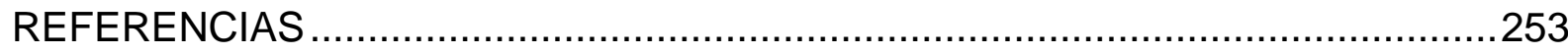

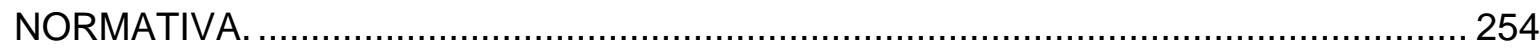


CAPÍTULO VI: AHORROS ENERGÉTICOS EN VENTILACIÓN Y CALEFACCIÓN

228 


\section{LISTA DE FIGURAS:}

Figura VI.1.- Ahorros obtenidos por zonas climáticas solares (entre paréntesis se indica la zona climática de invierno).

Figura VI.2.- Ahorros obtenidos para la comprobación del comportamiento del C.T.S con los niveles 2 y 3 de irradiancia presentados por zona climática solar (entre paréntesis se indica la zona climática de invierno). 249

Figura VI.3.-Porcentaje de horas en los que la temperatura de salida del aire del colector supera los $22^{\circ} \mathrm{C}$, para cada localidad y caudal de aire estudiados presentadas por zona climática solar (entre paréntesis se indica la zona climática de invierno). 250

\section{LISTA DE TABLAS:}

Tabla VI.1.- Zonas climáticas y latitud geográfica de las localidades estudiadas. ..........................235

Tabla VI.2.- Grados día para el mes de abril de las localidades estudiadas..................................2 236

Tabla VI.3.- Inclinación óptima calculada del C.T.S. para las localidades estudiadas......................241

Tabla VI.4.- Ahorros obtenidos y porcentaje de horas con cobertura total de la demanda de ventilación para la localidad de Almería. ...................................................................................... 242

Tabla VI.5.- Ahorros obtenidos y porcentaje de horas con cobertura total de la demanda de

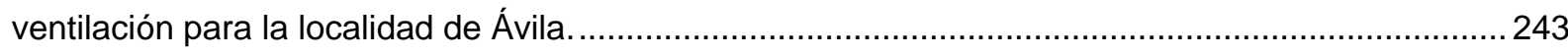

Tabla VI.6.- Ahorros obtenidos y porcentaje de horas con cobertura total de la demanda de ventilación para la localidad de Barcelona. ................................................................................... 243

Tabla VI.7.- Ahorros obtenidos y porcentaje de horas con cobertura total de la demanda de

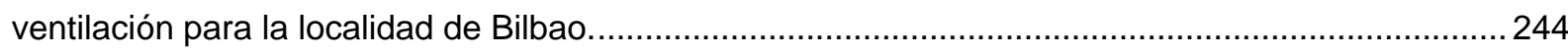

Tabla VI.8.- Ahorros obtenidos y porcentaje de horas con cobertura total de la demanda de ventilación para la localidad de Madrid. 244

Tabla VI.9.- Ahorros obtenidos y porcentaje de horas con cobertura total de la demanda de ventilación para la localidad de Pamplona. .................................................................................... 245

Tabla VI.10.- Ahorros obtenidos y porcentaje de horas con cobertura total de la demanda de ventilación para la localidad de Sevilla. 245

Tabla VI.11.- Ahorros obtenidos y porcentaje de horas con cobertura total de la demanda de ventilación para la localidad de Valencia. 246 


\section{CAPÍTULO VI: AHORROS ENERGÉTICOS EN VENTILACIÓN Y CALEFACCIÓN}

Tabla VI.12.- Ahorros obtenidos y porcentaje de horas con cobertura total de la demanda de ventilación para la localidad de Valladolid.......

246

Tabla VI.13.- Resumen de los ahorros totales obtenidos y porcentaje de horas con cobertura total de la demanda de ventilación en todo el periodo de invierno de todas las localidades....... 247

Tabla VI.14.- Clasificación de las localidades en función del máximo ahorro obtenido. 249 


\section{Nomenclatura:}

$C_{p}$ : calor específico $(\mathrm{kJ} / \mathrm{kgK})$

I: Irradiancia $\left(\mathrm{W} / \mathrm{m}^{2}\right)$

T: Temperatura $\left[{ }^{\circ} \mathrm{C}\right]$

$\Delta T$ : Salto térmico alcanzado en el colector $\left({ }^{\circ} \mathrm{C}\right)$

$k$ : factor de corrección de irradiancia para superficies inclinadas.

$\beta$ : inclinación del colector respecto de la horizontal $\left(^{\circ}\right)$

m: flujo másico $[\mathrm{kg} / \mathrm{s}]$

\section{Subíndices:}

$a$ : aire

lat. latitud

hor: horizontal

out. salida del colector 
CAPÍTULO VI: AHORROS ENERGÉTICOS EN VENTILACIÓN Y CALEFACCIÓN

232 


\section{VI.1.- INTRODUCCIÓN: APLICACIONES DE LOS C.T.S. DE AIRE PARA EL AHORRO DE ENERGÍA EN EDIFICIOS.}

La aplicación más extendida de los colectores solares en edificios emplea casi siempre agua como fluido caloportador de la energía captada, para el calentamiento de piscinas y como sistemas de producción de agua caliente sanitaria [1]. El otro campo de aplicación de los colectores solares en edificios es el acondicionamiento térmico de estos, empleándose para calentar los espacios. Habitualmente el empleo de los colectores solares en calefacción se basa en calentar agua glicolada en sistemas de baja temperatura como suelo radiante o fancoils, disipando en el aire de los espacios a calentar el calor captado en los colectores [2].

Como se ha visto en el capítulo II, los colectores térmicos solares de aire no tienen la cuota de penetración en el mercado de los colectores de agua pese a contar con numerosas ventajas [3] [4]. También se ha visto que la aplicación más extendida de los CTS de aire en edificios es el aporte de calor para el calentamiento y ventilación de espacios acondicionados. Una de las causas de este bajo nivel de implantación de los CTS de aire en edificios es la estacionalidad de utilización. La falta de aplicabilidad cuando no es necesario aporte de calor para calentar o ventilar el edificio supone un inconveniente para los CTS de aire.

El análisis de las aplicaciones de los CTS de aire para el ahorro de energía en edificios obliga a establecer dos periodos o modos de operación de los CTS en función de la demanda prevista: uno de ellos es un periodo de "invierno" o de demanda de calor de las instalaciones de calefacción y/o ventilación; y el otro, un periodo de "verano" en el que no existe demanda de calor para el calentamiento del aire de calefacción o ventilación. El primero de los periodos, el de "invierno", es analizado en este capítulo, mientras que en capítulo VII de esta Tesis Doctoral se presentan y analizan las alternativas de aprovechamiento de los CTS de aire en el periodo de "verano".

La integración de los colectores dentro del edificio debe tener en cuenta un criterio que permita obtener las máximas prestaciones energéticas del sistema de captación solar. La configuración formal de los componentes del captador (absorbedor, cubierta, etc.), la inclinación y la orientación con la que es instalado el C.T.S. son los principales factores a tener en cuenta para la optimización de la captación de energía. La proyección de sombras y la existencia de polvo o suciedad sobre la superficie de los captadores son otras circunstancias a evitar para alcanzar el máximo aprovechamiento [5].

Numerosos trabajos recogidos en la bibliografía han estudiado y propuesto métodos más o menos complejos para la obtención de la inclinación adecuada en la captación solar [6-16]. Diferentes resultados se han obtenido para la inclinación en función de la aplicación, localización y periodo estudiados. muchos de estos trabajos emplean la latitud de la localización del captador como 
referencia del ángulo óptimo, como por ejemplo: latitud $\varphi+(10 \ldots 30)^{\circ}[7], 0,917 \cdot \varphi+0,321$ [16]. Chang presenta relaciones más complejas entre el ángulo de inclinación óptimo y la latitud con diferentes constantes para cada mes o estación [8]. Numerosos autores estudian las inclinaciones óptimas para determinadas localizaciones; algunos de estos casos son Irán [17], Egipto [18], Siria [14]. Gunerhan.y Hepbasli calculan la mejor orientación para cada mes en Turquía [9]. Shariah et al, en un estudio para un sistema de captadores solares de agua para ACS por termosifón en Jordania, realizado con el software TRNSYS, obtienen resultados que indican que la inclinación óptima varía entre $0^{\circ}$ y $20^{\circ}$ más la latitud en función de la situación geográfica estudiada dentro del país [10].

En cuanto a la bibliografía técnica, esta define el ángulo de inclinación óptimo dependiendo del periodo de utilización del captador [19]:

- Para un consumo anual constante del sistema asociado a los captadores la inclinación más adecuada es igual al valor de la latitud geográfica.

- Para un consumo preferente en invierno, la inclinación adecuada es la latitud geográfica más $10^{\circ}$.

- Para un consumo preferente en verano, la inclinación más favorable es la latitud geográfica menos $10^{\circ}$.

El estudio de ahorros alcanzados por el uso del C.T.S. analizado se plantea para las condiciones óptimas de aprovechamiento, planteándose en cada uno de los casos para la inclinación más adecuada del CTS, en función de la localización geográfica y la irradiación recibida para el periodo de trabajo considerado a partir de los datos climáticos disponibles [20].

En este capítulo se estudian los ahorros energéticos obtenidos por la utilización de los CTS, calentando directamente el aire empleado en las instalaciones de ventilación y/o calefacción. Este análisis se realiza para varias ciudades españolas que cuentan con diferentes condiciones climáticas y situaciones geográficas. 


\section{VI.2.- SIMULACIÓN DE LOS C.T.S. DE AIRE EN INVIERNO.}

El estudio de los ahorros obtenidos por la utilización de los captadores solares de aire se basa en el cálculo de los aportes de calor obtenidos mediante la simulación de su operación en las condiciones óptimas para las localizaciones seleccionadas.

El modelado de los C.T.S. se fundamenta en los resultados de los trabajos experimentales realizados para la caracterización del colector TwinSolar 4.0-SLK [21] y que se encuentran recogidos en el capítulo IV de esta memoria.

La implementación del modelo del captador para esta aplicación se realiza a través de las regresiones obtenidas para los saltos térmicos obtenidos en función de la irradiancia sobre la superficie del colector, la temperatura seca del aire y el caudal de aire de paso por el colector. La irradiación sobre la superficie del colector y la temperatura seca del aire a la entrada del colector vienen definidas por las condiciones climáticas de cada una de las localidades estudiadas [20]. En cuanto al caudal de aire por el colector, se simulan los tres niveles también experimentados: $\mathrm{Q} 1=100 \mathrm{~m}^{3} / \mathrm{h}, \mathrm{Q} 2=200 \mathrm{~m}^{3} / \mathrm{h}$ y $\mathrm{Q} 3=300 \mathrm{~m}^{3} / \mathrm{h}$.

\section{VI.2.1.- LOCALIDADES CONTEMPLADAS EN EL ESTUDIO.}

La selección de las localidades estudiadas se ha llevado a cabo de manera que se analizan todos los tipos de zonas climáticas de invierno peninsulares y los diferentes tipos de zonas climáticas solares [22], seleccionando localidades que permitan analizar resultados de combinaciones de zonas climáticas de invierno y solares. Las localidades seleccionadas pueden observarse en la tabla VI.1:

Tabla VI.1.- Zonas climáticas y latitud geográfica de las localidades estudiadas.

\begin{tabular}{|l|c|c|c|c|}
\hline & $\begin{array}{c}\text { ZONA } \\
\text { CLIMÁTICA } \\
\text { INVIERNO }\end{array}$ & $\begin{array}{c}\text { ZONA } \\
\text { CLIMÁTICA } \\
\text { VERANO }\end{array}$ & $\begin{array}{c}\text { ZONA } \\
\text { CLIMÁTICA } \\
\text { SOLAR }\end{array}$ & LATITUD \\
\hline ALMERIA & $\mathrm{A}$ & 4 & $\mathrm{~V}$ & $36^{\circ} 50^{\prime} \mathrm{N}$ \\
\hline ÁVILA & $\mathrm{E}$ & 1 & $\mathrm{IV}$ & $40^{\circ} 39^{\prime} \mathrm{N}$ \\
\hline BARCELONA & $\mathrm{C}$ & 2 & $\mathrm{III}$ & $41^{\circ} 23^{\prime} \mathrm{N}$ \\
\hline BILBAO & $\mathrm{C}$ & 1 & $\mathrm{I}$ & $43^{\circ} 15^{\prime} \mathrm{N}$ \\
\hline MADRID & $\mathrm{D}$ & 3 & $\mathrm{IV}$ & $40^{\circ} 24^{\prime} \mathrm{N}$ \\
\hline PAMPLONA & $\mathrm{D}$ & 1 & $\mathrm{II}$ & $42^{\circ} 49^{\prime} \mathrm{N}$ \\
\hline SEVILLA & $\mathrm{B}$ & 4 & $\mathrm{~V}$ & $37^{\circ} 22^{\prime} \mathrm{N}$ \\
\hline VALENCIA & $\mathrm{B}$ & 3 & $\mathrm{IV}$ & $39^{\circ} 28^{\prime} \mathrm{N}$ \\
\hline VALLADOLID & $\mathrm{D}$ & 2 & $\mathrm{IV}$ & $41^{\circ} 39^{\prime} \mathrm{N}$ \\
\hline
\end{tabular}




\section{VI.2.2.- PERIODO DE ESTUDIO CONSIDERADO.}

Este capítulo se centrará en el estudio de los aportes energéticos durante el modo de operación de "invierno" de los C.T.S. Para ello se debe establecer el periodo temporal que contempla este modo de operación, el cual se ha establecido teniendo en cuenta la posibilidad de demanda de calor para el calentamiento del aire de calefacción y ventilación.

El periodo de estudio para el modo "invierno" se ha considerado el comprendido entre los meses de octubre y abril, ambos incluidos. Inicialmente se considera que la inclusión del mes de abril en este periodo puede ser interesante para algunas de las localidades estudiadas, en las que el período de demanda de calefacción puede alargarse durante la primavera. Tras llevar a cabo un breve análisis de la demanda de calor a través del estudio de los grados día de calefacción (base 15) para las horas del día en el que existe radiación sobre los paneles en el mes de abril, se ha decidido su inclusión en este periodo de "invierno". La siguiente tabla muestra los resultados del análisis mencionado de los grados día base 15 para las diferentes localidades en el mes de abril.

Tabla VI.2.- Grados día para el mes de abril de las localidades estudiadas en horas con irradiancia.

\begin{tabular}{|l|c|}
\cline { 2 - 2 } & $\begin{array}{c}\text { GD B15 } \\
\text { ABRIL }\end{array}$ \\
\hline ALMERIA & 11,74 \\
\hline ÁVILA & 81,96 \\
\hline BARCELONA & 24,11 \\
\hline BILBAO & 27,60 \\
\hline MADRID & 26,01 \\
\hline PAMPLONA & 43,75 \\
\hline SEVILLA & 10,35 \\
\hline VALENCIA & 15,05 \\
\hline VALLADOLID & 51,16 \\
\hline
\end{tabular}

La incorporación del mes de abril en el periodo de invierno a la hora de analizar los ahorros obtenidos por el uso de los C.T.S. de aire responde a dos razones fundamentales:

- La primera es que en las localidades de zonas climáticas de invierno más severas, zonas $D$ y E, la demanda de calor en este mes muestra que existe un considerable potencial de aporte de calor a través de los colectores.

- Segundo, dado que el periodo considerado de verano es de mayo a septiembre (como se estudiará en el Capítulo VII), se muestra interesante completar la anualidad con la incorporación del mes de abril a este periodo de invierno para así abordar el estudio del potencial del uso anual de estos sistemas. 
Así, y de forma complementaria, en el capítulo VII se estudian alternativas de uso de los C.T.S para la consecución de ahorros energéticos en el periodo estival, donde se contempla como "verano" el periodo comprendido entre los meses de mayo y septiembre, ambos incluidos. De este modo se propone un uso no estacional de los C.T.S., analizando un periodo de operación que cubre todo el año con estos dos modos de operación de "verano" e "invierno".

\section{VI.2.3.- INCLINACIÓN ÓPTIMA DEL C.T.S. PARA EL USO PROPUESTO.}

La obtención de los ángulos de inclinación óptimos para cada uno de los casos estudiados se lleva a cabo teniendo en cuenta los datos disponibles de irradiancia directa incidente sobre la horizontal hora a hora durante el periodo considerado y el factor de corrección $k$ para superficies inclinadas[20][19]. Este factor $k$ representa el cociente entre la energía total incidente en un día sobre una superficie orientada hacia el ecuador e inclinada un determinado ángulo, y otra horizontal.

La inclinación óptima considerada es aquella que reciba mayor irradiancia en el periodo estudiado; para ello, el cálculo de la irradiancia recibida sobre la superficie del C.T.S. se calculará según:

$$
I_{\beta}=I_{h o r} \cdot k_{l a t, \beta}
$$

Siendo $k$ el factor de corrección para la latitud geográfica e inclinación correspondiente.

Para la obtención del ángulo de inclinación óptimo del colector en cada localidad, se calcula la irradiancia recibida para cada inclinación estudiada (desde $35^{\circ}$ a $55^{\circ}$ con respecto a la horizontal) aplicando la ecuación E-VI.1. El ángulo óptimo de inclinación será el que arroje el valor más alto de la suma de las irradiancias corregidas por inclinación hora a hora en el periodo de invierno.

Obtenemos los valores de $k$ a partir de la tabla AC.1 que figura en el Anexo C. 


\section{VI.2.4.- NIVELES DE IRRADIANCIA.}

El trabajo experimental presentado en el capítulo IV se realizó para dos niveles determinados de irradiancia, obteniendo las expresiones matemáticas relativas al salto térmico obtenido en el colector y rendimientos correspondientes para esos dos niveles. Se propone para este estudio un rango de valores de irradiancia más amplio que el estudiado en la caracterización del C.T.S., adoptando los siguientes niveles:

- Nivel $0 \rightarrow \quad$ Irradiancia Mínima

- Nivel $1 \rightarrow$ Irradiancia Baja

- Nivel $2 \rightarrow \quad$ Irradiancia Media

- Nivel $3 \rightarrow \quad$ Irradiancia Alta
$\mathrm{I}<50 \mathrm{~W} / \mathrm{m}^{2}$

$50 \mathrm{~W} / \mathrm{m}^{2}<1<300 \mathrm{~W} / \mathrm{m}^{2}$

$300 \mathrm{~W} / \mathrm{m}^{2}<\mathrm{I}<600 \mathrm{~W} / \mathrm{m}^{2}$

$\mathrm{I}>600 \mathrm{~W} / \mathrm{m}^{2}$

Los valores de irradiancia solar menores a $50 \mathrm{~W} / \mathrm{m}^{2}$ (considerados como irradiancia mínima) no se tienen en cuenta para el cálculo de los ahorros. Gran parte de estos valores adoptan valor nulo, coinciden con horas del día en las que no hay radiación solar y las instalaciones se encuentran paradas. Hay una parte de estos valores que no son nulos y, optando por una posición conservadora en cuanto a los resultados, no se han considerado para el cálculo de los ahorros obtenidos ya que las correlaciones calculadas no presentaban resultados representativos de estos valores tan bajos de irradiancia.

Para el nivel 2 y 3 se emplearán las correlaciones que definen el comportamiento del colector obtenidas en la experimentación para los dos niveles ensayados. Para el nivel 1, irradiancia baja, se calculan nuevas expresiones a partir de las obtenidas experimentalmente que aproximan el comportamiento del colector para este rango de irradiancias. Estas expresiones para el nivel 1 se obtienen por extrapolación de los datos existentes para los niveles 2 y 3 y se presentan en el siguiente apartado.

\section{VI.2.5.- SALTOS TÉRMICOS ALCANZADOS EN EL C.T.S.}

Los saltos térmicos obtenidos en el C.T.S. se calculan a partir de las expresiones obtenidas en la experimentación para los dos niveles de irradiancia y los tres caudales de aire ensayados, en función de la temperatura de entrada del aire al colector.

Como se ha visto en el apartado anterior, el limitado número de valores de irradiancia experimentados hacen necesario definir más niveles de irradiancia para poder estudiar la operación del C.T.S. ante las distintas condiciones de funcionamiento previsibles. Para salvar esta limitación se ha planteado la extrapolación de resultados experimentales. De esta forma, a partir de los dos niveles de irradiancia ensayados, anteriormente definidos como "Nivel 2" y "Nivel 3", obtendremos la 
regresión para el salto térmico en el nivel 1 por extrapolación de los valores de los dos niveles experimentados. La cuestionable validez de los resultados derivados de la extrapolación hace que estos sean tratados con cuidado, como se verá en apartados posteriores.

Para el cálculo de las correlaciones de este nivel 1 se ha tomado como valor de referencia la irradiancia media en el Nivel $1\left(50 \mathrm{~W} / \mathrm{m}^{2}<\mathrm{I}<300 \mathrm{~W} / \mathrm{m}^{2}\right)$ para el periodo considerado de invierno y en las localidades estudiadas. El valor de esta irradiancia media dentro del nivel 1 obtenido a partir de los datos climáticos empleados para estas localidades es de $154,07 \mathrm{~W} / \mathrm{m}^{2}$.

Las expresiones que definen el salto térmico en el nivel 3 son:

- Para el caudal de aire $\mathrm{Q} 1=100 \mathrm{~m}^{3} / \mathrm{h}$ :

$$
\Delta T=-0,5546 \cdot T_{a}+55,644
$$

- Para el caudal de aire Q2 $=200 \mathrm{~m}^{3} / \mathrm{h}$ :

$$
\Delta T=-0,2157 \cdot T_{a}+35,65
$$

- Para el caudal de aire $\mathrm{Q} 3=300 \mathrm{~m}^{3} / \mathrm{h}$ :

$$
\Delta T=-0,1196 \cdot T_{a}+27,586
$$

En el nivel 2 de irradiancia el salto térmico está definido por:

- Para el caudal de aire $\mathrm{Q} 1=100 \mathrm{~m}^{3} / \mathrm{h}$ :

$$
\Delta T=-0,3721 \cdot T_{a}+34,544
$$

- Para el caudal de aire Q2 $=200 \mathrm{~m}^{3} / \mathrm{h}$ :

$$
\Delta T=-0,3027 \cdot T_{a}+21,89
$$

- Para el caudal de aire $\mathrm{Q} 3=300 \mathrm{~m}^{3} / \mathrm{h}$ :

$$
\Delta T=-0,0934 \cdot T_{a}+15,669
$$

Para valores de irradiancia comprendidos entre $50 \mathrm{~W} / \mathrm{m}^{2}$ y $300 \mathrm{~W} / \mathrm{m}^{2}$, considerados como irradiancia baja y nivel 1 , se han obtenido nuevas correlaciones por extrapolación de los dos niveles anteriores, 2 y 3 :

- Para el caudal de aire $\mathrm{Q} 1=100 \mathrm{~m}^{3} / \mathrm{h}$ :

$$
\Delta T=-0,234 \cdot T_{a}+18,2534
$$

- Para el caudal de aire $Q 2=200 \mathrm{~m}^{3} / \mathrm{h}$ :

$$
\Delta T=-0,431 \cdot T_{a}+11,2556
$$


- Para el caudal de aire Q3 $=300 \mathrm{~m}^{3} / \mathrm{h}$ :

$$
\Delta T=-0,073 \cdot T_{a}+6,4613
$$

A partir de estos saltos térmicos podremos calcular la temperatura de salida del aire del colector:

$$
T_{a \text { out }}=T_{a}+\Delta T
$$

Calcular la temperatura de salida del aire del C.T.S. nos permite conocer cuándo la temperatura del aire supera la temperatura establecida para el aire de impulsión de ventilación; es decir, cuándo se cubren todas las cargas de ventilación y podríamos aportar también energía para cubrir parcial o totalmente las cargas de calefacción.

\section{VI.2.6.- AHORRO DE ENERGÍA.}

Los ahorros de energía alcanzados se calculan a partir del salto térmico obtenido en la corriente de aire calentada por el colector y que es empleada como aire primario o de ventilación (ecuación E-VI.12). El salto térmico se obtiene según lo considerado en el apartado anterior en función del nivel de irradiancia y el caudal de aire empleado.

$$
\text { Ahorro }=\dot{\mathrm{m}}_{a} \cdot \mathrm{c}_{\mathrm{p} a} \cdot \Delta \mathrm{T}
$$

El ahorro total obtenido será el resultante de las suma de cada uno de los valores obtenidos hora a hora durante el periodo estudiado en las horas de operación.

También se plantea el análisis de las horas en las que la temperatura de salida del C.T.S. es superior a la temperatura establecida para el aire de impulsión de ventilación. Durante esas horas en las que el aire es impulsado por encima de esa consigna, todas las cargas de ventilación están cubiertas y podríamos a aportar energía para satisfacer al menos parcialmente la demanda de calefacción. Para ello se calcula el porcentaje de horas en el que todas las cargas de ventilación están cubiertas, considerando para ello el porcentaje de horas en las que la temperatura de salida del aire del C.T.S. es superior o igual a $22^{\circ} \mathrm{C}[\mathrm{N}-1]$.

La temperatura de salida del aire del colector queda definida según la ecuación E-VI.11. 


\section{VI.3.- RESULTADOS Y DISCUSIÓN.}

En el apartado VI.2 se han definido los casos de estudio y las consideraciones establecidas para el cálculo de los ahorros energéticos obtenidos por el uso de los C.T.S. en el periodo de invierno en las localidades seleccionadas.

De la implementación en Excel del modelo del colector empleado y del cálculo de las condiciones óptimas de operación se han obtenido los siguientes resultados.

\section{VI.3.1.- INCLINACIONES ÓPTIMAS PARA LAS LOCALIDADES DE ESTUDIO.}

Los resultados del cálculo de las inclinaciones óptimas para el periodo y localidades definidas en el apartado VI.2 se presentan en la tabla VI.3:

Tabla VI.3.- Inclinación óptima calculada del C.T.S. para las localidades estudiadas.

\begin{tabular}{|c|c|c|c|c|}
\hline & $\begin{array}{c}\text { Zona } \\
\text { climática } \\
\text { Invierno }\end{array}$ & $\begin{array}{c}\text { Zona } \\
\text { climática } \\
\text { Solar }\end{array}$ & Latitud & $\begin{array}{c}\text { INCLINACIÓN } \\
\text { ÓPTIMA DEL } \\
\text { CTS MODO } \\
\text { "INVIERNO” }\end{array}$ \\
\hline ALMERIA & $\mathrm{A}$ & $\mathrm{V}$ & $36^{\circ} 50^{\prime} \mathrm{N}$ & $\mathbf{4 0}$ \\
\hline ÁVILA & $\mathrm{E}$ & $\mathrm{IV}$ & $40^{\circ} 39^{\prime} \mathrm{N}$ & $\mathbf{4 1}$ \\
\hline BARCELONA & $\mathrm{C}$ & $\mathrm{III}$ & $41^{\circ} 23^{\prime} \mathrm{N}$ & $\mathbf{4 2}$ \\
\hline BILBAO & $\mathrm{C}$ & $\mathrm{I}$ & $43^{\circ} 15^{\prime} \mathrm{N}$ & $\mathbf{4 4}$ \\
\hline MADRID & $\mathrm{D}$ & $\mathrm{IV}$ & $40^{\circ} 24^{\prime} \mathrm{N}$ & $\mathbf{4 1}$ \\
\hline PAMPLONA & $\mathrm{D}$ & $\mathrm{II}$ & $42^{\circ} 49^{\prime} \mathrm{N}$ & $\mathbf{4 2}$ \\
\hline SEVILLA & $\mathrm{B}$ & $\mathrm{V}$ & $37^{\circ} 22^{\prime} \mathrm{N}$ & $\mathbf{4 0}$ \\
\hline VALENCIA & $\mathrm{B}$ & $\mathrm{IV}$ & $39^{\circ} 28^{\prime} \mathrm{N}$ & $\mathbf{4 0}$ \\
\hline VALLADOLID & $\mathrm{D}$ & $\mathrm{IV}$ & $41^{\circ} 39^{\prime} \mathrm{N}$ & $\mathbf{4 1}$ \\
\hline
\end{tabular}

Como ya se ha introducido en el apartado introductorio de este capítulo, numerosos trabajos han estudiado métodos y relaciones para la obtención de la inclinación óptima de un captador solar [616], obteniendo resultados diferentes según la aplicación y sistema estudiado.

Se puede observar que todos los ángulos de inclinación óptimos se encuentran entre los $40^{\circ}$ y 44․ Los resultados para cada localidad no guardan una misma relación con respecto a su latitud geográfica, siendo las que se sitúan en zonas climáticas con más alta incidencia solar (zona V), como Almería y Sevilla, en las que más alejados se encuentran los valores de su latitud geográfica e 
inclinación óptima. En el resto de localidades, su ángulo de inclinación óptimo se encuentra en un margen de $\pm 1^{\circ}$ con respecto a su latitud.

\section{VI.3.2.- AHORROS ENERGÉTICOS EN INVIERNO.}

Los resultados de los ahorros de energía obtenidos y los porcentajes de horas en los que la demanda de ventilación está cubierta para cada una de las localidades son presentados en las tablas VI.4 a VI.12.

Se presentan los resultados para los tres caudales de aire estudiados en cada mes del periodo considerado.

Tabla VI.4.- Ahorros obtenidos y porcentaje de horas con cobertura total de la demanda de ventilación para la localidad de Almería.

\begin{tabular}{|c|c|c|c|c|}
\hline \multicolumn{2}{|l|}{ ALMERÍA } & $\begin{array}{c}\text { Q1 }\left(\mathrm{m}^{3} / \mathrm{h}\right) \\
100\end{array}$ & $\begin{array}{c}\text { Q2 }\left(\mathrm{m}^{3} / \mathrm{h}\right) \\
200\end{array}$ & $\begin{array}{c}\text { Q3 }\left(\mathrm{m}^{3} / \mathrm{h}\right) \\
300\end{array}$ \\
\hline \multirow{2}{*}{ Enero } & Ahorro (kWh) & 167,91 & 170,14 & 225,06 \\
\hline & $\%$ horas $\mathrm{T}_{\text {out }}>22^{\circ} \mathrm{C}$ & $31,32 \%$ & $16,26 \%$ & $17,88 \%$ \\
\hline \multirow{2}{*}{ Febrero } & Ahorro (kWh) & 171,95 & 179,73 & 240,45 \\
\hline & $\%$ horas $\mathrm{T}_{\text {out }}>22^{\circ} \mathrm{C}$ & $33,33 \%$ & $18,75 \%$ & $22,32 \%$ \\
\hline \multirow{2}{*}{ Marzo } & Ahorro (kWh) & 223,13 & 245,67 & 325,63 \\
\hline & $\%$ horas $\mathrm{T}_{\text {out }}>22^{\circ} \mathrm{C}$ & $36,56 \%$ & $23,66 \%$ & $25,94 \%$ \\
\hline \multirow{2}{*}{ Abril } & Ahorro (kWh) & 232,03 & 258,30 & 346,04 \\
\hline & $\%$ horas $\mathrm{T}_{\text {out }}>22^{\circ} \mathrm{C}$ & $40,56 \%$ & $29,31 \%$ & $32,50 \%$ \\
\hline \multirow{2}{*}{ Octubre } & Ahorro (kWh) & 221,03 & 235,37 & 338,09 \\
\hline & $\%$ horas $\mathrm{T}_{\text {out }}>22^{\circ} \mathrm{C}$ & $47,31 \%$ & $42,88 \%$ & $44,76 \%$ \\
\hline \multirow{2}{*}{ Noviembre } & Ahorro (kWh) & 173,68 & 175,79 & 244,91 \\
\hline & $\%$ horas $\mathrm{T}_{\text {out }}>22^{\circ} \mathrm{C}$ & $33,89 \%$ & $24,58 \%$ & $27,50 \%$ \\
\hline \multirow{2}{*}{ Diciembre } & Ahorro (kWh) & 162,90 & 159,46 & 217,34 \\
\hline & $\%$ horas $\mathrm{T}_{\text {out }}>22^{\circ} \mathrm{C}$ & $31,32 \%$ & $17,07 \%$ & $20,03 \%$ \\
\hline \multirow{2}{*}{$\begin{array}{c}\text { Total } \\
\text { Invierno }\end{array}$} & Ahorro (kWh) & $1.352,63$ & $1.424,45$ & $1.937,51$ \\
\hline & $\%$ horas $\mathrm{T}_{\text {out }}>22^{\circ} \mathrm{C}$ & $36,33 \%$ & $24,64 \%$ & $27,27 \%$ \\
\hline
\end{tabular}


Tabla VI.5.- Ahorros obtenidos y porcentaje de horas con cobertura total de la demanda de ventilación para la localidad de Ávila.

\begin{tabular}{|c|c|c|c|c|}
\hline \multicolumn{2}{|l|}{ ÁVILA } & $\begin{array}{c}\text { Q1 }\left(\mathrm{m}^{3} / \mathrm{h}\right) \\
100\end{array}$ & $\begin{array}{c}\text { Q2 }\left(\mathrm{m}^{3} / \mathrm{h}\right) \\
200\end{array}$ & $\begin{array}{c}\text { Q3 }\left(\mathrm{m}^{3} / \mathrm{h}\right) \\
300\end{array}$ \\
\hline \multirow{2}{*}{ Enero } & Ahorro (kWh) & 136,64 & 159,03 & 173,38 \\
\hline & $\%$ horas $\mathrm{T}_{\text {out }}>22^{\circ} \mathrm{C}$ & $17,20 \%$ & $8,60 \%$ & $3,76 \%$ \\
\hline \multirow{2}{*}{ Febrero } & Ahorro (kWh) & 158,75 & 188,92 & 211,19 \\
\hline & $\%$ horas $\mathrm{T}_{\text {out }}>22^{\circ} \mathrm{C}$ & $22,17 \%$ & $13,54 \%$ & $8,04 \%$ \\
\hline \multirow{2}{*}{ Marzo } & Ahorro (kWh) & 215,39 & 254,56 & 292,99 \\
\hline & $\%$ horas $\mathrm{T}_{\text {out }}>22^{\circ} \mathrm{C}$ & $27,55 \%$ & $15,99 \%$ & $12,23 \%$ \\
\hline \multirow{2}{*}{ Abril } & Ahorro (kWh) & 224,47 & 263,78 & 312,70 \\
\hline & $\%$ horas $\mathrm{T}_{\text {out }}>22^{\circ} \mathrm{C}$ & $31,81 \%$ & $18,06 \%$ & $16,25 \%$ \\
\hline \multirow{2}{*}{ Octubre } & Ahorro (kWh) & 226,42 & 263,79 & 326,02 \\
\hline & $\%$ horas $\mathrm{T}_{\text {out }}>22^{\circ} \mathrm{C}$ & $33,06 \%$ & $20,43 \%$ & $22,04 \%$ \\
\hline \multirow{2}{*}{ Noviembre } & Ahorro (kWh) & 154,42 & 181,60 & 211,07 \\
\hline & $\%$ horas $\mathrm{T}_{\text {out }}>22^{\circ} \mathrm{C}$ & $21,81 \%$ & $12,64 \%$ & $9,86 \%$ \\
\hline \multirow{2}{*}{ Diciembre } & Ahorro (kWh) & 114,62 & 130,91 & 141,19 \\
\hline & $\%$ horas $\mathrm{T}_{\text {out }}>22^{\circ} \mathrm{C}$ & $14,78 \%$ & $6,85 \%$ & $2,69 \%$ \\
\hline \multirow{2}{*}{$\begin{array}{c}\text { Total } \\
\text { Invierno }\end{array}$} & Ahorro (kWh) & $1.230,71$ & $1.442,58$ & $1.668,53$ \\
\hline & $\%$ horas $\mathrm{T}_{\text {out }}>22^{\circ} \mathrm{C}$ & $24,06 \%$ & $13,73 \%$ & $10,70 \%$ \\
\hline
\end{tabular}

Tabla VI.6.- Ahorros obtenidos y porcentaje de horas con cobertura total de la demanda de ventilación para la localidad de Barcelona.

\begin{tabular}{|c|c|c|c|c|}
\hline \multicolumn{2}{|c|}{ BARCELONA } & $\begin{array}{c}\text { Q1 }\left(\mathrm{m}^{3} / \mathrm{h}\right) \\
100\end{array}$ & $\begin{array}{c}\text { Q2 }\left(\mathrm{m}^{3} / \mathrm{h}\right) \\
200\end{array}$ & $\begin{array}{c}\text { Q3 }\left(\mathrm{m}^{3} / \mathrm{h}\right) \\
300\end{array}$ \\
\hline \multirow{2}{*}{ Enero } & Ahorro (kWh) & 127,57 & 134,83 & 165,58 \\
\hline & $\%$ horas $\mathrm{T}_{\text {out }}>22^{\circ} \mathrm{C}$ & $22,58 \%$ & $10,75 \%$ & $11,29 \%$ \\
\hline \multirow{2}{*}{ Febrero } & Ahorro (kWh) & 154,87 & 164,92 & 205,58 \\
\hline & $\%$ horas $\mathrm{T}_{\text {out }}>22^{\circ} \mathrm{C}$ & $29,76 \%$ & $13,84 \%$ & $15,18 \%$ \\
\hline \multirow{2}{*}{ Marzo } & Ahorro (kWh) & 198,01 & 217,83 & 276,19 \\
\hline & $\%$ horas $\mathrm{T}_{\text {out }}>22{ }^{\circ} \mathrm{C}$ & $32,12 \%$ & $16,67 \%$ & $19,09 \%$ \\
\hline \multirow{2}{*}{ Abril } & Ahorro (kWh) & 211,93 & 223,38 & 294,42 \\
\hline & $\%$ horas $\mathrm{T}_{\text {out }}>22^{\circ} \mathrm{C}$ & $37,92 \%$ & $17,92 \%$ & $22,78 \%$ \\
\hline \multirow{2}{*}{ Octubre } & Ahorro (kWh) & 194,06 & 211,79 & 290,27 \\
\hline & $\%$ horas $\mathrm{T}_{\text {out }}>22^{\circ} \mathrm{C}$ & $32,53 \%$ & $26,21 \%$ & $27,55 \%$ \\
\hline \multirow{2}{*}{ Noviembre } & Ahorro (kWh) & 137,09 & 144,15 & 188,32 \\
\hline & $\%$ horas $\mathrm{T}_{\text {out }}>22^{\circ} \mathrm{C}$ & $25,00 \%$ & $13,47 \%$ & $15,56 \%$ \\
\hline \multirow{2}{*}{ Diciembre } & Ahorro (kWh) & 128,77 & 133,97 & 167,08 \\
\hline & $\%$ horas $\mathrm{T}_{\text {out }}>22^{\circ} \mathrm{C}$ & $23,52 \%$ & $10,62 \%$ & $11,56 \%$ \\
\hline \multirow{2}{*}{$\begin{array}{c}\text { Total } \\
\text { Invierno }\end{array}$} & Ahorro (kWh) & $1.152,29$ & $1.230,87$ & $1.587,44$ \\
\hline & $\%$ horas $\mathrm{T}_{\text {out }}>22^{\circ} \mathrm{C}$ & $29,06 \%$ & $15,64 \%$ & $17,57 \%$ \\
\hline
\end{tabular}


Tabla VI.7.- Ahorros obtenidos y porcentaje de horas con cobertura total de la demanda de ventilación para la localidad de Bilbao.

\begin{tabular}{|c|c|c|c|c|}
\hline \multicolumn{2}{|l|}{ BILBAO } & $\begin{array}{c}\text { Q1 }\left(\mathrm{m}^{3} / \mathrm{h}\right) \\
100\end{array}$ & $\begin{array}{c}\text { Q2 }\left(\mathrm{m}^{3} / \mathrm{h}\right) \\
200\end{array}$ & $\begin{array}{c}\text { Q3 }\left(\mathrm{m}^{3} / \mathrm{h}\right) \\
300\end{array}$ \\
\hline \multirow{2}{*}{ Enero } & Ahorro (kWh) & 54,22 & 50,56 & 64,65 \\
\hline & $\%$ horas $\mathrm{T}_{\text {out }}>22^{\circ} \mathrm{C}$ & $11,83 \%$ & $2,15 \%$ & $2,15 \%$ \\
\hline \multirow{2}{*}{ Febrero } & Ahorro (kWh) & 77,61 & 78,03 & 99,74 \\
\hline & $\%$ horas $\mathrm{T}_{\text {out }}>22^{\circ} \mathrm{C}$ & $16,22 \%$ & $5,95 \%$ & $6,99 \%$ \\
\hline \multirow{2}{*}{ Marzo } & Ahorro (kWh) & 101,69 & 94,23 & 127,45 \\
\hline & $\%$ horas $\mathrm{T}_{\text {out }}>22^{\circ} \mathrm{C}$ & $21,51 \%$ & $5,78 \%$ & $7,26 \%$ \\
\hline \multirow{2}{*}{ Abril } & Ahorro (kWh) & 98,51 & 93,32 & 127,58 \\
\hline & $\%$ horas $\mathrm{T}_{\text {out }}>22^{\circ} \mathrm{C}$ & $20,14 \%$ & $7,08 \%$ & $10,00 \%$ \\
\hline \multirow{2}{*}{ Octubre } & Ahorro (kWh) & 111,25 & 108,85 & 157,58 \\
\hline & $\%$ horas $\mathrm{T}_{\text {out }}>22^{\circ} \mathrm{C}$ & $23,52 \%$ & $17,88 \%$ & $19,35 \%$ \\
\hline \multirow{2}{*}{ Noviembre } & Ahorro (kWh) & 64,68 & 56,71 & 80,38 \\
\hline & $\%$ horas $\mathrm{T}_{\text {out }}>22^{\circ} \mathrm{C}$ & $14,58 \%$ & $4,03 \%$ & $6,94 \%$ \\
\hline \multirow{2}{*}{ Diciembre } & Ahorro (kWh) & 56,08 & 54,06 & 69,39 \\
\hline & $\%$ horas $\mathrm{T}_{\text {out }}>22^{\circ} \mathrm{C}$ & $11,42 \%$ & $3,23 \%$ & $3,23 \%$ \\
\hline \multirow{2}{*}{$\begin{array}{c}\text { Total } \\
\text { Invierno }\end{array}$} & Ahorro (kWh) & 564,05 & 535,75 & 726,77 \\
\hline & $\%$ horas $\mathrm{T}_{\text {out }}>22^{\circ} \mathrm{C}$ & $17,03 \%$ & $6,59 \%$ & $7,99 \%$ \\
\hline
\end{tabular}

Tabla VI.8.- Ahorros obtenidos y porcentaje de horas con cobertura total de la demanda de ventilación para la localidad de Madrid.

\begin{tabular}{|c|c|c|c|c|}
\hline \multicolumn{2}{|l|}{ MADRID } & $\begin{array}{c}\text { Q1 }\left(\mathrm{m}^{3} / \mathrm{h}\right) \\
100\end{array}$ & $\begin{array}{c}\text { Q2 }\left(\mathrm{m}^{3} / \mathrm{h}\right) \\
200\end{array}$ & $\begin{array}{c}\text { Q3 }\left(\mathrm{m}^{3} / \mathrm{h}\right) \\
300\end{array}$ \\
\hline \multirow{2}{*}{ Enero } & Ahorro (kWh) & 112,67 & 121,52 & 139,31 \\
\hline & $\%$ horas $\mathrm{T}_{\text {out }}>22^{\circ} \mathrm{C}$ & $18,95 \%$ & $6,45 \%$ & $5,38 \%$ \\
\hline \multirow{2}{*}{ Febrero } & Ahorro (kWh) & 136,91 & 152,01 & 179,89 \\
\hline & $\%$ horas $\mathrm{T}_{\text {out }}>22^{\circ} \mathrm{C}$ & $24,11 \%$ & $10,86 \%$ & $8,93 \%$ \\
\hline \multirow{2}{*}{ Marzo } & Ahorro (kWh) & 186,71 & 207,51 & 258,21 \\
\hline & $\%$ horas $\mathrm{T}_{\text {out }}>22^{\circ} \mathrm{C}$ & $29,97 \%$ & $13,44 \%$ & $13,71 \%$ \\
\hline \multirow{2}{*}{ Abril } & Ahorro (kWh) & 216,82 & 249,26 & 314,93 \\
\hline & $\%$ horas $\mathrm{T}_{\text {out }}>22^{\circ} \mathrm{C}$ & $33,61 \%$ & $19,86 \%$ & $23,47 \%$ \\
\hline \multirow{2}{*}{ Octubre } & Ahorro (kWh) & 196,35 & 219,75 & 288,54 \\
\hline & $\%$ horas $\mathrm{T}_{\text {out }}>22^{\circ} \mathrm{C}$ & $31,45 \%$ & $20,56 \%$ & $23,12 \%$ \\
\hline \multirow{2}{*}{ Noviembre } & Ahorro (kWh) & 133,16 & 142,88 & 176,87 \\
\hline & $\%$ horas $\mathrm{T}_{\text {out }}>22^{\circ} \mathrm{C}$ & $24,03 \%$ & $9,31 \%$ & $9,44 \%$ \\
\hline \multirow{2}{*}{ Diciembre } & Ahorro (kWh) & 105,92 & 114,73 & 132,77 \\
\hline & $\%$ horas $\mathrm{T}_{\text {out }}>22{ }^{\circ} \mathrm{C}$ & $17,61 \%$ & $6,85 \%$ & $6,18 \%$ \\
\hline \multirow{2}{*}{$\begin{array}{c}\text { Total } \\
\text { Invierno }\end{array}$} & Ahorro (kWh) & $1.088,54$ & $1.207,65$ & $1.490,52$ \\
\hline & $\%$ horas $\mathrm{T}_{\text {out }}>22{ }^{\circ} \mathrm{C}$ & $25,68 \%$ & $12,48 \%$ & $12,89 \%$ \\
\hline
\end{tabular}


Tabla VI.9.- Ahorros obtenidos y porcentaje de horas con cobertura total de la demanda de ventilación para la localidad de Pamplona.

\begin{tabular}{|c|c|c|c|c|}
\hline \multicolumn{2}{|c|}{ PAMPLONA } & $\begin{array}{c}\text { Q1 }\left(\mathrm{m}^{3} / \mathrm{h}\right) \\
100\end{array}$ & $\begin{array}{c}\text { Q2 }\left(\mathrm{m}^{3} / \mathrm{h}\right) \\
200\end{array}$ & $\begin{array}{c}\text { Q3 }\left(\mathrm{m}^{3} / \mathrm{h}\right) \\
300\end{array}$ \\
\hline \multirow{2}{*}{ Enero } & Ahorro (kWh) & 105,19 & 118,37 & 133,38 \\
\hline & $\%$ horas $\mathrm{T}_{\text {out }}>22{ }^{\circ} \mathrm{C}$ & $15,19 \%$ & $6,18 \%$ & $4,97 \%$ \\
\hline \multirow{2}{*}{ Febrero } & Ahorro (kWh) & 144,20 & 161,36 & 188,92 \\
\hline & $\%$ horas $\mathrm{T}_{\text {out }}>22^{\circ} \mathrm{C}$ & $23,36 \%$ & $10,42 \%$ & $9,08 \%$ \\
\hline \multirow{2}{*}{ Marzo } & Ahorro (kWh) & 192,66 & 224,88 & 271,07 \\
\hline & $\%$ horas $\mathrm{T}_{\text {out }}>22{ }^{\circ} \mathrm{C}$ & $26,34 \%$ & $15,59 \%$ & $15,46 \%$ \\
\hline \multirow{2}{*}{ Abril } & Ahorro (kWh) & 212,84 & 238,80 & 298,17 \\
\hline & $\%$ horas $\mathrm{T}_{\text {out }}>22^{\circ} \mathrm{C}$ & $33,47 \%$ & $17,78 \%$ & $19,31 \%$ \\
\hline \multirow{2}{*}{ Octubre } & Ahorro (kWh) & 192,65 & 214,16 & 280,68 \\
\hline & $\%$ horas $\mathrm{T}_{\text {out }}>22{ }^{\circ} \mathrm{C}$ & $30,51 \%$ & $20,43 \%$ & $22,85 \%$ \\
\hline \multirow{2}{*}{ Noviembre } & Ahorro (kWh) & 128,94 & 143,75 & 174,11 \\
\hline & $\%$ horas $\mathrm{T}_{\text {out }}>22^{\circ} \mathrm{C}$ & $20,83 \%$ & $9,03 \%$ & $8,75 \%$ \\
\hline \multirow{2}{*}{ Diciembre } & Ahorro (kWh) & 93,37 & 102,70 & 117,22 \\
\hline & $\%$ horas $\mathrm{T}_{\text {out }}>22^{\circ} \mathrm{C}$ & $14,38 \%$ & $6,18 \%$ & $3,76 \%$ \\
\hline \multirow{2}{*}{$\begin{array}{c}\text { Total } \\
\text { Invierno }\end{array}$} & Ahorro (kWh) & $1.069,86$ & $1.204,03$ & $1.463,54$ \\
\hline & $\%$ horas $\mathrm{T}_{\text {out }}>22^{\circ} \mathrm{C}$ & $23,44 \%$ & $12,23 \%$ & $12,03 \%$ \\
\hline
\end{tabular}

Tabla VI.10.- Ahorros obtenidos y porcentaje de horas con cobertura total de la demanda de ventilación para la localidad de Sevilla.

\begin{tabular}{|c|c|c|c|c|}
\hline \multicolumn{2}{|l|}{ SEVILLA } & $\begin{array}{c}\text { Q1 }\left(\mathrm{m}^{3} / \mathrm{h}\right) \\
100\end{array}$ & $\begin{array}{c}\text { Q2 }\left(\mathrm{m}^{3} / \mathrm{h}\right) \\
200\end{array}$ & $\begin{array}{c}\text { Q3 }\left(\mathrm{m}^{3} / \mathrm{h}\right) \\
300\end{array}$ \\
\hline \multirow{2}{*}{ Enero } & Ahorro (kWh) & 156,84 & 164,89 & 211,19 \\
\hline & $\%$ horas $\mathrm{T}_{\text {out }}>22^{\circ} \mathrm{C}$ & $28,09 \%$ & $14,25 \%$ & $17,47 \%$ \\
\hline \multirow{2}{*}{ Febrero } & Ahorro (kWh) & 180,08 & 194,27 & 252,04 \\
\hline & $\%$ horas $\mathrm{T}_{\text {out }}>22^{\circ} \mathrm{C}$ & $33,18 \%$ & $19,05 \%$ & $22,32 \%$ \\
\hline \multirow{2}{*}{ Marzo } & Ahorro (kWh) & 228,85 & 262,30 & 339,69 \\
\hline & $\%$ horas $\mathrm{T}_{\text {out }}>22^{\circ} \mathrm{C}$ & $35,48 \%$ & $25,54 \%$ & $28,36 \%$ \\
\hline \multirow{2}{*}{ Abril } & Ahorro (kWh) & 242,21 & 281,78 & 370,67 \\
\hline & $\%$ horas $\mathrm{T}_{\text {out }}>22^{\circ} \mathrm{C}$ & $37,92 \%$ & $30,56 \%$ & $31,81 \%$ \\
\hline \multirow{2}{*}{ Octubre } & Ahorro (kWh) & 230,79 & 255,71 & 358,97 \\
\hline & $\%$ horas $\mathrm{T}_{\text {out }}>22^{\circ} \mathrm{C}$ & $44,76 \%$ & $39,92 \%$ & $40,99 \%$ \\
\hline \multirow{2}{*}{ Noviembre } & Ahorro (kWh) & 178,79 & 191,47 & 255,26 \\
\hline & $\%$ horas $\mathrm{T}_{\text {out }}>22^{\circ} \mathrm{C}$ & $32,08 \%$ & $22,78 \%$ & $24,72 \%$ \\
\hline \multirow{2}{*}{ Diciembre } & Ahorro (kWh) & 144,67 & 149,84 & 194,14 \\
\hline & $\%$ horas $\mathrm{T}_{\text {out }}>22^{\circ} \mathrm{C}$ & $26,34 \%$ & $13,98 \%$ & $16,40 \%$ \\
\hline \multirow{2}{*}{$\begin{array}{c}\text { Total } \\
\text { Invierno }\end{array}$} & Ahorro (kWh) & $1.362,24$ & $1.500,25$ & $1.981,95$ \\
\hline & $\%$ horas $\mathrm{T}_{\text {out }}>22^{\circ} \mathrm{C}$ & $33,98 \%$ & $23,72 \%$ & $26,01 \%$ \\
\hline
\end{tabular}


Tabla VI.11.- Ahorros obtenidos y porcentaje de horas con cobertura total de la demanda de ventilación para la localidad de Valencia.

\begin{tabular}{|c|c|c|c|c|}
\hline \multicolumn{2}{|l|}{ VALENCIA } & $\begin{array}{c}\text { Q1 }\left(\mathrm{m}^{3} / \mathrm{h}\right) \\
100\end{array}$ & $\begin{array}{c}\text { Q2 }\left(\mathrm{m}^{3} / \mathrm{h}\right) \\
200\end{array}$ & $\begin{array}{c}\text { Q3 }\left(\mathrm{m}^{3} / \mathrm{h}\right) \\
300\end{array}$ \\
\hline \multirow{2}{*}{ Enero } & Ahorro (kWh) & 139,52 & 143,71 & 184,32 \\
\hline & $\%$ horas $\mathrm{T}_{\text {out }}>22^{\circ} \mathrm{C}$ & $25,67 \%$ & $12,63 \%$ & $14,25 \%$ \\
\hline \multirow{2}{*}{ Febrero } & Ahorro (kWh) & 159,11 & 173,56 & 222,18 \\
\hline & $\%$ horas $\mathrm{T}_{\text {out }}>22^{\circ} \mathrm{C}$ & $28,72 \%$ & $16,82 \%$ & $19,79 \%$ \\
\hline \multirow{2}{*}{ Marzo } & Ahorro (kWh) & 214,35 & 241,10 & 311,03 \\
\hline & $\%$ horas $\mathrm{T}_{\text {out }}>22^{\circ} \mathrm{C}$ & $33,33 \%$ & $21,37 \%$ & $25,40 \%$ \\
\hline \multirow{2}{*}{ Abril } & Ahorro (kWh) & 213,06 & 222,90 & 303,24 \\
\hline & $\%$ horas $\mathrm{T}_{\text {out }}>22^{\circ} \mathrm{C}$ & $38,47 \%$ & $23,75 \%$ & $29,17 \%$ \\
\hline \multirow{2}{*}{ Octubre } & Ahorro (kWh) & 206,15 & 219,09 & 308,51 \\
\hline & $\%$ horas $\mathrm{T}_{\text {out }}>22^{\circ} \mathrm{C}$ & $38,17 \%$ & $32,93 \%$ & $33,74 \%$ \\
\hline \multirow{2}{*}{ Noviembre } & Ahorro (kWh) & 148,14 & 152,92 & 206,95 \\
\hline & $\%$ horas $\mathrm{T}_{\text {out }}>22^{\circ} \mathrm{C}$ & $27,78 \%$ & $17,64 \%$ & $19,58 \%$ \\
\hline \multirow{2}{*}{ Diciembre } & Ahorro (kWh) & 134,27 & 129,59 & 172,85 \\
\hline & $\%$ horas $\mathrm{T}_{\text {out }}>22^{\circ} \mathrm{C}$ & $26,75 \%$ & $11,16 \%$ & $15,32 \%$ \\
\hline \multirow{2}{*}{$\begin{array}{c}\text { Total } \\
\text { Invierno }\end{array}$} & Ahorro (kWh) & $1.214,61$ & $1.282,86$ & $1.709,08$ \\
\hline & $\%$ horas $\mathrm{T}_{\text {out }}>22^{\circ} \mathrm{C}$ & $31,27 \%$ & $19,47 \%$ & $22,46 \%$ \\
\hline
\end{tabular}

Tabla VI.12.- Ahorros obtenidos y porcentaje de horas con cobertura total de la demanda de ventilación para la localidad de Valladolid.

\begin{tabular}{|c|c|c|c|c|}
\hline \multicolumn{2}{|c|}{ VALLADOLID } & $\begin{array}{c}\text { Q1 }\left(\mathrm{m}^{3} / \mathrm{h}\right) \\
100\end{array}$ & $\begin{array}{c}\text { Q2 }\left(\mathrm{m}^{3} / \mathrm{h}\right) \\
200\end{array}$ & $\begin{array}{c}\text { Q3 }\left(\mathrm{m}^{3} / \mathrm{h}\right) \\
300\end{array}$ \\
\hline \multirow{2}{*}{ Enero } & Ahorro (kWh) & 81,32 & 87,93 & 98,09 \\
\hline & $\%$ horas $\mathrm{T}_{\text {out }}>22^{\circ} \mathrm{C}$ & $11,83 \%$ & $3,90 \%$ & $3,23 \%$ \\
\hline \multirow{2}{*}{ Febrero } & Ahorro (kWh) & 123,50 & 139,65 & 163,10 \\
\hline & $\%$ horas $\mathrm{T}_{\text {out }}>22^{\circ} \mathrm{C}$ & $19,94 \%$ & $10,12 \%$ & $8,63 \%$ \\
\hline \multirow{2}{*}{ Marzo } & Ahorro (kWh) & 204,26 & 231,93 & 281,99 \\
\hline & $\%$ horas $\mathrm{T}_{\text {out }}>22^{\circ} \mathrm{C}$ & $30,24 \%$ & $15,19 \%$ & $14,92 \%$ \\
\hline \multirow{2}{*}{ Abril } & Ahorro (kWh) & 234,16 & 272,89 & 333,82 \\
\hline & $\%$ horas $\mathrm{T}_{\text {out }}>22^{\circ} \mathrm{C}$ & $33,47 \%$ & $19,86 \%$ & $20,56 \%$ \\
\hline \multirow{2}{*}{ Octubre } & Ahorro (kWh) & 189,07 & 203,98 & 269,73 \\
\hline & $\%$ horas $\mathrm{T}_{\text {out }}>22^{\circ} \mathrm{C}$ & $31,72 \%$ & $20,30 \%$ & $22,58 \%$ \\
\hline \multirow{2}{*}{ Noviembre } & Ahorro (kWh) & 109,43 & 116,50 & 141,37 \\
\hline & $\%$ horas $\mathrm{T}_{\text {out }}>22^{\circ} \mathrm{C}$ & $19,58 \%$ & $6,39 \%$ & $6,81 \%$ \\
\hline \multirow{2}{*}{ Diciembre } & Ahorro (kWh) & 70,00 & 75,81 & 83,05 \\
\hline & $\%$ horas $\mathrm{T}_{\text {out }}>22^{\circ} \mathrm{C}$ & $11,29 \%$ & $2,96 \%$ & $1,08 \%$ \\
\hline \multirow{2}{*}{$\begin{array}{c}\text { Total } \\
\text { Invierno }\end{array}$} & Ahorro (kWh) & $1.011,75$ & $1.128,68$ & $1.371,15$ \\
\hline & $\%$ horas $\mathrm{T}_{\text {out }}>22^{\circ} \mathrm{C}$ & $22,58 \%$ & $11,24 \%$ & $11,11 \%$ \\
\hline
\end{tabular}


En la tabla VI.13 se recopilan los resultados de los ahorros totales durante todo el invierno y los porcentajes de horas con la totalidad de la demanda de ventilación cubierta ( $T_{\text {out }}>20^{\circ} \mathrm{C}$ ).

Tabla VI.13.- Resumen de los ahorros totales obtenidos y porcentaje de horas con cobertura total de la demanda de ventilación en todo el periodo de invierno de todas las localidades.

\begin{tabular}{|c|c|c|c|c|c|c|}
\hline & \multicolumn{3}{|c|}{ AHORROS TOTAL INVIERNO (kWh) } & \multicolumn{3}{|c|}{$\%$ de HORAS con $\mathrm{T}_{\text {out }}>22^{\circ}$} \\
\hline & Q1 $100 \mathrm{~m}^{3} / \mathrm{h}$ & Q2 $200 \mathrm{~m}^{3} / \mathrm{h}$ & Q3 $300 \mathrm{~m}^{3} / \mathrm{h}$ & Q1 $100 \mathrm{~m}^{3} / \mathrm{h}$ & Q2 $200 \mathrm{~m}^{3} / \mathrm{h}$ & Q3 $300 \mathrm{~m}^{3} / \mathrm{h}$ \\
\hline ALMERIA & 1352,63 & 1424,45 & 1937,51 & $35,45 \%$ & $22,01 \%$ & $24,65 \%$ \\
\hline ÁVILA & 1230,71 & 1442,58 & 1668,53 & $24,69 \%$ & $14,03 \%$ & $10,07 \%$ \\
\hline BARCELONA & 1152,29 & 1230,87 & 1587,44 & $30,56 \%$ & $14,79 \%$ & $17,08 \%$ \\
\hline BILBAO & 564,05 & 535,75 & 726,77 & $17,43 \%$ & $5,21 \%$ & $6,56 \%$ \\
\hline MADRID & 1088,54 & 1207,65 & 1490,52 & $26,67 \%$ & $12,64 \%$ & $12,88 \%$ \\
\hline PAMPLONA & 1069,86 & 1204,03 & 1463,54 & $24,55 \%$ & $12,50 \%$ & $12,22 \%$ \\
\hline SEVILLA & 1362,24 & 1500,25 & 1981,95 & $33,65 \%$ & $22,36 \%$ & $25,00 \%$ \\
\hline VALENCIA & 1214,61 & 1282,86 & 1709,08 & $31,56 \%$ & $18,65 \%$ & $22,15 \%$ \\
\hline VALLADOLID & 1011,75 & 1128,68 & 1371,15 & $23,89 \%$ & $12,26 \%$ & $11,84 \%$ \\
\hline
\end{tabular}

La figura VI.1 representa gráficamente la recopilación de resultados de los ahorros para cada una de las localidades y caudales estudiados.

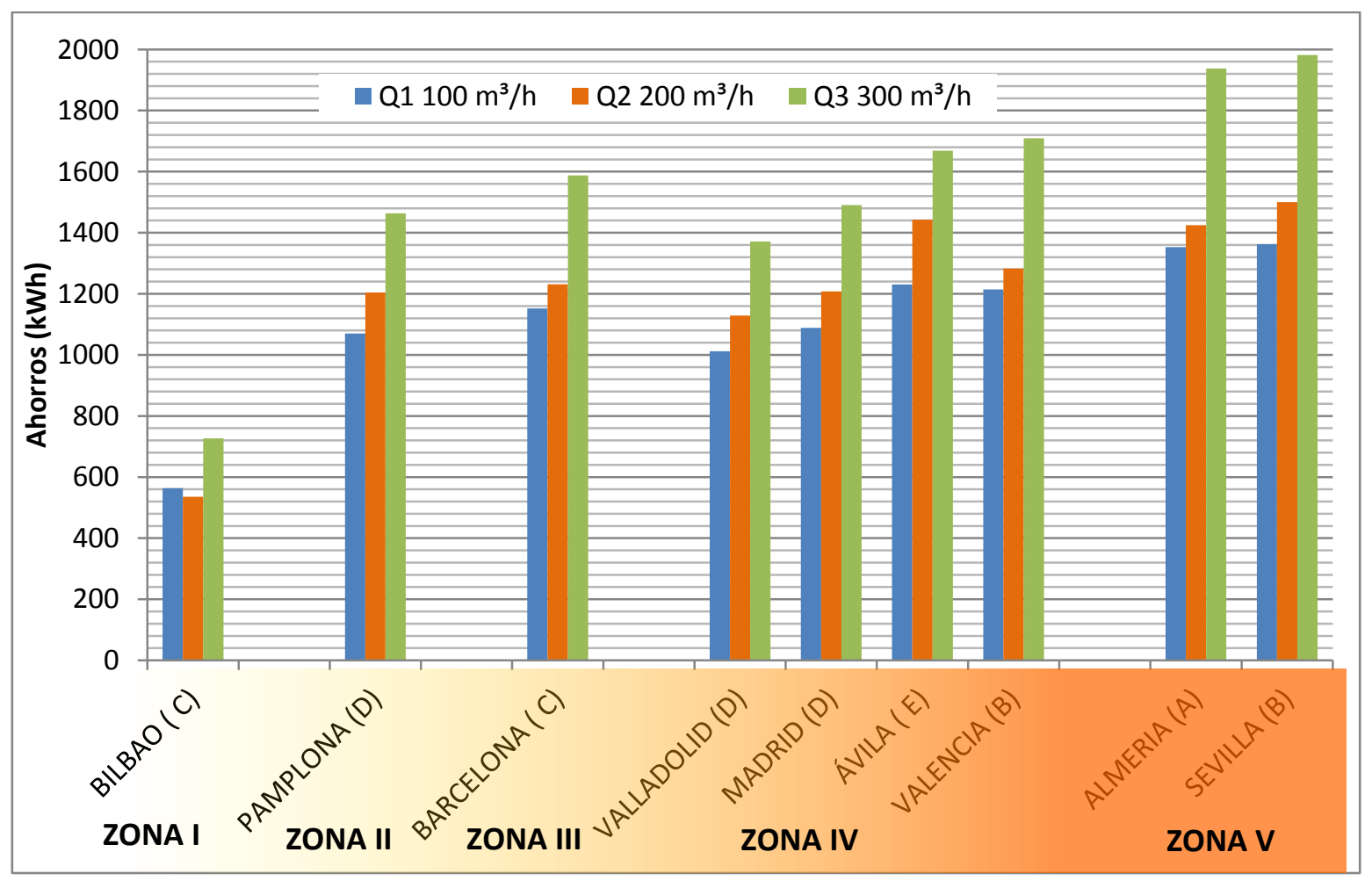

Figura VI.1.- Ahorros obtenidos por zonas climáticas solares (entre paréntesis se indica la zona climática de invierno). 
Los resultados presentados en la figura II.1 muestran la influencia de la zona climática solar, relacionada directamente con la irradiancia recibida. Los mayores ahorros se alcanzan en las localidades con más altos valores de irradiación sobre la superficie del colector. Dentro de la misma zona climática, como el caso de la zona IV, los mayores ahorros son obtenidos por las localidades con mayores valores de irradiancia sobre la superficie del colector en el periodo de estudio, siguiendo la misma tendencia que para el análisis global de las 9 localidades. La zona climática de invierno queda definida por la severidad climática de la zona, factor definido por la temperatura exterior existente. Esta figura también nos permite comprobar que la temperatura de entrada del aire al colector (temperatura exterior de la localidad) es un factor menos influyente que el caudal de aire y la zona climática solar para la obtención de ahorros a través del empleo del C.T.S.

Como puede observarse en los resultados obtenidos, y como era de prever tras la conclusiones alcanzadas en el capítulo IV de esta tesis, en todas las localidades estudiadas los mayores ahorros son alcanzados para el caudal de aire más alto. A medida que el caudal de aire aumenta obtenemos mayores ahorros de energía, excepto para el caso de Bilbao, en el que los ahorros obtenidos para $100 \mathrm{~m}^{3} / \mathrm{h}$ son mayores que los de $200 \mathrm{~m}^{3} / \mathrm{h}$. Esta circunstancia está relacionada con la limitada validez de las correlaciones de cálculo del salto térmico obtenidas por extrapolación para bajos niveles de irradiancia. Esta desviación observada en el comportamiento del colector para bajos niveles de irradiancia es más notoria para el caudal Q2 $\left(200 \mathrm{~m}^{3} / \mathrm{h}\right)$, caudal para el que las regresiones obtenidas experimentalmente presentaban peor ajuste, como ya se indicó en el capítulo IV.

A fin de comprobar la justificación anteriormente enunciada y para confirmar que el comportamiento del C.T.S. sigue la misma tendencia, se han calculado los ahorros obtenidos sin tener en consideración los casos correspondientes al nivel N1 no experimental. La figura VI.2 representa los ahorros solo empleando los niveles 2 y 3 de irradiancia y la figura VI.3 con todos los niveles considerados. Los bajos valores de irradiancia que se dan en Bilbao provocan que esta circunstancia sea más influyente que en otras localidades. 


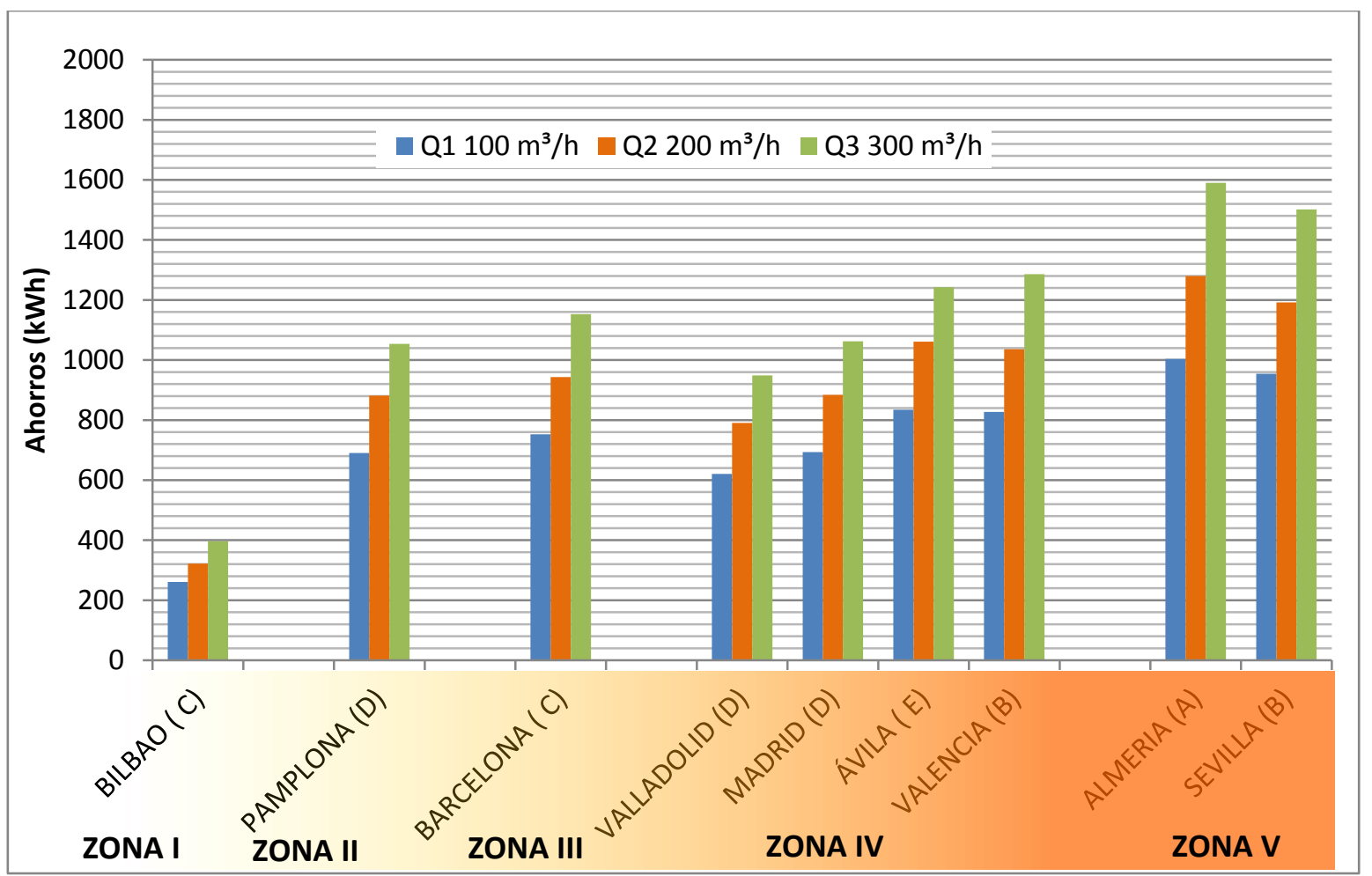

Figura VI.2.- Ahorros obtenidos para la comprobación del comportamiento del C.T.S con los niveles 2 y 3 de irradiancia presentados por zona climática solar (entre paréntesis se indica la zona climática de invierno).

Para cualquiera de los caudales de aire estudiados, Sevilla es la localidad que obtiene mayores ahorros, seguida de Almería. Valencia y Ávila son las siguientes en esta clasificación con valores similares. En la tabla VI.14 se puede ver está clasificación en función los máximos ahorros alcanzados:

Tabla VI.14.- Clasificación de las localidades en función del máximo ahorro obtenido.

\begin{tabular}{|l|l|c|}
\hline \multicolumn{3}{|c|}{ AHORROS MÁXIMOS INVIERNO (kWh) } \\
\hline $\mathbf{1}$ & SEVILLA & 1973,04 \\
\hline $\mathbf{2}$ & ALMERIA & 1927,52 \\
\hline $\mathbf{3}$ & VALENCIA & 1699,50 \\
\hline $\mathbf{4}$ & ÁVILA & 1659,64 \\
\hline $\mathbf{5}$ & BARCELONA & 1577,80 \\
\hline $\mathbf{6}$ & MADRID & 1481,25 \\
\hline $\mathbf{7}$ & PAMPLONA & 1454,73 \\
\hline $\mathbf{8}$ & VALLADOLID & 1362,10 \\
\hline $\mathbf{9}$ & BILBAO & 719,42 \\
\hline
\end{tabular}


La figura VI.3 representa gráficamente la recopilación de resultados de los porcentajes de horas en los que se superan los $22^{\circ} \mathrm{C}$ en el aire a la salida del colector para cada una de las localidades y caudales estudiados.

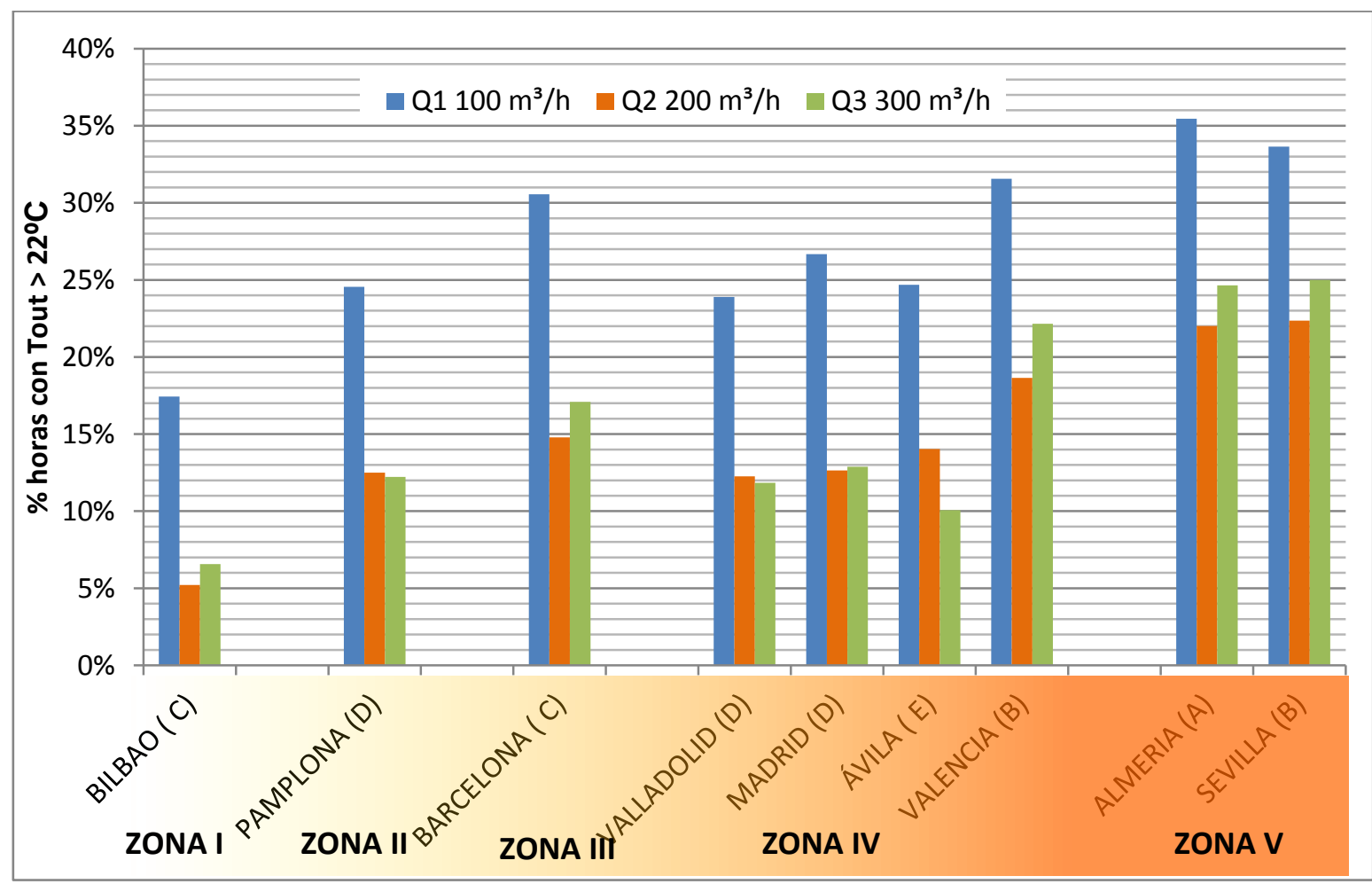

Figura VI.3.-Porcentaje de horas en los que la temperatura de salida del aire del colector supera los $22^{\circ} \mathrm{C}$, para cada localidad y caudal de aire estudiados presentadas por zona climática solar (entre paréntesis se indica la zona climática de invierno).

En cuanto al tiempo en el que las cargas de ventilación quedan cubiertas con el calor captado en el C.T.S., los mayores porcentajes de horas son los obtenidos para el caudal de aire más bajo, Q1 $\left(100 \mathrm{~m}^{3} / \mathrm{h}\right)$. Estos resultados son los esperables tras la observación de los obtenidos en el capítulo IV de caracterización del C.T.S.: a menor caudal, mayor salto térmico alcanzado. A diferencia de lo ocurrido para los ahorros, el factor caudal (flujo másico) no está involucrado directamente en el cálculo de la temperatura de salida (sí indirectamente a través del empleo de una correlación u otra). Esto implica que la desviación de los resultados por el empleo de las correlaciones no experimentales, obtenidas por extrapolación para el nivel de irradiancia 1 definido, sea más perceptible; como se observa en muchas de las localidades, el \% de horas con temperatura de salida superior a la de consigna en Q2 es menor que en Q3. Aplicando el mismo criterio que para el ahorro obtenido, se ha estudiado este parámetro sin tener en cuenta los saltos térmicos en el nivel 1 de irradiancia. En la figura VI.6 se observa la tendencia para este estudio con únicamente los niveles 2 y 3. 
El mayor número de horas es obtenido para localidades con zonas climáticas de invierno con temperaturas exteriores más altas y zonas climáticas de alta incidencia solar, como es el caso de Almería, Barcelona, Sevilla y Valencia.

En cuanto a los resultados por zonas climáticas solares, también se observa una tendencia ascendente en el número de horas con la demanda cubierta -a medida que la localidad dispone de un mayor índice de irradiancia recibida. Ciudades como Ávila, Madrid o Valladolid tienen una clasificación más alta en cuanto a zona climática, pero sus resultados son inferiores a otras ciudades como Barcelona con menor clasificación solar debido a las condiciones de temperatura exterior que se dan.

\section{VII.4.- CONCLUSIONES.}

El ahorro energético obtenido por el uso de los C.T.S. de aire en los edificios para las instalaciones de ventilación y calefacción es la mejor carta de presentación de esta tecnología para su incorporación como alternativa de ahorro e implantación de tecnologías de origen renovable en edificios.

Un adecuado estudio previo a la instalación de los C.T.S. teniendo en cuenta las condiciones climáticas y el periodo de uso preferente permite optimizar el aporte de energía de un determinado colector. En esta optimización el factor inclinación del colector tiene un importante papel. Se han calculado las inclinaciones óptimas para las localidades y periodo de invierno considerado, encontrándose en todas ellas el ángulo óptimo entre $40^{\circ}$ y $44^{\circ}$. A excepción de las localidades de Almería y Sevilla, el ángulo óptimo en todas ellas se encuentran en un rango de $\pm 1^{\circ}$ con respecto a su latitud (para Almería y Sevilla se encuentra en torno $a+4^{\circ}$ ).

La consideración del mes de abril en el periodo de invierno no presenta discusión para las localidades de zonas climáticas de invierno más severas ( $D$ y $E$ ). Resulta recomendable su incorporación en el resto de localidades por dos motivos principales: a) cubrir las demandas de calor que se den en ese mes (aunque reducidas, suponen cierto ahorro); y b) la complementariedad de este análisis frente al estudio de las aplicaciones de verano realizado en el capítulo VII, llevado a cabo para los meses de mayo a octubre.

Se ha observado una limitación de aplicabilidad de las correlaciones definitorias del comportamiento del C.T.S. obtenidas experimentalmente. Esta limitación está relacionada con los escasos niveles de irradiancia empleados en la experimentación (nivel 2: 447,9 W/m² y nivel 3: $828,4 \mathrm{~W} / \mathrm{m}^{2}$ ). Existe un considerable número de horas en las que los niveles de irradiancia de las localidades estudiadas no alcanzan los valores experimentados; esto obliga a extrapolar los resultados experimentales para definir otros niveles de irradiancia y poder aplicar las correlaciones a 
la generalidad de condiciones de funcionamiento esperadas en el período invernal considerado. Se ha comprobado que las expresiones obtenidas para el nivel 1 implementado en el estudio no se ajustan de forma óptima para alguno de los caudales de aire estudiados (Q2: $200 \mathrm{~m}^{3} / \mathrm{h}$ ). Se recomienda trabajar en este sentido en futuros estudios de desarrollo del trabajo realizado en esta tesis.

En cuanto a los resultados obtenidos, se ha podido comprobar que los ahorros obtenidos por el empleo de los C.T.S. de aire son importantes y hacen más que recomendable su implantación para el ahorro energético en instalaciones de ventilación y calefacción por aire.

Los mayores ahorros son alcanzados en localidades con mayores niveles de irradiancia, como son las localidades clasificadas como zona climáticas solares IV y V. El mismo colector situado en Sevilla aporta 1,7 veces más de energía que en Bilbao. Como era de prever por los resultados del capítulo IV también los mejores resultados son los obtenidos para el caudal de aire más alto estudiado $\left(\mathrm{Q} 3=300 \mathrm{~m}^{3} / \mathrm{h}\right)$. La zona climática de invierno es el factor menos influyente de los estudiados.

El porcentaje de horas en las que se supera la temperatura establecida para la impulsión del aire de ventilación $\left(22^{\circ}\right.$ C) nos aporta información sobre las horas en las que la demanda de ventilación puede ser cubierta con el aporte de calor desde los colectores. En este sentido, los valores más altos se han obtenido para las zonas climáticas solares IV y V, alcanzándose valores superiores al $30 \%$. El caudal de aire que mejores resultados ofrece para este parámetro es el de $100 \mathrm{~m}^{3} / \mathrm{h}$.

Se considera por lo tanto que, aunque las condiciones térmicas del aire de entrada se habían presentado como un factor importante en el comportamiento del captador, según el estudio experimental y posterior ANOVA realizado sobre el equipo de referencia, en la práctica resulta más relevante a la hora de considerar la instalación de un CTS de aire la clasificación climática de la localidad por su nivel de irradiancia.

Finalmente, se muestra necesario contemplar la aplicabilidad de estos sistemas durante los meses del año restantes, para asegurar el interés de su instalación salvando el principal problema que es su inicialmente aparente estacionalidad. 


\section{REFERENCIAS}

[1] F. Mauthner, W. Weiss, M. Spörk-Dür, Solar Heat Worldwide. Markets and Contribution to the Energy Supply 2014, (2016).

[2] F. Javier, R. Martínez, E.V. Gómez, R.R. Valdivieco, L.G. González, A.T. González, Characterization of solar air heaters for ventilation in buildings, (n.d.) 1-10.

[3] M.K. Selcuk, Solar air heaters and their applications, Sol. Energy Eng. (A78-27852 10-44). (1977) 155-182.

[4] R. Chandra, M.S. Sodha, Testing procedures for solar air heaters: A review, Energy Convers. Manag. 32 (1991) 11-33. doi:10.1016/0196-8904(91)90139-A.

[5] J. Appelbaum, J. Bany, Shadow effect of adjacent solar collectors in large scale systems, Sol. Energy. 23 (1979). doi:10.1016/0038-092X(79)90073-2.

[6] G.R. Saraf, F.A.W. Hamad, Optimum tilt angle for a flat plate solar collector, Energy Convers. Manag. 28 (1988) 185-191. doi:10.1016/0196-8904(88)90044-1.

[7] G.O.G. Löf, R.A. Tybout, Cost of house heating with solar energy, Sol. Energy. 14 (1973) 253278. doi:10.1016/0038-092X(73)90094-7.

[8] T.P. Chang, The Sun's apparent position and the optimal tilt angle of a solar collector in the northern hemisphere, Sol. Energy. 83 (2009) 1274-1284. doi:10.1016/j.solener.2009.02.009.

[9] H. Gunerhan, A. Hepbasli, Determination of the optimum tilt angle of solar collectors for building applications, Build. Environ. 42 (2007). doi:10.1016/j.buildenv.2005.09.012.

[10] A. Shariah, M.-A. Al-Akhras, I.A. Al-Omari, Optimizing the tilt angle of solar collectors, Renew. Energy. 26 (2002). doi:10.1016/S0960-1481(01)00106-9.

[11] J. Kern, I. Harris, On the optimum tilt of a solar collector, Sol. Energy. 17 (1975). doi:10.1016/0038-092X(75)90064-X.

[12] G. Lewis, Optimum tilt of a solar collector, Sol. Wind Technol. 4 (1987). doi:10.1016/0741983X(87)90073-7.

[13] C. Stanciu, D. Stanciu, Optimum tilt angle for flat plate collectors all over the World - A declination dependence formula and comparisons of three solar radiation models, Energy Convers. Manag. 81 (2014). doi:10.1016/j.enconman.2014.02.016.

[14] K. Skeiker, Optimum tilt angle and orientation for solar collectors in Syria, Energy Convers. Manag. 50 (2009) 2439-2448. doi:10.1016/j.enconman.2009.05.031.

[15] K. Ulgen, Optimum tilt angle for solar collectors, Energy Sources, Part A Recover. Util. Environ. Eff. 28 (2006). doi:10.1080/00908310600584524.

[16] H. Moghadam, F.F. Tabrizi, A.Z. Sharak, Optimization of solar flat collector inclination, Desalination. 265 (2011) 107-111. doi:10.1016/j.desal.2010.07.039.

[17] M.M. Elsayed, Optimum orientation of absorber plates, Sol. Energy. 42 (1989) 89-102. doi:10.1016/0038-092X(89)90136-9. 
[18] H.K. Elminir, A.E. Ghitas, F. El-Hussainy, R. Hamid, M.M. Beheary, K.M. Abdel-Moneim, Optimum solar flat-plate collector slope: Case study for Helwan, Egypt, Energy Convers. Manag. 47 (2006) 624-637. doi:10.1016/j.enconman.2005.05.015.

[19] IDAE (Instituto para la Diversificación y Ahorro de la Energía), Pliego de Condiciones Técnicas de Instalaciones de Baja Temperatura, 2009. doi:10.1017/CBO9781107415324.004.

[20] G. de E. Ministerio de Fomento, Archivos de datos climáticos de todas las zonas CTE, (2014).

[21] G. Solar, Manual técnico TwinSolar-SLK TopSolar, (2004).

[22] G. de E. Ministerio de Fomento, Código Técnico de la Edificicación. Documento Básico Ahorro de Energía (CTE DB HE), 2017.

\section{NORMATIVA.}

[N-1] Ministerio de Industria, Turismo y Comercio y Ministerio de Vivienda de España, "Real Decreto 1027/2007: Reglamento de Instalaciones Térmicas en Edificios". 


\section{CAPÍTULO VII.- \\ AHORROS ENERGÉTICOS EN VERANO.}

\section{CONTENIDOS DEL CAPÍTULO:}

VII.1.- INTRODUCCIÓN: USO ANUAL DE LOS COLECTORES SOLARES DE AIRE. ALTERNATIVAS. 261

VII.2.- PROPUESTA DE USO DE LOS COLECTORES SOLARES PARA PRODUCCIÓN DE ACS. 264

VII.3.- METODOLOGÍA DE ESTUDIO. 267

VII.3.1.- MODELOS MATEMÁTICOS DE LOS ELEMENTOS DEL SISTEMA. 267

VII.3.1.1.- Modelado de la batería de tubos aleteados. 267

VII.3.1.2.- Modelado de los captadores solares de aire. 273

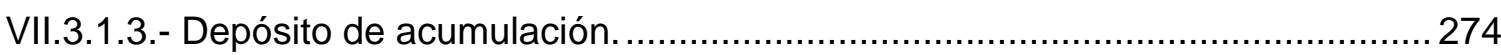

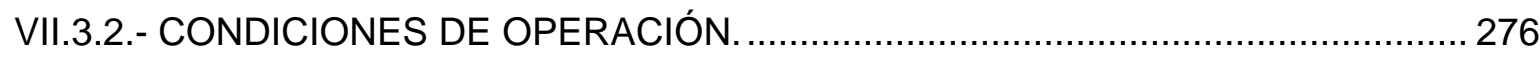

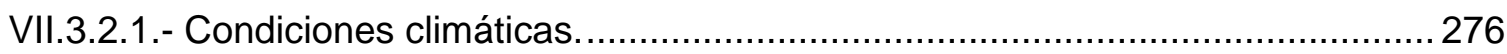

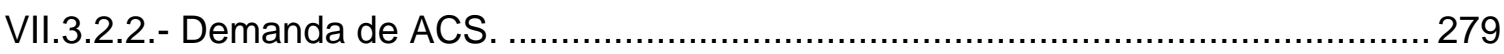

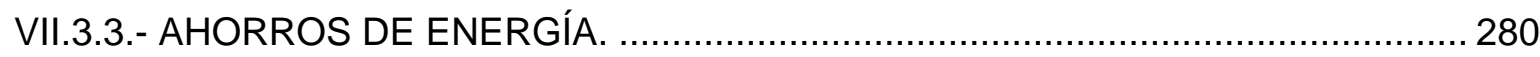

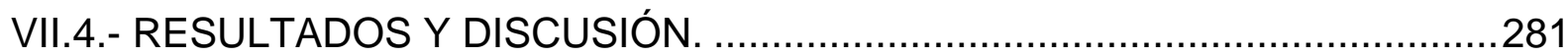

VII.4.1.- FUNCIONAMIENTO CON DOS ACUMULADORES....................................... 281

VII.4.2.- EVOLUCIÓN DE LA TEMPERATURA DEL AGUA EN EL DEPÓSITO. ............ 284

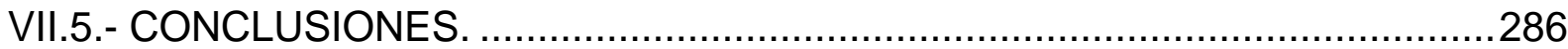

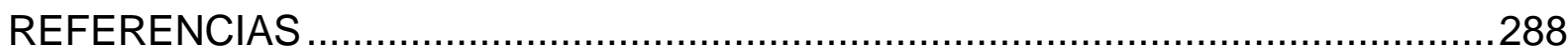


CAPÍTULO VII: AHORROS ENERGÉTICOS EN VERANO

256 


\section{LISTA DE FIGURAS:}

Figura VII.1.- Esquema para la producción de ACS mediante generación instantánea. …..............264

Figura VII.2.- Esquema para la producción de ACS con acumulación en un único depósito. ............265

Figura VII.3.- Esquema de generación de ACS mediante acumulación en dos depósitos.

Configuración 1.

Figura VII.4.- Esquema de generación de ACS mediante acumulación en dos depósitos.

Configuración 2. 266

Figura VII.5.- Esquema para el cálculo de ACS en ambas configuraciones. 279

Figura VII.6.- Evolución de la temperatura del agua en el depósito para el día tipo de julio con un caudal de aire de paso por el colector de $300 \mathrm{~m}^{3} / \mathrm{h}$. Capacidad del depósito: 100 litros. 285

Figura VII.7.- Evolución de la temperatura del agua en el depósito para el día tipo de julio con un caudal de aire de paso por el colector de $300 \mathrm{~m}^{3} / \mathrm{h}$. Capacidad del depósito: 500 litros. 285

\section{LISTA DE TABLAS:}

Tabla VII.1.- Características de la superficie de intercambio [28]. 268

Tabla VII.2.- Evolución de las temperaturas y de la irradiación sobre superficie horizontal durante un día tipo de los meses estivales en Valladolid [29].

Tabla VII.3.-Coeficientes de las regresiones polinómicas para la evolución diaria de temperatura e irradiación sobre superficie horizontal. 278

Tabla VII.4.- Factores de corrección de la irradiación por inclinación de $42^{\circ}$ en Valladolid. 278

Tabla VII.5.- Temperatura del agua de red ${ }^{\circ}$ en Valladolid 278

Tabla VII.6.- Ahorros conseguidos durante los días típicos de cada mes de verano para un depósito de 100 litros

Tabla VII.7.- Ahorros conseguidos durante los días típicos de cada mes de verano para un depósito de 300 litros 282

Tabla VII.8.- Ahorros conseguidos durante los días típicos de cada mes de verano para un depósito de 500 litros 


\section{Nomenclatura:}

A: área $\left[\mathrm{m}^{2}\right]$

C. capacidad calorífica $\left[\mathrm{kW} /{ }^{\circ} \mathrm{C}\right]$

$C_{p}$ : calor específico $\left[\mathrm{kJ} /\left(\mathrm{kg}^{\circ} \mathrm{C}\right)\right]$

f. factor de fricción

$h$ : coeficiente de transferencia de calor por convección $\left[\mathrm{W} /\left(\mathrm{m}^{2}{ }^{\circ} \mathrm{C}\right)\right]$

$H:$ humedad específica [kgv/kga]

$k$. conductividad térmica $\left[\mathrm{W} /\left(\mathrm{m}^{\circ} \mathrm{C}\right)\right]$

I: irradiancia $\left(\mathrm{kW} / \mathrm{m}^{2}\right)$

$L:$ longitud [m]

Mm: masa molecular $[\mathrm{kg} / \mathrm{kmol}]$

$P$ : presión $[\mathrm{kPa}]$

$Q$ : transferencia de calor [W]

$R$ :constante para gas $[\mathrm{kJ} /(\mathrm{kmolK})]$

$r$ : radio $[\mathrm{m}]$

T: temperatura $\left[{ }^{0} \mathrm{C}\right]$

$U$ : coeficiente global de transferencia de calor $\left[\mathrm{W} /\left(\mathrm{m}^{2}{ }^{\circ} \mathrm{C}\right)\right]$

$u$ : velocidad $[\mathrm{m} / \mathrm{s}]$

$v$ : volumen específico $\left[\mathrm{m}^{3} / \mathrm{kg}\right]$

$X$ : factor de corrección

$\alpha_{a}$ : Área total de transferencia de calor del lado del aire/ Volumen total

$\alpha_{w}:$ Área total de transferencia de calor del lado del agua/ Volumen total

$\varepsilon$ : eficacia de las aletas $[0 / 1]$

$\mu$ : viscosidad $[\mathrm{kg} /(\mathrm{m} \cdot \mathrm{s})]$

$\rho:$ densidad $\left[\mathrm{kg} / \mathrm{m}^{3}\right]$

$\delta:$ espesor de la aleta

$\sigma_{w}:$ flujo libre agua/ área frontal

$\sigma_{a}$ : flujo libre aire/ área frontal 
Subíndices:

a: aire

av: promedio

c: calor específico

$d:$ densidad

ext: exterior

h: hidráulico

In: flujo interior

Out: flujo exterior

w: agua

Números adimensionales:

$\mathrm{Nu}:$ Nusselt

$R e:$ Reynolds

Pr : Prandt

St : Stanton 
CAPÍTULO VII: AHORROS ENERGÉTICOS EN VERANO

260 


\section{VII.1.- INTRODUCCIÓN: USO ANUAL DE LOS COLECTORES SOLARES DE AIRE. ALTERNATIVAS.}

Se ha visto en el capítulo VI que el calentamiento solar de aire en invierno mediante el uso de captadores solares de aire es energéticamente interesante. Asimismo, ya se argumentó su interés adicional asociado a la sencillez y bajo coste de su implantación [1][2]. Por otro lado, la ventaja que presenta el calentamiento solar de aire frente al uso de agua, además de la simplicidad de la instalación y el hecho de que los efectos de las fugas o corrosión no son tan críticos [3] [4], radica en que el sobrecalentamiento no supone un riesgo en los colectores solares de aire. Sin embargo, la falta de demanda de calefacción durante determinadas temporadas limita el uso anual y, en consecuencia, el interés de estos sistemas [5].

Por lo tanto, resulta necesario contemplar la posibilidad de extender su uso a períodos estivales e interestacionales a fin de maximizar los ahorros energéticos y así optimizar tanto la inversión como el impacto de los colectores. La aplicación estival más inmediata del calentamiento solar del aire radica en favorecer la ventilación natural para alcanzar corrientes de aire en el interior que resulten en un ambiente agradable. Sin embargo, la mayor parte de estas alternativas proponen sistemas que pertenecen intrínsecamente a la misma estructura del edificio, tales como muros trombe, chimeneas solares y captadores solares en cubiertas. Cuando el objetivo es mejorar la ventilación natural, los colectores solares con cubierta tienen la ventaja de captar más radiación cuando el sol se encuentra en posiciones más altas, pero tienen un menor efecto chimenea debido a la inclinación con la que están colocados, comparándolos con las chimeneas solares [6] [7]. Numerosas propuestas para su empleo en la mejora de la ventilación natural han sido estudiadas y están recogidas en la bibliografía [8] [2] [9] [10]. Sin embargo, estas estrategias solo serían viables si se tiene en cuenta su incorporación durante la fase de diseño del edificio [11].

En cualquier caso, existen diferentes formas de integrar o incorporar sistemas de colectores solares de aire en edificios existentes. Existen diferentes alternativas para calentar gratuitamente el aire que se emplea con posterioridad en el calentamiento del edificio, situando los sistemas de captación en la cubierta, muros o ventanas del propio edificio; también su integración como elemento de sombreamiento sobre las ventanas $u$ otros hueco de fachada puede ser una alternativa a pesar de ser menos eficiente y más caro [12]. En la actualidad, se pueden encontrar alternativas muy diversas e interesantes para integrar de forma eficaz los colectores solares de aire en edificios existentes.

Ubertini y Desideri [11] proponen instalar una especie de colector solar de aire de dos vías bajo el alfeizar de las ventanas de un edificio, que además de calentar la corriente de aire de ventilación permite la recuperación parcial del calor de la corriente de aire expulsado. Visagabel y Srnivasan [13] proponen un captador solar de aire integrado en la terraza, conectado con el espacio a ventilar, lo que permite su integración en edificios residenciales o terciarios sin necesidad de grandes modificaciones 
constructivas. Ji et al plantean un colector solar de doble función como parte de la envolvente del edificio, instalado en la cubierta para aportar aire caliente a diferentes zonas del edificio [14], o en la fachada aportando aire caliente al espacio inmediato, en cuyo caso estudian el efecto en la transmitancia térmica de la envolvente modificada [15] [16]. Yoshie et al también proponen la integración del captador en el balcón [17].

Algunos de estos autores contemplan la posibilidad de extender el uso de los colectores solares de aire más allá de la temporada de calefacción. En este sentido varias estrategias han sido propuestas por estos autores.

La opción más inmediata resulta la del sombreamiento del colector durante el verano. Esto es propuesto por Ubertini y Desideri [11], no solamente pensando en anular el colector en verano, sino también en poderlo utilizar para mejorar la ventilación, esta cuestión quedó pendiente para un estudio posterior que, al menos hasta donde alcanza el conocimiento del doctorando autor de este trabajo, no llegó a tener lugar. Esta misma opción es propuesta por Budea [18] en el uso de colectores semejantes a los analizados en este trabajo de tesis doctoral, en el sentido de combinación de energía solar térmica para el calentamiento de aire y fotovoltaica para el accionamiento del ventilador necesario para su circulación. De esta forma, el simple sombreamiento en verano anularía el aporte térmico mientras que continuaría permitiendo el funcionamiento del ventilador con energía solar fotovoltaica, utilizándose así el sistema en modo ventilación que además podría asegurar una corriente de aire confortable en el interior del espacio (semejante a lo buscado por los sistemas solares térmicos pasivos de captación en verano indicados con anterioridad). El funcionamiento complementario a esta alternativa sería la operación en modo nocturno con el fin de lograr el "enfriamiento gratuito" del interior [11][17].

Una opción un poco más enrevesada es la propuesta por Yoshie et al [17]. Ellos presentan en este caso un colector solar de aire combinado con un intercambiador de calor para recuperación de energía. Podría trabajar en cuatro modos de operación: calentamiento de aire en invierno durante el día, que sería aportado a un espacio bajo el suelo desde donde el aire sería distribuido, o desviado durante la noche; y en verano sería desviado durante el día y en verano trabajaría durante la noche para ventilación, argumentando que el aire sería enfriado "por la radiación de onda larga".

En el caso de colectores solares de aire integrados en la cubierta, los cuales forman parte de la envolvente del edificio, permiten llevar a cabo una ventilación natural inducida en verano por el efecto chimenea generado, sin necesidad de aporte de energía adicional para el ventilador. Extensos trabajos han sido desarrollados a favor de esta estrategia. Debido a que el efecto chimenea es menos eficiente en climas cálidos y húmedos debido a las bajas diferencias de temperatura que se dan, es particularmente interesante favorecer este efecto en estos casos a través del calentamiento solar del aire; las principales consideraciones a tener en cuenta en este tipo de climas son una adecuada ventilación y unas bajas ganancias solares [8][9]. Con este objetivo, Yusoff et al [6][7] proponen un 
prototipo de colector solar de aire combinado con una chimenea vertical. Khedari et al [9] adecuan la misma estructura de la cubierta para actuar como un colector solar para ventilación en verano. Una idea similar es propuesta por Hirunlabh et al [8], estudiando el comportamiento de cuatro configuraciones diferentes.

Una alternativa más completa es la ventilación natural inducida mediante combinación del calentamiento solar de aire en unas zonas de la vivienda y su enfriamiento mediante enfriamiento evaporativo en otras. Esta alternativa también puede ser interesante en climas húmedos y cálidos, Chungloo y Limmeechokchai [19][20] estudian esta posibilidad proponiendo un sistema de techo frío húmedo y chimenea solar. Miyazaki et al [21] también proponen, para climas cálidos y húmedos, un sistema de chimenea solar apoyado por un sistema de enfriamiento evaporativo instalado en el techo. Al Touma et al [22] combinan una chimenea solar con un sistema de refrigeración evaporativo consistente en hojas absorbentes de agua colocadas en la parte inferior de las ventanas, permitiendo reducir la temperatura de las ventanas, mejorando la asimetría radiante, y por lo tanto el confort térmico. El sistema de refrigeración evaporativa se puede instalar de forma independiente al de la chimenea solar, en la entrada de aire a un espacio ventilado, como por ejemplo en una torre de viento [23]. En este sentido, Maerefat y Haghighi [24] proponen, para climas cálidos y secos, un diseño de una chimenea solar apoyada por un sistema separado de enfriamiento evaporativo que aporta aire enfriado por la zona inferior del espacio, permitiendo en el interior confort incluso con situaciones de baja irradiación. Para mejorar este diseño, Abdallah et al [25] proponen una almohadilla en lugar de una cavidad con la finalidad de aumentar la superficie mojada.

La última opción considerada en la literatura, es la de extender el uso de los colectores solares de aire a las temporadas de verano usando el aire para calentar el agua caliente sanitaria (ACS). Esta idea es propuesta por lto et al [26], aunque no es desarrollada por ellos. No obstante, existen prototipos de colectores solares para el empleo de la radiación solar para calefacción ya sea a través de agua o aire. Ji et al [5][14][16] desarrollan un prototipo para calentar aire durante la temporada de invierno y calentar agua durante la temporada de verano [5]. Por el contrario, Assari et al [27] desarrollan un prototipo con el objetivo de proporcionar simultáneamente ambos, aire y agua caliente. A pesar de que la primera opción permitiría superar las limitaciones estacionales del uso de los colectores solares de aire, contemplando la necesidad de establecer una integración factible en los edificios existentes [14][16], la integración real en los edificios aún es complicada.

En este capítulo, se propone y estudia un método de utilización de los colectores solares de aire para la obtención de ACS, alternativo al presentado en la literatura existente: recircular el caudal de aire calentado en los colectores dentro de un circuito en el que se intercambie el calor del aire al agua destinada a ACS en una batería de tubos aleteados. A continuación, se procede a describir el sistema y configuraciones propuestas, así como la metodología seguida para su estudio y los resultados obtenidos. 


\section{VII.2.- PROPUESTA DE USO DE LOS COLECTORES SOLARES PARA PRODUCCIÓN DE ACS.}

A la hora de plantear el uso de los captadores solares de aire para producción de ACS, mediante la utilización del aire procedente de los captadores en circuito cerrado para calentar agua en un intercambiador, se muestran posibles varias opciones de diseño según se considere o no acumulación del agua caliente generada y, en caso de optar por acumulación, dependiendo del número de acumuladores y su configuración.

La opción más inmediata sería la generación instantánea del ACS para soportal la demanda puntual. El diseño de instalación planteado en este caso se puede ver en la figura VII.1.

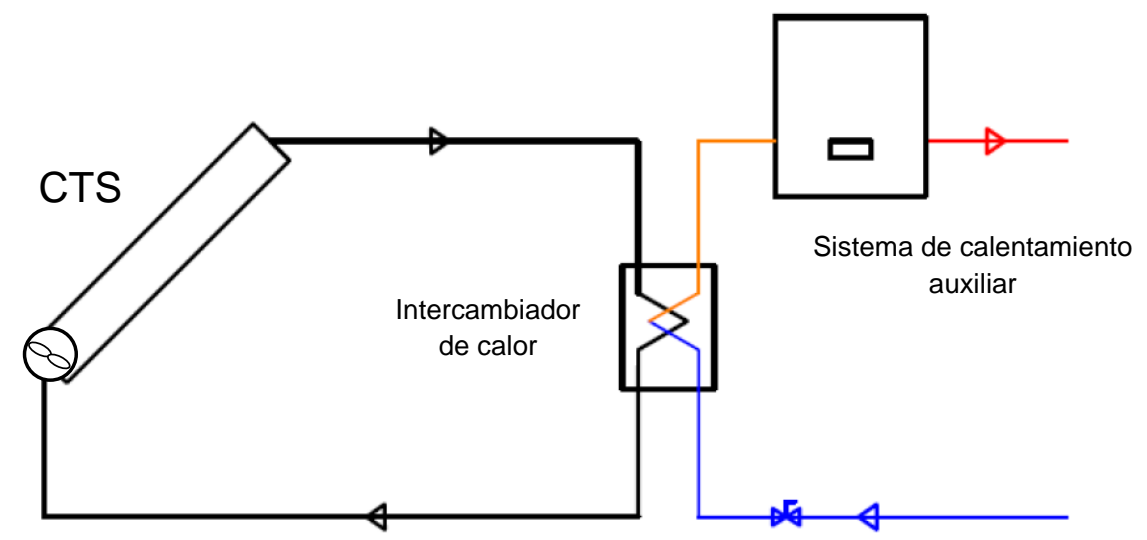

Figura VII.1.- Esquema para la producción de ACS mediante generación instantánea.

Esta configuración estaría compuesta por un intercambiador de calor al que se conectaría un circuito primario de aire procedente del colector solar y un circuito secundario de agua para el consumo. El intercambiador a emplear para la producción de ACS con los colectores solares de aire sería una batería de aire-agua. La instalación deberá de disponer del resto de elementos necesarios que permitan el cumplimiento de la normativa de aplicación y que garanticen la seguridad y el adecuado funcionamiento de la instalación, como son filtro en la entrada de agua de red, llaves de corte en distintos puntos, válvula antirretorno, contador para el control del consumo, válvulas de seguridad, vasos de expansión y demás elementos que puedan ser necesarios.

La generación instantánea tiene la característica de tener que dimensionar el intercambiador para poder cubrir la demanda máxima o el pico de demanda de la instalación, dada la necesidad de tener que calentar el agua en el instante en el que se produce la demanda. Esto conlleva en la mayoría de las ocasiones el requerimiento de necesitar intercambiadores de mayor tamaño que en los sistemas con acumulación. Otro factor que puede presentarse como una importante desventaja de los sistemas de producción instantánea solares sin acumulación es la no coincidencia temporal de la 
demanda de ACS (fundamentalmente en sector residencial) y los valores más altos de irradiancia solar. En cambio, al no disponer de depósito de acumulación necesita menos espacio para su instalación.

La configuración de la opción con acumulación es similar a la de producción instantánea. Se emplea el mismo tipo de batería (de menor tamaño) para el intercambio de calor entre la corriente de aire y la de agua. La diferencia estriba en que en este circuito secundario de agua se interpone el depósito acumulador, partiendo y retornando al depósito la alimentación a consumo y el retorno.

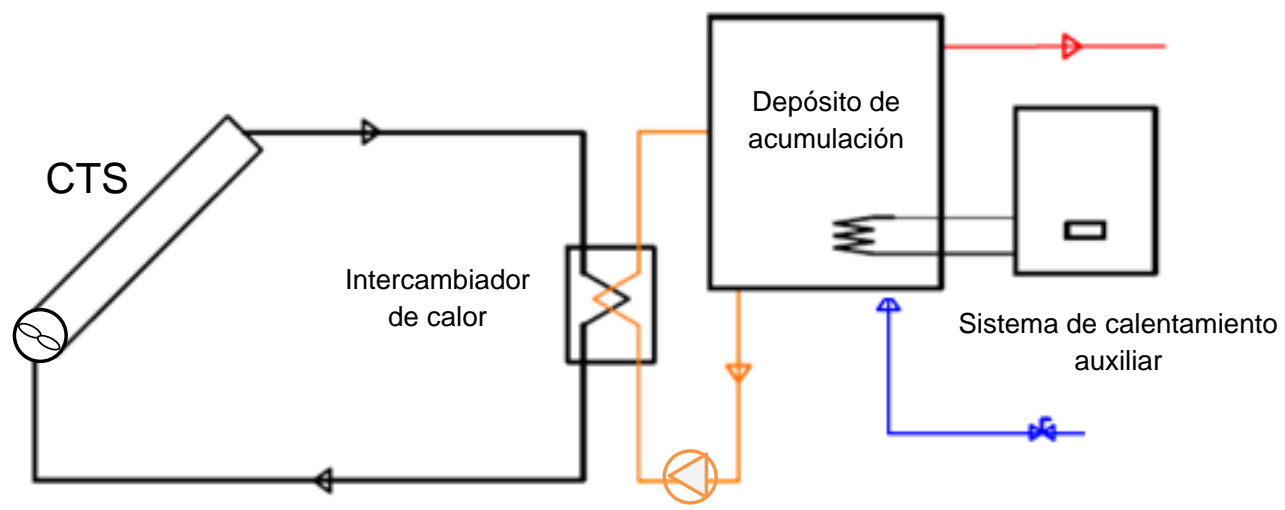

Figura VII.2.- Esquema para la producción de ACS con acumulación en un único depósito.

Entre las opciones de acumulación, la más básica corresponde al uso de un único depósito, según se muestra en la figura VII.2. Para el caso particular que nos ocupa, esta configuración no resulta óptima ya que al necesitar acumular o mantener el agua en el depósito a una temperatura adecuada para su distribución, unos $60^{\circ} \mathrm{C}$, nos obligaría a recircular por el secundario del intercambiador el agua a una temperatura demasiado alta, que impediría obtener un aprovechamiento óptimo en el intercambio con la corriente de aire al no alcanzar esta niveles térmicos adecuados para ceder energía al agua.

En cuanto al uso de dos depósitos de acumulación, las figuras VII.3 y VII.4 muestran dos posibles configuraciones alternativas según se contemple el aporte de agua de red, necesaria para reposición y para adecuar la temperatura del primer depósito a $60^{\circ} \mathrm{C}$ en los casos en los que por la operación de los captadores se exceda esta, directamente al depósito o a la batería. Desde el depósito 2 se llevará a cabo la distribución, acumulará agua a la temperatura establecida, unos $60^{\circ} \mathrm{C}$, contando con un sistema de apoyo auxiliar para cuando el sistema solar no consiga alcanzar esta consigna de acumulación.

La primera de las configuraciones, figura VII.3, va a ser denominada en este estudio "configuración 1". Dado que en determinadas circunstancias la temperatura del depósito 1 supera los $60^{\circ} \mathrm{C}$ es preciso mezclarla con agua de red. El agua de red para llenar el depósito durante la demanda se aporta directamente a este. El agua que se introduce en la batería procede íntegramente del depósito. 
En esta configuración el agua de aporte de red se hace directamente al depósito de preparación. El aporte de agua de red a este depósito se hará cuando exista demanda de ACS o cuando sea necesario bajar la temperatura del depósito

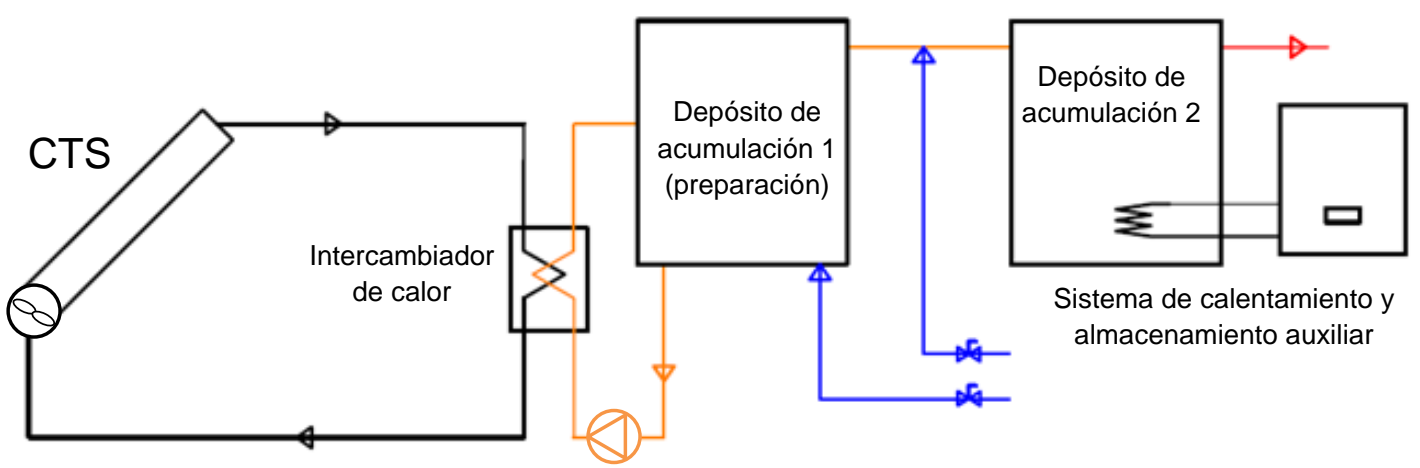

Figura VII.3.- Esquema de generación de ACS mediante acumulación en dos depósitos.

Configuración 1.

La segunda de las configuraciones con dos depósitos se puede observar en la figura VII.4, la denominaremos "configuración 2". Al igual que en la anterior configuración, en determinadas circunstancias la temperatura del depósito 1 supera los $60^{\circ} \mathrm{C}$ por lo que es necesario mezclarla con agua de red. En este caso, el agua de aporte necesaria por la demanda se incorpora al depósito mezclada con el agua de éste antes de la batería.

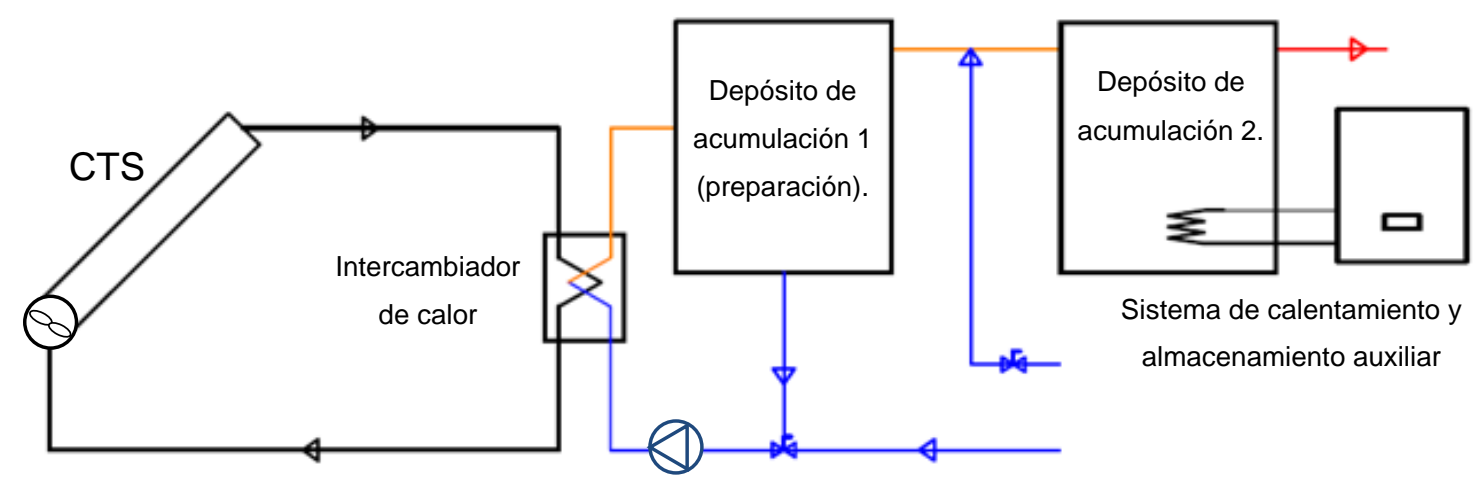

Figura VII.4.- Esquema de generación de ACS mediante acumulación en dos depósitos.

Configuración 2.

La configuración 2, incorpora una válvula de tres vías mezcladora del agua del depósito con el agua de red necesaria por la demanda, esto permite que el descenso de temperatura en el depósito 1 sea menor que si se incorpora el agua de red directamente al depósito (configuración 1). También, la configuración 2 permite incorporar el agua a la entrada de la batería a una temperatura inferior que si se hace directamente desde el depósito (configuración 1), aumentando de este modo la eficiencia del 
intercambio en la batería. En instantes sin demanda y con una misma temperatura de acumulación en el depósito 1, el comportamiento y operación de ambas configuraciones es similar.

\section{VII.3.- METODOLOGÍA DE ESTUDIO.}

El estudio de la operación de los captadores solares de aire para producción de ACS según las configuraciones anteriormente descritas se ha realizado mediante simulación en distintas condiciones climáticas. A continuación, se describen los modelos matemáticos utilizados para la simulación, así como las condiciones de funcionamiento consideradas.

\section{VII.3.1.- MODELOS MATEMÁTICOS DE LOS ELEMENTOS DEL SISTEMA.}

Para desarrollar la simulación ha sido necesario modelar los elementos básicos del sistema completo: el intercambiador de calor, los colectores solares de aire y el depósito de acumulación (primario). Todos estos modelos se han implementado en un libro Excel habilitado para macros.

\section{VII.3.1.1.- MODELADO DE LA BATERÍA DE TUBOS ALETEADOS.}

Un intercambiador de calor consistente en una batería de tubos aleteados es un sistema extensamente estudiado y desarrollado, por lo que su modelado no ha requerido de ninguna base experimental previa. El modelo descrito a continuación está por lo tanto simplemente basado en el procedimiento estandarizado recogido en la bibliografía [28].

En el análisis del intercambiador de calor son seguidos una serie de pasos para el cálculo, en el orden dado, de los siguientes factores:

1. Caracterizar la superficie de intercambio.

2. Determinar las propiedades de los fluidos.

3. Calcular los números de Reynolds.

4. Determinar $S t P r^{2 / 3}$ y el factor de fricción de Fanning a partir de las características básicas de la superficie.

5. Calcular los coeficientes de transferencia de calor.

6. Determinar la efectividad de las aletas.

7. Determinar la efectividad de la superficie. 
8. Determinar el coeficiente global de transferencia de calor U.

9. Calcular el NTU y la efectividad del intercambiador.

10. Determinar las temperaturas de salida.

11. Calcular la pérdida de presión.

A continuación se describen cada uno de estos pasos:

1. Caracterizar la superficie de intercambio.

Obtenemos las características de la superficie de intercambio a partir de la Tabla AC.4 que figura en el Anexo C.

Dado que la batería que se modeló es real, los parámetros geométricos son datos conocidos. Dicha geometría está recogida en la bibliografía [11], por lo que algunos de los valores necesarios para el modelado se extraen directamente de ella.

Tabla VII.1.- Características de la superficie de intercambio [28].

\begin{tabular}{|l|c|}
\hline \multicolumn{2}{|c|}{ DIMENSIONES } \\
\hline Área frontal lado del aire & $0,09 \mathrm{~m}^{2}$ \\
\hline Área frontal lado del agua & $0,0264 \mathrm{~m}^{2}$ \\
\hline Volumen del intercambiador & $0,00792 \mathrm{~m}^{3}$ \\
\hline \multicolumn{2}{|c|}{ LADO DEL AGUA } \\
\hline \multicolumn{2}{|c|}{} \\
\hline Radio hidráulico & $0,004 \mathrm{~m}$ \\
\hline Área total de transferencia del lado del agua/Volumen total; $\alpha_{\mathrm{w}}$ & $45,695 \mathrm{~m}^{2} / \mathrm{m}^{3}$ \\
\hline Diámetro exterior & $0,01 \mathrm{~m}$ \\
\hline Diámetro interior & $0,008 \mathrm{~m}$ \\
\hline Área frontal asociada con un tubo & $5,5 \cdot 10^{-4}$ \\
\hline Área de flujo libre de un tubo & $0,50264 \cdot 10^{-4}$ \\
\hline Periferia interior de un tubo & $0,025132741 \mathrm{~m}$ \\
\hline Flujo libre/área frontal $\sigma_{\mathrm{w}}$ & 0,091 \\
\hline & \multicolumn{1}{|c|}{ LADO DEL AIRE } \\
\hline Radio hidráulico & $0,9075 \cdot 10^{-3} \mathrm{~m}$ \\
\hline Área total de transferencia del lado del aire/Volumen total; $\alpha_{\mathrm{a}}$ & $587 \mathrm{~m}^{2} / \mathrm{m}^{3}$ \\
\hline Área de una aleta/área total & 0,913 \\
\hline Espesor de la aleta $\delta$ & $0,00033 \mathrm{~m}$ \\
\hline Aletas de aluminio, conductividad & $235 \mathrm{~W} / \mathrm{m}^{\prime} \mathrm{K}$ \\
\hline Longitud de la aleta (media distancia entre tubos) & $0,012 \mathrm{~m}$ \\
\hline Flujo libre/área frontal ; $\sigma_{\mathrm{a}}$ & 0,534 \\
\hline
\end{tabular}


2. Determinar las propiedades de los fluidos.

Para determinar las propiedades de los fluidos será necesario asumir en primera aproximación, una temperatura del aire y del agua a la salida de la batería. Esta aproximación será validada posteriormente.

Se tomará el promedio de temperaturas:

$$
\begin{aligned}
& \mathrm{T}_{\mathrm{av} \_\mathrm{w}}=\frac{\left(\mathrm{T}_{\mathrm{in} \_\mathrm{w}}+\mathrm{T}_{\mathrm{out} \_\mathrm{w}}\right)}{2}
\end{aligned}
$$

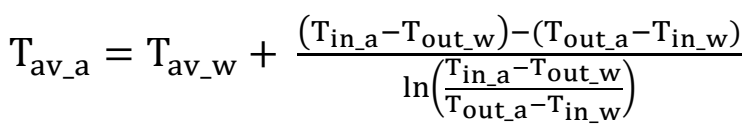

De los valores tabulados e incluidos en el anexo $\mathrm{C}$ se construyen las expresiones que correlacionan las variables siguientes con la temperatura tomada en unidades de grados centígrados:

$$
\begin{array}{ll}
\text { AIRE SECO A PRESIÓN ATMOSFÉRICA } \\
\begin{array}{ll}
\text { Calor específico }(\mathrm{kJ} / \mathrm{kg} \cdot \mathrm{C}): & \mathrm{Cp}=4 \cdot 10^{-7} \cdot \mathrm{T}^{2}+10^{-5} \cdot \mathrm{T}+1.0057 \ldots \ldots \ldots \ldots \\
\text { Densidad }(\mathrm{kg} / \mathrm{m} \cdot \mathrm{s}) & \rho=6 \cdot 10^{-7} \cdot \mathrm{T}^{2}-0.002 \cdot \mathrm{T}+0.7174 \ldots \ldots \ldots \ldots \\
\text { Prandtl: } & \mathrm{Pr}=-4 \cdot 10^{-5} \cdot \mathrm{T}^{2}+0.076 \cdot \mathrm{T}+24.063 \ldots \ldots \ldots \\
\text { Conductividad }(\mathrm{W} / \mathrm{m} \cdot \mathrm{C}) & \mathrm{k} \cdot 10^{3}=9 \cdot 10^{-6} \cdot \mathrm{T}^{2}-0.0043 \cdot \mathrm{T}+1.2885 \\
\text { Viscosidad }(\mathrm{kg} / \mathrm{m} \cdot \mathrm{s}): & \mu \cdot 10^{6}=0.0442 \cdot \mathrm{T}+17.314 \ldots \ldots \ldots \ldots \ldots \ldots \ldots \ldots \ldots \ldots \ldots \ldots
\end{array}
\end{array}
$$

\section{AGUA SATURADA}

Calor específico $(\mathrm{kJ} / \mathrm{Kg} \cdot \mathrm{C}): \quad \mathrm{Cp}=-4 \cdot 10^{-8} \cdot \mathrm{T}^{3}+2 \cdot 10^{-5} \cdot \mathrm{T}^{2}-0.0015 \cdot \mathrm{T}+4.2096 \ldots \ldots$ (E-VII.8)

$\operatorname{Densidad}(\mathrm{Kg} / \mathrm{m} \cdot \mathrm{s}): \quad \rho=-0.0026 \cdot \mathrm{T}^{2}-0.1785 \cdot \mathrm{T}+1002.4$

Prandtl:

$$
\operatorname{Pr}=-10^{-5} \cdot \mathrm{T}^{3}+0.003 \cdot \mathrm{T}^{2}-0.3009 \cdot \mathrm{T}+12.218
$$

Conductividad $(\mathrm{W} / \mathrm{m} \cdot \mathrm{C})$ :

$$
\mathrm{k} \cdot 10^{3}=-6 \cdot 10^{-6} \cdot \mathrm{T}^{2}-0.0017 \cdot \mathrm{T}+0.5685
$$

Viscosidad $(\mathrm{Kg} / \mathrm{m} \cdot \mathrm{s})$ :

$$
\mu \cdot 10^{6}=-10^{-6} \cdot \mathrm{T}^{3}+0.0004 \cdot \mathrm{T}^{2}-0.0405 \cdot \mathrm{T}+1.7073 \ldots(E-\text { VII.12) }
$$

Tanto el calor específico como la densidad del aire deben ser corregidas en función de su humedad. Las expresiones que correlacionan el factor de corrección con la cantidad de agua contenida en el aire, se obtienen de la figura AC. 1 incluida en el Anexo C. 
Factor de corrección de humedad para el calor específico del aire:

$$
\mathrm{X}_{\mathrm{cw}}=0.0866 \cdot \mathrm{H}+0.9998
$$

Factor de corrección de humedad para la densidad del aire:

$$
\mathrm{X}_{\mathrm{dw}}=-0.0562 \cdot \mathrm{H}+1.0001
$$

donde $\mathrm{H}$ es la humedad tomada en unidades de lbs $\mathrm{H}_{2} \mathrm{O}$ / lbs aire húmedo.

Como condición inicial del proceso de cálculo, se asumirá una pérdida de presión en el lado del aire del $1 \%$, y se determinará el promedio de presión como:

$$
\mathrm{P}_{\mathrm{av}}=\frac{\left(\mathrm{P}_{\text {in }}+\mathrm{P}_{\text {out }}\right)}{2}
$$

En el caso del lado del aire, el volumen específico a la entrada y a la salida, se puede evaluar empleando la ecuación de estado de los gases ideales y la corrección para la humedad como:

$$
v=\frac{1}{\rho}=\frac{1}{\mathrm{X}_{\mathrm{dw}}} \frac{\mathrm{RT}}{\mathrm{M}_{\mathrm{m}} \mathrm{P}}
$$

Pero para esta aplicación el volumen específico no varía linealmente con el área de transferencia y el volumen específico evaluado como el promedio del volumen a la entrada y a la salida no es buena aproximación. Es mejor aproximación de los resultados usar la temperatura promedio del aire calculada anteriormente:

$$
\frac{v_{a v}}{v_{\text {in }}}=\frac{P_{\text {in_a }}}{P_{\text {av }}} \frac{T_{\text {av } \_a}}{T_{\text {in } \_a}}
$$

3. Calcular los números de Reynolds.

Los números de Reynolds se calculan de la misma forma independientemente de si se trata del lado del aire o del agua:

$$
\operatorname{Re}=\frac{\rho \mathrm{u} 4 \mathrm{r}_{\mathrm{h}}}{\mu}
$$

4. Determinar StPr2/3 y el factor de fricción de Fanning a partir de las características básicas de la superficie.

A partir de las figuras AC.2 y AC.3 contenidas en el Anexo $C$ se obtienen las rectas que correlacionan el factor de fricción de Fanning y $\mathrm{StPr}^{2 / 3}$ con el número de Reynolds:

LADO DEL AIRE

$$
\begin{aligned}
& \log f=-0.2113 \cdot \log \left(\operatorname{Re} \cdot 10^{-3}\right)-1.5262 \\
& \log \operatorname{StPr}^{2 / 3}=-0.4051 \cdot \log \left(\operatorname{Re} \cdot 10^{-3}\right)-1.9712
\end{aligned}
$$




\section{LADO DEL AGUA}

Hacemos uso de la ecuación de Karman-Nikuradse:

Para $\mathrm{Re}<6 \cdot 10^{4}$

$\mathrm{f}=0.079 \cdot \mathrm{Re}^{-0.25}$

(E-VII.21)

Para $\operatorname{Re}>6 \cdot 10^{4}$

$$
\mathrm{f}=0.046 \cdot \mathrm{Re}^{-0.2}
$$

\section{Calcular los coeficientes de transferencia de calor.}

\section{LADO DEL AIRE}

$$
\mathrm{h}=\mathrm{St} \cdot \rho \cdot \mathrm{u} \cdot \mathrm{Cp}_{\mathrm{corr}}
$$

\section{LADO DEL AGUA}

Correlación para flujo forzado en el interior de tubos:

Ecuación de Seider-Tate:

$$
\begin{aligned}
& \mathrm{Nu}=0.027 \cdot \mathrm{Re}^{0.8} \cdot \operatorname{Pr}^{1 / 3} \\
& \mathrm{~h}=\frac{\mathrm{Nu} \cdot \mathrm{k}}{4 \cdot \mathrm{r}_{\mathrm{h}}}
\end{aligned}
$$

\section{Determinar la efectividad de las aletas.}

La efectividad de una aleta se define como el cociente entre el calor que disipa la aleta y el máximo calor que podría disipar suponiendo ésta a la temperatura de la base:

$$
\varepsilon=\frac{Q_{\text {aleta }}}{Q_{\max }}
$$

El rendimiento de una aleta se define a partir de funciones de Bessel modificadas como:

$$
\eta_{\text {aleta }}=G_{2}\left(\alpha_{2} \beta_{2}\right)=\frac{2 \alpha_{a n}}{\beta_{a n}\left(1-\alpha_{a n}^{2}\right)} \frac{K_{1}\left(\alpha_{a n} \beta_{a n}\right) I_{1}\left(\beta_{a n}\right)-I_{1}\left(\alpha_{a n} \beta_{a n}\right) K_{1}\left(\beta_{a n}\right)}{K_{1}\left(\beta_{a n}\right) I_{0}\left(\alpha_{a n} \beta_{a n}\right)+I_{1}\left(\beta_{a n}\right) K_{0}\left(\alpha_{a n} \beta_{a n}\right)}
$$

Donde:

$$
\begin{aligned}
& \alpha_{\mathrm{an}}=\frac{\mathrm{r}_{\text {base }}}{\mathrm{r}_{\text {ext }}} \\
& \beta_{\mathrm{an}}=\sqrt{\frac{2 \mathrm{~h} \mathrm{r_{ \text {ext } } ^ { 2 }}}{\mathrm{ke}}}
\end{aligned}
$$

En el anexo C, figura AC.4, podemos encontrar la gráfica de la función G2 para el flujo calorífico en una aleta anular de espesor uniforme. 
7. Determinar la efectividad de la superficie.

Obtenida la efectividad de las aletas la efectividad de la superficie se determina como:

$$
\eta_{0}=1-\frac{A_{\text {aleta }}}{A}\left(1-\eta_{\text {aleta }}\right)
$$

8. Determinar el coeficiente global de transferencia de calor U.

$$
\frac{1}{\mathrm{U}_{\mathrm{a}}}=\frac{1}{\eta_{0} \mathrm{~h}_{\mathrm{a}}}+\frac{1}{\left(\frac{\alpha_{\mathrm{w}}}{\alpha_{\mathrm{a}}}\right) \mathrm{h}_{\mathrm{w}}}
$$

9. Calcular el NTU y la efectividad del intercambiador.

$$
\begin{aligned}
& \mathrm{C}_{\mathrm{a}}=\mathrm{m}_{\mathrm{a}} \cdot \mathrm{Cp}_{\mathrm{cor}} \\
& \mathrm{C}_{\mathrm{w}}=\mathrm{m}_{\mathrm{w}} \cdot \mathrm{Cp}_{\mathrm{w}} \\
& \mathrm{NTU}_{\max }=\frac{\mathrm{A}_{\mathrm{a}} \mathrm{U}_{\mathrm{a}}}{\mathrm{C}_{\min }}
\end{aligned}
$$

La efectividad del intercambiador para flujos cruzados sin mezcla es:

$$
\varepsilon=1-\mathrm{e}^{\frac{\left(1-\mathrm{e}^{-\frac{\mathrm{C}_{\min }}{\mathrm{C}_{\max }}} \mathrm{NTU}^{0.78}\right)\left(-\mathrm{NTU}^{0.22}\right)}{\frac{\mathrm{C}_{\min }}{\mathrm{C}_{\max }}}}
$$

10. Determinar las temperaturas de salida de la batería.

$$
\begin{aligned}
& \mathrm{T}_{\text {out } \_\mathrm{a}}=-1 \cdot\left(\varepsilon \cdot\left(\mathrm{T}_{\mathrm{in} \_\mathrm{a}}-\mathrm{T}_{\mathrm{in} \_\mathrm{w}}\right)\right)-\mathrm{T}_{\mathrm{in} \_\mathrm{a}} \\
& \mathrm{T}_{\text {out_w }}=\frac{\mathrm{C}_{\mathrm{a}}}{\mathrm{C}_{\mathrm{w}}}\left(\mathrm{T}_{\text {in_a }}-\mathrm{T}_{\text {out_a }}\right)+\mathrm{T}_{\text {in_w }}
\end{aligned}
$$

11. Calcular la pérdida de presión.

LADO DEL AIRE

$$
\Delta \mathrm{P}=\frac{\rho u^{2}}{2}\left[\left(1+\sigma^{2}\right)\left(\frac{v_{\text {out }}}{v_{\text {in }}}-1\right)+\mathrm{f} \frac{\mathrm{L}}{\mathrm{r}_{\mathrm{h}}}\left(\frac{v_{\mathrm{av}}}{v_{\text {in }}}\right)\right]
$$


LADO DEL AGUA

$$
\begin{aligned}
& \mathrm{v}=\text { constante } \\
& \Delta \mathrm{P}=\frac{\rho \mathrm{u}^{2}}{2}\left[\mathrm{f} \frac{\mathrm{L}}{4 \mathrm{r}_{\mathrm{h}}}\right]
\end{aligned}
$$

Estos cálculos muestran el procedimiento seguido para determinar las características de un intercambiador dado.

En caso de que las temperaturas de salida obtenidas no coincidan con las supuestas inicialmente se deben repetir los cálculos de forma iterativa, motivo por el cual estos cálculos son implementados en una hoja de Excel habilitada para Macros. Se puede consultar el código creado para caracterizar el intercambiador en el apartado 2 del anexo $\mathrm{C}$.

\section{VII.3.1.2.- MODELADO DE LOS CAPTADORES SOLARES DE AIRE.}

Para el modelado de los captadores solares de aire, al ser sistemas menos estudiados y por ello objeto de trabajo de esta tesis doctoral, sí ha sido ,por el contrario, necesario recurrir a una base experimental que se ha realizado a tal efecto y que se encuentra descrita en el capítulo IV de esta memoria.

Una vez disponibles las rectas de rendimiento obtenidas experimentalmente, la implementación del modelo del captador es sin embargo sencilla. Siendo posible obtener del comportamiento experimental el salto de temperaturas previsto en el aire que atraviesa el colector, la temperatura de salida del aire de este se toma como temperatura de entrada del aire a la batería. Con este parámetro de entrada, la simulación del código planteado para la batería permite determinar como salidas la temperatura del agua y del aire a la salida de la batería.

Para implementar la función colector se plantea el siguiente balance de energía:

$\mathrm{M} \cdot \mathrm{c}_{\mathrm{pa}} \frac{\mathrm{dT}}{\mathrm{dt}}=\dot{\mathrm{m}}_{\mathrm{a}} \cdot \mathrm{c}_{\mathrm{pa}}\left(\mathrm{T}_{\text {in }}-\mathrm{T}_{\text {out }}\right)+\mathrm{Q}=\dot{\mathrm{m}}_{\mathrm{a}} \cdot \mathrm{c}_{\mathrm{pa}}\left(\mathrm{T}_{\text {in }}-\mathrm{T}_{\text {out }}\right)+\mathrm{I} \cdot \mathrm{S} \cdot \eta$

Siendo:

M: masa de aire en el colector

$Q$ : Aporte de calor que sufre el fluido en el interior del colector y que es función de la superficie y rendimiento de este, y de la intensidad radiante recibida. 
La integración de esta ecuación diferencial, suponiendo constantes las temperaturas de entrada y salida, el caudal de aire y el aporte de calor recibido durante el intervalo de tiempo, $\Delta \mathrm{t}$, conduce a la siguiente ecuación:

$$
\mathrm{M} \cdot \mathrm{c}_{\mathrm{pa}} \frac{\mathrm{T}_{\text {col out }_{(\mathrm{i}+1)}-\mathrm{T}_{\text {col out }}(\mathrm{i})}}{\Delta \mathrm{t}}=\dot{\mathrm{m}}_{\mathrm{a}} \cdot \mathrm{c}_{\mathrm{pa}}\left(\mathrm{T}_{\mathrm{in}}-\mathrm{T}_{\text {out }}\right)+\mathrm{I} \cdot \mathrm{S} \cdot \eta
$$

Siendo:

Tcol out $_{(\mathrm{i})}$ : Temperatura inicial del intervalo simulado en el colector, la temperatura de salida final del intervalo anterior

Tcol out $_{(\mathrm{i}+1)}$ : Temperatura de salida al final del intervalo simulado en el colector

El resto de variables también son evaluadas en el instante de tiempo $i$, de manera que conocidas las variables en un instante dado, la única incógnita es la temperatura del colector en el instante siguiente.

Se puede consultar el código implementado para la simulación del comportamiento del colector en el apartado 4 del anexo $\mathrm{C}$.

\section{VII.3.1.3.- DEPÓSITO DE ACUMULACIÓN.}

Para los casos de estudio de demanda no instantánea, va a ser necesario realizar el modelo del depósito de acumulación.

El comportamiento del depósito se estudia a través del planteamiento de un balance de energía en el mismo. A continuación se plantea la ecuación que representa el balance de energía, considerando una temperatura uniforme en todo el depósito, un depósito perfectamente mezclado.

$$
\mathrm{M}_{\mathrm{dep}} \cdot \mathrm{c}_{\mathrm{pw}} \cdot \frac{\mathrm{dT}_{\mathrm{dep}}}{\mathrm{dt}}=\dot{\mathrm{m}}_{\mathrm{w}} \cdot \mathrm{c}_{\mathrm{pw}} \cdot\left(\mathrm{T}_{\text {out_bat }}-\mathrm{T}_{\mathrm{dep}}\right)
$$

Siendo:

M: masa de agua en el depósito

$d T / d t=$ Variación de la temperatura de la masa de agua del interior del depósito en función del tiempo

La integración de esta ecuación diferencial, suponiendo constantes las temperaturas y el caudal de agua durante el intervalo de simulación, $\Delta t$, conduce a la siguiente ecuación:

$$
M_{\text {dep }} \cdot \mathrm{c}_{\mathrm{pw}} \cdot \frac{\mathrm{T}_{\mathrm{dep}(\mathrm{i}+1)}-\mathrm{T}_{\mathrm{dep} \_\mathrm{i}}}{\Delta \mathrm{t}}=\dot{\mathrm{m}}_{\mathrm{w}} \cdot \mathrm{c}_{\mathrm{pw}} \cdot\left(\mathrm{T}_{\text {out_bat_i }}-\mathrm{T}_{\mathrm{dep}_{-} \mathrm{i}}\right)
$$


Siendo:

$\mathrm{T}_{\mathrm{dep}(\mathrm{i}+1)}$ : Temperatura en el depósito al final del intervalo simulado

$\mathrm{T}_{\text {dep_i }_{i}}$ : Temperatura inicial del intervalo simulado, la final del intervalo anterior

$\mathrm{T}_{\text {out_bat_i }}:$ Temperatura del agua a la salida de la batería en el intervalo anterior.

Un parámetro de interés en el estudio del funcionamiento de la instalación es la evolución de la temperatura del agua en el depósito. Esta temperatura va a ser determinante a la hora de estudiar la fracción de la demanda cubierta por la instalación solar en las primeras horas de la mañana, cuando aún no sería efectiva la radiación incidente.

Para ello se considera que la demanda a primera hora de la mañana es cubierta con el agua caliente acumulada en el depósito al finalizar el día anterior, teniendo en cuenta las pérdidas que se producen desde la finalización del aporte de energía (considerada a las 22 horas) y el inicio hipotético de la demanda de ACS (a las 8 horas de la mañana).

El cálculo de la temperatura del depósito a las 8 de la mañana se realiza resolviendo la siguiente ecuación:

$$
\mathrm{M} \cdot \mathrm{c}_{\mathrm{p}} \frac{\mathrm{dT}_{\mathrm{dep}}}{\mathrm{dt}}=-\mathrm{U} \cdot\left(\mathrm{T}_{\mathrm{dep}}-\mathrm{T}_{\mathrm{sala}}\right)
$$

Resolvemos:

$$
\begin{aligned}
& \int_{t_{i}}^{t_{f}} \frac{d T_{\text {dep }}}{T_{d e p}-T_{\text {sala }}}=\int_{t_{i}}^{t_{f}}-\frac{U}{M c_{p w}} d t \\
& \left.\operatorname{Ln}\left(T_{\text {dep }}-T_{\text {sala }}\right)\right]_{t_{i}}^{t_{f}}=-\frac{U}{M c_{p w}}\left(t_{\text {fin }}-t_{\text {ini }}\right)
\end{aligned}
$$

Quedando:

$\mathrm{T}_{\text {dep_fin }_{-}}=\mathrm{T}_{\text {sala }}+\left(\mathrm{T}_{\text {dep_ini }}-\mathrm{T}_{\text {sala }}\right) \exp \left[-\frac{\mathrm{U}}{M c_{\mathrm{p}}}\left(\mathrm{t}_{\mathrm{fin}}-\mathrm{t}_{\text {ini }}\right)\right]$

Se considera tiempo de cálculo:

$$
\begin{gathered}
t_{\text {fin }}=8 \mathrm{~h} \\
\mathrm{t}_{\text {ini }}=22 \mathrm{~h} \\
\mathrm{t}_{\text {fin }}-\mathrm{t}_{\text {ini }}=10 \mathrm{~h}
\end{gathered}
$$

La temperatura de la sala se considera constante e igual a $15^{\circ} \mathrm{C}$. 
Para la estimación de $U$ se ha empleado la siguiente ecuación:

$$
\mathrm{U}_{\text {int }}=\frac{1}{\frac{1}{\mathrm{~h}_{\text {int }}}+\mathrm{A}_{\text {int }} \frac{\operatorname{Ln}\left({ }^{\mathrm{r}} \mathrm{ext} / \mathrm{r}_{\text {int }}\right)}{2 \pi \mathrm{kL}}+\frac{\mathrm{A}_{\text {int }}}{\mathrm{A}_{\text {ext }} \mathrm{h}_{\text {ext }}}}
$$

Considerando el caso más desfavorable, es decir, una masa del depósito de $500 \mathrm{~kg}$ y un espesor de aislante de dos centímetros, el valor utilizado es $U A=1,5 \mathrm{~W} / \mathrm{K}$

\section{VII.3.2.- CONDICIONES DE OPERACIÓN.}

Las condiciones de operación a determinar para simular el comportamiento del sistema son: parámetros climáticos, incluyendo la temperatura de agua de red y demanda de ACS.

\section{VII.3.2.1.- CONDICIONES CLIMÁTICAS.}

Se ha estudiado el funcionamiento del sistema de captadores-batería operando en condiciones climáticas de Valladolid (zona climática D2 según CTE DB HE [N-1]) en verano, correspondiente a 5 meses: de mayo a septiembre. Por simplicidad, se ha realizado el estudio de la demanda para un día tipo de cada mes. Los datos climáticos requeridos para el modelado son la temperatura seca exterior y la irradiación sobre superficie horizontal. Estos datos se han extraído de los archivos de datos climáticos de las zonas establecidas en el CTE [29] disponibles en la página web del mismo [W-1] 
Tabla VII.2.- Evolución de las temperaturas y de la irradiación sobre superficie horizontal durante un día tipo de los meses estivales en Valladolid [29].

\begin{tabular}{|c|c|c|c|c|c|c|c|c|c|c|}
\hline \multirow{3}{*}{ HORA } & \multicolumn{10}{|c|}{ MES } \\
\hline & \multicolumn{2}{|c|}{ MAYO } & \multicolumn{2}{|c|}{ JUNIO } & \multicolumn{2}{|c|}{ JULIO } & \multicolumn{2}{|c|}{ AGOSTO } & \multicolumn{2}{|c|}{ SEPTIEMBRE } \\
\hline & Text & I hztal & Text & I hztal & Text & I hztal & Text & I hztal & Text & I hztal \\
\hline 1 & 17 & & 18,5 & & 20 & & 21 & & 20 & \\
\hline 2 & 16 & & 17,5 & & 19 & & 20 & & 19 & \\
\hline 3 & 15,5 & & 17 & & 18,5 & & 19 & & 18 & \\
\hline 4 & 15 & & 16,5 & & 18 & & 18,5 & & 17,5 & \\
\hline 5 & 15 & & 16,5 & 30 & 18 & 10 & 18 & & 17 & \\
\hline 6 & 15,5 & & 17,5 & 200 & 18,5 & 180 & 18,5 & 90 & 16,5 & \\
\hline 7 & 17 & 130 & 19 & 390 & 20 & 340 & 19,5 & 280 & 17,5 & 130 \\
\hline 8 & 19 & 310 & 21 & 560 & 22 & 520 & 21 & 320 & 19 & 310 \\
\hline 9 & 21,5 & 490 & 23,5 & 710 & 24,5 & 700 & 23,5 & 490 & 21,5 & 490 \\
\hline 10 & 24 & 620 & 26 & 840 & 27 & 800 & 26,5 & 620 & 24 & 620 \\
\hline 11 & 26 & 700 & 28 & 910 & 29,5 & 900 & 29 & 700 & 27 & 700 \\
\hline 12 & 28 & 740 & 30 & 930 & 31,5 & 910 & 31,5 & 730 & 29,5 & 740 \\
\hline 13 & 29,5 & 700 & 31 & 910 & 32,5 & 900 & 32,5 & 700 & 31,5 & 700 \\
\hline 14 & 30 & 620 & 31,5 & 840 & 33 & 800 & 33 & 620 & 32 & 620 \\
\hline 15 & 29,5 & 490 & 31,5 & 710 & 32,5 & 700 & 33 & 490 & 31,5 & 490 \\
\hline 16 & 29 & 310 & 31 & 560 & 32 & 520 & 32,5 & 320 & 31 & 310 \\
\hline 17 & 28,5 & 130 & 30 & 390 & 31,5 & 340 & 32 & 280 & 30,5 & 130 \\
\hline 18 & 27 & & 29 & 200 & 30,5 & 180 & 31 & 90 & 29,5 & \\
\hline 19 & 26 & & 28 & 30 & 29 & 10 & 30 & & 28,5 & \\
\hline 20 & 24,5 & & 26 & & 27,5 & & 28 & & 27 & \\
\hline 21 & 23 & & 24,5 & & 26 & & 26,5 & & 26 & \\
\hline 22 & 21 & & 23 & & 24,5 & & 25 & & 24,5 & \\
\hline 23 & 20 & & 21,5 & & 22,5 & & 23,5 & & 22,5 & \\
\hline 24 & 18 & & 20 & & 21,5 & & 22 & & 21,5 & \\
\hline
\end{tabular}

De estos datos podemos obtener, por regresión polinómica, unas funciones de evolución de la temperatura y de la irradiación solar incidente sobre superficie horizontal con la hora solar. Se ha comprobado que un polinomio de orden 4 resulta adecuado para simular la evolución de la irradiación y uno de orden 5 para la evolución de la temperatura exterior. Estos coeficientes se encuentran recopilados en la Tabla VII.3: 
Tabla VII.3.-Coeficientes de las regresiones polinómicas para la evolución diaria de temperatura e irradiación sobre superficie horizontal.

\begin{tabular}{|l|r|r|r|r|r|r|r|r|r|r|}
\cline { 2 - 11 } \multicolumn{1}{c|}{} & \multicolumn{2}{|c|}{ MAYO } & \multicolumn{2}{c|}{ JUNIO } & \multicolumn{2}{c|}{ JULIO } & \multicolumn{2}{c|}{ AGOSTO } & \multicolumn{2}{c|}{ SEPTIEMBRE } \\
\hline & Text & I hztal & Text & I hztal & Text & I hztal & Text & I hztal & Text & I hztal \\
\cline { 2 - 11 } & {$\left[{ }^{\circ} \mathrm{C}\right]$} & {$\left[\mathrm{kW} / \mathrm{m}^{2}\right]$} & {$\left[{ }^{\circ} \mathrm{C}\right]$} & {$\left[\mathrm{kW} / \mathrm{m}^{2}\right]$} & {$\left[{ }^{\circ} \mathrm{C}\right]$} & {$\left[\mathrm{kW} / \mathrm{m}^{2}\right]$} & {$\left[{ }^{\circ} \mathrm{C}\right]$} & {$\left[\mathrm{kW} / \mathrm{m}^{2}\right]$} & {$\left[{ }^{\circ} \mathrm{C}\right]$} & {$\left[\mathrm{kW} / \mathrm{m}^{2}\right]$} \\
\hline $\mathbf{c 5}$ & $3,14 \mathrm{E}-05$ & & $2,77 \mathrm{E}-05$ & & $3,26 \mathrm{E}-05$ & & $5,06 \mathrm{E}-05$ & & $6,41 \mathrm{E}-05$ & \\
\hline $\mathbf{c 4}$ & $-0,001$ & 0,2214 & $-0,0008$ & 0,1459 & $-0,001$ & 0,181 & $-0,0022$ & 0,2662 & $-0,0031$ & 0,2214 \\
\hline $\mathbf{c 3}$ & $-0,0125$ & $-10,6294$ & $-0,0183$ & $-7,0051$ & $-0,0124$ & $-8,6873$ & 0,0126 & $-12,7766$ & 0,0322 & $-10,6294$ \\
\hline $\mathbf{c 2}$ & 0,5945 & 161,5501 & 0,646 & 100,4843 & 0,6022 & 129,0505 & 0,3983 & 203,4442 & 0,2213 & 161,5501 \\
\hline $\mathbf{c 1}$ & $-3,713$ & $-815,9441$ & $-3,8134$ & $-394,145$ & $-3,7632$ & $-595,255$ & $-3,4035$ & $-1202,9905$ & $-2,9446$ & $-815,9441$ \\
\hline $\mathbf{c 0}$ & 20,8151 & 1038,5082 & 22,3254 & 273,0172 & 23,8747 & 736,4292 & 24,7229 & 2417,536 & 23,4613 & 1038,5082 \\
\hline
\end{tabular}

En relación a los datos de irradiancia horizontal, hay que destacar que los datos se corresponden con un día tipo de cada mes considerando únicamente la trayectoria solar (sin nubosidad, aerosoles, etc.). Los resultados obtenidos son representativos, por lo tanto, de ese día tipo.

Por otro lado, para determinar la irradiación sobre la superficie del captador es necesario corregir estos valores en función de su inclinación. La inclinación seleccionada para los captadores situados en Valladolid es la inclinación de $42^{\circ}$ respecto a la horizontal. El factor de corrección por inclinación en este caso es, para los meses de estudio, el indicado en la tabla VII.4:

Tabla VII.4.- Factores de corrección de la irradiación por inclinación de $42^{\circ}$ en Valladolid.

\begin{tabular}{|l|c|c|c|c|c|}
\hline & MAYO & JUNIO & JULIO & AGOSTO & SEPTIEMBRE \\
\hline $\mathrm{f}$ & 0,958 & 0,924 & 0,958 & 1,068 & 1,236 \\
\hline
\end{tabular}

Adicionalmente, para la simulación del sistema en las condiciones esperables de funcionamiento en Valladolid, será necesario conocer la temperatura del agua de red en esta localidad durante los meses de estudio (tabla VII.5).

Tabla VII.5.- Temperatura del agua de red en Valladolid.

\begin{tabular}{|l|c|c|c|c|c|}
\hline & MAYO & JUNIO & JULIO & AGOSTO & SEPTIEMBRE \\
\hline Tred $\left[{ }^{\circ} \mathrm{C}\right]$ & 11,00 & 12,00 & 13,00 & 12,00 & 11,00 \\
\hline
\end{tabular}




\section{VII.3.2.2.- DEMANDA DE ACS.}

También es necesario determinar la demanda de ACS esperada. Suponiendo que la superficie de captación de $4 \mathrm{~m}^{2}$ permite abastecer a una vivienda unifamiliar con 4 ocupantes. Conforme a lo especificado en el CTE [N-1], el consumo de ACS, a $60^{\circ} \mathrm{C}$, debe establecerse en $30 \mathrm{l} /$ persona/día. Según este criterio se considera un valor de caudal de 40 l/persona/día (160 l/día).

Es previsible que este consumo no sea continuo, sino que por el contrario se ajuste a los hábitos de los ocupantes de la vivienda. Se considera así un patrón de consumo repartido en tres picos de demanda a lo largo del día: de 8:00 a 9:00, de 15:00 a 15:30 y de 21:00 a 21:30 horas, requiriéndose por lo tanto en cada período una demanda de 1,33 l/min.

Las simulaciones llevadas a cabo han permitido observar que en determinadas circunstancias la temperatura del agua acumulada en el depósito supera los $60^{\circ} \mathrm{C}$ (temperatura de agua establecida para la distribución a usuarios). Cuando se da esta circunstancia, para conseguir las condiciones de operación y evitar que el agua suministrada supere la temperatura fijada, se lleva a cabo una mezcla de esta agua sobrecalentada con agua de red. Como se puede observar en las figuras VII.3 y VII.4 ambas configuraciones cuentan con esta mezcla en la conexión entre ambos depósitos de acumulación. Por lo tanto, en este caso, el caudal de agua extraído del depósito de acumulación 1 no coincidirá con el caudal demandado (este caudal extraído es menor al demandado ya que se mezcla con agua de red). El cálculo del caudal extraído del depósito 1 ( $\left.\dot{m}_{\text {real }}\right)$ se llevará a cabo de acuerdo al planteamiento establecido en la figura VII.5 y desarrollado a continuación:

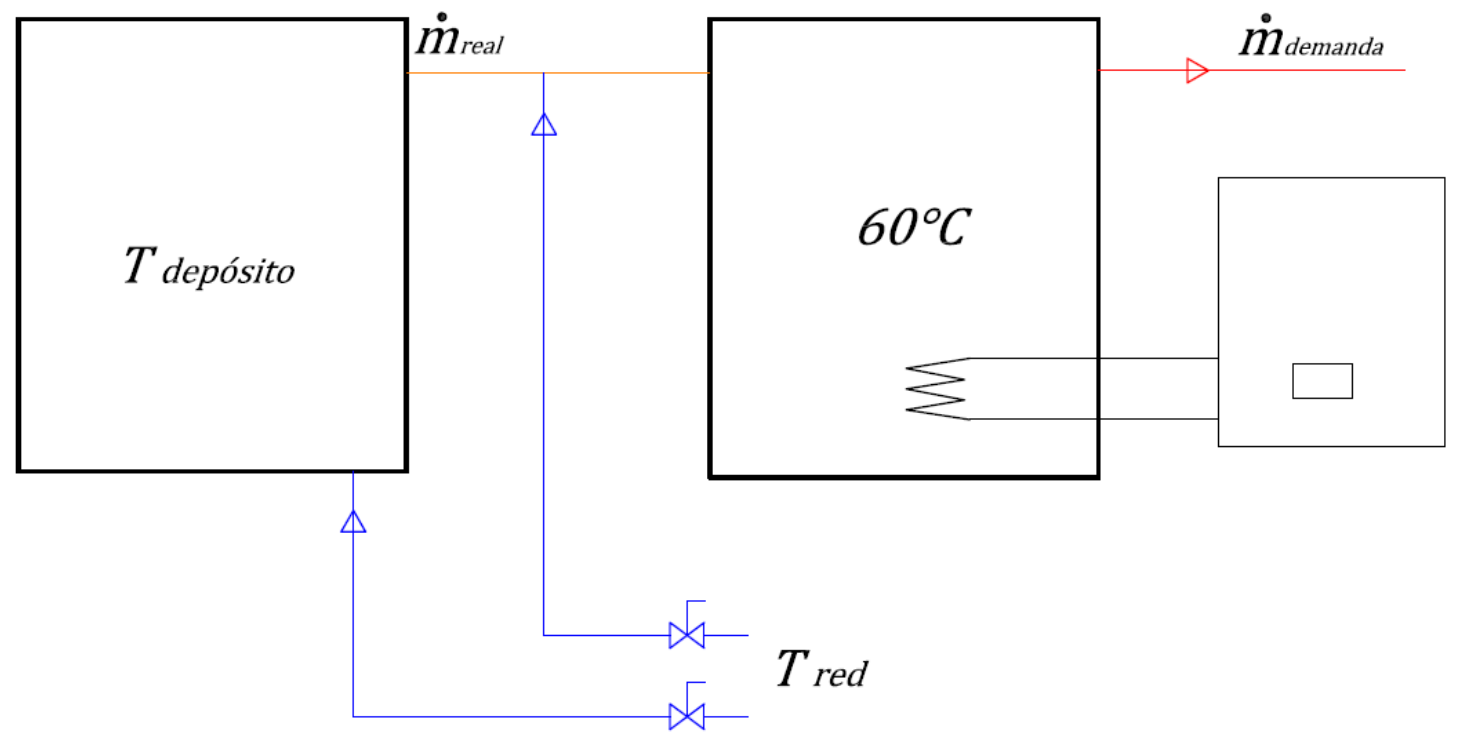

Figura VII.5.- Esquema para el cálculo de ACS en ambas configuraciones. 
Si $T_{\text {dep }}<60^{\circ} \mathrm{C}$ :

$$
\begin{aligned}
& \dot{\mathrm{m}}_{\text {real }} \mathrm{c}_{\mathrm{pw}}\left(60-\mathrm{T}_{\mathrm{dep}}\right)=\mathrm{Q}_{\text {consumo }} \\
& \dot{\mathrm{m}}_{\text {real }}=\dot{\mathrm{m}}_{\text {dem }}
\end{aligned}
$$

Si $T_{d e p}>60^{\circ} \mathrm{C}$ :

$$
\begin{aligned}
& \dot{\mathrm{m}}_{\text {real }} \mathrm{c}_{\mathrm{pw}} \mathrm{T}_{\mathrm{dep}}+\left(\dot{\mathrm{m}}_{\mathrm{dem}}-\dot{\mathrm{m}}_{\text {real }}\right) \mathrm{c}_{\mathrm{pw}} \mathrm{T}_{\text {red }}=\dot{\mathrm{m}}_{\mathrm{dem}} \mathrm{c}_{\mathrm{pw}} 60 \\
& \dot{\mathrm{m}}_{\text {real }}=\dot{\mathrm{m}}_{\mathrm{dem}} \frac{60-\mathrm{T}_{\mathrm{red}}}{\mathrm{T}_{\mathrm{dep}}-\mathrm{T}_{\text {red }}}
\end{aligned}
$$

\section{VII.3.3.- AHORROS DE ENERGÍA.}

Los ahorros de energía obtenidos se calculan a partir de la diferencia entre la energía demandada por el sistema para cubrir la demanda de ACS y la energía requerida por el sistema convencional de apoyo (ecuación E-VII.42). Esta relación depende de la temperatura del agua de red y de la temperatura alcanzada en el depósito.

Ahorros $=\dot{\mathrm{m}}_{\mathrm{dem}} \mathrm{c}_{\mathrm{pw}}\left(60-\mathrm{T}_{\text {red }}\right)-\dot{\mathrm{m}} \mathrm{c}_{\mathrm{pw}}\left(60-T_{\text {dep }}\right)$

Tal y como se considera en las condiciones de operación el apartado anterior, se dan dos posibilidades en cuanto a la temperatura alcanzada en el depósito:

a) Que el depósito alcance o supere los $60^{\circ} \mathrm{C}$, por lo que no necesita sistema auxiliar convencional para operar. Entonces, el caudal suministrado desde el depósito será menor al demandado y a una temperatura más alta, este caudal extraído del depósito se puede calcular según la ecuación E-VII.41. El ahorro obtenido en este caso sería (E-VII.43):

$$
\text { Ahorro }=\dot{m}_{d e m} c_{p w}\left(60-T_{\text {red }}\right)
$$

b) Que el agua del depósito no alcance la temperatura establecida, los $60^{\circ} \mathrm{C}$, entonces el sistema auxiliar convencional tendrá que calentar el agua desde la temperatura alcanzada en el depósito de acumulación 1 hasta los $60^{\circ} \mathrm{C}$ a los que se debe de encontrar el agua en el depósito 2. Ahora el caudal extraído del depósito 1 es el caudal demandado, a una temperatura inferior a $60^{\circ} \mathrm{C}$ (a la que se encuentra el agua en el depósito 1). En este caso el ahorro obtenido sería (E-VII.44):

$$
\text { Ahorro }=\dot{\mathrm{m}}_{\mathrm{dem}} \mathrm{c}_{\mathrm{pw}}\left(\mathrm{T}_{\mathrm{dep}}-\mathrm{T}_{\mathrm{red}}\right)
$$




\section{VIl.4.- RESULTADOS Y DISCUSIÓN.}

En el apartado VII.2 se han presentado los inconvenientes o desventajas que presentan las diferentes posibilidades de configuración del sistema de CTS para la producción de ACS. En base a lo descrito, se han descartado las opciones de generación instantánea y acumulación con un único depósito de acumulación, centrando el estudio en las dos configuraciones con dos depósitos de acumulación.

La presentación de los resultados se hace en base a los ahorros obtenidos por la operación con estas dos configuraciones y según lo establecido en el apartado anterior VII.3.2.

De la implementación en Excel de estos modelos se han obtenido los siguientes resultados.

\section{VII.4.1.- FUNCIONAMIENTO CON DOS ACUMULADORES.}

Los resultados de los ahorros de energía obtenidos y los porcentajes de la demanda de ACS cubierta con ambas configuraciones se presentan en las tablas VII.6, VII.7 y VII.8.

La tabla VII.6 presenta los resultados de ambas configuraciones empleando un depósito de acumulación de 100 litros, para los tres caudales de aire de paso por colectores establecidos:

Tabla VII.6.- Ahorros conseguidos durante los días típicos de cada mes de verano para un depósito de 100 litros.

\begin{tabular}{|c|c|c|c|c|c|c|c|}
\hline \multirow{2}{*}{\multicolumn{2}{|c|}{$\begin{array}{l}\text { VOLUMEN DEL } \\
\text { DEPÓSITO: } 100 \mathrm{~L}\end{array}$}} & \multicolumn{2}{|c|}{ Caudal de aire $\left(\mathrm{m}^{3} / \mathrm{h}\right)$} & \multicolumn{2}{|c|}{ Caudal de aire $\left(m^{3} / h\right)$} & \multicolumn{2}{|c|}{ Caudal de aire $\left(m^{3} / h\right)$} \\
\hline & & \multicolumn{2}{|c|}{100} & \multicolumn{2}{|c|}{200} & \multicolumn{2}{|c|}{300} \\
\hline \multicolumn{2}{|c|}{ AHORROS DE ENERGÍA } & Config.1 & Config. 2 & Config.1 & Config. 2 & Config.1 & Config. 2 \\
\hline \multirow{2}{*}{ Mayo } & (kWh/día) & 5,22 & 5,64 & 5,81 & 6,23 & 5,90 & 6,30 \\
\hline & (\%) & $57 \%$ & $62 \%$ & $64 \%$ & $68 \%$ & $65 \%$ & $69 \%$ \\
\hline \multirow{2}{*}{ Junio } & (kWh/día) & 6,73 & 7,12 & 7,13 & 7,51 & 7,10 & 7,45 \\
\hline & $(\%)$ & $75 \%$ & $80 \%$ & $80 \%$ & $84 \%$ & $80 \%$ & $84 \%$ \\
\hline \multirow{2}{*}{ Julio } & (kWh/día) & 6,98 & 7,29 & 7,44 & 7,69 & 7,43 & 7,64 \\
\hline & $(\%)$ & $77 \%$ & $80 \%$ & $82 \%$ & $85 \%$ & $82 \%$ & $84 \%$ \\
\hline \multirow{2}{*}{ Agosto } & (kWh/día) & 5,94 & 6,38 & 6,45 & 6,83 & 6,49 & 6,84 \\
\hline & $(\%)$ & $67 \%$ & $72 \%$ & $72 \%$ & $77 \%$ & $73 \%$ & $77 \%$ \\
\hline \multirow{2}{*}{ Septiembre } & (kWh/día) & 6,37 & 6,74 & 6,80 & 7,16 & 6,82 & 7,15 \\
\hline & $(\%)$ & $73 \%$ & $77 \%$ & $78 \%$ & $82 \%$ & $78 \%$ & $82 \%$ \\
\hline
\end{tabular}

Se puede observar que la configuración que obtiene mejores resultados es la configuración 2 (en la que el agua de entrada a la batería es la mezcla del agua del depósito y el agua de red). El 
comportamiento de ambas configuraciones sigue una misma tendencia, los aportes de energía en ambas configuraciones aumentan o disminuyen en la misma proporción de un mes a otro. Los ahorros con este depósito de 100 litros llegan al $85 \%$ en la configuración 2, y al $82 \%$ en la configuración 1, ambos para el mes de julio con un caudal de aire por colectores de $200 \mathrm{~m}^{3} / \mathrm{h}$. Los resultados para las diferentes opciones de caudal de aire de paso por colectores son muy similares, para 200 y $300 \mathrm{~m}^{3} / \mathrm{h}$ los resultados son iguales, mejorando ambos significativamente los obtenidos para $100 \mathrm{~m}^{3} / \mathrm{h}$.

La tabla VII.7 presenta los resultados de ambas configuraciones empleando un depósito de acumulación de 200 litros, para los tres caudales de aire de paso por colectores establecidos:

Tabla VII.7.- Ahorros conseguidos durante los días típicos de cada mes de verano para un depósito de 300 litros.

\begin{tabular}{|c|c|c|c|c|c|c|c|}
\hline \multirow{2}{*}{\multicolumn{2}{|c|}{$\begin{array}{l}\text { VOLUMEN DEL } \\
\text { DEPÓSITO: } 300 \mathrm{~L}\end{array}$}} & \multicolumn{2}{|c|}{ Caudal de aire $\left(m^{3} / h\right)$} & \multicolumn{2}{|c|}{ Caudal de aire $\left(\mathrm{m}^{3} / \mathrm{h}\right)$} & \multicolumn{2}{|c|}{ Caudal de aire $\left(m^{3} / h\right)$} \\
\hline & & \multicolumn{2}{|c|}{100} & \multicolumn{2}{|c|}{200} & \multicolumn{2}{|c|}{300} \\
\hline \multicolumn{2}{|c|}{ AHORROS DE ENERGÍA } & Config.1 & Config. 2 & Config.1 & Config. 2 & Config.1 & Config. 2 \\
\hline \multirow{2}{*}{ Mayo } & (kWh/día) & 3,48 & 3,62 & 4,01 & 4,17 & 4,31 & 4,49 \\
\hline & $(\%)$ & $38 \%$ & $38 \%$ & $44 \%$ & $46 \%$ & $47 \%$ & $49 \%$ \\
\hline \multirow{2}{*}{ Junio } & (kWh/día) & 4,72 & 4,94 & 5,39 & 5,63 & 5,73 & 5,73 \\
\hline & $(\%)$ & $53 \%$ & $55 \%$ & $60 \%$ & $63 \%$ & $64 \%$ & $64 \%$ \\
\hline \multirow{2}{*}{ Julio } & (kWh/día) & 4,81 & 5,15 & 5,47 & 5,85 & 5,82 & 5,82 \\
\hline & $(\%)$ & $53 \%$ & $57 \%$ & $60 \%$ & $64 \%$ & $64 \%$ & $64 \%$ \\
\hline \multirow{2}{*}{ Agosto } & (kWh/día) & 3,98 & 4,17 & 4,58 & 4,79 & 4,92 & 4,92 \\
\hline & $(\%)$ & $45 \%$ & $47 \%$ & $51 \%$ & $54 \%$ & $55 \%$ & $55 \%$ \\
\hline \multirow{2}{*}{ Septiembre } & (kWh/día) & 4,26 & 4,44 & 4,89 & 5,10 & 5,24 & 5,24 \\
\hline & $(\%)$ & $49 \%$ & $51 \%$ & $56 \%$ & $58 \%$ & $60 \%$ & $60 \%$ \\
\hline
\end{tabular}

En estos resultados se observa que los ahorros o la energía aportada por el sistema es ligeramente mayor en la configuración 2 que en la 1. A medida que aumenta el caudal de aire por colectores el ahorro obtenido en ambas configuraciones se equipara, obteniendo el mismo en ambas configuraciones para el caudal de $300 \mathrm{~m}^{3} / \mathrm{h}$. La tendencia de aumento o reducción de energía aportada a lo largo de los meses estudiados en ambas configuraciones presenta diferencias en los meses centrales. En este caso, los mayores ahorros obtenidos son del $64 \%$ en ambas configuraciones para el mayor caudal de aire en el mes de julio. 
La tabla VII.8 muestra los resultados de ambas configuraciones empleando un depósito de acumulación de 500 litros:

Tabla VII.8.- Ahorros conseguidos durante los días típicos de cada mes de verano para un depósito de 500 litros.

\begin{tabular}{|c|c|c|c|c|c|c|c|}
\hline \multirow{2}{*}{\multicolumn{2}{|c|}{$\begin{array}{l}\text { VOLUMEN DEL } \\
\text { DEPÓSITO: } 500 \mathrm{~L}\end{array}$}} & \multirow{2}{*}{\multicolumn{2}{|c|}{$\begin{array}{c}\text { Caudal de aire }\left(\mathrm{m}^{3} / \mathrm{h}\right) \\
100\end{array}$}} & \multirow{2}{*}{\multicolumn{2}{|c|}{$\begin{array}{c}\text { Caudal de aire }\left(\mathrm{m}^{3} / \mathrm{h}\right) \\
200\end{array}$}} & \multirow{2}{*}{\multicolumn{2}{|c|}{$\begin{array}{c}\text { Caudal de aire }\left(\mathrm{m}^{3} / \mathrm{h}\right) \\
300\end{array}$}} \\
\hline & & & & & & & \\
\hline \multicolumn{2}{|c|}{ AHORROS DE ENERGÍA } & Config. 1 & Config. 2 & Config. 1 & Config. 2 & Config. 1 & Config. 2 \\
\hline \multirow{2}{*}{ Mayo } & (kWh/día) & 2,45 & 2,54 & 2,84 & 2,94 & 3,11 & 3,21 \\
\hline & (\%) & $27 \%$ & $28 \%$ & $31 \%$ & $32 \%$ & $34 \%$ & $35 \%$ \\
\hline \multirow{2}{*}{ Junio } & (kWh/día) & 3,30 & 3,42 & 3,80 & 3,94 & 4,12 & 4,26 \\
\hline & $(\%)$ & $37 \%$ & $38 \%$ & $43 \%$ & $44 \%$ & $46 \%$ & $48 \%$ \\
\hline \multirow{2}{*}{ Julio } & (kWh/día) & 3,41 & 3,62 & 3,90 & 4,15 & 4,22 & 4,48 \\
\hline & $(\%)$ & $37 \%$ & $40 \%$ & $43 \%$ & $46 \%$ & $46 \%$ & $49 \%$ \\
\hline \multirow{2}{*}{ Agosto } & (kWh/día) & 2,81 & 2,94 & 3,26 & 3,41 & 3,53 & 3,66 \\
\hline & $(\%)$ & $32 \%$ & $33 \%$ & $37 \%$ & $38 \%$ & $40 \%$ & $41 \%$ \\
\hline \multirow{2}{*}{ Septiembre } & (kWh/día) & 2,89 & 3,00 & 3,36 & 3,48 & 3,67 & 3,80 \\
\hline & $(\%)$ & $33 \%$ & $34 \%$ & $38 \%$ & $40 \%$ & $42 \%$ & $43 \%$ \\
\hline
\end{tabular}

En esta tercera opción contemplada, para acumulación de 500 litros de agua en el depósito, los resultados obtenidos para la configuración 2 también son ligeramente mejores que los de la configuración 1. El aumento de caudal de aire de paso por colectores permite un significativo aumento de energía aportada en ambas configuraciones. En este caso, la tendencia temporal para los días tipo de los meses estudiados no sigue un desarrollo igual en ambas configuraciones, haciéndose más perceptible en los meses centrales estudiados. Para esta opción, los máximos ahorros obtenidos son del $49 \%$ para la configuración 2 con $300 \mathrm{~m}^{3} / \mathrm{h}$ de caudal de aire, y del $46 \%$ para la configuración 1 con ese mismo caudal de aire.

Del estudio de los resultados para las diferentes combinaciones estudiadas, se puede concluir que la configuración 2, que incorpora el agua al intercambiador como mezcla de agua de red y de agua del depósito, obtiene mejores rendimientos que la configuración 1 en todas las circunstancias. Esto es debido a que la configuración 2 permite que la temperatura del agua a la entrada el intercambiador sea más baja, mejorando la transferencia de calor en el mismo. Al comparar los ahorros en ambas configuraciones, los valores se aproximan entre ambas al aumentar el tamaño del depósito de acumulación, ya que la temperatura alcanzada por el agua al aumentar el volumen del depósito es más baja. 
Como era de prever, los ahorros obtenidos son mayores cuando las condiciones climáticas son más severas, siendo el día tipo de julio considerado el que mejores resultados obtiene en ambas configuraciones. El incremento del ahorro de energía entre el mes con mayor severidad (julio) y el más suave (mayo), considerando este incremento como la diferencia entre los valores de ahorro de energía para ambos meses, es más notable para depósitos pequeños, caudales de aire bajos y para la configuración 1 (aumenta de mayo a junio un 20\%). A medida que aumentamos la capacidad del depósito de acumulación, el incremento del ahorro entre estos meses se hace más notable en la configuración 2.

También, como era de esperar tras los resultados experimentales de caracterización de los CTS, al aumentar el caudal de aire de paso por los CTS, el ahorro obtenido en el sistema propuesto también se ve incrementado.

Si nos centramos en el tamaño del depósito de acumulación, se puede concluir que al aumentar el volumen de agua acumulado en el depósito los ahorros se ven sustancialmente disminuidos. El ahorro de energía puede llegar al $85 \%$ en el caso más favorable, considerando un depósito de 100 litros de capacidad. Mientras que para el mayor volumen de depósito considerado, 500 litros, los ahorros no llegan al $50 \%$. Esto es debido a que con menor cantidad de agua acumulada el sistema es capaz de conseguir elevar más la temperatura. En cambio, temperaturas más bajas del agua en el depósito conlleva que el salto térmico en el intercambiador sea mayor, mejorando la transferencia de calor en el mismo. Para caudales de aire de paso por colectores bajos, los ahorros obtenidos para la opción de 500 litros son la mitad de los obtenidos para la opción de 100 litros. Al aumentar el caudal de aire esta diferencia se reduce ligeramente, pero aún alcanza el $40 \%$ en varios casos. A pesar de obtener mejores resultados de los esperados para el sistema equipado con el depósito de acumulación más grande, el hecho de no ser capaz de alcanzar la temperatura establecida para el ACS limitaría la capacidad de poder suministrar el caudal de ACS a las condiciones requeridas. Por lo tanto, la optimización del sistema se basa en la obtención del volumen mínimo de acumulación que garantice el suministro de los caudales pico de demanda durante el día.

\section{VII.4.2.- EVOLUCIÓN DE LA TEMPERATURA DEL AGUA EN EL DEPÓSITO.}

El modelo incorpora un código que permite mostrar la evolución dela temperatura del agua en el depósito en cada uno de los días típicos para los diferentes casos que se proponen.

En el anexo $\mathrm{C}$ se presentan todas las evoluciones para las diferentes combinaciones posibles de caudal de aire de paso por colector, de día tipo de cada mes y de capacidad de depósito estudiados. 
Las figuras VII.6, VII.7 muestran algunas de las evoluciones de la temperatura del agua obtenidas.

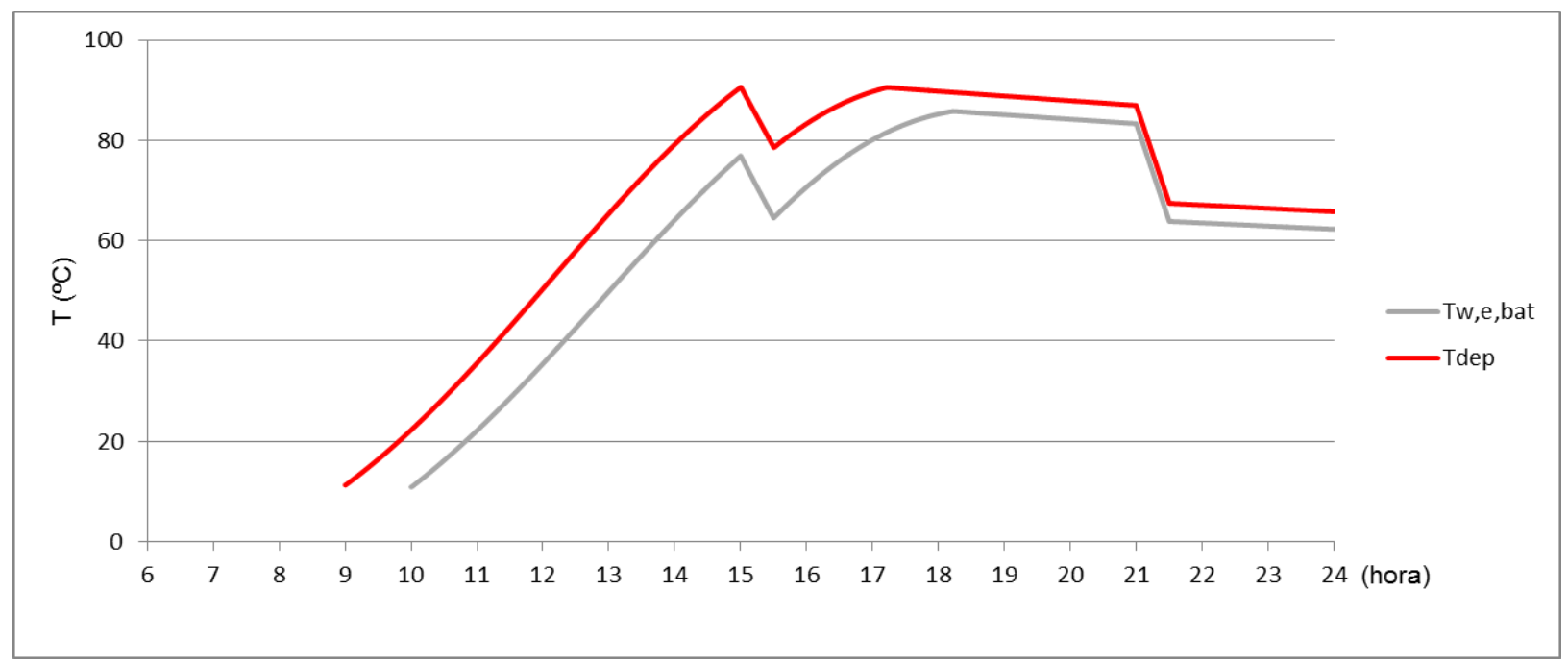

Figura VII.6.- Evolución de la temperatura del agua en el depósito para el día tipo de julio con un caudal de aire de paso por el colector de $300 \mathrm{~m}^{3} / \mathrm{h}$. Capacidad del depósito: 100 litros.

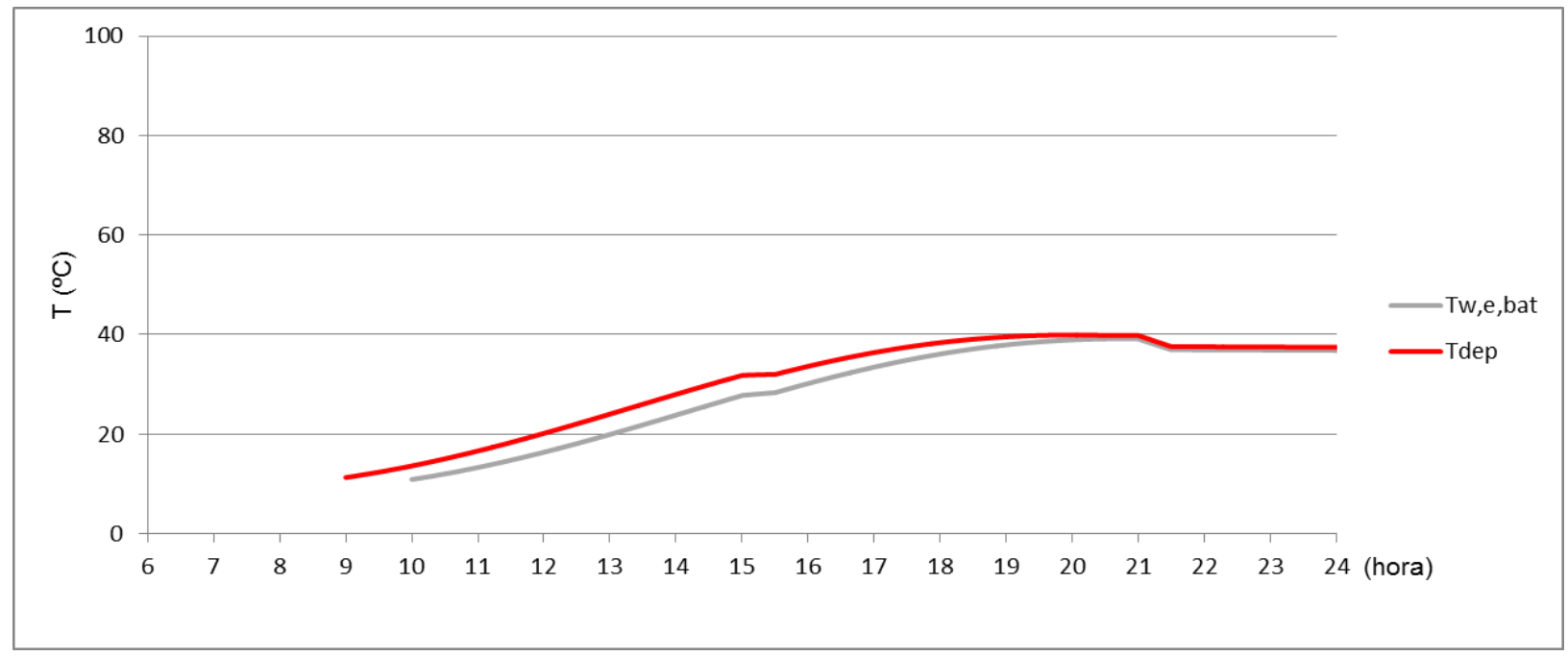

Figura VII.7.- Evolución de la temperatura del agua en el depósito para el día tipo de julio con un caudal de aire de paso por el colector de $300 \mathrm{~m}^{3} / \mathrm{h}$. Capacidad del depósito: 500 litros.

El gráfico de la figura VII.6 muestra cómo se superan los $60^{\circ} \mathrm{C}$ en el agua del depósito de acumulación con una capacidad de 100 litros durante gran parte del día para el día tipo de julio observado en esta figura. Por lo tanto, en este caso, el sistema sería capaz de suministrar parcialmente agua caliente durante los dos picos de demanda de las 15 PM y las 21 PM. En cambio, para el pico de demanda de las 9 horas, dependiendo del agua almacenada al final de la jornada anterior, el sistema auxiliar tendría que aportar la energía restante necesaria. 
En cambio, el gráfico de la figura VII.7 muestra que el sistema no es capaz de alcanzar los $60^{\circ} \mathrm{C}$ en ningún periodo del día, por lo que, aunque se consiguen ahorros energéticos, sería necesario el empleo del sistema de apoyo auxiliar para poder suministrar el agua a la temperatura establecida.

Estos resultados ponen de manifiesto lo ya concluido en base a los ahorros obtenidos en el apartado anterior, la obtención del volumen mínimo que permita el suministro del ACS necesario es fundamental para garantizar el alcance de la temperatura establecida con el mínimo aporte de energía del sistema auxiliar.

\section{VII.5.- CONCLUSIONES.}

La posibilidad de utilizar los CTS de aire en periodo estival eliminando así la estacionalidad y mejorando su rendimiento global, amplía la capacidad e interés de estos sistemas para su implementación en edificios. La alternativa aquí planteada para el uso de los CTS en verano para la generación de ACS permite importantes ahorros complementarios a los conseguidos por estos sistemas en los servicios de ventilación y calefacción en otros periodos.

Las simulaciones se han llevado a cabo para las condiciones climáticas de un día tipo de cada mes de verano en Valladolid, para la demanda de ACS de una vivienda unifamiliar ocupada por cuatro personas. El estudio previo acotó el estudio a dos de las alternativas planteadas para la generación de ACS, ambas alternativas relativas a la generación de ACS con un sistema de acumulación del agua en dos depósitos.

Los resultados obtenidos muestran que la opción que mejores resultados presenta, en términos de ahorro de energía, es la denominada configuración 2, en donde el agua de entrada al intercambiador es mezcla del agua del depósito 1 y de agua de red (en la configuración 1 el agua de entrada al intercambiador proviene únicamente del depósito). Además, la optimización del sistema se basa en el diseño de un depósito de acumulación del menor tamaño posible, los ahorros obtenidos para la opción de acumulación de 500 litros son la mitad de los obtenidos para la opción de 100 litros. En este diseño se tiene que tener en cuenta el garantizar los caudales de ACS demandados.

De las alternativas estudiadas, la que mejores resultados ha obtenido es la configuración 2, con el depósito de acumulación de menor capacidad (100 litros) y el mayor caudal de aire en colectores, $300 \mathrm{~m}^{3} / \mathrm{h}$.

La evolución de la temperatura alcanzada por el agua del depósito calentada con el sistema solar, permite afirmar que la opción del depósito de acumulación de 100 litros es capaz de cubrir los picos de demanda de ACS considerados. 
Los mejores resultados son los obtenidos para los meses con condiciones climáticas más severas, lo que aumenta el interés en ampliar el uso de los CTS a los meses de verano a través de estas alternativas. En este sentido, una simulación para todo el periodo estival daría una idea más precisa de los ahorros de energía alcanzables, permitiendo un mayor interés en el sistema. Además, la comparación en términos de análisis de ciclo de vida con instalaciones convencionales de solar térmica para ACS podría permitir comprobar la viabilidad de este tipo de tecnología. 


\section{REFERENCIAS}

[1] M.A. Wazed, Y. Nukman, M.T. Islam, Design and fabrication of a cost effective solar air heater for Bangladesh, Appl. Energy. 87 (2010) 3030-3036. doi:10.1016/j.apenergy.2010.02.014.

[2] X.Q. Zhai, Y.J. Dai, R.Z. Wang, Comparison of heating and natural ventilation in a solar house induced by two roof solar collectors, Appl. Therm. Eng. 25 (2005) 741-757. doi:10.1016/j.applthermaleng.2004.08.001.

[3] A. Saxena, Varun, A.A. El-Sebaii, A thermodynamic review of solar air heaters, Renew. Sustain. Energy Rev. 43 (2015) 863-890. doi:10.1016/j.rser.2014.11.059.

[4] H.D. Ammari, A mathematical model of thermal performance of a solar air heater with slats, Renew. Energy. 28 (2003) 1597-1615. doi:10.1016/S0960-1481(02)00253-7.

[5] J. Ma, W. Sun, J. Ji, Y. Zhang, A. Zhang, W. Fan, Experimental and theoretical study of the efficiency of a dual-function solar collector, Appl. Therm. Eng. 31 (2011) 1751-1756. doi:10.1016/j.applthermaleng.2011.02.019.

[6] W.F.M. Yusoff, A.R. Sapia, E. Salleh, N.M. Adam, Z. Hamzah, M.H.H. Mamat, Using computational fluid dynamics in the determination of solar collector orientation and stack height of a solar induced ventilation prototype, Pertanika J. Sci. Technol. 22 (2014) 273-288.

[7] W.F.M. Yusoff, E. Salleh, N.M. Adam, A.R. Sapian, M. Yusof Sulaiman, Enhancement of stack ventilation in hot and humid climate using a combination of roof solar collector and vertical stack, Build. Environ. 45 (2010) 2296-2308. doi:10.1016/j.buildenv.2010.04.018.

[8] J. Hirunlabh, S. Wachirapuwadon, N. Pratinthong, J. Khedari, New configurations of a roof solar collector maximizing natural ventilation, Build. Environ. 36 (2001) 383-391. doi:10.1016/S0360-1323(00)00016-0.

[9] J. Khedari, W. Mansirisub, S. Chaima, N. Pratinthong, J. Hirunlabh, Field measurements of performance of roof solar collector, Energy Build. 31 (2000) 171-178. doi:10.1016/S03787788(99)00003-1.

[10] X.Q. Zhai, Y.J. Dai, R.Z. Wang, Experimental investigation on air heating and natural ventilation of a solar air collector, Energy Build. 37 (2005) 373-381. doi:10.1016/j.enbuild.2004.07.006.

[11] S. Ubertini, U. Desideri, Design of a solar collector for year-round climatization, Renew. Energy. 28 (2003) 623-645. doi:10.1016/S0960-1481(02)00071-X.

[12] N. Fuschillo, Semi-transparent solar collector window systems, Sol. Energy. 17 (1975) 159165. doi:10.1016/0038-092X(75)90054-7.

[13] K. Visagavel, P.S.S. Srinivasan, Experimental investigation on solar air heater assisted natural ventilation in single-sided ventilated room, Indian J. Sci. Technol. 3 (2010) 802-806. doi:10.17485/ijst/2010/v3i7/29819.

[14] J. Ji, W. Wang, W. Sun, Z. Yu, Study of space heating by dual-function solar collectors, Chinese Sci. Bull. 59 (2014) 1890-1895. doi:10.1007/s11434-014-0217-6.

[15] J. Ji, C. Luo, T.T. Chow, W. Sun, W. He, Thermal characteristics of a building-integrated dualfunction solar collector in water heating mode with natural circulation, Energy. 36 (2011) 566- 
574. doi:10.1016/j.energy.2010.10.004.

[16] J. Ji, C.L. Luo, W. Sun, W. He, G. Pei, C.W. Han, A numerical and experimental study of a dual-function solar collector integrated with building in passive space heating mode, Chinese Sci. Bull. 55 (2010) 1568-1573. doi:10.1007/s11434-010-3117-4.

[17] R. Yoshie, A. Satake, A. Mochida, S. Kato, H. Yoshino, Energy conservation effect of new HVAC system for condominiums with solar collectors integrated with the balcony handrail, Energy Build. 38 (2006) 1360-1367. doi:10.1016/j.enbuild.2006.04.009.

[18] S. Budea, Solar air collectors for space heating and ventilation applications-performance and case studies under Romanian climatic conditions, Energies. 7 (2014) 3781-3792. doi:10.3390/en7063781.

[19] S. Chungloo, B. Limmeechokchai, Utilization of cool ceiling with roof solar chimney in Thailand: The experimental and numerical analysis, Renew. Energy. 34 (2009) 623-633. doi:10.1016/j.renene.2008.05.026.

[20] S. Chungloo, B. Limmeechokchai, Application of passive cooling systems in the hot and humid climate: The case study of solar chimney and wetted roof in Thailand, Build. Environ. 42 (2007) 3341-3351. doi:10.1016/j.buildenv.2006.08.030.

[21] T. Miyazaki, A. Akisawa, I. Nikai, The cooling performance of a building integrated evaporative cooling system driven by solar energy, Energy Build. 43 (2011) 2211-2218. doi:10.1016/j.enbuild.2011.05.004.

[22] A. Al Touma, K. Ghali, N. Ghaddar, N. Ismail, Solar chimney integrated with passive evaporative cooler applied on glazing surfaces, Energy. 115 (2016) 169-179. doi:10.1016/j.energy.2016.09.020.

[23] B.R. Hughes, J.K. Calautit, S.A. Ghani, The development of commercial wind towers for natural ventilation: A review, Appl. Energy. 92 (2012) 606-627. doi:10.1016/j.apenergy.2011.11.066.

[24] M. Maerefat, A.P. Haghighi, Natural cooling of stand-alone houses using solar chimney and evaporative cooling cavity, Renew. Energy. 35 (2010) 2040-2052.

doi:10.1016/j.renene.2010.02.005.

[25] A.S. Abdallah, H. Yoshino, T. Goto, N. Enteria, M.M. Radwan, M.A. Eid, Integration of evaporative cooling technique with solar chimney to improve indoor thermal environment in the New Assiut City, Egypt, Int. J. Energy Environ. Eng. 4 (2013) 45. doi:10.1186/2251-6832-4-45.

[26] S. Ito, M. Kashima, N. Miura, Flow Control and Unsteady-State Analysis on Thermal Performance of Solar Air Collectors, J. Sol. Energy Eng. 128 (2006) 354. doi:10.1115/1.2210493.

[27] M.R. Assari, H. Basirat Tabrizi, I. Jafari, Experimental and theoretical investigation of dual purpose solar collector, Sol. Energy. 85 (2011) 601-608. doi:10.1016/j.solener.2011.01.006.

[28] A.L. Kays, W.M., London, Compact-heat-exchangers, McGraw-Hill Inc, New York, 1984.

[29] G. de E. Ministerio de Fomento, Archivos de datos climáticos de todas las zonas CTE, (2014). 


\section{NORMATIVA.}

[N-1] Ministerio de Vivienda de España, Real Decreto 314/2006 de 17 de marzo por el que se aprueba el Código Técnico de la Edificación.

\section{PÁGINAS WEB.}

[W-1] Página oficial del Código Técnico de la Edificación de España. https://www.codigotecnico.org/ (Último día de consulta: 11 de agosto de 2017) 


\section{PARTE IV: CONCLUSIONES}

CAPÍTULO VIII:

CONCLUSIONES Y

FUTUROS TRABAJOS. 


\section{CAPÍTULO VIII.- \\ CONCLUSIONES Y FUTUROS TRABAJOS.}

\section{CONTENIDOS DEL CAPÍTULO:}

VIII.1.- CONCLUSIONES 295

CARACTERIZACIÓN DE UN COLECTOR TÉRMICO SOLAR DE AIRE ......................... 296

SIMULACIÓN DE UN COLECTOR TÉRMICO SOLAR DE AIRE …….......................... 297

AHORROS ENERGÉTICOS OBTENIDOS EN VENTILACIÓN Y CALEFACCIÓN ......... 297

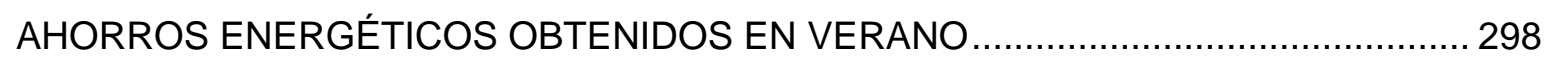

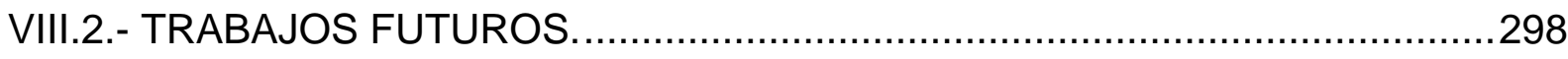


CAPÍTULO VIII: CONCLUSIONES Y FUTUROS TRABAJOS 


\section{VIII.1.- CONCLUSIONES.}

En el presente capítulo se recogen las conclusiones extraídas del trabajo desarrollado en esta tesis doctoral.

El aprovechamiento de la energía solar en al acondicionamiento térmico de los edificios no es algo novedoso. Ha habido muchos avances en las técnicas de aprovechamiento, desde el aprovechamiento pasivo en la antigua Grecia hasta los diseños actuales de colectores solares más avanzados pasando por los primeros diseños de captadores en forma de cajas acristaladas expuestas al Sol. Sin embargo, las cifras actuales de potencia mundial instalada de las tecnologías solares térmicas aportan una visión global del estado de madurez que demuestra las aún amplias posibilidades de aumentar la capacidad de estas tecnologías.

Los C.T.S. de aire se presentan como una alternativa a considerar para reducir el consumo y sustituir a las energías convencionales en las instalaciones térmicas de los edificios. Se han observado notorias ventajas de los C.T.S. de aire con respecto a los de agua, existe una amplia variedad de tecnologías de C.T.S. de aire existentes y un elevado interés en aplicaciones como la climatización de edificios y el secado. En un escenario en el que las cada vez más exigentes normativas preparan el camino para alcanzar próximamente los edificios de consumo de energía casi nula, con requisitos de calidad de ambientes interiores que implican caudales de ventilación cada vez más altos, queda justificada una mayor dedicación de la labor investigadora en este campo para identificar el potencial de reducción de las cargas térmicas de ventilación en invierno.

Por otro lado, fruto de los trabajos iniciales de documentación, estudio y análisis de la tecnología se ha identificado la necesidad de plantear alternativas a las ya estudiadas por otros autores en relación al uso anual de los C.T.S. de aire para aumentar la competitividad de esta tecnología en el mercado frente a otras tecnologías. Así, la propuesta presentada en esta tesis doctoral de contribuir a la generación de agua caliente sanitaria en verano contempla el aprovechamiento de los colectores fuera del período de demanda de calefacción, cuando los colectores reciben más irradiancia y son capaces de captar más energía.

La aplicación invernal de los colectores para calentar o precalentar el aire de ventilación y/o calefacción resulta conveniente a tenor de los resultados obtenidos. Los resultados del uso propuesto en el periodo estival demuestran que se pueden conseguir importantes ahorros complementarios a los anteriores. A continuación se detallan las conclusiones más específicas derivadas de dicho estudio. 


\section{CARACTERIZACIÓN DE UN COLECTOR TÉRMICO SOLAR DE AIRE}

La caracterización del colector térmico de aire comercial es la base del estudio de ahorros energéticos planteado para las diferentes aplicaciones propuestas.

La instalación del colector (TwinSolar 4.0-SLK de Grammer Solar) en el banco de ensayos del laboratorio permite caracterizar el equipo en diferentes condiciones de operación con independencia de las condiciones climáticas. Como estaba previsto, los tres factores estudiados para caracterizar el colector (caudal de aire, irradiancia térmica sobre la superficie del colector y temperatura del aire) resultaron ser determinantes en el comportamiento del mismo.

La caracterización se centró en el estudio de los parámetros salto térmico obtenido en el colector, energía aportada a la corriente de aire y rendimiento. Los resultados de la caracterización arrojaron las siguientes conclusiones:

Como se esperaba, el salto térmico alcanzado en el colector es mayor para caudales de aire más bajos, debido al mayor tiempo de residencia de la corriente de aire tratado. Los saltos térmicos obtenidos para valores bajos de caudal $\left(100 \mathrm{~m}^{3} / \mathrm{h}\right)$ son importantes, de entorno a los $50^{\circ} \mathrm{C}$ con irradiancias altas. Asimismo, el mayor nivel de irradiancia sobre el captador aumenta el salto térmico.

Según el ANOVA realizado, los factores que más influencia tienen en el salto térmico alcanzado son el caudal de aire de paso por el colector y la irradiancia incidente, en ese orden. Se ha comprobado que la temperatura de entrada no es determinante para el salto térmico alcanzado.

En cuanto a la energía o calor aportado, el factor más influyente es la irradiancia; al ser un parámetro proporcional al salto térmico, el factor irradiancia influye en el mismo sentido que el visto para el salto térmico. En este caso, a medida que aumentamos el caudal de aire obtenemos mayores valores de energía aprovechada. Tampoco aquí la temperatura de entrada del aire resulta determinante.

El rendimiento del colector está principalmente afectado por el caudal de aire que lo atraviesa: mayores caudales resultan en mejores comportamientos del captador.

El comportamiento observado del colector para estos parámetros sigue una tendencia definida que permite plantear expresiones que representen su comportamiento a partir de los factores estudiados, las cuales se han utilizado a lo largo del trabajo. 


\section{SIMULACIÓN DE UN COLECTOR TÉRMICO SOLAR DE AIRE}

El planteamiento de un modelo matemático para definir el comportamiento del colector a través de un balance energético en los componentes del C.T.S. de aire permite simular resultados de su comportamiento bajo diferentes condiciones de operación.

El modelo ha proporcionado resultados satisfactorios que han permitido su validación frente a los datos obtenidos experimentalmente, operando bajo un rango de condiciones climáticas típicas de una localidad del interior de España.

Los resultados para caudales bajos presentan pequeñas desviaciones que a medida que aumenta este factor se minimizan. Lo que muestra interesante replantear la discretización utilizada en el modelo para los caudales más bajos. Estos resultados permiten validar el modelo para su aplicación como herramienta de estudio del potencial de los C.T.S. de aire para su incorporación como sistema de acondicionamiento parcial o total del aire de ventilación o calefacción y el cálculo de los ahorros obtenidos con su utilización en aplicaciones concretas.

\section{AHORROS ENERGÉTICOS OBTENIDOS EN VENTILACIÓN Y CALEFACCIÓN}

Los resultados aquí obtenidos son una buena carta de presentación para su incorporación como alternativa de ahorro de energía en los edificios.

Se ha comprobado la importancia de un estudio previo a la instalación de los colectores para que el ángulo de inclinación sea el adecuado para la aplicación deseada, viéndose influenciado este ángulo óptimo no únicamente por la latitud de la localidad, si no por ese periodo de operación y las condiciones particulares de irradiancia de la localidad.

En este estudio se ha observado una limitación en la aplicación de las correlaciones definitorias del comportamiento del colector obtenidas en la caracterización experimental, debido a los escasos niveles de irradiancia empleados en la misma. Un considerable número de horas los valores de irradiancia en las localidades estudiadas se sitúan por debajo de los ensayados experimentalmente. Esta circunstancia ha obligado a obtener nuevas correlaciones por extrapolación para un nivel adicional inferior de irradiancia, que han permitido contemplar su operación en esas condiciones, pero que se han tenido que analizar con especial cuidado.

Los resultados obtenidos han permitido comprobar que los ahorros de energía obtenidos son importantes y hacen recomendable su uso en estas instalaciones.

Los mejores resultados se corresponden con las ciudades con mayores niveles de irradiancia, las de zonas climáticas solares IV y V; aunque todas las localidades consideradas de diferentes zonas climáticas de invierno y solares derivan ahorros importantes. Este estudio permite concluir que 
resulta más relevante considerar la zona climática solar que la zona climática de invierno, la cual no se muestra como representativa para evaluar el interés de esta aplicación.

\section{AHORROS ENERGÉTICOS OBTENIDOS EN VERANO}

Resulta de vital importancia para potenciar el interés de los C.T.S. de aire el poder ampliar el periodo de uso para salvar la estacionalidad de los ahorros energéticos y optimizar así la inversión. El estudio de la alternativa de uso para el calentamiento del ACS ha permitido concluir que se obtienen importantes ahorros complementarios al uso invernal.

Las instalaciones propuestas calientan el agua a través de un intercambiador aire- agua conectado al colector de aire y a la propia instalación de ACS con dos depósitos de acumulación.

Los resultados demuestran que, dentro de las posibles configuraciones del sistema propuestas, la más interesante es en la que la entrada del agua al intercambiador proviene de una mezcla de agua del depósito 1 o preparación y del agua de red (la otra alternativa es que el agua de entrada al intercambiador provenga únicamente del depósito).

También es interesante destacar que la optimización del tamaño del depósito para ajustarse a la demanda es clave, ya que menores depósitos permiten mayores ahorros. Los resultados de la configuración con el depósito más pequeño cubren incluso los picos de demanda en horas punta.

Los resultados obtenidos de los diferentes estudios planteados en esta tesis doctoral sobre el C.T.S. de aire permiten afirmar que su incorporación como sistema de aporte de energía gratuita en los edificios puede servir para obtener importantes ahorros energéticos en las instalaciones de ventilación, calefacción y agua caliente sanitaria.

\section{VIII.2.- TRABAJOS FUTUROS.}

Se ha comentado ya la limitación de la aplicación de las expresiones obtenidas que definen el comportamiento del colector para bajos niveles de irradiancia. Este aspecto puede ser uno de los campos de trabajo futuro, no profundizado en esta tesis por las limitaciones del dispositivo experimental disponible. Un mayor rango de niveles del factor irradiancia sobre el colector, particularmente para niveles inferiores a los ensayados, permitiría prescindir de las expresiones de comportamiento del C.T.S. de aire obtenidas por extrapolación.

Debido al peso determinante y principal del factor irradiancia, un factor asociado de suma relevancia en la captación de energía en los colectores es la inclinación con la que se instala el colector. Para las aplicaciones y periodos aquí propuestos, calentamiento del aire de ventilación y 
calefacción en invierno y calentamiento del ACS en verano, una interesante línea de estudio es la obtención del ángulo óptimo teniendo en cuenta la explotación durante todo el año del C.T.S. y/o priorizando si es necesario alguna de las aplicaciones propuestas. Esta optimización, que requiere un análisis en mayor profundidad, se presenta así como una interesante línea de trabajo a desarrollar, tomando como referencia los trabajos revisados de la literatura actualmente existente.

Los valores de los ahorros aquí obtenidos permitirían también estimar las emisiones evitadas de gases contaminantes, como el $\mathrm{CO}_{2}$, gracias al empleo de esta tecnología en sustitución o apoyo de otras convencionales en las instalaciones de los edificios.

El análisis de los ahorros económicos que supone el empleo del C.T.S. de aire en una instalación convencional permitiría poner en valor los resultados. El desarrollo de este análisis en un caso práctico, con el planteamiento de un adecuado encaje técnico en la instalación de referencia, puede aportar una perspectiva más práctica al estudio llevado a cabo.

En esta línea, otra posibilidad que puede arrojar resultados interesantes teniendo en cuenta la sencillez del sistema del C.T.S. de aire es el Análisis del Ciclo de Vida y su comparativa con otros sistemas alternativos que cubren los mismos servicios o aplicaciones.

Tanto el trabajo desarrollado en esta tesis doctoral como los futuros trabajos propuestos aquí se enmarcan dentro de la línea de trabajo existente y que sigue desarrollando el grupo de Termotecnia de la Universidad de Valladolid, en la que se plantea la combinación de los C.T.S. de aire con otros sistemas de alta eficiencia para la obtención de ahorros en las instalaciones de los edificios. 
CAPÍTULO VIII: CONCLUSIONES Y FUTUROS TRABAJOS 


\section{ANEXOS:}

ANEXO A:

CALIBRACIONES

ANEXO B:

PROCEDIMIENTO DE

DISEÑO DE EXPERIMENTOS Y ANÁLISIS DE VARIANZA.

ANEXO C:

CONSIDERACIONES Y

CÓDIGOS DE SIMULACIÓN. 


\section{ANEXO A.-}

\section{CALIBRACIONES.}

\section{CONTENIDOS:}

AA.1.-CALIBRACIÓN DE LAS SONDAS DE TEMPERATURA. ............................307

AA.2.- CALIBRACIÓN DE LAS SONDAS DE HUMEDAD. .................................311

AA.3.-CALIBRACIÓN DE LOS MANÓMETROS DE PRESIÓN. ...............................312

AA.4.-CALIBRACIÓN DE LAS PLACAS ORIFICIO............................................313 
ANEXO A: CALIBRACIONES 


\section{LISTA DE FIGURAS:}

Figura AA.1: Gráficas de las calibraciones de las sondas de temperatura. ..................................308

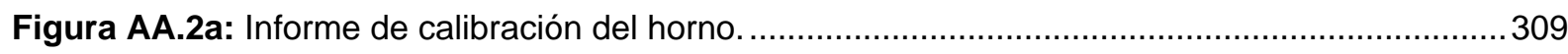

Figura AA.2b: Informe de calibración del horno (continuación).................................................310

Figura AA.3: Gráficas de las calibraciones de las sondas de humedad......................................311

Figura AA.4: Gráficas de calibración de los manómetros de presión. ............................................312

Figura AA.5: Gráficas de calibración de las placas orificio. ....................................................... 313

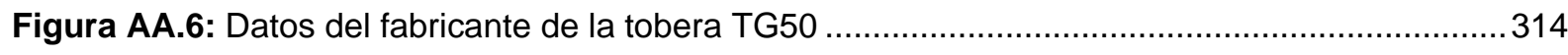

Figura AA.7: Datos de la gama de toberas TG del fabricante TECNER Ingeniería. ........................315 
ANEXO A: CALIBRACIONES 


\section{AA.1.-CALIBRACIÓN DE LAS SONDAS DE TEMPERATURA.}

A continuación se proporcionan las gráficas de las calibraciones de las sondas de temperatura desarrolladas mediante el horno de calibración FLUKE 9103 (rango de calibración entre -25 hasta $\left.140^{\circ} \mathrm{C}\right)$ utilizado como patrón primario.
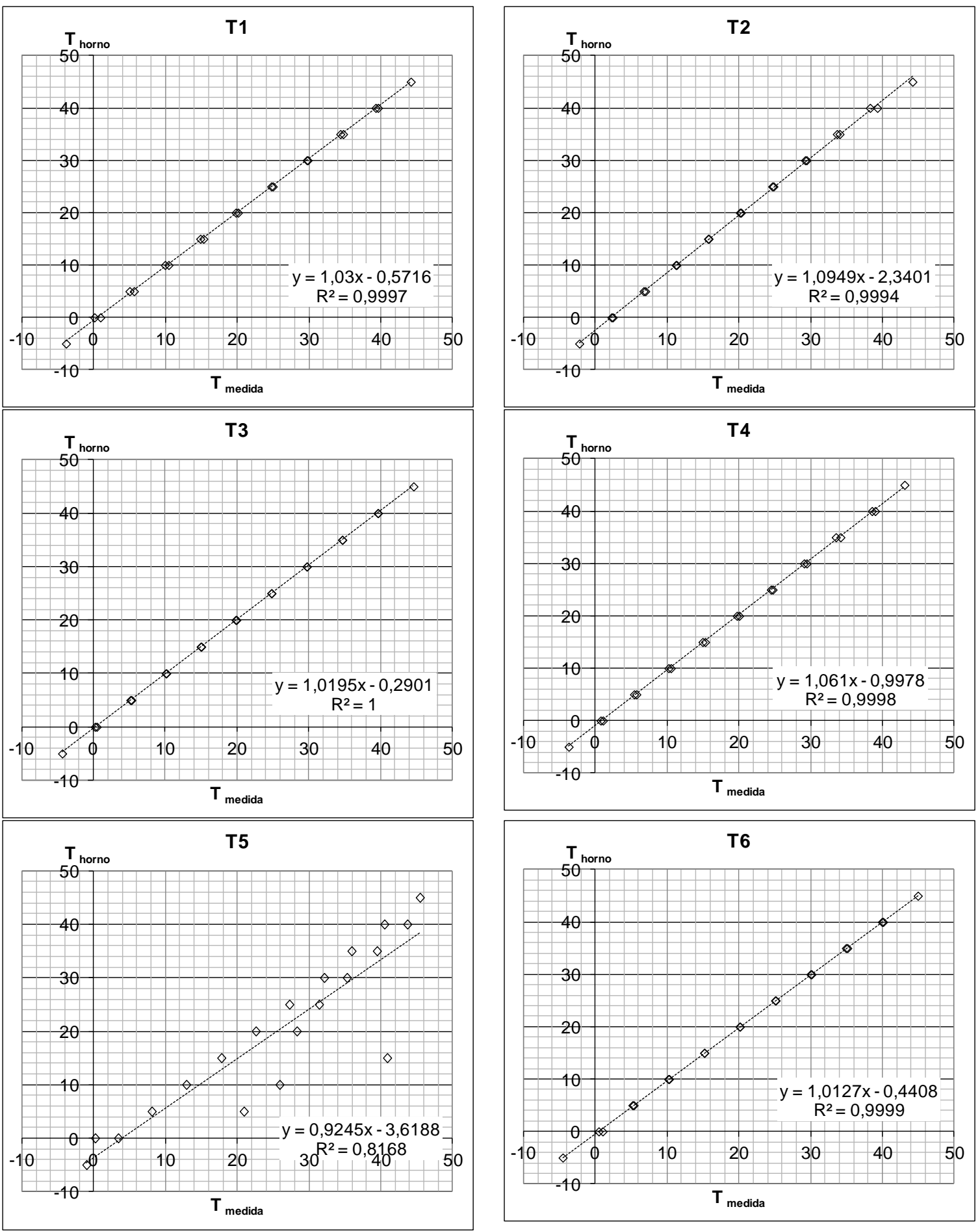

Figura AA.1: Gráficas de las calibraciones de las sondas de temperatura. 

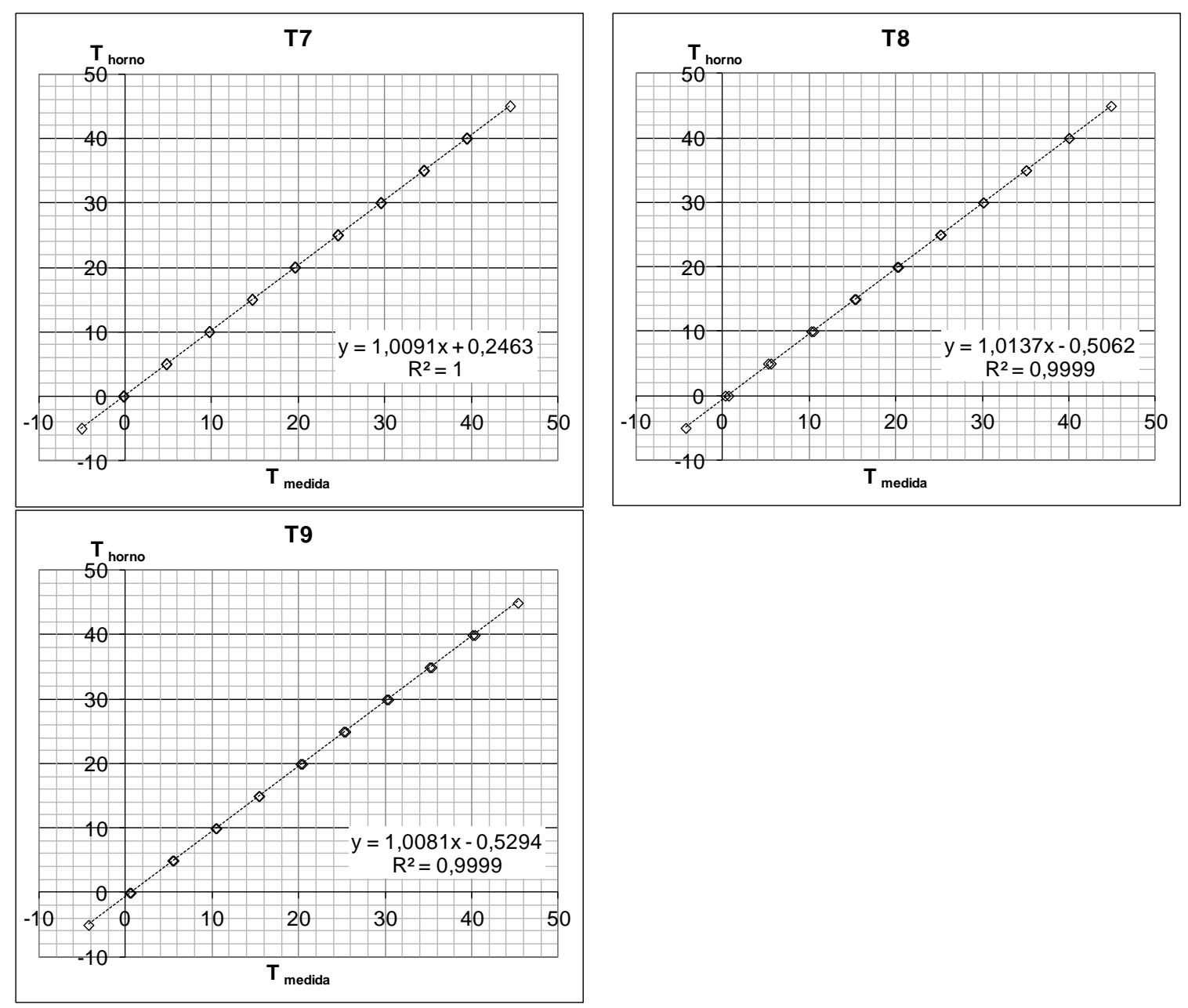

Figura AA.1: Gráficas de las calibraciones de las sondas de temperatura (continuación).

En las páginas siguientes se proporciona el informe del fabricante sobre la calibración de dicho horno. 
Calibration Performed At:

Fluke Corporation

Hart Scientific Division

799 E Utah Valley Drive

American Fork, Utah 84003-9775

\section{Report of Calibration}

\begin{tabular}{|l|l|l|l|}
\hline $\begin{array}{l}\text { Model: } \\
9103\end{array}$ & $\begin{array}{l}\text { Serial No: } \\
\text { B06593 }\end{array}$ & $\begin{array}{l}\text { Customer: } \\
\text { FLUKE EUROPE DISTRIBUTION CENTRE } \\
\text { EINDHOVEN 5651 GH } \\
\text { NL }\end{array}$ \\
\hline $\begin{array}{l}\text { Description: } \\
\text { Drywell Calibrator }\end{array}$ & & \\
\hline $\begin{array}{l}\text { Received Condition: } \\
\text { New }\end{array}$ & $\begin{array}{c}\text { Procedure: } \\
\text { HST168 -2 }\end{array}$ & $\begin{array}{l}\text { As Left Condition: } \\
\text { In Tolerance }\end{array}$ & $\begin{array}{l}\text { Calibration Range (Limited or full): } \\
\text { Full }\end{array}$ \\
\hline
\end{tabular}

The above referenced instrument was calibrated by direct measurement of generated temperatures using the reference standards listed in the "Test Equipment" table at the bottom of this report. The internal calibration constants and the data obtained are shown on page 2. A Test Uncertainty Ratio (TUR) of at least 4:1 was maintained unless otherwise indicated. This calibration is traceable to NIST or natural physical constants and is in compliance with ANSI/NCSL Z540-1 and MIL-STD 45662A.

NOTE: In accordance with recommended calibration interval policy as described in Hart Scientific Terms and Conditions of Sale, new instrument Report of Calibrations reflect OEM recommended one year calibration interval.

Test Equipment

Instrument

Model

Digital Thermometer

1560

Precision Digital Thermometer

2562-H

Platinum Resistance Thermometer

5628

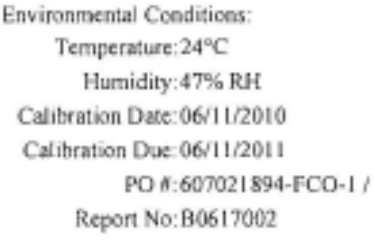

Serial No.

Recall Date

A25008

NCR

1505

$12 / 19 / 2010$

$07 / 06 / 2010$

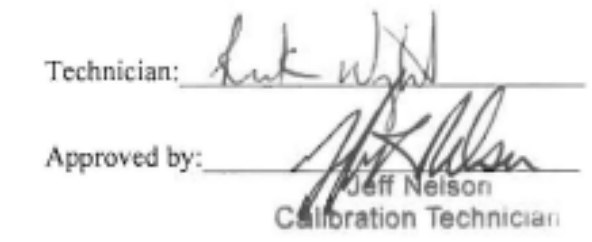

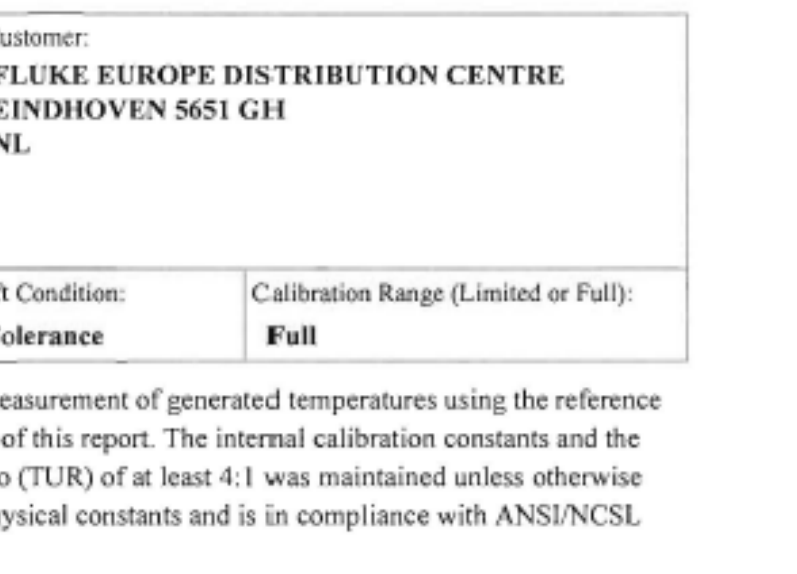




\section{Report of Calibration}

Model: 9103

Serial No: B06593

Report No:B0617002

-As Found Data

No As Found Data Required

As Left Data

Calibration Constants

\begin{tabular}{r|r}
\hline R0 & 100.097 \\
Alpha & 0.0038414 \\
Delta & 1.5127 \\
Beta & 1.0603 \\
Proportional Band & 15.0000
\end{tabular}

\begin{tabular}{|c|c|c|c|c|}
\hline Set-point ${ }^{\circ} \mathrm{C}$ & Actual ${ }^{\circ} \mathrm{C}$ & Error ${ }^{\circ} \mathrm{C}$ & $\begin{array}{c}\text { Calibration } \\
\text { Tolerance }\end{array}$ & Pass/Fail \\
\hline-25.00 & -24.802 & 0.198 & \pm 0.250 & $\mathbf{P}$ \\
\hline 0.00 & 0.118 & 0.118 & \pm 0.250 & $\mathbf{P}$ \\
\hline 25.00 & 24.985 & -0.015 & \pm 0.250 & $\mathbf{P}$ \\
\hline 50.00 & 49.952 & -0.048 & \pm 0.250 & $\mathbf{P}$ \\
\hline 75.00 & 74.947 & -0.053 & \pm 0.250 & $\mathbf{P}$ \\
\hline 100.00 & 99.953 & -0.047 & \pm 0.250 & $\mathrm{P}$ \\
\hline $\mid 40.00$ & 139.987 & -0.013 & \pm 0.250 & $\mathbf{P}$ \\
\hline
\end{tabular}

Figura AA.2b: Informe de calibración del horno (continuación). 


\section{AA.2.- CALIBRACIÓN DE LAS SONDAS DE HUMEDAD.}

Las gráficas mostradas seguidamente se corresponden con las calibraciones de las sondas de humedad realizadas.
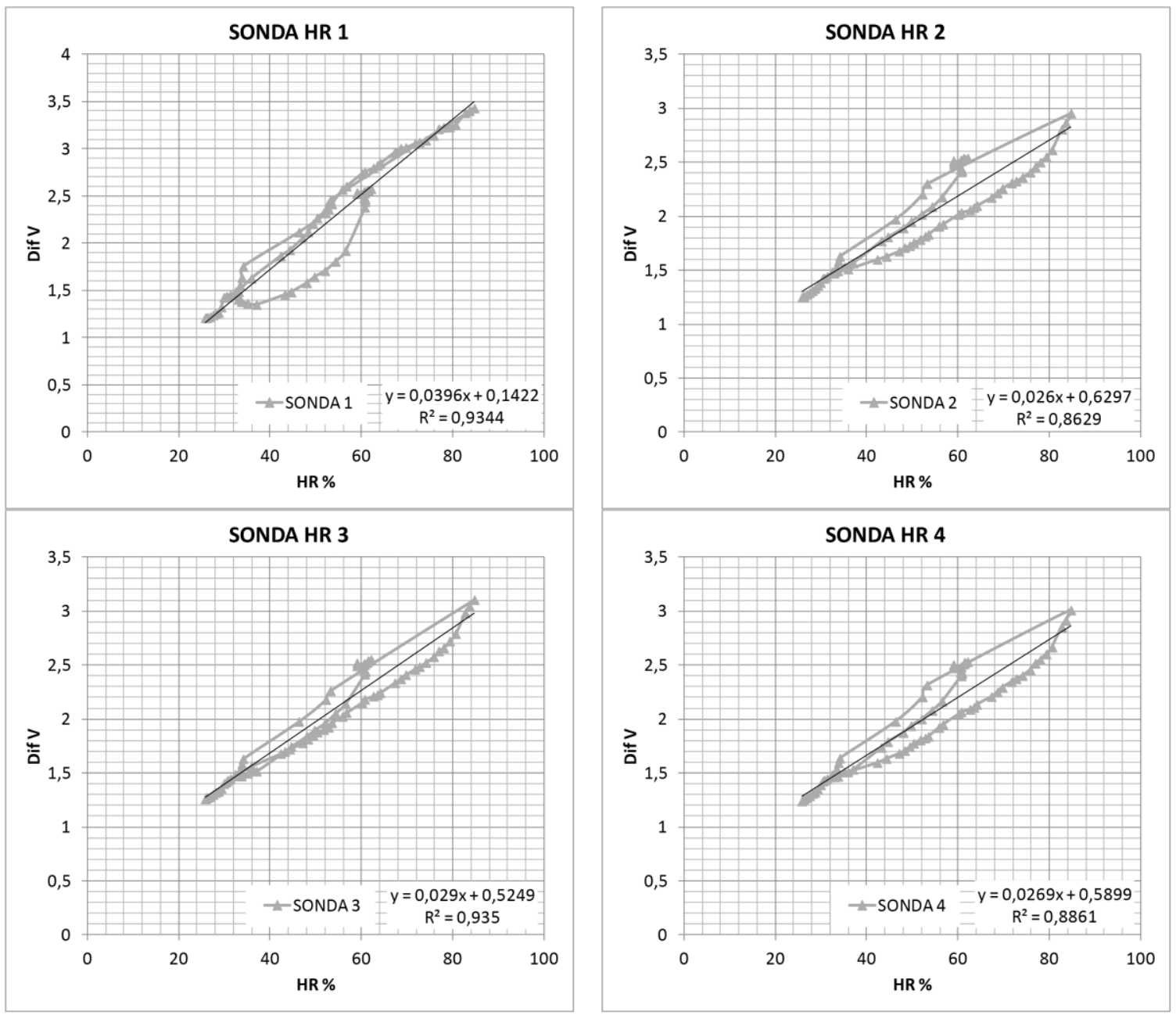

Figura AA.3: Gráficas de las calibraciones de las sondas de humedad. 


\section{AA.3.-CALIBRACIÓN DE LOS MANÓMETROS DE PRESIÓN.}

Los manómetros de presión utilizados en la determinación del caudal de aire circulante se han calibrado registrando su respuesta ante presiones manométricas del aire comprendidas entre 0 y 90 mmca. Las rectas de regresión resultan:
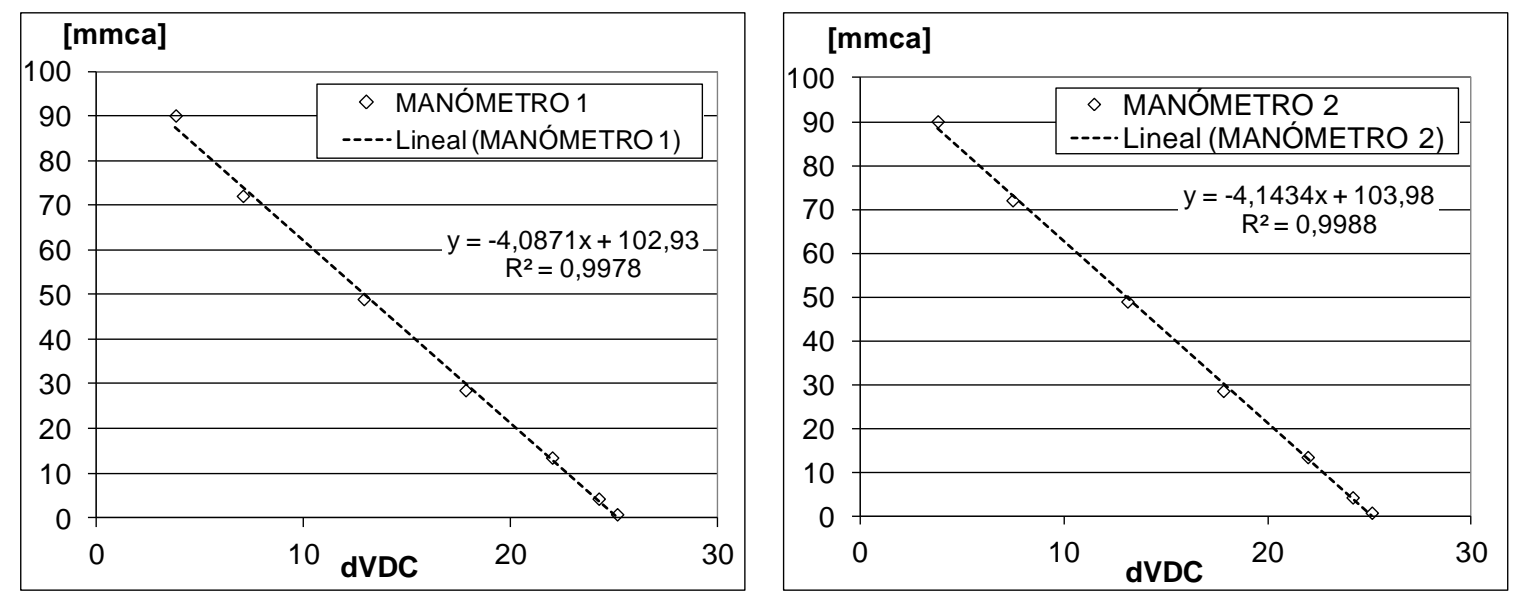

Figura AA.4: Gráficas de calibración de los manómetros de presión. 


\section{AA.4.-CALIBRACIÓN DE LAS PLACAS ORIFICIO.}

Los resultados de las calibraciones de las placas orificio se muestran en las gráficas presentadas a continuación.
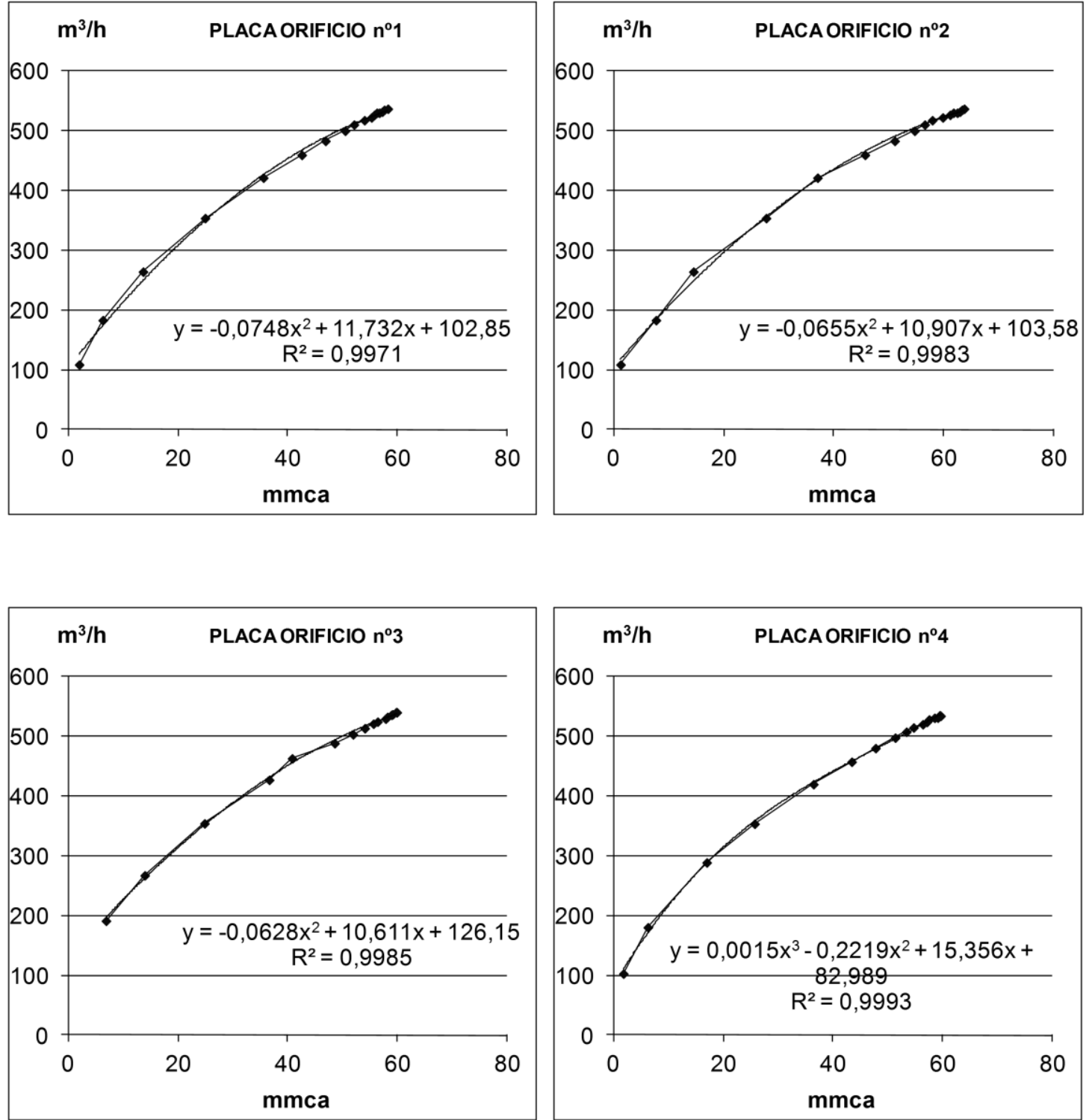

Figura AA.5: Gráficas de calibración de las placas orificio. 
Estas calibraciones se han realizado en base a los datos de la tobera extraídos de la información dada por el fabricante, según la gráfica siguiente

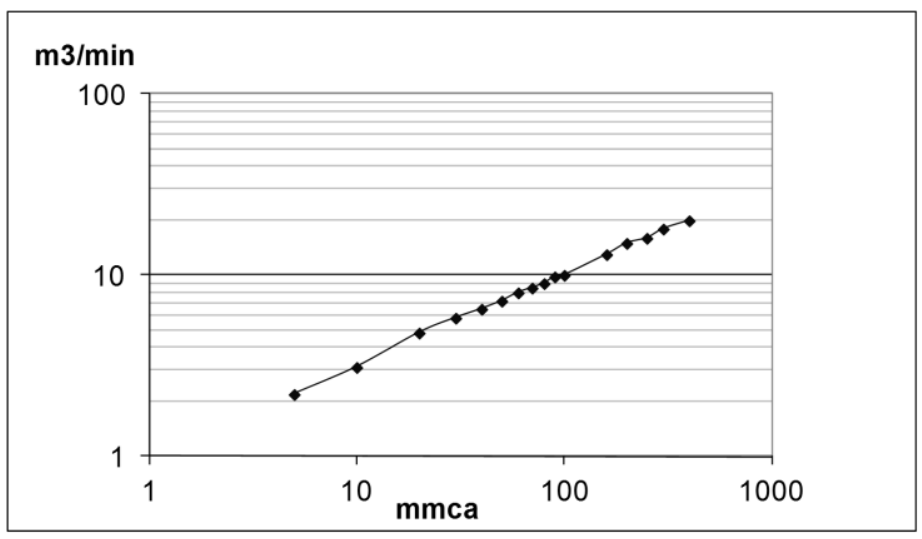

Figura AA.6: Datos del fabricante de la tobera TG50

A continuación se muestra la gráfica original proporcionada por el fabricante: 

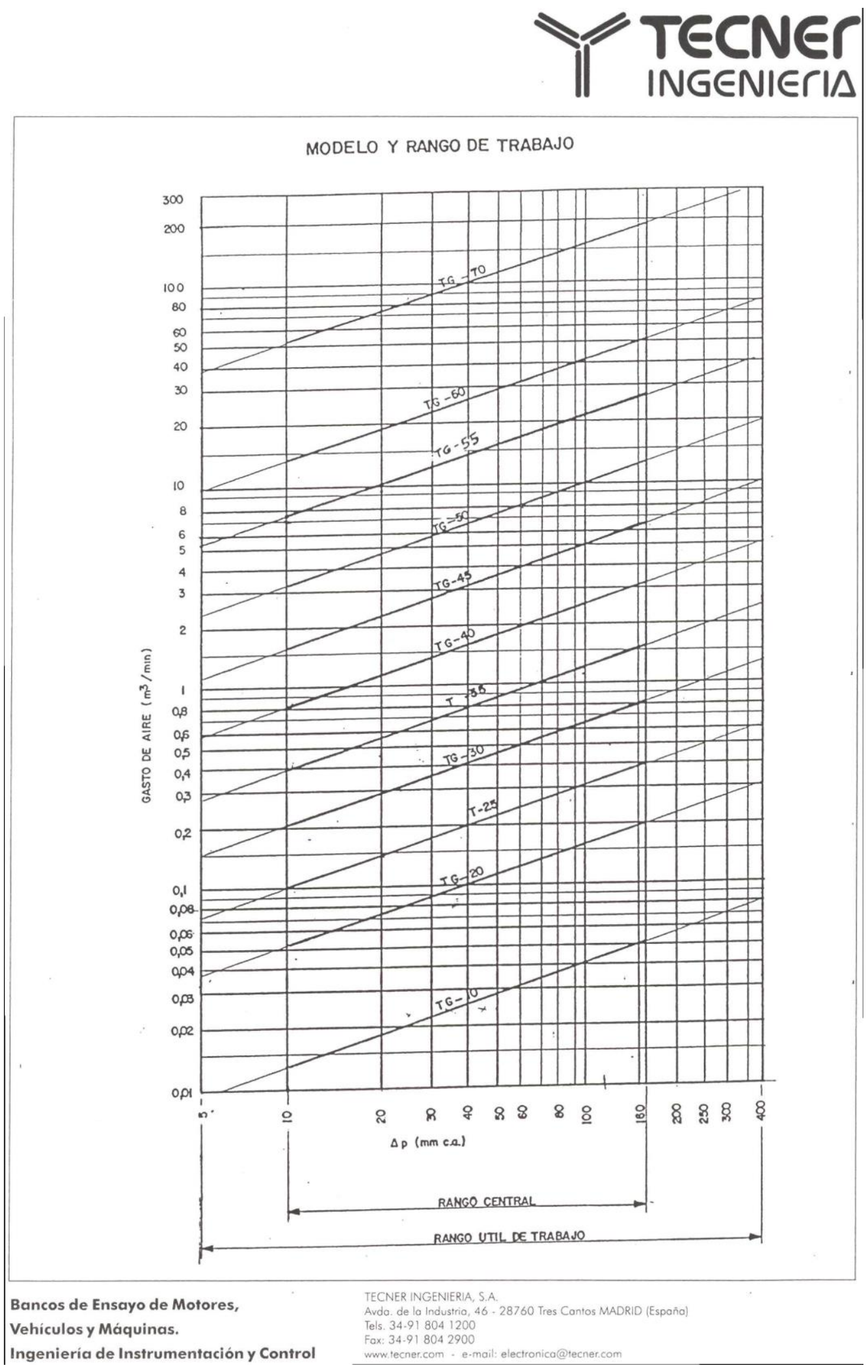

Figura AA.7: Datos de la gama de toberas TG del fabricante TECNER Ingeniería. 
ANEXO A: CALIBRACIONES 


\section{ANEXO B.-}

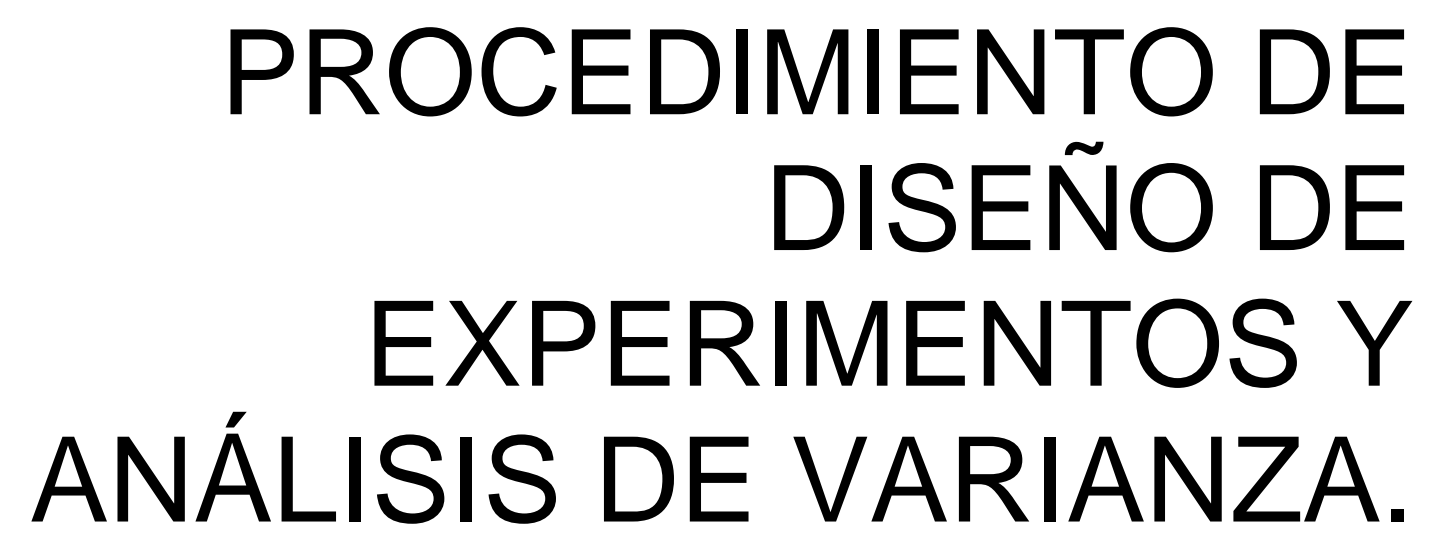

\section{CONTENIDOS:}

AB.1.- TEORÍA DEL DISEÑO DE EXPERIMENTOS. 321

Diseño de un factor a la vez. 323

Diseño factorial completo. 323

Diseño ortogonal fraccional y arreglos ortogonales 325 AB2.- ANÁLISIS DE VARIANZA. 326 REFERENCIAS 330 
ANEXO B: PROCEDIMIENTO DE DISEÑO DE EXPERIMENTOS Y ANÁLISIS DE VARIANZA

318 


\section{LISTA DE FIGURAS:}

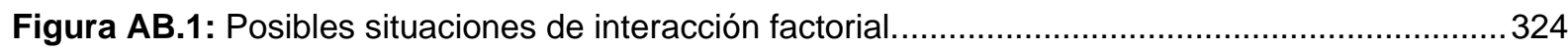

\section{LISTA DE TABLAS:}

Tabla AB.1.- Diseño factorial completo $L_{8}$ 


\section{Nomenclatura:}

$Y_{i}: \quad \quad$ Medida i-ésima.

SS: $\quad$ Suma de cuadrados correspondiente a X (factor, interacción o error).

$N$ : Número total de observaciones.

T: $\quad$ Suma de todas las medidas Yi.

$\bar{Y}: \quad$ Media de las medidas Yi.

$A_{i}: \quad \quad$ Suma de todas las observaciones para el nivel i del factor $\mathrm{A}$.

$(A x B)_{j}: \quad \quad \quad \quad$ Suma de todos los valores de la interacción $A x B$, en su cruce $j$.

$N_{A i}: \quad \quad$ Número de observaciones bajo el nivel i del factor $A$.

$N_{(A \times B) j}: \quad \quad \quad$ Número de valores del cruce j, de la interacción AxB.

$k_{A}: \quad \quad$ Número de niveles del factor $\mathrm{A}$.

$k_{A} x k_{B}: \quad \quad \quad \quad \quad \quad \quad$ úmero de cruces existentes en la interacción del factor A con el factor B. 


\section{AB.1.- TEORÍA DEL DISEÑO DE EXPERIMENTOS.}

En el presente anexo se describe la teoría del diseño de experimentos para justificar los estudios realizados previamente a la caracterización experimental de los equipos analizados en los capítulos de la memoria de este trabajo de tesis doctoral.

El objetivo de un diseño de experimentos es caracterizar el comportamiento de un proceso cuando se introducen cambios deliberados en aquellas variables que intervienen en el proceso.

Antes de realizar una descripción de la técnica experimental, que vamos a utilizar en la caracterización de la batería de tubos de calor, se van a definir algunos de los conceptos que se emplearán durante el desarrollo del presente capítulo, con el fin de precisar el significado que poseen en el contexto donde van a ser utilizados.

Factor: Aquella variable o circunstancia bajo la que se desarrolla el experimento, y que puede afectar de alguna manera a la característica seleccionada. Se definen dos tipos de factores dependiendo de cómo intervienen en el desarrollo del ensayo: factor de control y factor de ruido.

Factor de control.- Variable que podemos controlar durante el desarrollo de la experimentación.

Factor de ruido.- Variable que no podemos controlar durante el desarrollo de la experimentación [1].

Niveles: Valores que adquieren los distintos factores que actúan sobre la característica de calidad.

Característica: Aquella propiedad o propiedades analizadas con cada uno de los experimentos realizados. Estos valores son los que permiten realizar el análisis de los experimentos, para obtener el resultado del diseño, determinar los índices de contribución de los diferentes factores analizados, los óptimos de papel o económicos, etc.

Efectos: Se entiende por efecto de un factor, al cambio de respuesta identificado en la característica que se mide, cuando se cambia de nivel al factor.

Interacción: Se dice que existe interacción cuando los efectos de los factores contemplados conjuntamente no son aditivos; o dicho de otra manera, cuando el efecto de un factor sobre una característica depende del nivel a que se encuentre otro factor.

Óptimos: Es la combinación de niveles de los factores que proporciona el mejor resultado sobre una determinada característica.

Grados de libertad: Se define como el número de comparaciones que hay que realizar para determinar el mejor nivel de un factor. Coincide con el número de niveles menos 1. 
Ortogonalidad: Cuando un conjunto de experimentos guardan entre sí ortogonalidad, al ensayar cada nivel de un factor el mismo número de veces con todos los niveles del resto de los factores, de tal manera que, aceptando que el comportamiento de los factores sobre una determinada característica es lineal, la contribución a la media del resto de los factores se anula. Esto facilita el análisis de los resultados obtenidos, pues el resultado para el nivel de un factor se obtiene como la media del conjunto de ensayos en los que interviene, pero obliga a realizar unas determinadas experiencias programadas previamente. En la tabla AB.1 se presenta un ejemplo de conjunto de experimentos que cumplen esta característica.

Tabla AB.1.- Diseño factorial completo $L_{8}$.

\begin{tabular}{|l|c|c|c|c|c|c|c|}
\hline & Factor A & Factor B & Int. AxB & Factor C & Int. AxC & Int. BxC & Int.AxBxC \\
\hline Ensayo 1 & Nivel 1 & Nivel 1 & Nivel 1 & Nivel 1 & Nivel 1 & Nivel 1 & Nivel 1 \\
\hline Ensayo 2 & Nivel 1 & Nivel 1 & Nivel 1 & Nivel 2 & Nivel 2 & Nivel 2 & Nivel 2 \\
\hline Ensayo 3 & Nivel 1 & Nivel 2 & Nivel 2 & Nivel 1 & Nivel 1 & Nivel 2 & Nivel 2 \\
\hline Ensayo 4 & Nivel 1 & Nivel 2 & Nivel 2 & Nivel 2 & Nivel 2 & Nivel 1 & Nivel 1 \\
\hline Ensayo 5 & Nivel 2 & Nivel 1 & Nivel 2 & Nivel 1 & Nivel 2 & Nivel 1 & Nivel 2 \\
\hline Ensayo 6 & Nivel 2 & Nivel 1 & Nivel 2 & Nivel 2 & Nivel 1 & Nivel 2 & Nivel 1 \\
\hline Ensayo 7 & Nivel 2 & Nivel 2 & Nivel 1 & Nivel 1 & Nivel 2 & Nivel 2 & Nivel 1 \\
\hline Ensayo 8 & Nivel 2 & Nivel 2 & Nivel 1 & Nivel 2 & Nivel 1 & Nivel 1 & Nivel 2 \\
\hline
\end{tabular}

En la tabla se observa como para cualquier nivel (nivel 1 o nivel 2) de un factor o interacción, siempre el resto de los factores o interacciones se ensayan el mismo número de veces en el nivel 1 que en el nivel 2. La importancia de estas técnicas ha proporcionado una gran documentación existente al respecto en la que se presentan varios métodos experimentales que tienen como característica común la ortogonalidad de sus diseños [1], [2], [3], [4], [5].

Los arreglos ortogonales han sido tradicionalmente relacionados con las técnicas experimentales utilizadas en metodología Taguchi, que es el que más ha difundido su uso, aunque no fue el que primero en desarrollarla [1]. La principal contribución de la metodología Taguchi es que utiliza los denominados arreglos ortogonales fraccionales, que mantienen la ortogonalidad en el planteamiento del diseño, pero que no analizan las interacciones dobles entre factores que, a priori y derivado del conocimiento del proceso, se supone que no van a afectar al resultado de la experimentación. En la metodología Taguchi siempre se desprecian las interacciones superiores al segundo orden.

Las técnicas de diseño de experimentos, fueron propuestas ya por el profesor R. A. Fisher en la década de los años 1920 [3], [5], pero su principal desarrollo se ha derivado de su utilización como herramientas de calidad para conseguir mejores rendimientos de proceso. Su objetivo es conseguir la mayor cantidad de información de un proceso con pocas experiencias, permitiendo establecer los niveles de los factores que mejores resultados proporcionan al proceso, las zonas donde el proceso 
tiene un comportamiento estable, etc., pero siempre con un número de experiencias reducido, dado el coste asociado a su realización a nivel industrial.

De las técnicas más utilizadas en diseño de experimentos, anteriormente ya mencionada, es la metodología Taguchi, cuya principal contribución ha sido la forma en que relaciona los resultados obtenidos de los experimentos con la evaluación económica de los mismos. Por otra parte, introduce una nueva filosofía en el diseño, permitiendo perder parte de la información en favor de una reducción en el número de experimentos a realizar. Esta metodología es la más aplicada en la actualidad para optimizar los procesos productivos [6], [7].

Los diseños de experimentos permiten programar los ensayos que hay que realizar, para poder determinar cómo afectan los valores de los factores (niveles), sobre la característica (resultados) que se obtiene de un proceso. Las principales técnicas experimentales son las que se presentan a continuación.

\section{DISEÑO DE UN FACTOR A LA VEZ.}

Se trata de la forma de experimentar más tradicional. De entre todos los factores seleccionados, sólo se cambia el nivel de uno de ellos permaneciendo el resto invariable, observando el efecto que ocasiona ese cambio de nivel. Una vez determinado el mejor nivel de ese factor, se mantiene fijo y se analiza otro factor de los que afectan a la característica seleccionada. Este método no permite contemplar interacciones entre factores.

\section{DISEÑO FACTORIAL COMPLETO.}

Se trata de un diseño en el que se consideran todas las combinaciones posibles de los niveles de los factores. Con este método se obtiene toda la información posible de la influencia de los niveles de los factores analizados sobre el proceso objeto de estudio.

Este tipo de diseño es el utilizado durante la caracterización de los equipos planteados en la memoria de la presente tesis doctoral. La fórmula que determina el número de experimentos que se precisan es (ecuación $E-A B$.1):

$$
N \text { ” de Experimentos }=\prod_{i=1}^{n} N_{i}
$$

Siendo Ni es el número de niveles del factor $i$.

Por ejemplo, para un diseño ortogonal completo de 2 factores a 2 niveles, 1 factor a 3 niveles y 2 factores a 4 niveles, el número de experiencias sería de: $2 \times 2 \times 3 \times 4 \times 4=192$ experimentos. 
Existe una regla, dada por Yates, que permite construir el diseño experimental. Su desarrollo sería similar al mostrado en la tabla AB.1. Este tipo de diseño permite determinar si existen, entre los factores, interacciones importantes. Las interacciones se determinan como el número de combinaciones que se pueden realizar con los factores.

Una interacción doble será aquella en la que intervienen dos factores, triple en la que intervienen tres, y así sucesivamente. La contribución de las interacciones triples o de orden superior al resultado se considera despreciable, y sólo se contemplan como significativas las interacciones dobles.

La existencia de interacción se manifiesta gráficamente con dos rectas no paralelas, y si esas rectas se cruzan se interpreta como que existe una interacción fuerte. En la figura AB.1 se representan gráficamente las posibles situaciones que pueden presentar los niveles de dos factores analizados conjuntamente.

Existe Interaccin

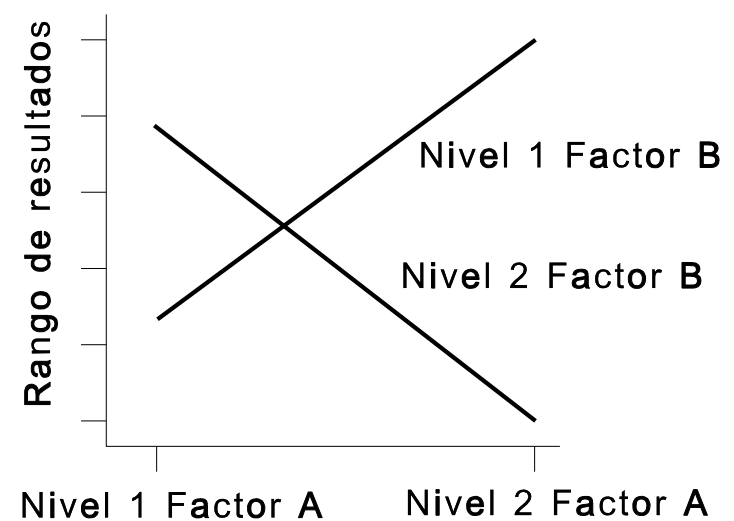

No Existe Interaccin

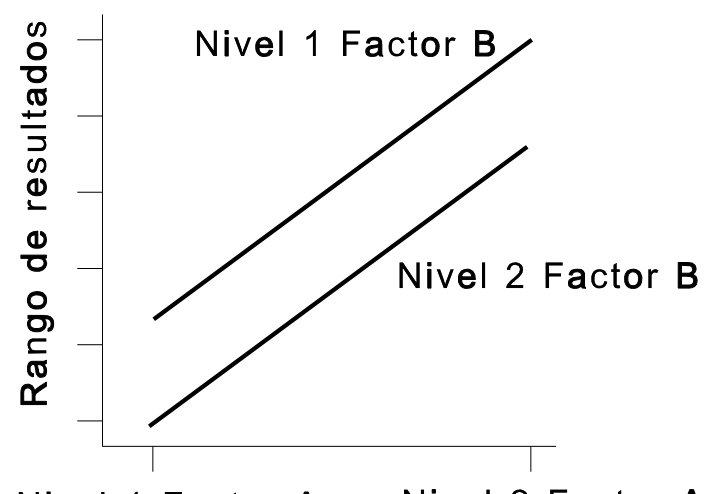

Figura AB.1: Posibles situaciones de interacción factorial.

Dado que se han realizado los ensayos para todas las posibles combinaciones de los factores, y a todos sus niveles, los ensayos correspondientes a las combinaciones óptimas de niveles de los factores, se observa durante la experimentación. 


\section{DISEÑO ORTOGONAL FRACCIONAL Y ARREGLOS ORTOGONALES}

El problema del diseño factorial completo es el elevado número de ensayos que hay que realizar cuando aumenta el número de factores o de niveles, por eso, se plantea reducir el número de experiencias manteniendo el máximo de información posible. Esto se logra con el diseño factorial fraccional y con los arreglos ortogonales.

Este tipo de diseño lo creó en 1934 Tippet, siendo desarrollados posteriormente por D.I. Finney, Yates, Placket \& Burman, C. R. Rao, S. Hunter y G. Taguchi [5].

Esto se consigue conociendo las interacciones que van a ser significativas y cuáles no lo van a ser, lo que siempre es consecuencia de la experiencia y el conocimiento del proceso. Cuando una interacción no va a contribuir al resultado final de un proceso, la columna asignada a esa interacción, o lo que es lo mismo, los grados de libertad que precisa su determinación, pueden ser empleados para determinar la contribución de otro factor. El número de grados de libertad determina la cantidad de información que puede obtenerse de un diseño de experimentos.

Cuando se investigan factores que se comportan de manera independiente respecto de los demás, luego no poseen interacciones con otros factores, puede asignarse un factor a cada columna del diseño de experimentos. Entonces se dice que tenemos un diseño factorial fraccional saturado. Una muestra esquemáticamente de las reglas para la asignación de los grados de libertad es:

a) Un diseño de experimentos que contemple 16 experimentos posee 15 grados de libertad (siempre 1 menos que el número de ensayos necesarios para realizar el diseño).

b) El análisis de un factor requiere un número de grados de libertad igual al número de niveles del factor menos 1 . Se necesitan 3 grados de libertad para determinar la influencia sobre el proceso de un factor a 4 niveles.

c) Cada columna de un diseño de experimentos está asociada a un grado de libertad, y puede soportar un factor a 2 niveles o una interacción de dos factores a dos niveles. Un factor a tres niveles requiere 2 columnas de 1 grado de libertad o 1 columna que soporte dos grados de libertad.

d) El número de grados de libertad asignados a una interacción se calcula como el producto de los grados de libertad de los factores que intervienen en la interacción. Ej. Una interacción de dos factores a 2 niveles precisa de 1 grado de libertad, mientras que si fueran a tres niveles necesita 4.

La utilización de este tipo de diseño es muy importante en procesos industriales, en los que existe ya un conocimiento del proceso elevado, en los cuales sólo se buscan óptimos de operación y donde la realización de un ensayo posee un coste económico muy elevado, por lo que no es muy importante el hecho de perder algo de información relativa a las interacciones. 
En nuestro caso se va a desarrollar un diseño factorial completo, consecuencia de la necesidad de determinar cómo afectan todos los factores que vamos a considerar en la caracterización de los sistemas, así como sus posibles interacciones; además de ser posible gracias al bajo coste que lleva asociada cada una de las experiencias que hay que realizar, etc.

\section{AB2.- ANÁLISIS DE VARIANZA.}

La variabilidad generada entre los resultados de la experimentación no se debe sólo al tipo y número de factores que entran en juego, si no también se debe a que existen causas desconocidas que influyen en ella. La técnica del Análisis de la Varianza (ANOVA) es una herramienta de amplia utilidad que va a permitir además estudiar la influencia de los distintos factores en la variabilidad del proceso.

Cuando se fijan todos los factores menos 1 , la variabilidad se produce por multitud de causas que, teóricamente, es posible dividir en dos partes, la originada por el factor en estudio, y la variación producida por los restantes factores que entran en juego conocidos o no, controlables o no, que se conoce con el nombre de error experimental. Con el análisis de la varianza se mide la variación debida a los distintos niveles del factor estudiado, y también la originada por el error experimental. Si mediante los contrastes estadísticos adecuados la variación producida por el factor es mayor que la variación debida al error experimental, es aceptable la hipótesis de que los distintos niveles del factor actúan de forma distinta.

El análisis de varianza es un procedimiento basado en el método de mínimos cuadrados. Así la varianza debida al error, es el mínimo valor de la suma de cuadrados en torno a un valor de referencia, dividido por los grados de libertad del error. Esa suma de cuadrados es mínima cuando el valor de referencia coincide con la media.

El objetivo es el establecimiento de un modelo simple de comportamiento a partir de estas ideas, el cual se puede formalizar matemáticamente.

De la misma manera que se analiza el comportamiento de los niveles de un factor (como la temperatura del aire exterior), podemos estudiar el de dos o más (el segundo factor en los casos de estudio podría ser el caudal). En el caso de dos factores el modelo matemático es una extensión del establecido para uno, sin más que tener en cuenta la ampliación de la fuente de variación.

Dependiendo del número de factores controlados durante la experimentación, se precisarán análisis estadísticos diferentes que permitan determinar la contribución a la variación del error, los factores, sus interacciones dobles, triples, etc., y denominaremos a esos análisis de varianza como 
ANOVA de 0 vías, 1 vía, 2 vías, etc, dependiendo del número de factores controlados durante la experimentación y cuya contribución a la variación en los resultados se pretende determinar.

Puede plantearse la situación de que dos factores $A$ y $B$, no actúen independientemente; en estas condiciones se dice que existe interacción entre ambos factores, no siendo el modelo aditivo.

Un ANOVA de 0 vías, nos permite determinar únicamente la contribución del error en la experimentación. EI ANOVA de 1 vía, determina la contribución del error y la correspondiente al factor controlado. El de 2 vías, caracteriza las contribuciones del error, de dos factores y de su interacción doble.

En la presente tesis, se han tenido casos de trabajo con dos y tres cuatro factores controlados, luego se han realizado análisis de varianza (ANOVA) de 2 y 3 vías. Las contribuciones que podemos plantear son, en el primer caso, las correspondientes al error, los 2 factores y su interacción doble; y en el segundo a los 3 factores, las dos interacciones dobles posibles y la interacción triple, además de las del error. Los resultados proporcionados vendrán a certificar la validez de los obtenidos con los valores medios de los factores y sus interacciones.

Existen dos posibilidades de plantear el análisis de varianza (ANOVA), dependiendo de si se incluye o no la media. En ambos casos el resultado de la contribución a la variación para los factores, las interacciones y el error tienen que ser igual, pues la diferencia entre un método y otro es contemplar directamente los resultados obtenidos, o esos resultados menos la media. En el caso particular se utiliza el método de exclusión de la media.

La contribución a la variabilidad de las medidas se analiza calculando la suma de cuadrados asociada a cada uno de los factores y sus interacciones. A continuación se presentan las ecuaciones definidas para su evaluación.

Cada una de esas contribuciones pueden evaluarse por separado, y el valor obtenido del cálculo de su suma de cuadrados es proporcional a la variación que introducen sobre la media los cambios de nivel que experimentan los factores. En las ecuaciones $E-A B .2$ a $E-A B .5$, se muestra como se realizan los cálculos de las correspondientes sumas de cuadrados.

Suma de cuadrados del total de las medidas:

$$
S S_{\text {Total }}=\sum_{i=1}^{N} Y_{i}^{2}-\frac{T^{2}}{N}
$$

Los índices de contribución a la suma de cuadrados totales (SST), se corresponderá con la suma de los de los factores, las interacciones y el error, obtenidos como: 
Suma de cuadrados de un factor:

$$
S S_{A}=\sum_{j=1}^{k A} \frac{A_{j}^{2}}{N_{A_{j}}}-\frac{T^{2}}{N}
$$

Suma de cuadrados de una interacción doble:

$$
S S_{A x B}=\sum_{j=1}^{k A x k B} \frac{(A x B)_{j}^{2}}{N_{(A x B)_{j}}}-\frac{T^{2}}{N}-\left(S S_{A}+S S_{B}\right)
$$

Suma de cuadrados de una interacción triple:

$$
S S_{A x B x C}=\sum_{j=1}^{k A x k B x k C} \frac{(A x B x C)_{j}^{2}}{N_{(A x B x C)_{j}}}-\frac{T^{2}}{N}-\left(S S_{A}+S S_{B}+S S_{C}+S S_{(A x B)}+S S_{(A x C)}+S S_{(B x C)}\right)
$$

La suma de cuadrados del error se obtiene por diferencia entre la $S S_{\text {Total }}$ y el resto de las contribuciones de los factores.

La contribución a la variabilidad de las interacciones siempre será inferior que la debida a los factores, y prácticamente nunca se evalúan las de orden superior a dos. En los casos particulares abordados en la presente tesis, por disponer de un número de datos tan elevado, se utiliza para cada experimento un solo valor que es la media de todos los obtenidos para cada ensayo, por lo que la suma de cuadrados del error de experimentación no se puede precisar, dado que no se contemplan repeticiones en los ensayos.

La contribución del error de experimentación a la variabilidad, en este caso, se puede asociar a la calculada con las interacciones de orden superior a dos, y aquellas dobles cuya suma de cuadrados sea pequeña, en comparación con los valores obtenidos para el resto de los factores e interacciones.

Cuando se estudia mediante análisis de varianza el comportamiento de los niveles de un factor fijo, no se persigue como única finalidad del análisis saber si los distintos niveles del factor son significativamente distintos entre sí; sino que interesa conocer, una vez contrastado que las diferencias son significativas, qué niveles producen un efecto superior a los otros. Para ello se precisa de las "pruebas de significación", que utilizan los valores medios de los ensayos y del ANOVA. Estas pruebas de significación son múltiples, como el Test F, el Test de Duncan, el de Student-NewmanKeuls (SNK), Test de Tukey (HSD), Test de la diferencia mínima significativa (LSD) o el Test de Scheffe.

Para evitar aumentar la complejidad del tratamiento de los resultados, en el presente trabajo no se presentan las pruebas de significación asociadas al tratamiento estadístico de los datos, puesto 
que el interés del diseño de experimentos es determinar cómo afectan los factores analizados sobre las diferentes características, y no tanto los valores numéricos obtenidos para esas características en los diferentes niveles. 


\section{REFERENCIAS}

[1] G. Stuart Peace, Taguchi methods, A hands-on approach to quality engineering, 1995.

[2] W.G. Cochram, G.M. Cox, Diseños experimentales, $10^{\mathrm{a}}, 1987$.

[3] M.S. Phadke, Quality engineering using robust design, AT\&T Bell, England, n.d.

[4] A. Bendell, J. Disney, W.A. Pridmore, Taguchi methods, applications in world industry, United Kingdom, 1989.

[5] R.K. Roy, A primer on the Taguchi method, New York, 1990.

[6] G. Taguchi, E.A. Elsayed, T. Hsiang, Quality engieering in production systems, United States, 1989.

[7] P.J. Ross, Taguchi techniques for quality engineering. Loss function, orthogonald experiments, parameter and tolerance design, United States, 1988. 


\section{ANEXO C.-}

\section{CONSIDERACIONES Y CÓDIGOS DE SIMULACIÓN.}

\section{CONTENIDOS:}

AC.1.- FACTOR DE CORRECCIÓN $K$ PARA SUPERFICIES INCLINADAS.........339 AC.2.- CONSIDERACIONES PARA EL DISEÑO DEL INTERCAMBIADOR DE

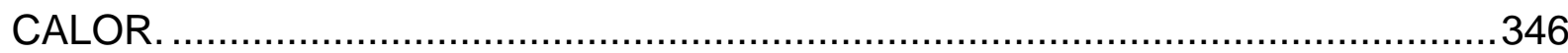

AC.3.- CÓDIGO DE SIMULACIÓN DE LA BATERÍA AIRE - AGUA. ......................351

AC.4.- CÓDIGO DE SIMULACIÓN DEL COLECTOR............................................357

AC.5.- TEMPERATURAS DEL AGUA DE RED EN ESPAÑA..............................359

AC.6.- EVOLUCIÓN DE LA TEMPERATURA DEL AGUA EN EL DEPÓSITO DE

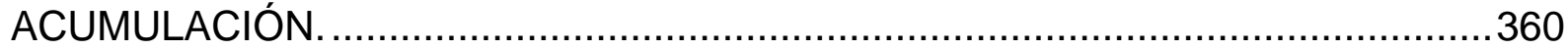

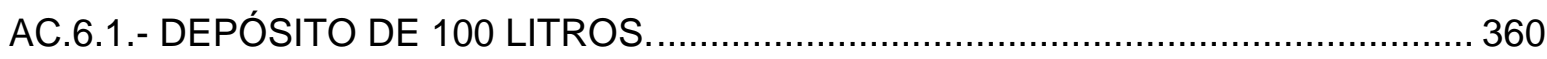

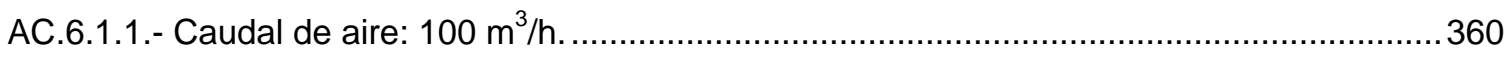

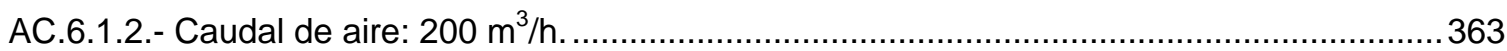

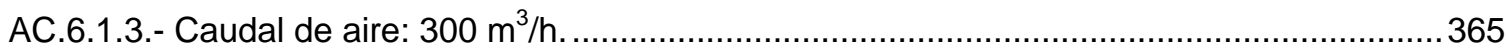

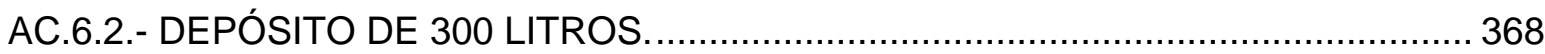

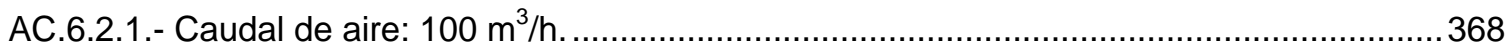

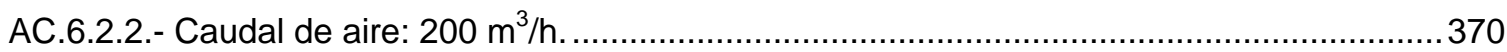

AC.6.2.3.- Caudal de aire: $300 \mathrm{~m}^{3} / \mathrm{h}$........................................................................... 373

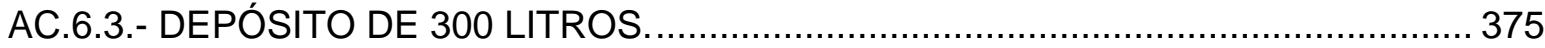

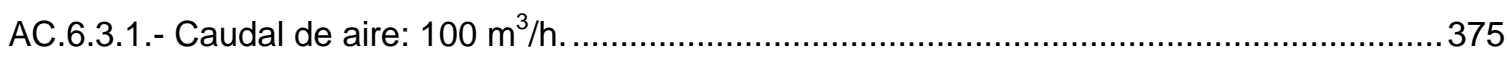

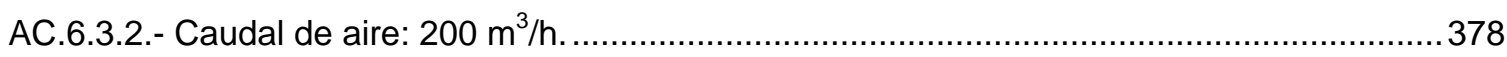

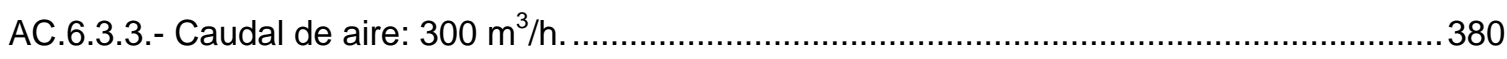

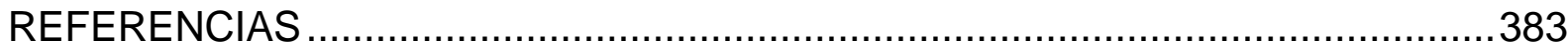


$332)$ 


\section{LISTA DE FIGURAS:}

Figura AC.1: Factor de corrección de la humedad para la densidad y el calor específico [2] 348

Figura AC.2: Factor de fricción para flujo turbulento completamente desarrollado en tubos circulares [2]. 348

Figura AC.3: Tubos circulares aleteados [2] 349

Figura AC.4: Función G2 para el cálculo de la eficiencia de aletas anulares de espesor uniforme [1]

Figura AC.5.- Evolución de la temperatura del agua en el depósito para el día tipo de MAYO con un caudal de aire de paso por el colector de $100 \mathrm{~m}^{3} / \mathrm{h}$. Capacidad del depósito: 100 litros

Figura AC.6.- Evolución de la temperatura del agua en el depósito para el día tipo de JUNIO con un caudal de aire de paso por el colector de $100 \mathrm{~m}^{3} / \mathrm{h}$. Capacidad del depósito: 100 litros.

Figura AC.7.- Evolución de la temperatura del agua en el depósito para el día tipo de JULIO con un caudal de aire de paso por el colector de $100 \mathrm{~m}^{3} / \mathrm{h}$. Capacidad del depósito: 100 litros

Figura AC.8.- Evolución de la temperatura del agua en el depósito para el día tipo de AGOSTO con un caudal de aire de paso por el colector de $100 \mathrm{~m}^{3} / \mathrm{h}$. Capacidad del depósito: 100 litros. 362

Figura AC.9.- Evolución de la temperatura del agua en el depósito para el día tipo de SEPTIEMBRE con un caudal de aire de paso por el colector de $100 \mathrm{~m}$ 3/h. Capacidad del depósito: 100 litros.........362

Figura AC.10.- Evolución de la temperatura del agua en el depósito para el día tipo de MAYO con un caudal de aire de paso por el colector de $200 \mathrm{~m}^{3} / \mathrm{h}$. Capacidad del depósito: 100 litros.

Figura AC.11.- Evolución de la temperatura del agua en el depósito para el día tipo de JUNIO con un caudal de aire de paso por el colector de $200 \mathrm{~m}^{3} / \mathrm{h}$. Capacidad del depósito: 100 litros.

Figura AC.12.- Evolución de la temperatura del agua en el depósito para el día tipo de JULIO con un caudal de aire de paso por el colector de $200 \mathrm{~m}^{3} / \mathrm{h}$. Capacidad del depósito: 100 litros. 364

Figura AC.13.- Evolución de la temperatura del agua en el depósito para el día tipo de AGOSTO con un caudal de aire de paso por el colector de $200 \mathrm{~m}^{3} / \mathrm{h}$. Capacidad del depósito: 100 litros. 364

Figura AC.14.- Evolución de la temperatura del agua en el depósito para el día tipo de SEPTIEMBRE con un caudal de aire de paso por el colector de $200 \mathrm{~m}^{3} / \mathrm{h}$. Capacidad del depósito: 100 litros.........365

Figura AC.15.- Evolución de la temperatura del agua en el depósito para el día tipo de MAYO con un caudal de aire de paso por el colector de $300 \mathrm{~m}^{3} / \mathrm{h}$. Capacidad del depósito: 100 litros. 365 
Figura AC.16.- Evolución de la temperatura del agua en el depósito para el día tipo de JUNIO con un caudal de aire de paso por el colector de $300 \mathrm{~m}^{3} / \mathrm{h}$. Capacidad del depósito: 100 litros.

Figura AC.17.- Evolución de la temperatura del agua en el depósito para el día tipo de JULIO con un caudal de aire de paso por el colector de $300 \mathrm{~m}^{3} / \mathrm{h}$. Capacidad del depósito: 100 litros. 366

Figura AC.18.- Evolución de la temperatura del agua en el depósito para el día tipo de AGOSTO con un caudal de aire de paso por el colector de $300 \mathrm{~m}^{3} / \mathrm{h}$. Capacidad del depósito: 100 litros.

Figura AC.19.- Evolución de la temperatura del agua en el depósito para el día tipo de SEPTIEMBRE con un caudal de aire de paso por el colector de $300 \mathrm{~m}^{3} / \mathrm{h}$. Capacidad del depósito: 100 litros.........367

Figura AC.20.- Evolución de la temperatura del agua en el depósito para el día tipo de MAYO con un caudal de aire de paso por el colector de $100 \mathrm{~m}^{3} / \mathrm{h}$. Capacidad del depósito: 300 litros.

Figura AC.21.- Evolución de la temperatura del agua en el depósito para el día tipo de JUNIO con un caudal de aire de paso por el colector de $100 \mathrm{~m}^{3} / \mathrm{h}$. Capacidad del depósito: 300 litros.

Figura AC.22.- Evolución de la temperatura del agua en el depósito para el día tipo de JULIO con un caudal de aire de paso por el colector de $100 \mathrm{~m}^{3} / \mathrm{h}$. Capacidad del depósito: 300 litros.

Figura AC.23.- Evolución de la temperatura del agua en el depósito para el día tipo de AGOSTO con un caudal de aire de paso por el colector de $100 \mathrm{~m}^{3} / \mathrm{h}$. Capacidad del depósito: 300 litros.

Figura AC.24.- Evolución de la temperatura del agua en el depósito para el día tipo de SEPTIEMBRE con un caudal de aire de paso por el colector de $100 \mathrm{~m}^{3} / \mathrm{h}$. Capacidad del depósito: 300 litros

Figura AC.25.- Evolución de la temperatura del agua en el depósito para el día tipo de MAYO con un caudal de aire de paso por el colector de $200 \mathrm{~m}^{3} / \mathrm{h}$. Capacidad del depósito: 300 litros.

Figura AC.26.- Evolución de la temperatura del agua en el depósito para el día tipo de JUNIO con un caudal de aire de paso por el colector de $200 \mathrm{~m}^{3} / \mathrm{h}$. Capacidad del depósito: 300 litros.

Figura AC.27.- Evolución de la temperatura del agua en el depósito para el día tipo de JULIO con un caudal de aire de paso por el colector de $200 \mathrm{~m}^{3} / \mathrm{h}$. Capacidad del depósito: 300 litros.

Figura AC.28.- Evolución de la temperatura del agua en el depósito para el día tipo de AGOSTO con un caudal de aire de paso por el colector de $200 \mathrm{~m}^{3} / \mathrm{h}$. Capacidad del depósito: 300 litros.

Figura AC.29.- Evolución de la temperatura del agua en el depósito para el día tipo de SEPTIEMBRE con un caudal de aire de paso por el colector de $200 \mathrm{~m}^{3} / \mathrm{h}$. Capacidad del depósito: 300 litros........372

Figura AC.30.- Evolución de la temperatura del agua en el depósito para el día tipo de MAYO con un caudal de aire de paso por el colector de $300 \mathrm{~m}^{3} / \mathrm{h}$. Capacidad del depósito: 300 litros.

Figura AC.31.- Evolución de la temperatura del agua en el depósito para el día tipo de JUNIO con un caudal de aire de paso por el colector de $300 \mathrm{~m}^{3} / \mathrm{h}$. Capacidad del depósito: 300 litros. 
Figura AC.32.- Evolución de la temperatura del agua en el depósito para el día tipo de JULIO con un caudal de aire de paso por el colector de $300 \mathrm{~m}^{3} / \mathrm{h}$. Capacidad del depósito: 300 litros. 374

Figura AC.33.- Evolución de la temperatura del agua en el depósito para el día tipo de AGOSTO con un caudal de aire de paso por el colector de $300 \mathrm{~m}^{3} / \mathrm{h}$. Capacidad del depósito: 300 litros.

Figura AC.34.- Evolución de la temperatura del agua en el depósito para el día tipo de SEPTIEMBRE con un caudal de aire de paso por el colector de $300 \mathrm{~m} 3 / \mathrm{h}$. Capacidad del depósito: 300 litros

Figura AC.35.- Evolución de la temperatura del agua en el depósito para el día tipo de MAYO con un caudal de aire de paso por el colector de $100 \mathrm{~m}^{3} / \mathrm{h}$. Capacidad del depósito: 500 litros.

Figura AC.36.- Evolución de la temperatura del agua en el depósito para el día tipo de JUNIO con un caudal de aire de paso por el colector de $100 \mathrm{~m}^{3} / \mathrm{h}$. Capacidad del depósito: 500 litros.

Figura AC.37.- Evolución de la temperatura del agua en el depósito para el día tipo de JULIO con un caudal de aire de paso por el colector de $100 \mathrm{~m}^{3} / \mathrm{h}$. Capacidad del depósito: 500 litros.

Figura AC.38.- Evolución de la temperatura del agua en el depósito para el día tipo de AGOSTO con un caudal de aire de paso por el colector de $100 \mathrm{~m}^{3} / \mathrm{h}$. Capacidad del depósito: 500 litros.

Figura AC.39.- Evolución de la temperatura del agua en el depósito para el día tipo de SEPTIEMBRE con un caudal de aire de paso por el colector de $100 \mathrm{~m}^{3} / \mathrm{h}$. Capacidad del depósito: 500 litros

Figura AC.40.- Evolución de la temperatura del agua en el depósito para el día tipo de MAYO con un caudal de aire de paso por el colector de $200 \mathrm{~m}^{3} / \mathrm{h}$. Capacidad del depósito: 500 litros.

Figura AC.41.- Evolución de la temperatura del agua en el depósito para el día tipo de JUNIO con un caudal de aire de paso por el colector de $200 \mathrm{~m}^{3} / \mathrm{h}$. Capacidad del depósito: 500 litros.

Figura AC.42.- Evolución de la temperatura del agua en el depósito para el día tipo de JULIO con un caudal de aire de paso por el colector de $200 \mathrm{~m}^{3} / \mathrm{h}$. Capacidad del depósito: 500 litros.

Figura AC.43.- Evolución de la temperatura del agua en el depósito para el día tipo de AGOSTO con un caudal de aire de paso por el colector de $200 \mathrm{~m}^{3} / \mathrm{h}$. Capacidad del depósito: 500 litros.

Figura AC.44.- Evolución de la temperatura del agua en el depósito para el día tipo de SEPTIEMBRE con un caudal de aire de paso por el colector de $200 \mathrm{~m}^{3} / \mathrm{h}$. Capacidad del depósito: 500 litros

Figura AC.45.- Evolución de la temperatura del agua en el depósito para el día tipo de MAYO con un caudal de aire de paso por el colector de $300 \mathrm{~m}^{3} / \mathrm{h}$. Capacidad del depósito: 500 litros.

Figura AC.46.- Evolución de la temperatura del agua en el depósito para el día tipo de JUNIO con un caudal de aire de paso por el colector de $300 \mathrm{~m}^{3} / \mathrm{h}$. Capacidad del depósito: 500 litros.

Figura AC.47.- Evolución de la temperatura del agua en el depósito para el día tipo de JULIO con un caudal de aire de paso por el colector de $300 \mathrm{~m}^{3} / \mathrm{h}$. Capacidad del depósito: 500 litros. 381 
Figura AC.48.- Evolución de la temperatura del agua en el depósito para el día tipo de AGOSTO con un caudal de aire de paso por el colector de $300 \mathrm{~m}^{3} / \mathrm{h}$. Capacidad del depósito: 500 litros.

Figura AC.49.- Evolución de la temperatura del agua en el depósito para el día tipo de SEPTIEMBRE con un caudal de aire de paso por el colector de $300 \mathrm{~m}^{3} / \mathrm{h}$. Capacidad del depósito: 500 litros........382

\section{LISTA DE TABLAS:}

Tabla AC.1.- Fcator de corrección $k$ para superficies inclinadas. 339

Tabla AC.2.- Propiedades del agua saturada [1] ............................................................... 346

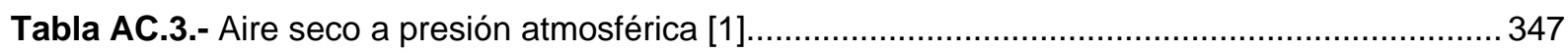

Tabla AC.4. Geometría de la superficie, flujo normal en tubos aleteados. Tubos circulares, aletas continuas [2]. 


\section{Nomenclatura:}

$C_{p}$ : calor específico $(\mathrm{J} / \mathrm{kgK})$

$D_{h}$ : diámetro hidráulico [m]

$F$. factor de visión $\left[\mathrm{m}^{-2}\right]$

$F_{R}$ : factor de ganancia de la ecuación de Bliss

$h$ : coeficiente de transferencia de calor por convección o radiación $\left[\mathrm{W} /\left(\mathrm{m}^{2} \mathrm{~K}\right)\right]$

I: Irradiancia $\left(\mathrm{W} / \mathrm{m}^{2}\right)$

$L$ : longitud del colector [m]

$M$ : Masa [kg]

$Q$ : Flujo de calor (W)

$R$ : resistencia a la transferencia de calor $\left[\mathrm{m}^{2} \mathrm{~K} / \mathrm{W}\right]$

$S$ : superficie del colector $\left(\mathrm{m}^{2}\right)$

T. Temperatura $\left[{ }^{\circ} \mathrm{C}\right]$

$U$ : coeficiente de pérdidas $\left[\mathrm{W} /\left(\mathrm{m}^{2} \mathrm{~K}\right)\right]$

$V$ : velocidad del viento $[\mathrm{m} / \mathrm{s}]$

$\alpha:$ absortividad

$\varepsilon$ : emisividad

$\tau$. transmisividad

\section{Subíndices:}

a: ambiente

abs: absorbedor

$b$ : base o fondo

c. convección

cam: aire en la cámara entre absorbedor y cubierta

$f$ flujo de aire

$p$ : paredes de los conductos

$r$ radiación

sky: cielo

v. cubierta (vidrio)

$W$. viento

Números adimensionales:
$\mathrm{Nu}:$ Nusselt
Ra : Rayleigh
Re : Reynolds
Pr : Prandt 
ANEXO C: SIMULACIONES 


\section{AC.1.- FACTOR DE CORRECCIÓN $K$ PARA SUPERFICIES \\ INCLINADAS.}

Tabla AC.1.- Factor de corrección $k$ para superficies inclinadas.

\begin{tabular}{|c|c|c|c|c|c|c|c|c|c|c|c|c|}
\hline Incli. & ENE & FEB & MAR & ABR & MAY & JUN & JUL & AGO & SEP & OCT & NOV & DIC \\
\hline 0 & 1 & 1 & 1 & 1 & 1 & 1 & 1 & 1 & 1 & 1 & 1 & 1 \\
\hline 5 & 1,05 & 1,04 & 1,03 & 1,01 & 1 & 1 & 1 & 1,02 & 1,03 & 1,05 & 1,06 & 1,06 \\
\hline 10 & 1,1 & 1,08 & 1,05 & 1,02 & 1 & 0,99 & 1 & 1,02 & 1,06 & 1,1 & 1,12 & 1,12 \\
\hline 15 & 1,14 & 1,11 & 1,07 & 1,02 & 0,99 & 0,98 & 0,99 & 1,03 & 1,08 & 1,13 & 1,17 & 1,17 \\
\hline 20 & 1,17 & 1,13 & 1,08 & 1,02 & 0,97 & 0,95 & 0,97 & 1,02 & 1,09 & 1,16 & 1,21 & 1,21 \\
\hline 25 & 1,2 & 1,15 & 1,08 & 1 & 0,95 & 0,93 & 0,95 & 1,01 & 1,09 & 1,19 & 1,25 & 1,24 \\
\hline 30 & 1,22 & 1,15 & 1,07 & 0,98 & 0,92 & 0,89 & 0,92 & 0,99 & 1,09 & 1,2 & 1,27 & 1,27 \\
\hline 35 & 1,23 & 1,16 & 1,06 & 0,96 & 0,88 & 0,85 & 0,88 & 0,96 & 1,08 & 1,21 & 1,29 & 1,29 \\
\hline 40 & 1,24 & 1,15 & 1,04 & 0,92 & 0,84 & 0,8 & 0,84 & 0,93 & 1,06 & 1,21 & 1,3 & 1,3 \\
\hline 45 & 1,23 & 1,14 & 1,01 & 0,89 & 0,79 & 0,75 & 0,79 & 0,89 & 1,04 & 1,2 & 1,3 & 1,3 \\
\hline 50 & 1,22 & 1,12 & 0,98 & 0,84 & 0,73 & 0,69 & 0,73 & 0,84 & 1 & 1,18 & 1,3 & 1,3 \\
\hline 55 & 1,2 & 1,09 & 0,94 & 0,79 & 0,68 & 0,63 & 0,67 & 0,79 & 0,96 & 1,15 & 1,28 & 1,28 \\
\hline 60 & 1,18 & 1,05 & 0,9 & 0,73 & 0,61 & 0,57 & 0,61 & 0,73 & 0,92 & 1,12 & 1,26 & 1,26 \\
\hline 65 & 1,14 & 1,01 & 0,85 & 0,67 & 0,55 & 0,5 & 0,54 & 0,67 & 0,86 & 1,08 & 1,22 & 1,23 \\
\hline 70 & 1,1 & 0,97 & 0,79 & 0,61 & 0,48 & 0,42 & 0,47 & 0,6 & 0,81 & 1,03 & 1,18 & 1,19 \\
\hline 75 & 1,06 & 0,91 & 0,73 & 0,54 & 0,4 & 0,35 & 0,39 & 0,53 & 0,74 & 0,97 & 1,14 & 1,15 \\
\hline 80 & 1 & 0,86 & 0,66 & 0,47 & 0,33 & 0,27 & 0,32 & 0,46 & 0,67 & 0,91 & 1,08 & 1,1 \\
\hline 85 & 0,94 & 0,79 & 0,59 & 0,39 & 0,25 & 0,19 & 0,24 & 0,38 & 0,6 & 0,84 & 1,02 & 1,04 \\
\hline 90 & 0,88 & 0,72 & 0,52 & 0,32 & 0,17 & 0,11 & 0,16 & 0,31 & 0,53 & 0,77 & 0,95 & 0,98 \\
\hline
\end{tabular}

\section{LATITUD $=29^{\circ}$}

\begin{tabular}{|c|c|c|c|c|c|c|c|c|c|c|c|c|}
\hline Incli. & ENE & FEB & MAR & ABR & MAY & JUN & JUL & AGO & SEP & OCT & NOV & DIC \\
\hline 0 & 1 & 1 & 1 & 1 & 1 & 1 & 1 & 1 & 1 & 1 & 1 & 1 \\
\hline 5 & 1,05 & 1,04 & 1,03 & 1,02 & 1 & 1 & 1 & 1,02 & 1,03 & 1,05 & 1,07 & 1,06 \\
\hline 10 & 1,1 & 1,08 & 1,05 & 1,02 & 1 & 0,99 & 1 & 1,03 & 1,06 & 1,1 & 1,12 & 1,12 \\
\hline 15 & 1,15 & 1,11 & 1,07 & 1,03 & 0,99 & 0,98 & 0,99 & 1,03 & 1,08 & 1,14 & 1,18 & 1,17 \\
\hline 20 & 1,18 & 1,14 & 1,08 & 1,02 & 0,98 & 0,96 & 0,98 & 1,03 & 1,1 & 1,17 & 1,22 & 1,22 \\
\hline 25 & 1,21 & 1,15 & 1,08 & 1,01 & 0,95 & 0,93 & 0,95 & 1,01 & 1,1 & 1,2 & 1,26 & 1,25 \\
\hline 30 & 1,23 & 1,16 & 1,08 & 0,99 & 0,92 & 0,9 & 0,92 & 1 & 1,1 & 1,21 & 1,28 & 1,28 \\
\hline 35 & 1,24 & 1,17 & 1,07 & 0,97 & 0,89 & 0,86 & 0,89 & 0,97 & 1,09 & 1,22 & 1,3 & 1,3 \\
\hline 40 & 1,25 & 1,16 & 1,05 & 0,93 & 0,85 & 0,81 & 0,85 & 0,94 & 1,07 & 1,22 & 1,32 & 1,31 \\
\hline 45 & 1,24 & 1,15 & 1,02 & 0,9 & 0,8 & 0,76 & 0,8 & 0,9 & 1,05 & 1,21 & 1,32 & 1,32 \\
\hline 50 & 1,23 & 1,13 & 0,99 & 0,85 & 0,75 & 0,71 & 0,74 & 0,85 & 1,02 & 1,19 & 1,31 & 1,31 \\
\hline 55 & 1,22 & 1,1 & 0,95 & 0,8 & 0,69 & 0,64 & 0,68 & 0,8 & 0,98 & 1,17 & 1,3 & 1,3 \\
\hline 60 & 1,19 & 1,07 & 0,91 & 0,75 & 0,63 & 0,58 & 0,62 & 0,75 & 0,93 & 1,14 & 1,28 & 1,28 \\
\hline 65 & 1,16 & 1,03 & 0,86 & 0,69 & 0,56 & 0,51 & 0,55 & 0,69 & 0,88 & 1,1 & 1,24 & 1,25 \\
\hline 70 & 1,12 & 0,98 & 0,8 & 0,62 & 0,49 & 0,44 & 0,48 & 0,62 & 0,82 & 1,05 & 1,2 & 1,22 \\
\hline 75 & 1,07 & 0,93 & 0,74 & 0,55 & 0,42 & 0,36 & 0,41 & 0,55 & 0,76 & 0,99 & 1,16 & 1,17 \\
\hline 80 & 1,02 & 0,87 & 0,68 & 0,48 & 0,34 & 0,28 & 0,33 & 0,48 & 0,69 & 0,93 & 1,1 & 1,12 \\
\hline 85 & 0,96 & 0,81 & 0,61 & 0,41 & 0,26 & 0,21 & 0,25 & 0,4 & 0,62 & 0,87 & 1,04 & 1,06 \\
\hline 90 & 0,9 & 0,74 & 0,54 & 0,33 & 0,18 & 0,13 & 0,17 & 0,32 & 0,54 & 0,79 & 0,97 & 1 \\
\hline
\end{tabular}


Tabla AC.1.- Factor de corrección $k$ para superficies inclinadas (continuación).

\begin{tabular}{|c|c|c|c|c|c|c|c|c|c|c|c|c|}
\hline Incli. & ENE & FEB & MAR & $\mathrm{ABR}$ & MAY & JUN & JUL & AGO & SEP & OCT & NOV & DIC \\
\hline 0 & 1 & 1 & 1 & 1 & 1 & 1 & 1 & 1 & 1 & 1 & 1 & 1 \\
\hline 5 & 1,06 & 1,05 & 1,04 & 1,02 & 1,01 & 1,01 & 1,01 & 1,02 & 1,04 & 1,06 & 1,08 & 1,07 \\
\hline 10 & 1,12 & 1,1 & 1,07 & 1,04 & 1,01 & 1,01 & 1,02 & 1,04 & 1,08 & 1,12 & 1,14 & 1,14 \\
\hline 15 & 1,17 & 1,13 & 1,09 & 1,05 & 1,01 & 1 & 1,01 & 1,05 & 1,11 & 1,17 & 1,21 & 1,2 \\
\hline 20 & 1,21 & 1,16 & 1,11 & 1,05 & 1 & 0,98 & 1 & 1,05 & 1,13 & 1,21 & 1,26 & 1,25 \\
\hline 25 & 1,25 & 1,19 & 1,12 & 1,04 & 0,98 & 0,96 & 0,99 & 1,05 & 1,14 & 1,24 & 1,31 & 1,3 \\
\hline 30 & 1,27 & 1,2 & 1,12 & 1,03 & 0,96 & 0,94 & 0,96 & 1,03 & 1,14 & 1,27 & 1,34 & 1,33 \\
\hline 35 & 1,29 & 1,21 & 1,11 & 1,01 & 0,93 & 0,9 & 0,93 & 1,01 & 1,14 & 1,28 & 1,37 & 1,36 \\
\hline 40 & 1,31 & 1,21 & 1,1 & 0,98 & 0,89 & 0,86 & 0,89 & 0,99 & 1,13 & 1,29 & 1,39 & 1,38 \\
\hline 45 & 1,31 & 1,21 & 1,08 & 0,95 & 0,85 & 0,81 & 0,85 & 0,95 & 1,11 & 1,29 & 1,4 & 1,4 \\
\hline 50 & 1,31 & 1,19 & 1,05 & 0,91 & 0,8 & 0,76 & 0,8 & 0,91 & 1,09 & 1,28 & 1,41 & 1,4 \\
\hline 55 & 1,3 & 1,17 & 1,02 & 0,86 & 0,75 & 0,7 & 0,75 & 0,87 & 1,05 & 1,26 & 1,4 & 1,39 \\
\hline 60 & 1,28 & 1,14 & 0,98 & 0,81 & 0,69 & 0,64 & 0,69 & 0,82 & 1,01 & 1,23 & 1,38 & 1,38 \\
\hline 65 & 1,25 & 1,11 & 0,93 & 0,75 & 0,63 & 0,58 & 0,62 & 0,76 & 0,96 & 1,2 & 1,36 & 1,36 \\
\hline 70 & 1,21 & 1,06 & 0,88 & 0,69 & 0,56 & 0,51 & 0,55 & 0,69 & 0,91 & 1,15 & 1,32 & 1,32 \\
\hline 75 & 1,17 & 1,01 & 0,82 & 0,63 & 0,49 & 0,43 & 0,48 & 0,63 & 0,85 & 1,1 & 1,28 & 1,28 \\
\hline 80 & 1,12 & 0,96 & 0,76 & 0,56 & 0,41 & 0,36 & 0,41 & 0,56 & 0,78 & 1,04 & 1,23 & 1,24 \\
\hline 85 & 1,06 & 0,9 & 0,69 & 0,48 & 0,34 & 0,28 & 0,33 & 0,48 & 0,71 & 0,98 & 1,17 & 1,18 \\
\hline 90 & 1 & 0,83 & 0,62 & 0,41 & 0,26 & 0,2 & 0,25 & 0,4 & 0,64 & 0,91 & 1,1 & 1,12 \\
\hline
\end{tabular}

\section{LATITUD $=35^{\circ}$}

\begin{tabular}{|c|c|c|c|c|c|c|c|c|c|c|c|c|}
\hline Incli. & ENE & FEB & MAR & ABR & MAY & JUN & JUL & AGO & SEP & OCT & NOV & DIC \\
\hline 0 & 1 & 1 & 1 & 1 & 1 & 1 & 1 & 1 & 1 & 1 & 1 & 1 \\
\hline 5 & 1,06 & 1,05 & 1,04 & 1,02 & 1,01 & 1,01 & 1,01 & 1,03 & 1,04 & 1,06 & 1,08 & 1,07 \\
\hline 10 & 1,12 & 1,1 & 1,07 & 1,04 & 1,02 & 1,01 & 1,02 & 1,04 & 1,08 & 1,12 & 1,15 & 1,14 \\
\hline 15 & 1,17 & 1,14 & 1,09 & 1,05 & 1,02 & 1 & 1,02 & 1,05 & 1,11 & 1,17 & 1,21 & 1,21 \\
\hline 20 & 1,22 & 1,17 & 1,11 & 1,05 & 1,01 & 0,99 & 1,01 & 1,06 & 1,13 & 1,22 & 1,27 & 1,26 \\
\hline 25 & 1,25 & 1,2 & 1,12 & 1,05 & 0,99 & 0,97 & 0,99 & 1,05 & 1,15 & 1,25 & 1,32 & 1,31 \\
\hline 30 & 1,28 & 1,21 & 1,13 & 1,04 & 0,97 & 0,94 & 0,97 & 1,04 & 1,15 & 1,28 & 1,36 & 1,35 \\
\hline 35 & 1,31 & 1,22 & 1,12 & 1,02 & 0,94 & 0,91 & 0,94 & 1,02 & 1,15 & 1,29 & 1,39 & 1,38 \\
\hline 40 & 1,32 & 1,23 & 1,11 & 0,99 & 0,9 & 0,87 & 0,9 & 1 & 1,14 & 1,3 & 1,41 & 1,4 \\
\hline 45 & 1,33 & 1,22 & 1,09 & 0,96 & 0,86 & 0,82 & 0,86 & 0,97 & 1,13 & 1,3 & 1,42 & 1,41 \\
\hline 50 & 1,32 & 1,21 & 1,07 & 0,92 & 0,81 & 0,77 & 0,81 & 0,93 & 1,1 & 1,3 & 1,43 & 1,42 \\
\hline 55 & 1,31 & 1,19 & 1,03 & 0,87 & 0,76 & 0,72 & 0,76 & 0,88 & 1,07 & 1,28 & 1,42 & 1,41 \\
\hline 60 & 1,29 & 1,16 & 0,99 & 0,82 & 0,7 & 0,66 & 0,7 & 0,83 & 1,03 & 1,25 & 1,41 & 1,4 \\
\hline 65 & 1,27 & 1,12 & 0,95 & 0,77 & 0,64 & 0,59 & 0,64 & 0,77 & 0,98 & 1,22 & 1,38 & 1,38 \\
\hline 70 & 1,23 & 1,08 & 0,9 & 0,71 & 0,57 & 0,52 & 0,57 & 0,71 & 0,93 & 1,18 & 1,35 & 1,35 \\
\hline 75 & 1,19 & 1,03 & 0,84 & 0,64 & 0,5 & 0,45 & 0,5 & 0,64 & 0,87 & 1,13 & 1,31 & 1,31 \\
\hline 80 & 1,14 & 0,98 & 0,78 & 0,57 & 0,43 & 0,37 & 0,42 & 0,57 & 0,8 & 1,07 & 1,26 & 1,26 \\
\hline 85 & 1,09 & 0,92 & 0,71 & 0,5 & 0,35 & 0,29 & 0,34 & 0,5 & 0,73 & 1 & 1,2 & 1,21 \\
\hline 90 & 1,02 & 0,85 & 0,64 & 0,42 & 0,27 & 0,21 & 0,26 & 0,42 & 0,66 & 0,93 & 1,13 & 1,15 \\
\hline
\end{tabular}


Tabla AC.1.- Factor de corrección $k$ para superficies inclinadas (continuación).

\begin{tabular}{|c|c|c|c|c|c|c|c|c|c|c|c|c|}
\hline Incli. & ENE & FEB & MAR & $\mathrm{ABR}$ & MAY & JUN & JUL & AGO & SEP & OCT & NOV & DIC \\
\hline 0 & 1 & 1 & 1 & 1 & 1 & 1 & 1 & 1 & 1 & 1 & 1 & 1 \\
\hline 5 & 1,07 & 1,05 & 1,04 & 1,02 & 1,01 & 1,01 & 1,01 & 1,03 & 1,05 & 1,07 & 1,08 & 1,08 \\
\hline 10 & 1,13 & 1,1 & 1,07 & 1,04 & 1,02 & 1,01 & 1,02 & 1,05 & 1,08 & 1,13 & 1,15 & 1,15 \\
\hline 15 & 1,18 & 1,14 & 1,1 & 1,05 & 1,02 & 1,01 & 1,02 & 1,06 & 1,12 & 1,18 & 1,22 & 1,21 \\
\hline 20 & 1,22 & 1,18 & 1,12 & 1,06 & 1,01 & 0,99 & 1,01 & 1,06 & 1,14 & 1,22 & 1,28 & 1,27 \\
\hline 25 & 1,26 & 1,2 & 1,13 & 1,05 & 1 & 0,98 & 1 & 1,06 & 1,16 & 1,26 & 1,33 & 1,32 \\
\hline 30 & 1,29 & 1,22 & 1,13 & 1,04 & 0,98 & 0,95 & 0,98 & 1,05 & 1,16 & 1,29 & 1,37 & 1,36 \\
\hline 35 & 1,32 & 1,23 & 1,13 & 1,02 & 0,95 & 0,92 & 0,95 & 1,03 & 1,16 & 1,31 & 1,4 & 1,39 \\
\hline 40 & 1,33 & 1,24 & 1,12 & 1 & 0,91 & 0,88 & 0,91 & 1,01 & 1,16 & 1,32 & 1,43 & 1,41 \\
\hline 45 & 1,34 & 1,23 & 1,1 & 0,97 & 0,87 & 0,84 & 0,87 & 0,98 & 1,14 & 1,32 & 1,44 & 1,43 \\
\hline 50 & 1,34 & 1,22 & 1,08 & 0,93 & 0,82 & 0,78 & 0,82 & 0,94 & 1,12 & 1,31 & 1,45 & 1,44 \\
\hline 55 & 1,33 & 1,2 & 1,05 & 0,89 & 0,77 & 0,73 & 0,77 & 0,9 & 1,08 & 1,3 & 1,44 & 1,43 \\
\hline 60 & 1,31 & 1,17 & 1,01 & 0,84 & 0,71 & 0,67 & 0,71 & 0,84 & 1,05 & 1,27 & 1,43 & 1,42 \\
\hline 65 & 1,29 & 1,14 & 0,96 & 0,78 & 0,65 & 0,6 & 0,65 & 0,79 & 1 & 1,24 & 1,41 & 1,4 \\
\hline 70 & 1,25 & 1,1 & 0,91 & 0,72 & 0,59 & 0,53 & 0,58 & 0,73 & 0,95 & 1,2 & 1,37 & 1,37 \\
\hline 75 & 1,21 & 1,05 & 0,85 & 0,66 & 0,52 & 0,46 & 0,51 & 0,66 & 0,89 & 1,15 & 1,33 & 1,33 \\
\hline 80 & 1,16 & 1 & 0,79 & 0,59 & 0,44 & 0,39 & 0,44 & 0,59 & 0,82 & 1,09 & 1,28 & 1,29 \\
\hline 85 & 1,11 & 0,94 & 0,73 & 0,52 & 0,37 & 0,31 & 0,36 & 0,51 & 0,75 & 1,03 & 1,23 & 1,23 \\
\hline 90 & 1,05 & 0,87 & 0,65 & 0,44 & 0,29 & 0,23 & 0,28 & 0,44 & 0,68 & 0,96 & 1,16 & 1,17 \\
\hline
\end{tabular}

\section{LATITUD $=37^{\circ}$}

\begin{tabular}{|c|c|c|c|c|c|c|c|c|c|c|c|c|}
\hline Incli. & ENB & FEB & MAR & ABR & MAY & JUN & JUL & AGO & SEP & OCT & NOV & DIC \\
\hline 0 & 1 & 1 & 1 & 1 & 1 & 1 & 1 & 1 & 1 & 1 & 1 & 1 \\
\hline 5 & 1,07 & 1,06 & 1,04 & 1,03 & 1,01 & 1,01 & 1,02 & 1,03 & 1,05 & 1,07 & 1,08 & 1,08 \\
\hline 10 & 1,13 & 1,1 & 1,08 & 1,05 & 1,02 & 1,01 & 1,02 & 1,05 & 1,09 & 1,13 & 1,16 & 1,15 \\
\hline 15 & 1,18 & 1,15 & 1,1 & 1,06 & 1,02 & 1,01 & 1,02 & 1,06 & 1,12 & 1,19 & 1,23 & 1,22 \\
\hline 20 & 1,23 & 1,18 & 1,12 & 1,06 & 1,02 & 1 & 1,02 & 1,07 & 1,15 & 1,23 & 1,29 & 1,28 \\
\hline 25 & 1,27 & 1,21 & 1,14 & 1,06 & 1 & 0,98 & 1 & 1,07 & 1,16 & 1,27 & 1,34 & 1,33 \\
\hline 30 & 1,3 & 1,23 & 1,14 & 1,05 & 0,98 & 0,96 & 0,98 & 1,06 & 1,17 & 1,3 & 1,38 & 1,37 \\
\hline 35 & 1,33 & 1,24 & 1,14 & 1,03 & 0,96 & 0,93 & 0,96 & 1,04 & 1,17 & 1,32 & 1,42 & 1,41 \\
\hline 40 & 1,35 & 1,25 & 1,13 & 1,01 & 0,92 & 0,89 & 0,92 & 1,02 & 1,17 & 1,34 & 1,44 & 1,43 \\
\hline 45 & 1,35 & 1,25 & 1,11 & 0,98 & 0,88 & 0,85 & 0,88 & 0,99 & 1,15 & 1,34 & 1,46 & 1,45 \\
\hline 50 & 1,35 & 1,24 & 1,09 & 0,94 & 0,84 & 0,8 & 0,84 & 0,95 & 1,13 & 1,33 & 1,47 & 1,46 \\
\hline 55 & 1,35 & 1,22 & 1,06 & 0,9 & 0,78 & 0,74 & 0,78 & 0,91 & 1,1 & 1,32 & 1,47 & 1,45 \\
\hline 60 & 1,33 & 1,19 & 1,02 & 0,85 & 0,73 & 0,68 & 0,73 & 0,86 & 1,06 & 1,3 & 1,45 & 1,44 \\
\hline 65 & 1,31 & 1,16 & 0,98 & 0,8 & 0,67 & 0,62 & 0,66 & 0,8 & 1,02 & 1,26 & 1,43 & 1,42 \\
\hline 70 & 1,27 & 1,12 & 0,93 & 0,74 & 0,6 & 0,55 & 0,6 & 0,74 & 0,97 & 1,22 & 1,4 & 1,4 \\
\hline 75 & 1,23 & 1,07 & 0,87 & 0,67 & 0,53 & 0,48 & 0,53 & 0,68 & 0,91 & 1,17 & 1,36 & 1,36 \\
\hline 80 & 1,19 & 1,02 & 0,81 & 0,6 & 0,46 & 0,4 & 0,45 & 0,6 & 0,84 & 1,12 & 1,31 & 1,31 \\
\hline 85 & 1,13 & 0,96 & 0,74 & 0,53 & 0,38 & 0,32 & 0,38 & 0,53 & 0,77 & 1,05 & 1,26 & 1,26 \\
\hline 90 & 1,07 & 0,89 & 0,67 & 0,46 & 0,3 & 0,25 & 0,3 & 0,45 & 0,7 & 0,98 & 1,19 & 1,2 \\
\hline
\end{tabular}


Tabla AC.1.- Factor de corrección $k$ para superficies inclinadas (continuación).

\begin{tabular}{|c|c|c|c|c|c|c|c|c|c|c|c|c|}
\hline Incli. & ENB & FEB & MAR & ABR & MAY & $\pi \mathrm{N}$ & JUL & AGO & SEP & OCT & NOV & DIC \\
\hline 0 & 1 & 1 & 1 & 1 & 1 & 1 & 1 & 1 & 1 & 1 & 1 & 1 \\
\hline 5 & 1,07 & 1,06 & 1,04 & 1,03 & 1,02 & 1,01 & 1,02 & 1,03 & 1,05 & 1,07 & 1,08 & 1,08 \\
\hline 10 & 1,13 & 1,11 & 1,08 & 1,05 & 1,02 & 1,02 & 1,03 & 1,05 & 1,09 & 1,14 & 1,16 & 1,16 \\
\hline 15 & 1,19 & 1,15 & 1,11 & 1,06 & 1,03 & 1,01 & 1,03 & 1,07 & 1,13 & 1,19 & 1,23 & 1,22 \\
\hline 20 & 1,24 & 1,19 & 1,13 & 1,07 & 1,02 & 1,01 & 1,02 & 1,07 & 1,15 & 1,24 & 1,3 & 1,29 \\
\hline 25 & 1,28 & 1,22 & 1,14 & 1,07 & 1,01 & 0,99 & 1,01 & 1,08 & 1,17 & 1,28 & 1,35 & 1,34 \\
\hline 30 & 1,31 & 1,24 & 1,15 & 1,06 & 0,99 & 0,97 & 0,99 & 1,07 & 1,18 & 1,31 & 1,4 & 1,38 \\
\hline 35 & 1,34 & 1,25 & 1,15 & 1,04 & 0,96 & 0,94 & 0,97 & 1,05 & 1,19 & 1,34 & 1,43 & 1,42 \\
\hline 40 & 1,36 & 1,26 & 1,14 & 1,02 & 0,93 & 0,9 & 0,93 & 1,03 & 1,18 & 1,35 & 1,46 & 1,45 \\
\hline 45 & 1,37 & 1,26 & 1,13 & 0,99 & 0,89 & 0,86 & 0,89 & 1 & 1,17 & 1,36 & 1,48 & 1,47 \\
\hline 50 & 1,37 & 1,25 & 1,1 & 0,96 & 0,85 & 0,81 & 0,85 & 0,97 & 1,15 & 1,35 & 1,49 & 1,48 \\
\hline 55 & 1,36 & 1,23 & 1,07 & 0,91 & 0,8 & 0,75 & 0,8 & 0,92 & 1,12 & 1,34 & 1,49 & 1,48 \\
\hline 60 & 1,35 & 1,21 & 1,04 & 0,86 & 0,74 & 0,69 & 0,74 & 0,87 & 1,08 & 1,32 & 1,48 & 1,47 \\
\hline 65 & 1,33 & 1,18 & 0,99 & 0,81 & 0,68 & 0,63 & 0,68 & 0,82 & 1,04 & 1,29 & 1,46 & 1,45 \\
\hline 70 & 1,29 & 1,14 & 0,94 & 0,75 & 0,61 & 0,56 & 0,61 & 0,76 & 0,98 & 1,25 & 1,43 & 1,42 \\
\hline 75 & 1,25 & 1,09 & 0,89 & 0,69 & 0,54 & 0,49 & 0,54 & 0,69 & 0,93 & 1,2 & 1,39 & 1,39 \\
\hline 80 & 1,21 & 1,04 & 0,83 & 0,62 & 0,47 & 0,42 & 0,47 & 0,62 & 0,86 & 1,14 & 1,34 & 1,34 \\
\hline 85 & 1,15 & 0,98 & 0,76 & 0,55 & 0,4 & 0,34 & 0,39 & 0,55 & 0,79 & 1,08 & 1,29 & 1,29 \\
\hline 90 & 1,09 & 0,91 & 0,69 & 0,47 & 0,32 & 0,26 & 0,31 & 0,47 & 0,72 & 1,01 & 1,22 & 1,23 \\
\hline
\end{tabular}

\section{LATITUD $=39^{\circ}$}

\begin{tabular}{|c|c|c|c|c|c|c|c|c|c|c|c|c|}
\hline Incli. & ENB & FEB & MAR & ABR & MAY & JUN & JUL & AGO & SEP & OCT & NOV & DIC \\
\hline 0 & 1 & 1 & 1 & 1 & 1 & 1 & 1 & 1 & 1 & 1 & 1 & 1 \\
\hline 5 & 1,07 & 1,06 & 1,04 & 1,03 & 1,02 & 1,01 & 1,02 & 1,03 & 1,05 & 1,07 & 1,09 & 1,08 \\
\hline 10 & 1,14 & 1,11 & 1,08 & 1,05 & 1,03 & 1,02 & 1,03 & 1,06 & 1,1 & 1,14 & 1,17 & 1,16 \\
\hline 15 & 1,19 & 1,16 & 1,11 & 1,07 & 1,03 & 1,02 & 1,03 & 1,07 & 1,13 & 1,2 & 1,24 & 1,23 \\
\hline 20 & 1,25 & 1,2 & 1,14 & 1,07 & 1,03 & 1,01 & 1,03 & 1,08 & 1,16 & 1,25 & 1,31 & 1,29 \\
\hline 25 & 1,29 & 1,23 & 1,15 & 1,07 & 1,02 & 1 & 1,02 & 1,08 & 1,18 & 1,29 & 1,36 & 1,35 \\
\hline 30 & 1,33 & 1,25 & 1,16 & 1,07 & 1 & 0,97 & 1 & 1,08 & 1,19 & 1,33 & 1,41 & 1,4 \\
\hline 35 & 1,35 & 1,27 & 1,16 & 1,05 & 0,97 & 0,94 & 0,98 & 1,06 & 1,2 & 1,35 & 1,45 & 1,43 \\
\hline 40 & 1,37 & 1,27 & 1,15 & 1,03 & 0,94 & 0,91 & 0,94 & 1,04 & 1,19 & 1,37 & 1,48 & 1,46 \\
\hline 45 & 1,38 & 1,27 & 1,14 & 1 & 0,9 & 0,87 & 0,9 & 1,01 & 1,18 & 1,37 & 1,5 & 1,48 \\
\hline 50 & 1,39 & 1,26 & 1,12 & 0,97 & 0,86 & 0,82 & 0,86 & 0,98 & 1,16 & 1,37 & 1,51 & 1,5 \\
\hline 55 & 1,38 & 1,25 & 1,09 & 0,93 & 0,81 & 0,77 & 0,81 & 0,94 & 1,13 & 1,36 & 1,51 & 1,5 \\
\hline 60 & 1,37 & 1,22 & 1,05 & 0,88 & 0,75 & 0,71 & 0,75 & 0,89 & 1,1 & 1,34 & 1,51 & 1,49 \\
\hline 65 & 1,35 & 1,19 & 1,01 & 0,83 & 0,69 & 0,65 & 0,69 & 0,83 & 1,05 & 1,31 & 1,49 & 1,47 \\
\hline 70 & 1,32 & 1,15 & 0,96 & 0,77 & 0,63 & 0,58 & 0,63 & 0,77 & 1 & 1,27 & 1,46 & 1,45 \\
\hline 75 & 1,28 & 1,11 & 0,91 & 0,7 & 0,56 & 0,51 & 0,56 & 0,71 & 0,95 & 1,23 & 1,42 & 1,41 \\
\hline 80 & 1,23 & 1,06 & 0,84 & 0,64 & 0,49 & 0,43 & 0,48 & 0,64 & 0,88 & 1,17 & 1,37 & 1,37 \\
\hline 85 & 1,18 & 1 & 0,78 & 0,56 & 0,41 & 0,35 & 0,41 & 0,56 & 0,81 & 1,11 & 1,32 & 1,32 \\
\hline 90 & 1,12 & 0,93 & 0,71 & 0,49 & 0,33 & 0,28 & 0,33 & 0,49 & 0,74 & 1,04 & 1,25 & 1,26 \\
\hline
\end{tabular}


Tabla AC.1.- Factor de corrección $k$ para superficies inclinadas (continuación).

\begin{tabular}{|c|c|c|c|c|c|c|c|c|c|c|c|c|}
\hline Incli. & ENE & FEB & MAR & ABR & MAY & JUN & JUL & AGO & SEP & OCT & Nov & DIC \\
\hline 0 & 1 & 1 & 1 & 1 & 1 & 1 & 1 & 1 & 1 & 1 & 1 & 1 \\
\hline 5 & 1,07 & 1,06 & 1,05 & 1,03 & 1,02 & 1,01 & 1,02 & 1,03 & 1,05 & 1,08 & 1,09 & 1,09 \\
\hline 10 & 1,14 & 1,11 & 1,08 & 1,05 & 1,03 & 1,02 & 1,03 & 1,06 & 1,1 & 1,14 & 1,17 & 1,16 \\
\hline 15 & 1,2 & 1,16 & 1,12 & 1,07 & 1,03 & 1,02 & 1,04 & 1,08 & 1,14 & 1,21 & 1,25 & 1,24 \\
\hline 20 & 1,25 & 1,2 & 1,14 & 1,08 & 1,03 & 1,02 & 1,03 & 1,09 & 1,17 & 1,26 & 1,32 & 1,3 \\
\hline 25 & 1,3 & 1,23 & 1,16 & 1,08 & 1,02 & 1 & 1,02 & 1,09 & 1,19 & 1,3 & 1,38 & 1,36 \\
\hline 30 & 1,34 & 1,26 & 1,17 & 1,07 & 1,01 & 0,98 & 1,01 & 1,09 & 1,2 & 1,34 & 1,43 & 1,41 \\
\hline 35 & 1,37 & 1,28 & 1,17 & 1,06 & 0,98 & 0,95 & 0,98 & 1,07 & 1,21 & 1,37 & 1,47 & 1,45 \\
\hline 40 & 1,39 & 1,29 & 1,16 & 1,04 & 0,95 & 0,92 & 0,95 & 1,05 & 1,21 & 1,39 & 1,5 & 1,48 \\
\hline 45 & 1,4 & 1,29 & 1,15 & 1,01 & 0,91 & 0,88 & 0,92 & 1,03 & 1,2 & 1,39 & 1,52 & 1,5 \\
\hline 50 & 1,41 & 1,28 & 1,13 & 0,98 & 0,87 & 0,83 & 0,87 & 0,99 & 1,18 & 1,39 & 1,54 & 1,52 \\
\hline 55 & 1,4 & 1,27 & 1,1 & 0,94 & 0,82 & 0,78 & 0,82 & 0,95 & 1,15 & 1,38 & 1,54 & 1,52 \\
\hline 60 & 1,39 & 1,24 & 1,07 & 0,89 & 0,77 & 0,72 & 0,77 & 0,9 & 1,12 & 1,36 & 1,53 & 1,51 \\
\hline 65 & 1,37 & 1,21 & 1,03 & 0,84 & 0,71 & 0,66 & 0,71 & 0,85 & 1,07 & 1,34 & 1,51 & 1,5 \\
\hline 70 & 1,34 & 1,17 & 0,98 & 0,78 & 0,64 & 0,59 & 0,64 & 0,79 & 1,02 & 1,3 & 1,49 & 1,47 \\
\hline 75 & 1,3 & 1,13 & 0,92 & 0,72 & 0,57 & 0,52 & 0,57 & 0,73 & 0,97 & 1,25 & 1,45 & 1,44 \\
\hline 80 & 1,25 & 1,08 & 0,86 & 0,65 & 0,5 & 0,45 & 0,5 & 0,66 & 0,9 & 1,2 & 1,41 & 1,4 \\
\hline 85 & 1,2 & 1,02 & 0,8 & 0,58 & 0,43 & 0,37 & 0,42 & 0,58 & 0,84 & 1,14 & 1,35 & 1,35 \\
\hline 90 & 1,14 & 0,95 & 0,73 & 0,5 & 0,35 & 0,29 & 0,34 & 0,5 & 0,76 & 1,07 & 1,29 & 1,29 \\
\hline
\end{tabular}

\section{LATITUD $=41^{\circ}$}

\begin{tabular}{|c|c|c|c|c|c|c|c|c|c|c|c|c|}
\hline Incli. & ENE & FEB & MAR & ABR & MAY & JUN & JUL & AGO & SEP & OCT & NOV & DIC \\
\hline 0 & 1 & 1 & 1 & 1 & 1 & 1 & 1 & 1 & 1 & 1 & 1 & 1 \\
\hline 5 & 1,07 & 1,06 & 1,05 & 1,03 & 1,02 & 1,02 & 1,02 & 1,03 & 1,05 & 1,08 & 1,09 & 1,09 \\
\hline 10 & 1,14 & 1,12 & 1,09 & 1,06 & 1,03 & 1,02 & 1,03 & 1,06 & 1,1 & 1,15 & 1,18 & 1,17 \\
\hline 15 & 1,21 & 1,17 & 1,12 & 1,07 & 1,04 & 1,03 & 1,04 & 1,08 & 1,14 & 1,21 & 1,26 & 1,24 \\
\hline 20 & 1,26 & 1,21 & 1,15 & 1,08 & 1,04 & 1,02 & 1,04 & 1,09 & 1,17 & 1,27 & 1,33 & 1,31 \\
\hline 25 & 1,31 & 1,24 & 1,17 & 1,09 & 1,03 & 1,01 & 1,03 & 1,1 & 1,2 & 1,32 & 1,39 & 1,37 \\
\hline 30 & 1,35 & 1,27 & 1,18 & 1,08 & 1,01 & 0,99 & 1,02 & 1,09 & 1,21 & 1,35 & 1,44 & 1,42 \\
\hline 35 & 1,38 & 1,29 & 1,18 & 1,07 & 0,99 & 0,96 & 0,99 & 1,08 & 1,22 & 1,38 & 1,49 & 1,47 \\
\hline 40 & 1,4 & 1,3 & 1,18 & 1,05 & 0,96 & 0,93 & 0,96 & 1,06 & 1,22 & 1,4 & 1,52 & 1,5 \\
\hline 45 & 1,42 & 1,3 & 1,16 & 1,03 & 0,93 & 0,89 & 0,93 & 1,04 & 1,21 & 1,41 & 1,55 & 1,52 \\
\hline 50 & 1,42 & 1,3 & 1,14 & 0,99 & 0,88 & 0,84 & 0,88 & 1,01 & 1,19 & 1,41 & 1,56 & 1,54 \\
\hline 55 & 1,42 & 1,28 & 1,12 & 0,95 & 0,83 & 0,79 & 0,84 & 0,97 & 1,17 & 1,41 & 1,57 & 1,54 \\
\hline 60 & 1,41 & 1,26 & 1,08 & 0,91 & 0,78 & 0,73 & 0,78 & 0,92 & 1,14 & 1,39 & 1,56 & 1,54 \\
\hline 65 & 1,39 & 1,23 & 1,04 & 0,85 & 0,72 & 0,67 & 0,72 & 0,87 & 1,09 & 1,36 & 1,54 & 1,53 \\
\hline 70 & 1,36 & 1,19 & 0,99 & 0,8 & 0,66 & 0,61 & 0,66 & 0,81 & 1,04 & 1,32 & 1,52 & 1,5 \\
\hline 75 & 1,32 & 1,15 & 0,94 & 0,73 & 0,59 & 0,54 & 0,59 & 0,74 & 0,99 & 1,28 & 1,48 & 1,47 \\
\hline 80 & 1,28 & 1,1 & 0,88 & 0,67 & 0,52 & 0,46 & 0,52 & 0,67 & 0,93 & 1,23 & 1,44 & 1,43 \\
\hline 85 & 1,23 & 1,04 & 0,82 & 0,6 & 0,44 & 0,39 & 0,44 & 0,6 & 0,86 & 1,16 & 1,38 & 1,38 \\
\hline 90 & 1,17 & 0,98 & 0,74 & 0,52 & 0,36 & 0,31 & 0,36 & 0,52 & 0,78 & 1,09 & 1,32 & 1,32 \\
\hline
\end{tabular}


Tabla AC.1.- Factor de corrección $k$ para superficies inclinadas (continuación).

\begin{tabular}{|c|c|c|c|c|c|c|c|c|c|c|c|c|}
\hline Incli. & ENE & FEB & MAR & $\mathrm{ABR}$ & MAY & $\pi N$ & JUL & AGO & SEP & OCT & Nov & DIC \\
\hline 0 & 1 & 1 & 1 & 1 & 1 & 1 & 1 & 1 & 1 & 1 & 1 & 1 \\
\hline 5 & 1,08 & 1,06 & 1,05 & 1,03 & 1,02 & 1,02 & 1,02 & 1,04 & 1,06 & 1,08 & 1,09 & 1,09 \\
\hline 10 & 1,15 & 1,12 & 1,09 & 1,06 & 1,04 & 1,03 & 1,04 & 1,06 & 1,11 & 1,15 & 1,18 & 1,17 \\
\hline 15 & 1,21 & 1,17 & 1,13 & 1,08 & 1,04 & 1,03 & 1,04 & 1,09 & 1,15 & 1,22 & 1,26 & 1,25 \\
\hline 20 & 1,27 & 1,21 & 1,15 & 1,09 & 1,04 & 1,03 & 1,05 & 1,1 & 1,18 & 1,28 & 1,34 & 1,32 \\
\hline 25 & 1,32 & 1,25 & 1,17 & 1,09 & 1,04 & 1,01 & 1,04 & 1,1 & 1,21 & 1,33 & 1,4 & 1,38 \\
\hline 30 & 1,36 & 1,28 & 1,19 & 1,09 & 1,02 & 1 & 1,02 & 1,1 & 1,23 & 1,37 & 1,46 & 1,44 \\
\hline 35 & 1,39 & 1,3 & 1,19 & 1,08 & 1 & 0,97 & 1 & 1,09 & 1,23 & 1,4 & 1,51 & 1,48 \\
\hline 40 & 1,42 & 1,31 & 1,19 & 1,06 & 0,97 & 0,94 & 0,97 & 1,08 & 1,24 & 1,42 & 1,54 & 1,52 \\
\hline 45 & 1,43 & 1,32 & 1,18 & 1,04 & 0,94 & 0,9 & 0,94 & 1,05 & 1,23 & 1,43 & 1,57 & 1,54 \\
\hline 50 & 1,44 & 1,31 & 1,16 & 1 & 0,89 & 0,86 & 0,9 & 1,02 & 1,21 & 1,44 & 1,59 & 1,56 \\
\hline 55 & 1,44 & 1,3 & 1,13 & 0,97 & 0,85 & 0,8 & 0,85 & 0,98 & 1,19 & 1,43 & 1,59 & 1,57 \\
\hline 60 & 1,43 & 1,28 & 1,1 & 0,92 & 0,79 & 0,75 & 0,8 & 0,93 & 1,15 & 1,41 & 1,59 & 1,57 \\
\hline 65 & 1,41 & 1,25 & 1,06 & 0,87 & 0,74 & 0,69 & 0,74 & 0,88 & 1,11 & 1,39 & 1,57 & 1,55 \\
\hline 70 & 1,38 & 1,21 & 1,01 & 0,81 & 0,67 & 0,62 & 0,67 & 0,82 & 1,07 & 1,35 & 1,55 & 1,53 \\
\hline 75 & 1,35 & 1,17 & 0,96 & 0,75 & 0,6 & 0,55 & 0,6 & 0,76 & 1,01 & 1,31 & 1,52 & 1,5 \\
\hline 80 & 1,3 & 1,12 & 0,9 & 0,68 & 0,53 & 0,48 & 0,53 & 0,69 & 0,95 & 1,25 & 1,47 & 1,46 \\
\hline 85 & 1,25 & 1,06 & 0,83 & 0,61 & 0,46 & 0,4 & 0,46 & 0,62 & 0,88 & 1,19 & 1,42 & 1,41 \\
\hline 90 & 1,19 & 1 & 0,76 & 0,54 & 0,38 & 0,32 & 0,38 & 0,54 & 0,81 & 1,12 & 1,36 & 1,35 \\
\hline
\end{tabular}

\section{LATITUD $=43^{\circ}$}

\begin{tabular}{|c|c|c|c|c|c|c|c|c|c|c|c|c|}
\hline Incli. & ENE & FEB & MAR & ABR & MAY & JUN & JUL & AGO & SEP & оCT & NOV & DIC \\
\hline 0 & 1 & 1 & 1 & 1 & 1 & 1 & 1 & 1 & 1 & 1 & 1 & 1 \\
\hline 5 & 1,08 & 1,07 & 1,05 & 1,03 & 1,02 & 1,02 & 1,02 & 1,04 & 1,06 & 1,08 & 1,1 & 1,09 \\
\hline 10 & 1,15 & 1,12 & 1,09 & 1,06 & 1,04 & 1,03 & 1,04 & 1,07 & 1,11 & 1,16 & 1,19 & 1,18 \\
\hline 15 & 1,22 & 1,18 & 1,13 & 1,08 & 1,05 & 1,03 & 1,05 & 1,09 & 1,15 & 1,23 & 1,27 & 1,26 \\
\hline 20 & 1,28 & 1,22 & 1,16 & 1,09 & 1,05 & 1,03 & 1,05 & 1,1 & 1,19 & 1,29 & 1,35 & 1,33 \\
\hline 25 & 1,33 & 1,26 & 1,18 & 1,1 & 1,04 & 1,02 & 1,04 & 1,11 & 1,22 & 1,34 & 1,42 & 1,4 \\
\hline 30 & 1,37 & 1,29 & 1,2 & 1,1 & 1,03 & 1 & 1,03 & 1,11 & 1,24 & 1,38 & 1,48 & 1,45 \\
\hline 35 & 1,41 & 1,31 & 1,2 & 1,09 & 1,01 & 0,98 & 1,01 & 1,1 & 1,25 & 1,42 & 1,52 & 1,5 \\
\hline 40 & 1,43 & 1,33 & 1,2 & 1,07 & 0,98 & 0,95 & 0,98 & 1,09 & 1,25 & 1,44 & 1,56 & 1,54 \\
\hline 45 & 1,45 & 1,33 & 1,19 & 1,05 & 0,95 & 0,91 & 0,95 & 1,06 & 1,24 & 1,45 & 1,59 & 1,57 \\
\hline 50 & 1,46 & 1,33 & 1,17 & 1,02 & 0,91 & 0,87 & 0,91 & 1,03 & 1,23 & 1,46 & 1,61 & 1,58 \\
\hline 55 & 1,46 & 1,32 & 1,15 & 0,98 & 0,86 & 0,82 & 0,86 & 1 & 1,21 & 1,45 & 1,62 & 1,59 \\
\hline 60 & 1,45 & 1,3 & 1,12 & 0,94 & 0,81 & 0,76 & 0,81 & 0,95 & 1,17 & 1,44 & 1,62 & 1,59 \\
\hline 65 & 1,43 & 1,27 & 1,08 & 0,89 & 0,75 & 0,7 & 0,75 & 0,9 & 1,13 & 1,41 & 1,61 & 1,58 \\
\hline 70 & 1,41 & 1,23 & 1,03 & 0,83 & 0,69 & 0,64 & 0,69 & 0,84 & 1,09 & 1,38 & 1,58 & 1,56 \\
\hline 75 & 1,37 & 1,19 & 0,98 & 0,77 & 0,62 & 0,57 & 0,62 & 0,78 & 1,03 & 1,34 & 1,55 & 1,53 \\
\hline 80 & 1,33 & 1,14 & 0,92 & 0,7 & 0,55 & 0,49 & 0,55 & 0,71 & 0,97 & 1,28 & 1,51 & 1,49 \\
\hline 85 & 1,28 & 1,08 & 0,85 & 0,63 & 0,47 & 0,42 & 0,47 & 0,64 & 0,9 & 1,22 & 1,45 & 1,44 \\
\hline 90 & 1,22 & 1,02 & 0,78 & 0,56 & 0,4 & 0,34 & 0,39 & 0,56 & 0,83 & 1,16 & 1,39 & 1,38 \\
\hline
\end{tabular}


Tabla AC.1.- Factor de corrección $k$ para superficies inclinadas (continuación).

\begin{tabular}{|c|c|c|c|c|c|c|c|c|c|c|c|c|}
\hline Incli. & ENE & FEB & MAR & $\mathrm{ABR}$ & MAY & $\pi N$ & JUL & AGO & SEP & OCT & NOV & DIC \\
\hline 0 & 1 & 1 & 1 & 1 & 1 & 1 & 1 & 1 & 1 & 1 & 1 & 1 \\
\hline 5 & 1,08 & 1,07 & 1,05 & 1,04 & 1,02 & 1,02 & 1,02 & 1,04 & 1,06 & 1,09 & 1,1 & 1,1 \\
\hline 10 & 1,16 & 1,13 & 1,1 & 1,06 & 1,04 & 1,03 & 1,04 & 1,07 & 1,11 & 1,16 & 1,19 & 1,18 \\
\hline 15 & 1,22 & 1,18 & 1,13 & 1,09 & 1,05 & 1,04 & 1,05 & 1,09 & 1,16 & 1,23 & 1,28 & 1,27 \\
\hline 20 & 1,28 & 1,23 & 1,17 & 1,1 & 1,05 & 1,04 & 1,06 & 1,11 & 1,2 & 1,3 & 1,36 & 1,34 \\
\hline 25 & 1,34 & 1,27 & 1,19 & 1,11 & 1,05 & 1,03 & 1,05 & 1,12 & 1,23 & 1,35 & 1,43 & 1,41 \\
\hline 30 & 1,38 & 1,3 & 1,2 & 1,11 & 1,04 & 1,01 & 1,04 & 1,12 & 1,25 & 1,4 & 1,49 & 1,47 \\
\hline 35 & 1,42 & 1,32 & 1,21 & 1,1 & 1,02 & 0,99 & 1,02 & 1,11 & 1,26 & 1,43 & 1,54 & 1,52 \\
\hline 40 & 1,45 & 1,34 & 1,21 & 1,08 & 0,99 & 0,96 & 1 & 1,1 & 1,26 & 1,46 & 1,59 & 1,56 \\
\hline 45 & 1,47 & 1,35 & 1,2 & 1,06 & 0,96 & 0,92 & 0,96 & 1,08 & 1,26 & 1,48 & 1,62 & 1,59 \\
\hline 50 & 1,48 & 1,34 & 1,19 & 1,03 & 0,92 & 0,88 & 0,92 & 1,05 & 1,25 & 1,48 & 1,64 & 1,61 \\
\hline 55 & 1,48 & 1,33 & 1,16 & 0,99 & 0,87 & 0,83 & 0,88 & 1,01 & 1,22 & 1,48 & 1,65 & 1,62 \\
\hline 60 & 1,47 & 1,32 & 1,13 & 0,95 & 0,82 & 0,78 & 0,82 & 0,97 & 1,19 & 1,47 & 1,65 & 1,62 \\
\hline 65 & 1,46 & 1,29 & 1,09 & 0,9 & 0,76 & 0,72 & 0,77 & 0,92 & 1,16 & 1,44 & 1,64 & 1,61 \\
\hline 70 & 1,43 & 1,26 & 1,05 & 0,85 & 0,7 & 0,65 & 0,7 & 0,86 & 1,11 & 1,41 & 1,62 & 1,59 \\
\hline 75 & 1,4 & 1,21 & 1 & 0,78 & 0,64 & 0,58 & 0,64 & 0,8 & 1,06 & 1,37 & 1,59 & 1,56 \\
\hline 80 & 1,36 & 1,16 & 0,94 & 0,72 & 0,56 & 0,51 & 0,56 & 0,73 & 0,99 & 1,32 & 1,54 & 1,52 \\
\hline 85 & 1,31 & 1,11 & 0,87 & 0,65 & 0,49 & 0,43 & 0,49 & 0,66 & 0,93 & 1,26 & 1,49 & 1,48 \\
\hline 90 & 1,25 & 1,04 & 0,8 & 0,57 & 0,41 & 0,35 & 0,41 & 0,58 & 0,85 & 1,19 & 1,43 & 1,42 \\
\hline
\end{tabular}

\section{LATITUD $=45^{\circ}$}

\begin{tabular}{|c|c|c|c|c|c|c|c|c|c|c|c|c|}
\hline Incli. & ENE & FEB & MAR & ABR & MAY & $\pi N$ & JUL & AGO & SEP & ост & NOV & DIC \\
\hline 0 & 1 & 1 & 1 & 1 & 1 & 1 & 1 & 1 & 1 & 1 & 1 & 1 \\
\hline 5 & 1,08 & 1,07 & 1,05 & 1,04 & 1,03 & 1,02 & 1,03 & 1,04 & 1,06 & 1,09 & 1,1 & 1,1 \\
\hline 10 & 1,16 & 1,13 & 1,1 & 1,07 & 1,04 & 1,04 & 1,05 & 1,07 & 1,12 & 1,17 & 1,2 & 1,19 \\
\hline 15 & 1,23 & 1,19 & 1,14 & 1,09 & 1,05 & 1,04 & 1,06 & 1,1 & 1,17 & 1,24 & 1,29 & 1,27 \\
\hline 20 & 1,29 & 1,24 & 1,17 & 1,11 & 1,06 & 1,04 & 1,06 & 1,12 & 1,21 & 1,31 & 1,37 & 1,35 \\
\hline 25 & 1,35 & 1,28 & 1,2 & 1,11 & 1,06 & 1,03 & 1,06 & 1,13 & 1,24 & 1,36 & 1,45 & 1,42 \\
\hline 30 & 1,4 & 1,31 & 1,21 & 1,12 & 1,04 & 1,02 & 1,05 & 1,13 & 1,26 & 1,41 & 1,51 & 1,48 \\
\hline 35 & 1,43 & 1,34 & 1,22 & 1,11 & 1,03 & 1 & 1,03 & 1,12 & 1,27 & 1,45 & 1,56 & 1,53 \\
\hline 40 & 1,46 & 1,35 & 1,22 & 1,09 & 1 & 0,97 & 1,01 & 1,11 & 1,28 & 1,48 & 1,61 & 1,58 \\
\hline 45 & 1,49 & 1,36 & 1,22 & 1,07 & 0,97 & 0,93 & 0,97 & 1,09 & 1,28 & 1,5 & 1,64 & 1,61 \\
\hline 50 & 1,5 & 1,36 & 1,2 & 1,04 & 0,93 & 0,89 & 0,94 & 1,06 & 1,26 & 1,51 & 1,67 & 1,63 \\
\hline 55 & 1,5 & 1,35 & 1,18 & 1,01 & 0,89 & 0,84 & 0,89 & 1,03 & 1,24 & 1,5 & 1,68 & 1,65 \\
\hline 60 & 1,5 & 1,34 & 1,15 & 0,97 & 0,84 & 0,79 & 0,84 & 0,98 & 1,21 & 1,49 & 1,68 & 1,65 \\
\hline 65 & 1,48 & 1,31 & 1,11 & 0,92 & 0,78 & 0,73 & 0,78 & 0,93 & 1,18 & 1,47 & 1,67 & 1,64 \\
\hline 70 & 1,46 & 1,28 & 1,07 & 0,86 & 0,72 & 0,67 & 0,72 & 0,88 & 1,13 & 1,44 & 1,65 & 1,62 \\
\hline 75 & 1,43 & 1,24 & 1,02 & 0,8 & 0,65 & 0,6 & 0,65 & 0,82 & 1,08 & 1,4 & 1,62 & 1,6 \\
\hline 80 & 1,38 & 1,19 & 0,96 & 0,74 & 0,58 & 0,53 & 0,58 & 0,75 & 1,02 & 1,35 & 1,58 & 1,56 \\
\hline 85 & 1,33 & 1,13 & 0,89 & 0,66 & 0,51 & 0,45 & 0,51 & 0,67 & 0,95 & 1,29 & 1,53 & 1,51 \\
\hline 90 & 1,28 & 1,07 & 0,82 & 0,59 & 0,43 & 0,37 & 0,43 & 0,6 & 0,88 & 1,22 & 1,47 & 1,45 \\
\hline
\end{tabular}




\section{AC.2.- CONSIDERACIONES PARA EL DISEÑO DEL INTERCAMBIADOR DE CALOR.}

Tabla AC.2.- Propiedades del agua saturada [1].

\begin{tabular}{|c|c|c|c|c|c|}
\hline $\mathrm{T}^{\mathrm{a}}(\mathrm{C})$ & $\mathrm{Cp}(\mathrm{kJ} / \mathrm{kg} \mathrm{C})$ & $\begin{array}{c}\text { Densidad } \\
(\mathrm{kg} / \mathrm{ms})\end{array}$ & $\begin{array}{c}\text { Viscosidad } 10^{6} \\
(\mathrm{~kg} / \mathrm{ms})\end{array}$ & $k \cdot 10^{3}(W / m ~ C)$ & $\operatorname{Pr}$ \\
\hline 0 & 4,218 & 999,8 & 1,791 & 0,5619 & 12,45 \\
\hline 5 & 4,203 & 1000 & 1,52 & 0,5723 & 11,16 \\
\hline 10 & 4,193 & 999,8 & 1,308 & 0,582 & 9,42 \\
\hline 15 & 4,187 & 999,2 & 1,139 & 0,5911 & 8,07 \\
\hline 20 & 4,182 & 998,3 & 1,003 & 0,5996 & 6,99 \\
\hline 25 & 4,18 & 997,1 & 0,8908 & 0,6076 & 6,13 \\
\hline 30 & 4,18 & 995,7 & 0,7978 & 0,615 & 5,42 \\
\hline 35 & 4,179 & 994,1 & 0,7196 & 0,6221 & 4,83 \\
\hline 40 & 4,179 & 992,3 & 0,6531 & 0,6286 & 4,34 \\
\hline 45 & 4,182 & 990,2 & 0,5962 & 0,6347 & 3,93 \\
\hline 50 & 4,182 & 988 & 0,5471 & 0,6405 & 3,57 \\
\hline 55 & 4,184 & 985,7 & 0,5043 & 0,6458 & 3,27 \\
\hline 60 & 4,186 & 983,1 & 0,4468 & 0,6507 & 3 \\
\hline 65 & 4,187 & 980,5 & 0,4338 & 0,6553 & 2,77 \\
\hline 70 & 4,191 & 977,7 & 0,4044 & 0,6594 & 2,57 \\
\hline 75 & 4,191 & 974,7 & 0,3783 & 0,6633 & 2,39 \\
\hline 80 & 4,195 & 971,6 & 0,355 & 0,6668 & 2,23 \\
\hline 85 & 4,201 & 968,4 & 0,3339 & 0,6699 & 2,09 \\
\hline 90 & 4,203 & 965,1 & 0,315 & 0,6727 & 1,97 \\
\hline 95 & 4,21 & 961,7 & 0,2978 & 0,6753 & 1,86 \\
\hline 100 & 4,215 & 958,1 & 0,2822 & 0,6775 & 1,76 \\
\hline 120 & 4,246 & 942,8 & 0,2321 & 0,6833 & 1,44 \\
\hline 140 & 4,282 & 925,9 & 0,1921 & 0,6845 & 1,23 \\
\hline
\end{tabular}


Tabla AC.3.- Aire seco a presión atmosférica [1].

\begin{tabular}{|c|c|c|c|c|c|c|}
\hline$T^{a}(C)$ & $\mathrm{Cp}(\mathrm{kJ} / \mathrm{kg} \mathrm{C})$ & $\begin{array}{c}\text { Densidad } \\
\text { (kg/ms) }\end{array}$ & $\begin{array}{l}\text { Viscosidad } 10^{6} \\
(\mathrm{~kg} / \mathrm{ms})\end{array}$ & $\begin{array}{c}\text { Viscosidad } \\
\text { dinamica } 10^{6} \\
\left(\mathrm{~m}^{2} / \mathrm{s}\right)\end{array}$ & $k \cdot 10^{3}(\mathrm{~W} / \mathrm{m} \mathrm{C})$ & Pr \\
\hline 0 & 1,0057 & 1,2923 & 17,2 & 13,31 & 24,08 & 0,718 \\
\hline 10 & 1,0058 & 1,2467 & 17,69 & 14,19 & 24,87 & 0,716 \\
\hline 20 & 1,0061 & 1,2042 & 18,17 & 15,09 & 25,64 & 0,713 \\
\hline 30 & 1,0064 & 1,1644 & 18,65 & 16,01 & 26,01 & 0,712 \\
\hline 40 & 1,0068 & 1,1273 & 19,11 & 16,96 & 27,1 & 0,71 \\
\hline 50 & 1,0074 & 1,0924 & 19,57 & 17,92 & 27,81 & 0,709 \\
\hline 60 & 1,008 & 1,0596 & 20,03 & 18,9 & 28,52 & 0,708 \\
\hline 70 & 1,0087 & 1,0287 & 20,47 & 19,9 & 29,22 & 0,707 \\
\hline 80 & 1,0095 & 0,9996 & 20,92 & 20,92 & 29,91 & 0,706 \\
\hline 90 & 1,0100 & 0,9721 & 21,35 & 21,96 & 30,59 & 0,705 \\
\hline 100 & 1,0113 & 0,946 & 21,78 & 23,02 & 31,27 & 0,704 \\
\hline 110 & 1,0123 & 0,9213 & 22,2 & 24,1 & 31,94 & 0,704 \\
\hline 120 & 1,0134 & 0,8979 & 22,62 & 25,19 & 32,61 & 0,703 \\
\hline 130 & 1,0146 & 0,8756 & 23,03 & 26,31 & 33,28 & 0,702 \\
\hline 140 & 1,0159 & 0,8544 & 23,44 & 27,44 & 33,94 & 0,702 \\
\hline 150 & 1,0172 & 0,8342 & 23,84 & 28,58 & 34,59 & 0,701 \\
\hline
\end{tabular}

Tabla AC.4. Geometría de la superficie, flujo normal en tubos aleteados. Tubos circulares, aletas continuas [2]

\begin{tabular}{|c|c|c|c|c|c|c|c|c|c|c|c|c|c|}
\hline \multirow{2}{*}{$\begin{array}{c}\text { Surface } \\
\text { designation }\end{array}$} & \multirow{2}{*}{$\begin{array}{c}\text { Tube } \\
\text { arrangement }\end{array}$} & \multicolumn{2}{|c|}{ Tube diameter } & \multirow{2}{*}{ Fin type } & \multirow{2}{*}{ Fins/in } & \multicolumn{2}{|c|}{$\begin{array}{c}\text { Hydraulic diameter, } \\
4 r_{k}\end{array}$} & \multicolumn{2}{|c|}{ Fin thickncs $\delta$} & \multirow{2}{*}{$\begin{array}{c}\text { Free-flow/ } \\
\text { frontal } \\
\text { area } \sigma\end{array}$} & \multicolumn{2}{|c|}{$\begin{array}{c}\text { Heat transfer arca/ } \\
\text { total volume } \alpha\end{array}$} & \multirow{2}{*}{$\begin{array}{l}\text { Fin area/ } \\
\text { total area }\end{array}$} \\
\hline & & in & $10^{-3} \mathrm{~m}$ & & & $\mathrm{ft}$ & $10^{-4} \mathrm{~m}$ & in & $10^{-9}$ & & $\mathrm{ft}^{2} / \mathrm{ft}^{3}$ & $\mathrm{~m}^{2} / \mathrm{m}^{9}$ & \\
\hline $8.0-5 \mathrm{~T}$ & Staggered & 0.402 & 10.21 & Plain & 8.0 & 0.01192 & 3.63 & 0.013 & 0.33 & 0.534 & 179 & 587 & 0.913 \\
\hline $7.75-1 \mathrm{~T}$ & Staggered & 0.676 & 17.17 & Plain & 7.75 & 0.0114 & 3.48 & 0.016 & 0.41 & 0.481 & 169 & 554 & 0.950 \\
\hline
\end{tabular}




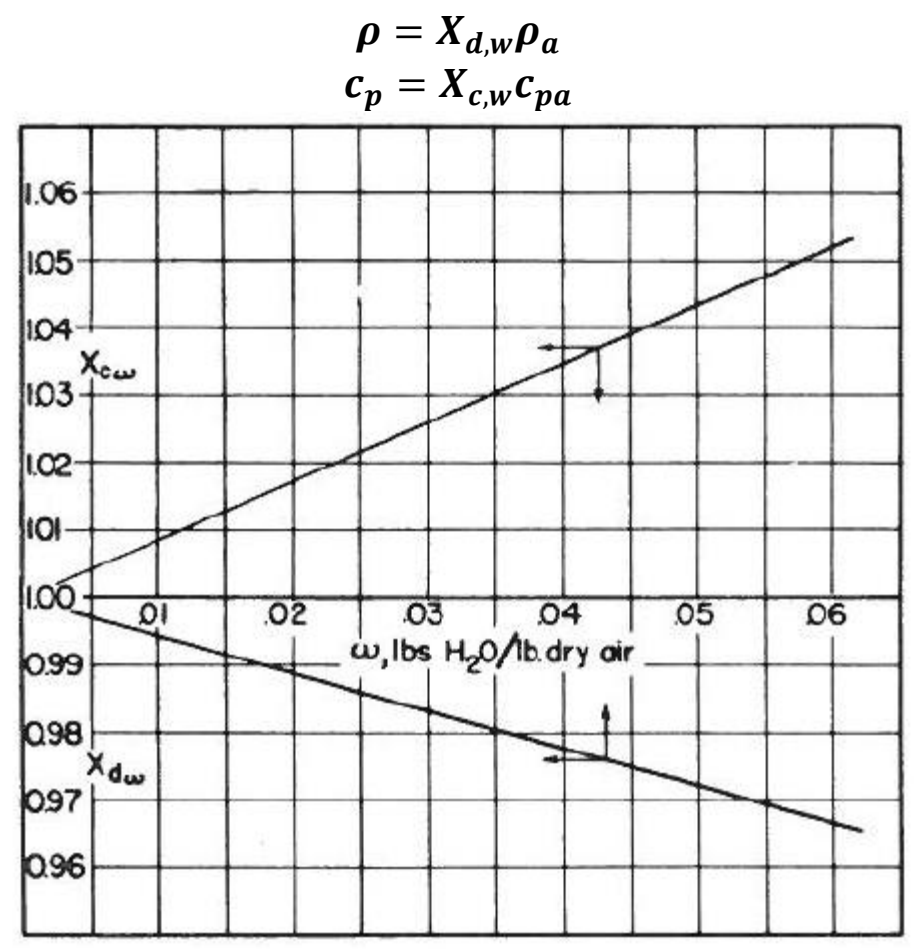

Figura AC.1: Factor de corrección de la humedad para la densidad y el calor específico [2].

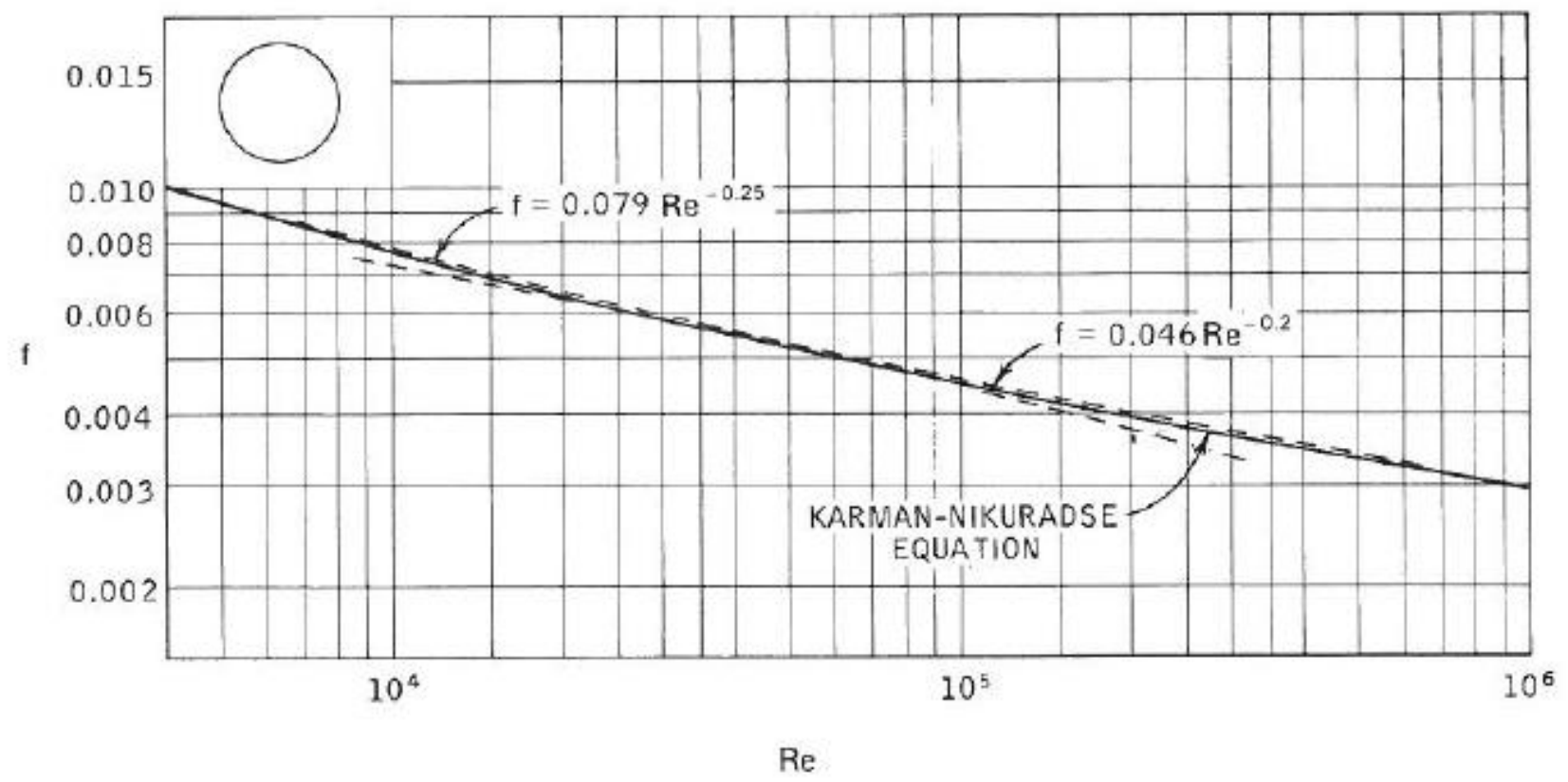

Figura AC.2: Factor de fricción para flujo turbulento completamente desarrollado en tubos circulares [2]. 


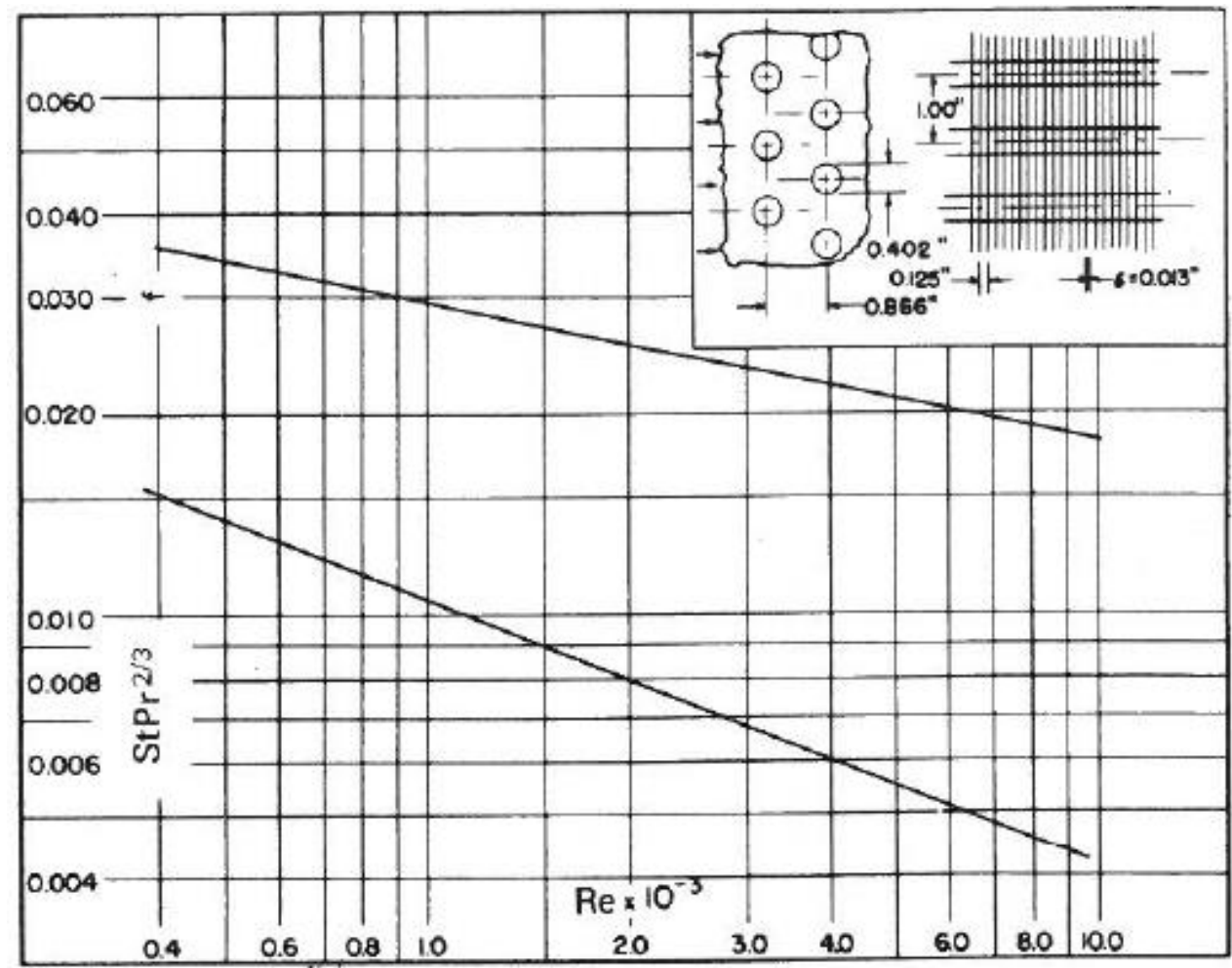

Tube outside diameter $=0.402$ in $=10.2 \times 10^{-3} \mathrm{~m}$

Fin pitch $=8.0$ per in $=315$ per $\mathrm{m}$

Flow passage hydraulic diameter, $4 r_{h}=0.01192 \mathrm{ft}=3.632 \times 10^{-3} \mathrm{~m}$

Fin thickness $=0.013$ in $=0.33 \times 10^{-3} \mathrm{~m}$

Free-flow area/frontal area, $\sigma=0.534$

Heat transfer area/total volume, $\alpha=179 \mathrm{ft}^{2} / \mathrm{ft}^{3}=587 \mathrm{~m}^{2} / \mathrm{m}^{3}$

Fin area/total area $=0.913$

Note: Minimum free-flow area in spaces transverse to flow.

Figura AC.3: Tubos circulares aleteados [2]. 


\section{ANEXO C: SIMULACIONES}

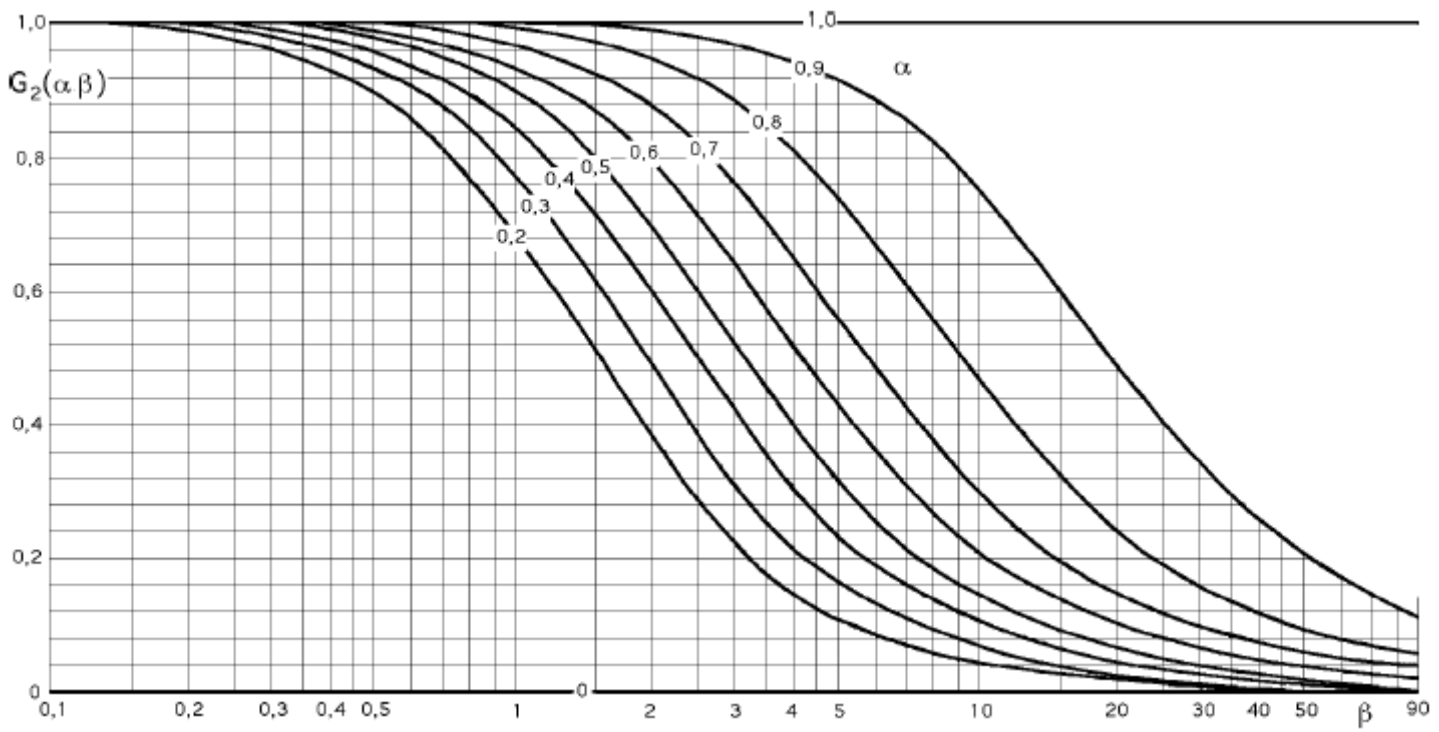

Figura AC.4: Función G2 para el cálculo de la eficiencia de aletas anulares de espesor uniforme [1] 


\section{AC.3.- CÓDIGO DE SIMULACIÓN DE LA BATERÍA AIRE - AGUA.}

La función batería emplea como datos iniciales las temperaturas de entrada y salida del agua y del aire de la batería, la presión y humedad del aire y los flujos másico de éstos. Las temperaturas de salida del agua y del aire de la batería y la temperatura de entrada del aire deben suponerse inicialmente. Dicha función devuelve los valores a la salida de las temperaturas del agua y del aire y de la presión.

El código implementado se presenta a continuación:

Public Function Bateria(TempEntradaWater As Double, TempSalWaterIni As Double, TempEntradaAire As Double, TempSalAirelni As Double, Pentrada As Double, HumedadAire As Double, mwater As Double, mair As Double, Selec As String) As Double Dim RhAir, alfaAir, sigmaA , AreafrontalAir, RhWater, alfaWater, sigmaW, Pr As Double Dim delta, Kmetal, I, areafin_areatot, Dext, Dint, areafrontal_tubos, Kair, Cp As Double Dim areaflujolibre_tubo, insideperife_tubos, Vollntercambiador, Cpcorregido As Double Dim Profundidad, Altura, TempSalWater0, TempSalAire0, TempSalWater1 As Double Dim TempSalAire1, incrementoEAirSWater, incrementoSaireEWater, viscosidad As Double Dim TempPromedioAir, TempPromedioWater, Densidad, CorrHumedad As Double Dim Psalida0, Psalida1, Pav, vm_v1, G, Re, logf, logStPr, f, St, viscosidadwater As Double Dim Cpwater, densidadwater, Kwater, Prwater, Gwater, Rewater, Nuwater As Double Dim fwater, hair, hwater, efectaleta, efectsuperficie, U, Cair, Cwater, Cmin As Double Dim Cmax, NtUmax, Efectivintercambio, alfaan, betaan, alfabeta, termino1 As Double Dim k1_alfabeta, I1_beta , k1_beta, 10_alfabeta, K0_alfabeta, Perd_presión_air As Double Dim Perd_presión_agua,ToleranciaRelativa, AUX8, AUX1, AUX7, AUX3, AUX4 As Double Dim AUX5, AUX6, aux(2) As Double

' Parámetros del método

RhAir $=0.0009075 \mathrm{~m}$

alfaAir $=587$ ' $\mathrm{m} 2 / \mathrm{m3}$

sigmaA $=0.534$

AreafrontalAir $=0.09^{\prime} \mathrm{m} 2$

RhWater $=0.004 \mathrm{~m}$

alfaWater $=45.6958 \mathrm{~m} 2 / \mathrm{m3}$

sigmaW $=0.091$

AreafrontalWater $=0.0264^{\prime} \mathrm{m} 2$

delta $=0.00033 \mathrm{~m}$

Kmetal $=2355^{\prime} \mathrm{W} / \mathrm{m}^{*} \mathrm{~K}$

$\mathrm{I}=0.012 \mathrm{~m}$

areafin_areatot $=0.913$

Dext $=0.01$

Dint $=0.008$

areafrontal_tubo $=0.00055 \mathrm{~m} 2$

areaflujolibre_tubo $=0.000050264 \mathrm{~m} 2$

insideperife_tubo $=0.0251327 \mathrm{~m}$

Vollntercambiador $=0.00792 \mathrm{~m} 3$

Profundidad $=0.088$

Altura $=0.3$ 
ToleranciaRelativa $=0.01^{\prime} \mathrm{C}$

'Inicialización de variables

TempSalWater1 = TempSalWaterIni

TempSalAire1 $=$ TempSalAirelni

Psalida1 $=0.99 *$ Pentrada

Do

'Actualización de las temperaturas de salida y la presión en cada iteración

TempSalWater0 = TempSalWater1

TempSalAire0 $=$ TempSalAire1

Psalida0 = Psalida1

' Temperaturas promedio

TempPromedioWater $=($ TempEntradaWater + TempSalWater0 $) / 2$

incrementoEAirSWater $=$ TempEntradaAire - TempSalWater0

incrementoSaireEWater $=$ TempSalAire0 - TempEntradaWater

TempPromedioAir = TempPromedioWater + ((incrementoEAirSWater - incrementoSaireEWater) $/$

(Log(incrementoEAirSWater / incrementoSaireEWater)))

'Propiedades del aire

viscosidad $=0.0442 * 0.000001 *$ TempPromedioAir $+17.314 * 0.000001$

$\mathrm{Cp}=4 * 0.0000001 *$ TempPromedioAir ^ $2+0.00001 *$ TempPromedioAir +1.0056

Densidad $=9 * 0.000001 *$ TempPromedioAir^2-0.0043*TempPromedioAir +1.2885

Kair $=(-4 * 0.00001 *$ TempPromedioAir ^ $2+0.076 *$ TempPromedioAir +24.063$) * 0.001 \quad ' K$

$\operatorname{Pr}=6 * 0.0000001 *$ TempPromedioAir ^ $2-0.0002 *$ TempPromedioAir +0.7174

CorrHumedad $=0.0866 *$ HumedadAire +0.9998

Cpcorregido $=\mathrm{Cp} *$ CorrHumedad

Pav $=0.5 *$ (Psalida0 + Pentrada)

vm_v1 $=($ Pentrada $*($ TempPromedioAir +273$)) /($ Psalida0 $*($ TempEntradaAire +273$))$

'Correción humedad

'viscosidad

'Cp

'Densidad

'Pr

'Cp corregido

$\mathrm{G}=$ mair $/($ sigmaA $*$ AreafrontalAir)

$\operatorname{Re}=(4 *$ RhAir $* G) /$ viscosidad

'G

' Propiedades del agua

viscosidadwater $=(-1 * 0.000001 *$ TempPromedioWater $\wedge 3+0.0004 *$ TempPromedioWater $\wedge 2-0.0405 *$

TempPromedioWater +1.7073$) * 0.001$

'viscosidad agua

Cpwater $=(-4 * 0.00000001 *$ TempPromedioWater $\wedge 3+2 * 0.00001 *$ TempPromedioWater $\wedge 2-0.0015 *$

TempPromedioWater +4.2096$) \quad$ 'Cp agua

densidadwater $=-0.0026 *$ TempPromedioWater ^ $2-0.1785 *$ TempPromedioWater +1002.4

'Densidad agua

Kwater $=(-6 * 0.000001 *$ TempPromedioWater $\wedge 2+0.0017 *$ TempPromedioWater +0.5685$)$

'Kagua

Prwater $=-1 * 0.00001 *$ TempPromedioWater ^ $3+0.003 *$ TempPromedioWater ^ $2-0.3009 *$

TempPromedioWater +12.218

'Pragua

Gwater=mwater $/$ (AreafrontalWater * sigmaW)

Rewater $=(4 *$ RhWater*Gwater $) /$ viscosidadwater

'Factores de pérdida de carga

$\log f=-0.2113 *(\log (\operatorname{Re} * 0.001) / \log (10))-1.5262$

$f=10^{\wedge}(\log f)$

If Rewater $<6 * 10^{\wedge} 4$ Then

fwater $=0.079 *$ Rewater $\wedge(-0.25)$

Else

fwater $=0.046 *$ Rewater ${ }^{\wedge}(-0.2)$

End If

'Coeficientes de transferencia de calor

$\log \mathrm{StPr}=-0.4051 *(\log (\operatorname{Re} * 0.001) / \log (10))-1.9712$

$\mathrm{St}=\left(10^{\wedge} \operatorname{logStPr}\right) /(\operatorname{Pr} \wedge(2 / 3))$

hair $=\mathrm{St} * \mathrm{G} *$ Cpcorregido

'log fair

'St

$\log \operatorname{StPr}^{\wedge}(2 / 3)$

'h aire $k w / k^{*} m 2$ 


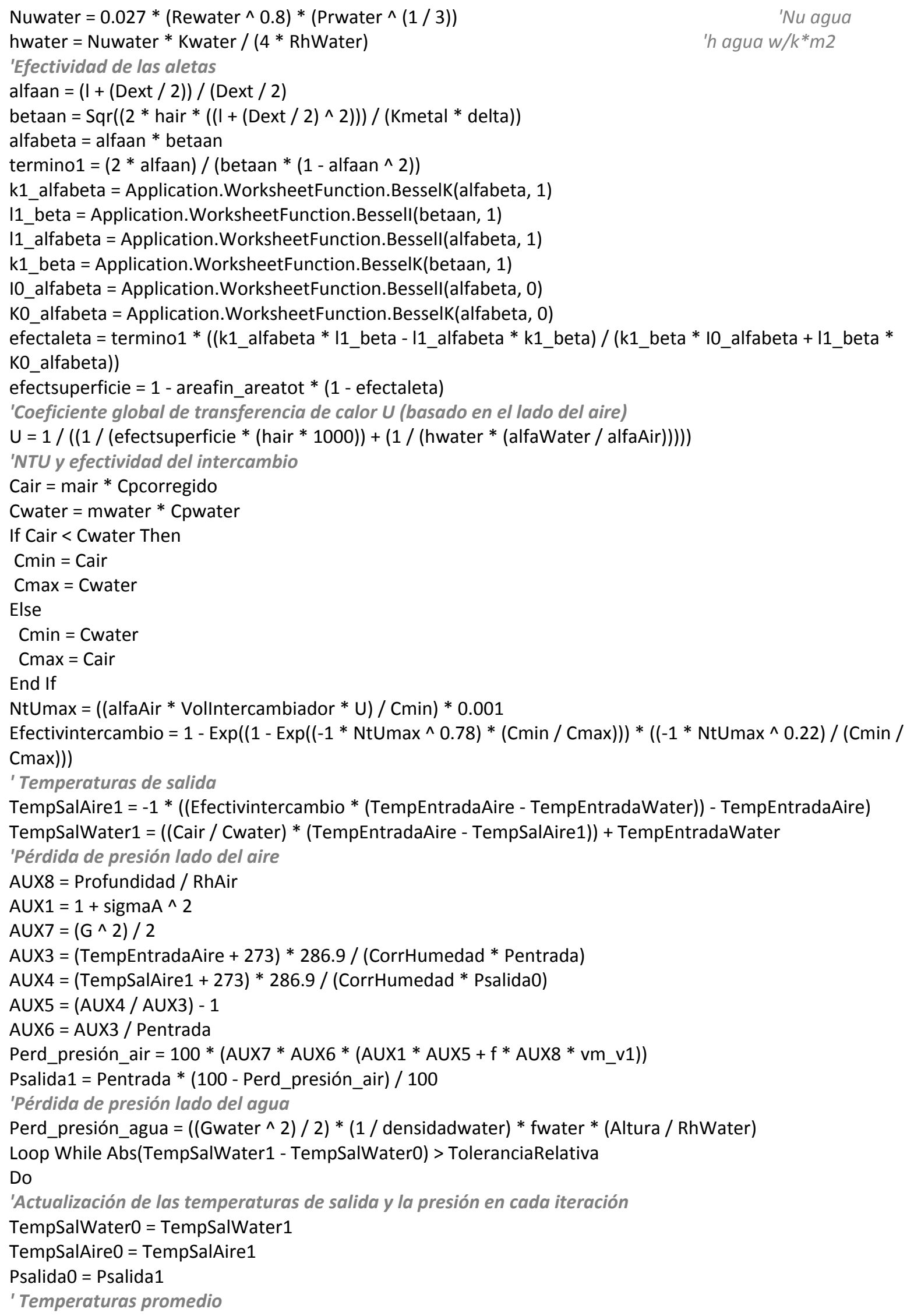


TempPromedioWater $=($ TempEntradaWater + TempSalWater0 $) / 2$

incrementoEAirSWater $=$ TempEntradaAire - TempSalWaterO

incrementoSaireEWater $=$ TempSalAire0 - TempEntradaWater

TempPromedioAir = TempPromedioWater + ((incrementoEAirSWater - incrementoSaireEWater) /

(Log(incrementoEAirSWater / incrementoSaireEWater)))

'Propiedades del aire

viscosidad $=0.0442 * 0.000001 *$ TempPromedioAir $+17.314 * 0.000001$

$\mathrm{Cp}=4 * 0.0000001 *$ TempPromedioAir ^ $2+0.00001 *$ TempPromedioAir +1.0056

Densidad $=9 * 0.000001 *$ TempPromedioAir^2-0.0043*TempPromedioAir +1.2885

Kair $=(-4 * 0.00001 *$ TempPromedioAir ^ $2+0.076 *$ TempPromedioAir +24.063$) * 0.001$

$\operatorname{Pr}=6 * 0.0000001 *$ TempPromedioAir $\wedge 2-0.0002 *$ TempPromedioAir +0.7174

CorrHumedad $=0.0866 *$ HumedadAire +0.9998

Cpcorregido $=\mathrm{Cp} *$ CorrHumedad

Pav $=0.5 *$ (Psalida0 + Pentrada)

'viscosidad

'Cp

'Densidad

' $K$

'Pr

'Correción humedad

'Cp corregido 'Pa

vm_v1 $=($ Pentrada * $($ TempPromedioAir +273$)) /($ Psalida0 * (TempEntradaAire +273$)) \quad$ 'vm/v1

$\mathrm{G}=$ mair $/$ (sigmaA * AreafrontalAir)

$\operatorname{Re}=(4 *$ RhAir * G) / viscosidad

' $G$

'Re

' Propiedades del agua

viscosidadwater $=\left(-1 * 0.000001 *\right.$ TempPromedioWater $\wedge 3+0.0004 *$ TempPromedioWater $^{\wedge} 2-0.0405 *$

TempPromedioWater +1.7073$) * 0.001 \quad$ 'viscosidad agua

Cpwater $=(-4 * 0.00000001 *$ TempPromedioWater $\wedge 3+2 * 0.00001 *$ TempPromedioWater $\wedge 2-0.0015 *$

TempPromedioWater +4.2096$) \quad$ 'Cp agua

densidadwater $=-0.0026 *$ TempPromedioWater ^ $2-0.1785 *$ TempPromedioWater +1002.4

'Factores de pérdida de carga

$\log f=-0.2113 *(\log (\operatorname{Re} * 0.001) / \log (10))-1.5262$

$\mathrm{f}=10^{\wedge}(\log \mathrm{f})$

'faire

'log fair

If Rewater $<6 * 10^{\wedge} 4$ Then

fwater $=0.079 *$ Rewater $\wedge(-0.25)$

Else

fwater $=0.046 *$ Rewater ${ }^{\wedge}(-0.2)$

End If

'Coeficientes de transferencia de calor

$\log \operatorname{StPr}=-0.4051 *(\log (\operatorname{Re} * 0.001) / \log (10))-1.9712$

$\mathrm{St}=\left(10^{\wedge} \operatorname{logStPr}\right) /(\operatorname{Pr} \wedge(2 / 3))$

hair $=\mathrm{St} * \mathrm{G} *$ Cpcorregido

Nuwater $=0.027 *\left(\operatorname{Rewater}^{\wedge} 0.8\right) *\left(\operatorname{Prwater}^{\wedge}(1 / 3)\right)$

hwater $=$ Nuwater $*$ Kwater $/(4 *$ RhWater $)$

'fwater

'Efectividad de las aletas

alfaan $=(I+($ Dext $/ 2)) /($ Dext $/ 2)$

betaan $=\operatorname{Sqr}((2 *$ hair $*((1+($ Dext $/ 2) \wedge 2))) /($ Kmetal $*$ delta $))$

alfabeta $=$ alfaan $*$ betaan

termino $1=(2 *$ alfaan $) /\left(\right.$ betaan $*\left(1-\right.$ alfaan $\left.\left.{ }^{\wedge} 2\right)\right)$

k1_alfabeta $=$ Application.WorksheetFunction.BesselK(alfabeta, 1)

I1_beta = Application.WorksheetFunction.Bessell(betaan, 1)

I1_alfabeta = Application.WorksheetFunction.Bessell(alfabeta, 1)

k1_beta = Application.WorksheetFunction.BesselK(betaan, 1)

I0_alfabeta = Application.WorksheetFunction.Bessell(alfabeta, 0 )

KO_alfabeta $=$ Application. WorksheetFunction.BesselK(alfabeta, 0 )

efectaleta $=$ termino $1 *((k 1$ _alfabeta $*$ I__beta - I1_alfabeta * k1_beta) / (k1_beta * I0_alfabeta + I1_beta *

K0_alfabeta))

efectsuperficie $=1$ - areafin_areatot $*$ (1 - efectaleta)

'Coeficiente global de transferencia de calor U (basado en el lado del aire)

$\mathrm{U}=1 /((1 /($ efectsuperficie * (hair * 1000) $)+(1 /($ hwater * (alfaWater / alfaAir $)))))$ 
'NTU y efectividad del intercambio

Cair $=$ mair $*$ Cpcorregido

Cwater $=$ mwater $*$ Cpwater

If Cair < Cwater Then

$\mathrm{Cmin}=$ Cair

$\mathrm{Cmax}=$ Cwater

Else

Cmin $=$ Cwater

Cmax = Cair

End If

NtUmax $=(($ alfaAir $*$ Vollntercambiador $* U) /$ Cmin $) * 0.001$

Efectivintercambio $=1-\operatorname{Exp}\left(\left(1-\operatorname{Exp}\left(\left(-1 * N \operatorname{NUmax}^{\wedge} 0.78\right) *(\mathrm{Cmin} / \mathrm{Cmax})\right)\right) *((-1 * \mathrm{NtUmax} \wedge 0.22) /(\mathrm{Cmin} /\right.$

(max)))

' Temperaturas de salida

TempSalAire1 = -1 * ((Efectivintercambio * (TempEntradaAire - TempEntradaWater $))$ - TempEntradaAire)

TempSalWater1 $=(($ Cair $/$ Cwater $) *($ TempEntradaAire - TempSalAire1 $))+$ TempEntradaWater

'Pérdida de presión lado del aire

AUX8 $=$ Profundidad $/$ RhAir

$\mathrm{AUX1}=1+\operatorname{sigmaA}^{\wedge} 2$

$A U X 7=(G \wedge 2) / 2$

AUX3 $=($ TempEntradaAire +273$) * 286.9 /($ CorrHumedad $*$ Pentrada $)$

AUX4 $=($ TempSalAire $1+273) * 286.9 /($ CorrHumedad $*$ Psalida0 $)$

AUX5 = (AUX4 / AUX3) -1

AUX6 = AUX3 / Pentrada

Perd_presión_air $=100 *(A U X 7 *$ AUX6 * (AUX1 * AUX5 +f * AUX8 * vm_v1))

Psalida1 $=$ Pentrada * (100 - Perd_presión_air) $/ 100$

'Pérdida de presión lado del agua

Perd_presión_agua $=(($ Gwater $\wedge 2) / 2) *(1 /$ densidadwater $) *$ fwater $*$ (Altura / RhWater)

Loop While Abs(TempSalWater1 - TempSalWater0) > ToleranciaRelativa

'Actualización de las temperaturas de salida y la presión en cada iteración

TempSalWater0 = TempSalWater1

TempSalAire0 $=$ TempSalAire1

Psalida0 $=$ Psalida1

'Temperaturas promedio

TempPromedioWater $=($ TempEntradaWater + TempSalWater0 $) / 2$

incrementoEAirSWater $=$ TempEntradaAire - TempSalWater0

incrementoSaireEWater $=$ TempSalAire0 - TempEntradaWater

TempPromedioAir = TempPromedioWater + ((incrementoEAirSWater - incrementoSaireEWater) $/$

(Log(incrementoEAirSWater / incrementoSaireEWater)))

'Propiedades del aire

viscosidad $=0.0442 * 0.000001 *$ TempPromedioAir $+17.314 * 0.000001$

$\mathrm{Cp}=4 * 0.0000001 *$ TempPromedioAir ^ $2+0.00001 *$ TempPromedioAir +1.0056

Densidad $=9 * 0.000001 * T^{*}$ TempPromedioAir^2-0.0043*TempPromedioAir +1.2885

Kair $=(-4 * 0.00001 *$ TempPromedioAir ^ $2+0.076 *$ TempPromedioAir +24.063$) * 0.001$

'viscosidad

'Cp

'Densidad

$\operatorname{Pr}=6 * 0.0000001 *$ TempPromedioAir ^ $2-0.0002 *$ TempPromedioAir +0.7174

CorrHumedad $=0.0866 *$ HumedadAire +0.9998

'Correción humedad

Cpcorregido $=\mathrm{Cp} *$ CorrHumedad

Pav $=0.5 *$ (Psalida0 + Pentrada)

'Cp corregido

vm_v1 $=($ Pentrada $*($ TempPromedioAir +273$)) /($ Psalida0 $*($ TempEntradaAire +273$))$ 'Pav

$\mathrm{G}=$ mair $/$ (sigmaA $*$ AreafrontalAir)

' $G$

$\operatorname{Re}=(4 *$ RhAir $* \mathrm{G}) /$ viscosidad

'Re

'Propiedades del agua 


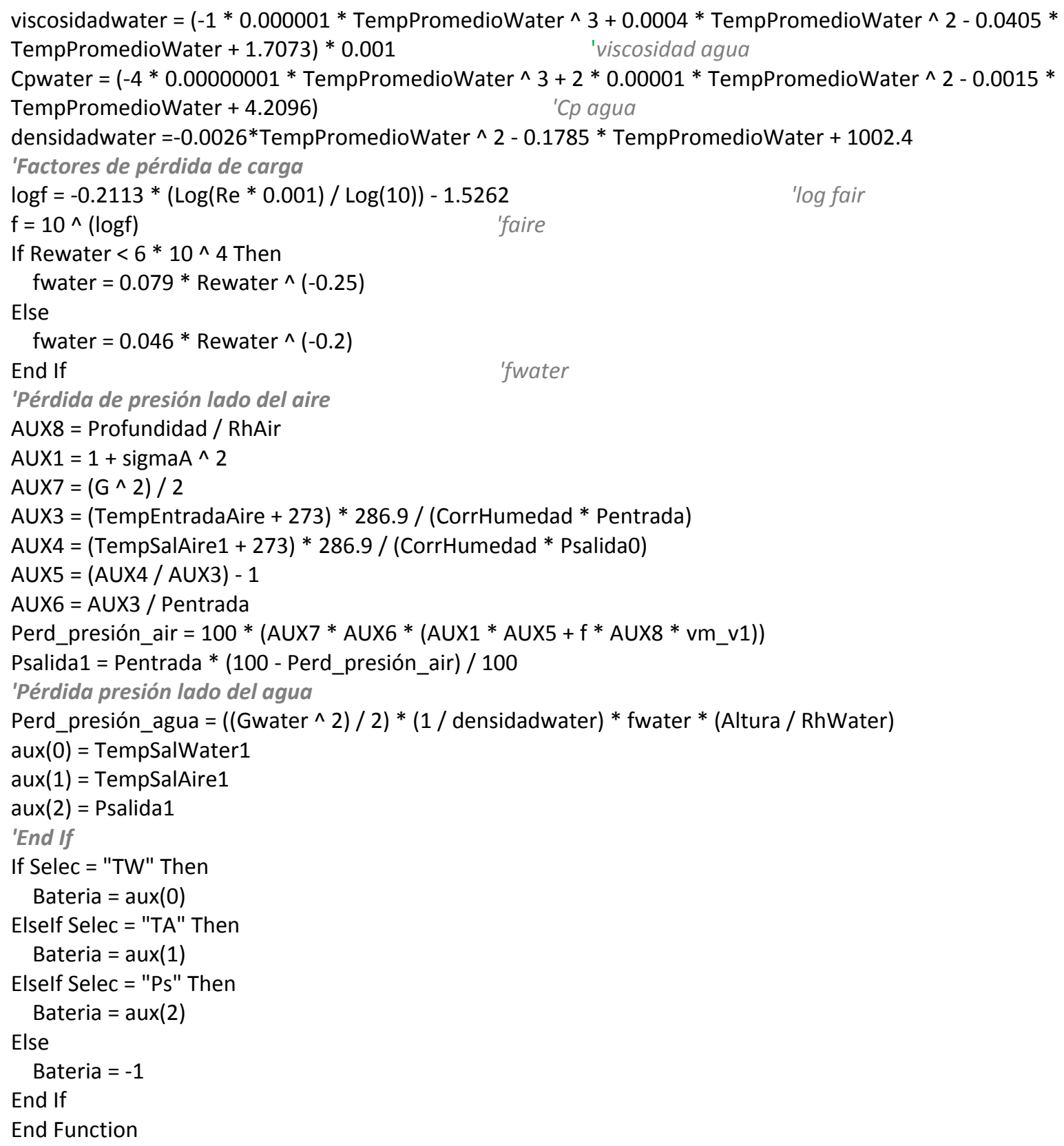




\section{AC.4.- CÓDIGO DE SIMULACIÓN DEL COLECTOR.}

La función colector emplea a la función batería, a partir de la temperatura de entrada de agua en la batería, se suponen inicialmente las temperaturas de agua y de aire a la salida de la batería, éstas son tomadas como valores de entrada de la función batería, junto con la presión a la entrada y la humedad del aire, las cuales se han considerado constantes, el flujo másico de agua y de aire, la temperatura ambiente, la intensidad y la recta de rendimiento del colector solar, la función colector devuelve los valores de temperatura de aire a la entrada y salida del colector y la temperatura de salida del agua en la batería.

El código implementado se presenta a continuación:

Public Function Colector(TempEntradaWater As Double, TempSalWaterlni As Double, Tentcol_inicial As Double, Pentrada As Double, HumedadAire As Double, mwater As Double, mair As Double, A As Double, b As Double, Tambiente As Double, Intensidad As Double, Selec As String) As Double

Dim superficie, ToleranciasRelativas, Cpaire, rendimiento, $X$ As Double

Dim Tent_1, Tw_sal_bat0, Tent_0 As Double

Dim Tw_sal_bat1, incrementosT, Tsalida, aux(2) As Double

' Parámetros del método

superficie $=4$ 'm2

ToleranciaRelativa $=0.1$

'Inicializacion de la temperatura de entrada al colector

Tent_1 = Tentcol_inicial

Tw_sal_bat1 = TempSalWaterlni

Do

'Actualización de las temperaturas en cada iteración

Tent_0 = Tent_1

Tw_sal_bat0 = Tw_sal_bat1

'Calculos previos

Cpaire $=4 * 10^{\wedge}(-7) *$ Tent_0^ $2+10^{\wedge}(-5) *$ Tent_0 +1.0056

$\mathrm{X}=$ (Tent_0 - Tambiente) / Intensidad

rendimiento $=A * X+b$

incrementoT $=($ rendimiento $*$ Intensidad $*$ superficie * 0.01) / (Cpaire * $1000 *$ mair $)$

Tsalid = incrementoT + Tent_0

Tent_1 = Bateria(TempEntradaWater, Tw_sal_bat0, Tsalid, Tent_0, Pentrada, HumedadAire, mwater, mair, "TA")

Tw_sal_bat1 = Bateria(TempEntradaWater, Tw_sal_bat0, Tsalid, Tent_0, Pentrada, HumedadAire, mwater, mair, "TW")

Loop While Abs(Tent_1 - Tent_0) > ToleranciaRelativa

$\operatorname{aux}(0)=$ Tent_1

$\operatorname{aux}(1)=$ Tsalid

$\operatorname{aux}(2)=$ Tw_sal_bat1

If Selec = "Tae_col" Then

Colector $=\operatorname{aux}(0)$

Elself Selec $=$ "Tas_col" Then

Colector $=\operatorname{aux}(1)$

Elself Selec $=$ "Tws" Then

Colector $=\operatorname{aux}(2)$ 
ANEXO C: SIMULACIONES

Else

Colector $=-1$

End If

End Function 


\section{AC.5.- TEMPERATURAS DEL AGUA DE RED EN ESPAÑA.}

\begin{tabular}{|c|c|c|c|c|c|c|c|c|c|c|c|c|c|}
\hline & Ene & Feb & Mar & Abr & May & Jun & Jul & Ago & Sep & Oet & Nov & Dic & Año \\
\hline Álava & 5 & 6 & 8 & 10 & 11 & 12 & 13 & 12 & 11 & 10 & 8 & 5 & 9.3 \\
\hline Albacete & 5 & 6 & 8 & 10 & 11 & 12 & 13 & 12 & 11 & 10 & 8 & 5 & 9.3 \\
\hline Alicante & 8 & 9 & 11 & 13 & 14 & 15 & 16 & 15 & 14 & 13 & 11 & 8 & 12.3 \\
\hline Almería & 8 & 9 & 11 & 13 & 14 & 15 & 16 & 15 & 14 & 13 & 11 & 8 & 12.3 \\
\hline Asturias & 6 & 7 & 9 & 11 & 12 & 13 & 14 & 13 & 12 & 11 & 9 & 6 & 10.3 \\
\hline Ávila & 4 & 5 & 7 & 9 & 10 & 11 & 12 & 11 & 10 & 9 & 7 & 4 & 8.3 \\
\hline Badajoz & 6 & 7 & 9 & 11 & 12 & 13 & 14 & 13 & 12 & 11 & 9 & 6 & 10.3 \\
\hline Baleares & 8 & 9 & 11 & 13 & 14 & 15 & 16 & 15 & 14 & 13 & 11 & 8 & 12.3 \\
\hline Barcelona & 8 & 9 & 11 & 13 & 14 & 15 & 16 & 15 & 14 & 13 & 11 & 8 & 12.3 \\
\hline Burgos & 4 & 5 & 7 & 9 & 10 & 11 & 12 & 11 & 10 & 9 & 7 & 4 & 8.3 \\
\hline Cáceres & 6 & 7 & 9 & 11 & 12 & 13 & 14 & 13 & 12 & 11 & 9 & 6 & 10.3 \\
\hline Cádiz & 8 & 9 & 11 & 13 & 14 & 15 & 16 & 15 & 14 & 13 & 11 & 8 & 12.3 \\
\hline Cantabria & 8 & 9 & 11 & 13 & 14 & 15 & 16 & 15 & 14 & 13 & 11 & 8 & 12.3 \\
\hline Castellón & 8 & 9 & 11 & 13 & 14 & 15 & 16 & 15 & 14 & 13 & 11 & 8 & 12.3 \\
\hline Ceuta & 8 & 9 & 10 & 12 & 13 & 13 & 14 & 13 & 13 & 12 & 11 & 8 & 11.3 \\
\hline Ciudad Real & 5 & 6 & 8 & 10 & 11 & 12 & 13 & 12 & 11 & 10 & 8 & 5 & 9.3 \\
\hline Córdoba & 6 & 7 & 9 & 11 & 12 & 13 & 14 & 13 & 12 & 11 & 9 & 6 & 10.3 \\
\hline La Coruña & 8 & 9 & 11 & 13 & 14 & 15 & 16 & 15 & 14 & 13 & 11 & 8 & 12.3 \\
\hline Cuenca & 4 & 5 & 7 & 9 & 10 & 11 & 12 & 11 & 10 & 9 & 7 & 4 & 8.3 \\
\hline Gerona & 6 & 7 & 9 & 11 & 12 & 13 & 14 & 13 & 12 & 11 & 9 & 6 & 10.3 \\
\hline Granada & 6 & 7 & 9 & 11 & 12 & 13 & 14 & 13 & 12 & 11 & 9 & 6 & 10.3 \\
\hline Guadalajara & 6 & 7 & 9 & 11 & 12 & 13 & 14 & 13 & 12 & 11 & 9 & 6 & 10.3 \\
\hline Guipúzcoa & 8 & 9 & 11 & 13 & 14 & 15 & 16 & 15 & 14 & 13 & 11 & 8 & 12.3 \\
\hline Huelva & 8 & 9 & 11 & 13 & 14 & 15 & 16 & 15 & 14 & 13 & 11 & 8 & 12.3 \\
\hline Huesca & 5 & 6 & 8 & 10 & 11 & 12 & 13 & 12 & 11 & 10 & 8 & 5 & 9.3 \\
\hline Jaén & 8 & 9 & 11 & 13 & 14 & 15 & 17 & 16 & 14 & 13 & 11 & 7 & 12.3 \\
\hline León & 4 & 5 & 7 & 9 & 10 & 11 & 12 & 11 & 10 & 9 & 7 & 4 & 8.3 \\
\hline Lérida & 5 & 6 & 8 & 10 & 11 & 12 & 13 & 12 & 11 & 10 & 8 & 5 & 9.3 \\
\hline Lugo & 6 & 7 & 9 & 11 & 12 & 13 & 14 & 13 & 12 & 11 & 9 & 6 & 10.3 \\
\hline Madrid & 6 & 7 & 9 & 11 & 12 & 13 & 14 & 13 & 12 & 11 & 9 & 6 & 10.3 \\
\hline Málaga & 8 & 9 & 11 & 13 & 14 & 15 & 16 & 15 & 14 & 13 & 11 & 8 & 12.3 \\
\hline Melilla & 8 & 9 & 11 & 13 & 14 & 15 & 16 & 15 & 14 & 13 & 11 & 8 & 12.3 \\
\hline Murcia & 8 & 9 & 11 & 13 & 14 & 15 & 16 & 15 & 14 & 13 & 11 & 8 & 12.3 \\
\hline Navarra & 5 & 6 & 8 & 10 & 11 & 12 & 13 & 12 & 11 & 10 & 8 & 5 & 9.3 \\
\hline Orense & 5 & 7 & 9 & 11 & 12 & 13 & 14 & 13 & 12 & 11 & .9 & 6 & 10.2 \\
\hline Palencia & 5 & 6 & 8 & 10 & 11 & 12 & 13 & 12 & 11 & 10 & 8 & 5 & 9.3 \\
\hline Las Palmas & 8 & 9 & 11 & 13 & 14 & 15 & 16 & 15 & 14 & 13 & 11 & 8 & 12.3 \\
\hline Pontevedra & 8 & 9 & 11 & 13 & 14 & 15 & 16 & 15 & 14 & 13 & 11 & 8 & 12.3 \\
\hline La Rioja & 6 & 7 & 9 & 11 & 12 & 13 & 14 & 13 & 12 & 11 & 9 & 6 & 10.3 \\
\hline Salamanca & 5 & 6 & 8 & 10 & 11 & 12 & 13 & 12 & 11 & 10 & 8 & 5 & 9.3 \\
\hline S. C. Tenerife & 8 & 9 & 11 & 13 & 14 & 15 & 16 & 15 & 14 & 13 & 11 & 8 & 12.3 \\
\hline Segovia & 4 & 5 & 7 & 9 & 10 & 11 & 12 & 11 & 10 & 9 & 7 & 4 & 8.3 \\
\hline Sevilla & 8 & 9 & 11 & 13 & 14 & 15 & 16 & 15 & 14 & 13 & 11 & 8 & 12.3 \\
\hline Soria & 4 & 5 & 7 & 9 & 10 & 11 & 12 & 11 & 10 & 9 & 7 & 4 & 8.3 \\
\hline Tarragona & 6 & 7 & 9 & 11 & 12 & 13 & 14 & 13 & 12 & 11 & 9 & 6 & 10.3 \\
\hline Teruel & 4 & 5 & 7 & 9 & 10 & 11 & 12 & 11 & 10 & 9 & 7 & 4 & 8.3 \\
\hline Toledo & 6 & 7 & 9 & 11 & 12 & 13 & 14 & 13 & 12 & 11 & 9 & 6 & 10.3 \\
\hline Valencia & 8 & 9 & 11 & 13 & 14 & 15 & 16 & 15 & 14 & 13 & 11 & 8 & 12.3 \\
\hline Valladolid & 5 & 6 & 8 & 10 & 11 & 12 & 13 & 12 & 11 & 10 & 8 & 5 & 9.3 \\
\hline Vizcaya & 6 & 7 & 9 & 11 & 12 & 13 & 14 & 13 & 12 & 11 & 9 & 6 & 10.3 \\
\hline Zamora & 5 & 6 & 8 & 10 & 11 & 12 & 13 & 12 & 11 & 10 & 8 & 5 & 9.3 \\
\hline Zaragoza & 5 & 6 & 8 & 10 & 11 & 12 & 13 & 12 & 11 & 10 & 8 & 5 & 9.3 \\
\hline
\end{tabular}




\section{AC.6.- EVOLUCIÓN DE LA TEMPERATURA DEL AGUA EN EL DEPÓSITO DE ACUMULACIÓN.}

A continuación se muestran las gráficas que representan la evolución de la temperatura del agua en el depósito para todas las combinaciones estudiadas, resultantes de las diferentes combinaciones de tamaño de depósito, caudal de aire de paso por el CTS y día tipo estudiado para cada mes.

\section{AC.6.1.- DEPÓSITO DE 100 LITROS.}

\section{AC.6.1.1.- CAUDAL DE AIRE: $100 \mathrm{~m}^{3} / \mathrm{h}$.}

\section{MAYO}

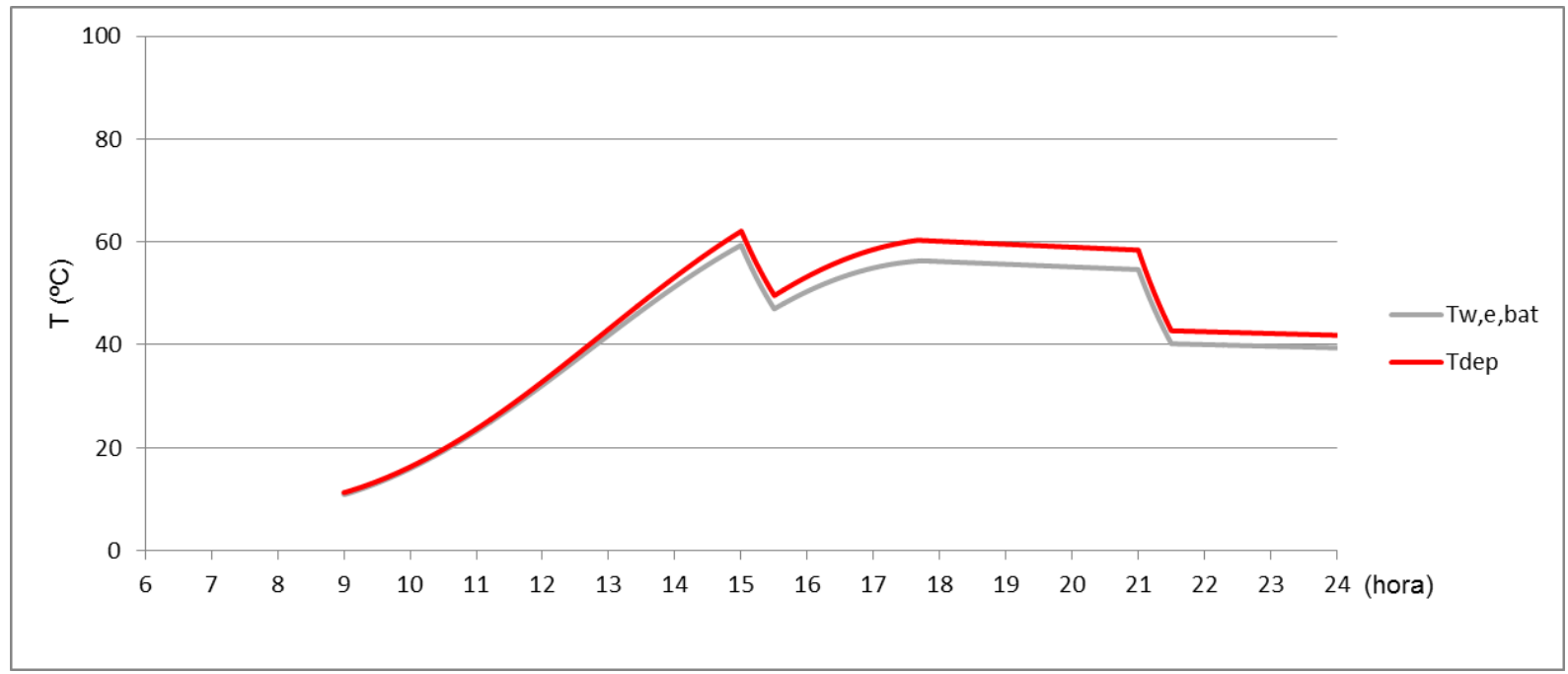

Figura AC.5.- Evolución de la temperatura del agua en el depósito para el día tipo de MAYO con un caudal de aire de paso por el colector de $100 \mathrm{~m}^{3} / \mathrm{h}$. Capacidad del depósito: 100 litros. 


\section{JUNIO}

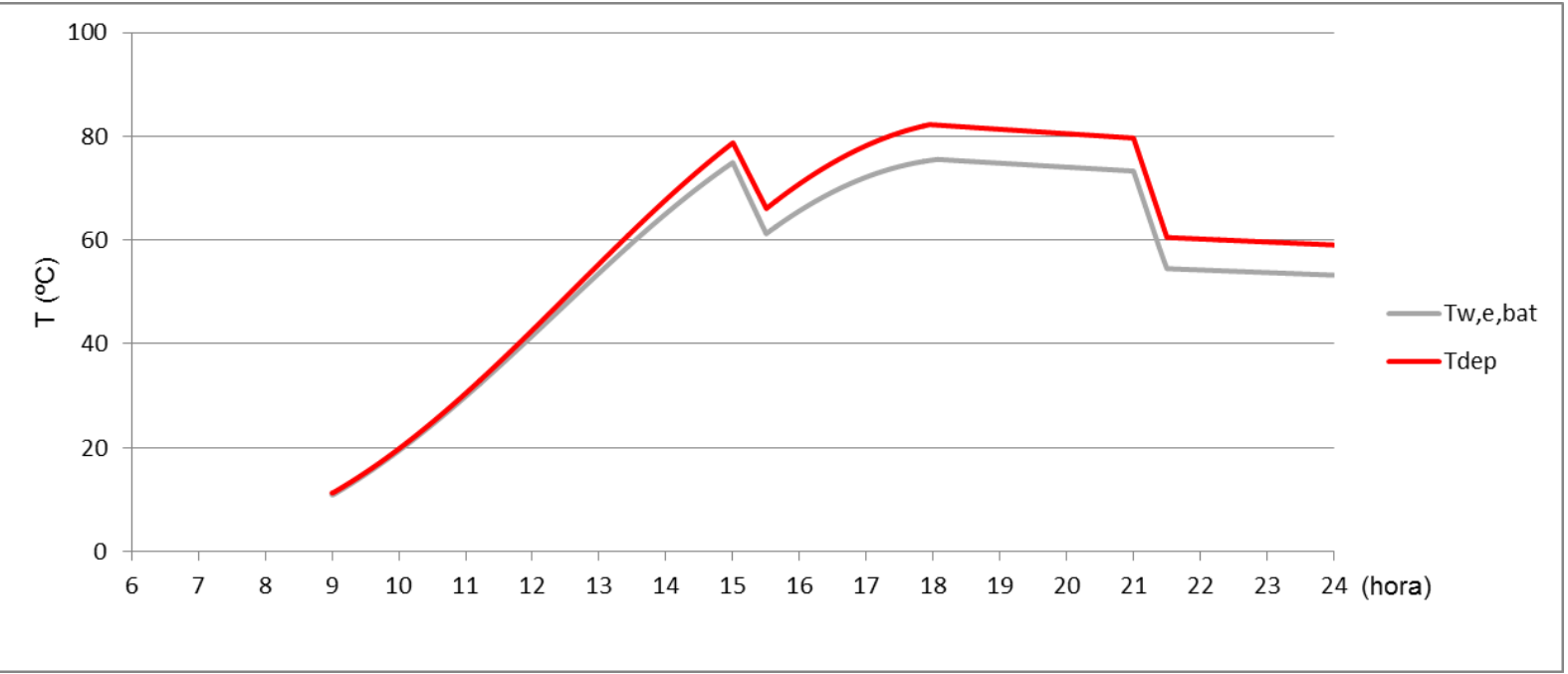

Figura AC.6.- Evolución de la temperatura del agua en el depósito para el día tipo de JUNIO con un caudal de aire de paso por el colector de $100 \mathrm{~m}^{3} / \mathrm{h}$. Capacidad del depósito: 100 litros.

\section{JULIO}

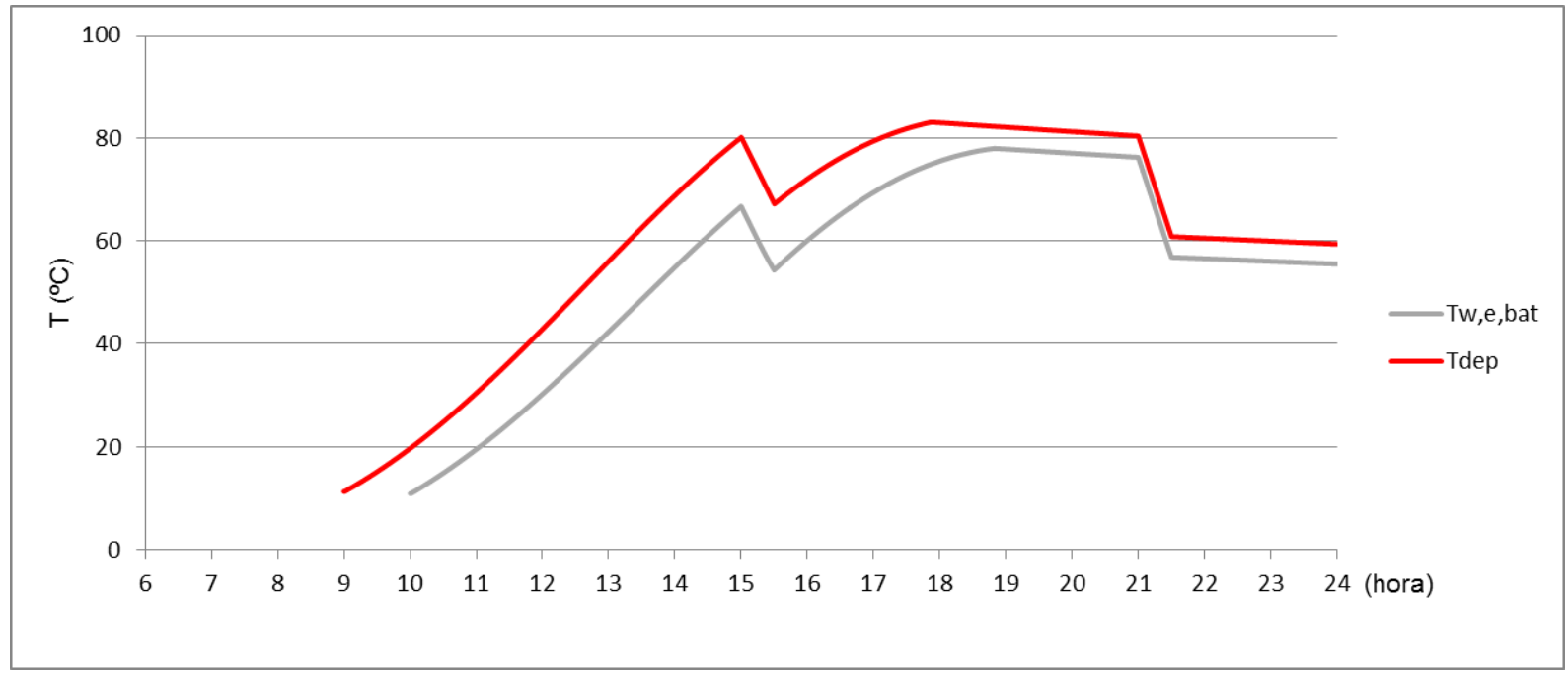

Figura AC.7.- Evolución de la temperatura del agua en el depósito para el día tipo de JULIO con un caudal de aire de paso por el colector de $100 \mathrm{~m}^{3} / \mathrm{h}$. Capacidad del depósito: 100 litros. 


\section{ANEXO C: SIMULACIONES}

\section{AGOSTO}

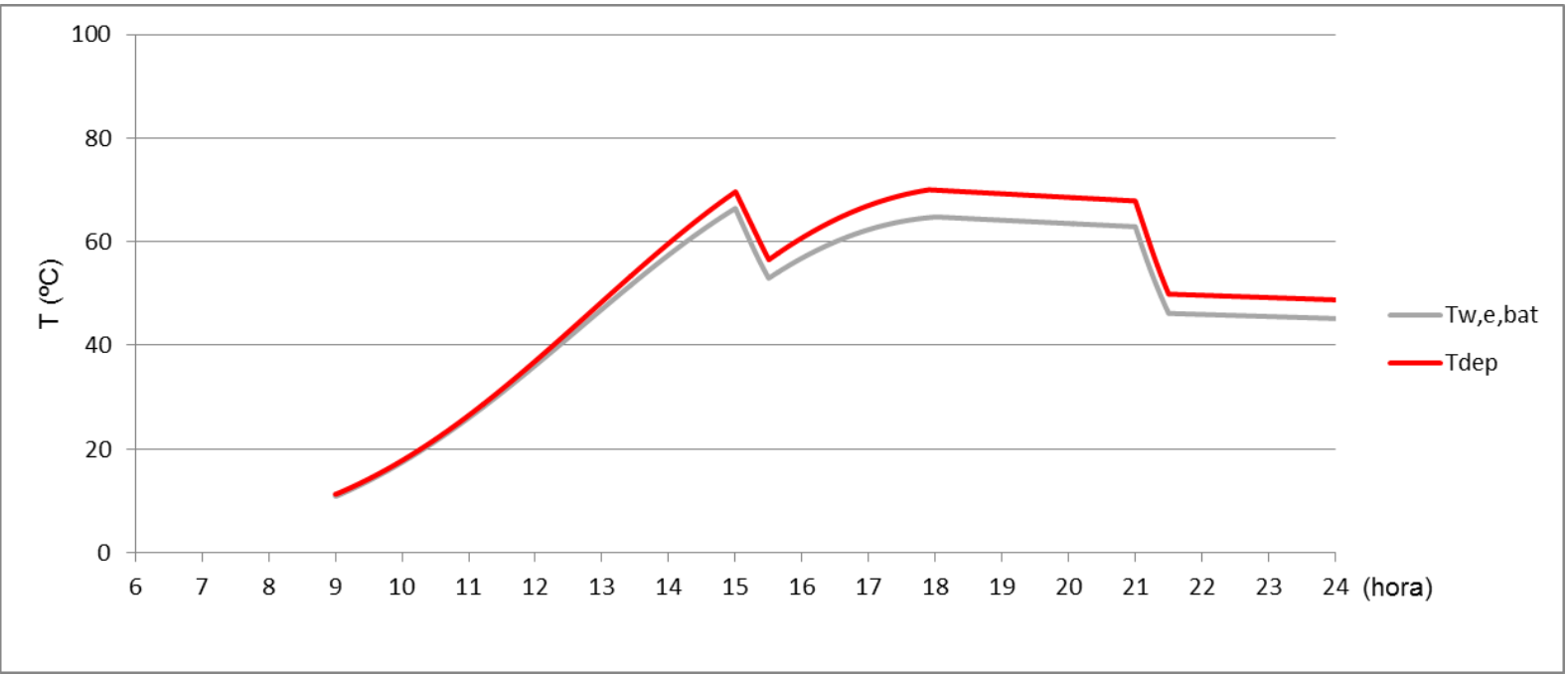

Figura AC.8.- Evolución de la temperatura del agua en el depósito para el día tipo de AGOSTO con un caudal de aire de paso por el colector de $100 \mathrm{~m}^{3} / \mathrm{h}$. Capacidad del depósito: 100 litros.

\section{SEPTIEMBRE}

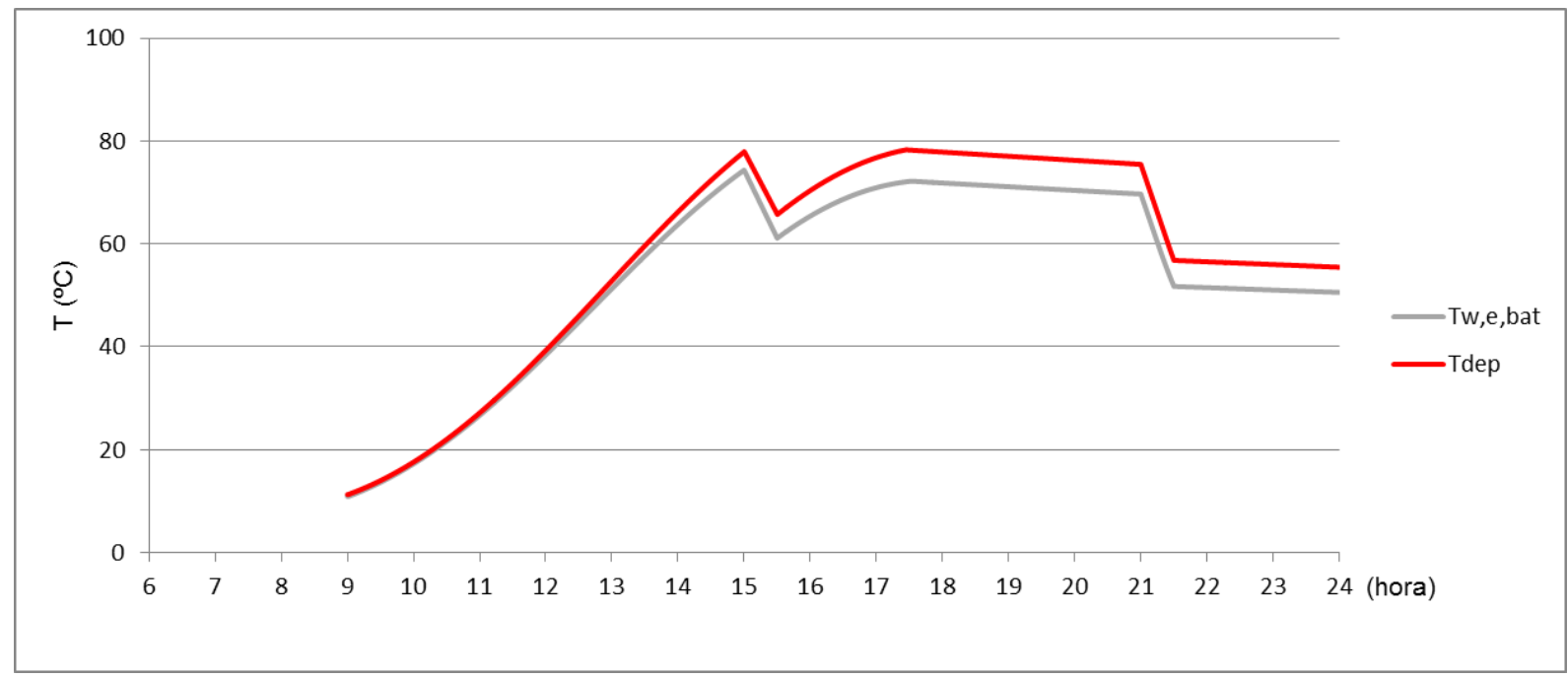

Figura AC.9.- Evolución de la temperatura del agua en el depósito para el día tipo de SEPTIEMBRE con un caudal de aire de paso por el colector de $100 \mathrm{~m}^{3} / \mathrm{h}$. Capacidad del depósito: 100 litros. 


\section{AC.6.1.2.- CAUDAL DE AIRE: $200 \mathrm{~m}^{3} / \mathrm{h}$.}

\section{MAYO}

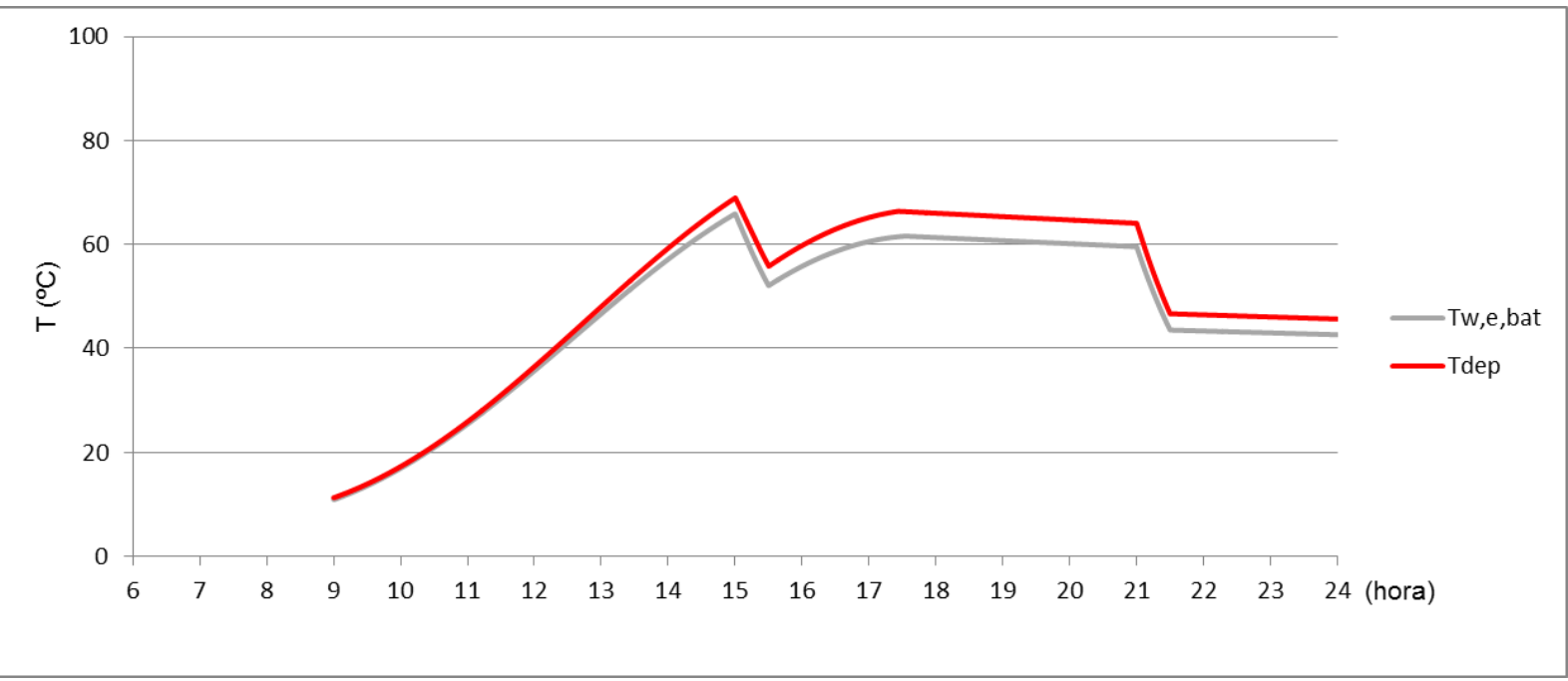

Figura AC.10.- Evolución de la temperatura del agua en el depósito para el día tipo de MAYO con un caudal de aire de paso por el colector de $200 \mathrm{~m}^{3} / \mathrm{h}$. Capacidad del depósito: 100 litros.

\section{$\underline{\text { JUNIO }}$}

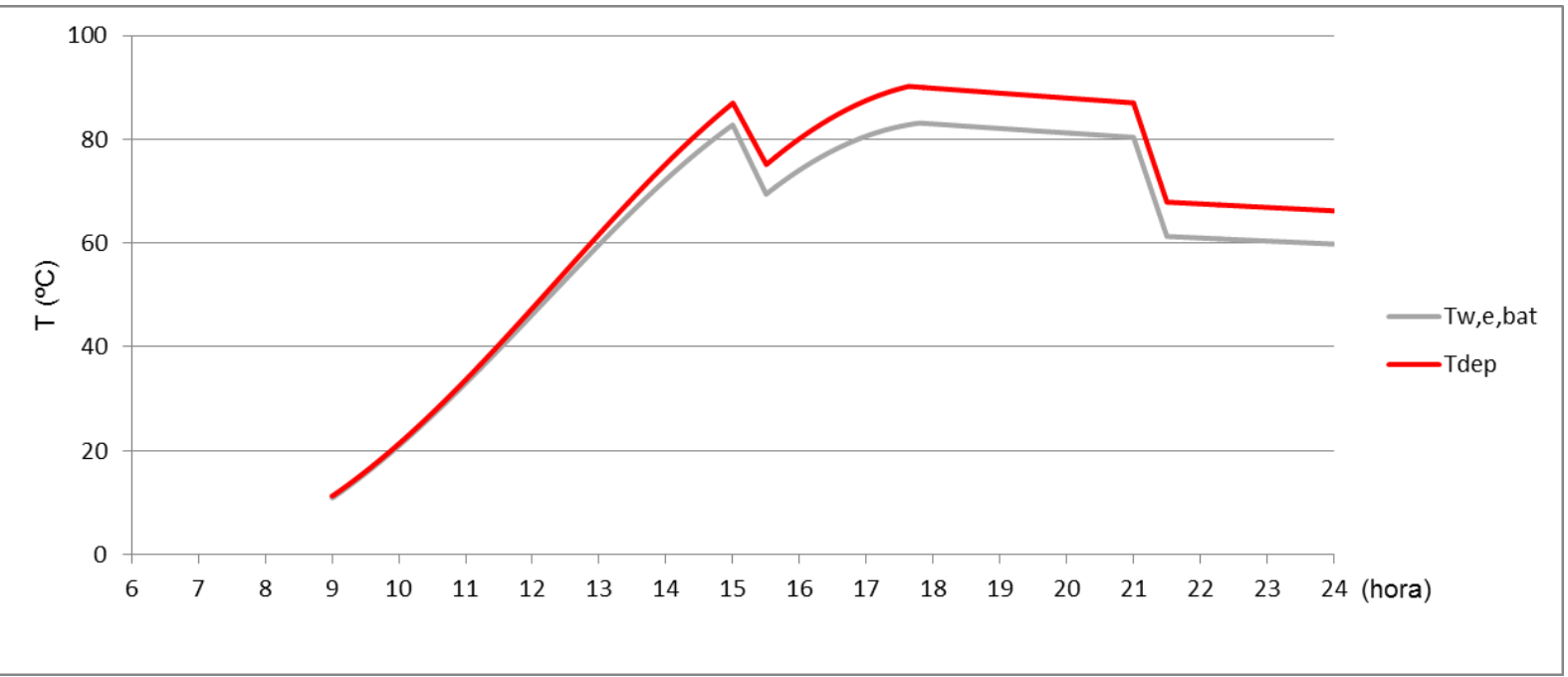

Figura AC.11.- Evolución de la temperatura del agua en el depósito para el día tipo de JUNIO con un caudal de aire de paso por el colector de $200 \mathrm{~m}^{3} / \mathrm{h}$. Capacidad del depósito: 100 litros. 


\section{ANEXO C: SIMULACIONES}

\section{JULIO}

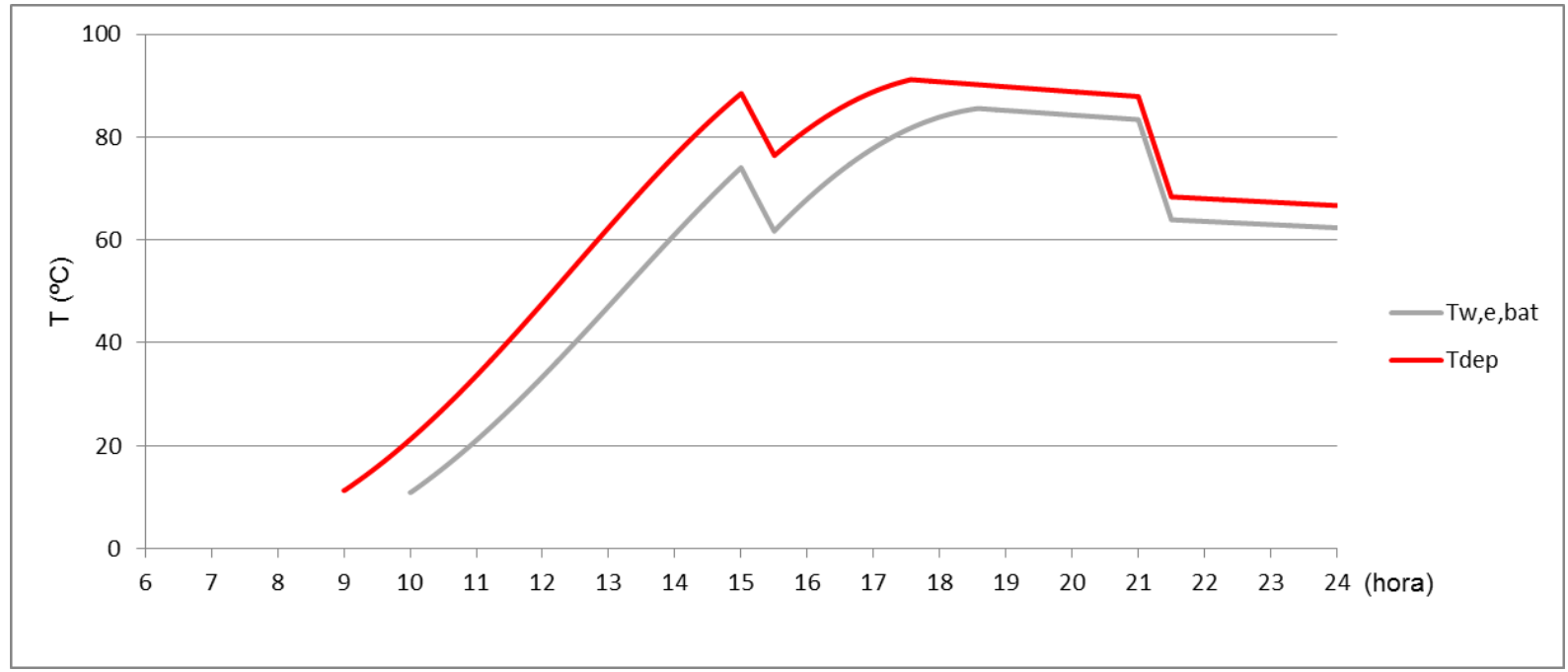

Figura AC.12.- Evolución de la temperatura del agua en el depósito para el día tipo de JULIO con un caudal de aire de paso por el colector de $200 \mathrm{~m}^{3} / \mathrm{h}$. Capacidad del depósito: 100 litros.

\section{AGOSTO}

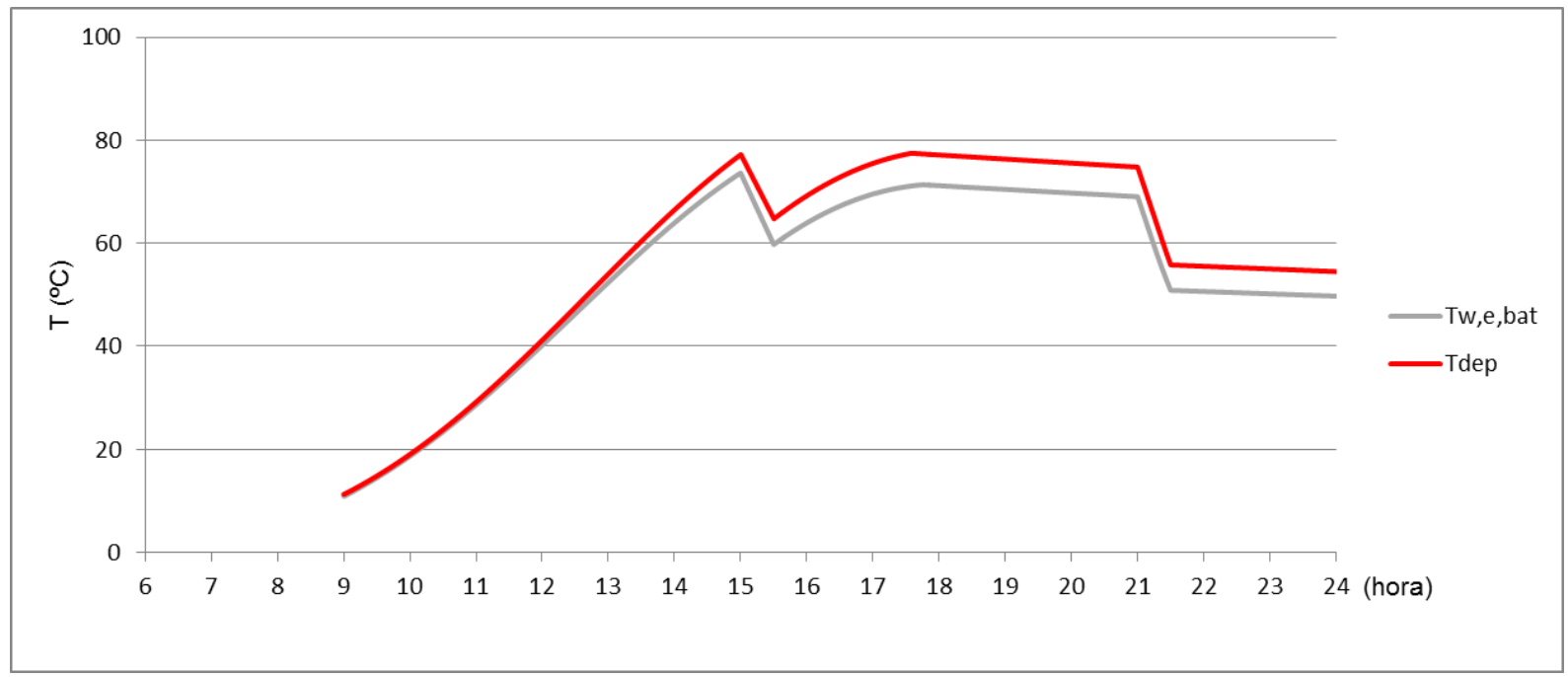

Figura AC.13.- Evolución de la temperatura del agua en el depósito para el día tipo de AGOSTO con un caudal de aire de paso por el colector de $200 \mathrm{~m}^{3} / \mathrm{h}$. Capacidad del depósito: 100 litros. 


\section{SEPTIEMBRE}

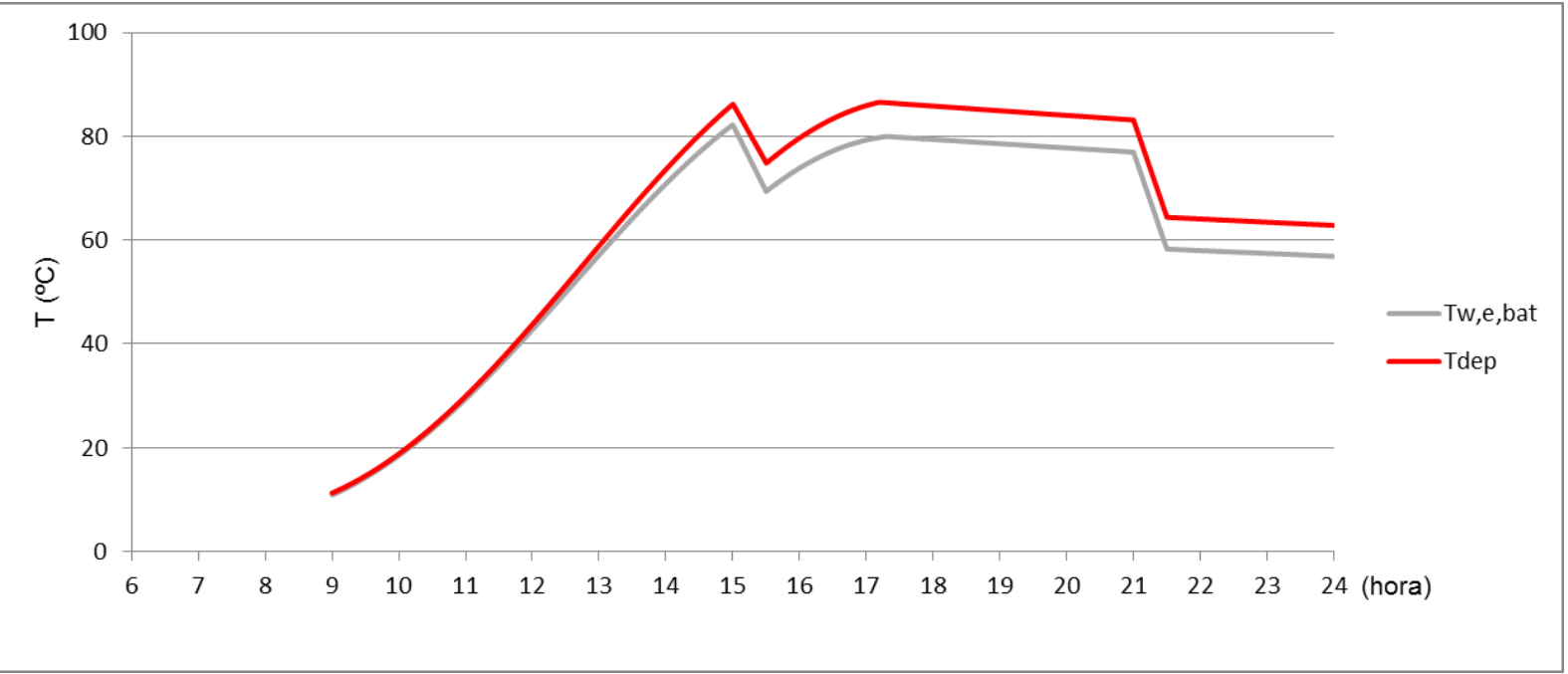

Figura AC.14.- Evolución de la temperatura del agua en el depósito para el día tipo de SEPTIEMBRE con un caudal de aire de paso por el colector de $200 \mathrm{~m}^{3} / \mathrm{h}$. Capacidad del depósito: 100 litros.

\section{AC.6.1.3.- CAUDAL DE AIRE: $300 \mathrm{~m}^{3} / \mathrm{h}$.}

\section{MAYO}

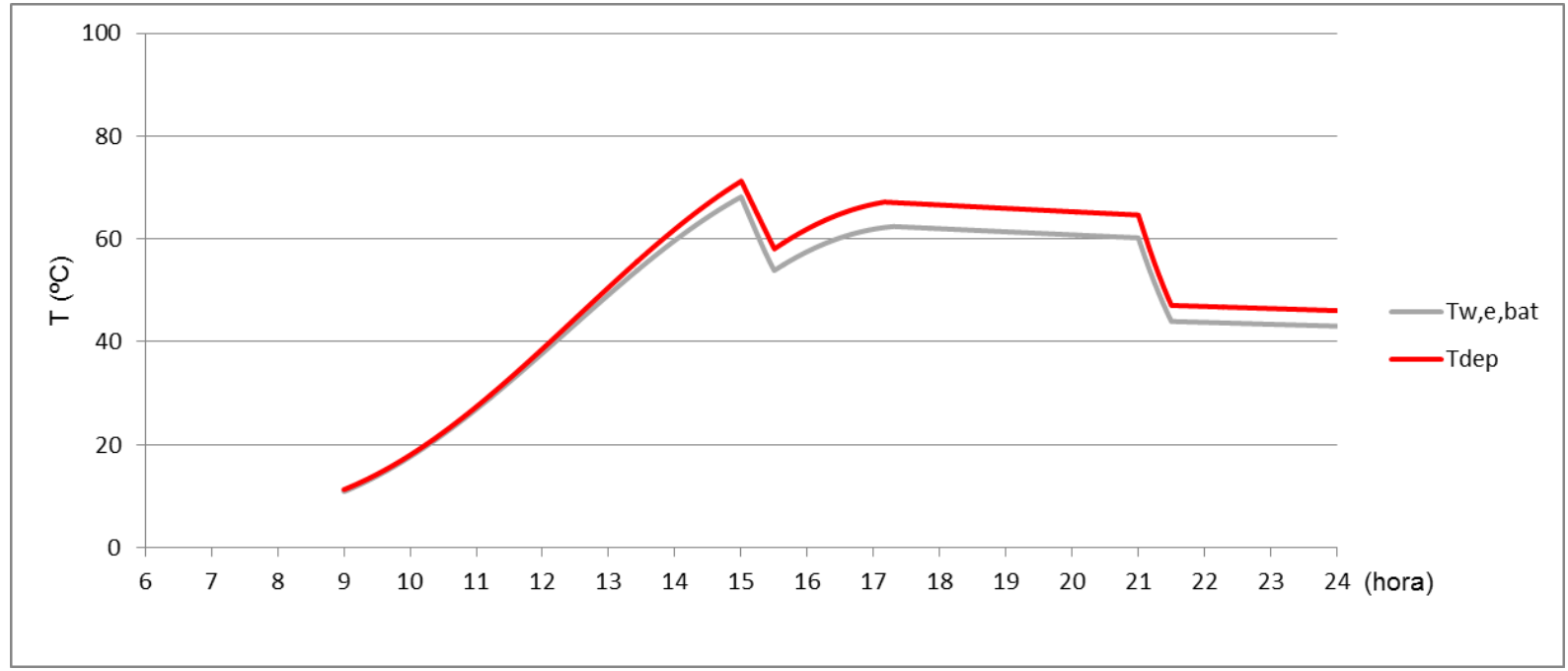

Figura AC.15.- Evolución de la temperatura del agua en el depósito para el día tipo de MAYO con un caudal de aire de paso por el colector de $300 \mathrm{~m}^{3} / \mathrm{h}$. Capacidad del depósito: 100 litros. 


\section{ANEXO C: SIMULACIONES}

\section{JUNIO}

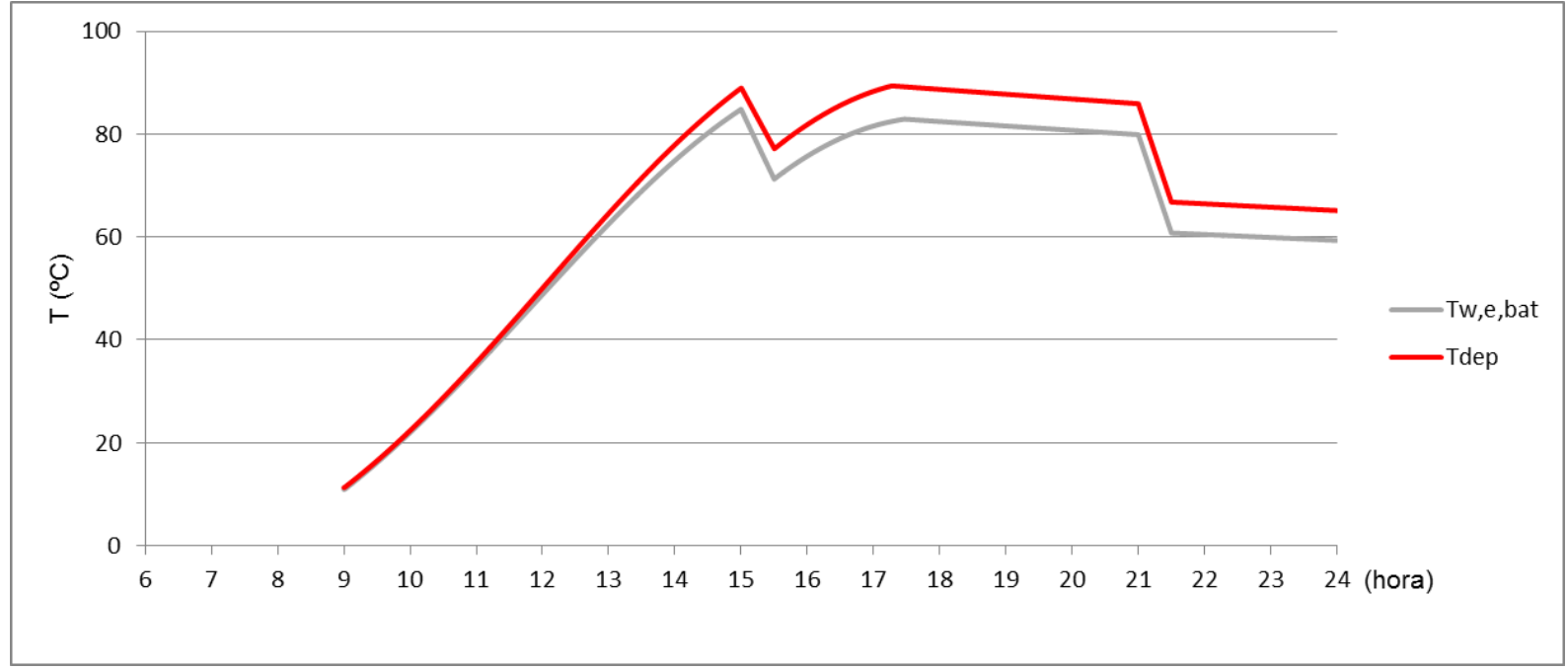

Figura AC.16.- Evolución de la temperatura del agua en el depósito para el día tipo de JUNIO con un caudal de aire de paso por el colector de $300 \mathrm{~m}^{3} / \mathrm{h}$. Capacidad del depósito: 100 litros.

\section{JULIO}

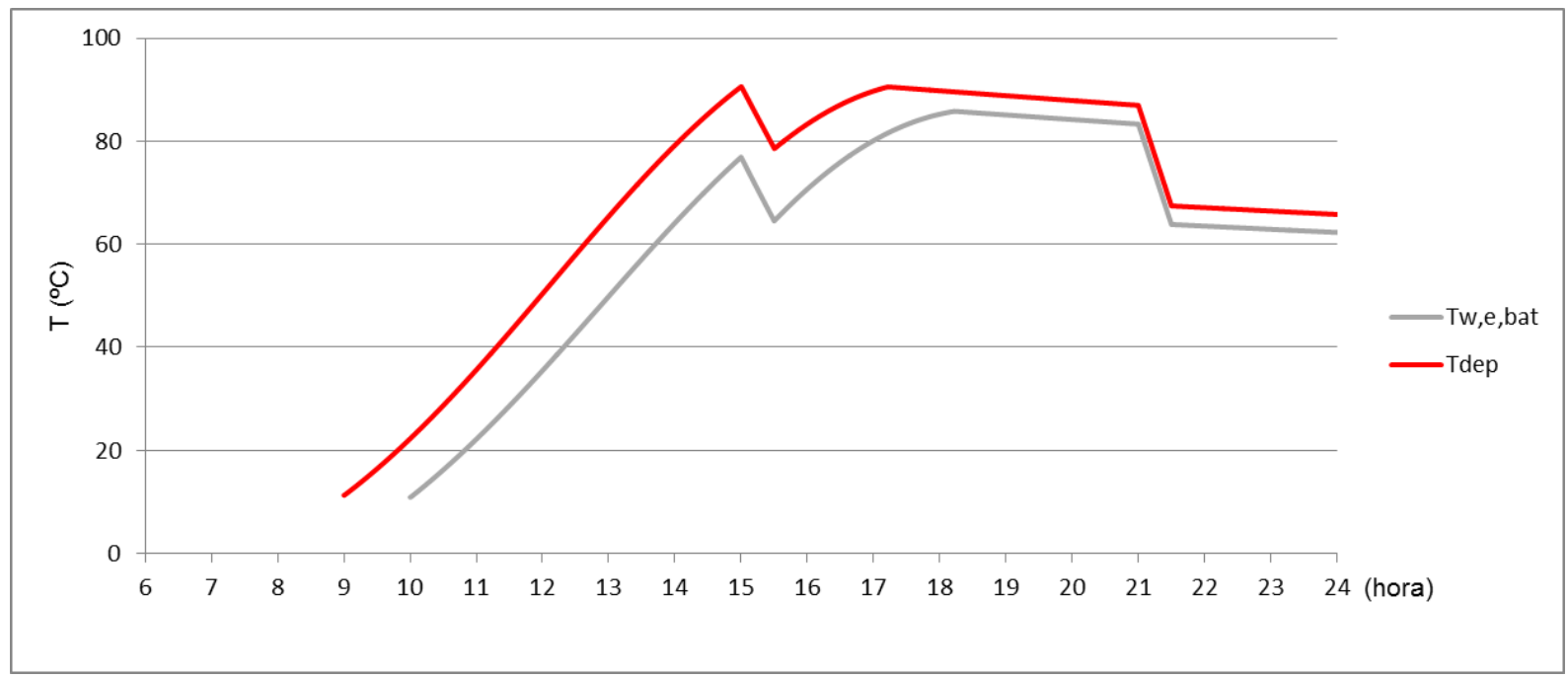

Figura AC.17.- Evolución de la temperatura del agua en el depósito para el día tipo de JULIO con un caudal de aire de paso por el colector de $300 \mathrm{~m}^{3} / \mathrm{h}$. Capacidad del depósito: 100 litros. 


\section{AGOSTO}

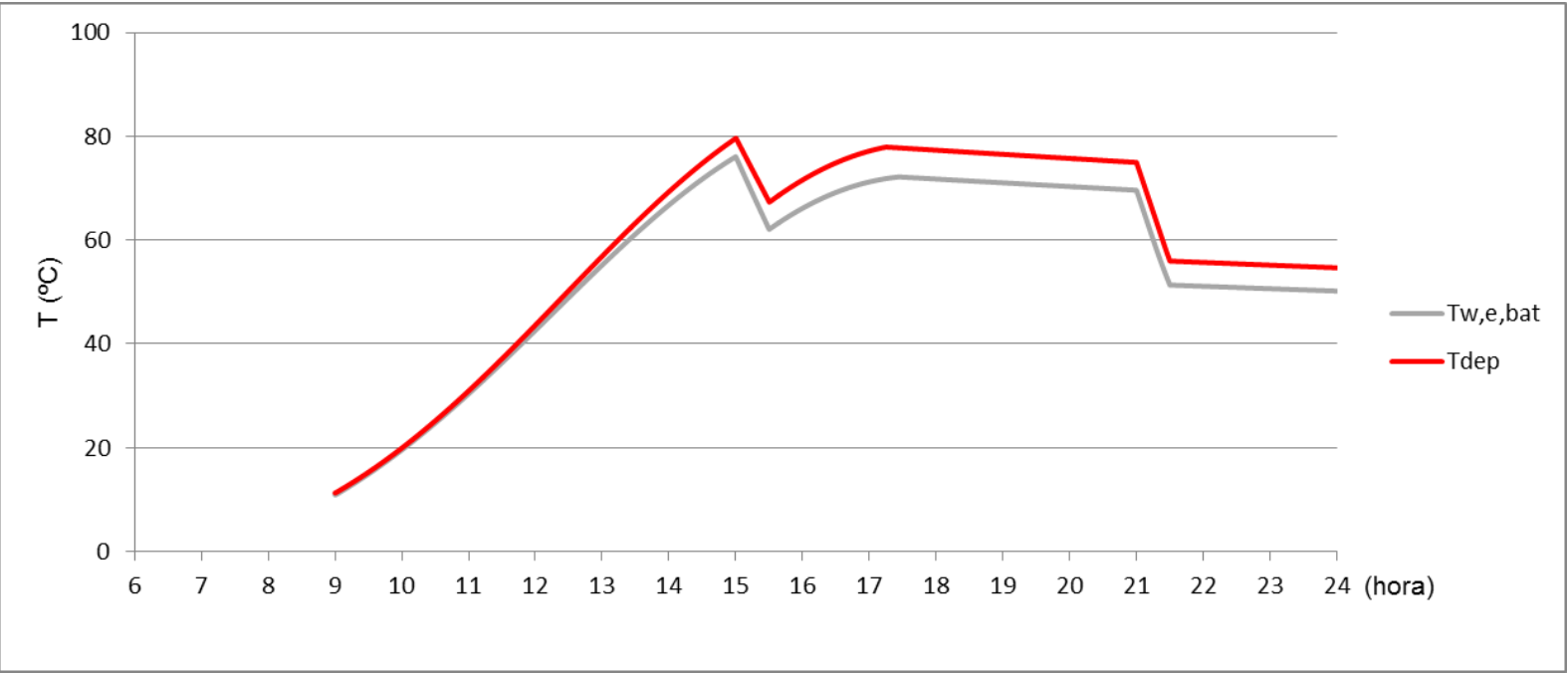

Figura AC.18.- Evolución de la temperatura del agua en el depósito para el día tipo de AGOSTO con un caudal de aire de paso por el colector de $300 \mathrm{~m}^{3} / \mathrm{h}$. Capacidad del depósito: 100 litros.

\section{SEPTIEMBRE}

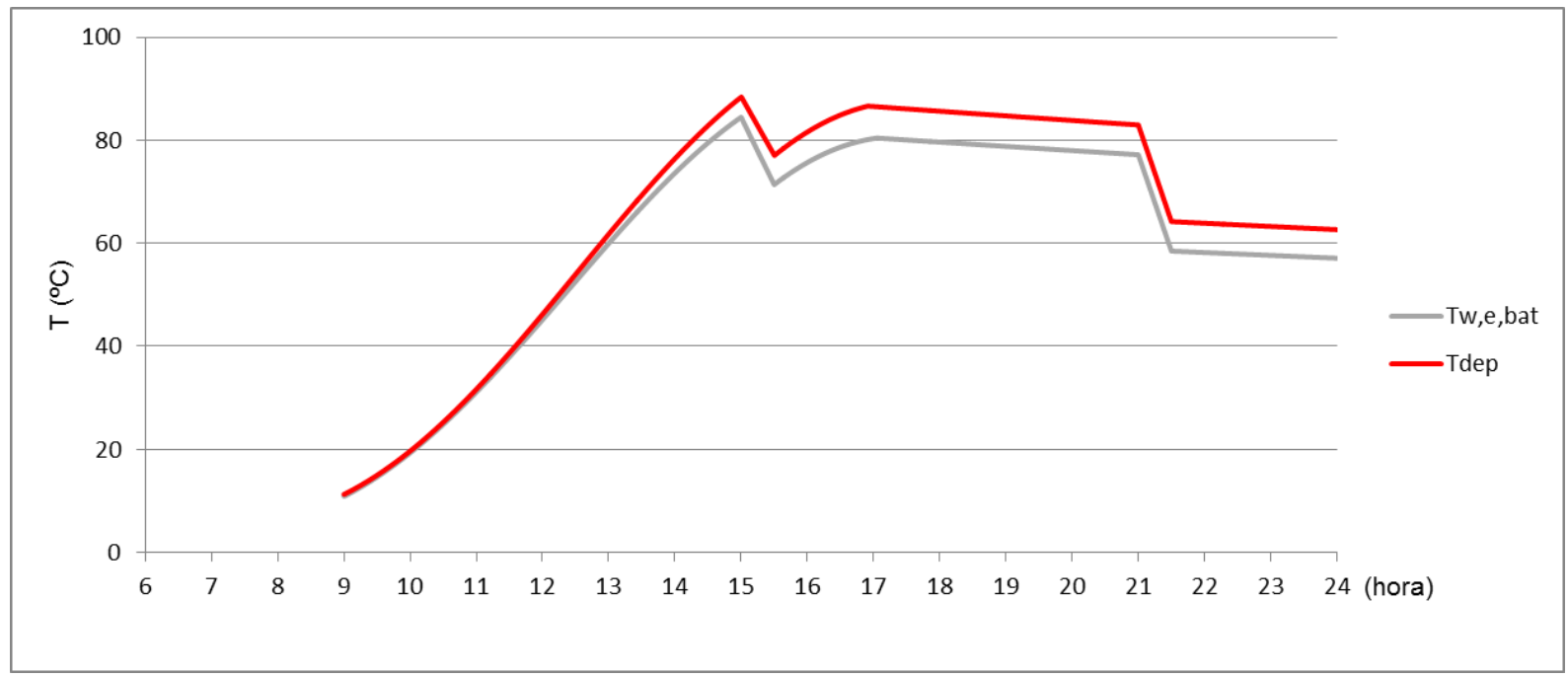

Figura AC.19.- Evolución de la temperatura del agua en el depósito para el día tipo de SEPTIEMBRE con un caudal de aire de paso por el colector de $300 \mathrm{~m}^{3} / \mathrm{h}$. Capacidad del depósito: 100 litros. 


\section{AC.6.2.- DEPÓSITO DE 300 LITROS.}

\section{AC.6.2.1.- CAUDAL DE AIRE: $100 \mathrm{~m}^{3} / \mathrm{h}$.}

\section{MAYO}

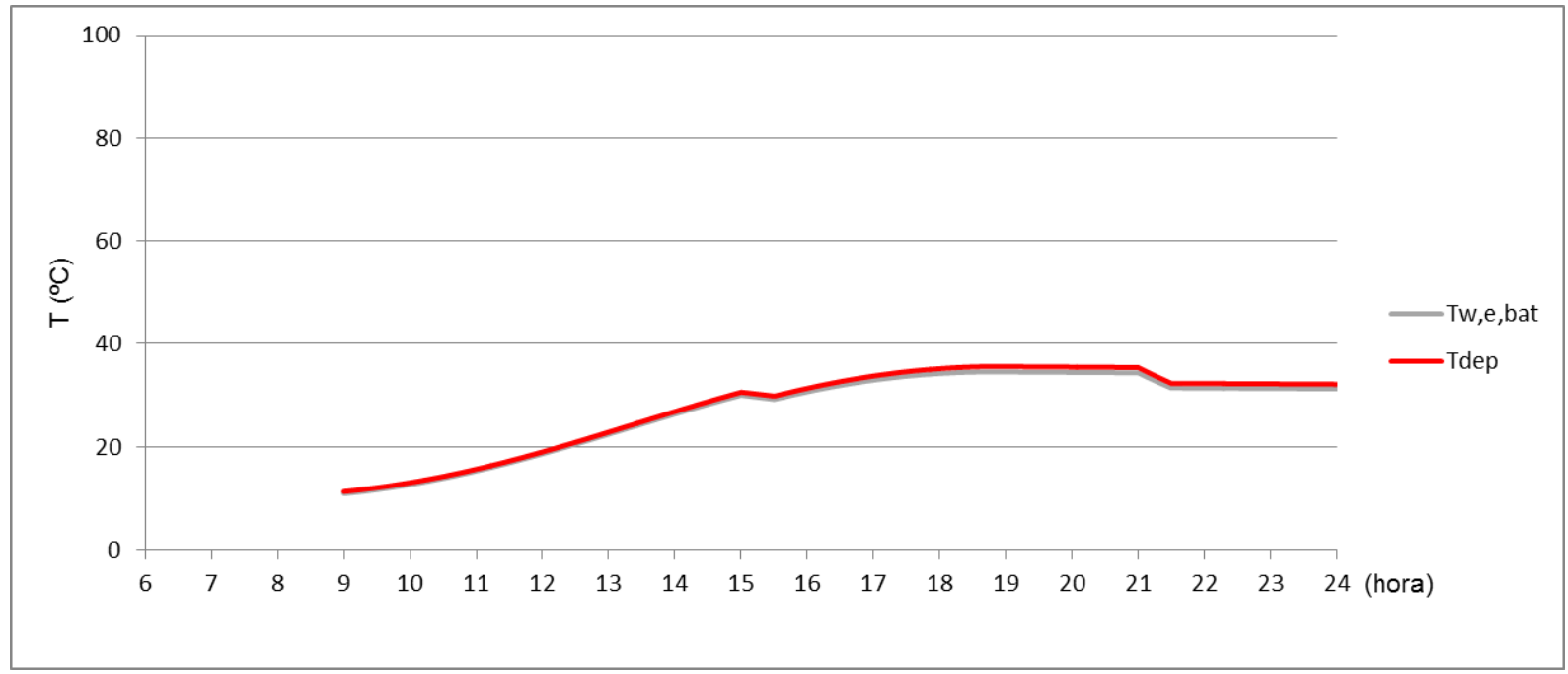

Figura AC.20.- Evolución de la temperatura del agua en el depósito para el día tipo de MAYO con un caudal de aire de paso por el colector de $100 \mathrm{~m}^{3} / \mathrm{h}$. Capacidad del depósito: 300 litros.

\section{$\underline{\text { JUNIO }}$}

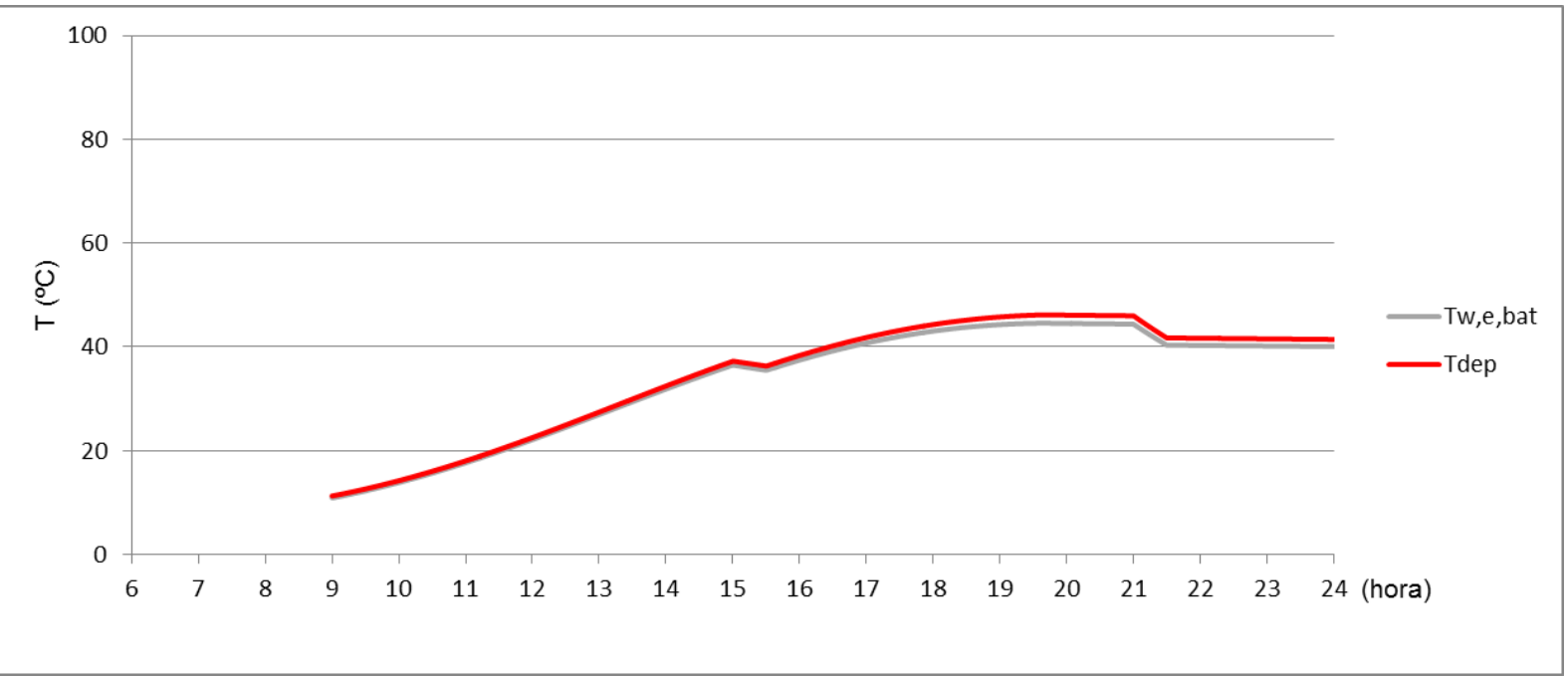

Figura AC.21.- Evolución de la temperatura del agua en el depósito para el día tipo de JUNIO con un caudal de aire de paso por el colector de $100 \mathrm{~m}^{3} / \mathrm{h}$. Capacidad del depósito: 300 litros. 


\section{JULIO}

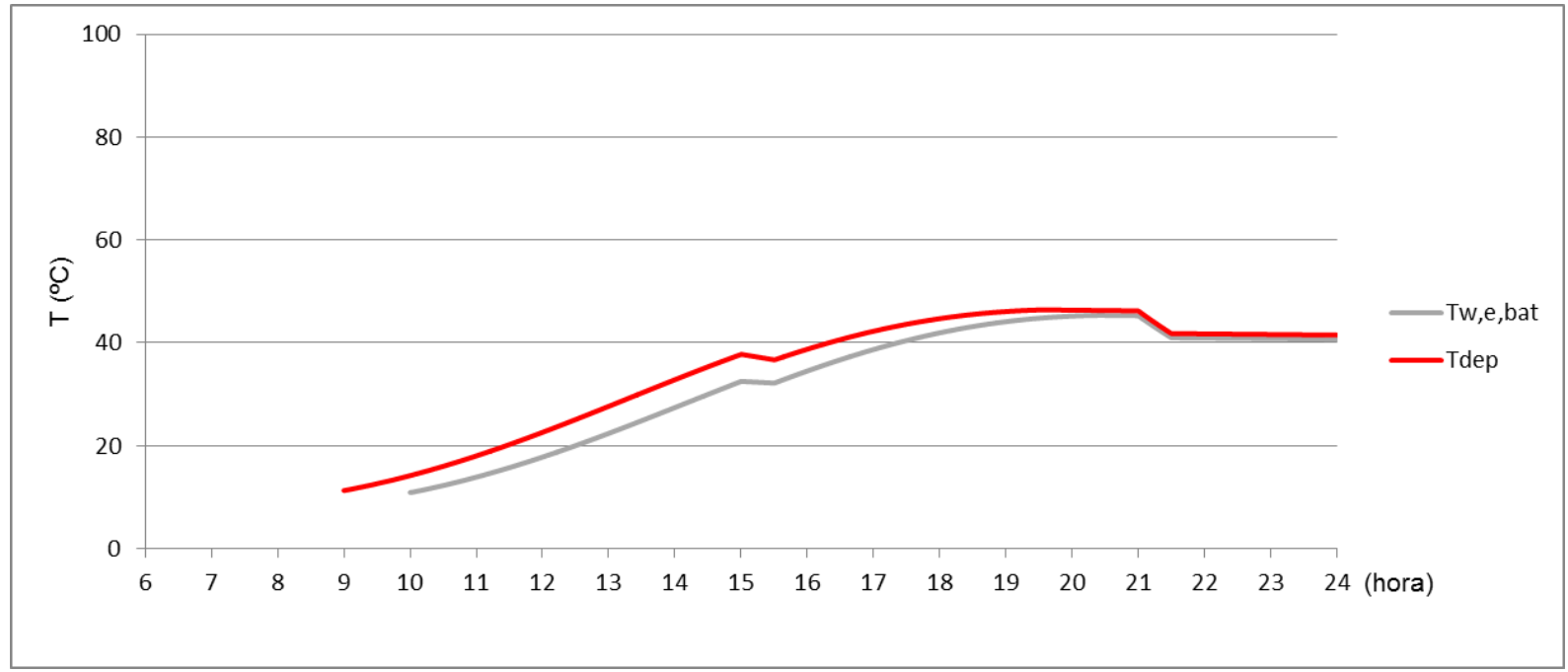

Figura AC.22.- Evolución de la temperatura del agua en el depósito para el día tipo de JULIO con un caudal de aire de paso por el colector de $100 \mathrm{~m}^{3} / \mathrm{h}$. Capacidad del depósito: 300 litros.

\section{AGOSTO}

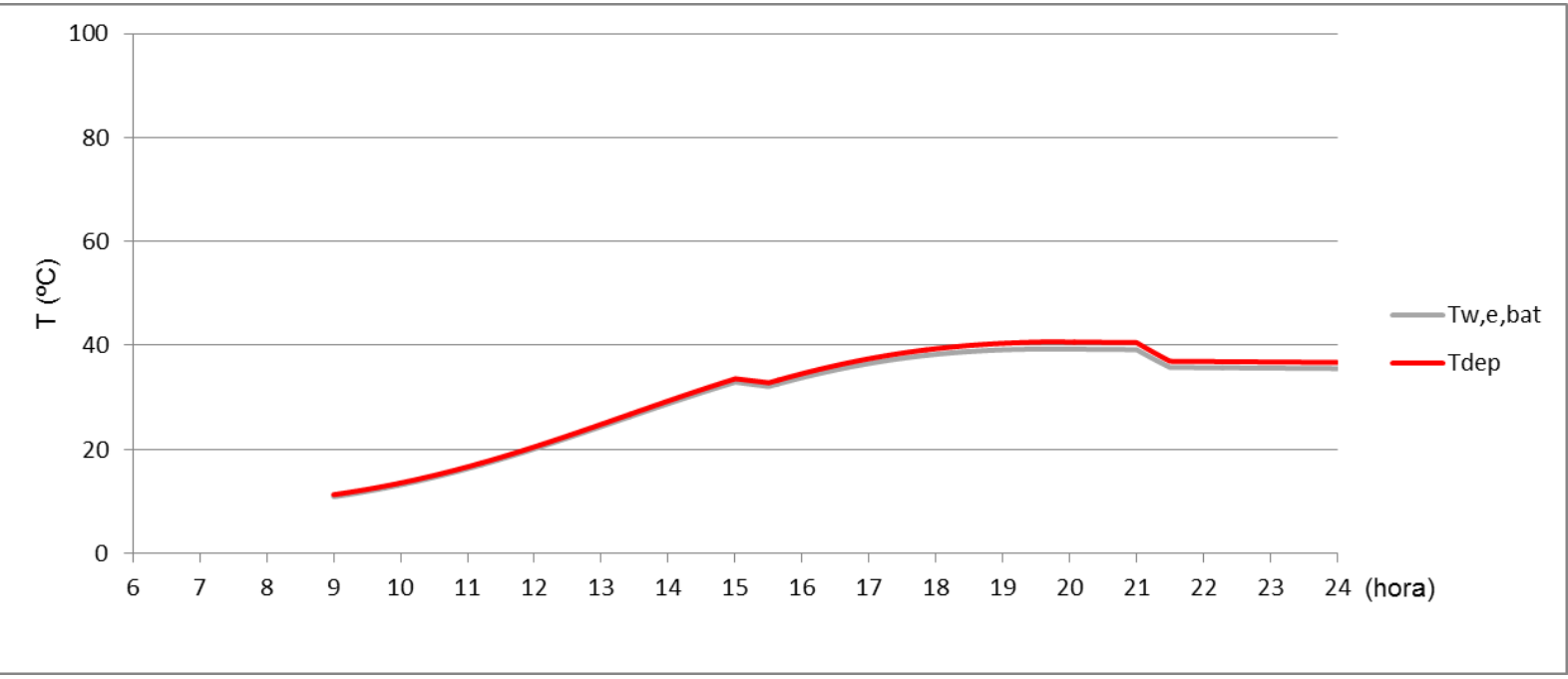

Figura AC.23.- Evolución de la temperatura del agua en el depósito para el día tipo de AGOSTO con un caudal de aire de paso por el colector de $100 \mathrm{~m}^{3} / \mathrm{h}$. Capacidad del depósito: 300 litros. 


\section{ANEXO C: SIMULACIONES}

\section{SEPTIEMBRE}

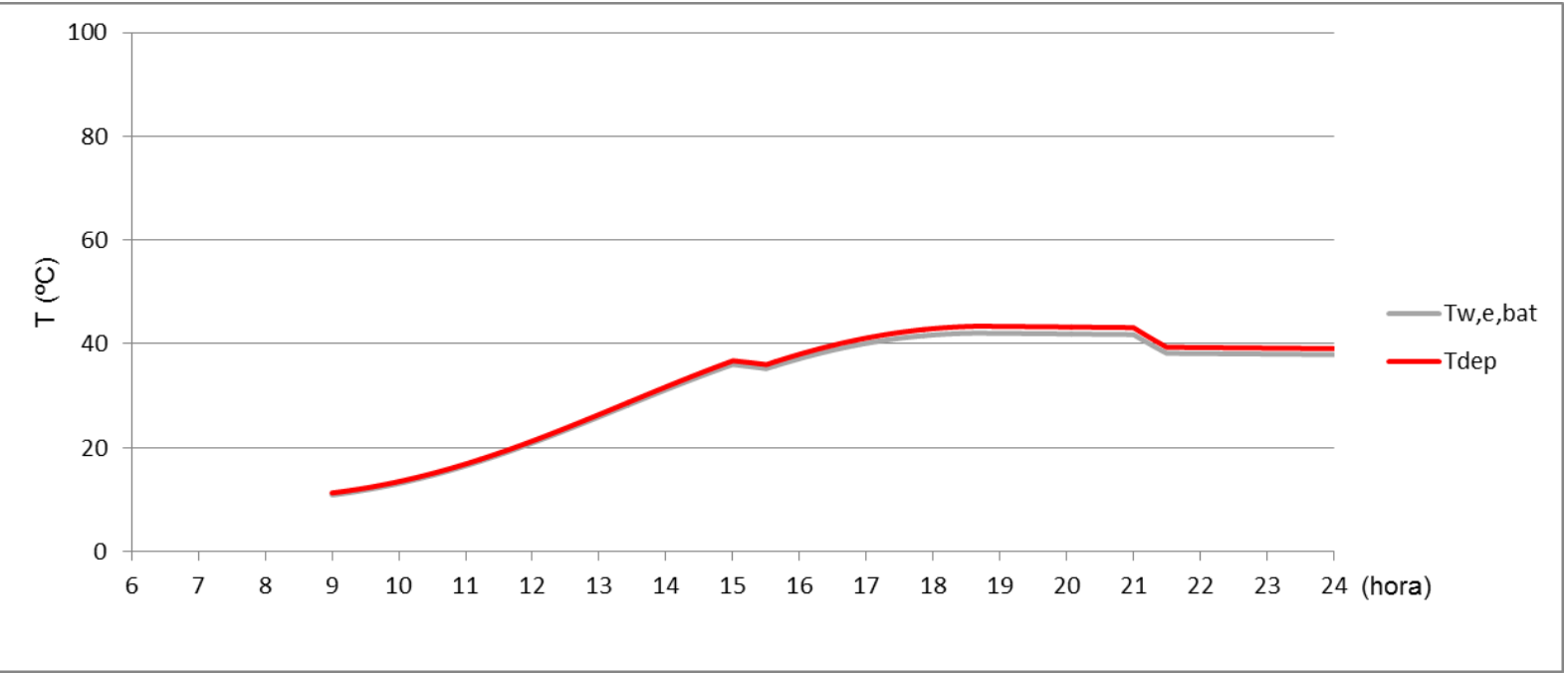

Figura AC.24.- Evolución de la temperatura del agua en el depósito para el día tipo de SEPTIEMBRE con un caudal de aire de paso por el colector de $100 \mathrm{~m}^{3} / \mathrm{h}$. Capacidad del depósito: 300 litros.

\section{AC.6.2.2.- CAUDAL DE AIRE: $200 \mathrm{~m}^{3} / \mathrm{h}$.}

\section{MAYO}

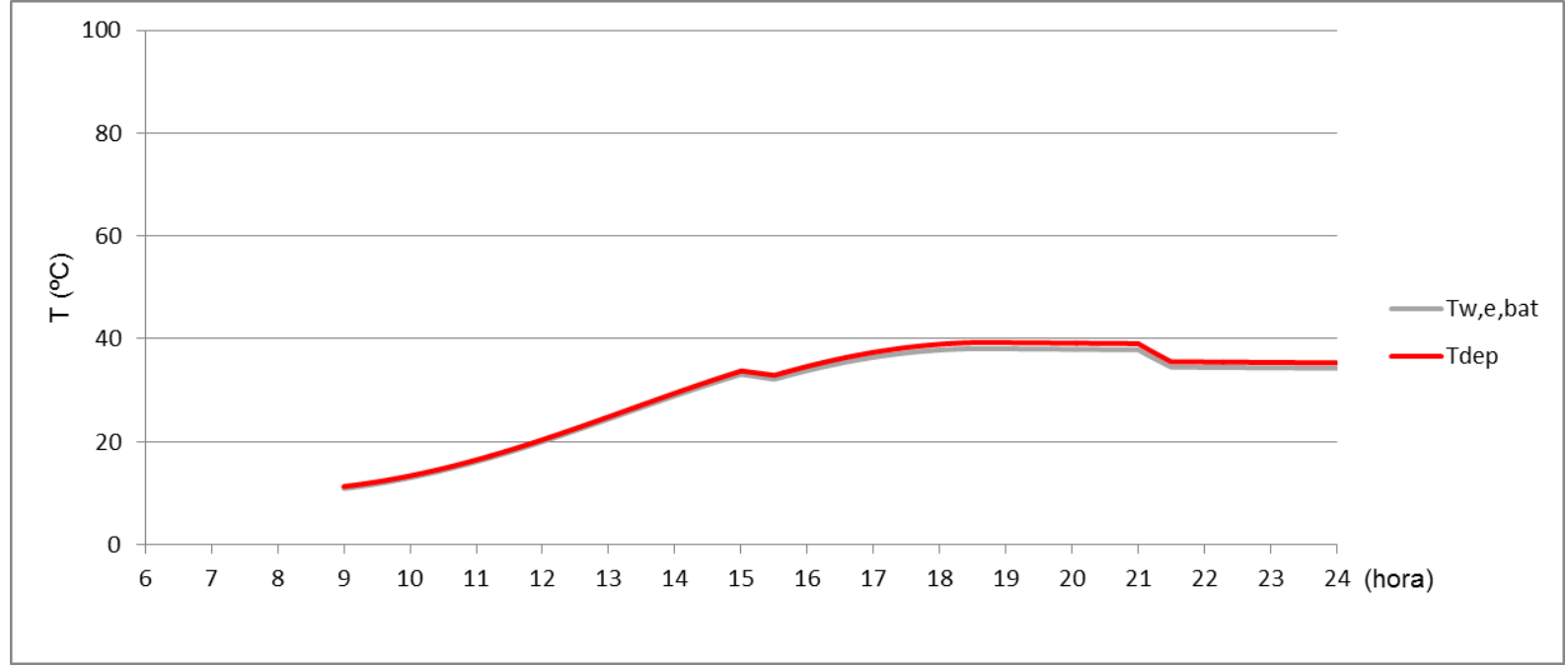

Figura AC.25.- Evolución de la temperatura del agua en el depósito para el día tipo de MAYO con un caudal de aire de paso por el colector de $200 \mathrm{~m}^{3} / \mathrm{h}$. Capacidad del depósito: 300 litros. 


\section{JUNIO}

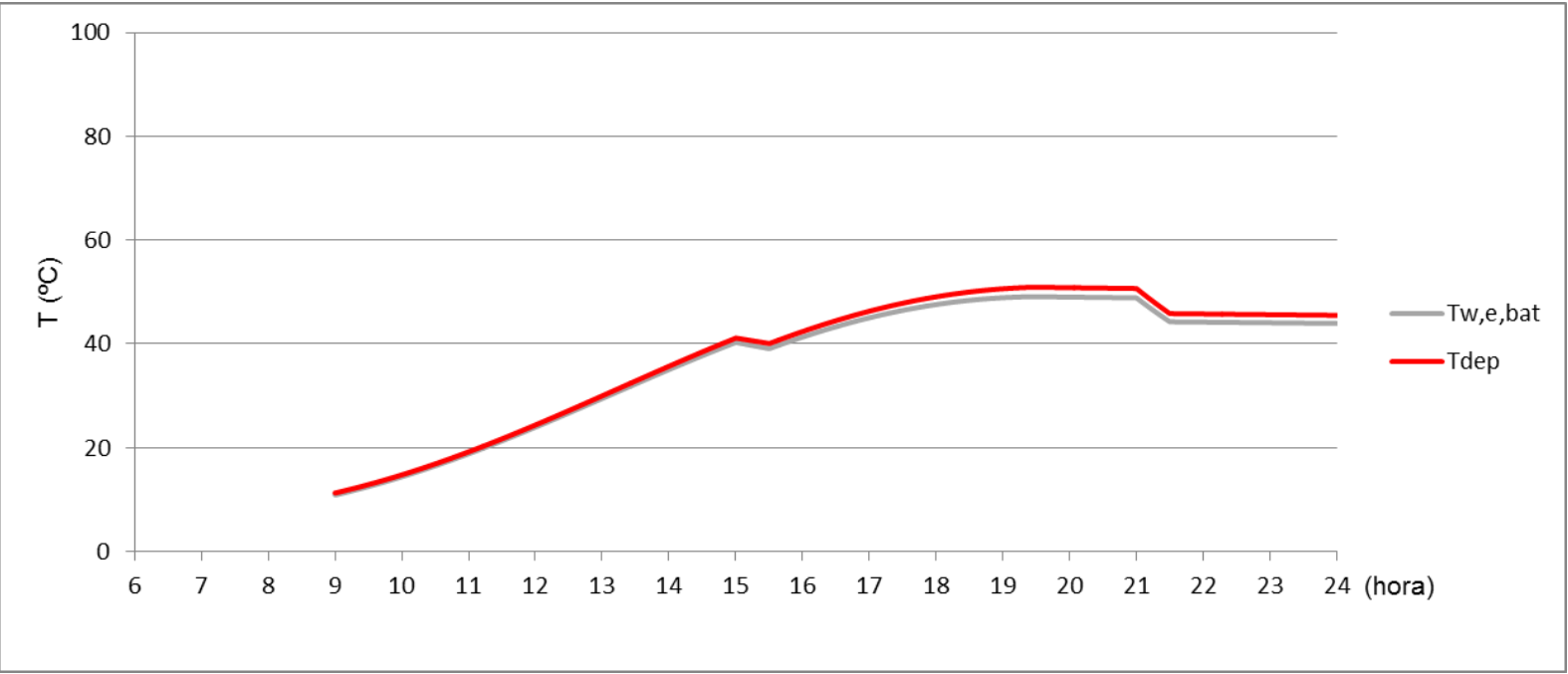

Figura AC.26.- Evolución de la temperatura del agua en el depósito para el día tipo de JUNIO con un caudal de aire de paso por el colector de $200 \mathrm{~m}^{3} / \mathrm{h}$. Capacidad del depósito: 300 litros.

\section{JULIO}

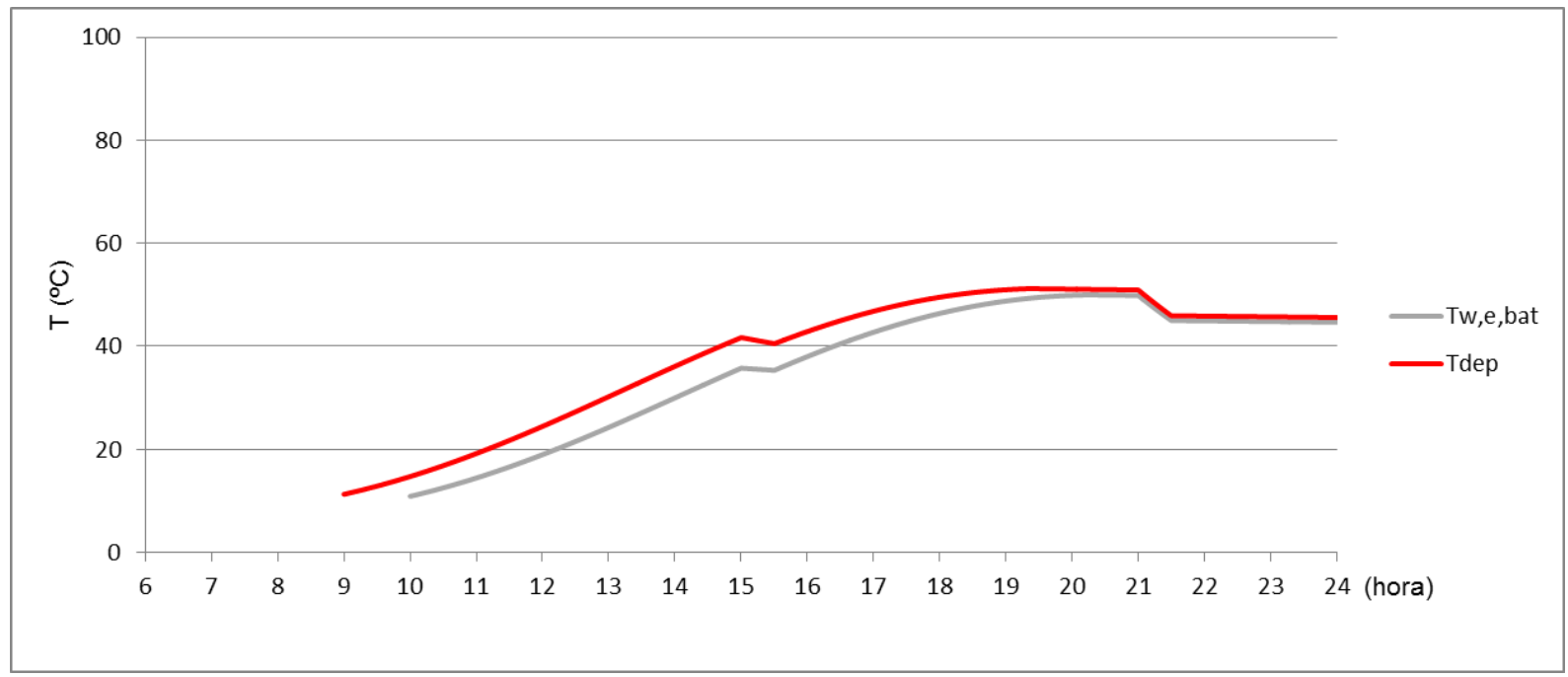

Figura AC.27.- Evolución de la temperatura del agua en el depósito para el día tipo de JULIO con un caudal de aire de paso por el colector de $200 \mathrm{~m}^{3} / \mathrm{h}$. Capacidad del depósito: 300 litros. 


\section{ANEXO C: SIMULACIONES}

\section{AGOSTO}

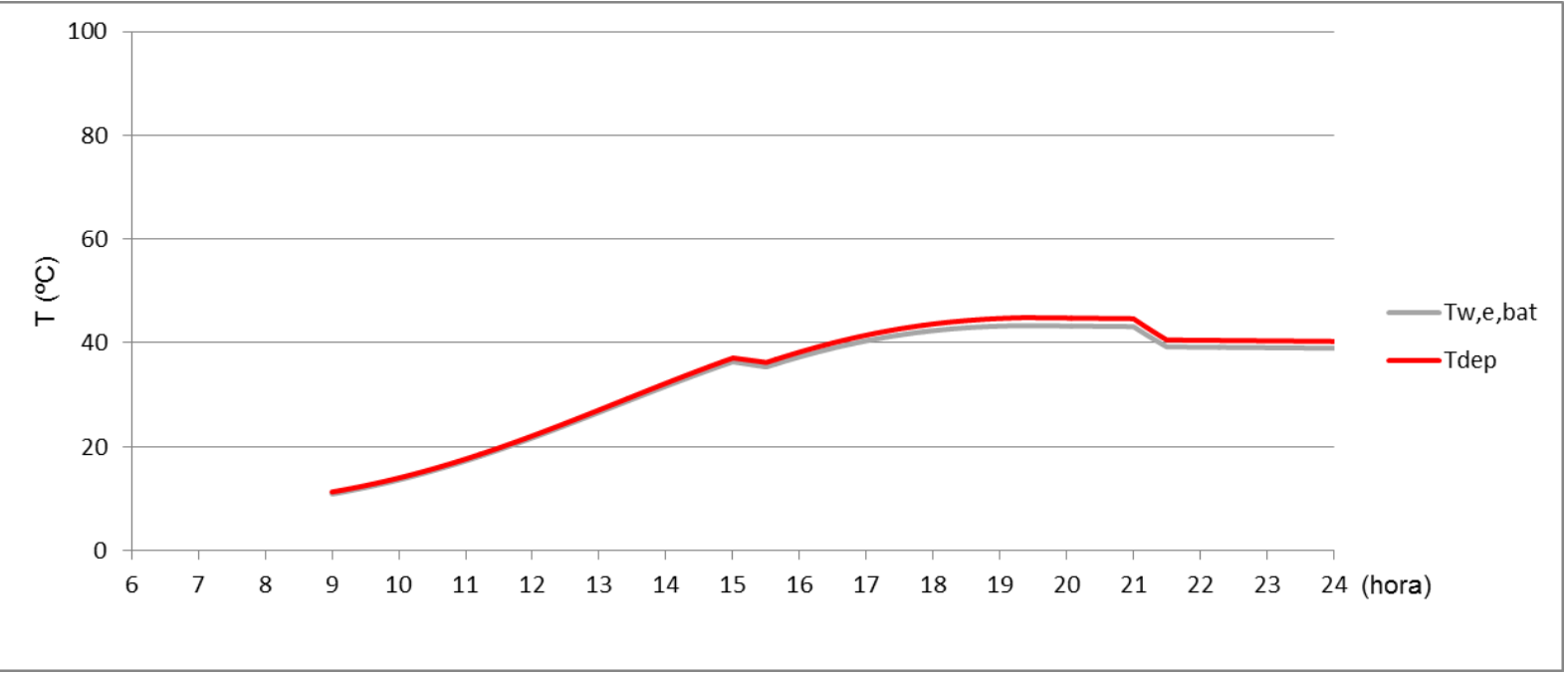

Figura AC.28.- Evolución de la temperatura del agua en el depósito para el día tipo de AGOSTO con un caudal de aire de paso por el colector de $200 \mathrm{~m}^{3} / \mathrm{h}$. Capacidad del depósito: 300 litros.

\section{SEPTIEMBRE}

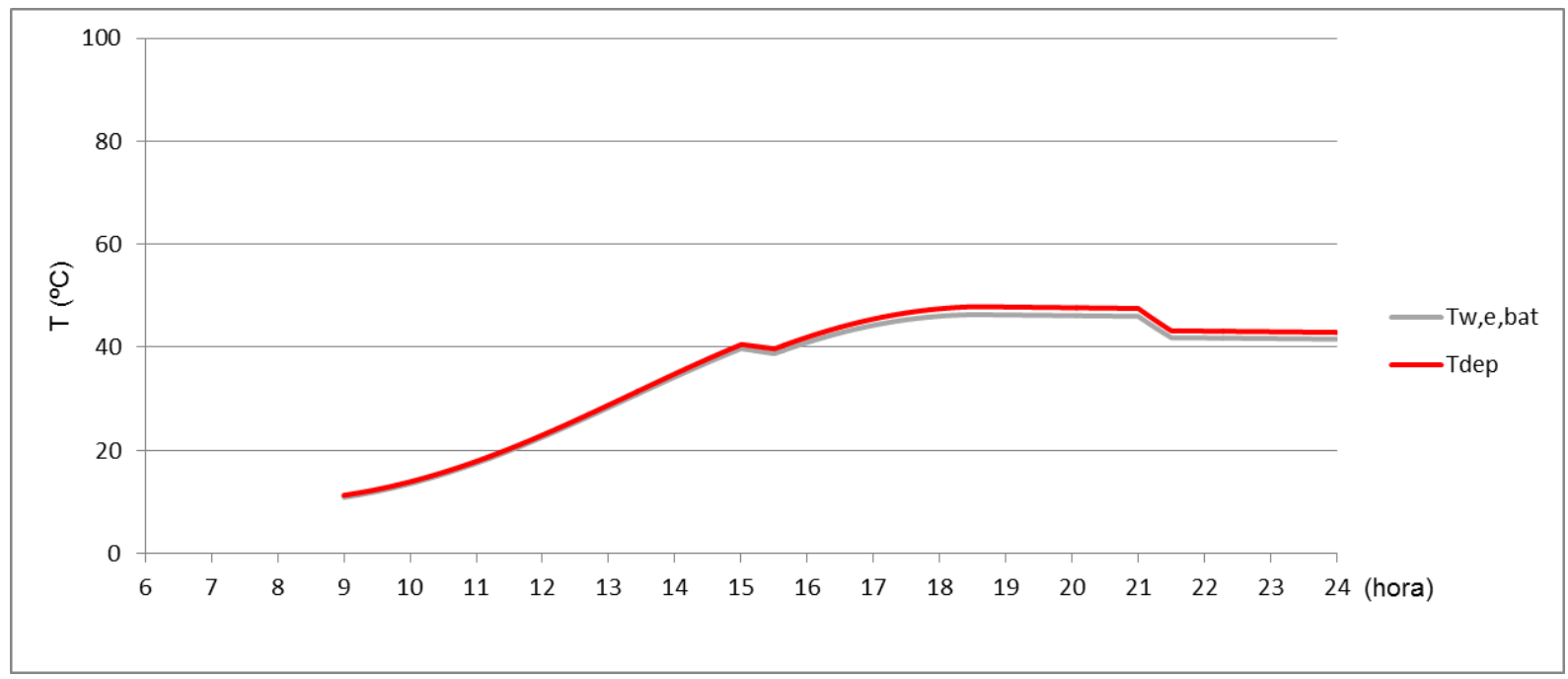

Figura AC.29.- Evolución de la temperatura del agua en el depósito para el día tipo de SEPTIEMBRE con un caudal de aire de paso por el colector de $200 \mathrm{~m}^{3} / \mathrm{h}$. Capacidad del depósito: 300 litros. 


\section{AC.6.2.3.- CAUDAL DE AIRE: $300 \mathrm{~m}^{3} / \mathrm{h}$.}

\section{MAYO}

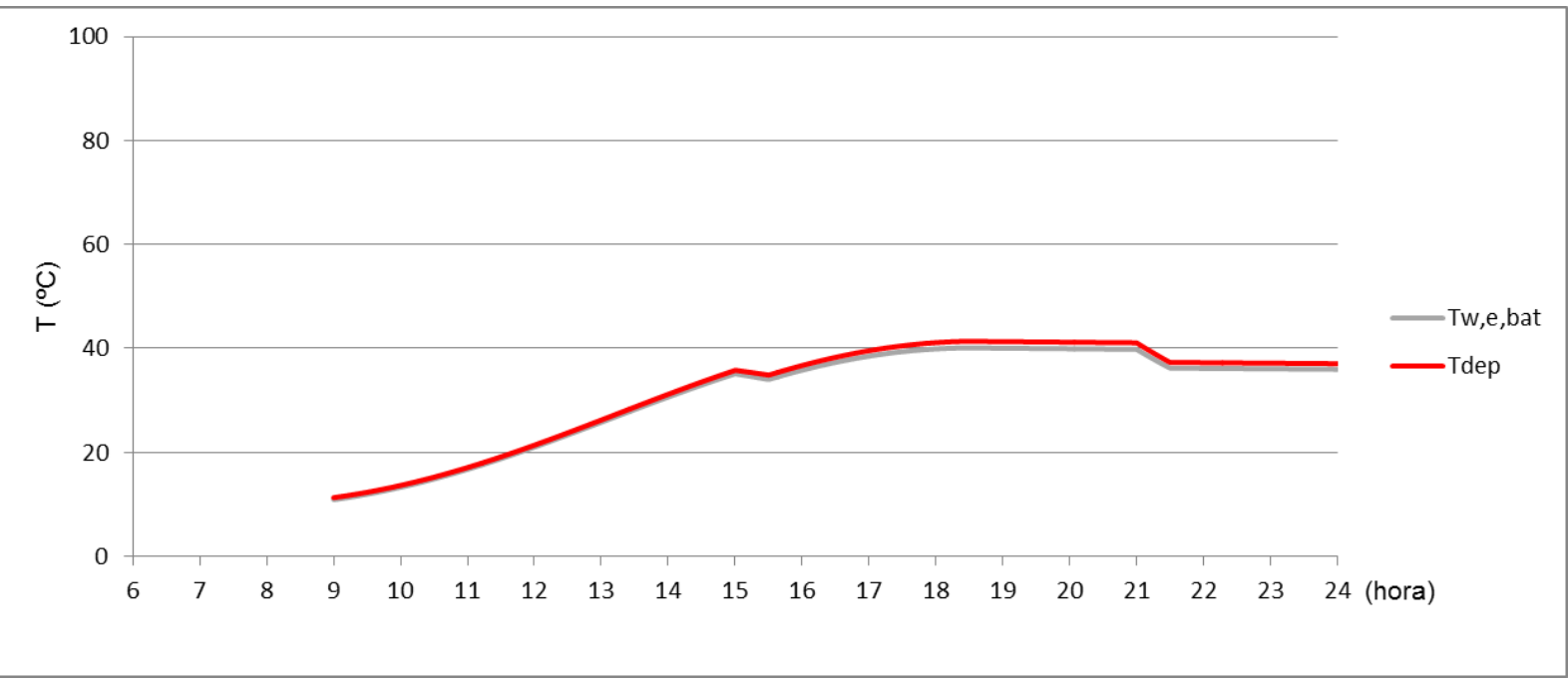

Figura AC.30.- Evolución de la temperatura del agua en el depósito para el día tipo de MAYO con un caudal de aire de paso por el colector de $300 \mathrm{~m}^{3} / \mathrm{h}$. Capacidad del depósito: 300 litros.

\section{$\underline{\text { JUNIO }}$}

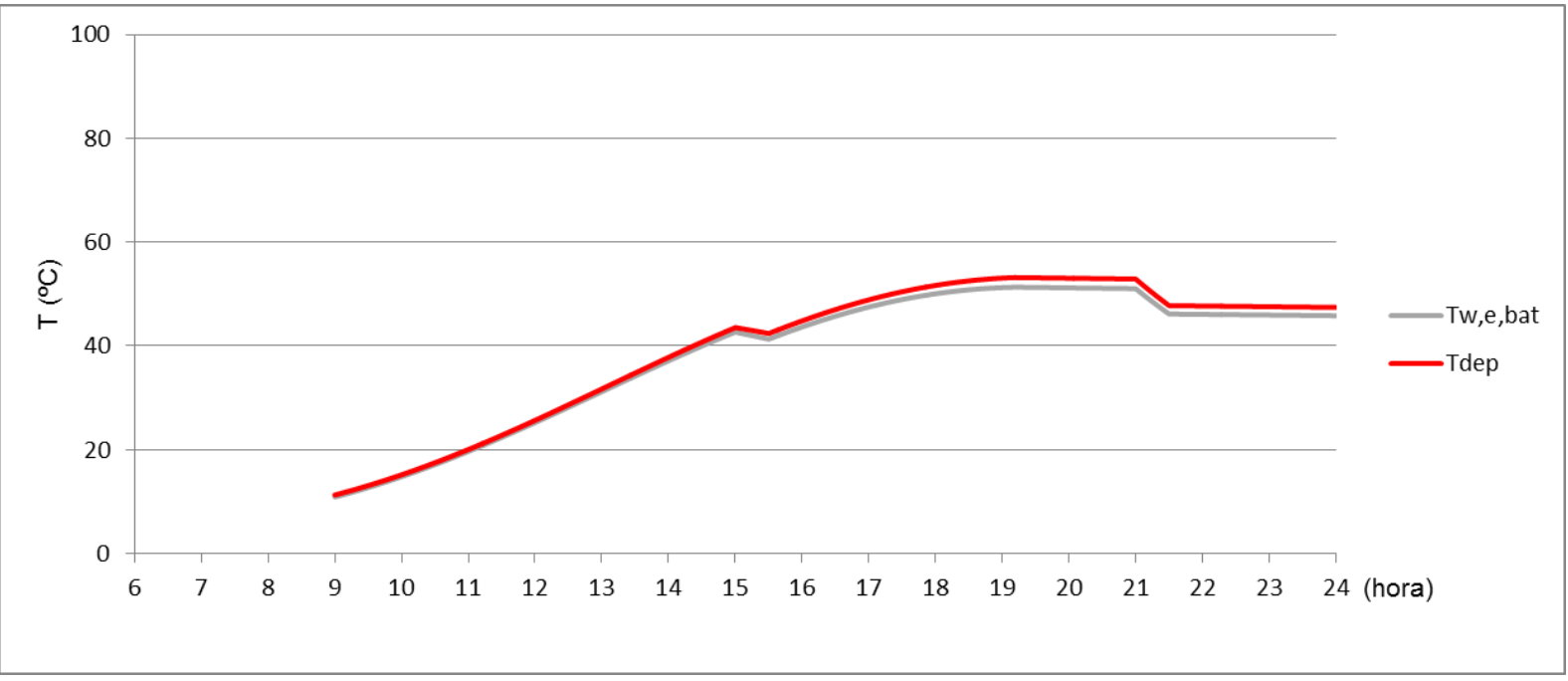

Figura AC.31.- Evolución de la temperatura del agua en el depósito para el día tipo de JUNIO con un caudal de aire de paso por el colector de $300 \mathrm{~m}^{3} / \mathrm{h}$. Capacidad del depósito: 300 litros. 


\section{ANEXO C: SIMULACIONES}

\section{JULIO}

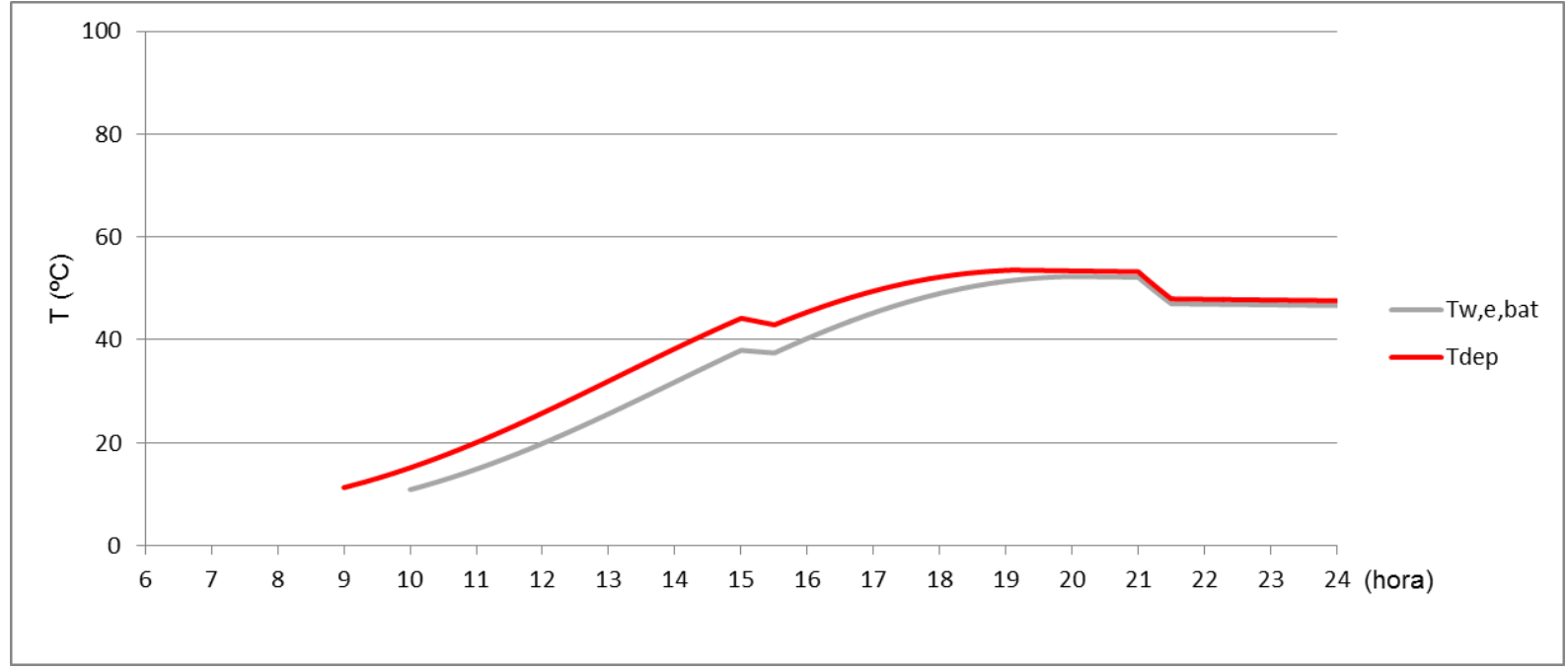

Figura AC.32.- Evolución de la temperatura del agua en el depósito para el día tipo de JULIO con un caudal de aire de paso por el colector de $300 \mathrm{~m}^{3} / \mathrm{h}$. Capacidad del depósito: 300 litros.

\section{AGOSTO}

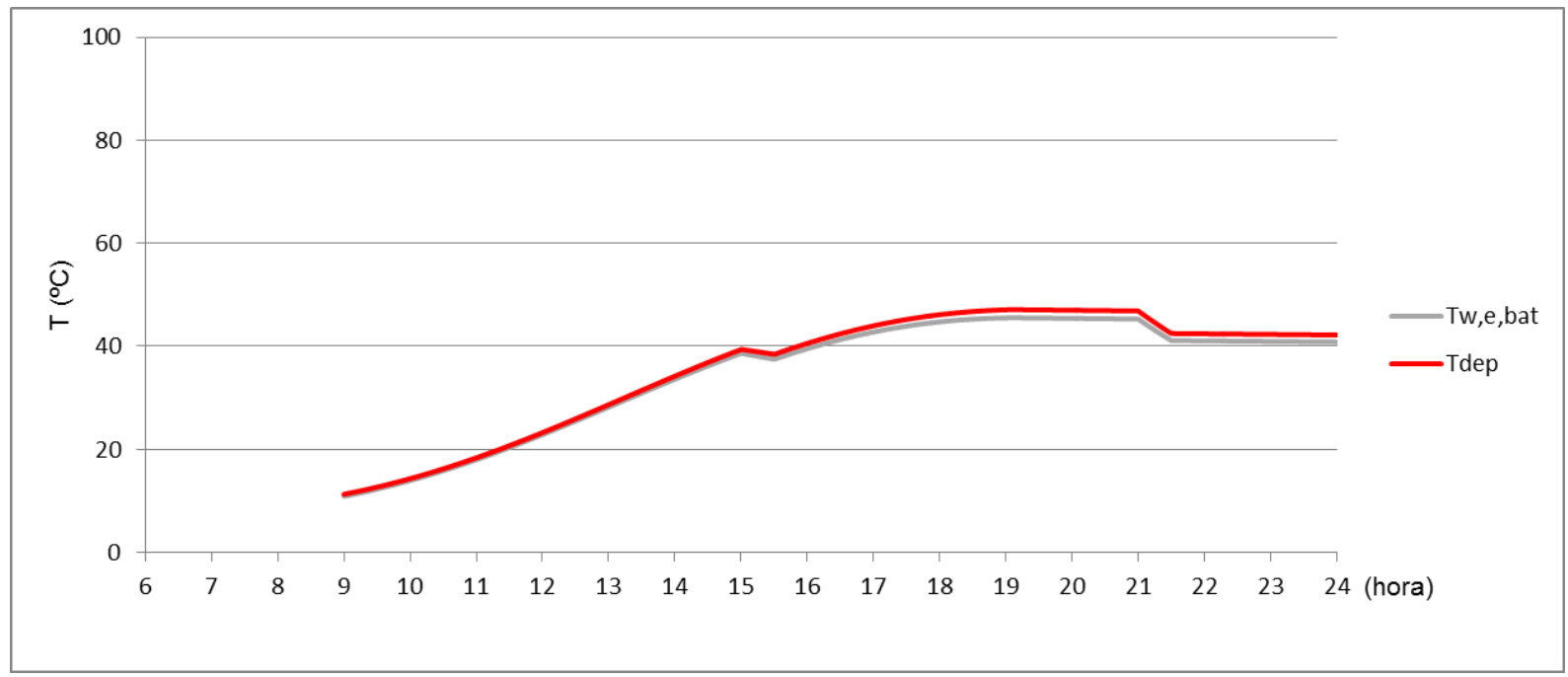

Figura AC.33.- Evolución de la temperatura del agua en el depósito para el día tipo de AGOSTO con un caudal de aire de paso por el colector de $300 \mathrm{~m}^{3} / \mathrm{h}$. Capacidad del depósito: 300 litros. 


\section{SEPTIEMBRE}

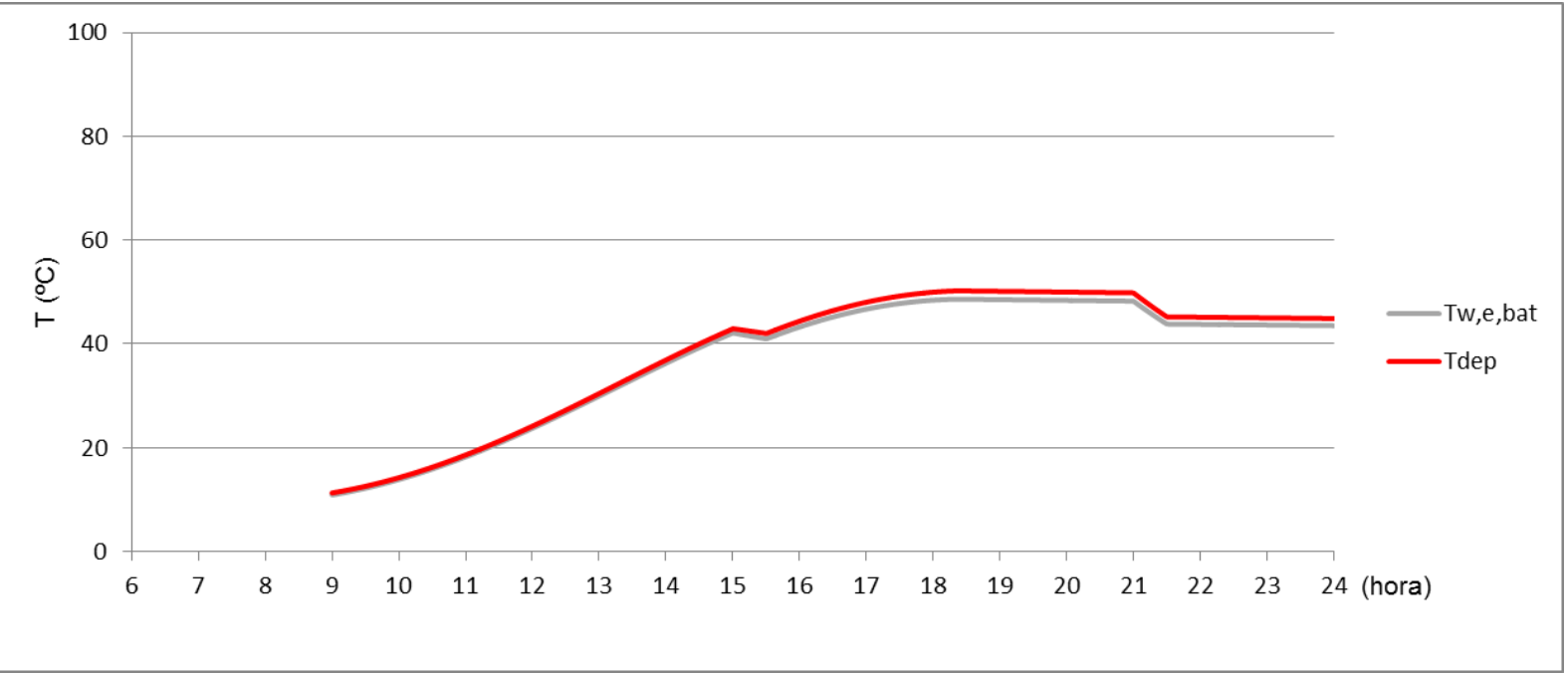

Figura AC.34.- Evolución de la temperatura del agua en el depósito para el día tipo de SEPTIEMBRE con un caudal de aire de paso por el colector de $300 \mathrm{~m}^{3} / \mathrm{h}$. Capacidad del depósito: 300 litros.

\section{AC.6.3.- DEPÓSITO DE 300 LITROS.}

\section{AC.6.3.1.- CAUDAL DE AIRE: $100 \mathrm{~m}^{3} / \mathrm{h}$.}

\section{MAYO}

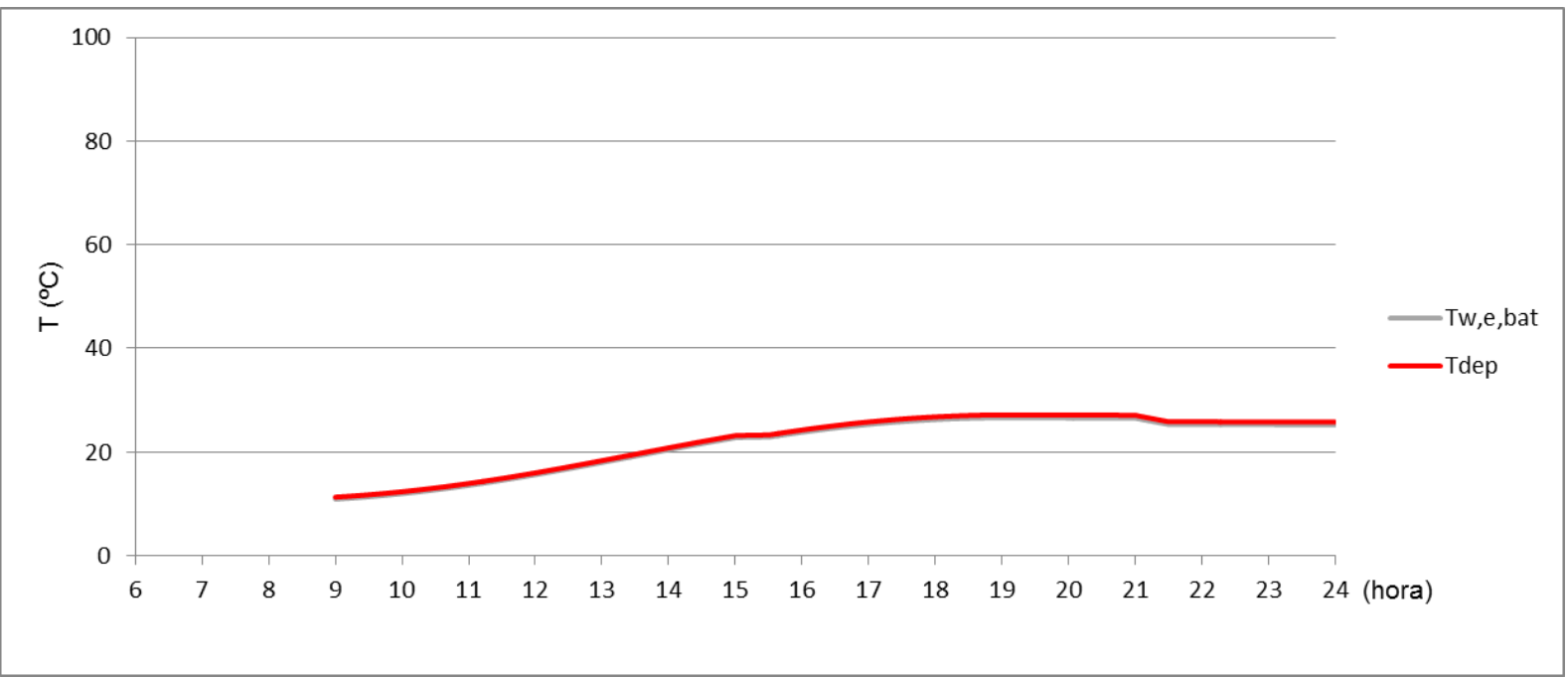

Figura AC.35.- Evolución de la temperatura del agua en el depósito para el día tipo de MAYO con un caudal de aire de paso por el colector de $100 \mathrm{~m}^{3} / \mathrm{h}$. Capacidad del depósito: 500 litros. 


\section{ANEXO C: SIMULACIONES}

\section{JUNIO}

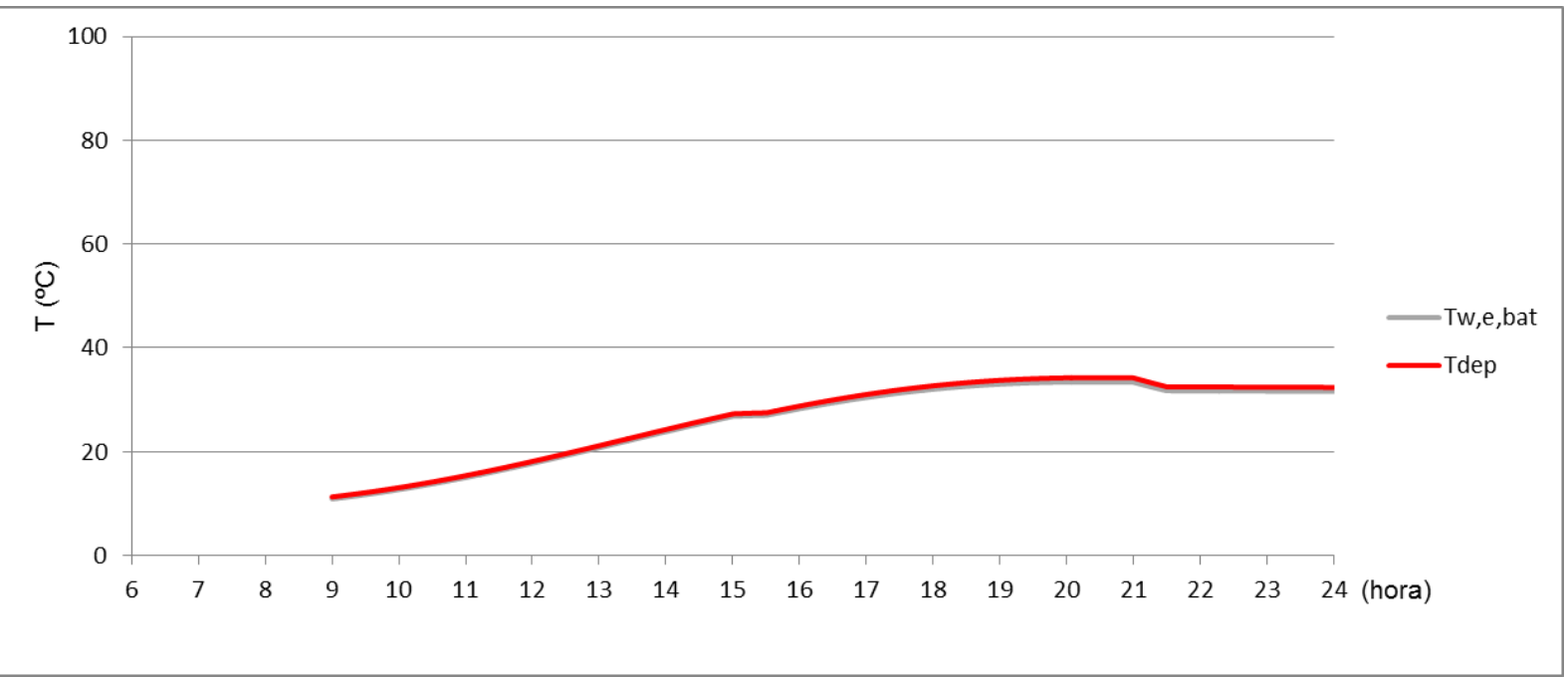

Figura AC.36.- Evolución de la temperatura del agua en el depósito para el día tipo de JUNIO con un caudal de aire de paso por el colector de $100 \mathrm{~m}^{3} / \mathrm{h}$. Capacidad del depósito: 500 litros.

\section{JULIO}

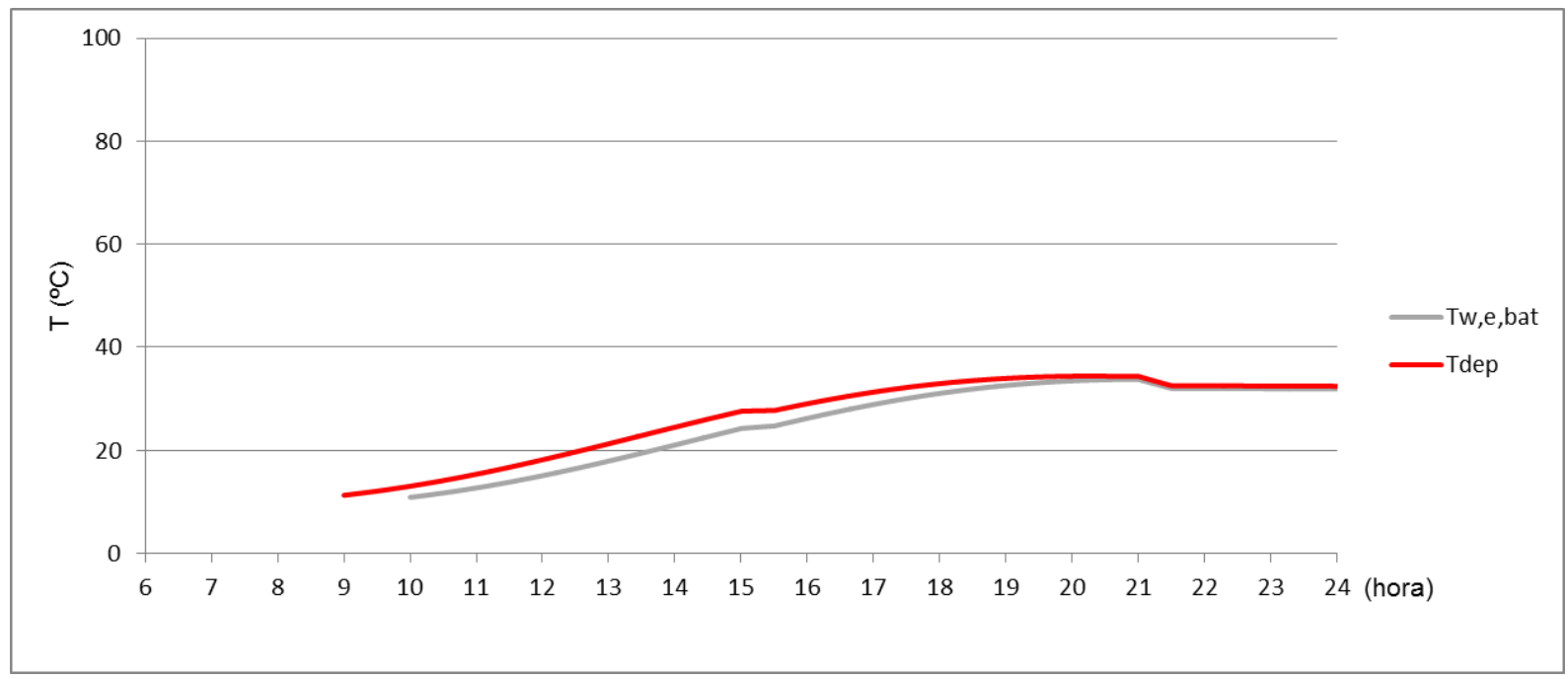

Figura AC.37.- Evolución de la temperatura del agua en el depósito para el día tipo de JULIO con un caudal de aire de paso por el colector de $100 \mathrm{~m}^{3} / \mathrm{h}$. Capacidad del depósito: 500 litros. 


\section{AGOSTO}

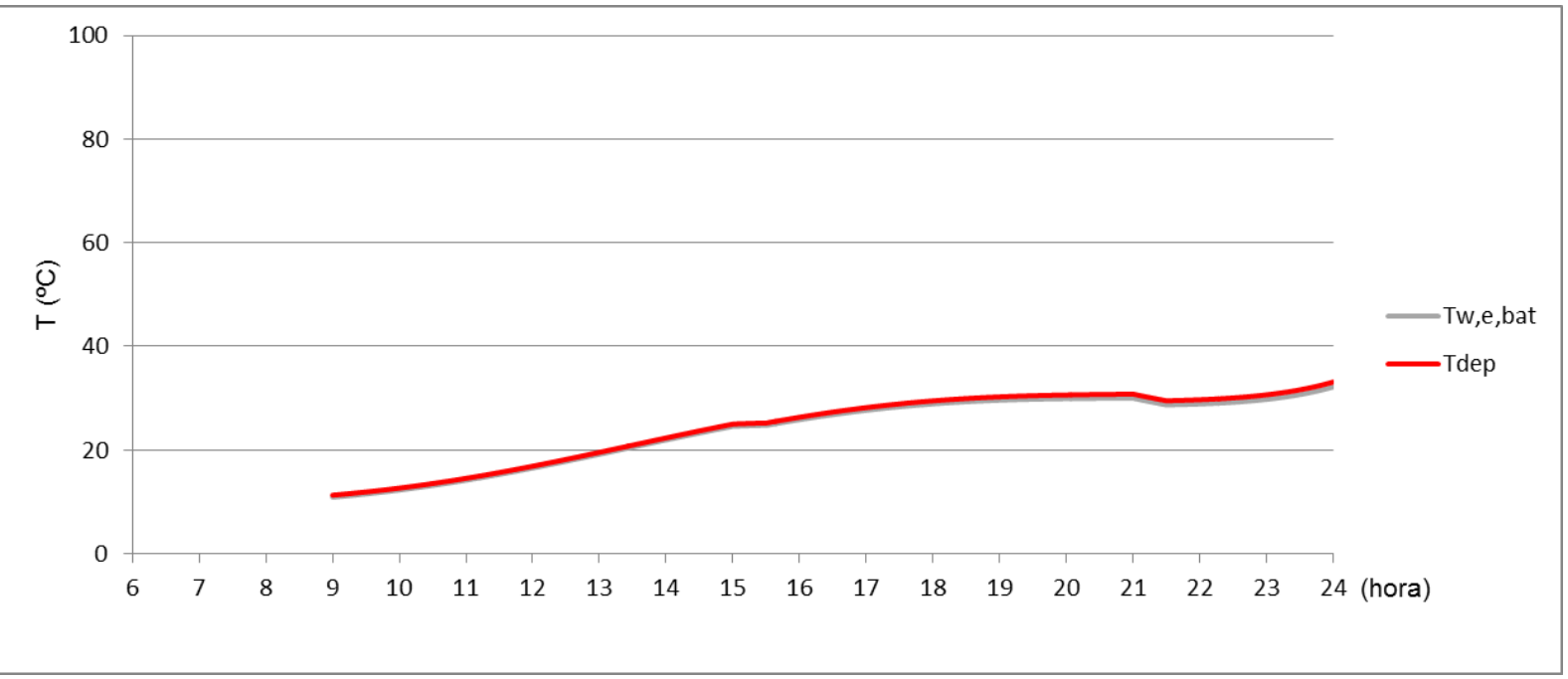

Figura AC.38.- Evolución de la temperatura del agua en el depósito para el día tipo de AGOSTO con un caudal de aire de paso por el colector de $100 \mathrm{~m}^{3} / \mathrm{h}$. Capacidad del depósito: 500 litros.

\section{SEPTIEMBRE}

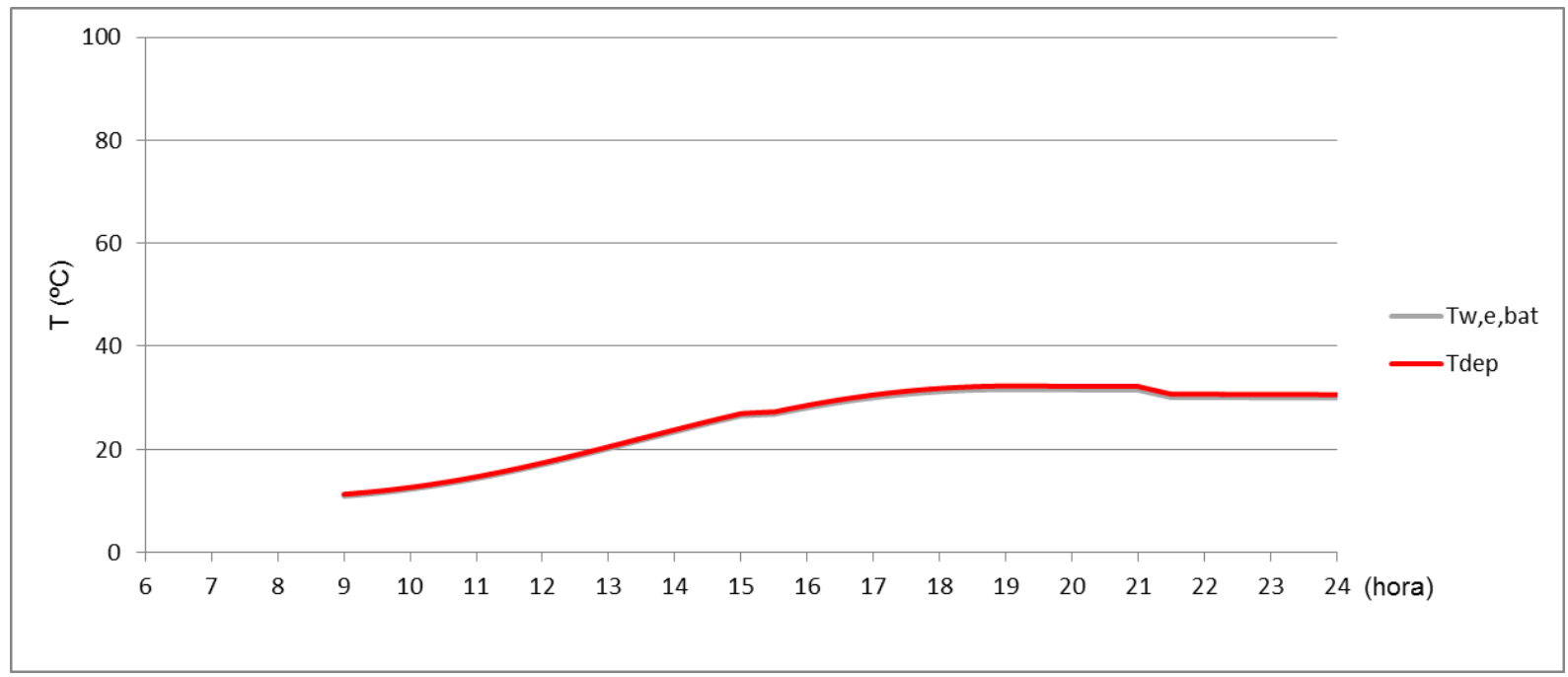

Figura AC.39.- Evolución de la temperatura del agua en el depósito para el día tipo de SEPTIEMBRE con un caudal de aire de paso por el colector de $100 \mathrm{~m}^{3} / \mathrm{h}$. Capacidad del depósito: 500 litros. 


\section{ANEXO C: SIMULACIONES}

\section{AC.6.3.2.- CAUDAL DE AIRE: $200 \mathrm{~m}^{3} / \mathrm{h}$.}

\section{MAYO}

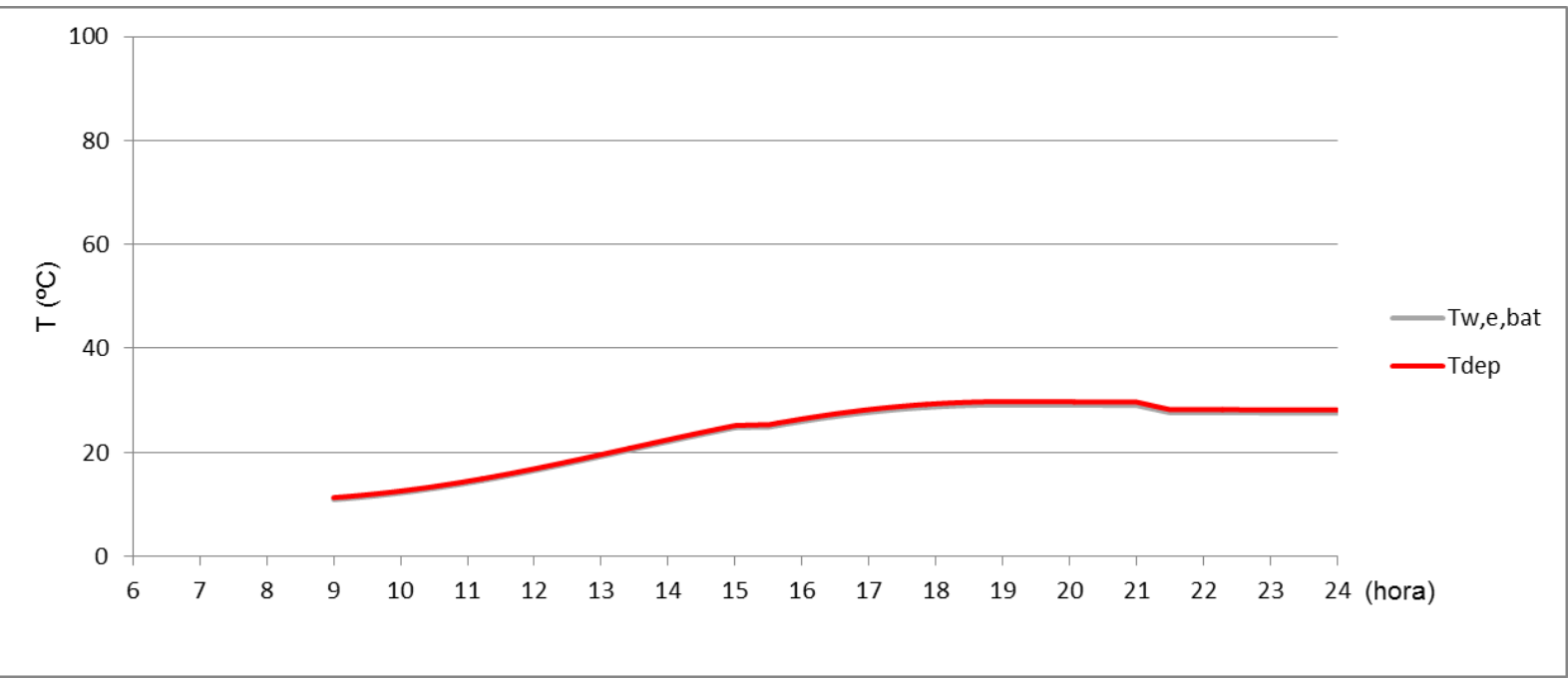

Figura AC.40.- Evolución de la temperatura del agua en el depósito para el día tipo de MAYO con un caudal de aire de paso por el colector de $200 \mathrm{~m}^{3} / \mathrm{h}$. Capacidad del depósito: 500 litros.

\section{$\underline{\text { JUNIO }}$}

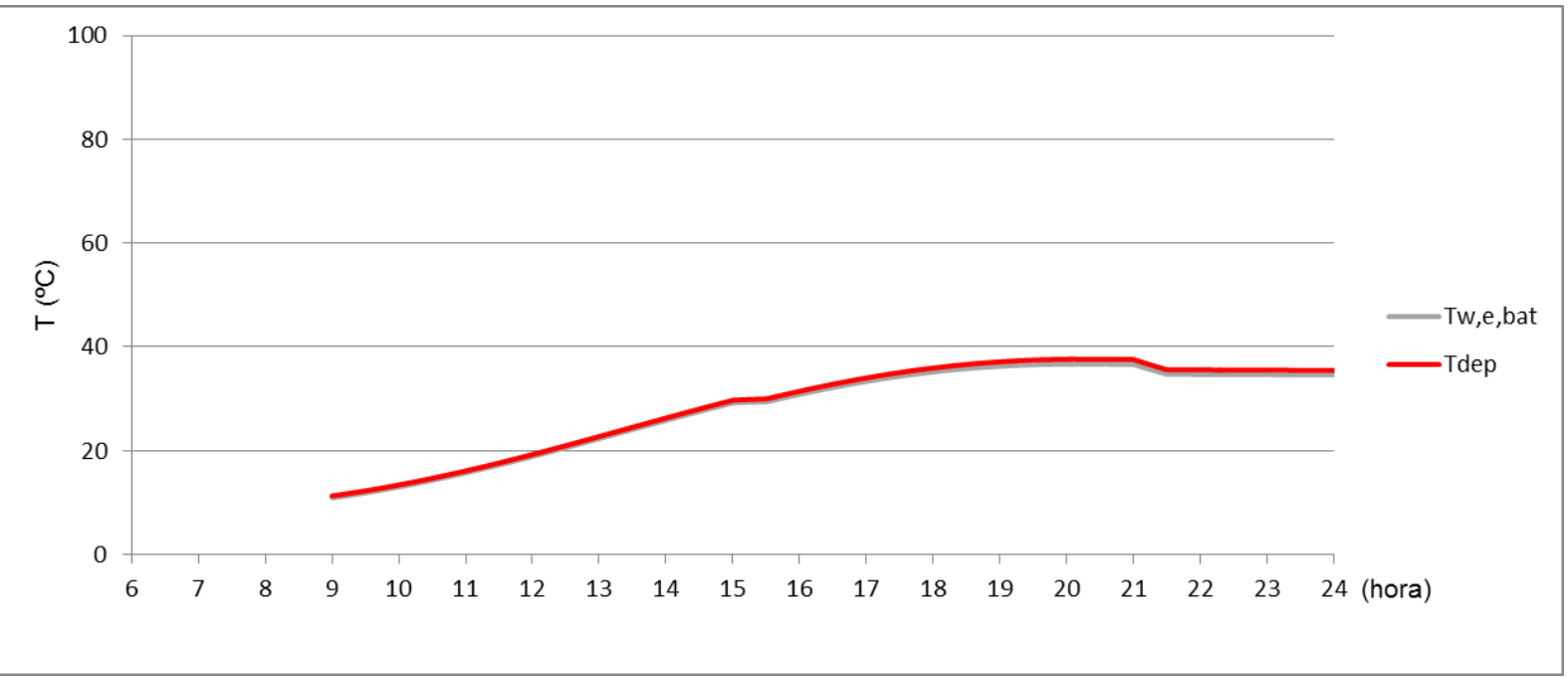

Figura AC.41.- Evolución de la temperatura del agua en el depósito para el día tipo de JUNIO con un caudal de aire de paso por el colector de $200 \mathrm{~m}^{3} / \mathrm{h}$. Capacidad del depósito: 500 litros. 


\section{JULIO}

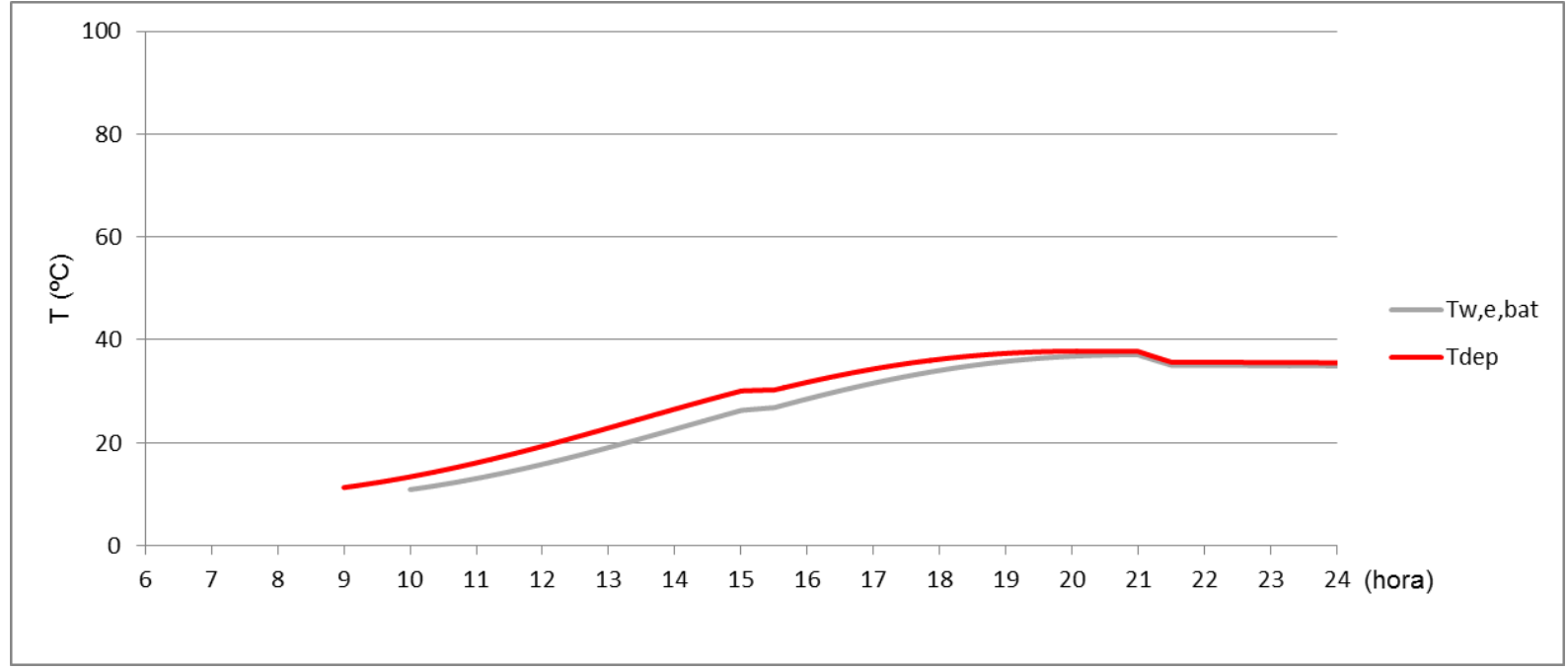

Figura AC.42.- Evolución de la temperatura del agua en el depósito para el día tipo de JULIO con un caudal de aire de paso por el colector de $200 \mathrm{~m}^{3} / \mathrm{h}$. Capacidad del depósito: 500 litros.

\section{AGOSTO}

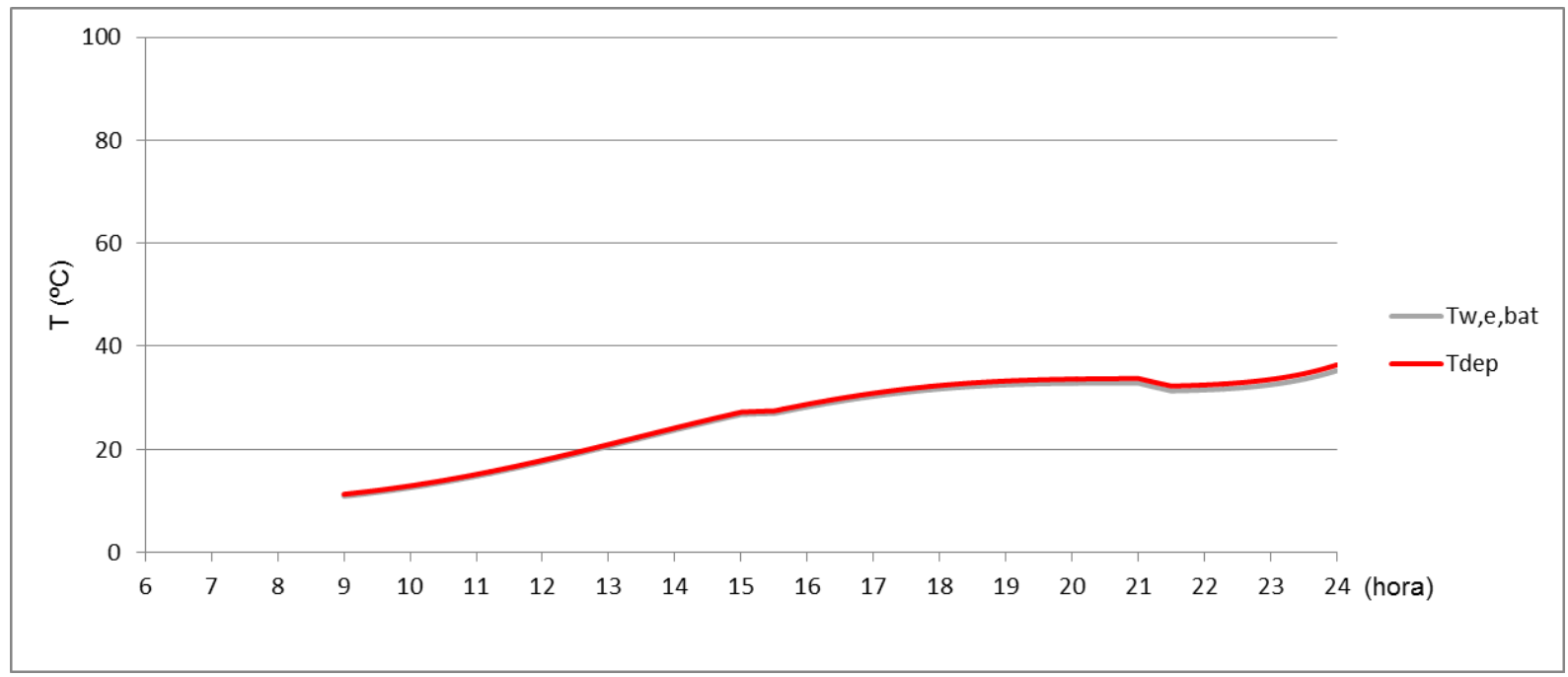

Figura AC.43.- Evolución de la temperatura del agua en el depósito para el día tipo de AGOSTO con un caudal de aire de paso por el colector de $200 \mathrm{~m}^{3} / \mathrm{h}$. Capacidad del depósito: 500 litros. 


\section{SEPTIEMBRE}

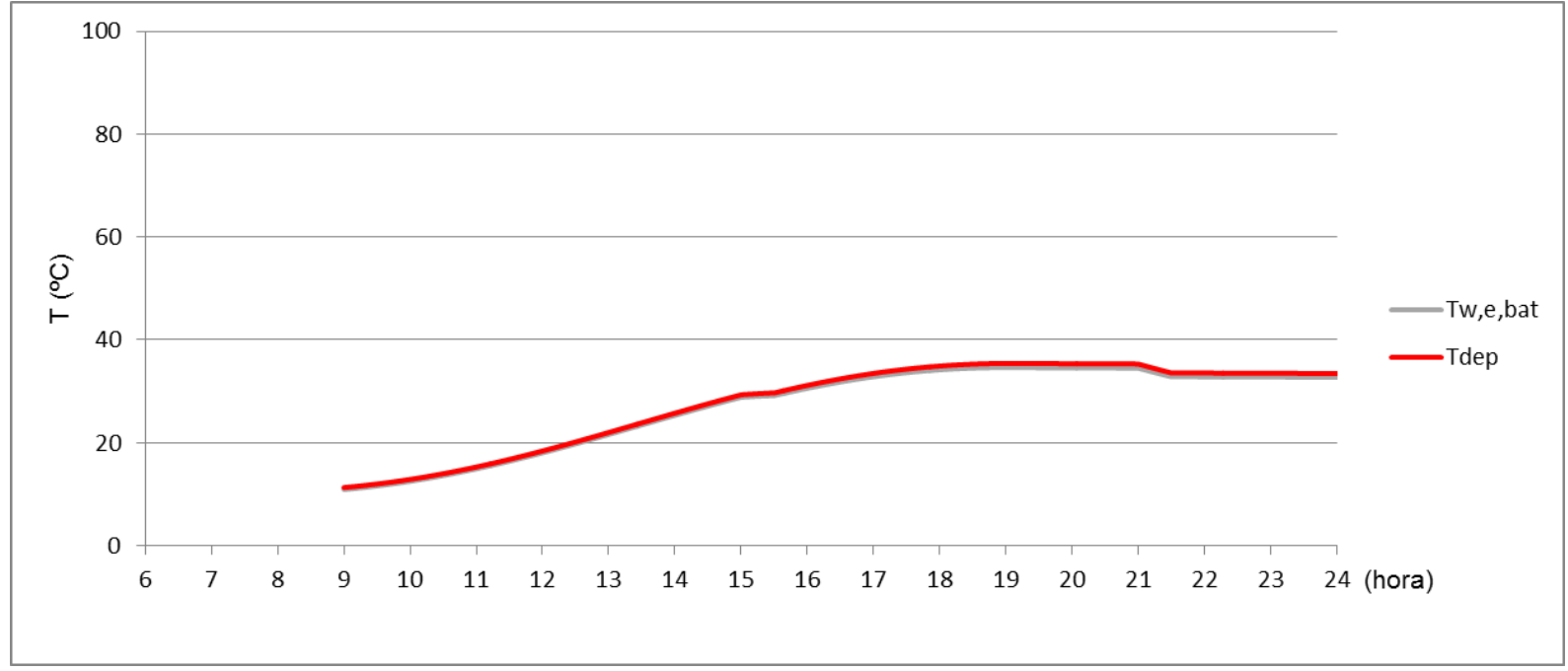

Figura AC.44.- Evolución de la temperatura del agua en el depósito para el día tipo de SEPTIEMBRE con un caudal de aire de paso por el colector de $200 \mathrm{~m}^{3} / \mathrm{h}$. Capacidad del depósito: 500 litros.

\section{AC.6.3.3.- CAUDAL DE AIRE: $300 \mathrm{~m}^{3} / \mathrm{h}$.}

\section{MAYO}

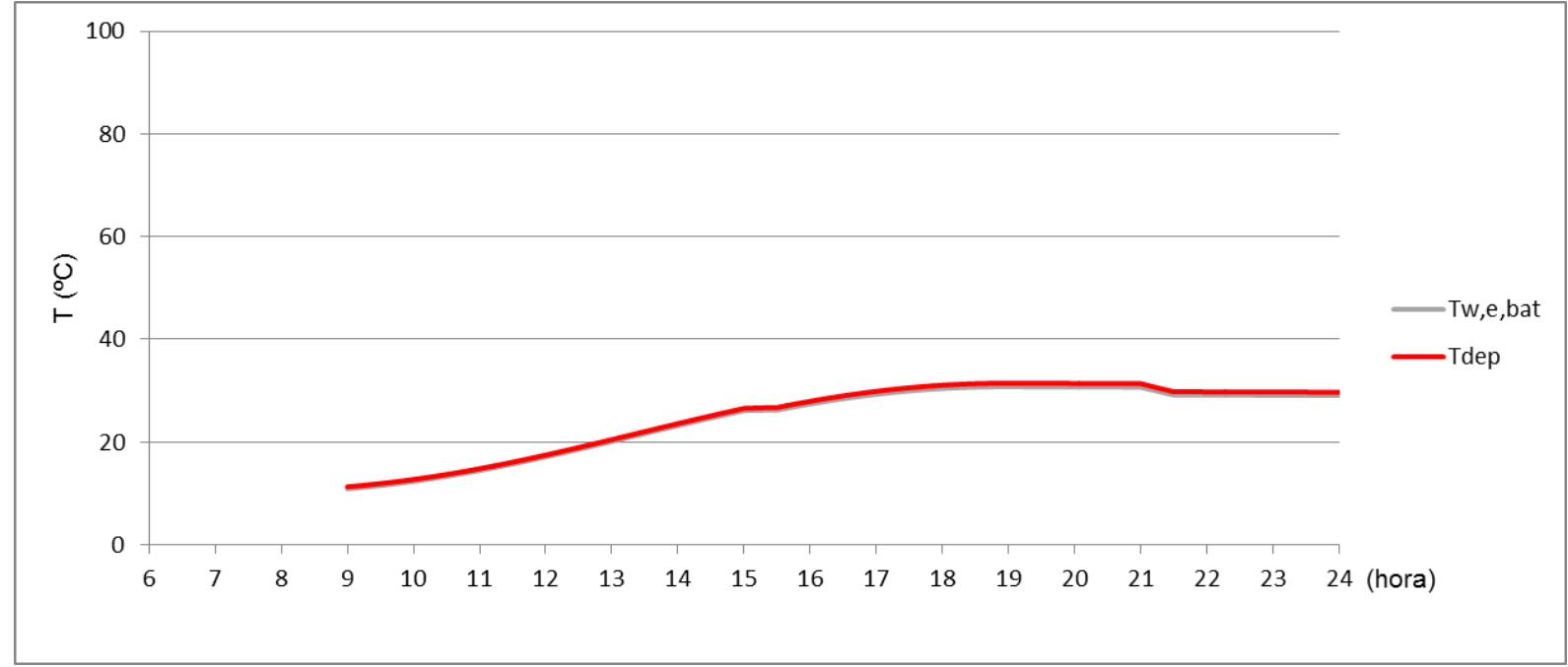

Figura AC.45.- Evolución de la temperatura del agua en el depósito para el día tipo de MAYO con un caudal de aire de paso por el colector de $300 \mathrm{~m}^{3} / \mathrm{h}$. Capacidad del depósito: 500 litros. 


\section{JUNIO}

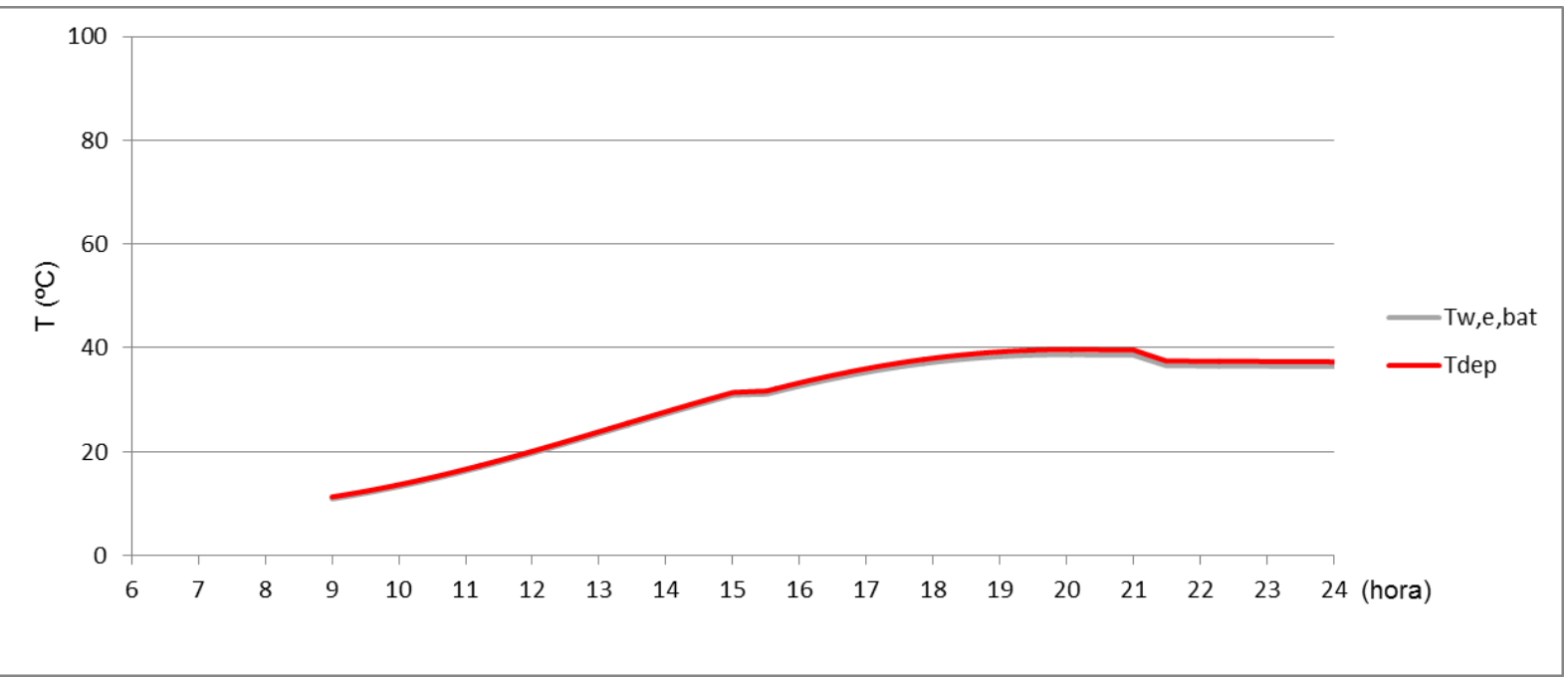

Figura AC.46.- Evolución de la temperatura del agua en el depósito para el día tipo de JUNIO con un caudal de aire de paso por el colector de $300 \mathrm{~m}^{3} / \mathrm{h}$. Capacidad del depósito: 500 litros.

\section{JULIO}

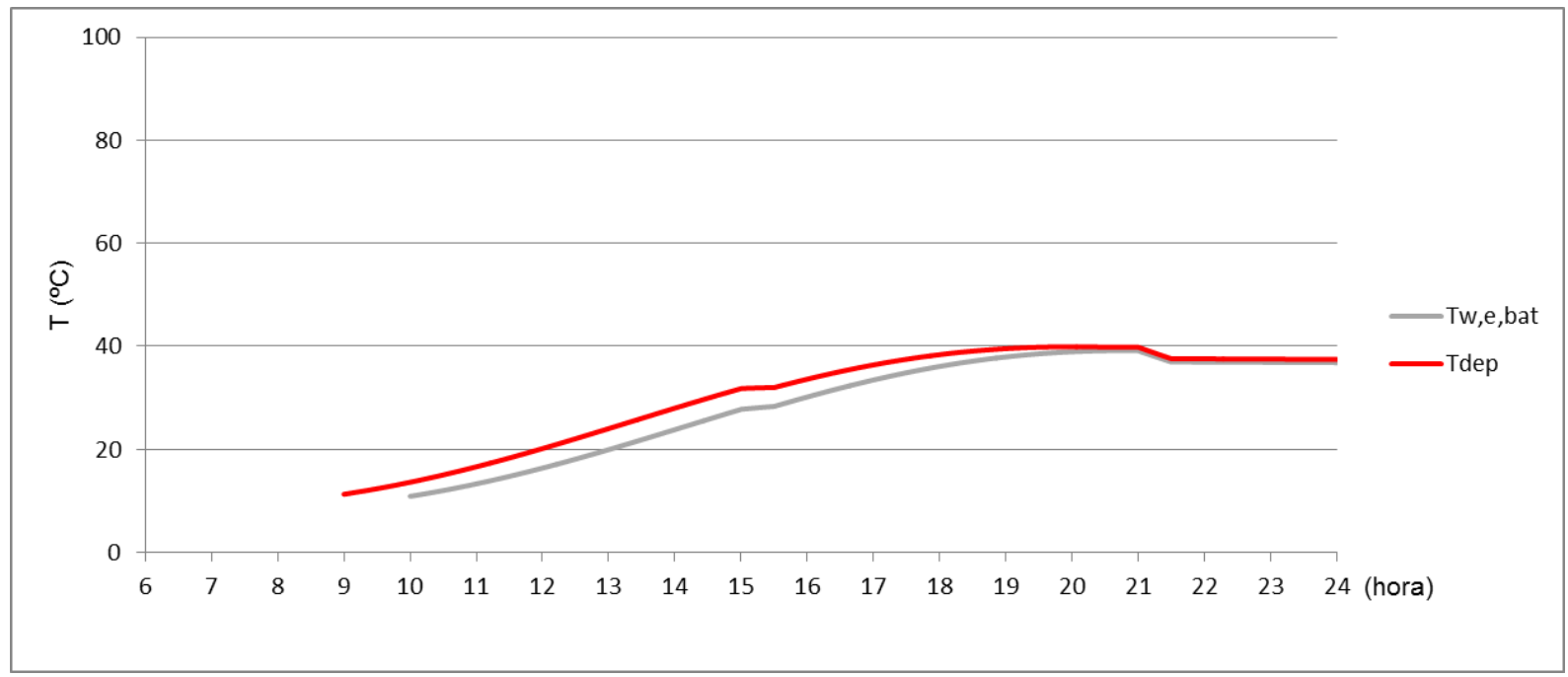

Figura AC.47.- Evolución de la temperatura del agua en el depósito para el día tipo de JULIO con un caudal de aire de paso por el colector de $300 \mathrm{~m}^{3} / \mathrm{h}$. Capacidad del depósito: 500 litros. 


\section{ANEXO C: SIMULACIONES}

\section{AGOSTO}

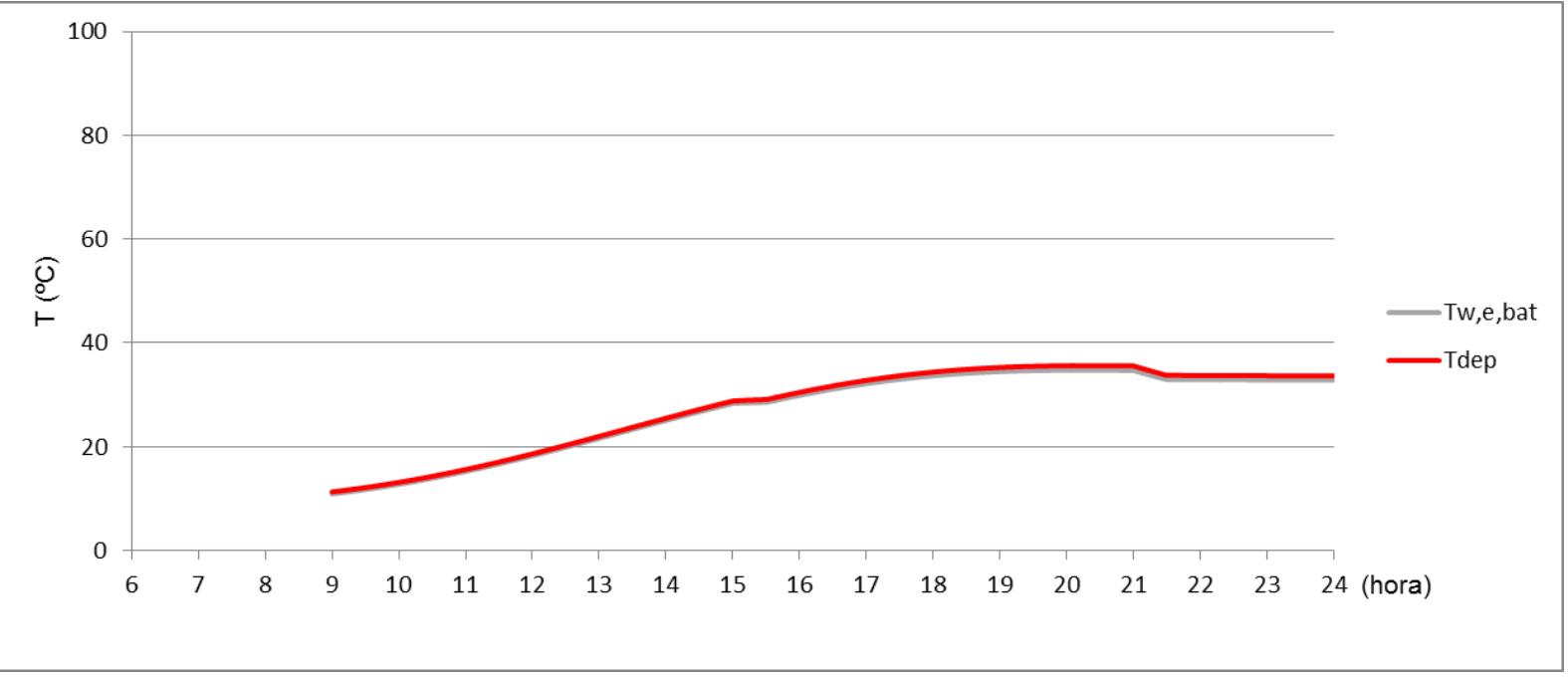

Figura AC.48.- Evolución de la temperatura del agua en el depósito para el día tipo de AGOSTO con un caudal de aire de paso por el colector de $300 \mathrm{~m}^{3} / \mathrm{h}$. Capacidad del depósito: 500 litros.

\section{SEPTIEMBRE}

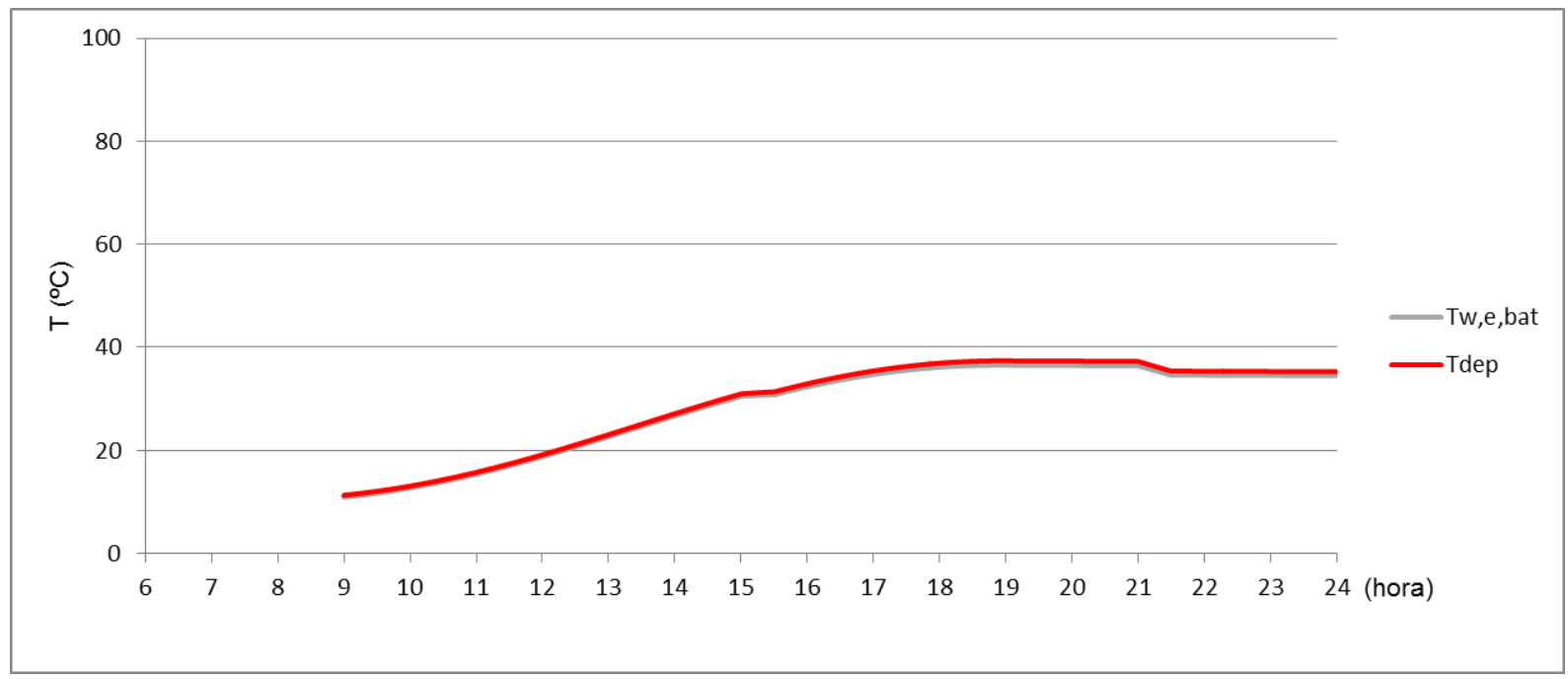

Figura AC.49.- Evolución de la temperatura del agua en el depósito para el día tipo de SEPTIEMBRE con un caudal de aire de paso por el colector de $300 \mathrm{~m}^{3} / \mathrm{h}$. Capacidad del depósito: 500 litros. 


\section{REFERENCIAS}

[1] P. (Universidad de C. Fernández Díez, I. (Universidad de C. Fernández, Ingeniería térmica, Universidad de Cantabria. Dpto de Ingeniería eléctrica y energética, 2002.

[2] A.L. Kays, W.M., London, Compact-heat-exchangers, McGraw-Hill Inc, New York, 1984. 
ANEXO C: SIMULACIONES 
